ORNL/TM-12973

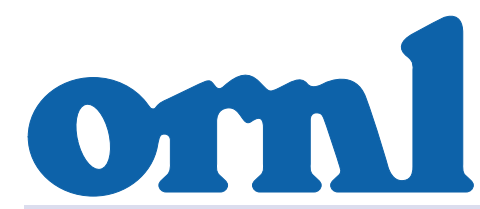

OAK RIDGE NATIONAL LABORATORY

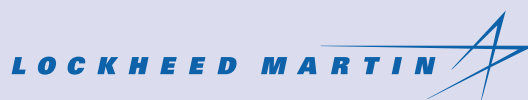

LOCKMEED MARTINT

\section{MANAGED AND OPERATED BY}

LOCKHEED MARTIN ENERGY RESEARCH CORPORATION FOR THE UNITED STATES

DEPARTMENT OF ENERGY

\section{Sensitivity and Parametric Evaluations of Significant Aspects of Burnup Credit for PWR Spent Fuel Packages}

M. D. DeHart 
This report has been reproduced directly from the best available copy.

Available to DOE and DOE contractors from the Office of Scientific and Technical Information, P.O. Box 62, Oak Ridge, TN 37831; prices available from (615) 576-8401.

Available to the public from the National Technical Information Service, U.S. Department of Commerce, 5285 Port Royal Rd., Springfield, VA 22161.

This report was prepared as an account of work sponsored by an agency of the United States Government. Neither the United States nor any agency thereof, nor any of their employees, makes any warranty, express or implied, or assumes any legal liability or responsibility for the accuracy, completeness, or usefulness of any information, apparatus, product, or process disclosed, or represents that its use would not infringe privately owned rights. Reference herein to any specific commercial product, process, or service by trade name, trademark, manufacturer, or otherwise, does not necessarily constitute or imply its endorsement, recommendation, or favoring by the United States Government or any agency thereof. The views and opinions of authors expressed herein do not necessarily state or reflect those of the United States Government or any agency thereof. 


$$
\text { Computational Physics and Engineering Division (10) }
$$

\title{
SENSITIVITY AND PARAMETRIC EVALUATIONS OF SIGNIFICANT ASPECTS OF BURNUP CREDIT FOR PWR SPENT FUEL PACKAGES
}

M. D. DeHart

Date Published: May 1996

\author{
Prepared by the \\ OAK RIDGE NATIONAL LABORATORY \\ managed by \\ LOCKHEED MARTIN ENERGY RESEARCH CORP. \\ for the \\ U.S. DEPARTMENT OF ENERGY \\ under contract DE-AC05-96OR22464
}





\section{CONTENTS}

Page

LIST OF FIGURES

LIST OF TABLES

ACKNOWLEDGMENTS

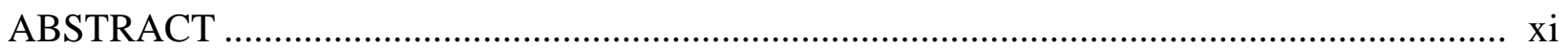

1. INTRODUCTION

2. THE SCALE CODE SYSTEM AS APPLIED TO BURNUP CREDIT CALCULATIONS.....3

2.1 THE SCALE-4 SHIELDING ANALYSIS SEQUENCE NO. 2H (SAS2H)................ 3

2.2 THE SCALE-4 CRITICALITY SAFETY ANALYSIS SEQUENCES (CSAS) .......... 5

3. SENSITIVITY ANALYSIS FOR FUNDAMENTAL PARAMETERS .......................... 7

3.1 DETERMINATION OF MOST IMPORTANT NUCLIDES FOR k $\mathrm{eff}$

CALCULATIONS

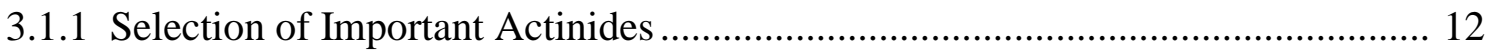

3.1.2 Selection of Important Fission Products ..................................................... 13

3.2 SENSITIVITY OF $\mathrm{k}_{\mathrm{eff}}$ TO VARIATIONS IN ISOTOPIC COMPOSITIONS ............. 15

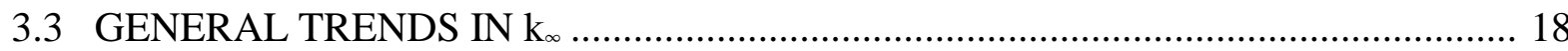

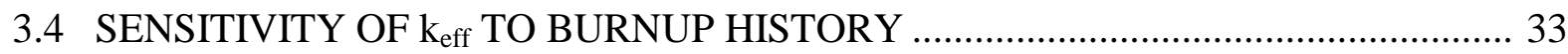

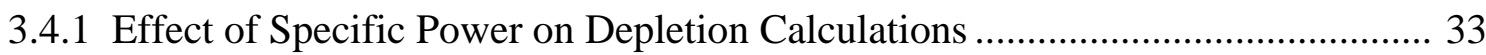

3.4.2 Effect of Time-Dependent Burnup Variations on Depletion Calculations.......... 40

3.4.2.1 Extended Downtimes.............................................................. 45

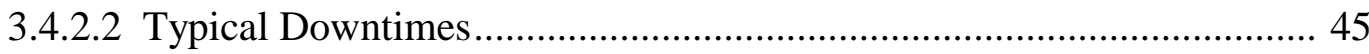

3.4.2.3 Specific Power Effects.............................................................. 46

3.5 EFFECT OF SELECTED DEPLETION PARAMETERS ON k ${ }_{\infty} \ldots \ldots \ldots \ldots \ldots \ldots \ldots \ldots \ldots . \ldots 7$

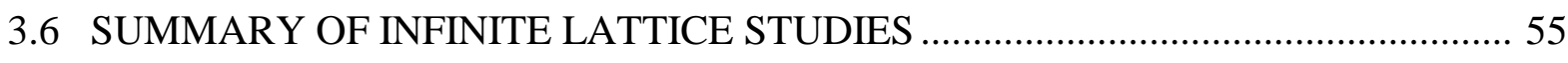

4. DEVELOPMENT OF A THREE-DIMENSIONAL CASK MODEL FOR

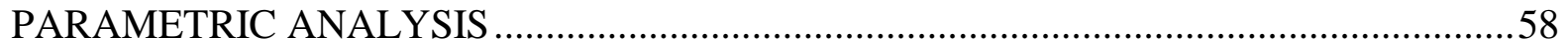

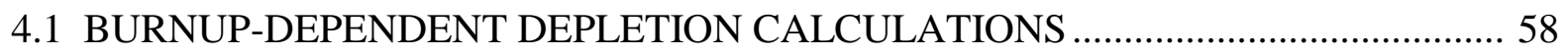

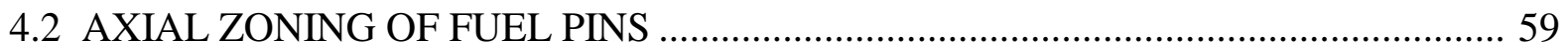

4.3 DETERMINATION OF AXIAL BURNUP PROFILES ........................................ 59

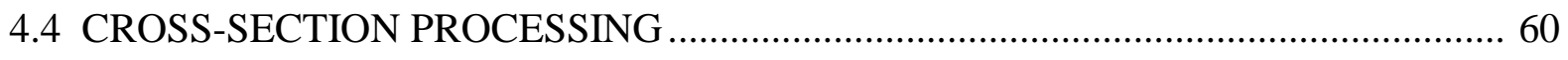

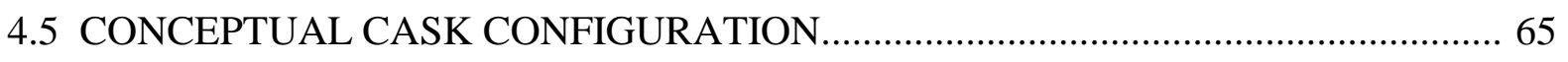

5. PARAMETRIC STUDIES OF A NOMINAL SPENT FUEL CASK

CONFIGURATION.

5.1 DETERMINATION OF A CONSERVATIVE BURNUP PROFILE FROM

DATABASE PROFILES. 


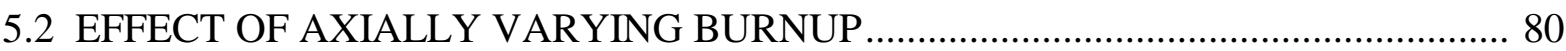

5.2.1 Determination of a Best-Estimate Axial Zoning Scheme................................. 80

5.2.2 Effect of a Uniform Burnup Assumption ....................................................... 88

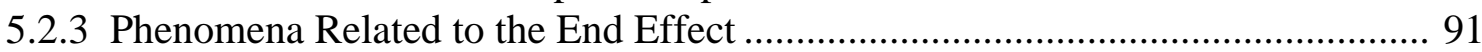

5.3 EFFECT OF AXIAL TEMPERATURE APPROXIMATIONS ................................... 94

5.4 EFFECT OF ISOTOPIC CORRECTION FACTORS ……...................................... 95

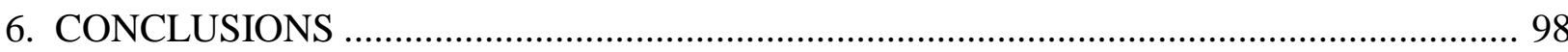

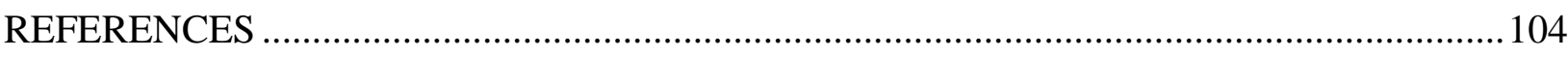

APPENDIX A. ISOTOPIC RANKINGS BY ABSORPTION FRACTIONS..............................109 APPENDIX B. STATISTICAL METHODS FOR TREATING ISOTOPIC

CALCULATIONAL BIAS .119

B.1 CHEMICAL ASSAY MEASUREMENTS ……...................................119

B.2 ISOTOPIC CORRECTION FACTORS ....................................................132 B.2.1 Statistical Method for Determination of Isotopic Correction Factors ............................................................133

B.2.2 Calculation of Isotopic Correction Factors ....................................135

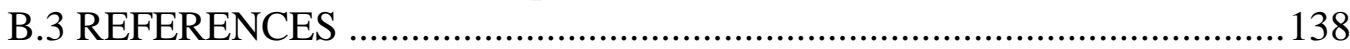

APPENDIX C. SENSITIVITY COEFFICIENTS FOR BURNUP CREDIT NUCLIDES .........141 APPENDIX D. RESULTS OF 1-D PARAMETRIC STUDY OF $\mathrm{k}_{\infty}$ WITH

ENRICHMENT, BURNUP, AND COOLING TIME

APPENDIX E. PHYSICAL AND NUMERICAL DESCRIPTIONS OF THE NOMINAL

CONDITIONS FOR DEPLETION AND CRITICALITY MODELS.

APPENDIX F. CONSIDERATIONS IN THE USE OF MONTE CARLO

CALCULATIONS IN 3-D CASK CONFIGURATIONS

APPENDIX G. SIMPLIFIED AXIAL MODELING 


\section{LIST OF FIGURES}

Figure

$\underline{\text { Page }}$

$1 \quad$ Flow path invoked in SAS2H depletion and decay sequences ................................... 4

$2 \quad \mathrm{k}_{\infty}$ as a function of cooling time from ORIGEN-S calculation $(3.0 \mathrm{wt} \%$ fuel) ................... 9

$3 \quad \mathrm{k}_{\infty}$ as a function of cooling time from ORIGEN-S calculation (3.6 wt \% fuel) .................. 10

$4 \quad \mathrm{k}_{\infty}$ as a function of cooling time from ORIGEN-S calculation (4.5 wt \% fuel) ................ 11

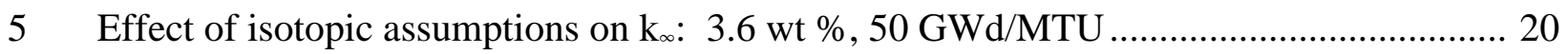

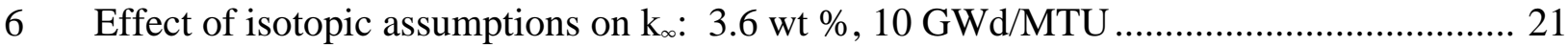

$7 \quad$ Relative behavior of $\mathrm{k}_{\infty}$ with and without fission products: $10 \mathrm{GWd} / \mathrm{MTU} \ldots \ldots \ldots \ldots \ldots \ldots \ldots . \ldots \ldots 2$

$8 \quad$ Relative behavior of $\mathrm{k}_{\infty}$ with and without fission products: $50 \mathrm{GWd} / \mathrm{MTU}$.................... 23

9 Effect of cooling time on $\mathrm{k}_{\infty}$ for various enrichments: actinides + fission products,

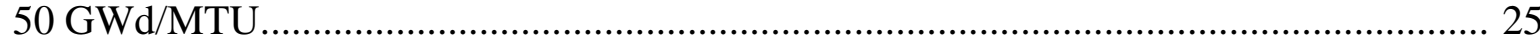

10 Effect of cooling time on $\mathrm{k}_{\infty}$ for various enrichments: actinides + fission products,

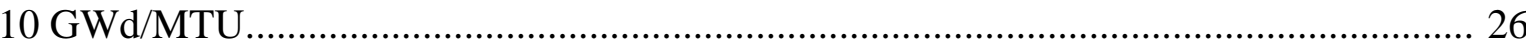

11 Effect of cooling time on $\mathrm{k}_{\infty}$ for various burnups: actinides + fission products ............... 27

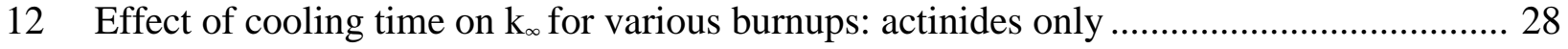

$13 \quad$ Short-term effect of burnup on $\mathrm{k}_{\infty}$ : actinides + fission products..................................... 29

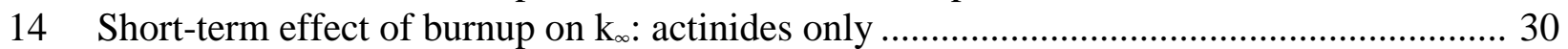

$15 \quad$ Effect of burnup on $\mathrm{k}_{\infty}(5$-year cooling period) .................................................. 31

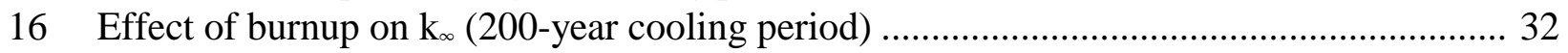

$17 \quad \mathrm{k}_{\infty}$ as a function of specific power for various enrichments and burnups

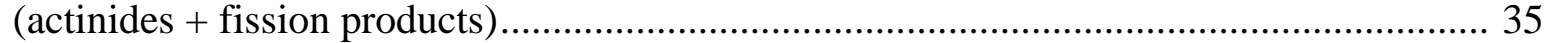

$18 \quad \mathrm{k}_{\infty}$ as a function of specific power for various enrichments and burnups (actinides only) .. 36

19 Spectral differences between low and high specific power depletion cases...................... 39

$20 \quad$ Three-cycle operating histories for sensitivity analyses ......................................... 41

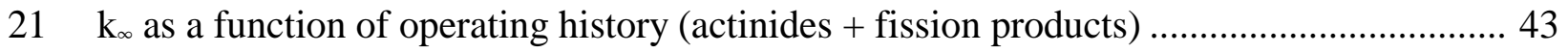

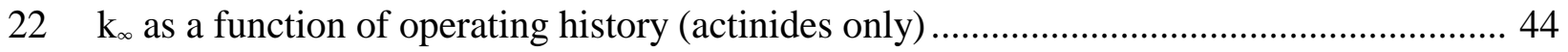

23 Trends in $\mathrm{k}_{\infty}$ with varying boron concentration during depletion ................................... 49

$24 \quad$ Trends in $\mathrm{k}_{\infty}$ with varying fuel temperature during depletion............................... 52

25 Trends in $\mathrm{k}_{\infty}$ with varying moderator temperature during depletion............................. 54

26 Burnup profiles for 8- to 12-GWd/MTU range from CE $14 \times 14$ database ..................... 61

27 Burnup profiles for 16- to 24-GWd/MTU range from CE $14 \times 14$ database .................. 62

28 Flowchart of calculational procedure required for multiple axial zone KENO V.a

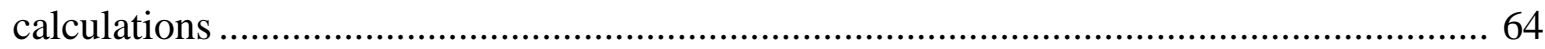

29 Maximum and minimum bounds for 8- to 12-GWd/MTU burnup profile range............... 67

30 Definition of burnup shape LLLLLHHHHHHHHHHLLLLL ..................................... 69

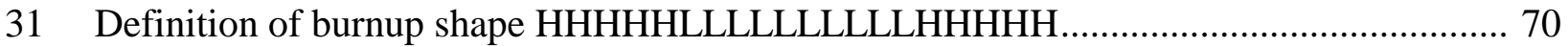

$32 \mathrm{k}_{\mathrm{eff}}$ as a function of burnup shape, $10 \mathrm{GWd} / \mathrm{MTU}$ with actinides and fission products ...... 73

$33 \quad \mathrm{k}_{\mathrm{eff}}$ as a function of burnup shape, $30 \mathrm{GWd} / \mathrm{MTU}$ with actinides and fission products ...... 74

$34 \quad \mathrm{k}_{\text {eff }}$ as a function of burnup shape, $50 \mathrm{GWd}$ /MTU with actinides and fission products ...... 75

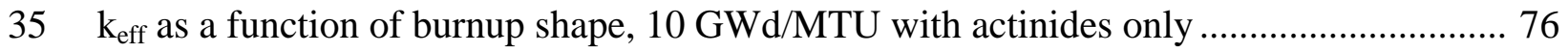

$36 \quad \mathrm{k}_{\mathrm{eff}}$ as a function of burnup shape, $30 \mathrm{GWd}$ /MTU with actinides only ............................ 77 


\section{LIST OF FIGURES (continued)}

$37 \quad \mathrm{k}_{\text {eff }}$ as a function of burnup shape, $50 \mathrm{GWd} / \mathrm{MTU}$ with actinides only ........................... 78

38 Conservative burnup profiles for CE $14 \times 14$ database burnup ranges ........................ 82

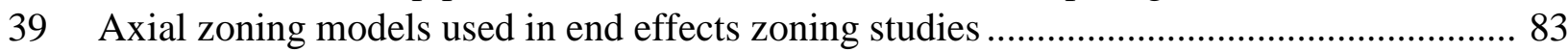

$40 \quad \mathrm{k}_{\text {eff }}$ as a function of various axial zoning models (actinides + fission products) ............... 86

$41 \quad \mathrm{k}_{\mathrm{eff}}$ as a function of various axial zoning models (actinides only) ............................... 87

$42 \quad$ Axial zoning burnup approximations to a continuous burnup profile ......................... 89

43 Relationship between burnup and end effect (actinides + fission products) ................... 91

44 Relationship between burnup and end effect (actinides only) ................................. 93

E-1 $\quad$ Westinghouse $17 \times 17$ assembly configuration within MPC basket design ..................... 159

E-2 MPC 21-position large cask design (end section view) ............................................. 177

E-3 MPC 21-position large cask deisgn (side section view) ...........................................178

E-4 Large transportation cask design (end section view) ................................................... 179

E-5 $\quad$ Large transportation cask design (side section view) ................................................ 180

F-1 $\quad$ Fission densities computed for various neutron source guesses..................................... 184

G-1 $\mathrm{k}_{\mathrm{eff}}$ as a function of axial burnup nodalization (actinides + fission products) ...................189

G-2 $\mathrm{k}_{\mathrm{eff}}$ as a function of axial burnup nodalization (actinides only) ................................. 190 


\section{LIST OF TABLES}

\section{$\underline{\text { Table }}$}

Page

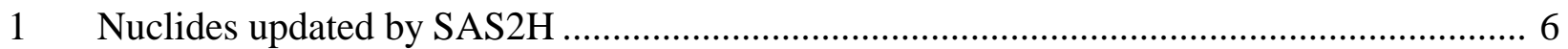

2 Fractional neutron absorption as a function of burnup for most important actinides

(5-year cooled).

$3 \quad$ Fractional neutron absorption as a function of burnup for most important fission products (5-year cooled)

$4 \quad$ Sensitivity coefficients with and without bias corrections for actinides and fission products in $3.6 \mathrm{wt} \%, 30 \mathrm{GWd} / \mathrm{MTU}$ burnup spent fuel.

$5 \quad$ Sensitivity coefficients with and without bias corrections for actinides only in

$3.6 \mathrm{wt} \%, 30 \mathrm{GWd} / \mathrm{MTU}$ burnup spent fuel.

$6 \quad \mathrm{k}_{\infty}$ as a function of depletion rate (actinides + fission products).................................. 34

$7 \quad \mathrm{k}_{\infty}$ as a function of depletion rate (actinides only) .................................................... 34

$8 \quad$ Final isotopic concentration for various depletion rates (3.6 wt \%,

$50 \mathrm{GWd} / \mathrm{MTU}$ burnup).

$9 \quad \mathrm{k}_{\infty}$ for various operating histories with fission products present in criticality calculations . 42

$10 \quad \mathrm{k}_{\infty}$ for various operating histories with actinides-only criticality calculations................. 42

11 Effect of moderator boron concentrations on $\mathrm{k}_{\infty}$ (actinides + fission products) .................48

12 Effect of moderator boron concentrations on $\mathrm{k}_{\infty}$ (actinides only) .............................. 48

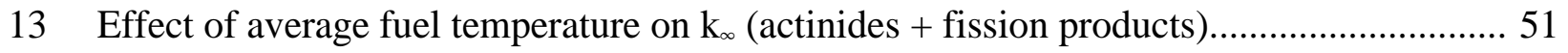

$14 \quad$ Effect of average fuel temperature on $\mathrm{k}_{\infty}$ (actinides only) ....................................... 51

15 Effect of average moderator temperature on $\mathrm{k}_{\infty}$ (actinides + fission products) ................. 53

$16 \quad$ Effect of average moderator temperature on $\mathrm{k}_{\infty}$ (actinides only) .................................... 53

17 Minimum recommended set of nuclides for full burnup credit ................................... 56

18 Upper and lower burnup bounds for CE $14 \times 14$ database burnup ranges ...................... 68

$19 \mathrm{k}_{\mathrm{eff}}$ computed for various burnup-dependent axial burnup shapes ................................... 72

$20 \quad$ Normalized conservative burnup profiles based on CE $14 \times 14$ database........................ 81

21 Results of axial zoning studies (actinides + fission products) ................................ 85

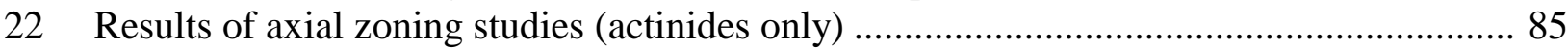

23 Assumed axial temperature and moderator density values .......................................... 96

24 Effect of axial temperature distributions during depletion calculations .......................... 96

25 Effect of isotopic correction factors on the calculation of $\mathrm{k}_{\mathrm{eff}}$ in a cask configuration ....... 97

26 Recommended treatment of important parameters in PWR burnup credit...................... 101

B-1 ATM-104, fuel assembly D047, rod MKP109 at $13.20 \mathrm{~cm}, 27.35 \mathrm{GWd} / \mathrm{MTU} . . . \ldots \ldots \ldots \ldots . .122$

B-2 ATM-104, fuel assembly D047, rod MKP109 at $27.70 \mathrm{~cm}, 37.12 \mathrm{GWd} / \mathrm{MTU} . . . \ldots \ldots \ldots \ldots . .123$

B-3 ATM-104, fuel assembly D047, rod MKP109 at $165.22 \mathrm{~cm}, 44.34 \mathrm{GWd} / \mathrm{MTU} . . . \ldots \ldots \ldots . . .124$

B-4 ATM-103, fuel assembly D101, rod MLA098 at $8.9 \mathrm{~cm}, 18.68 \mathrm{GWd} / \mathrm{MTU}$....................125

B-5 ATM-103, fuel assembly D101, rod MLA098 at $24.3 \mathrm{~cm}, 26.62 \mathrm{GWd} / \mathrm{MTU} . . . \ldots \ldots \ldots \ldots . . .125$

B-6 ATM-103, fuel assembly D101, rod MLA098 at $161.7 \mathrm{~cm}, 33.17 \mathrm{GWd} / \mathrm{MTU} . . . . . . . . . . . . . .126 .126$

B-7 ATM-106, fuel assembly BT03, rod NBD107 at $11.28 \mathrm{~cm}, 31.40 \mathrm{GWd} / \mathrm{MTU} \ldots \ldots \ldots \ldots \ldots . .126$

B-8 ATM-106, fuel assembly BT03, rod NBD107 at $19.92 \mathrm{~cm}, 37.27 \mathrm{GWd}$ /MTU.................127

B-9 ATM-106, fuel assembly BT03, rod NBD107 at $161.21 \mathrm{~cm}, 46.46 \mathrm{GWd} / \mathrm{MTU} . . . \ldots \ldots \ldots . . .127$ 


\section{LIST OF TABLES (continued)}

$\underline{\text { Table }}$

$\underline{\text { Page }}$

B-10 ATM-101, fuel assembly B0-5, rod N-9 at $11.00 \mathrm{~cm}, 16.02 \mathrm{GWd} / \mathrm{MTU} \ldots \ldots \ldots \ldots \ldots \ldots . . . . . .128$

B-11 ATM-101, fuel assembly B0-5, rod N-9 at 26.00 cm, 23.81 GWd/MTU.......................128

B-12 ATM-101, fuel assembly B0-5, rod N-9 at $199.0 \mathrm{~cm}, 28.47 \mathrm{GWd} / \mathrm{MTU} \ldots \ldots \ldots \ldots \ldots \ldots \ldots . . \ldots \ldots$

B-13 ATM-101, fuel assembly B0-5, rod N-9 at $226.0 \mathrm{~cm}, 31.66 \mathrm{GWd} / \mathrm{MTU}$....................... 129

B-14 Fuel assembly 170, batch 94, 25.93 GWd/MTU....................................................130

B-15 Fuel assembly 172, batch 92, 26.54 GWd/MTU....................................................130

B-16 Fuel assembly 176, batch 91, 27.99 GWd/MTU..................................................130

B-17 Fuel assembly 168, batch 86, 28.40 GWd/MTU....................................................... 131

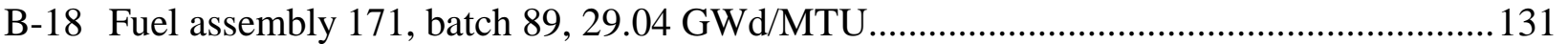

B-19 Fuel assembly 176, batch 90, 29.52 GWd/MTU................................................131

B-20 Normality tests for measured/calculated isotopic concentration data ............................ 136

B-21 Bias, uncertainty, and isotopic correction factors for burnup credit nuclides .................. 138

D-1 Best estimate $\mathrm{k}_{\infty}$ as a function of enrichment, burnup, and cooling time

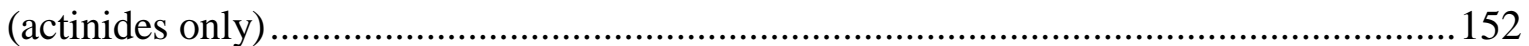

D-2 Best estimate $\mathrm{k}_{\infty}$ as a function of enrichment, burnup, and cooling time

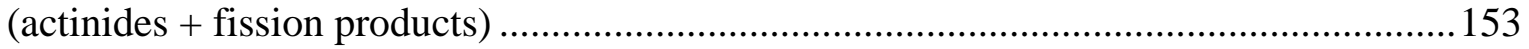

D-3 Conservative estimate $\mathrm{k}_{\infty}$ as a function of enrichment, burnup, and cooling time

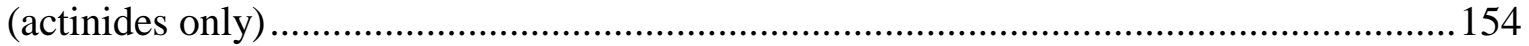

D-4 Conservative estimate $\mathrm{k}_{\infty}$ as a function of enrichment, burnup, and cooling time

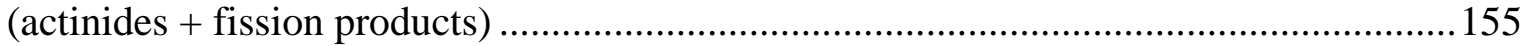

E-1 Westinghouse $17 \times 17$ fuel assembly design specifications................................ 158

E-2 Assumed reactor conditions for nominal depletion calculations .................................... 160

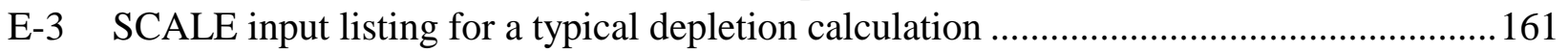

E-4 SCALE input listing for a 7-zone MPC criticality calculation .............................. 163

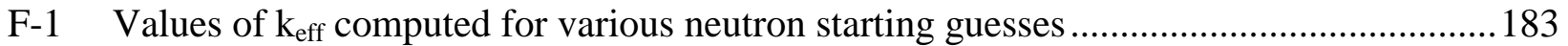

G-1 Results of axial zoning studies using simplified approach

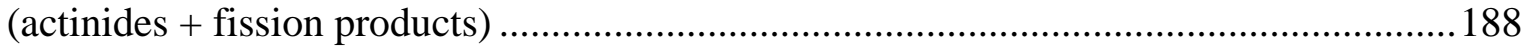

G-2 Results of axial zoning studies using simplified approach (actinides only) ..................188 


\section{ACKNOWLEDGMENTS}

The author wishes to express his appreciation to several individuals who contributed their ideas and efforts in the analyses described herein. Particular thanks go to M. C. Brady of Sandia National Laboratories, whose early work in burnup credit parametric and sensitivity analysis served as a basis for much of this work and who provided technical oversight for most of the duration of this work, and to C. V. Parks of Oak Ridge National Laboratory, who provided guidance and reviewed and commented on the draft report. The contributions of J. R. Thornton of Duke Engineering and Services, A. H. Wells, and L. A. Hassler of the Babcock \& Wilcox Fuel Company in discussions of driving phenomena were especially useful in determining additional areas for study. Statistical methods included in this report were provided by N. Coleman of TRW Environmental Safety Systems. An expression of gratitude to L. F. Norris for her continuing efforts in the text editing, formatting, and release of this report. This work was performed at the Oak Ridge National Laboratory under contract to Sandia National Laboratories as part of their support for the U.S. Department of Energy's (DOE) Office of Civilian Radioactive Waste Management (OCRWM) Transportation Support Program. Program management and oversight is provided by TRW Environmental Safety Systems under contract to DOE.

This report was prepared by the Oak Ridge National Laboratory in accordance with the technical and quality assurance requirements specified in Sandia National Laboratories' subcontract AD-4072. All work described in the subcontract Statement of Work was conducted under the Sandia Burnup Credit Quality Assurance Program and implementing procedures. Input and output from calculations reported in this work are qualified under these procedures. 


\begin{abstract}
Spent fuel transportation and storage cask designs based on a burnup credit approach must consider issues that are not relevant in casks designed under a fresh-fuel loading assumption. For example, the spent fuel composition must be adequately characterized and the criticality analysis model can be complicated by the need to consider axial burnup variations. Parametric analyses are needed to characterize the importance of fuel assembly and fuel cycle parameters on spent fuel composition and reactivity. Numerical models must be evaluated to determine the sensitivity of criticality safety calculations to modeling assumptions. The purpose of this report is to describe analyses and evaluations performed in order to demonstrate the effect physical parameters and modeling assumptions have on the criticality analysis of spent fuel. The analyses in this report include determination and ranking of the most important actinides and fission products; study of the effect of various depletion scenarios on subsequent criticality calculations; establishment of trends in neutron multiplication as a function of fuel enrichment, burnup, cooling time; and a parametric and modeling evaluation of three-dimensional effects (e.g., axially varying burnup and temperature/density effects) in a conceptual cask design. The sensitivity and parametric evaluations were performed with the consideration of two different burnup credit approaches: (1) only actinides in the fuel are considered in the criticality analysis, and (2) both actinides and fission products are considered.

Calculations described in this report were performed using the criticality and depletion sequences available in the SCALE code system and the SCALE 27-group burnup library. Although the results described herein do not constitute a validation of SCALE for use in spent fuel analysis, independent validation efforts have been completed and are described in other reports. Such validation is necessary in the acceptance of the results and conclusions included in this report.
\end{abstract}




\section{INTRODUCTION}

In the past, criticality analysis of pressurized-water-reactor (PWR) fuel stored in racks and casks has assumed that the fuel is fresh with the maximum allowable initial enrichment. This assumption has led to the design of widely spaced and/or highly poisoned storage and transport arrays. If credit is assumed for fuel burnup, more compact and economical arrays can be designed. Such reliance on the reduced reactivity of spent fuel for criticality control is referred to as "burnup credit." If burnup credit is applied in the design of a cask for use in the transport of spent lightwater-reactor (LWR) fuel to a repository, a significant reduction both in the cost of transport and in the risk to the public may be realized! 1 These benefits caused the U.S. Department of Energy (DOE) to initiate a program to investigate the technical issues associated with burnup credit in spent fuel cask design. These efforts have been led by Sandia National Laboratories (SNL) and carried out as part of the Cask Systems Development Program within the Office of Civilian Radioactive Waste Management. This report represents a portion of the work performed at Oak Ridge National Laboratory (ORNL) in support of SNL efforts to demonstrate the viability of burnup credit methods for cask design. Specifically, this report addresses the sensitivity of burnup credit methods to various modeling assumptions to determine the bias, if any, in the method as a function of such assumptions and to provide, through parametric analyses, a basic understanding of spent fuel behavior as a function of initial and operating conditions.

Criticality safety considerations require the inclusion of a safety margin in engineering design specifications; one component of this margin is an allowance for differences between theoretical (or modeled) states and actual physical conditions. Where sufficient data exist, it is reasonable to determine a modeling margin based on a conservative combination of bias and uncertainty derived from experimental and calculational results. However, some modeling assumptions are not easily quantified in this manner. Thus it is necessary to perform studies to ascertain the sensitivity of $k_{\text {eff }}$ to various modeling parameters. If $\mathrm{k}_{\mathrm{eff}}$ is found to be sensitive to a given parameter, the sensitivity results can be used either to estimate the calculational bias due to the given modeling assumption, or to recommend a value for the parameter which is conservative relative to nominal conditions [i.e., a value that results in conservatism (overprediction) in the value of $\left.k_{\text {eff }}\right]$.

Since the inception of burnup credit studies at ORNL, a significant number of analyses have been performed to study the effect of various parameters on the calculated value of $k_{\infty}$ or $k_{\text {eff }}$ for spent fuel configurations $\frac{1-9}{1}$ This work has included parametric studies of the effect of factors including burnup, cooling time, initial enrichment, use of an axial burnup profile, and the number of subdivisions necessary to accurately account for this profile, reactor operating history, specific power, assembly design, and the nuclides included in spent fuel modeling. However, this earlier work was performed using a variety of baseline model configurations and different versions of the SCALE code system, and was often directed at specific technical questions. For this reason, it was decided that the earlier studies should be repeated and/or updated to provide a consistent approach for addressing the range of parameter and sensitivity issues that have been identified relative to burnup credit. This report provides the results of the more recent analyses using consistent models and data.

The remainder of this report is broken into four major divisions: Section 2 discusses the key

portions of the SCALE code system used in burnup credit analyses. Section 3 provides analyses for basic parameters (important nuclides, sensitivity and trends in $\mathrm{k}_{\infty}$ with cooling time, enrichment, and 
operating history) using simple one-dimensional (1-D) pin-cell calculations. The results of these calculations will be used as a basis for the development of a nominal burnup credit cask model, which is described in Sect. 4. Section 5 presents results of parametric studies over a wide range of conditions based on this nominal design. Finally, the Conclusions section of this report summarizes the results, and provides a more global perspective of the significance and application of these results in burnup credit design. 


\section{THE SCALE CODE SYSTEM AS APPLIED TO BURNUP CREDIT CALCULATIONS}

To date, the SCALE code system, 10 developed at ORNL, has been the primary computational tool used by DOE to investigate technical issues related to burnup credit 6 Parametric studies performed in this investigation use various computational sequences of the SCALE system. SCALE is a well-established code system that has been widely used in away-from-reactor (AFR) applications for spent fuel characterization via the SAS2H analysis sequence 11 and criticality safety analyses via the CSAS analysis sequences 12 SAS2H is a multicode sequence that determines the isotopic composition of spent fuel using the ORIGEN-S code ${ }^{13}$ for depletion and decay calculations and a 1-D neutronics model of an LWR fuel assembly to prepare burnup-dependent cross sections for ORIGEN-S. The CSAS module is used to determine the neutron multiplication factor $\left(\mathrm{k}_{\infty}\right.$ or $\left.\mathrm{k}_{\mathrm{eff}}\right)$ of a system using either simple 1-D XSDRNPM 14 calculations, or more detailed three-dimensional (3-D) Monte Carlo calculations using KENO V.a! ${ }^{15}$ Isotopic concentrations used in the spent fuel criticality calculations are based on the results of SAS2H calculations. Both the SAS2H and CSAS sequences use the BONAMI ${ }^{16}$ and NITAWL ${ }^{17}$ codes to perform problem-specific (resonancecorrected) cross- section processing. Cross sections are obtained from the SCALE-4 27-group burnup library (identified within SCALE as 27BURNUPLIB), a hybrid library developed in the early 1980s for depletion analyses. This cross-section library contains ENDF/B-IV (actinide) and ENDF/B-V (fission product) data for isotopes important in spent fuel from commercial reactor fuel designs. The following subsections describe in more detail the capabilities and basis for each of the two SCALE-4 sequences and their component codes.

\subsection{THE SCALE-4 SHIELDING ANALYSIS SEQUENCE NO. 2H (SAS2H)}

The SAS2H control module was originally developed for the SCALE code system to provide a sequence that generated radiation source terms for spent fuel and subsequently utilized these sources with a 1-D shielding analysis of a shipping cask. However, in addition to the calculation of source terms, SAS2H is now often used to obtain decay heat and spent fuel isotopics. Within the scope of burnup credit applications described in this report, SAS2H is used solely for the prediction of spent fuel isotopics.

Five different codes are invoked by the SAS2H sequence for performing a complete fuel depletion analysis. BONAMI applies the Bondarenko method of resonance self-shielding for nuclides which have Bondarenko data included in the cross-section library. NITAWL-II performs Nordheim resonance self-shielding corrections for nuclides that have resonance parameters included with their cross-section data. XSDRNPM is a 1-D discrete ordinates code that performs radiation transport calculations based on geometric data passed to it by SAS2H, and produces cell-weighted cross sections for fuel depletion calculations. The COUPLE code 18 updates cross-section constants included on the ORIGEN-S nuclear data library with data from the cell-weighted cross-section library produced by XSDRNPM. COUPLE also uses the XSDRNPM-computed weighting spectrum to update nuclide cross sections for remaining nuclides. Finally, the ORIGEN-S code is used to perform nuclide generation and depletion calculations for a specified reactor fuel history.

The process used by SAS2H in calculation of spent fuel isotopics is illustrated schematically in Fig. 1. The calculation starts with input-specified data describing a fuel assembly as it is initially 


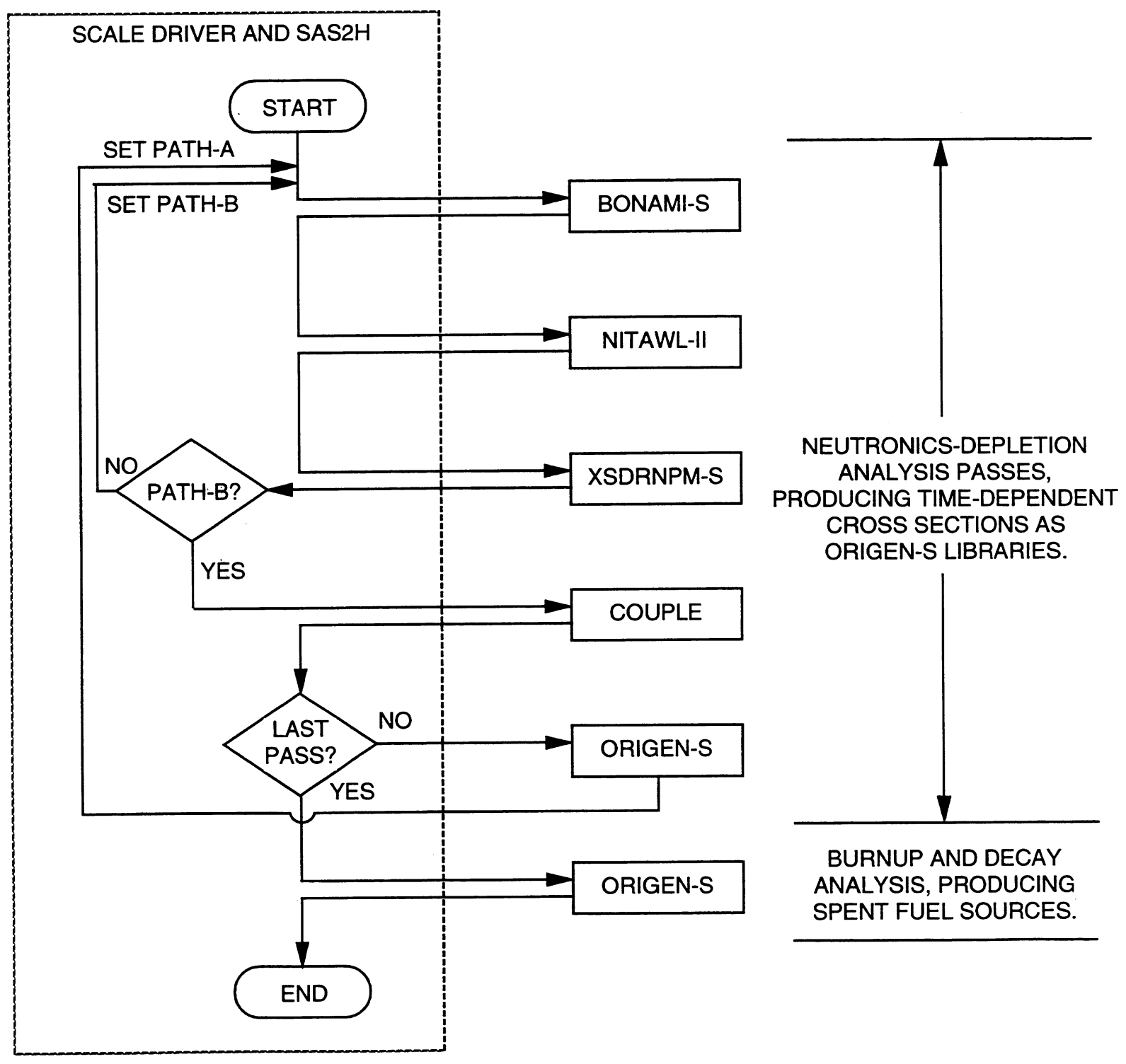

Fig. 1. Flow path invoked in SAS2H depletion and decay sequences. 
loaded into a reactor. The initial composition, average temperatures, geometry, and time-dependent specific power of the fuel assembly are required. The SAS2H sequence performs 1-D neutron transport analysis of the reactor fuel assembly using XSDRNPM and a two-part procedure with two separate unit-cell-lattice models. The first model (Path A of Fig. 1) is a unit fuel-pin cell from which cell-weighted cross sections are obtained. The second model (Path B of Fig. 1) represents a larger unit cell (e.g., an assembly) within an infinite lattice. The larger unit cell zones can be structured for different assembly designs to account for assembly-specific attributes (i.e., water holes, burnable poison rods, etc.). Problem-dependent resonance self-shielding of cross-sections is performed prior to each XSDRNPM calculation using the BONAMI and NITAWL-II codes. The neutron flux spectrum obtained from the second (assembly) unit-cell model is used to determine the appropriate nuclide cross sections for the burnup-dependent fuel composition. The cross sections derived from XSDRNPM calculations at each time step are used in an ORIGEN-S point-depletion computation that produces the burnup-dependent fuel compositions to be used in the next spectrum calculation. This sequence is repeated in user-specified burnup steps for a complete assembly operating history. The buildup and decay of nuclides in the fuel assembly is then computed by ORIGEN-S in a final pass based on the assembly's cooling time (i.e., the period of time after final exposure time). Note that ORIGEN-S calculations have no spatial dependence. The neutron flux used to produce the ORIGEN-S cross sections is based on a radial average of an infinitely long uniform assembly with characteristics per input specifications. These parameters (e.g., burnup, specific power, moderator temperature, etc.) can be specified via SAS2H to estimate the isotopic composition of any axial location along the fuel assembly or an axial average of the fuel assembly.

More than 1000 nuclides are tracked by ORIGEN-S during depletion and decay calculations. (Note that ORIGEN-S tracks all decay chains, but does not account for the loss of volatile isotopes; however, any released nuclides represent an insignificant fraction of the total fission-product inventory, and their inclusion should have an insignificant effect on the isotopic calculations.) Burnup-dependent cross sections are processed by SAS2H only for a select set of user-specified nuclides. These nuclides are those found to be most important for depletion calculations in LWR

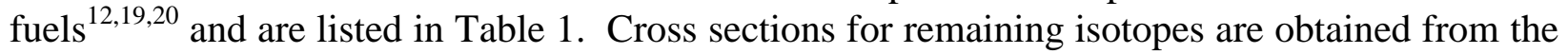
ORIGEN-S one-group LWR library and are adjusted with burnup using ORIGEN-S spectral parameters (THERM, RES, and FAST) ${ }^{13}$ calculated using fluxes determined by XSDRNPM. The ORIGEN-S one-group LWR library available in SCALE-4 has been updated to use cross sections from the SCALE-4 27-group burnup library for all 193 nuclides in that library. The update was performed by extracting one-group cross sections from the output of a low-burnup LWR-type fuel

A sample SAS2H input listing is provided in Appendix E. Appendix E also lists the basic reactor operation parameters (i.e., fuel, clad and moderator temperatures, moderator density, and boron concentration) assumed for depletion calculations.

\subsection{THE SCALE-4 CRITICALITY SAFETY ANALYSIS SEQUENCES (CSAS)}

The SCALE-4 system provides a number of different calculational sequences in support of criticality safety analyses. Of these sequences, the CSASN, CSAS1X, and CSAS25 sequences are most commonly used in burnup credit applications. For all CSAS sequences (as well as for the SAS2H sequence), the SCALE-4 system driver provides automated data handling and code execution as required for each sequence. All such sequences invoke a standardized procedure to provide appropriate cross sections for use in calculations. This procedure begins with the SCALE 
Table 1. Nuclides updated by SAS2H

\begin{tabular}{lllll}
\hline${ }^{234} \mathrm{U}^{a}$ & ${ }^{235} \mathrm{U}^{a}$ & ${ }^{236} \mathrm{U}^{a}$ & ${ }^{238} \mathrm{U}^{a}$ & ${ }^{237} \mathrm{~Np}^{a}$ \\
${ }^{238} \mathrm{Pu}^{a}$ & ${ }^{239} \mathrm{Pu}^{a}$ & ${ }^{240} \mathrm{Pu}^{a}$ & ${ }^{241} \mathrm{Pu}^{a}$ & ${ }^{242} \mathrm{Pu}^{a}$ \\
${ }^{241} \mathrm{Am}^{a}$ & ${ }^{242 m} \mathrm{Am}^{a}$ & ${ }^{243} \mathrm{Am}^{a}$ & ${ }^{242} \mathrm{Cm}^{a}$ & ${ }^{243} \mathrm{Cm}^{a}$ \\
${ }^{244} \mathrm{Cm}^{a}$ & ${ }^{83} \mathrm{Kr}$ & ${ }^{85} \mathrm{Kr}$ & ${ }^{90} \mathrm{Sr}$ & ${ }^{89} \mathrm{Y}$ \\
${ }^{95} \mathrm{Mo}$ & ${ }^{93} \mathrm{Zr}$ & ${ }^{94} \mathrm{Zr}$ & ${ }^{95} \mathrm{Zr}$ & ${ }^{94} \mathrm{Nb}$ \\
${ }^{16} \mathrm{O}^{b}$ & ${ }^{99} \mathrm{Tc}$ & ${ }^{101} \mathrm{Ru}$ & ${ }^{106} \mathrm{Ru}$ & ${ }^{103} \mathrm{Rh}$ \\
${ }^{105} \mathrm{Rh}$ & ${ }^{105} \mathrm{Pd}$ & ${ }^{108} \mathrm{Pd}$ & ${ }^{109} \mathrm{Ag}$ & ${ }^{124} \mathrm{Sb}$ \\
${ }^{131} \mathrm{Xe}$ & ${ }^{132} \mathrm{Xe}$ & ${ }^{135} \mathrm{Xe}$ & ${ }^{136} \mathrm{Xe}$ & ${ }^{133} \mathrm{Cs}^{a}$ \\
${ }^{134} \mathrm{Cs}$ & ${ }^{135} \mathrm{Cs}$ & ${ }^{137} \mathrm{Cs}$ & ${ }^{136} \mathrm{Ba}$ & ${ }^{139} \mathrm{La}$ \\
${ }^{144} \mathrm{Ce}$ & ${ }^{141} \mathrm{Pr}$ & ${ }^{143} \mathrm{Pr}$ & ${ }^{143} \mathrm{Nd}$ & ${ }^{145} \mathrm{Nd}$ \\
${ }^{147} \mathrm{Nd}$ & ${ }^{147} \mathrm{Pm}$ & ${ }^{148} \mathrm{Pm}$ & ${ }^{147} \mathrm{Sm}$ & ${ }^{149} \mathrm{Sm}$ \\
${ }^{150} \mathrm{Sm}$ & ${ }^{151} \mathrm{Sm}$ & ${ }^{152} \mathrm{Sm}$ & ${ }^{153} \mathrm{Eu}$ & ${ }^{154} \mathrm{Eu}$ \\
${ }^{155} \mathrm{Eu}$ & ${ }^{155} \mathrm{Gd}$ & & & \\
\hline
\end{tabular}

${ }^{a}$ Automatically updated by SAS2H.

${ }^{b}$ Not an actinide or fission product, but present in $\mathrm{UO}_{2}$ fuel.

Material Information Processor, 21 which generates number densities and related information, prepares geometry data for resonance self-shielding and flux-weighting cell calculations, and creates data input files for the cross-section processing codes.

The CSASN sequence is used to create a resonance-corrected microscopic cross-section library in AMPX-working-library forma $2^{22}$ by sequentially activating BONAMI and NITAWL. The resulting library can be used in a stand-alone KENO V.a calculation. The CSAS1X sequence begins with the same cross-section processing scheme, but then uses the resulting cross sections in a 1-D XSDRNPM eigenvalue calculation. This sequence may be used to determine a neutron multiplication factor for an infinite lattice of fuel pins $\left(\mathrm{k}_{\infty}\right)$ and to study the sensitivity of $\mathrm{k}_{\infty}$ to basic parameters (e.g., burnup, cooling time, enrichment, nuclides used, etc.). The deterministic calculation provided by CSAS1X enables accurate evaluation of small changes in $\mathrm{k}_{\infty}$. The CSAS25 sequence is similar to CSAS1X, except that the 1-D XSDRNPM calculation is replaced with a 3-D KENO V.a Monte Carlo calculation. This approach is necessary for the study of effects that are more configuration-sensitive (e.g., interaction between cask and fuel assemblies, etc.)

One current limitation of the CSAS sequences is that only one set of fuel pin isotopes can be used in the cross-section processing portion of the sequence. Thus to accurately consider the effect of different isotopic compositions (e.g., axially as a function of burnup) on resonance processing, a separate CSASN calculation must be performed for each fuel material to prepare material-specific cross-section libraries. The SCALE utility code WAX ${ }^{23}$ can then be used to combine all libraries into a single working library that can subsequently be used in a stand-alone KENO calculation. 


\section{SENSITIVITY ANALYSIS FOR FUNDAMENTAL PARAMETERS}

In order to develop an appropriate model of a cask loaded with spent fuel, it is essential to understand basic phenomena associated with spent fuel behavior. Based on relatively simple 1-D deterministic pin-cell calculations, one can develop an understanding of the behavior in $\mathrm{k}_{\infty}$ to variations in selected parameters (e.g., initial enrichment, burnup history, or cooling time). In addition, such analyses provide a basis for simplifying assumptions (e.g., relative to important nuclides or operating history) in the development of more detailed 3-D models. In this section, the most important nuclides (actinides and fission products) in spent fuel are determined as a function of enrichment, burnup, and cooling time, over the time frame from zero to 200 years post-irradiation. From these rankings, a subset of nuclides is recommended for use in burnup credit calculations. Based on this list, the sensitivity of $\mathrm{k}_{\infty}$ is demonstrated as a function of variations in the concentration of each burnup credit nuclide. Next, general trends in $\mathrm{k}_{\infty}$ as a function of enrichment, burnup, and cooling time are examined and discussed. The sensitivity of $\mathrm{k}_{\infty}$ to variations in the burnup history model is examined, both in terms of specific power and operating history effects, to determine if a simple, yet representative, depletion scheme can be used to conservatively estimate $\mathrm{k}_{\infty}$. Finally, the effect of assumptions made during depletion calculations (i.e., operating temperatures and boron concentrations) is studied in order to establish the most appropriate selection of such parameters to ensure conservatism in depletion calculations.

In the following sections, three representations of isotopic concentrations are discussed: (1) "as-computed" or "SAS2H," (2) "best-estimate" or "bias-corrected," and (3) "conservative" or "bounding." As-computed isotopics are the values predicted by a SAS2H depletion calculation. Bias-corrected isotopics are as-computed concentrations modified by estimated biases to provide a best estimate of actual fuel contents. Finally, bounding isotopic concentrations are SAS2H concentrations modified by statistically determined correction factors to obtain conservative estimates of isotopic concentrations. The derivation of bias-corrected and bounding isotopic concentrations are described later in this section. Unless otherwise specified, calculations performed for this report are bias-corrected.

\subsection{DETERMINATION OF MOST IMPORTANT NUCLIDES FOR $\mathrm{k}_{\text {eff }}$ CALCULATIONS}

Although ORIGEN-S is capable of tracking the inventories of more than 1000 unique nuclides, such detail is neither desirable nor necessary in the criticality phase of burnup credit calculations. Many nuclides decay away in relatively short periods of time (on the order of seconds to days); many others are not present in sufficient quantity or with a significant neutron capture potential to be important in terms of their effect on neutron multiplication. Thus it is necessary to develop a subset of nuclides that can adequately represent the behavior of spent fuel in criticality models. The following criteria are recommended as the basis of selection for this nuclide subset:

1. those nuclides that contribute significantly to the absorption of thermal neutrons in spent fuel are to be included;

2. all fissile nuclides are to be included; 
3. nuclides must be fixed in the fuel matrix (i.e., no credit taken for volatile elements); and

4. the predicted concentrations of selected nuclides in spent fuel must be verifiable by comparison with chemical assay measurements.

These selection criteria can be used to develop an approach for developing a set of "burnup credit nuclides." Sensitivity calculations can be performed to rank both actinides and fission products in terms of their fractional absorption. Criterion 2 simply requires that ${ }^{235} \mathrm{U},{ }^{239} \mathrm{Pu}$, and ${ }^{241} \mathrm{Pu}$ be included in the set of actinides. Criterion 3 requires that gaseous nuclides and nuclides with a significant degree of water solubility be omitted from the set. Finally, the last criterion requires that an isotope may be included only if experimentally measured isotopic data for spent fuel exist for that isotope. Criterion 4 can be used to expand the set of isotopes as more experimental data become available; however, criteria 2 and 3 will not change with time, and a ranking performed based on absorption calculations implied in criterion 1 is unlikely to change significantly even with the application of better methods and data for performing such calculations.

Throughout this report, the SAS2H sequence of SCALE (described in Sect. 2.1) is used for all depletion calculations. Hence all isotopic concentrations computed in this report include the calculational biases associated with the SAS2H code, its methodology and internal data, and the SCALE 27BURNUPLIB cross-section library. A method for determining the important isotopes in spent fuel as a function of burnup, cooling time, and enrichment using a combination of both SAS2H and ORIGEN-S is described in ref. 24; this reference provides isotopic rankings as a function of these parameters based on the relative fraction of absorptions occurring in each isotope. ORIGEN-S is used to calculate relative absorption fractions, using cross sections and as-computed isotopic concentrations provided by an independent SAS2H calculation. Using this approach, isotopic absorption fractions were computed based on a Westinghouse $17 \times 17$ assembly design, for initial enrichments of $3.0,3.6$, and $4.5 \mathrm{wt} \%{ }^{235} \mathrm{U}$, for burnups of 10,30 , and $50 \mathrm{GWd} / \mathrm{MTU}$, and for cooling times of $0,5,10,15$, and 30 years after shutdown. (Fuel pin and assembly data are provided in Appendix E. Because of the large number of Westinghouse $17 \times 17$ assemblies of this design used by commercial PWRs, this fuel pin model was selected for use for all 1-D and 3-D calculations in this report.) $k_{\infty}$ as a function of time is plotted in Figs. 2 through 4 These figures all demonstrate that $\mathrm{k}_{\infty}$ decreases for all times beyond 5 years for all enrichments and burnups, although for low burnup a slight increase is seen within the first 5 years of cooling time due to the decay of ${ }^{135} \mathrm{Xe}$. No such increase is observed for high-burnup cases. Xenon loss is offset by increased fission-product poisoning (e.g., ${ }^{155} \mathrm{Gd}$ ) for higher burnups. In addition, the magnitude of the drop in $\mathrm{k}_{\infty}$ is related to burnup; the more highly burned the fuel is, the greater the rate of decrease in $\mathrm{k}_{\infty}$.

Results of these calculations are provided in Appendix A in tabular form, ranked by absorption fraction for each cooling period; these calculations were based on as-computed SAS2H isotopic concentrations. Although ORIGEN-S tracks all actinides and fission products available in ORIGEN-S libraries and calculates fractions based on all nuclides, for brevity the tables list only the top 20 actinide absorbers and the top 30 fission-product absorbers as a function of cooling time. Tables are provided for each combination of enrichment and burnup. These rankings are consistent with the findings of earlier work 1144 performed based on this and other assembly designs. The previous work of ref. 1 was used in combination with the selection criteria discussed earlier to establish a set of 24 actinides and fission products for use in burnup credit calculations. The 


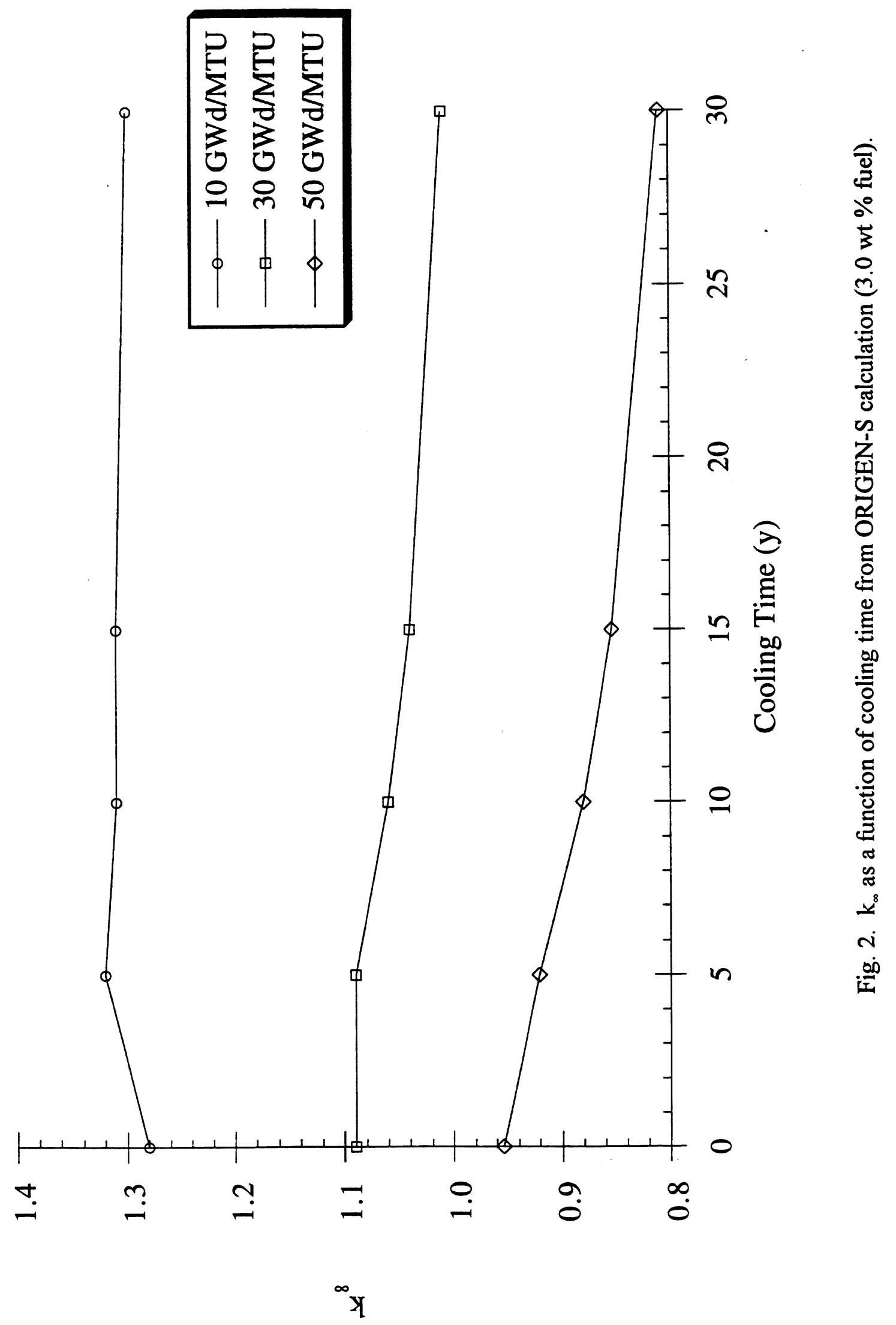




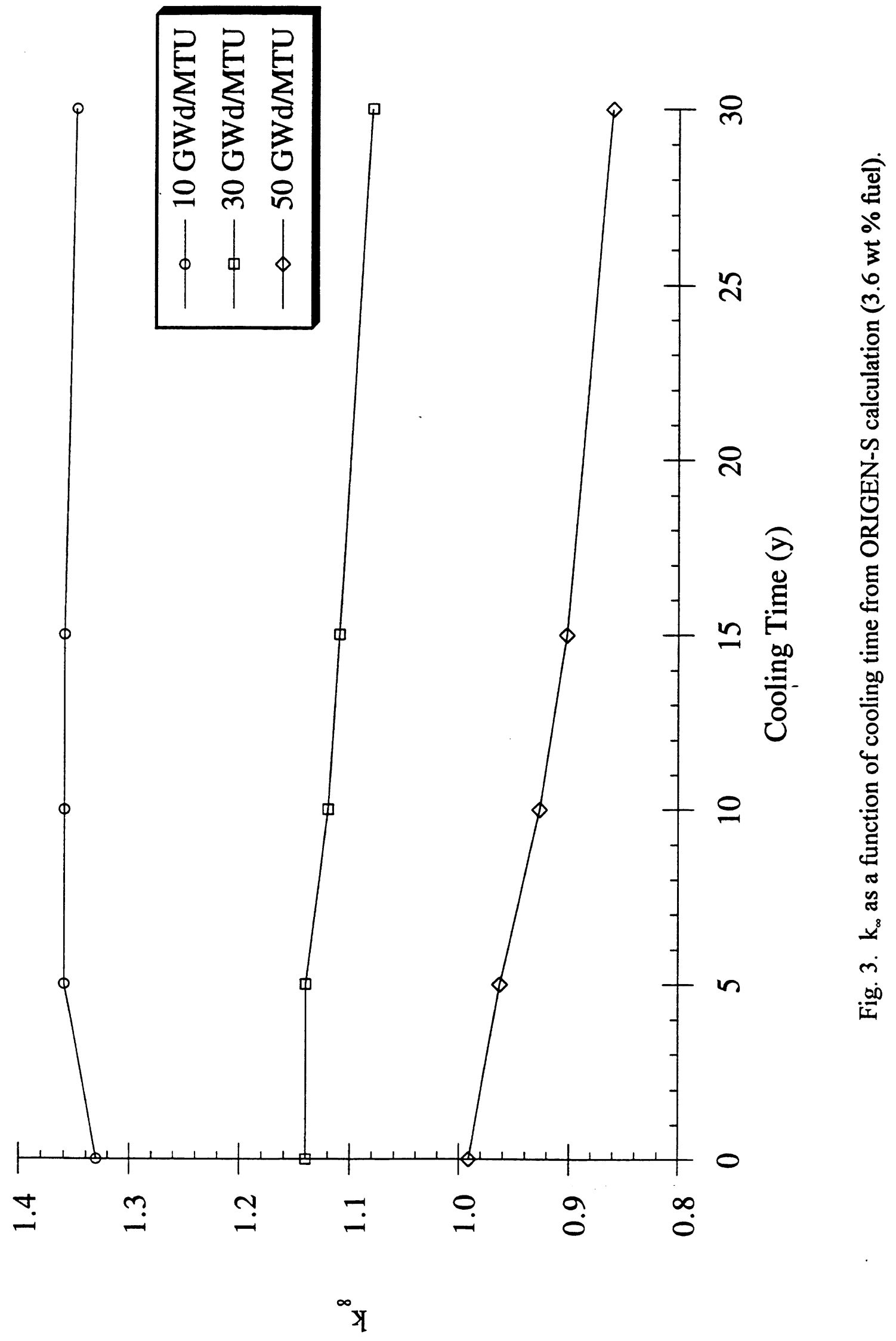




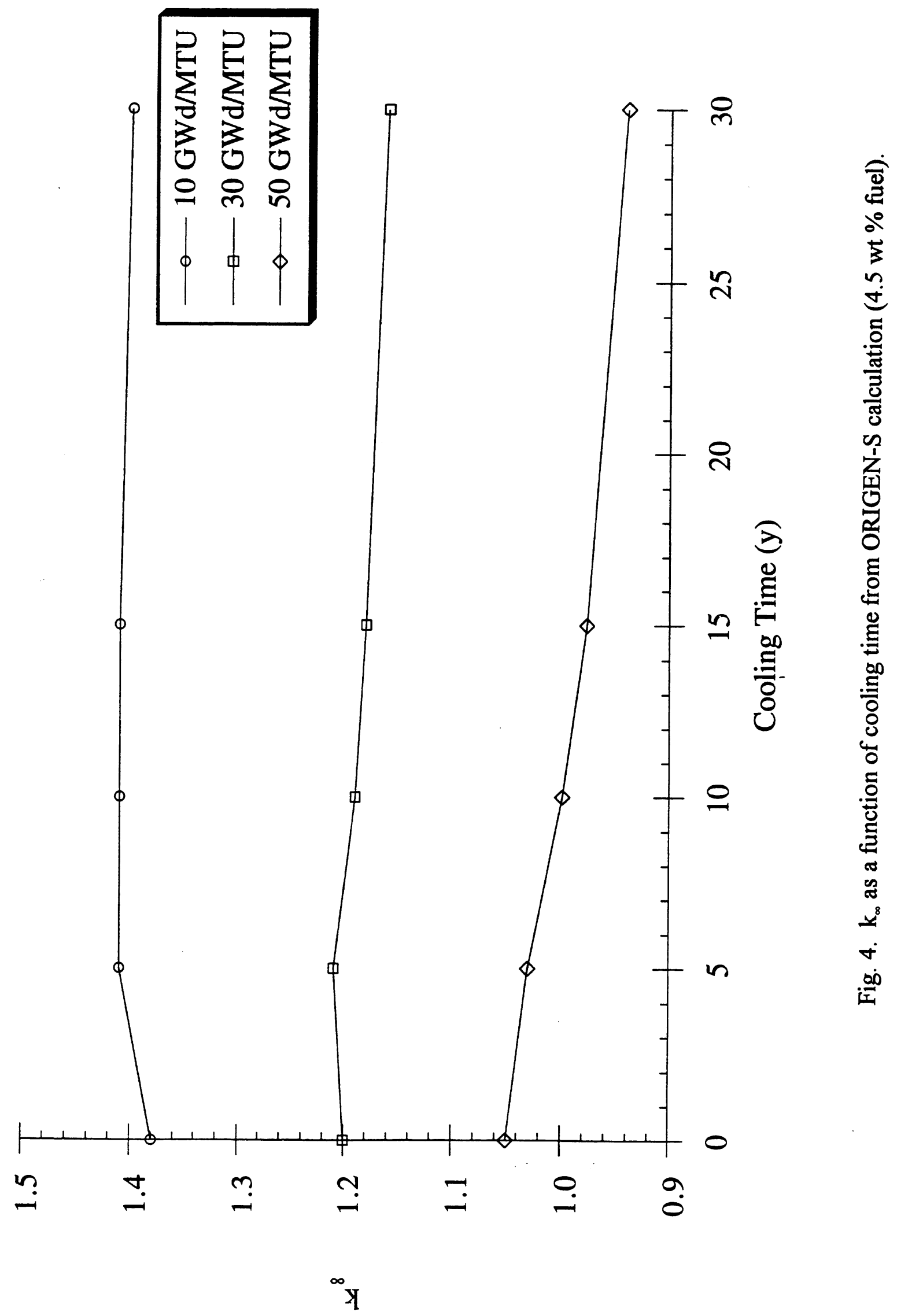


selection process of the earlier work has been repeated here to demonstrate consistency with earlier work, and to formally document the process.

The ORIGEN-S calculations used to obtain these rankings were based on internally computed isotopic concentrations. It is not straightforward to introduce bias-correction terms into ORIGEN-S, thus the absorption rankings are not based on bias-corrected isotopics. It would be possible to use subsequent XSDRNPM calculations to obtain absorption rates both with and without bias corrections. However, it was decided not to investigate this behavior, because it was felt to be more important to rank nuclides in terms of their direct effect on $\mathrm{k}_{\infty}$ rather than their absorption properties. Ranking by $\mathrm{k}_{\infty}$ is discussed in Sect. 3.2.

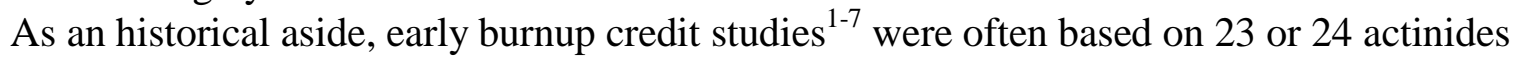
and fission products, while later (and current) calculations will be found to be based on only 22 important actinides and fission products. Originally, 24 important burnup credit nuclides were identified, based on existing and anticipated chemical assay data. Because of a subsequent inability to obtain measurements for ${ }^{103} \mathrm{Rh}$ and the small value of ${ }^{95} \mathrm{Mo}$ relative to the effort required to perform assay measurements, the list was later narrowed down to 23 and, ultimately, 22 nuclides. As will be discussed later, oxygen is also an important isotope in terms of its effect on $\mathrm{k}_{\infty}$ and $\mathrm{k}_{\mathrm{eff}}$ because of the quantity present in fuel. Even though it is not a significant absorber, oxygen strongly contributes to scattering and thermalization mechanisms. Although it is neither an actinide nor fission product, oxygen has often been included in lists summarizing the most important nuclides in burnup credit studies. Thus it is possible to see references to 23, 24, or 25 burnup credit nuclides. This report (and most burnup credit work performed since 1993) is based on a total of 23 burnup credit nuclides: 10 actinides, 12 fission products, and oxygen. The following paragraphs will identify the 10 most dominant actinides and 12 most dominant fission products, in terms of their ability to absorb neutrons.

\subsubsection{Selection of Important Actinides}

From the sets of important actinides listed in Appendix A, it can be seen that most of the actinide absorption is represented by 10 to 11 nuclides for all burnup/enrichment combinations and for cooling times greater than 5 years. In burnup credit applications, a minimum 5-year cooling time has been established before spent fuel is available for transportation, to allow for the decay of shortlived isotopes and to reduce decay heat levels. Thus rankings are important only for post-irradiation times greater than or equal to 5 years.

The important actinide isotopes after this 5-year period are ${ }^{234} \mathrm{U},{ }^{235} \mathrm{U},{ }^{236} \mathrm{U},{ }^{238} \mathrm{U},{ }^{238} \mathrm{Pu}$, ${ }^{239} \mathrm{Pu},{ }^{240} \mathrm{Pu},{ }^{241} \mathrm{Pu},{ }^{242} \mathrm{Pu},{ }^{241} \mathrm{Am},{ }^{237} \mathrm{~Np}$, and, for high burnups, ${ }^{243} \mathrm{Am}$. Because experimental measurements are not available for ${ }^{243} \mathrm{Am}$, because it is consistently among the lowest ranked of these isotopes, and because its net reactivity worth is small (due to its small fission cross section, which offsets its absorption worth), this nuclide is not considered here in the set of important actinides for burnup credit. The decision was made to also remove ${ }^{237} \mathrm{~Np}$ from the list of important actinides, because at the time of the initial selection of the burnup credit nuclides the experimental uncertainty associated with this isotope was large relative to other actinides. Thus the recommended list of actinides presently considered in burnup credit applications consists of 10 nuclides. However, 13 spent fuel samples have been chemically assayed to obtain ${ }^{237} \mathrm{~Np}$ isotopic data, and comparison to calculated SAS2H results have been made. ${ }^{25}$ Because ${ }^{237} \mathrm{~Np}$ is a significant absorber and a significant number of analyses have been performed, it is recommended that future burnup credit development consider the inclusion of this isotope. 
Because the cases studied represent a wide range of enrichments and burnups, three cases were selected to characterize very low, moderate, and very high burnups relative to the initial enrichment. "Very low" and "very high" burnups are intended to exaggerate the effect of burnup by representing extreme cases. Table 2 shows the relative absorption of the 10 burnup credit actinides after a 5-year cooling period for each of the three burnup cases. For each burnup, the first column gives the fraction of all neutron absorptions (actinide and fission product) in the fuel that are calculated to occur in each actinide, whereas the second column gives the fraction of actinide neutron absorptions that occur in the selected actinide. These results show that even though 80 to $94 \%$ of all neutron absorptions occur in actinides (with the fraction decreasing with increasing burnup due to competition with fission-product absorbers), the majority ( 99\%) of all neutron absorptions by actinides occur in the 10 burnup credit actinides. This high percentage is possible because the difference in absorption fractions between the top absorbers and the 20th-ranked absorbers is 6 to 7 orders of magnitude. Thus there are relatively few important absorbers in the set of spent fuel actinides.

\subsubsection{Selection of Important Fission Products}

Unlike the actinides, the fractional neutron absorption by fission-product nuclides is more evenly distributed over a broader range of nuclides. Thus the cutoff between "important" fission products and "unimportant" fission products is somewhat arbitrary. Considering the top 13 ranking positions for all burnup/enrichment sets and for cooling times greater than or equal to 5 years, a total of 16 fission-product nuclides are identified, as listed below.

$\begin{array}{llll}{ }^{155} \mathrm{Gd} & { }^{143} \mathrm{Nd} & { }^{103} \mathrm{Rh} & { }^{149} \mathrm{Sm} \\ { }^{151} \mathrm{Sm} & { }^{133} \mathrm{Cs} & { }^{131} \mathrm{Xe} & { }^{99} \mathrm{Tc} \\ { }^{153} \mathrm{Eu} & { }^{152} \mathrm{Sm} & { }^{145} \mathrm{Nd} & { }^{154} \mathrm{Eu} \\ { }^{109} \mathrm{Ag} & { }^{150} \mathrm{Sm} & { }^{95} \mathrm{Mo} & { }^{147} \mathrm{Sm}\end{array}$

From this list, it is necessary to eliminate ${ }^{131} \mathrm{Xe}$ because, as a gas, it is not fixed in the fuel matrix. Furthermore, ${ }^{109} \mathrm{Ag}$ and ${ }^{154} \mathrm{Eu}$ are important only for high-burnup cases, and even then are the least important of this subset; thus they can also be dropped. The remaining set of 13 fission products is consistent with those identified by an early burnup credit feasibility study 1 with one exception: the earlier study included ${ }^{147} \mathrm{Pm}$ in place of ${ }^{95} \mathrm{Mo}$. Earlier rankings were based on no post-reactor cooling period, whereas the rankings used to select the above isotopes were based on a 5-year cooling period. After 5 years of decay time, ${ }^{147} \mathrm{Pm}$, which was included in the original rankings, is no longer an important absorber; conversely, ${ }^{95}$ Mo becomes more important with time and is therefore included in the list of important isotopes.

Experimental measurements of fission products 3 were performed based on the important isotopes identified in the earlier ranking studies. Measurements for ${ }^{103} \mathrm{Rh}$ and ${ }^{95} \mathrm{Mo}$ require a different, more difficult procedure than that used for the other major fission products. Because ${ }^{95} \mathrm{Mo}$ is a minor contributor ( because ${ }^{103} \mathrm{Rh}$ consistently ranks as the third to fourth most important isotope, efforts are continuing 
Table 2. Fractional neutron absorption as a function of burnup for most important actinides (5-year cooled)

\begin{tabular}{|c|c|c|c|c|c|c|}
\hline \multirow[t]{2}{*}{ Isotope } & \multicolumn{2}{|c|}{$\begin{array}{c}\text { Low Burnup } \\
(4.5 \%, 10 \mathrm{GWd} / \mathrm{MTU})\end{array}$} & \multicolumn{2}{|c|}{$\begin{array}{c}\text { Moderate Burnup } \\
(3.6 \%, 30 \mathrm{GWd} / \mathrm{MTU})\end{array}$} & \multicolumn{2}{|c|}{$\begin{array}{c}\text { High Burnup } \\
(3.0 \%, 50 \mathrm{GWd} / \mathrm{MTU})\end{array}$} \\
\hline & $\begin{array}{c}\% \text { of } \\
\text { absorptions }\end{array}$ & $\begin{array}{l}\% \text { of absorptions } \\
\text { occurring in } \\
\text { actinides }\end{array}$ & $\begin{array}{c}\% \text { of } \\
\text { absorptions }\end{array}$ & $\begin{array}{c}\% \text { of absorptions } \\
\text { occurring in } \\
\text { actinides }\end{array}$ & $\begin{array}{c}\% \text { of } \\
\text { absorptions }\end{array}$ & $\begin{array}{c}\% \text { of absorptions } \\
\text { occurring in } \\
\text { actinides }\end{array}$ \\
\hline${ }^{234} \mathrm{U}$ & 0.1 & 0.2 & 0.1 & 0.1 & 0.1 & 0.1 \\
\hline${ }^{235} \mathrm{U}$ & 53.4 & 56.7 & 23.5 & 26.8 & 6.5 & 8.0 \\
\hline${ }^{236} \mathrm{U}$ & 0.4 & 0.5 & 0.7 & 0.8 & 0.7 & 0.9 \\
\hline${ }^{238} \mathrm{U}$ & 23.7 & 25.2 & 25.3 & 28.8 & 26.0 & 31.9 \\
\hline${ }^{238} \mathrm{Pu}$ & 0.0 & 0.0 & 0.2 & 0.2 & 0.7 & 0.8 \\
\hline${ }^{239} \mathrm{Pu}$ & 13.7 & 14.6 & 25.8 & 29.4 & 28.3 & 34.7 \\
\hline${ }^{240} \mathrm{Pu}$ & 1.9 & 2.1 & 5.9 & 6.8 & 8.2 & 10.0 \\
\hline${ }^{241} \mathrm{Pu}$ & 0.5 & 0.6 & 4.5 & 5.1 & 7.3 & 9.0 \\
\hline${ }^{242} \mathrm{Pu}$ & 0.0 & 0.0 & 0.2 & 0.3 & 0.7 & 0.8 \\
\hline${ }^{241} \mathrm{Am}$ & 0.1 & 0.1 & 1.0 & 1.2 & 1.6 & 2.0 \\
\hline Total & $94.0 \%$ & $99.8 \%$ & $87.3 \%$ & $99.4 \%$ & $80.1 \%$ & $98.4 \%$ \\
\hline
\end{tabular}

to develop a method to chemically separate this isotope for assay purposes. Nevertheless, for the purposes of this report, neither isotope is considered as acceptable for burnup credit analyses.

For historical reasons, the isotope ${ }^{135} \mathrm{Cs}$ has been included in the list of important fission products, although it generally ranks as the 20th to 25 th most important fission product. The exact rationale for its selection as a burnup credit nuclide is unclear; however, because chemical assay data exist for this fission product,it is certainly acceptable for validation purposes.

Based on the above discussion of fission products, a set of 12 fission-product nuclides is currently recommended for burnup credit applications. These nuclides are listed in Table 3, together with the fractional absorptions occurring in each nuclide, both as a fraction of all absorptions and as a fraction of absorptions occurring in all fission products (FP). As with the actinides presented in Table 2, fission-product absorption fractions are provided for low-, moderate-, and high-burnup cases in order to span the anticipated range of burnups for general burnup credit applications. This 
Table 3. Fractional neutron absorption as a function of burnup for most important fission products (5-year cooled)

\begin{tabular}{|c|c|c|c|c|c|c|}
\hline \multirow[t]{2}{*}{ Isotope } & \multicolumn{2}{|c|}{$\begin{array}{c}\text { Low Burnup } \\
(4.5 \%, 10 \mathrm{GWd} / \mathrm{MTU})\end{array}$} & \multicolumn{2}{|c|}{$\begin{array}{c}\text { Moderate Burnup } \\
(3.6 \%, 30 \mathrm{GWd} / \mathrm{MTU})\end{array}$} & \multicolumn{2}{|c|}{$\begin{array}{c}\text { High Burnup } \\
(3.0 \%, 50 \mathrm{GWd} / \mathrm{MTU})\end{array}$} \\
\hline & $\begin{array}{l}\% \text { of all } \\
\text { absorptions }\end{array}$ & $\begin{array}{c}\% \text { of FP } \\
\text { absorptions }\end{array}$ & $\begin{array}{c}\% \text { of all } \\
\text { absorptions }\end{array}$ & $\begin{array}{c}\% \text { of FP } \\
\text { absorptions }\end{array}$ & $\begin{array}{c}\% \text { of all } \\
\text { absorptions }\end{array}$ & $\begin{array}{c}\% \text { of FP } \\
\text { absorptions }\end{array}$ \\
\hline${ }^{99} \mathrm{Tc}$ & 0.16 & 2.67 & 0.44 & 3.59 & 0.66 & 3.54 \\
\hline${ }^{133} \mathrm{Cs}$ & 0.20 & 3.38 & 0.56 & 4.58 & 0.83 & 4.48 \\
\hline${ }^{135} \mathrm{Cs}$ & 0.02 & 0.36 & 0.06 & 0.49 & 0.09 & 0.49 \\
\hline${ }^{143} \mathrm{Nd}$ & 0.41 & 6.97 & 1.18 & 9.68 & 1.58 & 8.52 \\
\hline${ }^{145} \mathrm{Nd}$ & 0.09 & 1.54 & 0.26 & 2.14 & 0.40 & 2.13 \\
\hline${ }^{147} \mathrm{Sm}$ & 0.10 & 1.68 & 0.23 & 1.89 & 0.28 & 1.50 \\
\hline${ }^{149} \mathrm{Sm}$ & 0.90 & 15.24 & 1.04 & 8.53 & 1.04 & 5.61 \\
\hline${ }^{150} \mathrm{Sm}$ & 0.05 & 0.85 & 0.19 & 1.58 & 0.34 & 1.84 \\
\hline${ }^{151} \mathrm{Sm}$ & 0.40 & 6.85 & 0.70 & 5.74 & 0.94 & 5.06 \\
\hline${ }^{152} \mathrm{Sm}$ & 0.12 & 2.06 & 0.38 & 3.12 & 0.57 & 3.10 \\
\hline${ }^{153} \mathrm{Eu}$ & 0.05 & 0.91 & 0.30 & 2.49 & 0.61 & 3.27 \\
\hline${ }^{155} \mathrm{Gd}$ & 0.15 & 2.48 & 1.05 & 8.61 & 2.94 & 15.86 \\
\hline Total & 2.65 & 44.99 & 6.39 & 52.45 & 10.27 & 55.41 \\
\hline
\end{tabular}

table demonstrates that the 12 fission products used represent approximately half the worth of all fission products for all burnups. The trend is for this set of fission products to become the more dominant absorbers with increasing burnup.

\subsection{SENSITIVITY OF $\mathrm{k}_{\mathrm{eff}}$ TO VARIATIONS IN ISOTOPIC COMPOSITIONS}

Although the rankings provided in the previous section indicate which isotopes are the dominant absorbers in spent fuel, it is also important to understand the effect of each isotope on $\mathrm{k}_{\infty}$ itself. Because mechanisms other than absorption are important in the determination of $\mathrm{k}_{\infty}$ (e.g., scattering and fission), the sensitivity of $\mathrm{k}_{\infty}$ to changes in individual isotopic concentrations provides information that more accurately characterizes the importance of individual isotopes (and the uncertainty associated with that isotope) in criticality calculations. Limited studies have been performed in the past to determine the sensitivity of $\mathrm{k}_{\infty}$ to isotopic concentrations, 24 these calculations are repeated here to (1) formally document the approach, (2) show consistency with earlier work, and (3) account for the effect of biases in calculated isotopics. Reference 24 was based on the 44-group ENDF/B-V cross-section library; nevertheless, differences between sensitivity coefficients calculated using the two different libraries are, for the most part, consistent. 
As was mentioned earlier, when experimental measurements are available for comparison to computed isotopics, it is possible to determine a calculational bias relative to measured compositions. This bias can be folded into computed isotopics to improve the estimate of actual or anticipated fuel composition. Thus one may better predict the sensitivity of $\mathrm{k}_{\infty}$ to specific isotopes by more accurately representing the composition of spent fuel. Experimental data are available for the 22 burnup credit actinides and fission products. These data, a method to determine calculational biases, and bias terms computed for each isotope are provided in Appendix B. The approach for estimating the calculational bias is also included in Appendix B, along with bias terms computed for each isotope. Isotopic concentrations may be modified using these bias terms as described in the Appendix. Such a bias correction can be performed for each isotope to obtain a more precise estimate of the actual composition of spent fuel.

Earlier sensitivity studies described in ref. 24 were performed based on nominally computed isotopics. These sensitivity studies have been repeated both with and without bias-based isotopic corrections, so that the net effect of the corrections can be observed. The results are presented in tabular form in Appendix C, for initial enrichments of 3.0, 3.6, and $4.5 \mathrm{wt} \%{ }^{235} \mathrm{U}$, for burnups of 10, 30, and $50 \mathrm{GWd} / \mathrm{MTU}$, and for a 5-year cooling period. Typical results are given in Tables 4 (actinides + fission products) and 5 (actinides only), based on an assumed enrichment/burnup combination of $3.6 \mathrm{wt} \%{ }^{235} \mathrm{U}$ and $30 \mathrm{GWd} / \mathrm{MTU}$.

In these calculations, isotopics were computed using $\mathrm{SAS} 2 \mathrm{H}$, and $\mathrm{k}_{\infty}$ calculations were performed using an infinite lattice XSDRNPM pin-cell model. For each "without bias" case, isotopics were used directly as calculated by SAS2H, whereas for "with bias" cases, the isotopic concentration of each isotope was adjusted using Eq. (B.2) and the bias terms given in Appendix B (a bias of zero was assumed for oxygen, since oxygen is not significantly depleted during a fuel cycle and is therefore well characterized by its beginning-of-life concentration). Actinides + fission products cases were calculated with all burnup credit nuclides present (plus oxygen) in the XSDRNPM model; actinides-only cases were calculated with just the 10 burnup credit actinides and oxygen. Nominal $\mathrm{k}_{\infty}$ values were computed for both nominal and biased isotopic concentrations. Perturbation calculations were performed for each isotope in each isotope set (with and without bias, both with and without fission products present), using a decrease in the amount of isotope (percent perturbation in isotopic concentration) as given in Tables 4 and 5. Perturbation percentages were based on the anticipated sensitivity of each calculation to a given isotope, using the same perturbation values applied in the study of ref. 24. For each case, the magnitude of the sensitivity coefficient is ranked from highest to lowest. Sensitivity coefficients are given in units of $\frac{\left(\mathrm{k}-\mathrm{k}^{\prime}\right) / \mathrm{k}}{\left(\mathrm{N}-\mathrm{N}^{\prime}\right) / \mathrm{N}^{\prime}}$, which can be interpreted as the expected percentage reactivity $(\% \Delta \mathrm{k} / \mathrm{k})$ introduced by a $1 \%$ increase in the isotopic concentration for a given isotope.

The results given in Tables 4 and 5 (and Appendix C for other enrichments and burnups) are consistent with those of earlier work and with the absorption fraction rankings presented in Tables 2 and 3. Differences between absorption fraction rankings and sensitivity coefficient rankings result from the effect of other phenomena (e.g., scattering, fission, and differences between ORIGEN-S and XSDRNPM $\mathrm{k}_{\infty}$ calculations). For the most part, the use of bias correction terms has little effect on the rankings of sensitivity coefficients relative to as-computed isotopics. This situation is especially true for the actinides-only cases, due to the fact that bias terms are on the order of $5 \%$ or less for all but ${ }^{241} \mathrm{Am}$. Considering all burnups and enrichments studied, the only significant change 
Table 4. Sensitivity coefficients with and without bias corrections for actinides and fission products in $3.6 \mathrm{wt} \%, 30 \mathrm{GWd} / \mathrm{MTU}$ burnup spent fuel

\begin{tabular}{crcccc}
\hline & Perturbation & \multicolumn{3}{c}{ Sensitivity coefficient $(\Delta \mathrm{k} / \mathrm{k}) /(\Delta \mathrm{N}) / \mathrm{N})$} \\
Isotope & applied $(\%)$ & With bias & Rank & Without bias & Rank \\
\hline${ }^{234} \mathrm{U}$ & 100 & $-1.328 \mathrm{E}-03$ & $(22)$ & $-1.385 \mathrm{E}-03$ & $(22)$ \\
${ }^{235} \mathrm{U}$ & 1 & $+1.283 \mathrm{E}-01$ & $(2)$ & $+1.260 \mathrm{E}-01$ & $(2)$ \\
${ }^{236} \mathrm{U}$ & 25 & $-6.181 \mathrm{E}-03$ & $(12)$ & $-6.226 \mathrm{E}-03$ & $(12)$ \\
${ }^{238} \mathrm{U}$ & 1 & $-1.663 \mathrm{E}-01$ & $(1)$ & $-1.655 \mathrm{E}-01$ & $(1)$ \\
${ }^{23} \mathrm{Pu}$ & 100 & $-1.798 \mathrm{E}-03$ & $(21)$ & $-1.745 \mathrm{E}-03$ & $(21)$ \\
${ }^{239} \mathrm{Pu}$ & 1 & $+1.076 \mathrm{E}-01$ & $(3)$ & $+1.134 \mathrm{E}-01$ & $(3)$ \\
${ }^{240} \mathrm{Pu}$ & 2 & $-5.106 \mathrm{E}-02$ & $(4)$ & $-4.948 \mathrm{E}-02$ & $(4)$ \\
${ }^{241} \mathrm{Pu}$ & 2 & $+2.983 \mathrm{E}-02$ & $(5)$ & $+3.059 \mathrm{E}-02$ & $(5)$ \\
${ }^{242} \mathrm{Pu}$ & 25 & $-2.892 \mathrm{E}-03$ & $(18)$ & $-2.663 \mathrm{E}-03$ & $(18)$ \\
${ }^{241} \mathrm{Am}$ & 10 & $-1.211 \mathrm{E}-02$ & $(8)$ & $-1.134 \mathrm{E}-02$ & $(10)$ \\
${ }^{\mathrm{O}}$ & 25 & $-1.135 \mathrm{E}-02$ & $(9)$ & $-1.134 \mathrm{E}-02$ & $(9)$ \\
${ }^{99} \mathrm{Tc}$ & 25 & $-4.627 \mathrm{E}-03$ & $(14)$ & $-5.290 \mathrm{E}-03$ & $(14)$ \\
${ }^{133} \mathrm{Cs}$ & 25 & $-5.928 \mathrm{E}-03$ & $(13)$ & $-6.010 \mathrm{E}-03$ & $(13)$ \\
${ }^{135} \mathrm{Cs}$ & 100 & $-4.156 \mathrm{E}-04$ & $(23)$ & $-4.678 \mathrm{E}-04$ & $(23)$ \\
${ }^{143} \mathrm{Nd}$ & 10 & $-1.446 \mathrm{E}-02$ & $(7)$ & $-1.439 \mathrm{E}-02$ & $(7)$ \\
${ }^{145} \mathrm{Nd}$ & 25 & $-2.928 \mathrm{E}-03$ & $(17)$ & $-2.915 \mathrm{E}-03$ & $(17)$ \\
${ }^{147} \mathrm{Sm}$ & 25 & $-2.458 \mathrm{E}-03$ & $(19)$ & $-2.375 \mathrm{E}-03$ & $(19)$ \\
${ }^{149} \mathrm{Sm}$ & 10 & $-2.332 \mathrm{E}-02$ & $(6)$ & $-1.727 \mathrm{E}-02$ & $(6)$ \\
${ }^{150} \mathrm{Sm}$ & 25 & $-2.277 \mathrm{E}-03$ & $(20)$ & $-2.267 \mathrm{E}-03$ & $(20)$ \\
${ }^{151} \mathrm{Sm}$ & 10 & $-6.687 \mathrm{E}-03$ & $(11)$ & $-8.547 \mathrm{E}-03$ & $(11)$ \\
${ }^{152} \mathrm{Sm}$ & 25 & $-3.434 \mathrm{E}-03$ & $(16)$ & $-4.066 \mathrm{E}-03$ & $(15)$ \\
${ }^{153} \mathrm{Eu}$ & 25 & $-3.687 \mathrm{E}-03$ & $(15)$ & $-3.562 \mathrm{E}-03$ & $(16)$ \\
${ }^{155} \mathrm{Gd}$ & 25 & $-6.796 \mathrm{E}-03$ & $(10)$ & $-1.285 \mathrm{E}-02$ & $(8)$ \\
\hline
\end{tabular}


Table 5. Sensitivity coefficients with and without bias corrections for actinides only in $3.6 \mathrm{wt} \%, 30 \mathrm{GWd} / \mathrm{MTU}$ burnup spent fuel

\begin{tabular}{cccccc}
\hline Isotope & $\begin{array}{c}\text { Perturbation } \\
(\%)\end{array}$ & \multicolumn{4}{c}{ Sensitivity Coefficient $(\Delta \mathrm{k} / \mathrm{k}) /(\Delta \mathrm{N}) / \mathrm{N})$} \\
& With bias & Rank & Without bias & Rank \\
\hline${ }^{234} \mathrm{U}$ & 100 & $-1.442 \mathrm{E}-03$ & $(11)$ & $-1.505 \mathrm{E}-03$ & $(11)$ \\
${ }^{235} \mathrm{U}$ & 1 & $+1.033 \mathrm{E}-01$ & $(2)$ & $+1.000 \mathrm{E}-01$ & $(2)$ \\
${ }^{236} \mathrm{U}$ & 25 & $-6.567 \mathrm{E}-03$ & $(8)$ & $-6.581 \mathrm{E}-03$ & $(8)$ \\
${ }^{238} \mathrm{U}$ & 1 & $-1.817 \mathrm{E}-01$ & $(1)$ & $-1.811 \mathrm{E}-01$ & $(1)$ \\
${ }^{238} \mathrm{Pu}$ & 100 & $-2.033 \mathrm{E}-03$ & $(10)$ & $-1.984 \mathrm{E}-03$ & $(10)$ \\
${ }^{239} \mathrm{Pu}$ & 1 & $+8.250 \mathrm{E}-02$ & $(3)$ & $+8.598 \mathrm{E}-02$ & $(3)$ \\
${ }^{240} \mathrm{Pu}$ & 2 & $-5.417 \mathrm{E}-02$ & $(4)$ & $-5.209 \mathrm{E}-02$ & $(4)$ \\
${ }^{241} \mathrm{Pu}$ & 2 & $+2.500 \mathrm{E}-02$ & $(5)$ & $+2.563 \mathrm{E}-02$ & $(5)$ \\
${ }^{242} \mathrm{Pu}$ & 25 & $-3.000 \mathrm{E}-03$ & $(9)$ & $-2.712 \mathrm{E}-03$ & $(9)$ \\
${ }^{241} \mathrm{Am}$ & 10 & $-1.292 \mathrm{E}-02$ & $(6)$ & $-1.199 \mathrm{E}-02$ & $(6)$ \\
$\mathrm{O}$ & 25 & $-1.137 \mathrm{E}-02$ & $(7)$ & $-1.128 \mathrm{E}-02$ & $(7)$ \\
\hline
\end{tabular}

due to biasing occurs for gadolinium due to the large bias in uncertain calculations. Without biasing, it appears that ${ }^{155} \mathrm{Gd}$ is the most important fission product for high-burnup cases. Once the bias is applied, it drops several ranking positions, although it is still a relatively important absorber. [Note: the large bias in ${ }^{155} \mathrm{Gd}$ prediction results from a lack of resonance absorption data in the ${ }^{154} \mathrm{Eu}$ cross-section representation in the 27BURNUPLIB library $\left({ }^{154} \mathrm{Eu}+\mathrm{n} \rightarrow{ }^{155} \mathrm{Eu} \rightarrow{ }^{155} \mathrm{Gd}\right)$. Better results are obtained using ENDF/B-VI evaluations for $\left.{ }^{154} \mathrm{Eu}^{25,27}\right]$

\subsection{GENERAL TRENDS IN $\mathbf{k}_{\infty}$}

To provide a better understanding of spent fuel effects and the relative importance of actinides and fission products as a function of the key spent fuel characteristics (initial enrichment, burnup, and cooling time), this section provides the results of calculations performed over a broad range of these parameters. Infinite lattice calculations were performed using CSAS1X; depletion calculations performed using SAS2H were based on an assumed continuous power operation with no downtime. Initial enrichments of 3.0, 3.6, and $4.5 \mathrm{wt} \%{ }^{235} \mathrm{U}$ and burnups of 10, 30, and $50 \mathrm{GWd} / \mathrm{MTU}$ were studied for cooling times ranging from 0 to 200 years. Although enrichments and burnups beyond these ranges do occur, these values serve to illustrate the general behavior of $\mathrm{k}_{\infty}$ with changes in each parameter.

Results of these calculations $\left(\mathrm{k}_{\infty}\right)$ are listed in Appendix D. Calculations were performed both with and without fission products, using biased isotopic concentrations to obtain the best estimate of spent fuel composition. In addition, calculations were performed using conservative isotopic correction factors (see Appendix B, Table B-21) to obtain conservative (i.e., upper-bound) estimates of $\mathrm{k}_{\infty}$. These more conservative calculations allow a determination of the effect (in terms of $\Delta \mathrm{k}$ worth) of isotopic concentrations modified by conservative correction factors relative to expected (bias-modified) isotopics. 
Figures 5 and 6 illustrate the time-dependent reactivity of spent fuel for times varying from 0 to 200 years after irradiation. Figure 5 shows the behavior for highly burned $(50 \mathrm{GWd} / \mathrm{MTU})$ fuel with an initial enrichment of $3.6 \mathrm{wt} \%$; this level of burnup was selected to represent the fuel depletion in spent fuel discharged from a reactor at end of life (although for higher initial enrichments higher burnup at discharge would be expected). To demonstrate the relative behavior of spent fuel, Fig. 6 illustrates the cooling-time response for an underburned (10 GWd/MTU) sample of the same fuel. The following observations may be made with respect to these two figures:

\$ Total Worth: In all cases, reactivity worth decreases significantly after shutdown (due to the buildup of fission products and the decay of ${ }^{241} \mathrm{Pu}$ ). Actinides-only cases drop more than $15 \%$ with best estimate (i.e., bias-corrected) isotopics, and almost 13\% using conservative isotopics; when fission products are included, best estimate $\mathrm{k}_{\infty}$ values drop almost $20 \%$, conservative values drop more than $12 \%$. Also, in all cases reactivity begins to slowly increase after about 100 years, and continues to rise at a slow rate beyond 200 years.

\$ Fission Product Worth: Using best-estimate isotopics, the additional negative worth of fission products is roughly $10 \% \Delta \mathrm{k}$ relative to actinides only with zero cooling time; this value increases slightly over the first 30 to 50 years, but then becomes constant at roughly 12 to $13 \%$ $\Delta \mathrm{k}$. The same trend is seen when conservative isotopics are used; however, fission products have a negative worth of about $4 \%$ with zero cooling time, increasing to approximately $6 \% \Delta \mathrm{k}$ for cooling times greater than about 50 years. After 50 years, most fission products have reached their maximum concentrations.

\$ Conservative vs Best Estimate: When criticality calculations are performed omitting fission products, the conservative isotopics have a negative worth ranging from $5 \%$ (no cooling) to $8 \%$ (200 y). When fission products are included, the conservatism in negative worth increases to roughly $10 \% \Delta \mathrm{k}$ for zero cooling to $16 \%$ after 200 years. Because more measurement data are available for actinide isotopes (see Appendix B), their biases are better defined and have less uncertainty. Conservatism increases with the increasing uncertainty associated with the calculated fission-product biases, because the uncertainty is incorporated in the isotopic correction factors.

\$ High vs Low Burnup: Similar trends are noted for both high and low burnup. It is worth noting that for a given initial enrichment, the magnitude of the initial reactivity drop, the fissionproduct worth, and the difference between conservative and best-estimate values of $\mathrm{k}_{\infty}$ all increase with increased burnup. However, no consistent trend or correlation is observed between the behavior of these parameters as a function of burnup.

Figures 7 and 8 illustrate the relative behavior of $\mathrm{k}_{\infty}$ with cooling time for best-estimate calculations, assuming $3.6 \mathrm{wt} \%$ fuel at 10 and $50 \mathrm{GWd} / \mathrm{MTU}$ burnup. Values for $\mathrm{k}_{\infty}$ were normalized to a value of 1.0 for zero cooling time. As was shown earlier (see Figs. 2 through 4 , the magnitude of the drop in $\mathrm{k}_{\infty}$ with cooling time is burnup dependent. As one would expect, the worth of fission products is also burnup dependent. Both cases show that the worth of fission products increases with time, reaching a maximum after a cooling period of around 50 years. 


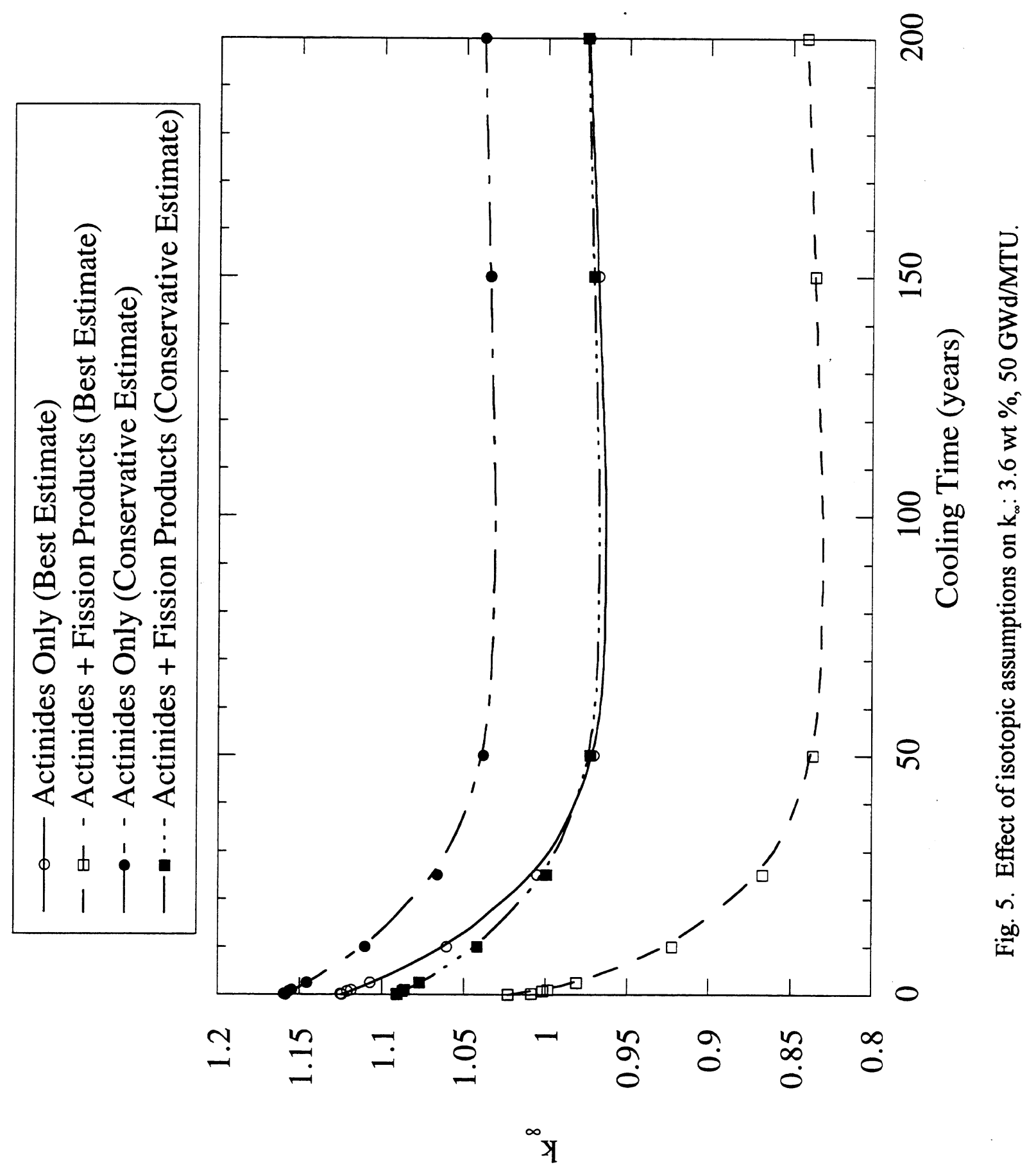




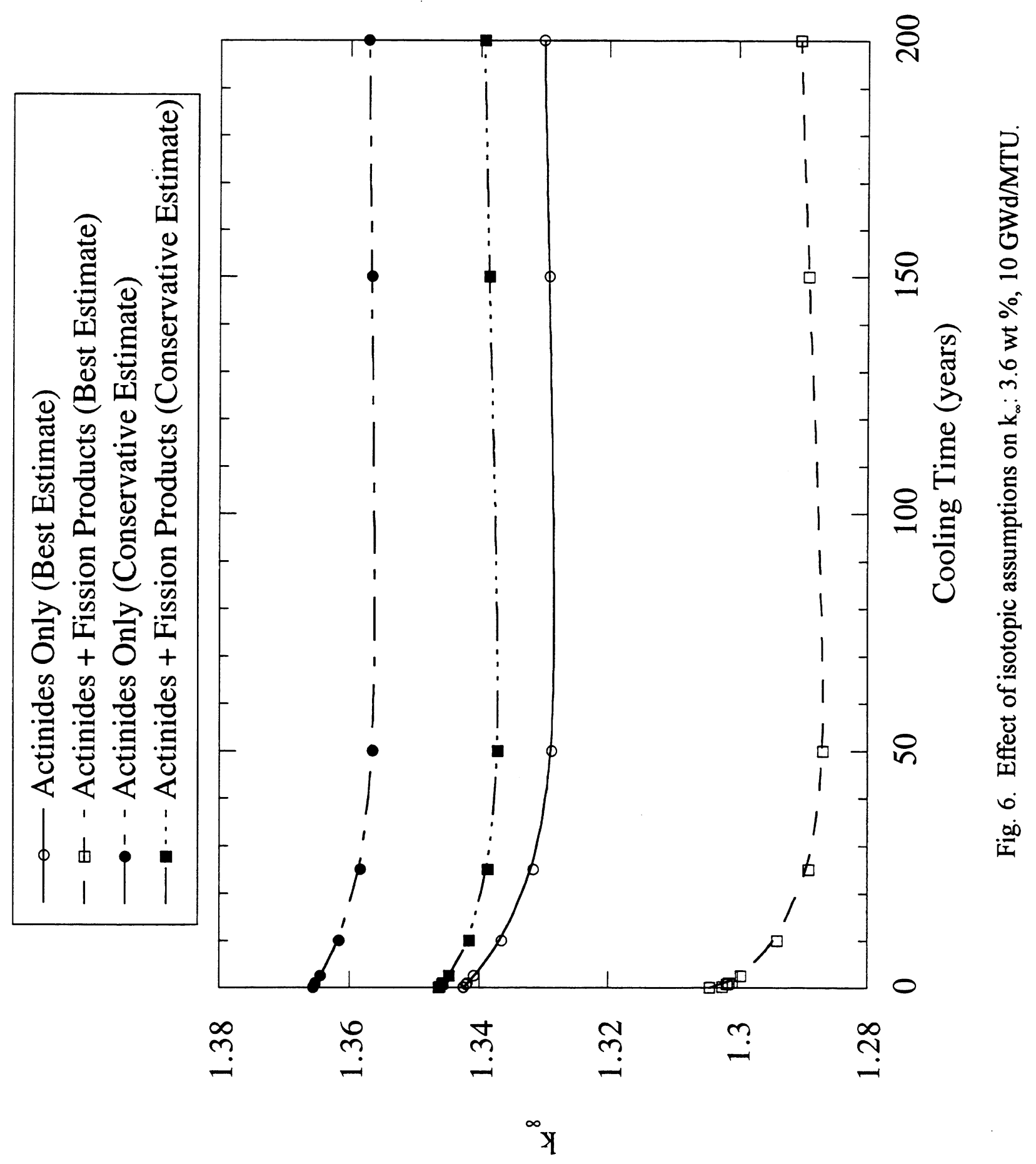




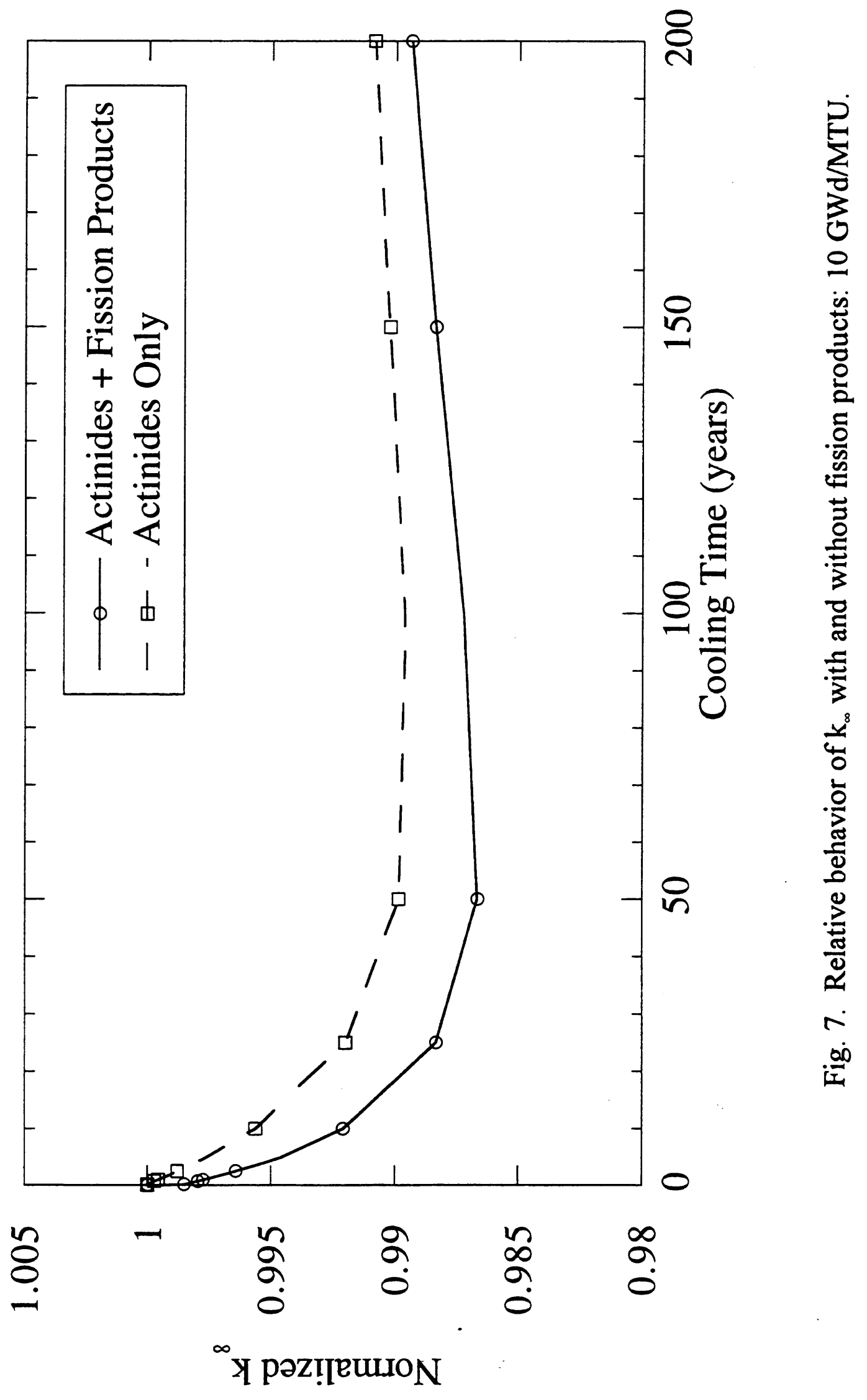




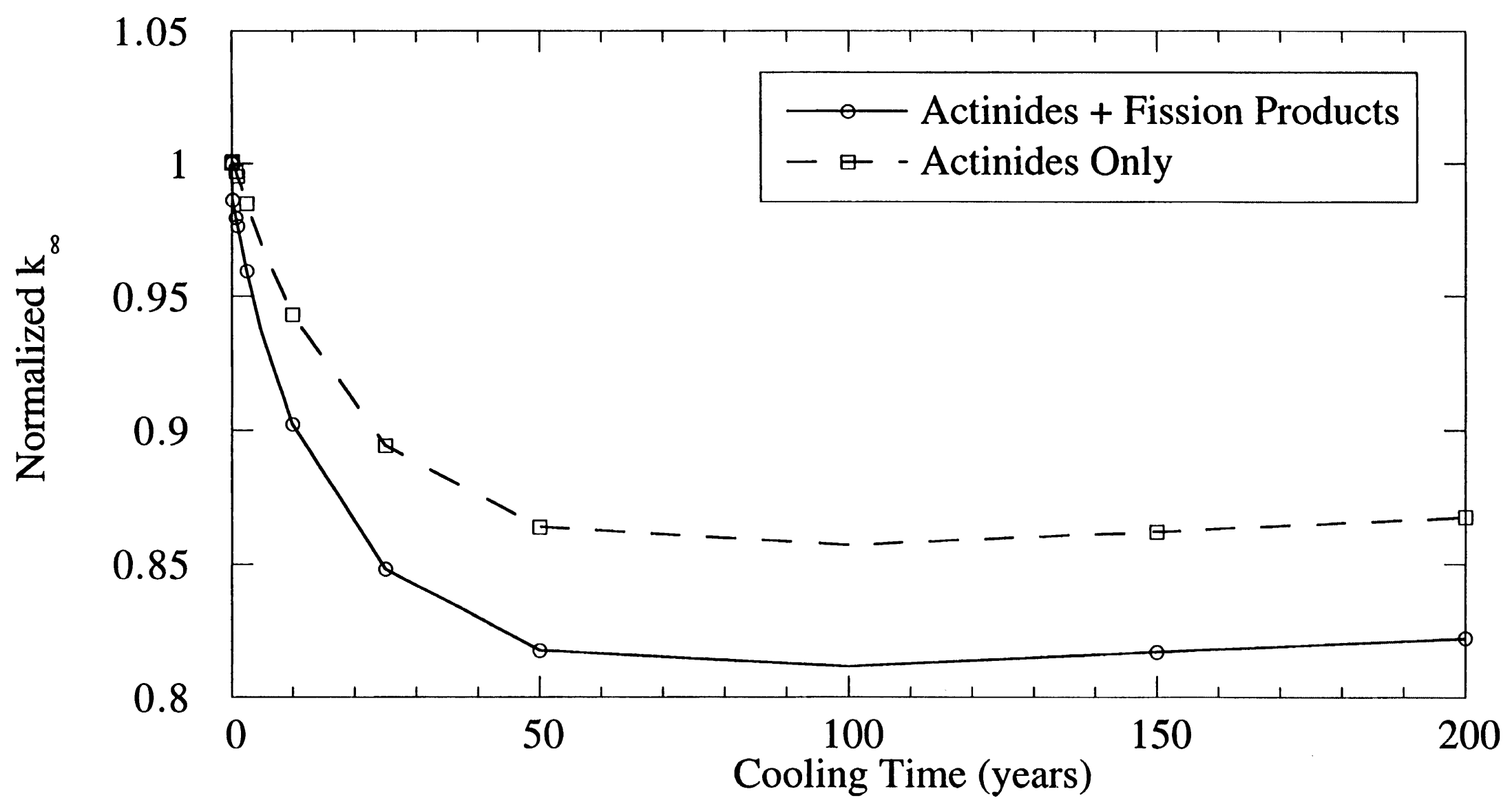

Fig. 8. Relative behavior of $\mathrm{k}_{\infty}$ with and without fission products: $50 \mathrm{GWd} / \mathrm{MTU}$. 
Figures 9 and 10 demonstrate the time-dependent behavior of spent fuel (containing both actinides and fission products) as a function of initial enrichment. For high-burnup fuel, the maximum change in reactivity ranges from $21 \%(3.0 \mathrm{wt} \%)$ to $17 \%(4.5 \mathrm{wt} \%)$; for low-burnup fuel, the reactivity change ranges from 1.2 to $2.2 \%$. Since at given level of burnup $3.0 \mathrm{wt} \%$ fuel is more heavily depleted than $4.5 \mathrm{wt} \%$ (more fissile depletion), one would expect a greater spent fuel effect. This trend is more easily illustrated by Fig. 11, which shows the behavior of $\mathrm{k}_{\infty}$ as a function of both initial enrichment and burnup for spent fuel including fission products. The same trend is observed in the absence of fission products, as shown in Fig. 12.

Figures 13 and 14 show the time-dependent behavior of $k_{\infty}$ for short times ( $<1$ year) after shutdown. For a relative comparison, both are plotted on the same scale. Figure 13 illustrates the behavior of calculations performed with actinides only, and shows an increase in reactivity within the 3 months after shutdown for highly burned fuels due to the rapid decay of ${ }^{239} \mathrm{~Np}$ to fissile ${ }^{239} \mathrm{Pu}$. However, the increase is small and is inconsequential within 6 months after shutdown. No such increase is observed when fission products are included in the criticality calculation, as shown in Fig. 14, where $\mathrm{k}_{\infty}$ is found to continually decrease after shutdown. In this case, the ${ }^{239} \mathrm{Pu}$ production is offset by the rapid production of ${ }^{149} \mathrm{Sm}$ and ${ }^{143} \mathrm{Nd}$.

Although time periods of less than 5 years are not of interest in burnup credit applications, it is important to understand the behavior of nuclide decay for short time periods, as these events contribute to the nuclide inventory after 5 years. These results also help to explain differences in reactivity observed between current results and the earlier ORIGEN-S calculations.

The small, short-term increase seen in Fig. 13 is in contrast to the behavior seen in the ORIGEN-S results shown in Figs. 2 through 4 . In the earlier calculations, a reactivity increase of a few percent is seen for low-burnup cases; reactivity does not drop below its time zero (discharge) level until about 30 years after shutdown. However, the ORIGEN-S calculations were based on all (>1000) nuclides available, instead of the 23 nuclides recommended in Sect. 3 and used to calculate the values of $\mathrm{k}_{\infty}$ plotted in Figs. 13 and 14 . Differences in time-dependent behavior thus result from the behavior of short-lived absorber nuclides (e.g., ${ }^{135} \mathrm{Xe}$ and ${ }^{147} \mathrm{Pm}$ ). Note that because these absorbers have decayed away after 5 years, they are unimportant as burnup credit nuclides.

Figures 15 and 16 illustrate the behavior of $\mathrm{k}_{\infty}$ as a function of burnup, and show that the effect of fission-product absorption increases with burnup. Figure 15 shows this trend after a 5-year cooling period. Figure 16 shows that the same trend is seen after a 200 -year cooling period. The difference between actinides only and actinides plus fission-product cases remains almost constant between the 5-year-cooled and 200-year-cooled calculations. Thus the decrease in $\mathrm{k}_{\infty}$ with increasing cooling time is primarily a function of actinide behavior. The most dominant effect would be due to the decay of ${ }^{241} \mathrm{Pu}$ to ${ }^{241} \mathrm{Am}$, which results in both the loss of a fissile nuclide and the concurrent production of an absorber. With a 14.35 -year half-life, most ${ }^{241} \mathrm{Pu}$ present at shutdown remains in the fuel after 5 years, but is gone after 200 years.

Note that little effect is seen due to the decay of ${ }^{155} \mathrm{Eu}$ to ${ }^{155} \mathrm{Gd}$. Because ${ }^{155} \mathrm{Eu}$ has a 4.73-year half-life, the inventory of ${ }^{155} \mathrm{Gd}$ will essentially double during the period between 5 and 200 years. However, ${ }^{151} \mathrm{Sm}$, also an important absorber, decays with a 90 -year half-life. Thus well over half of this absorber decays away during a 200 -year cooling period, practically offsetting the effect of ${ }^{155} \mathrm{Gd}$ production. 


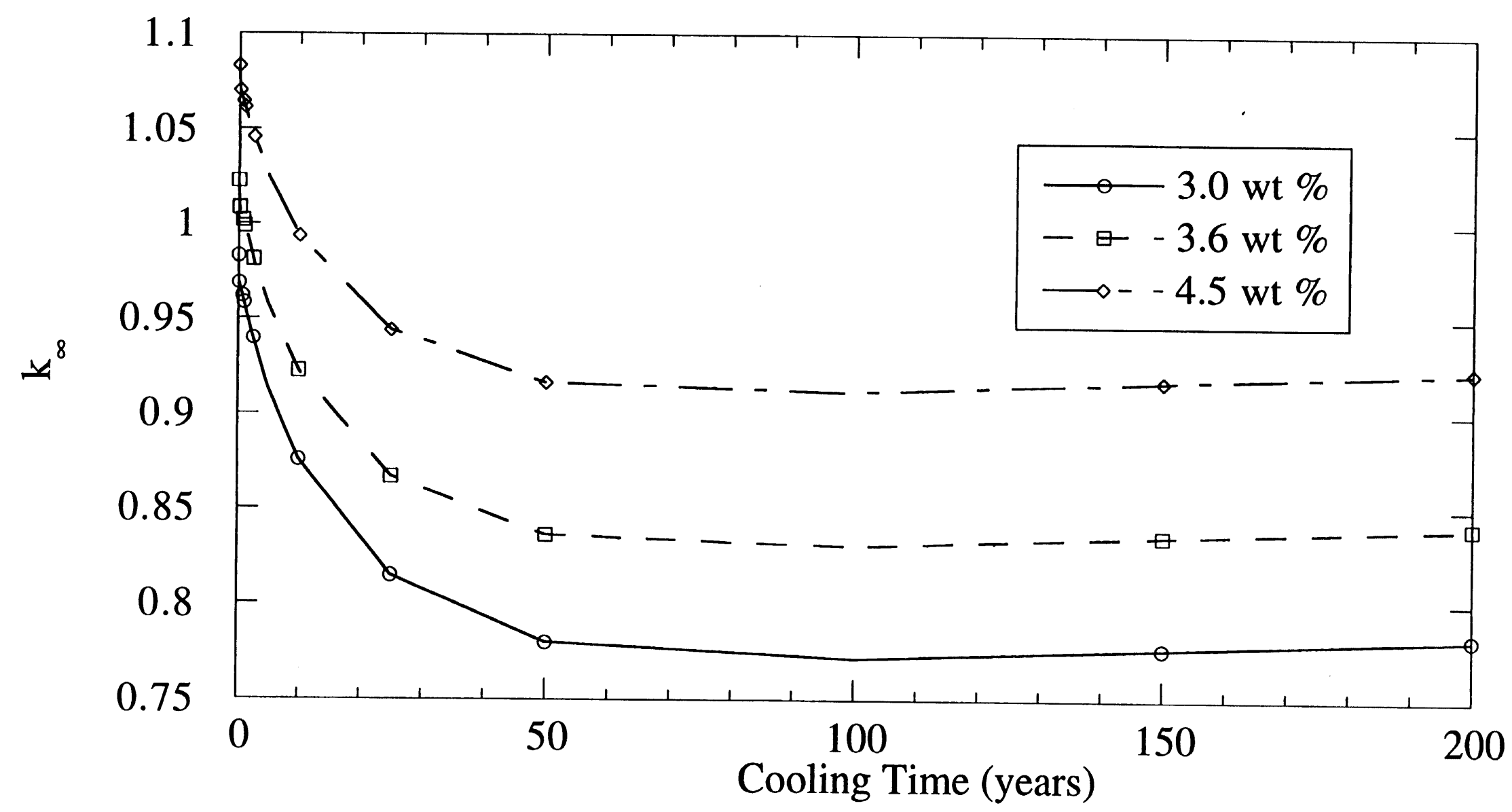

Fig. 9. Effect of cooling time on $\mathrm{k}_{\infty}$ for various enrichments: actinides + fission products, $50 \mathrm{GWd} / \mathrm{MTU}$. 


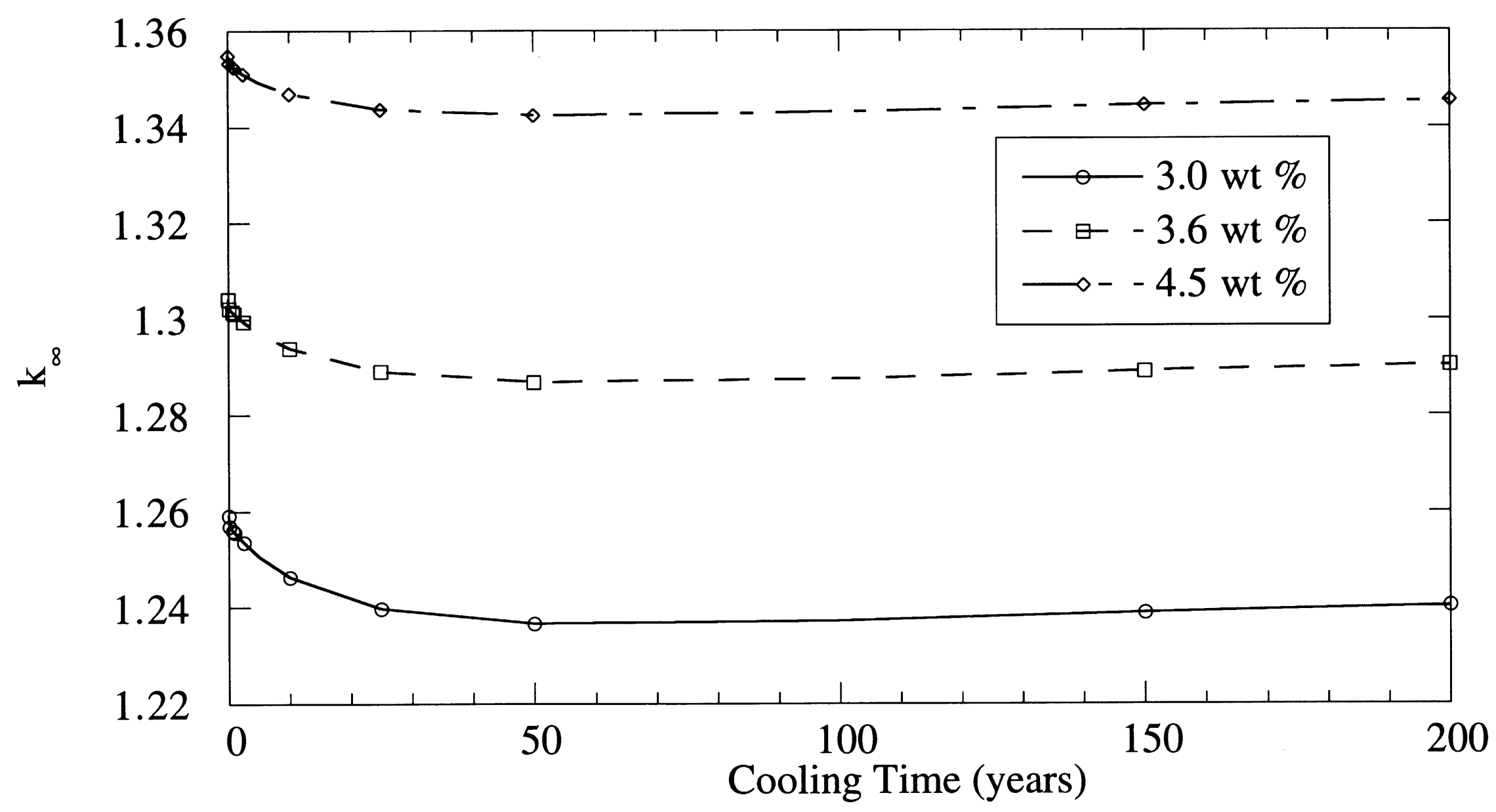

Fig. 10. Effect of cooling time on $\mathrm{k}_{\infty}$ for various enrichments: actinides + fission products, $10 \mathrm{GWd} / \mathrm{MTU}$. 


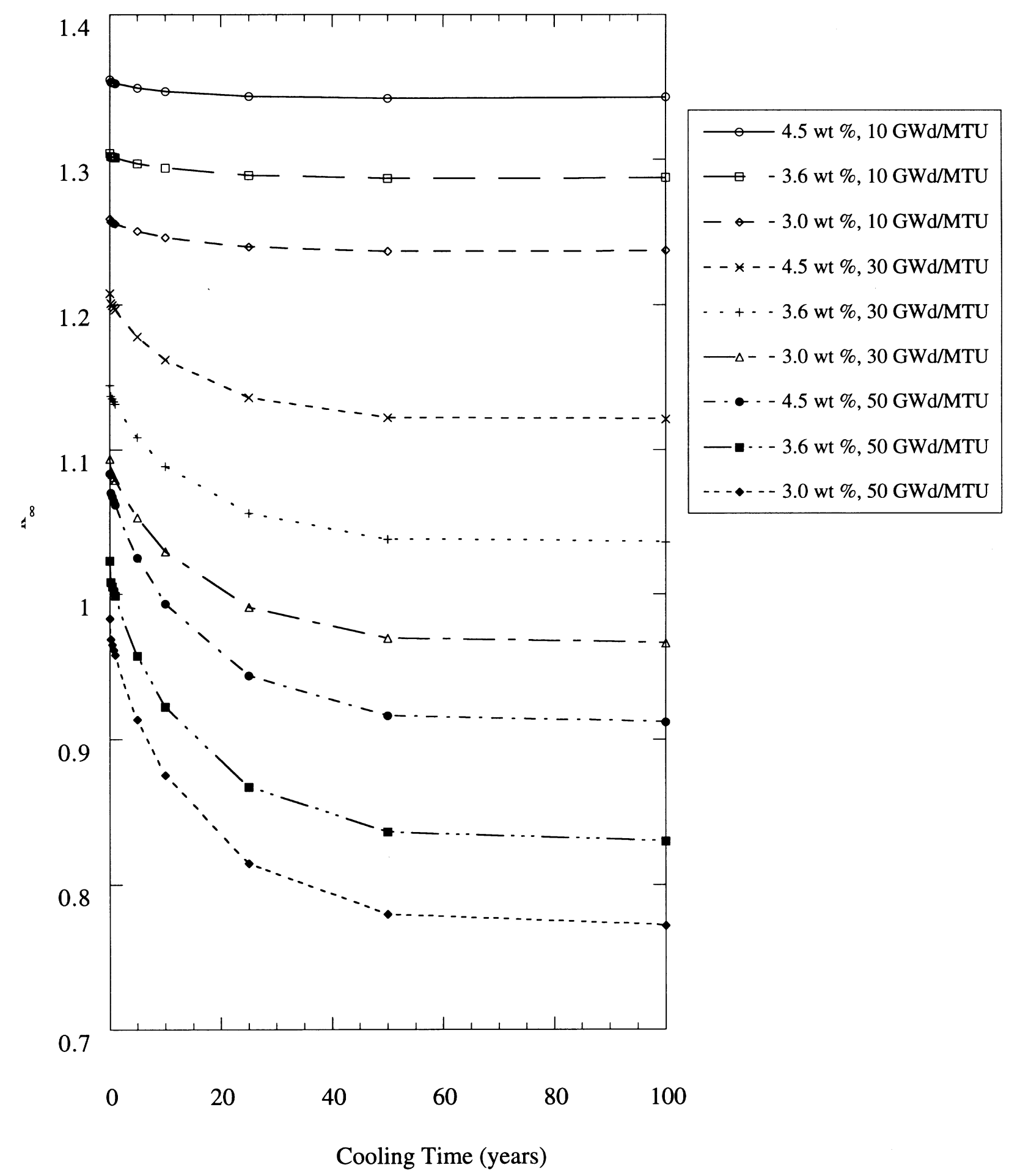

Fig. 11. Effect of cooling time on $\mathrm{k}_{\infty}$ for various burnups: actinides + fission products. 


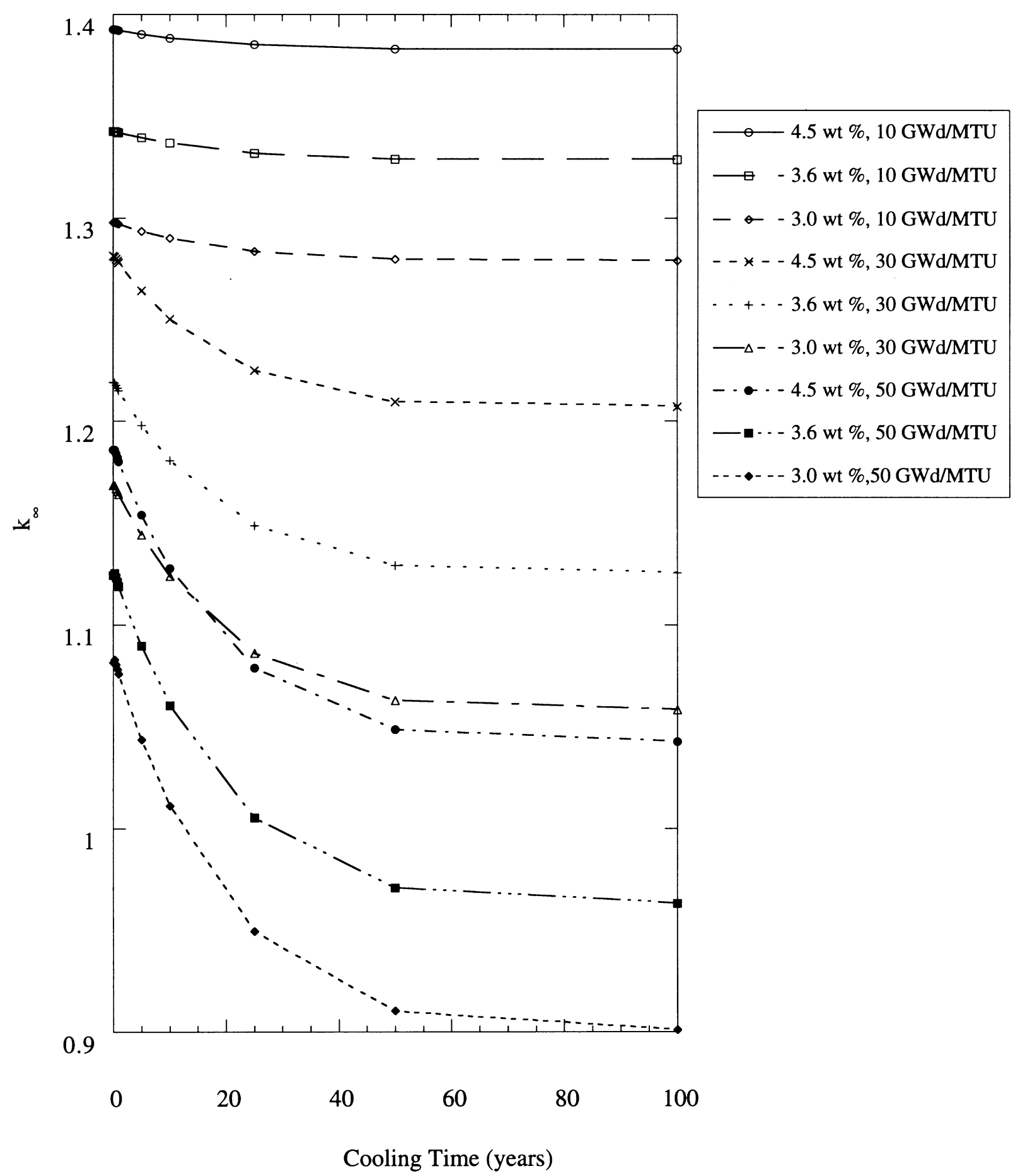

Fig. 12. Effect of cooling time on $\mathrm{k}_{\infty}$ for various burnups: actinides only. 


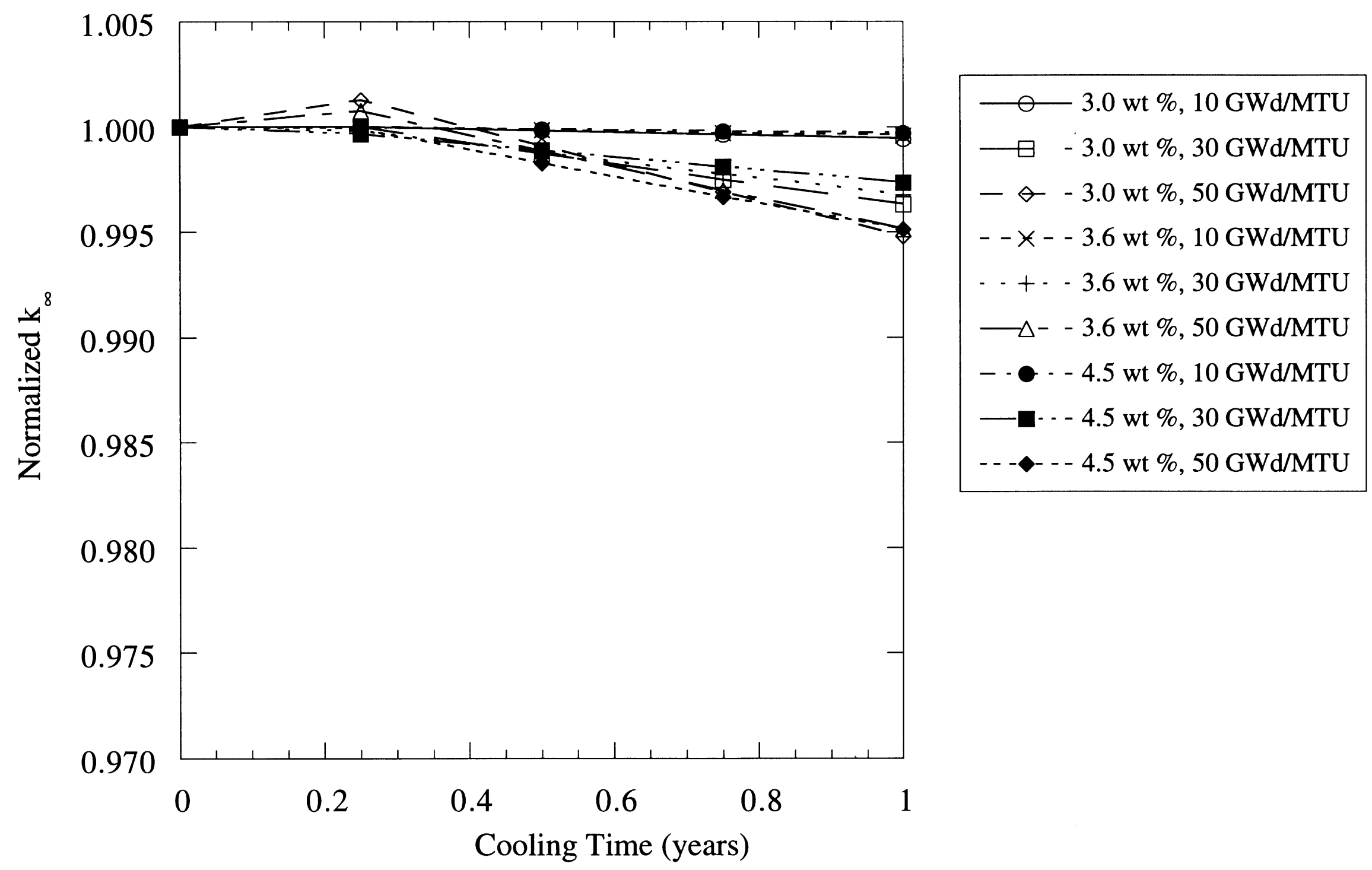

Fig. 13. Short-term effect of burnup on $\mathrm{k}_{\infty}$ : actinides only. 


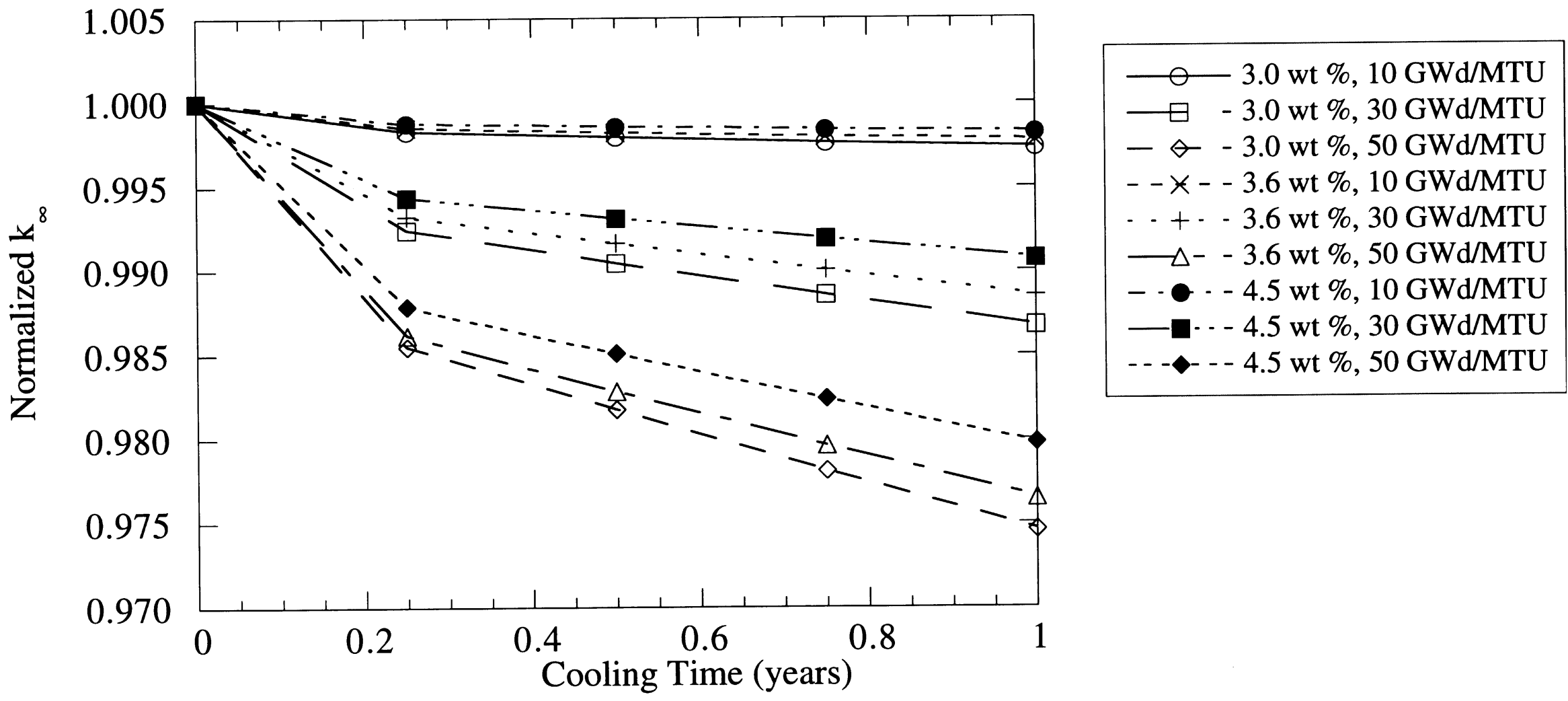

Fig. 14. Short-term effect of burnup on $\mathrm{k}_{\infty}$ : actinides + fission products. 


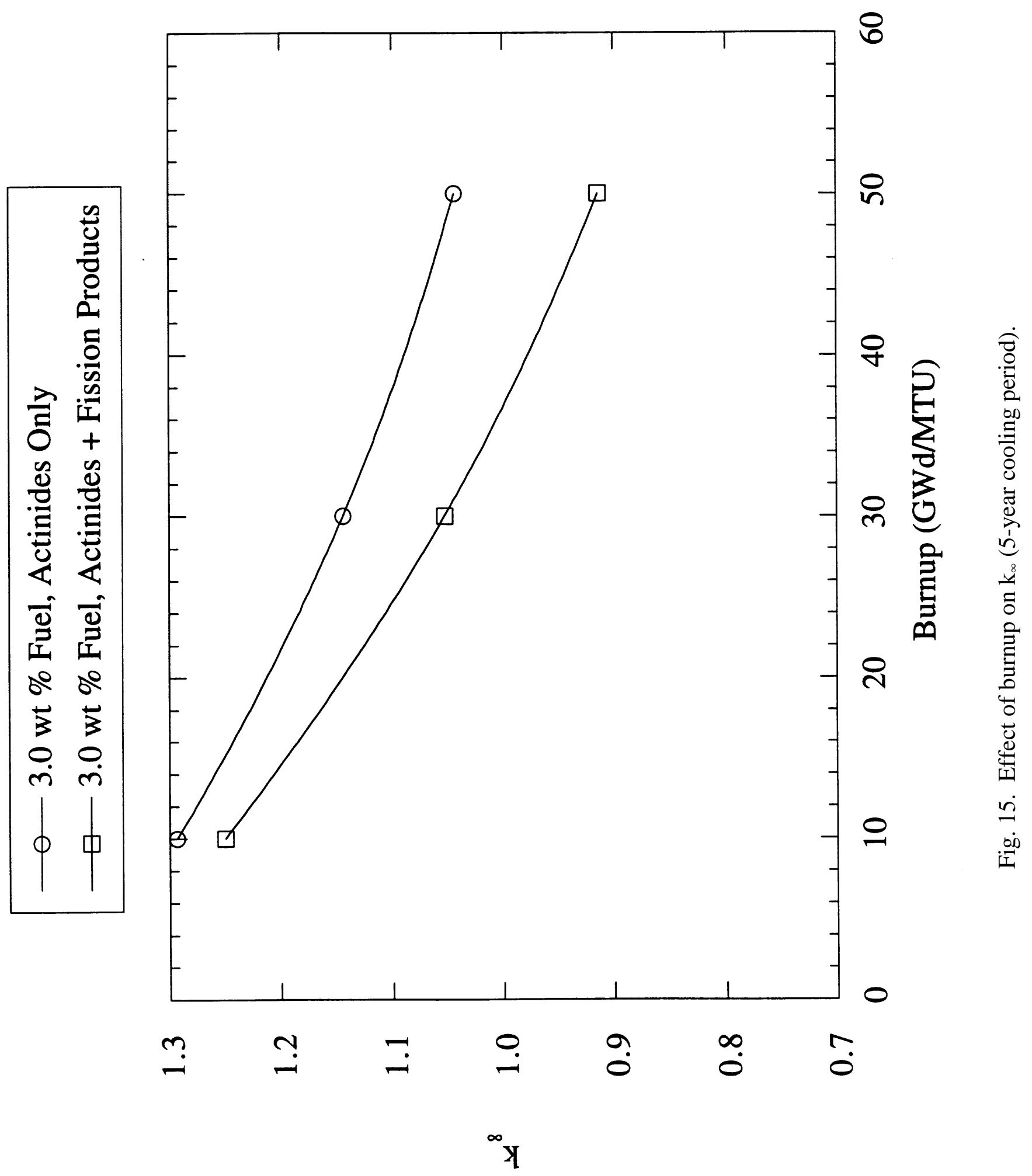




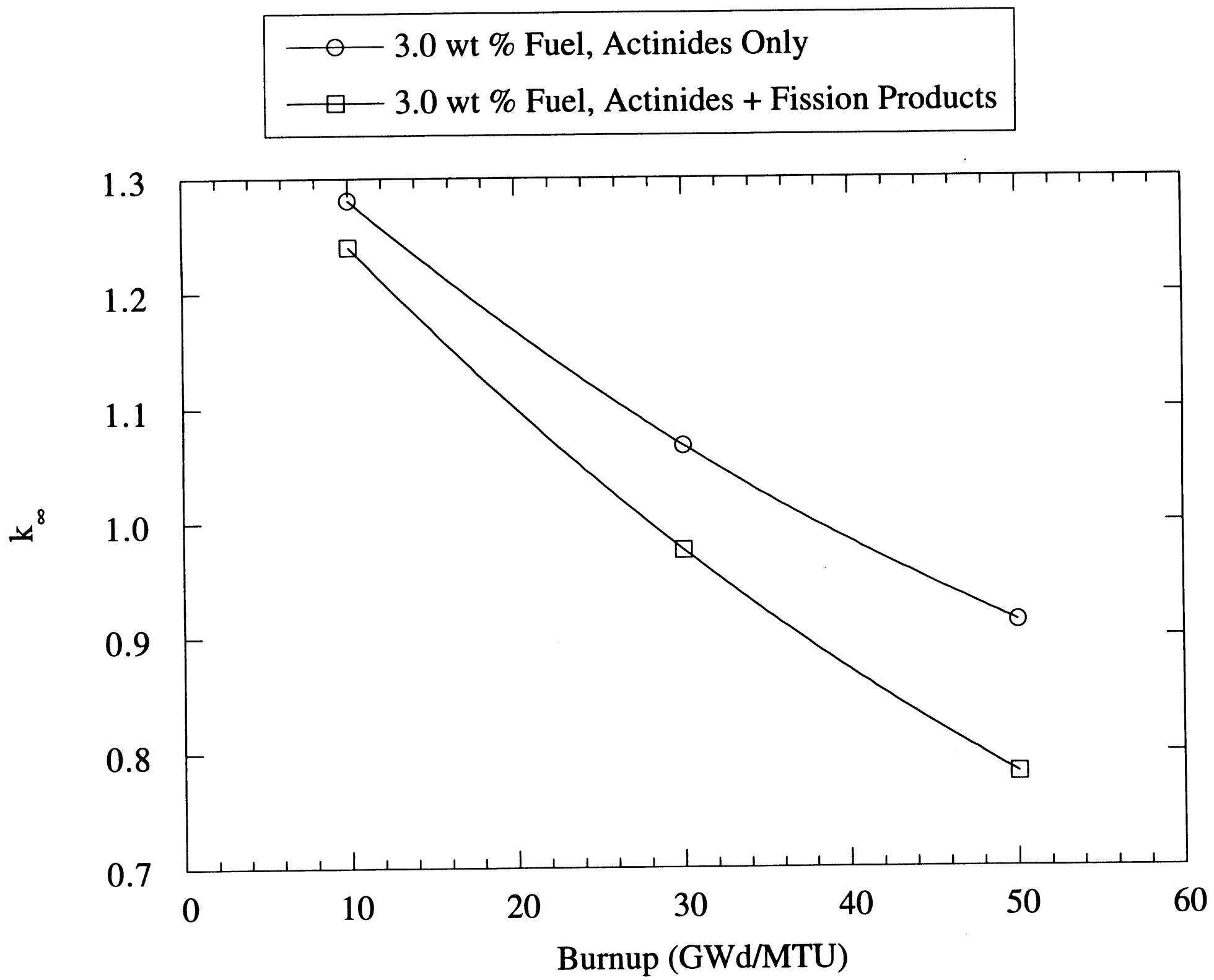

Fig. 16. Effect of burnup on $\mathrm{k}_{\infty}$ (200-year cooling period). 


\subsection{SENSITIVITY OF $\mathbf{k}_{\infty}$ TO BURNUP HISTORY}

Depletion calculations for a fuel assembly are based on the burnup history of that assembly. In reactor operation, the burnup history depends not only on the operational cycles in which the fuel was depleted, but also on the depletion rate (i.e., specific power) under which each fuel assembly was operated while in core. Such power variations are due to reactor-specific operation considerations, reactor type, and changes in core position resulting from fuel shuffling operations. Thus each spent fuel assembly to be considered for storage or transport is likely to possess a unique burnup history. Because the tracking of each candidate assembly's specific operating history is overly burdensome and is not possible for design and safety analysis purposes, it is necessary to identify a single assumed operating history which can, in terms of $\mathrm{k}_{\infty}$, conservatively bound anticipated histories. Since each isotope present will have a unique response to a given operating history (either positive or negative), $\mathrm{k}_{\infty}$ provides the best integral measure of burnup history effects.

In order to better understand operating history effects, the phenomena can be broken into two separate categories: average specific power and time-dependent variations in power. The former addresses the behavior of $\mathrm{k}_{\infty}$ as a function of the specific rate of burnup assumed, while the latter relates $\mathrm{k}_{\infty}$ to relative variations about the average as a function of burnup time. The following two subsections discuss studies to characterize the behavior of $\mathrm{k}_{\infty}$ as a function of each of these parameters. Because of the complex time-dependent behavior of the numerous nuclides tracked during depletion calculations, the explanation of reactivity variation is nontrivial. The following discussions attempt to capture the key elements of depletion effects.

\subsubsection{Effect of Specific Power on Depletion Calculations}

Calculations have been performed using SAS2H for depletion and CSAS1X to calculate an infinite-lattice value of $k_{\infty}$. These calculations are based on a Westinghouse $17 \times 17$-type fuel pin for burnups of 10,30, and $50 \mathrm{GWd} / \mathrm{MTU}$, for a 5-year cooling time. Cases were run both with and without fission products present in the $\mathrm{k}_{\infty}$ calculations. All calculations were based on biased isotopic concentrations (i.e., computed concentrations were modified by bias terms to estimate actual compositions). Results are provided in Tables 6 (actinides + fission products) and 7 (actinides only) for specific powers ranging from 10 to $50 \mathrm{MW} / \mathrm{MTU}$. These results are also plotted in Figs. 17 and 18. Note that burnups as high as $50 \mathrm{GWd} / \mathrm{MTU}$ are unlikely for specific powers as low as $10 \mathrm{GWd} / \mathrm{MTU}$. These values were computed merely to illustrate trends with specific power and burnup.

The tables provide the values of $\mathrm{k}_{\infty}$ as computed in an XSDRNPM calculation in CSAS1X. The two figures show results in terms of a normalized value of $\mathrm{k}_{\infty}$, so that the relative behavior of the various trends may be observed. The results show that the calculated value of $\mathrm{k}_{\infty}$ decreases with increasing specific power when fission products are present in the criticality calculation; conversely, $\mathrm{k}_{\infty}$ increases with increasing specific power when fission products are omitted from the criticality calculation. Additionally, when fission products are present, the magnitude of the variation is strongly tied to the fuel burnup, and to a lesser extent the initial enrichment. When fission products are not considered in the criticality calculation, both initial enrichment and burnup are significant factors affecting the range of variation. With fission products present, the change in $\mathrm{k}_{\infty}$ is roughly $2 \% \Delta \mathrm{k}$ over the 
Table $6 . \mathrm{k}_{\infty}$ as a function of depletion rate (actinides + fission products)

\begin{tabular}{|c|c|c|c|c|c|c|c|c|c|}
\hline $\begin{array}{c}\text { Specific power } \\
\text { during depletion } \\
\text { (MW/MTU) }\end{array}$ & \multicolumn{3}{|c|}{$3.0 \mathrm{wt} \%$} & \multicolumn{3}{|c|}{$3.6 \mathrm{wt} \%$} & \multicolumn{3}{|c|}{4.5 wt $\%$} \\
\hline Burnup & 10 & 30 & 50 & 10 & 30 & 50 & 10 & 30 & 50 \\
\hline 10 & 1.25124 & 1.05393 & 0.91916 & 1.29816 & 1.11041 & 0.96278 & 1.35051 & 1.18057 & 1.03096 \\
\hline 15 & 1.25119 & 1.05442 & 0.91889 & 1.29801 & 1.11073 & 0.96265 & 1.35023 & 1.18057 & 1.03057 \\
\hline 20 & 1.25091 & 1.05366 & 0.91716 & 1.29766 & 1.11003 & 0.96091 & 1.34989 & 1.17975 & 1.02884 \\
\hline 25 & 1.25059 & 1.05251 & 0.91491 & 1.29732 & 1.10893 & 0.95861 & 1.34951 & 1.17874 & 1.02659 \\
\hline 30 & 1.25026 & 1.05081 & 0.91228 & 1.29689 & 1.10752 & 0.95615 & 1.34909 & 1.17749 & 1.02412 \\
\hline 35 & 1.24988 & 1.04946 & 0.90961 & 1.29650 & 1.10606 & 0.95345 & 1.34872 & 1.17598 & 1.02166 \\
\hline 40 & 1.24947 & 1.04762 & 0.90687 & 1.29612 & 1.10442 & 0.95073 & 1.34846 & 1.17465 & 1.01890 \\
\hline 45 & 1.24905 & 1.04567 & 0.90410 & 1.29573 & 1.10274 & 0.94791 & 1.34809 & 1.17319 & 1.01626 \\
\hline 50 & 1.24864 & 1.04368 & 0.90145 & 1.29535 & 1.10093 & 0.94522 & 1.34773 & 1.17171 & 1.01353 \\
\hline
\end{tabular}

Table 7. $\mathrm{k}_{\infty}$ as a function of depletion rate (actinides only)

\begin{tabular}{|c|c|c|c|c|c|c|c|c|c|}
\hline $\begin{array}{l}\text { Specific power } \\
\text { during depletion } \\
\text { (MW/MTU) }\end{array}$ & \multicolumn{3}{|c|}{$3.0 \mathrm{wt} \%$} & \multicolumn{3}{|c|}{$3.6 \mathrm{wt} \%$} & \multicolumn{3}{|c|}{$4.5 \mathrm{wt} \%$} \\
\hline Burnup & 10 & 30 & 50 & 10 & 30 & 50 & 10 & 30 & 50 \\
\hline 10 & 1.29204 & 1.13684 & 1.03407 & 1.33839 & 1.19194 & 1.07851 & 1.38982 & 1.25954 & 1.14600 \\
\hline 15 & 1.29269 & 1.14049 & 1.03905 & 1.33889 & 1.19503 & 1.08349 & 1.39009 & 1.26200 & 1.15041 \\
\hline 20 & 1.29305 & 1.14247 & 1.04176 & 1.33910 & 1.19671 & 1.08610 & 1.39025 & 1.26328 & 1.15281 \\
\hline 25 & 1.29331 & 1.14386 & 1.04354 & 1.33929 & 1.19781 & 1.08776 & 1.39033 & 1.26415 & 1.15430 \\
\hline 30 & 1.29358 & 1.14467 & 1.04464 & 1.33940 & 1.19855 & 1.08895 & 1.39039 & 1.26472 & 1.15533 \\
\hline 35 & 1.29372 & 1.14541 & 1.04553 & 1.33948 & 1.19913 & 1.08974 & 1.39044 & 1.26509 & 1.15621 \\
\hline 40 & 1.29382 & 1.14587 & 1.04619 & 1.33957 & 1.19950 & 1.09039 & 1.39058 & 1.26544 & 1.15675 \\
\hline 45 & 1.29391 & 1.14624 & 1.04689 & 1.33962 & 1.19982 & 1.09087 & 1.39060 & 1.26564 & 1.15717 \\
\hline 50 & 1.29398 & 1.14664 & 1.04736 & 1.33967 & 1.20008 & 1.09130 & 1.39062 & 1.26583 & 1.15748 \\
\hline
\end{tabular}




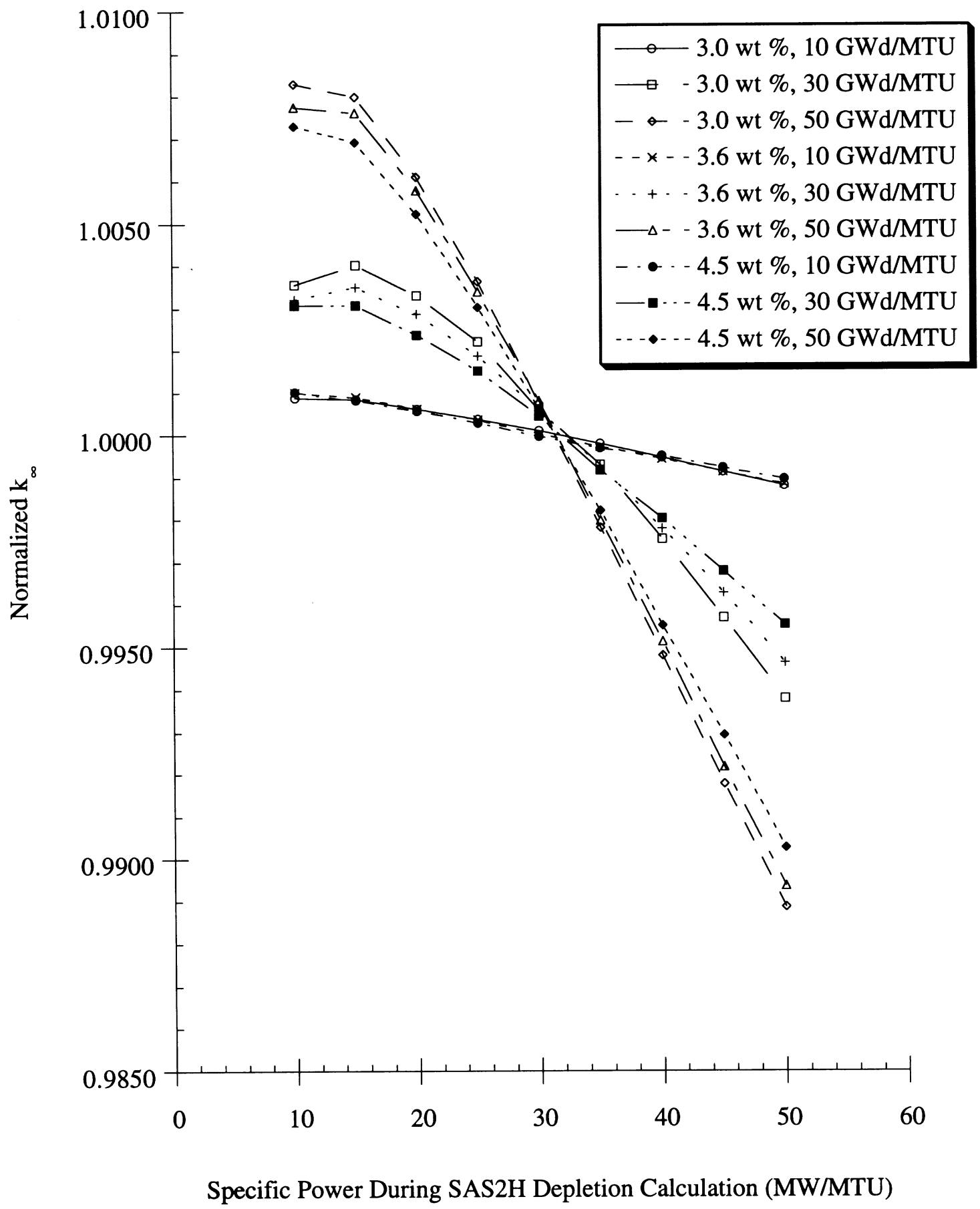

Fig. 17. $\mathrm{k}_{\infty}$ as a function of specific power for various enrichments and burnups (actinides fission products). 


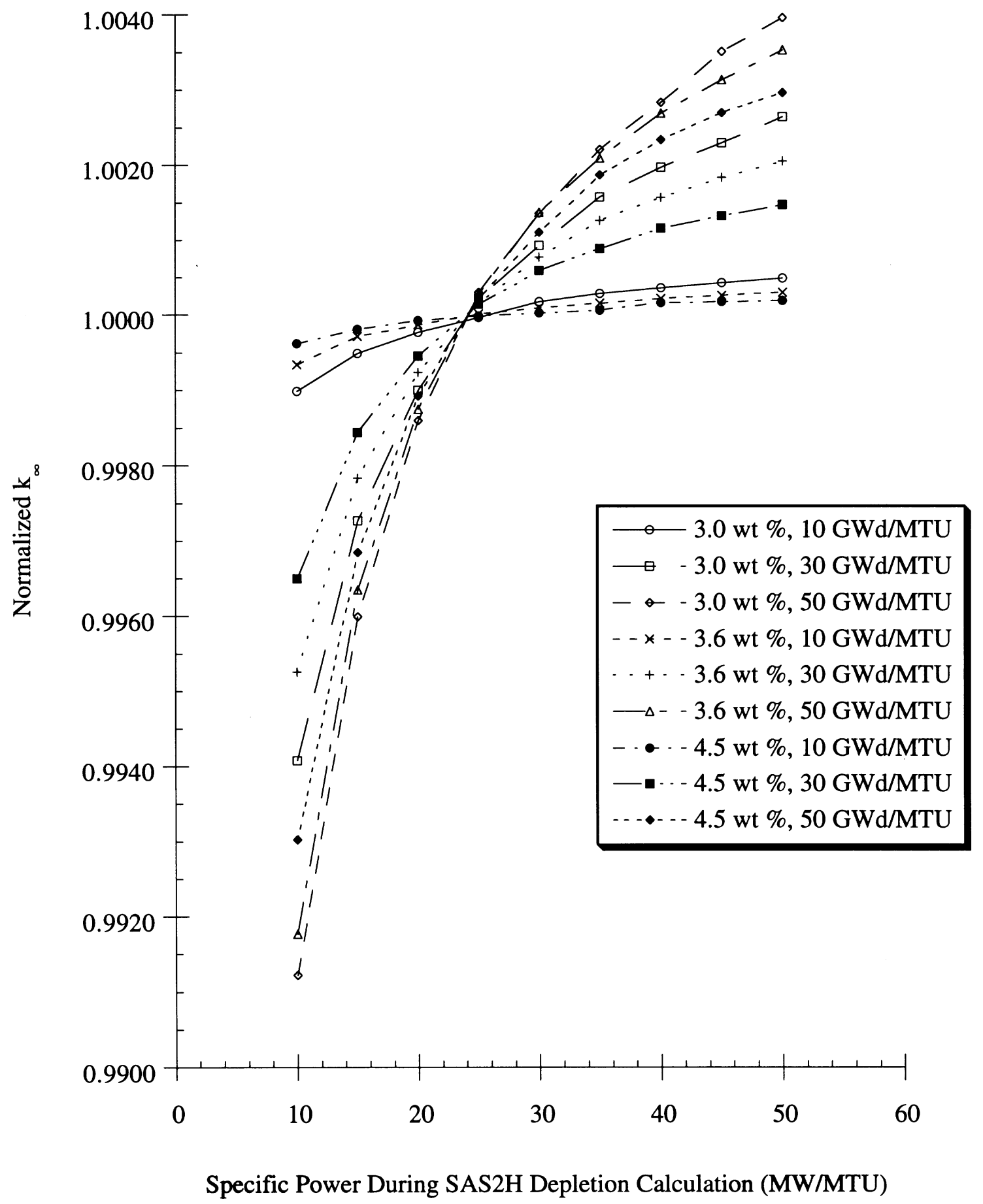

Fig. 18. $\mathrm{k}_{\infty}$ as a function of specific power for various enrichments and burnups (actinides only). 
range of specific powers studied; over the same range, the change in actinide-only worth is on the order of $1.2 \% \Delta \mathrm{k}$. Note that the range of specific powers studied exceeds typical operational values. Thus the $\Delta \mathrm{k}$ range represents a conservative upper bound to the $\Delta \mathrm{k}$ that may result from simplifying assumptions.

The behavior of $\mathrm{k}_{\infty}$ with specific power when fission products are present is probably due to the decay rate of unstable nuclides relative to the production rate, which is a function of specific power. At a specific power of $10 \mathrm{GWd} / \mathrm{MTU}$, fission-product nuclides are produced at only $20 \%$ of the rate of production for $50 \mathrm{GWd} / \mathrm{MTU}$; however, the decay rate is unchanged. Thus for short-lived nuclides in which the decay rate approaches the production rate, the equilibrium level of the nuclide is much lower at the lower specific power. For example, consider ${ }^{155} \mathrm{Eu}$. It is produced directly by fission and by the decay of ${ }^{155} \mathrm{Sm}\left(\mathrm{T}_{2}=22\right.$ minutes), which is a very common fission product. ${ }^{155} \mathrm{Eu}$ decays to ${ }^{155} \mathrm{Gd}$ (a stable burnup credit fission product important because of its large absorption cross section) with a 4.76-year half-life. Since ${ }^{155} \mathrm{Gd}$ is rapidly burned out during operation, post-shutdown inventories result primarily from the ${ }^{155} \mathrm{Eu}$ present at shutdown. Because of the increased production rate at higher specific powers, there will be more ${ }^{155} \mathrm{Eu}$ present at shutdown for fuel burned at a high specific power, which will result in an increased inventory of ${ }^{155} \mathrm{Gd}$ after a 5 -year cooling period. Because ${ }^{155} \mathrm{Gd}$ ranks among the most important fission products for highly burned (50 GWd/MTU) fuel for all enrichments (see sensitivity rankings discussed earlier), but is of lesser importance for lower burnups, this isotope may be the most significant contributor to specific power behavior. However, since all fission products are poisons, any such nuclide produced primarily from the decay of a moderate-lifetime parent (half-lives on the order of months to a few years) would result in the same effect.

Depletion calculations performed over a range of specific powers show a trend for increased inventories of fissile actinides with increasing specific power. Table 8 shows the isotopic concentrations for the five most important actinides calculated as a function of various specific powers during depletion of $3.6 \mathrm{wt} \%$ fuel to a burnup of $50 \mathrm{GWd} / \mathrm{MTU}$. Because the sensitivity coefficients of ${ }^{235} \mathrm{U}$, ${ }^{239} \mathrm{Pu}$, and ${ }^{241} \mathrm{Pu}$ are positive, and the concentration of ${ }^{238} \mathrm{U}$ does not change significantly, the net effect is for $\mathrm{k}_{\infty}$ to increase with increasing specific power. Thus the trend for $\mathrm{k}_{\infty}$ to increase with increasing depletion rate for a given level of burnup in the absence of fission products is caused by the behavior of the three fissile isotopes.

Table 8. Final isotopic concentration for various depletion rates (3.6 wt \%, $50 \mathrm{GWd} / \mathrm{MTU}$ Burnup)

\begin{tabular}{l|lllll}
\hline & \multicolumn{5}{|c}{ Isotopic concentration (atoms/b-cm) } \\
\cline { 2 - 6 } & \multicolumn{5}{|c}{ Specific power during depletion (MW/MTU) } \\
Isotope & \multicolumn{1}{|c}{10} & \multicolumn{1}{c}{20} & \multicolumn{1}{c}{30} & \multicolumn{1}{c}{40} & \multicolumn{1}{c}{50} \\
\hline${ }^{235} \mathrm{U}$ & 0.001181 & 0.001194 & 0.001196 & 0.001196 & 0.001194 \\
${ }^{238} \mathrm{U}$ & 0.2162 & 0.2161 & 0.2161 & 0.2161 & 0.2161 \\
${ }^{239} \mathrm{Pu}$ & 0.001341 & 0.001353 & 0.001361 & 0.001367 & 0.001373 \\
${ }^{240} \mathrm{Pu}$ & 0.0006897 & 0.0006913 & 0.0006939 & 0.0006969 & 0.0007002 \\
${ }^{241} \mathrm{Pu}$ & 0.0003116 & 0.0003228 & 0.0003275 & 0.0003304 & 0.0003325 \\
\hline
\end{tabular}


It is likely that the increased ${ }^{235} \mathrm{U}$ concentration with increased specific power results from an increased abundance of plutonium isotopes under such a condition; increased fissioning in ${ }^{239} \mathrm{Pu}$ and ${ }^{241} \mathrm{Pu}$ decreases the depletion rate of ${ }^{235} \mathrm{U}$ required to maintain a fixed power level. Assuming this is true, then the specific power trend is a result of increased plutonium production for increased specific powers. Both ${ }^{239} \mathrm{Pu}$ and ${ }^{241} \mathrm{Pu}$ are produced by neutron absorption in ${ }^{238} \mathrm{U}$, which typically occurs at higher neutron energies via resonance absorption. This behavior would suggest that cases computed for higher specific powers are subject to a somewhat harder spectrum than for lower specific powers, resulting in more resonance absorption in ${ }^{238} \mathrm{U}$ and thus more plutonium production. Figure 19 illustrates that spectral hardening does indeed occur, by showing the difference between normalized fluxes $[\Delta \Phi(\mathrm{E})=\Phi(\mathrm{E}, 10 \mathrm{MW} / \mathrm{MTU}) \mathrm{C} \Phi(\mathrm{E}, 50 \mathrm{MW} / \mathrm{MTU})]$ from an XSDRNPM calculation, based on $3.6 \mathrm{wt} \%$ fuel burned to $50 \mathrm{GWd} / \mathrm{MTU}$. Calculations were based on zero cooling time and were performed for both low specific power (10 MW/MTU) and at a high specific power (50 MW/MTU). Because depletion calculations include all isotopes available in the ORIGEN-S library, XSDRNPM calculations were performed using all isotopes available in the 27BURNUPLIB library in order to best estimate the spectrum seen during depletion calculations. Figure 19 shows that for lower energies $(<0.1 \mathrm{eV})$, fluxes are higher (difference $>0.0)$ for isotopics computed for low specific power operation, while for energies greater than $0.1 \mathrm{eV}$, fluxes are higher (difference $<0.0$ ) for isotopics derived from a high specific power assumption. Thus results indicate that the positive correlation between actinidesonly $\mathrm{k}_{\infty}$ and the specific power at which depletion is calculated may be at least partially due to the spectral hardening which occurs at higher specific powers.

One possible cause of such spectral hardening is the effect of fission-product poisoning. Xenon is a well-known fission-product poison during reactor operation, even though it decays away rapidly after shutdown. Xenon reaches an equilibrium state during operation that is proportionate to specific power. Although CSAS1X/XSDRNPM actinide-only criticality calculations were performed considering spent fuel with no fission products present, SAS2H depletion calculations were performed considering more than 1000 nuclides, most of which are products of fission. Hence trends in $\mathrm{k}_{\infty}$ as a function of the specific power assumed during depletion will depend on the effect of the presence of fission products, even if the fission products are ignored during the criticality calculation. Thus highspecific-power operation will build in higher levels of Xe than that which would occur at low-specificpower operation, resulting in greater loss of thermal neutrons and a spectral hardening during the depletion cycle. This spectral hardening in turn results in an increased abundance of plutonium isotopes and a corresponding increase in ${ }^{235} \mathrm{U}$ abundance, which causes an increased reactivity in subsequent criticality calculations.

A second effect, which would also result in specific power dependence for actinides-only criticality calculations, is the loss of ${ }^{241} \mathrm{Pu}$ by decay and the corresponding buildup of ${ }^{241} \mathrm{Am}$. With a relatively short 14.35-year half-life, the loss of this isotope is dominated by decay rather than fission when reactor operation is extended over a long period with a low specific power. This behavior would in turn result in a reduced value of $\mathrm{k}_{\infty}$ for lower power operation relative to the same burnup achieved with high power operation. However, the production of ${ }^{241} \mathrm{Pu}$ is tied to the spectral hardening phenomena described above. Thus it is difficult to isolate this phenomenon relative to spectral hardening effects. 


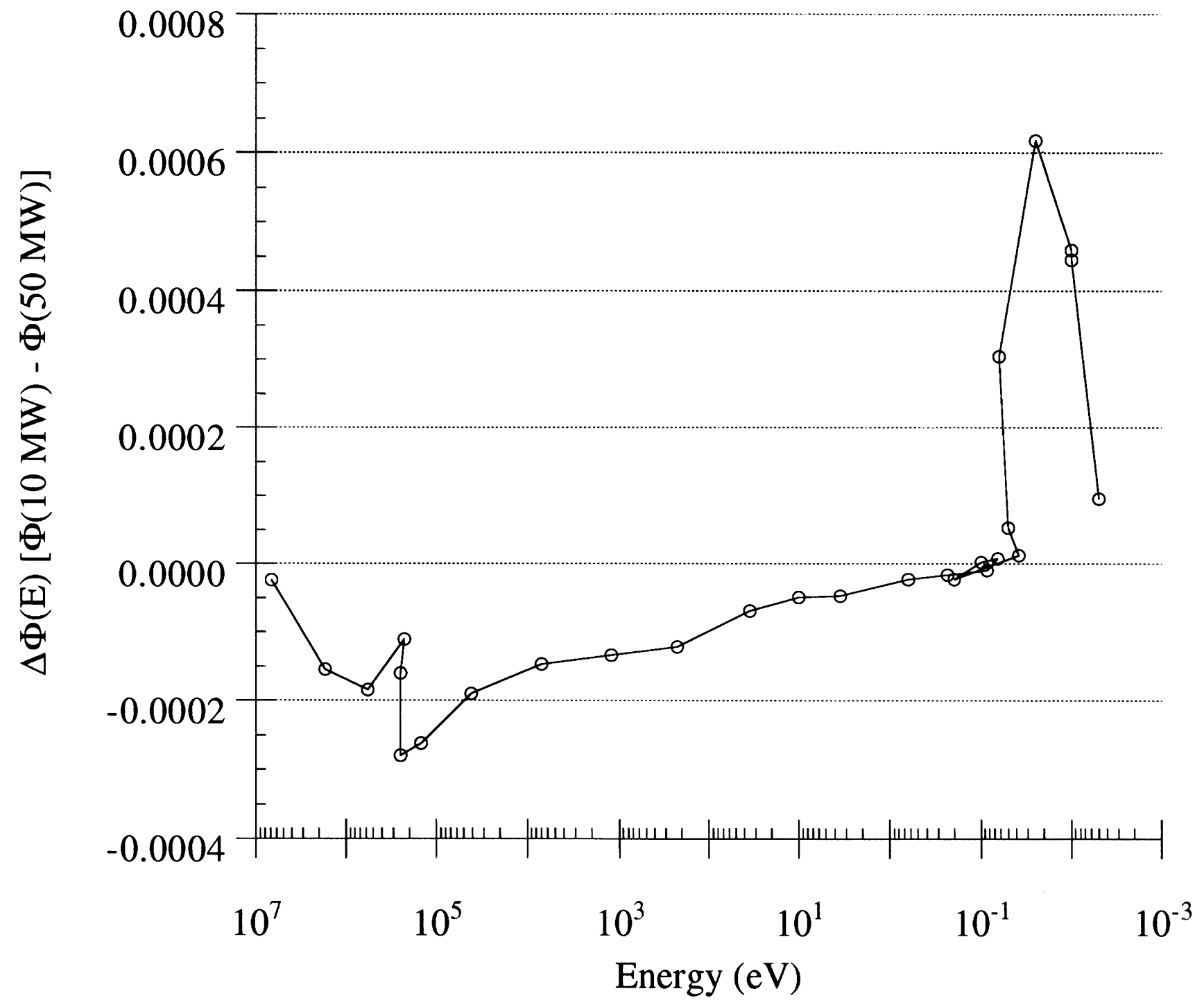

Fig. 19. Spectral differences between low and high specific power depletion cases. 


\subsubsection{Effect of Time Dependent Burnup Variations on Depletion Calculations}

Clearly, isotopic compositions at the end of life for a fuel assembly are dependent upon the path taken to reach this state. The previous subsection studied the effect of varying specific power for cases with continuous-power operation within a cycle. This subsection seeks to determine the effect of specific power variations, including downtimes, within a single fuel cycle on isotopic concentrations, and their collateral effect on $\mathrm{k}_{\infty}$. Several exposure scenarios have been selected in an attempt to represent and emphasize the key feature of the broad range of possible operating histories. These include burnup with varying downtimes, burnup with a moderately long downtime in one cycle, burnup with an extended downtime in one cycle, and operation with varying specific powers during different cycles. Although there are limitless possibilities for representing these generic features in a burnup cycle, the eleven cycles described below are felt to be appropriate for determining trends due to operating history effects.

Figure 20 illustrates schematically the 11 operating histories investigated. All cases represent three-cycle histories, with a downtime in the center of each cycle to represent all downtimes occurring within each cycle. Downtimes between cycles represent fuel discharge and reload periods. Cycle lengths and downtimes were chosen for convenience and are not meant to represent actual or typical periods in reactor operation, since such operational history varies between utilities and reactor designs, and have evolved and changed with reactor operating experience. However, these conceptual cycles are close enough to typical reactor periods to allow the study of effects that might be observed in actual operation.

Operating history case 1 (see Fig. 20) represents a continuous operation, no downtime scheme, which, although unrealistic, provides a lower bound for downtime effects. Cases 2 through 4 represent variations in downtime to determine if an increased length of downtime between uniform cycles has an effect on depletion characteristics. Cases 5 and 6 are similar, but test the effect of non-uniformities in downtime. Cases 7 and 8 do the same, but test the effect of extended downtimes which are on the order of the half-lives of important fission products. Cases 9-11 test the effect of nonuniform power operation over the cycle length, while retaining the same average power over the full burnup history.

Each of these cases has been analyzed using SAS2H for depletion calculations, followed by a CSAS1X pin-cell calculation for each set of depleted isotopics to determine the effect on $\mathrm{k}_{\infty}$. A 5-year post-irradiation cooling time was assumed for all depletion calculations. Fuels with initial enrichments of 3.0 and $4.5 \mathrm{wt} \%$ were studied for burnups of 10,30 , and $50 \mathrm{GWd} / \mathrm{MTU}$. Since each cycle was fixed at 1080 full-power days ( 6 periods $\times 180$ days/period), the specific power for each burnup was varied to provide the desired burnup after 1080 full-power days. Results for each of the $\mathrm{k}_{\infty}$ calculations are provided in Table 9 for CSAS1X criticality calculations performed using all 23 burnup credit nuclides, and in Table 10 for criticality calculations performed with the 12 fission- product nuclides removed. These results are also plotted in Figs. 21 and 22 for cases with and without fission products, respectively. The $\mathrm{k}_{\infty}$ values plotted in these figures are normalized to the average for each burnup/enrichment set, so that trends can be easily compared.

The study of these results has led to the conclusion that there are three significant phenomena that govern the history-dependent behavior of $\mathrm{k}_{\infty}$, both with and without fission products present in the criticality calculation: (1) the decay of isotopes with half-lives on the order of a few years has the 
$\begin{array}{llll}\text { Cycle } 1 & \text { Cycle } 2 & \text { Cycle } 3\end{array}$

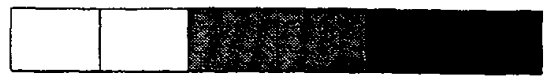

1) Six 180-day full-power periods, No downtime
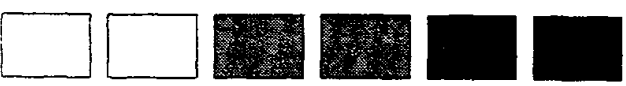

2) Six 180-day full-power periods, separated by 20 -day down periods (10\% downtime)
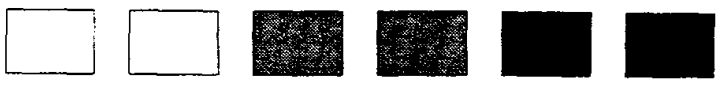

3) Six 180-day full-power periods, separated by 45 -day down periods (20\% downtime)

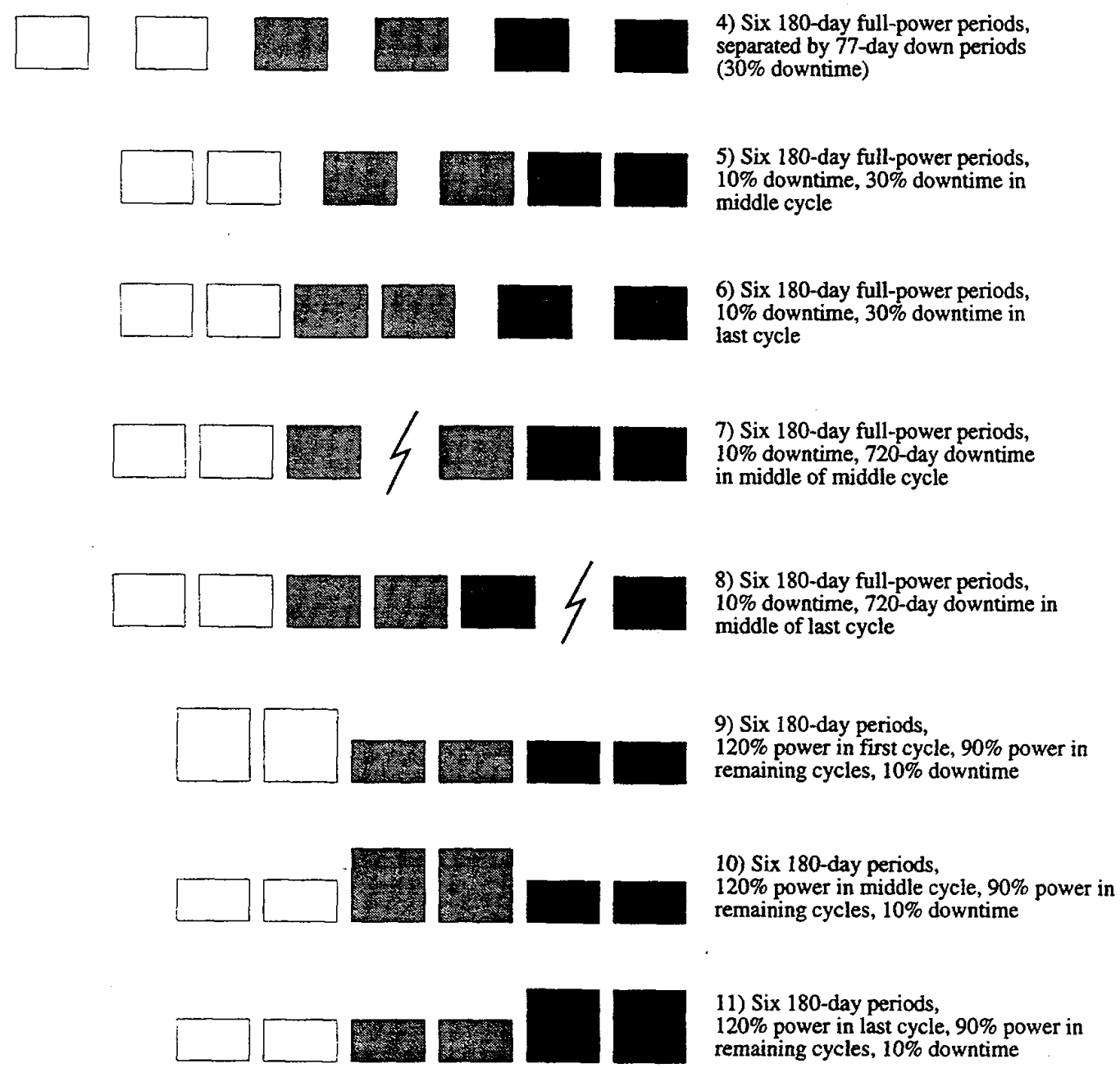

Fig. 20. Three-cycle operating histories for sensitivity analyses. 
Table $9 . \mathrm{k}_{\infty}$ for various operating histories with fission products present in criticality calculations

\begin{tabular}{ccccccc}
\hline & $\begin{array}{c}3.0 \mathrm{wt} \% \\
10 \mathrm{GWd} / \mathrm{MTU}\end{array}$ & $\begin{array}{c}3.0 \mathrm{wt} \% \\
30 \mathrm{GWd} / \mathrm{MTU}\end{array}$ & $\begin{array}{c}3.0 \mathrm{wt} \% \\
50 \mathrm{GWd} / \mathrm{MTU}\end{array}$ & $\begin{array}{c}4.5 \mathrm{wt} \% \\
10 \mathrm{GWd} / \mathrm{MTU}\end{array}$ & $\begin{array}{c}4.5 \mathrm{wt} \% \\
30 \mathrm{GWd} / \mathrm{MTU}\end{array}$ & $\begin{array}{c}4.5 \mathrm{wt} \% \\
50 \mathrm{GWd} / \mathrm{MTU}\end{array}$ \\
\hline 1 & 1.25053 & 1.05246 & 0.91349 & 1.34936 & 1.17808 & 1.02467 \\
2 & 1.25056 & 1.05268 & 0.91383 & 1.34940 & 1.17817 & 1.02517 \\
3 & 1.25058 & 1.05263 & 0.91378 & 1.34944 & 1.17821 & 1.02515 \\
4 & 1.25061 & 1.05254 & 0.91382 & 1.34949 & 1.17822 & 1.02520 \\
5 & 1.25059 & 1.05271 & 0.91386 & 1.34943 & 1.17825 & 1.02520 \\
6 & 1.25058 & 1.05256 & 0.91373 & 1.34945 & 1.17818 & 1.02504 \\
7 & 1.25066 & 1.05246 & 0.91373 & 1.34957 & 1.17828 & 1.02500 \\
8 & 1.25047 & 1.05102 & 0.91231 & 1.34956 & 1.17759 & 1.02414 \\
9 & 1.25075 & 1.05328 & 0.91447 & 1.34957 & 1.17871 & 1.02595 \\
10 & 1.25076 & 1.05345 & 0.91510 & 1.34957 & 1.17882 & 1.02653 \\
11 & 1.25015 & 1.05062 & 0.91179 & 1.34907 & 1.17715 & 1.02330 \\
\hline
\end{tabular}

Table $10 . \mathrm{k}_{\infty}$ for various operating histories with actinides only criticality calculations

\begin{tabular}{ccccccc}
\hline & $3.0 \mathrm{wt} \%$, & $3.0 \mathrm{wt} \%$, & $3.0 \mathrm{wt} \%$, & $4.5 \mathrm{wt} \%$, & $4.5 \mathrm{wt} \%$, & $4.5 \mathrm{wt} \%$, \\
\hline & $10 \mathrm{GWd} / \mathrm{MTU}$ & $30 \mathrm{GWd} / \mathrm{MTU}$ & $50 \mathrm{GWd} / \mathrm{MTU}$ & $10 \mathrm{GWd} / \mathrm{MTU}$ & $30 \mathrm{GWd} / \mathrm{MTU}$ & $50 \mathrm{GWd} / \mathrm{MTU}$ \\
\hline 1 & 1.29348 & 1.14391 & 1.04353 & 1.39037 & 1.26417 & 1.15401 \\
2 & 1.29342 & 1.14370 & 1.04338 & 1.39034 & 1.26397 & 1.15386 \\
3 & 1.29336 & 1.14333 & 1.04284 & 1.39031 & 1.26373 & 1.15336 \\
4 & 1.29328 & 1.14287 & 1.04230 & 1.39027 & 1.26341 & 1.15285 \\
5 & 1.2934 & 1.14355 & 1.04312 & 1.39033 & 1.26388 & 1.15362 \\
6 & 1.29331 & 1.14308 & 1.04255 & 1.39028 & 1.26354 & 1.15302 \\
7 & 1.29321 & 1.14237 & 1.04169 & 1.39023 & 1.26309 & 1.15213 \\
8 & 1.29255 & 1.13890 & 1.03714 & 1.38988 & 1.26063 & 1.14819 \\
9 & 1.29331 & 1.14312 & 1.04226 & 1.39027 & 1.26357 & 1.15292 \\
10 & 1.29339 & 1.14360 & 1.04309 & 1.39032 & 1.26389 & 1.15364 \\
11 & 1.29355 & 1.14448 & 1.04474 & 1.39042 & 1.26450 & 1.15504 \\
\hline
\end{tabular}




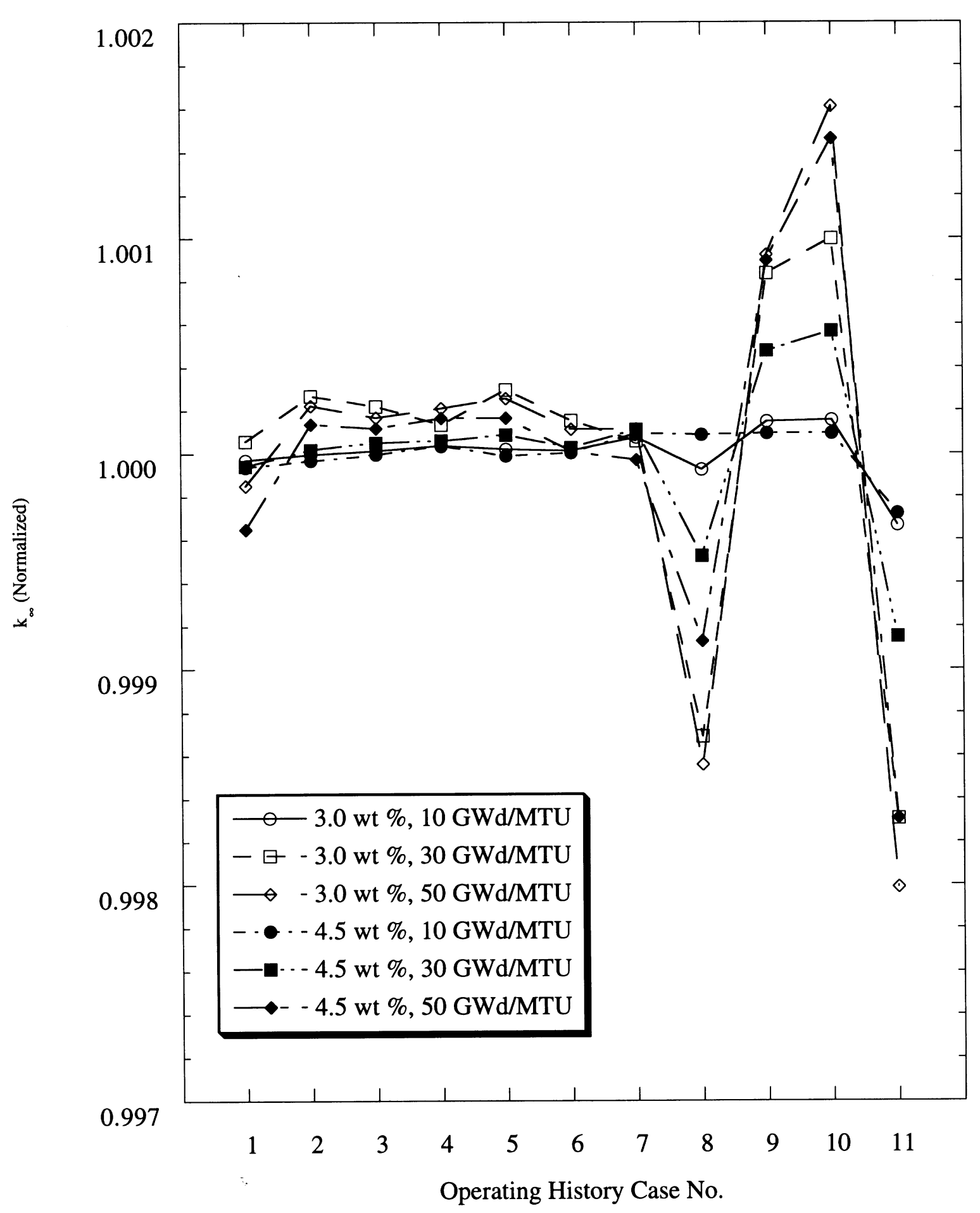

Fig. 21. $\mathrm{k}_{\infty}$ as a function of operating history (actinides + fission products). 


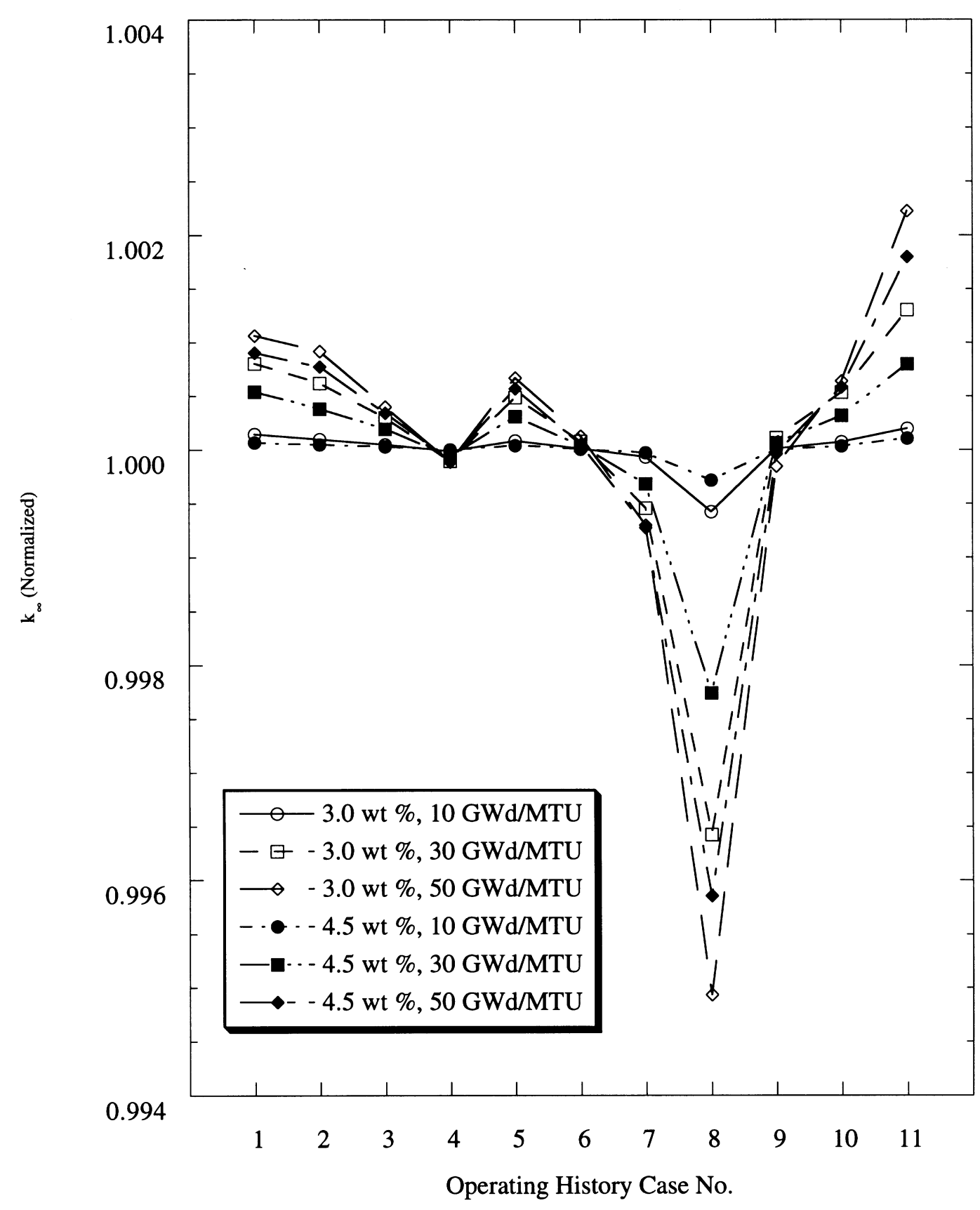

Fig. 22. $\mathrm{k}_{\infty}$ as a function of operating history (actinides only). 
largest effect for extended downtimes (cases 7 and 8); (2) the effects of much shorter half-life isotopes plays into the behavior of $\mathrm{k}_{\infty}$ with nominal variations in downtime; and (3) the effects of specific power, as discussed in Sect. 3.4.1 of this report. Items 1 and 2 are essentially the same phenomena, with different players due to different timeframes. Each of these three phenomena is discussed in the following paragraphs.

\subsubsection{Extended Downtimes}

The most distinctive feature of both Figs. 21 and 22 is the large drop in $\mathrm{k}_{\infty}$ for operating history case 8 , which was characterized by a long ( 2 years) downtime in the middle of the final cycle. Such a decrease in $\mathrm{k}_{\infty}$ must result from either the loss of fissile actinides due to decay, or the increase in nonfissile absorbers due to decay of parent nuclides during the extended downtime. The latter is unlikely for fission products, however, since the peak is most pronounced when fission products are removed from the criticality calculation, and the fact that important absorbers would be burned out during the final operating period, resulting in a relative increase in $\mathrm{k}_{\infty}$. Of the actinides present, only

${ }^{241} \mathrm{Pu}$, with a 14.35 -year half-life, would decay significantly during a 2-year downtime. Since this isotope is built in with burnup and is consistently ranked as the third to fifth most important isotope after moderate burnup, it would be expected to have the most pronounced effect on $\mathrm{k}_{\infty}$ for lower enrichments and higher burnups, as is seen in the two figures. The loss of fissile ${ }^{241} \mathrm{Pu}$ is magnified somewhat by the corresponding buildup of its absorber daughter ${ }^{241} \mathrm{Am}$.

A similar behavior is seen for case 7 in the actinides-only calculations, but to a much smaller extent. Case 7 represents the same extended downtime scenario, except the downtime occurs in the second cycle. In this case, less ${ }^{241} \mathrm{Pu}$ would have been produced by the time of shutdown, hence less loss by decay. Therefore, only long downtimes near the end of life for a fuel assembly are important, due to the loss of the fissile actinide ${ }^{241} \mathrm{Pu}$ by decay.

\subsubsection{Typical Downtimes}

Cases 1 through 4 indicate that for actinides-only calculations, shorter downtimes between cycles result in higher values of $\mathrm{k}_{\infty}$ after a 5-year cooling period for moderately to highly burned fuel. (This trend is observed for underburned fuel as well, but the effect is very small.) Furthermore, cases 5 and 6 demonstrate that downtimes occurring immediately before and during the final cycle have the strongest effect on $\mathrm{k}_{\infty}$. These results are consistent with the observations made for cases 7 and 8 , and are most likely due to the additional loss by decay of ${ }^{241} \mathrm{Pu}$ that occurs during downtime periods; the greater the downtime, the more ${ }^{241} \mathrm{Pu}$ decays away, resulting in a lower value of $\mathrm{k}_{\infty}$ after a 5-year cooling period.

When fission products are retained in criticality calculations, the opposite trend is observed, at least to some extent. The neutron multiplication factor is observed to increase when going from 0 to $10 \%$ downtime between cycles for moderately to highly burned fuel. The effect is small but slightly positive for underburned to moderately burned fuel. For the moderately to highly burned fuel cases the effect of downtimes greater than $10 \%$ of cycle length is for $\mathrm{k}_{\infty}$ to remain constant or decrease. As with the actinides-only study, cases 5 and 6 demonstrate that downtimes occurring immediately before and during the final cycle have the strongest effect on $\mathrm{k}_{\infty}$. These trends suggest that downtime periods allow 
the decay of short- to mid-lived parents of fission-product absorbers; the most important contributor to this phenomenon is ${ }^{155} \mathrm{Gd}$, produced by the decay of ${ }^{155} \mathrm{Eu}\left(\mathrm{T}_{2}=4.76\right.$ years). After restart, ${ }^{155} \mathrm{Gd}$ is quickly depleted. Downtimes in the last fuel cycle are more important since the inventory of ${ }^{155} \mathrm{Eu}$ is higher. This burnout of a key fission-product absorber results in the increase in $\mathrm{k}_{\infty}$ relative to a zero downtime case. It is important to remember that the effect of ${ }^{241} \mathrm{Pu}$ decay is still present during the same operating histories. Thus absorber effects outweigh ${ }^{241} \mathrm{Pu}$ effects for short downtimes, and are roughly balanced for longer downtimes. Note that at a 50-GWd/MTU burnup, a slightly larger effect is seen between zero and $10 \%$ downtime for $4.5 \mathrm{wt} \%$ fuel relative to $3.0 \mathrm{wt} \%$ fuel, even though the $3.0 \mathrm{wt} \%$ fuel is considerably overburned at this point. This behavior is probably due to the fact that the overburned $3.0 \mathrm{wt} \%$ fuel has a higher ${ }^{241} \mathrm{Pu}$ content, and is therefore more strongly influenced by the decay of this actinide.

Clearly, in terms of downtime and its effect on $\mathrm{k}_{\infty}$, actinides-only criticality models are most conservative when cycle downtime is ignored during depletion calculations, although the maximum effect was found to be only about $0.1 \% \Delta \mathrm{k} / \mathrm{k}$ for the cases studied. On the other hand, no definite downtime can be identified as most bounding in its effect on $\mathrm{k}_{\infty}$ when fission products are present. However, the maximum change for the cases studied was found to be roughly $0.06 \% \Delta \mathrm{k} / \mathrm{k}$. Therefore, since an assumed constant uptime (e.g., case 1) is the simplest modeling assumption, it would be the most reasonable approach to take in calculations with fission products present.

\subsubsection{Specific Power Effects}

Cases 9 through 11 tested the effect of variations in specific power over a three-cycle depletion period. Although the average specific power was maintained at a constant level, one cycle was calculated at an elevated power level relative to the other two cycles. Results of these three cases, which included $10 \%$ downtime distributed uniformly over the burnup period, should be compared to the results of case 2, which was based on the same downtime with constant $100 \%$ power.

For actinides-only analyses, $\mathrm{k}_{\infty}$ is found to increase as the fuel cycle in which the power increase occurs moves toward the end of the depletion period; the increase in $\mathrm{k}_{\infty}$ is consistent with the earlier study of specific power effects. For low burnups, the operating history makes little difference. For highpower operation in the first cycle, the reduced-power operation over the last two cycles overcompensates for the effect of the initial high power. When the high-power operation occurs near the middle of life, its effect is nearly balanced by reduced-power operation in the final cycle, since results are nearly the same as those of case 2 . The fact that case 2 results are slightly higher than those of case 10, especially for higher burnups, indicates that the lower power operation in the final cycle is more heavily weighted than the operating powers of earlier cycles. This is probably due to the fact that excess plutonium created early in a fuel lifetime by early high-power operation is depleted in subsequent operation at lower power (during which new plutonium is produced at a reduced rate), whereas plutonium created by higher power operation during the second cycle is not as heavily depleted by subsequent operation. This also helps to explain why high-power operation in the final cycle is so important in its effect on $\mathrm{k}_{\infty}$, since no depletion occurs at the end of this cycle. 
Trends are not as clear when the results of criticality calculations including fission products are considered. The reduced $\mathrm{k}_{\infty}$ values observed for higher power operation in the final cycle are consistent with trends observed earlier for higher specific power operation with fission products present. However, for power increases in the first and second cycles, $\mathrm{k}_{\infty}$ actually increases in a manner similar to actinides-only cases. As was discussed earlier in this section, half-lives of many important absorber isotopes or their parent isotopes are much shorter than one of the typical fuel cycles $(\sim 1$ year $)$ modeled here. Thus fission products produced during earlier cycles are burned out almost as fast as they are produced, and the behavior due to power variations is dominated by the effect of actinides. However, because there is no depletion following the final burn cycle, fission products are allowed to decay to stable absorbers; the effect of these fission products is then important and outweighs the positive actinide effect.

Again, it is clear that higher specific power, especially in the final fuel cycle, results in a more conservative prediction of $\mathrm{k}_{\infty}$ when only actinides are used in criticality calculations. However, it is not as obvious how to conservatively treat specific power variations when the effects of fission products are included in criticality calculations. The variation between the extremes is represented by the difference between cases 10 and 11 , which is as high as roughly $0.35 \%$ for the burnups and enrichments studied. However, the maximum nonconservatism is less than $0.2 \%$. Thus for simplicity, it is probably best to assume a no-downtime exposure history for cases with both actinides and fission products present, and then include a $0.2 \%$ uncertainty in $\mathrm{k}_{\mathrm{eff}}$.

\section{5 $\quad$ EFFECT OF SELECTED DEPLETION PARAMETERS ON $\mathbf{k}_{\infty}$}

As was discussed with fuel history effects, fuel assemblies considered for loading in a spent fuel cask can represent a broad variety of operating conditions. In addition to specific power and operating history, parameters such as fuel and moderator temperatures and moderator boron concentrations assumed during depletion calculations are potentially important in terms of their effect on $\mathrm{k}_{\infty}$. This section will study the sensitivity of $\mathrm{k}_{\infty}$ to variations in each parameter to determine the most conservative approach for applying these parameters in depletion calculations.

Based on nominal conditions of a $900 \mathrm{~K}$ fuel temperature, a $600 \mathrm{~K}$ moderator temperature, and an average boron concentration of $500 \mathrm{ppm}$, a series of depletion calculations was set up with independent variations of each parameter about nominal conditions (note that these nominal values are slightly different from those used elsewhere in this report, as given in Table E-2 of Appendix E). Spent fuel isotopics obtained from these calculations (assuming a 5-year cooling period) were used in CSAS1X criticality calculations, both with and without fission-product isotopes to determine $\mathrm{k}_{\infty}$.

Results of variations in soluble boron concentrations ranging from 0 to $1000 \mathrm{ppm}$ are provided in Tables 11 and 12 and are illustrated in Fig. 23 for $4.5 \mathrm{wt} \%$ fuel with fission products present. The figure presents $\mathrm{k}_{\infty}$ values normalized by the zero boron value so that trends may be more easily observed. Note that the same general behavior is seen for calculations performed with actinides only. Calculations performed with a lower $3.0 \mathrm{wt} \%$ enrichment fuel also show the same trends although the effect is greater for any given level of burnup, due to greater fissile depletion. In all cases, it is clear that the most conservative value of $\mathrm{k}_{\infty}$ is obtained when the highest cycle average boron concentration is used. This is likely to be the result of spectral hardening effects due to the loss of thermal neutrons by absorption in boron. As was discussed earlier for specific power effects spectral hardening results in 
Table 11. Effect of moderator boron concentrations on $\mathrm{k}_{\infty}$ (actinides + fission products)

\begin{tabular}{|c|c|c|c|c|c|c|}
\hline \multirow{2}{*}{$\begin{array}{l}\text { Boron } \\
\text { concentration } \\
(\mathrm{ppm})\end{array}$} & \multicolumn{6}{|c|}{ Infinite lattice neutron multiplication factor, $\mathrm{k}_{\infty}$} \\
\hline & $\begin{array}{c}3.0 \mathrm{wt} \% \\
10 \mathrm{GWd} / \mathrm{MTU}\end{array}$ & $\begin{array}{c}3.0 \mathrm{wt} \% \\
30 \mathrm{GWd} / \mathrm{MTU}\end{array}$ & $\begin{array}{c}3.0 \mathrm{wt} \% \\
50 \mathrm{GWd} / \mathrm{MTU}\end{array}$ & $\begin{array}{c}4.5 \mathrm{wt} \% \\
10 \mathrm{GWd} / \mathrm{MTU}\end{array}$ & $\begin{array}{c}4.5 \mathrm{wt} \% \\
30 \mathrm{GWd} / \mathrm{MTU}\end{array}$ & $\begin{array}{c}4.5 \mathrm{wt} \% \\
50 \mathrm{GWd} / \mathrm{MTU}\end{array}$ \\
\hline 0 & 0.85904 & 0.71966 & 0.62853 & 1.00340 & 0.86233 & 0.74181 \\
\hline 100 & 0.85981 & 0.72215 & 0.63221 & 1.00367 & 0.86353 & 0.74424 \\
\hline 200 & 0.86055 & 0.72464 & 0.63583 & 1.00395 & 0.86475 & 0.74651 \\
\hline 300 & 0.86132 & 0.72696 & 0.63943 & 1.00421 & 0.86593 & 0.74894 \\
\hline 400 & 0.86212 & 0.72943 & 0.64295 & 1.00449 & 0.86705 & 0.75117 \\
\hline 500 & 0.86282 & 0.73184 & 0.64626 & 1.00476 & 0.86832 & 0.75336 \\
\hline 600 & 0.86359 & 0.73403 & 0.64971 & 1.00509 & 0.86941 & 0.75557 \\
\hline 700 & 0.86428 & 0.73622 & 0.65292 & 1.00536 & 0.87053 & 0.75773 \\
\hline 800 & 0.86503 & 0.73855 & 0.65608 & 1.00562 & 0.87163 & 0.75983 \\
\hline 900 & 0.86575 & 0.74069 & 0.65924 & 1.00588 & 0.87281 & 0.76235 \\
\hline 1000 & 0.86644 & 0.74282 & 0.66231 & 1.00615 & 0.87391 & 0.76446 \\
\hline
\end{tabular}

Table 12. Effect of moderator boron concentrations on $\mathrm{k}_{\infty}$ (actinides only)

\begin{tabular}{|c|c|c|c|c|c|c|}
\hline \multirow{2}{*}{$\begin{array}{l}\text { Boron } \\
\text { concentration } \\
(\mathrm{ppm})\end{array}$} & \multicolumn{6}{|c|}{ Infinite lattice neutron multiplication factor, $\mathrm{k}_{\infty}$} \\
\hline & $\begin{array}{c}n=3.0 \mathrm{wt} \% \\
10 \mathrm{GWd} / \mathrm{MTU}\end{array}$ & $\begin{array}{c}3.0 \mathrm{wt} \% \\
30 \mathrm{GWd} / \mathrm{MTU}\end{array}$ & $\begin{array}{c}3.0 \mathrm{wt} \% \\
50 \mathrm{GWd} / \mathrm{MTU}\end{array}$ & $\begin{array}{c}4.5 \mathrm{wt} \% \\
10 \mathrm{GWd} / \mathrm{MTU}\end{array}$ & $\begin{array}{c}4.5 \mathrm{wt} \% \\
30 \mathrm{GWd} / \mathrm{MTU}\end{array}$ & $\begin{array}{c}4.5 \mathrm{wt} \% \\
50 \mathrm{GWd} / \mathrm{MTU}\end{array}$ \\
\hline 0 & 0.88294 & 0.76142 & 0.68045 & 1.02995 & 0.90926 & 0.80210 \\
\hline 100 & 0.88378 & 0.76408 & 0.68449 & 1.03027 & 0.91057 & 0.80476 \\
\hline 200 & 0.88458 & 0.76674 & 0.68845 & 1.03060 & 0.91190 & 0.80723 \\
\hline 300 & 0.88541 & 0.76922 & 0.69241 & 1.03092 & 0.91317 & 0.80988 \\
\hline 400 & 0.88628 & 0.77186 & 0.69627 & 1.03125 & 0.91440 & 0.81231 \\
\hline 500 & 0.88704 & 0.77444 & 0.69991 & 1.03156 & 0.91577 & 0.81470 \\
\hline 600 & 0.88787 & 0.77679 & 0.70369 & 1.03195 & 0.91697 & 0.81711 \\
\hline 700 & 0.88863 & 0.77914 & 0.70722 & 1.03227 & 0.91819 & 0.81947 \\
\hline 800 & 0.88944 & 0.78163 & 0.71070 & 1.03258 & 0.91938 & 0.82176 \\
\hline 900 & 0.89023 & 0.78392 & 0.71418 & 1.03289 & 0.92065 & 0.82405 \\
\hline 1000 & 0.89098 & 0.78621 & 0.71755 & 1.03322 & 0.92186 & 0.82633 \\
\hline
\end{tabular}




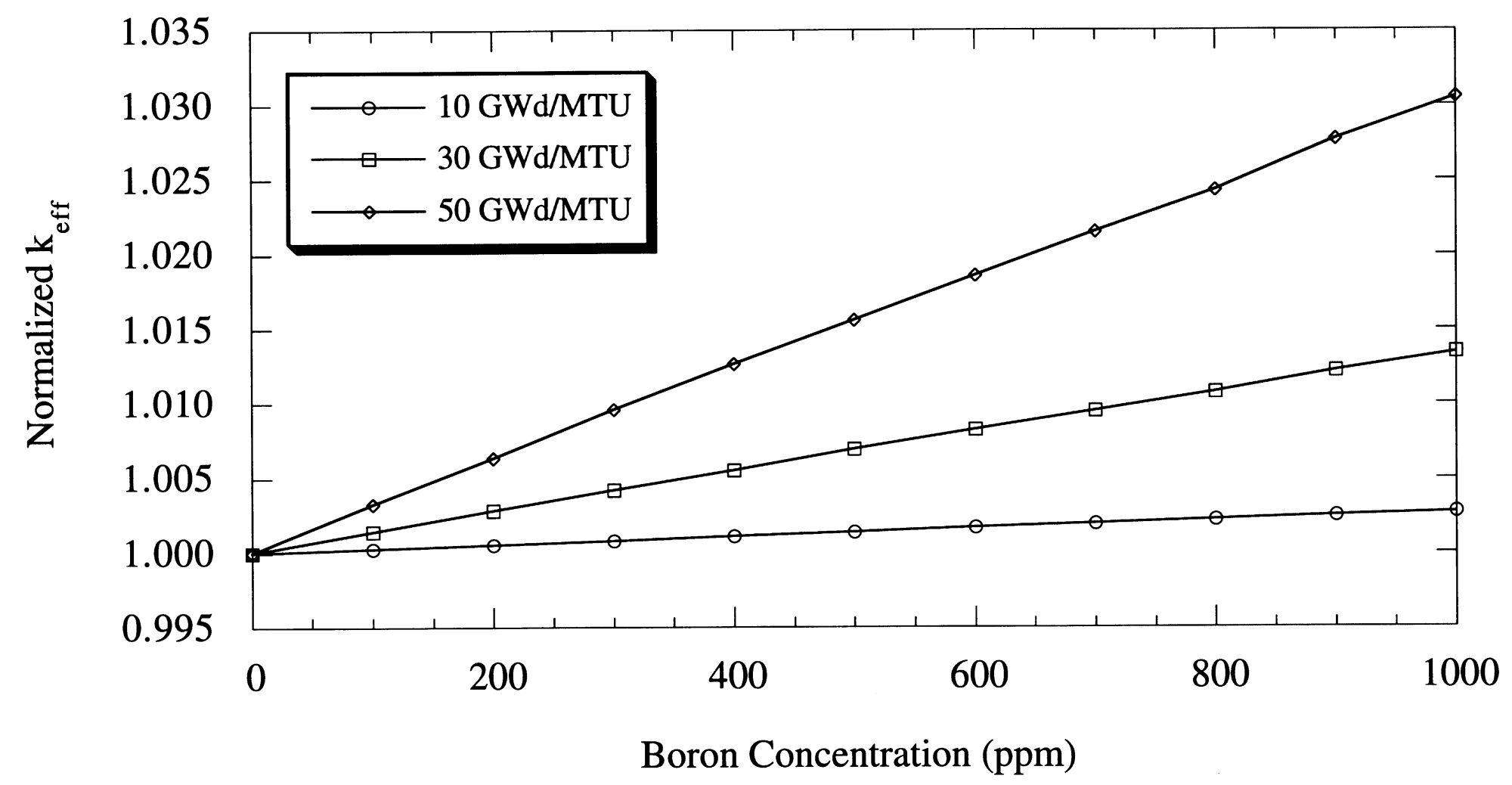

Fig. 23. Trends in $\mathrm{k}_{\infty}$ with varying boron concentration during depletion (4.5 wt $\%$ fuel). 
an increased reactivity in subsequently discharged fuel for a given level of burnup. As evidenced by Tables 11 and 12, the effect of the boron concentration can be large, especially for highly burned fuel [as much as $5 \% \Delta \mathrm{k} / \mathrm{k}$ over the range of conditions studied for overburned (50 GWd/MTU) $3.0 \mathrm{wt} \%$ fuel]. In the past, boron concentrations were typically on the order of $1100 \mathrm{ppm}$ at the beginning of cycle (BOC), with a cycle average of approximately $550 \mathrm{ppm}$. However, with the ongoing migration to increased cycle length, BOC boron concentrations are on the order of $1800 \mathrm{ppm}$ or more, with cycle averages of about $900 \mathrm{ppm}$. Thus although excessively conservative for most of the current PWR spent fuel inventory, it may be necessary to perform calculations with cycle-averaged boron concentrations on the order of $1000 \mathrm{ppm}$ to bound all types of spent fuel.

For average fuel temperature (i.e., effective resonance temperature) variations ranging from 700 to $1100 \mathrm{~K}$, a trend for $\mathrm{k}_{\infty}$ to increase with increasing temperature is also observed. Results are given in Table 13 for calculations performed with fission products present and in Table 14 for calculations without fission products. Results are also plotted in Fig. 24 for the case with $4.5 \mathrm{wt} \%$ fuel and fission products present. Again, results are normalized for the purposes of comparison of effects. The trends observed here are similar to those observed for boron concentration variations; the relationship is linear and positive. This behavior would be expected, since an increased fuel temperature results in increased Doppler broadening and thus increased resonance absorption. This phenomenon in turn results in spectral hardening, as well as a direct increase in ${ }^{238} \mathrm{U}$ conversion (i.e., plutonium production); these effects result in higher reactivity at discharge for a given level of burnup.

Obviously, the most conservative representation for the fuel temperature assumed during depletion effects would be to select an upper bound for the average temperature. However, as with boron concentrations, the response of $\mathrm{k}_{\infty}$ is sensitive enough to changes in temperature (3\% $\Delta \mathrm{k} / \mathrm{k}$ between 700 and $1100 \mathrm{~K}$ for $3.0 \mathrm{wt} \%, 50 \mathrm{GWd} / \mathrm{MTU}$ fuel) that it is recommended that a reasonable but not overly conservative method be used to determine an upper bound for the assumed value of the effective resonance temperature in the fuel in depletion calculations. Note, however, that typical temperatures range within 850 to $950 \mathrm{~K}$ and are well inside the assumed range.

Results of average moderator temperature variations ranging from 500 to $600 \mathrm{~K}$ are provided in Tables 15 and 16, and are illustrated in Fig. 25 for $4.5 \mathrm{wt} \%$ fuel with fission products present. Although the same trend for increasing $\mathrm{k}_{\infty}$ values with increasing temperature is observed here, the effect is much larger and is nonlinear. $\mathrm{A}_{\infty}$ change of more than $8 \% \Delta \mathrm{k}$ is seen between temperatures of 500 and $600 \mathrm{~K}$ for the $3.0 \mathrm{wt} \%, 50-\mathrm{GWd} / \mathrm{MTU}$ case. Fortunately, average moderator temperatures, driven by system pressures, are generally reasonably well known in reactor operations and vary little during normal reactor operation (generally within a range of 570 to $590 \mathrm{~K}$ ), such that a reasonable upper-bound estimate can be obtained.

The dominant temperature-dependent effect is due to loss of moderation which occurs as the moderator density decreases with increasing temperature. The nonlinear response of $\mathrm{k}_{\infty}$ to moderator temperatures is due to the nonlinear variation of moderator density as a function of temperature. In the depletion calculations described earlier, each moderator temperature change was accompanied by a corresponding moderator density change in the input specifications. The decreased moderation with increasing temperature also results in a spectral hardening of the neutron flux. Thus the positive correlation between the moderator temperature assumed during depletion and its subsequent effect 
Table 13. Effect of average fuel temperature on $\mathrm{k}_{\infty}$ (actinides + fission products)

\begin{tabular}{lllllll}
\hline & \multicolumn{5}{c}{ Infinite lattice neutron multiplication factor, $\mathrm{k}_{\infty}$} \\
\cline { 2 - 7 } $\begin{array}{c}\text { Ave. fuel } \\
\text { temperature } \\
\begin{array}{c}\text { (K) } \\
\text { GWd/MTU }\end{array}\end{array}$ & $\begin{array}{c}3.0 \mathrm{wt} \% \\
\text { 10 GW/MTU }\end{array}$ & $\begin{array}{c}3.0 \mathrm{wt} \% \\
30 \mathrm{GWd} / \mathrm{MTU}\end{array}$ & $\begin{array}{c}3.0 \mathrm{wt} \% \\
50 \mathrm{GWd} / \mathrm{MTU}\end{array}$ & $4.5 \mathrm{wt} \%$ & $4.5 \mathrm{wt} \%$ & $4.5 \mathrm{wt} \%$ \\
\hline 700 & 0.86070 & 0.72494 & 0.63645 & 1.00368 & 0.86387 & 0.74521 \\
800 & 0.86179 & 0.72848 & 0.64139 & 1.00421 & 0.86610 & 0.74940 \\
900 & 0.86282 & 0.73184 & 0.64626 & 1.00476 & 0.86832 & 0.75336 \\
1000 & 0.86383 & 0.73499 & 0.65094 & 1.00534 & 0.87034 & 0.75719 \\
1100 & 0.86471 & 0.73781 & 0.65515 & 1.00580 & 0.87224 & 0.76077 \\
\hline
\end{tabular}

Table 14. Effect of average fuel temperature on $\mathrm{k}_{\infty}$ (actinides only)

\begin{tabular}{|c|c|c|c|c|c|c|}
\hline \multirow{2}{*}{$\begin{array}{l}\text { Ave. fuel } \\
\text { temperature } \\
\text { (K) }\end{array}$} & \multicolumn{6}{|c|}{ Infinite lattice neutron multiplication factor, $\mathrm{k}_{\infty}$} \\
\hline & $\begin{array}{c}3.0 \mathrm{wt} \% \\
10 \mathrm{GWd} / \mathrm{MTU} \\
\end{array}$ & $\begin{array}{r}3.0 \text { wt \% } \\
30 \mathrm{GWd} / \mathrm{MTU} \\
\end{array}$ & $\begin{array}{c}3.0 \text { wt \% } \\
50 \mathrm{GWd} / \mathrm{MTU} \\
\end{array}$ & $\begin{array}{r}4.5 \text { wt \% } \\
10 \mathrm{GWd} / \mathrm{MTU} \\
\end{array}$ & $\begin{array}{r}4.5 \mathrm{wt} \% \\
30 \mathrm{GWd} / \mathrm{MTU} \\
\end{array}$ & $\begin{array}{r}4.5 \mathrm{wt} \% \\
50 \mathrm{GWd} / \mathrm{MTU} \\
\end{array}$ \\
\hline 700 & 0.88488 & 0.76726 & 0.68937 & 1.03046 & 0.91119 & 0.80611 \\
\hline 800 & 0.88598 & 0.77094 & 0.69468 & 1.03100 & 0.91348 & 0.81053 \\
\hline 900 & 0.88704 & 0.77444 & 0.69991 & 1.03156 & 0.91577 & 0.81470 \\
\hline 1000 & 0.88808 & 0.77772 & 0.70494 & 1.03216 & 0.91785 & 0.81874 \\
\hline 1100 & 0.88897 & 0.78066 & 0.70948 & 1.03263 & 0.91981 & 0.82251 \\
\hline
\end{tabular}




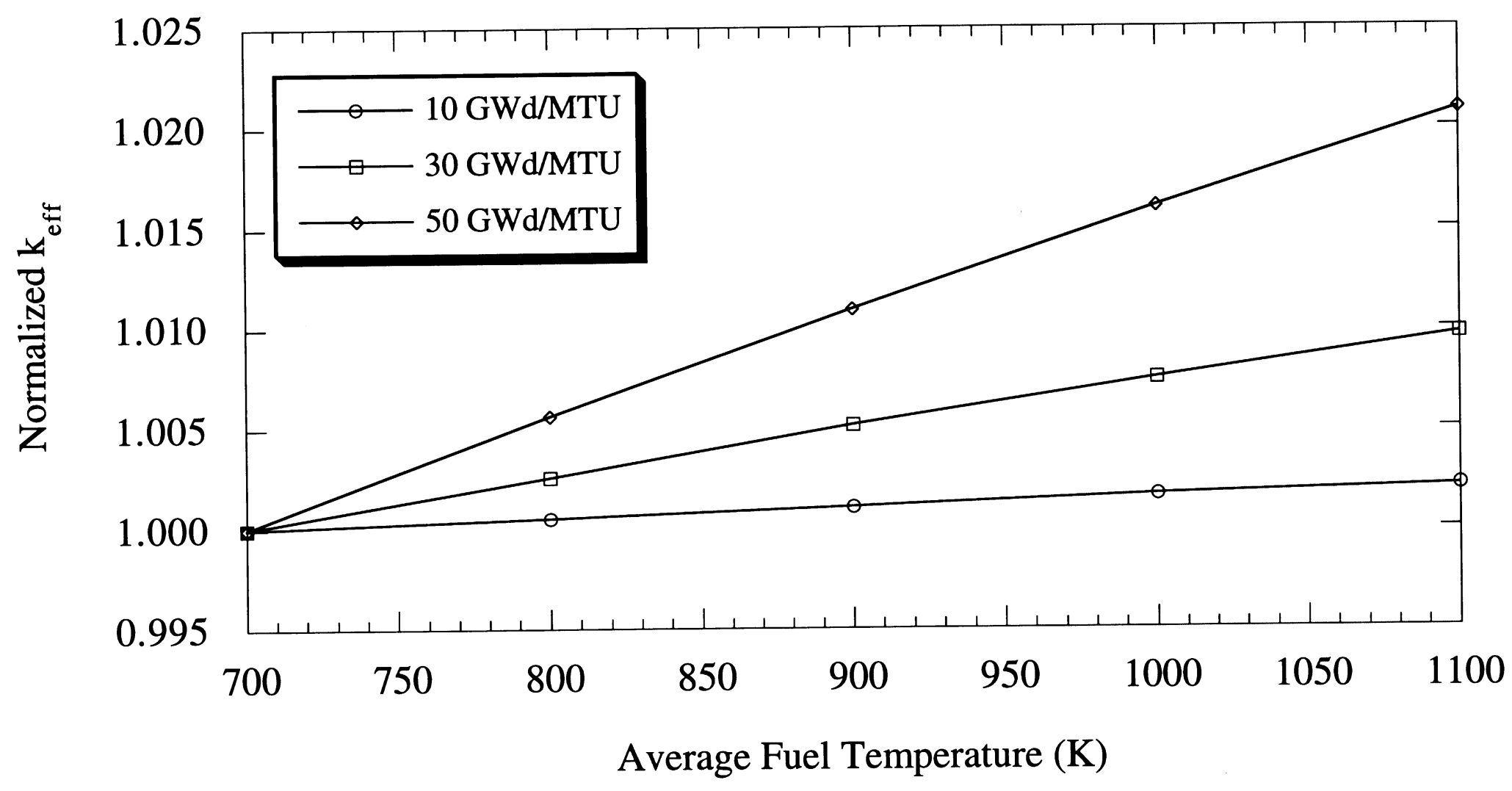

Fig. 24. Trends in $\mathrm{k}_{\infty}$ with varying fuel temperature during depletion (4.5 wt $\%$ fuel). 
Table 15. Effect of average moderator temperature on $\mathrm{k}_{\infty}$ (actinides + fission products)

\begin{tabular}{|c|c|c|c|c|c|c|}
\hline \multirow{2}{*}{$\begin{array}{l}\text { Ave. } \\
\text { moderator } \\
\text { temperature } \\
(\mathrm{K})\end{array}$} & \multicolumn{6}{|c|}{ Infinite lattice neutron multiplication factor, $\mathrm{k}_{\infty}$} \\
\hline & $\begin{array}{c}3.0 \mathrm{wt} \% \\
10 \mathrm{GWd} / \mathrm{MTU}\end{array}$ & $\begin{array}{r}3.0 \text { wt } \% \\
30 \mathrm{GWd} / \mathrm{MTU} \\
\end{array}$ & $\begin{array}{c}3.0 \mathrm{wt} \% \\
50 \mathrm{GWd} / \mathrm{MTU}\end{array}$ & $\begin{array}{r}4.5 \mathrm{wt} \% \\
10 \mathrm{GWd} / \mathrm{MTU}\end{array}$ & $\begin{array}{r}4.5 \text { wt \% } \\
30 \mathrm{GWd} / \mathrm{MTU}\end{array}$ & $\begin{array}{r}4.5 \text { wt } \% \\
50 \mathrm{GWd} / \mathrm{MTU}\end{array}$ \\
\hline 500 & 0.84784 & 0.67865 & 0.56747 & 0.99761 & 0.83523 & 0.68731 \\
\hline 520 & 0.84977 & 0.68588 & 0.57757 & 0.99852 & 0.83964 & 0.69622 \\
\hline 540 & 0.85212 & 0.69457 & 0.59033 & 0.99967 & 0.84505 & 0.70729 \\
\hline 560 & 0.85506 & 0.70484 & 0.60561 & 1.00109 & 0.85155 & 0.72031 \\
\hline 580 & 0.85867 & 0.71706 & 0.62403 & 1.00276 & 0.85912 & 0.73539 \\
\hline 600 & 0.86282 & 0.73184 & 0.64626 & 1.00476 & 0.86832 & 0.75336 \\
\hline
\end{tabular}

Table 16. Effect of average moderator temperature on $\mathrm{k}_{\infty}$ (actinides only)

\begin{tabular}{|c|c|c|c|c|c|c|}
\hline \multirow{2}{*}{$\begin{array}{c}\text { Ave. } \\
\text { moderator } \\
\text { temperature } \\
(\mathrm{K})\end{array}$} & \multicolumn{6}{|c|}{ Infinite lattice neutron multiplication factor, $\mathrm{k}_{\infty}$} \\
\hline & $\begin{array}{c}3.0 \mathrm{wt} \% \\
10 \mathrm{GWd} / \mathrm{MTU}\end{array}$ & $\begin{array}{c}3.0 \mathrm{wt} \% \\
30 \mathrm{GWd} / \mathrm{MTU}\end{array}$ & $\begin{array}{r}3.0 \mathrm{wt} \% \\
50 \mathrm{GWd} / \mathrm{MTU} \\
\end{array}$ & $\begin{array}{r}4.5 \mathrm{wt} \% \\
10 \mathrm{GWd} / \mathrm{MTU}\end{array}$ & $\begin{array}{l}4.5 \text { wt \% } \\
30 \mathrm{GWd} / \mathrm{MTU}\end{array}$ & $\begin{array}{l}4.5 \mathrm{wt} \% \\
50 \mathrm{GWd} / \mathrm{MTU}\end{array}$ \\
\hline 500 & 0.87081 & 0.71809 & 0.61374 & 1.02308 & 0.88006 & 0.74303 \\
\hline 520 & 0.87290 & 0.72544 & 0.62480 & 1.02415 & 0.88480 & 0.75269 \\
\hline 540 & 0.87545 & 0.73469 & 0.63874 & 1.02550 & 0.89060 & 0.76467 \\
\hline 560 & 0.887862 & 0.74562 & 0.65545 & 1.02717 & 0.89760 & 0.77878 \\
\hline 580 & 0.88241 & 0.75865 & 0.67559 & 1.02916 & 0.90579 & 0.79517 \\
\hline 600 & 0.88704 & 0.77444 & 0.69991 & 1.03156 & 0.91577 & 0.81470 \\
\hline
\end{tabular}




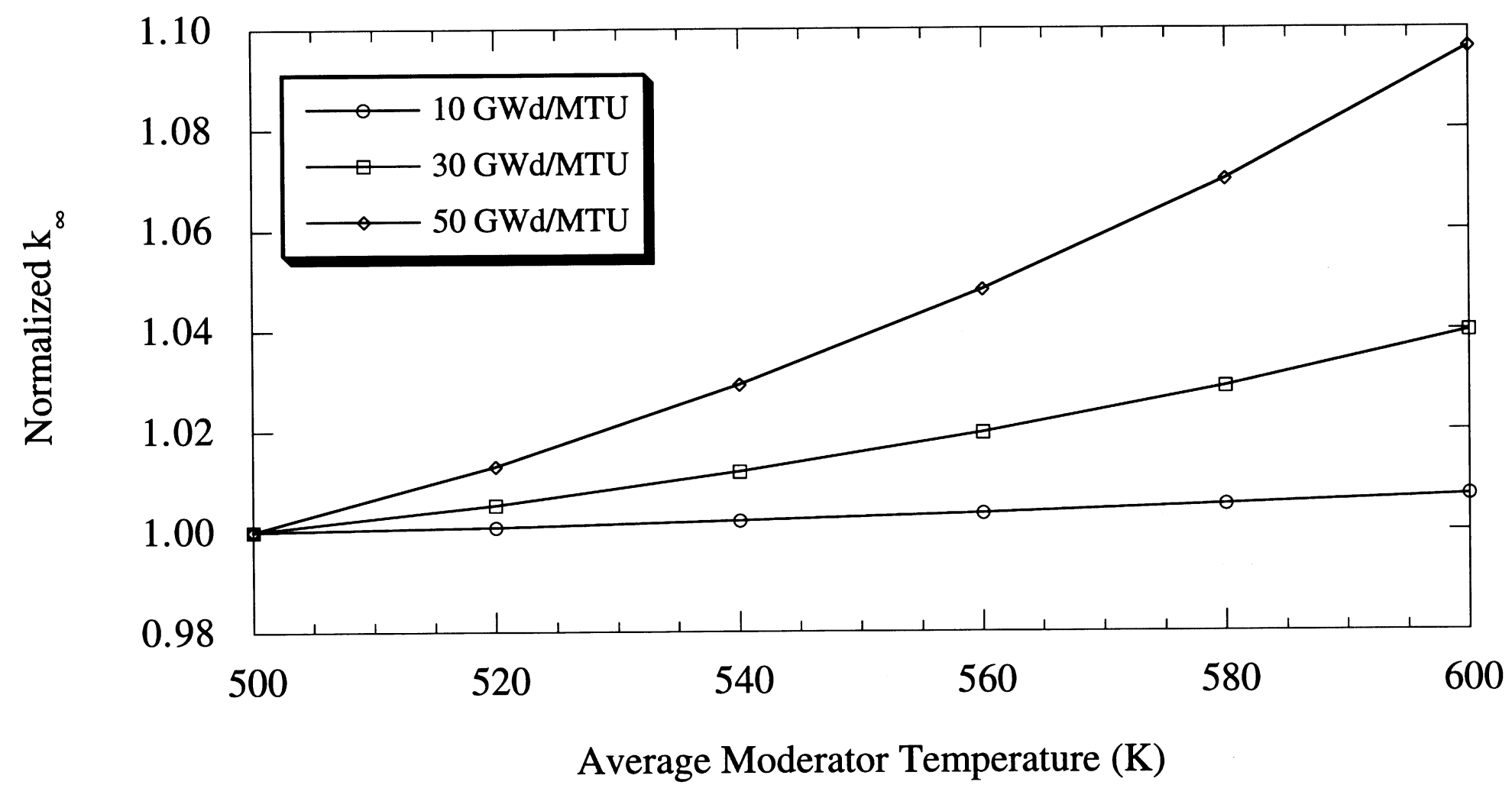

Fig. 25. Trends in $\mathrm{k}_{\infty}$ with varying moderator temperature during depletion (4.5 wt $\%$ fuel). 
on spent fuel $\mathrm{k}_{\infty}$ is expected and is consistent with the effect of boron concentration and average fuel temperature effects.

In all three sets of calculations (boron, fuel temperature, and moderator temperature), it is important to note that the reactivity associated with changes in each parameter are approximately the same whether fission products are present or not. These calculations support the earlier suggestion that spectral effects result in changes in the rate of production of plutonium, and that the increase in plutonium production results in a relative increase in reactivity for discharged spent fuel. These results also indicate that spectrum-induced changes in fission-product production and neutron absorption in fission products do not significantly affect the value of $\mathrm{k}_{\mathrm{eff}}$.

\subsection{SUMMARY OF INFINITE LATTICE STUDIES}

This section has presented parametric sensitivity studies to (1) determine a minimal set of nuclides that could adequately characterize spent fuel behavior in terms of their effect on the neutron multiplication factor and (2) characterize the basic behavior of spent fuel configurations under various depletion scenarios. All depletion calculations were performed using SAS2H, based on an assumed infinite lattice of Westinghouse $17 \times 17$ fuel pins; all nuclides available within SAS2H/ORIGEN-S were tracked in the depletion process. Criticality calculations were performed using the CSAS1X sequence, based on select sets of nuclides, for both actinides-only and actinides + fission products fuel models. Pin and lattice dimensions and base parameters used in all calculations (except as noted) are

provided in Appendix E. The results of these calculations will be applied in the development of a conservative methodology for modeling more complicated spent fuel cask configurations.

Section 3.1 has established the set of actinides and fission products that are most important in terms of neutron absorption over a range of spent fuel enrichments, burnups, and cooling times. These results were confirmed by the results of Sect. 3.2, which demonstrated essentially the same ranking of isotopes, based on the sensitivity of $k_{\infty}$ to changes in nuclide inventory, when no bias was applied to the computed isotopics. The ranking results changed very little, with the exception of the importance of ${ }^{155} \mathrm{Gd}$, when the computed isotopics were modified using a bias calculated based on comparisons between measured and calculated isotopics. As a result, it is concluded that the nuclides listed in Table17 represent a minimum set of isotopes recommended for consideration in a full burnup credit approach; of course, in a partial burnup credit implementation neglecting the effect of fission products, the 12 fission products listed in the table would be omitted. These nuclides were identified early in the burnup credit program; the appropriateness of each nuclide has been confirmed here. Experimental measurements are available for the validation of isotopic concentration prediction methods for each actinide and fission-product nuclide, although more data are available for actinides than for fission products at this time. As was mentioned earlier, ${ }^{237} \mathrm{~Np}$ was removed from the list of burnup credit nuclides because of a relatively large uncertainty in measurement data. However, further study indicates that ${ }^{237} \mathrm{~Np}$ measurement uncertainties are large only for one measurement and that with the removal of these measurements ${ }^{237} \mathrm{~Np}$ uncertainty is reduced to the order of $10 \%$. Thus additional measurements are likely to reduce the uncertainty for this isotope to an acceptable level. Furthermore, ${ }^{237} \mathrm{~Np}$ is a more important absorber than other burnup credit actinides and is fissionable via fast fission. Thus it is an important actinide and should be included in future work. Additionally, a future revision to burnup 
Table 17. Minimum recommended set of nuclides for burnup credit

\begin{tabular}{llll}
\hline $\begin{array}{ccc}\text { Actinides } \\
{ }^{234} \mathrm{U}\end{array}$ & ${ }^{235} \mathrm{U}$ & ${ }^{236} \mathrm{U}$ & ${ }^{238} \mathrm{U}$ \\
${ }^{238} \mathrm{Pu}$ & ${ }^{249} \mathrm{Pu}$ & ${ }^{240} \mathrm{Pu}$ & ${ }^{241} \mathrm{Pu}$ \\
& ${ }^{241} \mathrm{Am}$ & & \\
$\frac{}{\text { Fission Products }}$ & & & \\
${ }^{99} \mathrm{Tc}$ & ${ }^{133} \mathrm{Cs}$ & ${ }^{135} \mathrm{Cs}$ & ${ }^{143} \mathrm{Nd}$ \\
${ }^{145} \mathrm{Nd}$ & ${ }^{147} \mathrm{Sm}$ & ${ }^{149} \mathrm{Sm}$ & ${ }^{150} \mathrm{Sm}$ \\
Others & ${ }^{152} \mathrm{Sm}$ & ${ }^{153} \mathrm{Eu}$ & ${ }^{155} \mathrm{Gd}$ \\
\hline
\end{tabular}

credit nuclides should include ${ }^{103} \mathrm{Rh}$, a highly ranked fission-product absorber for whom measurement methods are currently being developed.

The sensitivity coefficients described in Sect. 3.2 (and listed for a range of initial enrichments and burnups in Appendix () allow an estimation of the effect on $\mathrm{k}_{\infty}$ of error in isotopic concentration of each nuclide under an infinite lattice approximation. General trends in the behavior of $k_{\infty}$ as a function of enrichment, burnup, and cooling time were discussed in Sect. 3.3. These studies demonstrated several important aspects of spent fuel behavior, including the following points: (1) both with and without fission products, fuel reactivity decreases with time for periods beyond $5 \mathrm{y}$ out to a time of approximately 100 years post-irradiation, followed by a very small increase in reactivity with time (exception: best-estimate fission products and actinides at low burnup reached a minimum before $100 \mathrm{y})$; (2) fission-product importance (reactivity worth) generally increases with cooling time over the first 50 years of cooling, and then remains roughly constant; (3) fission-product importance also increases with increasing burnup.

Section 3.4 discussed the results of calculations studying the effect of an assumed operating history on the results of depletion calculations after a 5-year cooling period. The results of these depletion calculations were evaluated by performing criticality calculations using all burnup credit nuclides and a subset of these nuclides in which fission products were omitted. Depletion isotopics were bias-corrected [Eq.(B.2)] to obtain realistic estimates of nuclide concentrations. Operating histories were studied in terms of specific power effects and the effect of time-dependent variations in burnup and downtimes. Results indicate that the specific power assumed for a depletion calculation has the more dominant effect on $\mathrm{k}_{\infty}$, especially for highly burned fuel, for which variations in specific power resulted in approximately a $1 \%$ variation in $\mathrm{k}_{\infty}$. Time-dependent variations in operating history were generally found to be important only when the variations occurred late in the fuel lifetime; even then, changes in $\mathrm{k}_{\infty}$ were only on the order of $0.1 \%$. For criticality calculations based on actinides only, it was found that a depletion scheme based on the highest specific power and which included no downtime would result in a conservative bound on $\mathrm{k}_{\infty}$. 
When fission products are present, there is no clear approach to obtain an estimate of $\mathrm{k}_{\infty}$ that bounds variations due to operating history effects. Even though an assumed low-specific-power depletion scheme is clearly more conservative than faster depletion rates, the most conservative treatment of time-dependent variations in power is not obvious. However, an assumed constant power operation has the benefit of being simple to implement and of being consistent with the conservative approach for actinides-only fuel, and is therefore recommended for burnup credit modeling. Based on the operating histories studied here, an approach that assumes a low-specific-power operation at constant power with no downtime should include an uncertainty margin of at least $0.2 \%$ to account for the effect of time-dependent burnup effects due to fission products. This $0.2 \%$ margin is based on the results shown in Fig. 21, which indicate roughly a $0.2 \% \Delta \mathrm{k}$ peak due to operating history effects for highly burned fuel. Further study may indicate that only the last few days of operation are important in terms of fission products and their effect on $\mathrm{k}_{\infty}$.

Finally, the effect of other depletion parameters on subsequent criticality calculations was examined in Sect 3.5. Specifically, the effect of fuel and moderator temperatures and soluble boron concentrations in the moderator were determined over a range of values for each parameter. Results indicated that increasing temperatures and increasing boron concentrations assumed during depletion calculations result in spectral hardening and in the enhanced production of ${ }^{239} \mathrm{Pu}$ and ${ }^{241} \mathrm{Pu}$ from resonance absorption in ${ }^{238} \mathrm{U}$. The presence of the additional fissile isotopes results in a decrease in the amount of ${ }^{235} \mathrm{U}$ depletion required for a given burnup. Thus fuel burned under such conditions (i.e., higher temperatures and boron concentrations) results in a higher value of $\mathrm{k}_{\infty}$ in subsequent criticality calculations. Conservatism is therefore ensured by selecting an upper bound for each of these parameters for use in depletion calculations. However, sensitivity of $\mathrm{k}_{\infty}$ to each parameter, especially moderator temperature, requires that a conservative upper bound should be based on a reasonable estimate of expected conditions, rather than an arbitrarily assumed and perhaps overconservative estimate of the upper limit. 


\section{DEVELOPMENT OF A THREE-DIMENSIONAL CASK MODEL FOR PARAMETRIC ANALYSIS}

Although the 1-D studies performed in the previous section provide broad insight to the important features of spent fuel depletion calculations, they cannot address many of the concerns related to a 3-D cask design. Such issues include the effect of several phenomena, both direct and indirect, on $\mathrm{k}_{\mathrm{eff}}$ : axial variations in fuel burnup, axial and radial reflection and leakage at the cask walls, axial temperature variations during depletion, and neutron absorbers between assemblies. The following section of this report presents results of sensitivity analyses of numerous phenomena related to 3-D effects associated with a conceptual cask design. To understand the basis for this cask model, this section provides a detailed description of the development of the model, including all assumptions and simplifying approximations. These approximations are based on the findings of the 1-D sensitivity studies discussed earlier in this report.

The procedure necessary to perform a spent fuel cask calculation is similar to that used in the earlier 1-D studies. The calculation consists of two steps: depletion calculations, followed by a criticality calculation. A conservative approach to depletion calculations may be developed based on the results of the 1-D calculations. In addition to the cask-specific geometrical configuration required for 3-D criticality calculations, it is necessary to determine an appropriate approach for modeling axially varying burnup.

Using the scheme typically used for cask loading calculations, it is assumed that all assemblies loaded in the candidate design are of the maximum reactivity allowed under burnup credit assumptions; it is then incumbent upon the designer to demonstrate that the multiplication factor for a cask with such a loading will not exceed an established administrative limit. Thus even though 1-D calculations were based on a single fuel pin in an infinite lattice, 3-D calculations will be based on a single assembly model placed in all cask positions. Furthermore, because depletion calculations are based on assemblyaveraged isotopics (see Sect. 2.1 each fuel pin in the assembly model will be identical, with an average burnup corresponding to the assembly-averaged burnup.

The following subsections describe the approaches taken in development of depletion and criticality models for application in cask configurations. Depletion calculations, performed using SAS2H, are essentially the same as those performed in the 1-D CSAS1X criticality calculations. The 3-D KENO V.a criticality calculations, however, require several special treatments and simplifying assumptions, as discussed below. General comments regarding limitations associated with Monte Carlo methods (e.g., KENO V.a), and their relationship to the current work are discussed in Appendix F.

\subsection{BURNUP-DEPENDENT DEPLETION CALCULATIONS}

For conservatism and for simplicity, depletion calculations are performed assuming a constant operating history (i.e., burnup calculations assume that during the in-core lifetime of each fuel assembly, the reactor in which the fuel was burned operated continuously at a constant power level). Results of the 1-D analysis of spent fuel presented earlier indicate that when only actinides are considered in the criticality calculation, continuous operation at the highest specific power possible would yield the most limiting value of $\mathrm{k}_{\mathrm{eff}}$; conversely, operation at a lower bound on specific power is conservative when 
fission products are included in the criticality calculation. For simplicity, the depletion calculations in subsequent models described in this report are based on continuous operation for $1080 \mathrm{~d}$ (three 360-d cycles with no downtime). A summary of key parameters assumed in these models is provided in Appendix E. Specific power is determined by this time period and the final burnup of the fuel in each study. Isotopic concentrations resulting from each calculation were modified by the bias factors and approach described in Appendix B.

\subsection{AXIAL ZONING OF FUEL PINS}

For 1-D criticality calculations, only one depletion calculation was required to generate isotopics; azimuthal asymmetry was treated by the depletion model, and therefore azimuthal symmetry could be assumed in the criticality calculation, radial variations were treated by cross-section processing codes, and axial variations were ignored. In reality, both azimuthal and axial variations in fuel burnup exist and are potentially important. In general, azimuthal variations in burnup are small and localized; assembly-averaged depletion calculations that account for water holes and other assembly asymmetries have been shown to provide an adequate treatment of azimuthal effects when assembly-averaged isotopics are applied across the assembly 25 However, axial variations in operational flux profiles due to leakage at the fuel ends results in nonuniform burnup distributions along the length of the fuel. This effect is most pronounced in highly burned fuel. Inaccuracies in the calculation of $\mathrm{k}_{\mathrm{eff}}$ can result from

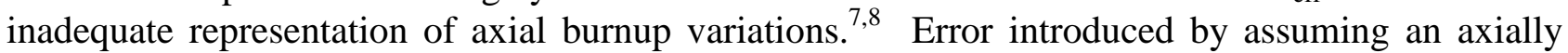
uniform burnup is often termed the "end effect." In order to study the effect of various axial burnup representations, and to assess the magnitude of the end effect as a function of enrichment and burnup, it is necessary to determine axially varying isotopic concentrations. In a numerical approximation of axially varying isotopics, it is necessary to discretize axial burnup into burnup zones. Within each burnup zone, burnup is assumed constant. Isotopic concentrations can therefore be estimated using a unique SAS2H depletion calculation for each burnup in each zone, to which isotope-specific bias factors are applied. The number and size of axial zones required to properly treat axial burnup variations remains to be determined, and will be addressed via parametric analysis..

\subsection{DETERMINATION OF AXIAL BURNUP PROFILES}

The previous subsection has described a method by which axial burnup effects can be modeled in a 3-D cask geometry. However, an appropriate representation of axial burnup profiles is necessary to implement such a procedure. The currently recommended approach is to base assumed axial burnup profiles on actual burnup profiles determined from reactor operational data for a large number of fuel assemblies. Such a database is currently being compiled for a wide range of initial enrichments, burnups, and assembly designs. A portion of this database, consisting of the burnup profiles for a total of 510 Combustion Engineering $14 \times 14$ assemblies, was used as a basis for axial profiles applied in the 3-D parametric calculations described later in this report. Although it is not consistent with the use of Westinghouse $17 \times 17$ fuel assemblies for other aspects of this work, it is the most complete database of its type currently available and should provide insight relative to the effect of burnup profile assumptions on $\mathrm{k}_{\mathrm{eff}}$ calculations. 
Because the characteristic shape of the axial burnup profile is burnup dependent, assemblyburnup profiles were grouped according to their corresponding burnups. The following burnup ranges, in GWd/MTU, are represented by the database: $8 \mathrm{~B} 12(10 \pm 20 \%), 16 \mathrm{~B} 24(20 \pm 20 \%), 24 \mathrm{~B} 36(30 \pm$ $20 \%), 36 \mathrm{~B} 44(40 \pm 10 \%)$, and 44B55 (50 $\pm \sim 10 \%)$. Rather than trying to match a known burnup to the shape of a similar burnup in the database, the burnup credit approach recommends use of the most bounding burnup shape for the burnup range corresponding to a given burnup. For example, a fuel assembly with a burnup of $39 \mathrm{GWd} / \mathrm{MTU}$ would be modeled assuming the most limiting burnup profile in the 36- to 44-GWd/MTU range. The most bounding shape (in terms of its effect on the conservative calculation of $\mathrm{k}_{\mathrm{eff}}$ ) will not necessarily be one of the shapes in the database; instead, it is likely to be a composite of shapes included in the database for each range. Efforts are underway to establish the characteristics that define the most bounding shape for criticality considerations, $\stackrel{28}{h}$ however, this report will also attempt to define bounding characteristics through the parametric analysis of various composite profiles.

Burnup profiles in the CE $14 \times 14$ database are represented by 20 discrete values at fuel lengths (measured in percentage of full length as measured from the bottom of the fuel) of $2.5,7.5,12.5, \ldots 92.5$, and 97.5. The burnup value of each region was normalized to an average burnup of 1.0. An example of database profiles is shown in Fig. 26 for the 49 burnup shapes in the 8- to 12-GWd/MTU burnup range. This particular burnup range shows the greatest variation between profiles. In general, burnup profiles tend to flatten out with increased burnup; this tendency can be seen in some of the burnup shapes of Fig. 26.

This trend is especially apparent in the high-burnup case of Fig. 27, which shows the burnup shapes for 24 assemblies in the 44- to 55-GWd/MTU burnup range. These burnup profiles are consistently flat over a broad central region. For the lower burnup assemblies, variations between flat and curved (more sinusoidal) shapes result primarily from differences in "fissile depletion." Fissile depletion, defined here as an unquantified measure of the depletion of fissile fuel, is a function not only of burnup, but also of the initial enrichment of the fuel. The assemblies in the 8- to 12-GWd/MTU burnup range include initial enrichments ranging from 2.0 to $3.5 \mathrm{wt} \%$, and therefore represent a broad range of fissile depletion. For the higher burnup assemblies in the 44- to 55-GWd/MTU range, initial enrichments ranging from 3.3 to $3.7 \mathrm{wt} \%$ are present; thus the fissile depletion is consistently high for all assemblies, and the burnup profiles are more closely grouped.

\subsection{CROSS-SECTION PROCESSING}

A thorough study of axial zoning effects will require the use of a large number of axial zones, each with its own burnup-dependent isotopic concentrations. Because the resonance processing of cross sections for certain nuclides can be strongly dependent on variations in isotopic concentrations (i.e., burnup variations), the SCALE CSAS25 sequence is not appropriate for multizone calculations where there is a wide variation in burnup. CSAS25 is designed to perform cross-section processing (using BONAMI and NITAWL-II) for one fuel type and to use those cross sections in the subsequent KENO V.a calculation. To perform calculations with multiple sets of cross sections (generated using 


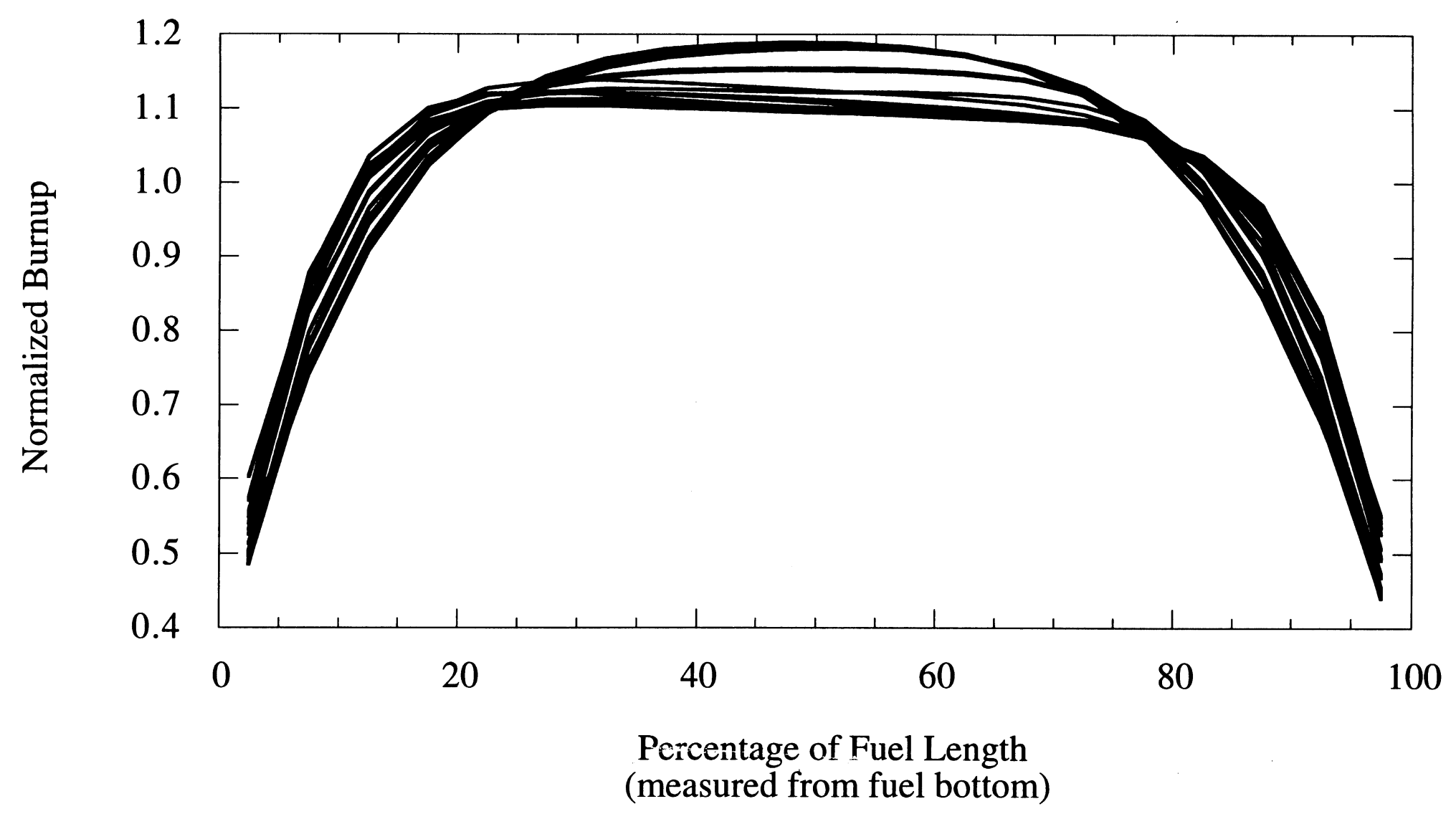

Fig. 26. Burnup profiles for 8- to $12-\mathrm{GWd} / \mathrm{MTU}$ range from CE $14 \times 14$ database. 


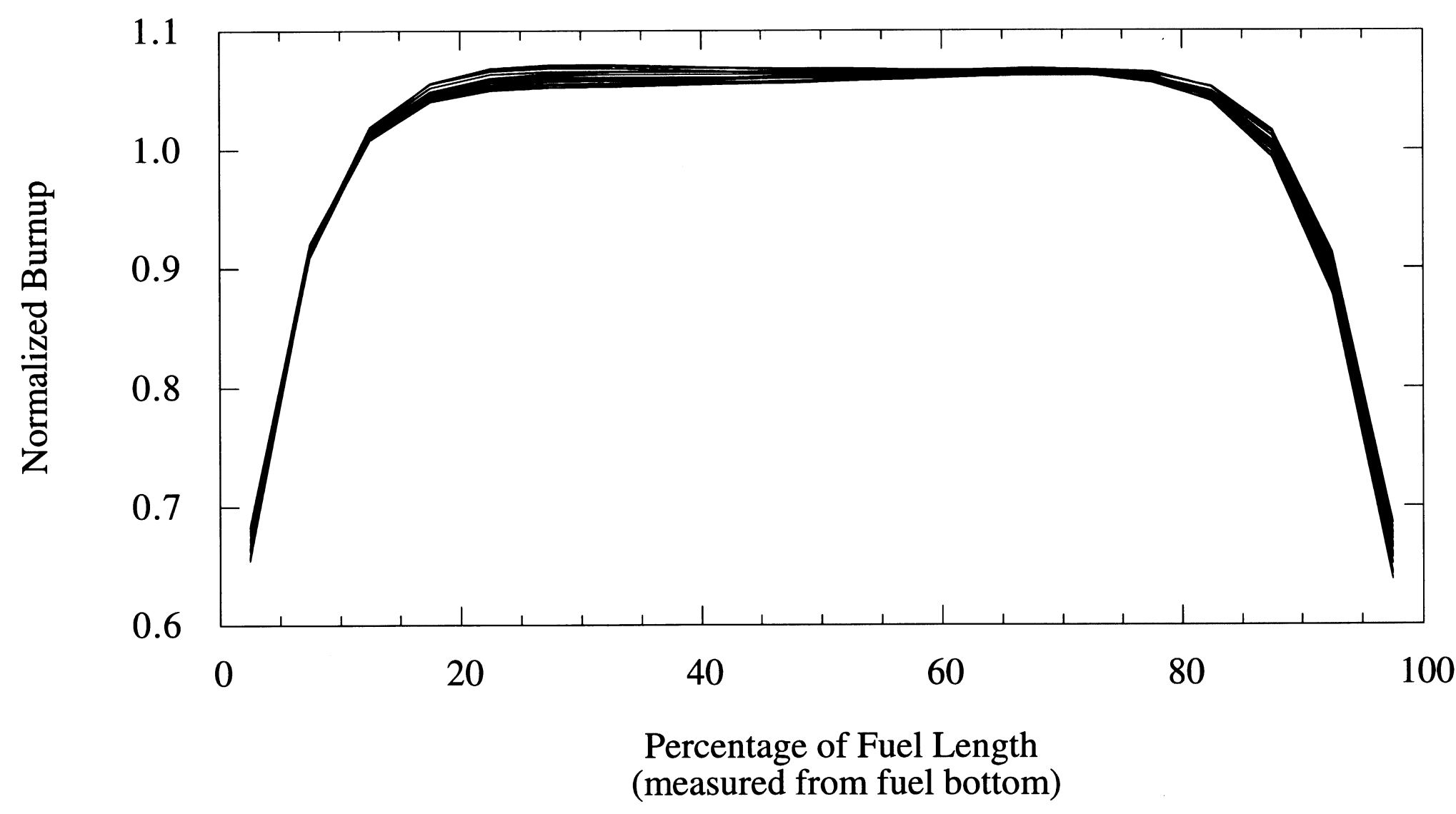

Fig. 27. Burnup profiles for 16 - to $24-\mathrm{GWd} / \mathrm{MTU}$ range from CE $14 \times 14$ database. 
varying isotopic compositions) will require the use of multiple CSASN calculations to perform crosssection processing for each burnup zone. The multiple cross-section libraries produced in these calculations can then be combined into a single library using the SCALE utility module WAX. The resulting combined library can then be used in a stand-alone KENO calculation.

Burnup dependence of criticality calculations has two components. Fuel reactivity is driven primarily by the number density of the various isotopes present in the fuel; however, cross sections required to compute $\mathrm{k}_{\text {eff }}$ also have a burnup dependence due to competition for neutrons among the nuclides present. Composition-specific cross sections must be performed to generate resonancecorrected cross sections for each fuel zone. However, collection and use of composition-specific cross sections for all 23 fuel isotopes for a KENO V.a model with multiple burnup zones has the potential to be an onerous and very time-consuming task when a large number of axial zones is desired. Experience has showr 29,30 that because fission-product nuclides represent only a small fraction of the total number density of the fuel isotopes, fission-product cross sections are relatively insensitive to changes in isotopic content, and therefore resonance-corrected cross sections calculated for any single burnup zone in a multizone fuel pin model are appropriate. This situation is also true of many fuel activation products and minor actinides; however, cross sections for seven actinides are known to have a more significant burnup dependence. These seven burnup-sensitive actinides are ${ }^{234} \mathrm{U},{ }^{235} \mathrm{U},{ }^{236} \mathrm{U}$, ${ }^{238} \mathrm{U},{ }^{239} \mathrm{Pu},{ }^{240} \mathrm{Pu}$, and ${ }^{241} \mathrm{Pu}$. Cross sections for each of these isotopes must be obtained from calculations based on burnup-dependent isotopics. For the remaining nuclides, the cross sections are obtained from a composition-specific calculation for the highest burnup zone because this zone represents the region of lowest resonance absorption; fission-product cross sections computed in this zone therefore result in a higher and more conservative value of $\mathrm{k}_{\mathrm{eff}}$. The effect of this approximation has been found to be small $(<0.1 \% \Delta \mathrm{k} / \mathrm{k}) \stackrel{29,30}{2}$

Composition-specific cross-section processing can be performed using the SCALE CSASN sequence. SAS2H calculations are performed to obtain burnup-dependent isotopics for each burnup zone in a multizone model. The isotopic concentrations for the burnup credit nuclides used are extracted from the SAS2H output and used in CSASN calculations performed for each burnup zone. Next, WAX is used to combine all cross-section working libraries into a single working library for subsequent use by KENO V.a. All cross sections from the highest burnup zone (containing all fission and activation isotopes together with clad, moderator, and structure materials) are copied into the combined library. For each of the remaining axial zone cross-section libraries, only the seven burnupdependent actinides are copied. In addition, for each of the seven burnup-dependent actinides in each zone, the cross-section ID number is modified by prefixing a zone-identifying number to the default SCALE cross-section ID so that the KENO V.a core model can reference the appropriate cross section for each fuel zone. The sample SCALE input given in Table E-4 of Appendix E shows the process of burnup-dependent CSASN calculations performed for each zone of a 7-zone model, followed by WAX calculations to extract and combine cross sections into a final library for use by KENO V.a.

This rather complicated modeling process is shown schematically in Fig. 28 for a hypothetical fuel pin with a 3-zone burnup representation, with burnups labeled as A, B, and C. Burnup B represents the highest burnup zone in the model. The figure shows separate WAX operations for extracting cross sections and subsequent combination of cross-section sets. Although this approach is valid, all WAX 


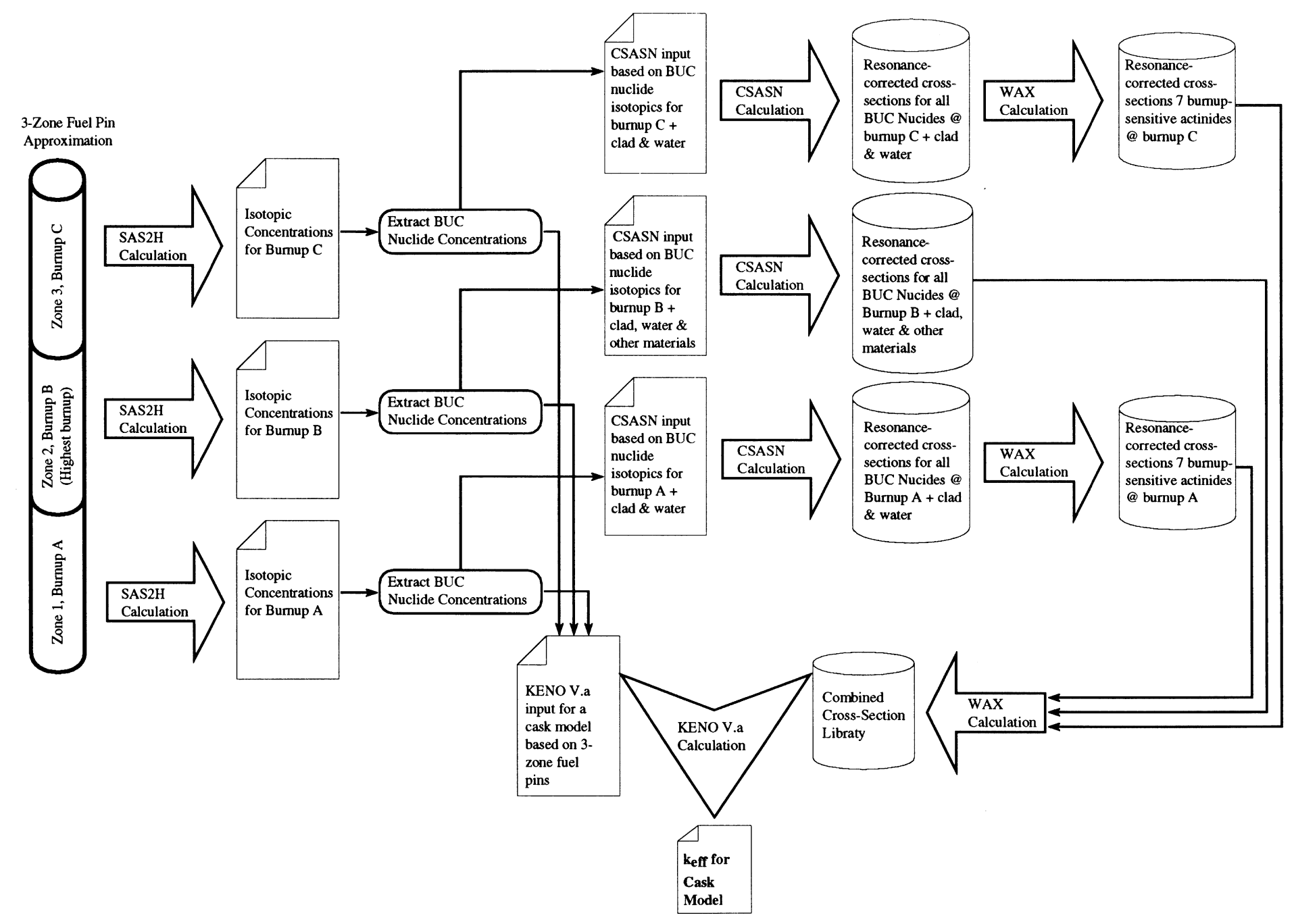

Fig. 28. Flowchart of calculational procedure required for multiple axial zone KENO V.a calculation. 


\section{5}

data manipulations could also be performed in one calculational step. Also, note that for models with more than three zones, additional zones would be treated exactly like zones 1 and 3 in the figure.

\subsection{CONCEPTUAL CASK CONFIGURATION}

A conceptual design has been completed for a multipurpose spent fuel transportation and

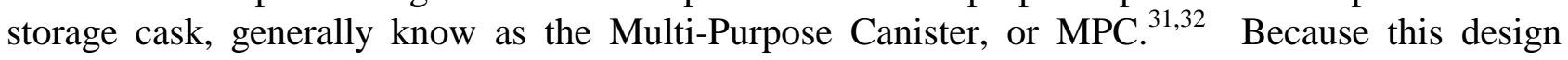
represents the general size, shape, and material composition expected in a final design, a KENO V.a model based on the design was felt to be appropriate for use as a base case in parametric calculations. The MPC design includes 21 assembly storage positions in a rectangular array. For the purposes of this study assemblies are assumed to be of a Westinghouse $17 \times 17$ design, with identical composition and burnup. Fuel pins within each assembly are also assumed to be identical, with a variable number of burnup-dependent axial divisions, depending on the study performed. The specifications used as a basis for the model, including fuel pin, assembly, and cask designs, are provided in Appendix E. Even though the details of the development and design of a KENO V.a input model are beyond the scope of this report, a listing of the KENO V.a input for a nominal multiple axial zone model is also included in Appendix E. 


\section{PARAMETRIC STUDIES OF A NOMINAL SPENT FUEL CASK CONFIGURATION}

Using the analysis assumptions and nominal MPC model described in the previous section, this section describes the setup and results of parametric analyses that examine: (1) bounding burnup profiles (based on a database of burnup-dependent axial burnup profiles), (2) axial burnup effects, (3) axial temperature and moderator density variations, and (4) conservative isotopic correction factors. In addition, the effect of initial enrichment, cooling time, and burnup on $\mathrm{k}_{\mathrm{eff}}$ are revisited to confirm within a cask environment those trends previously identified using 1-D infinite-lattice analyses.

\subsection{DETERMINATION OF A CONSERVATIVE BURNUP PROFILE FROM DATABASE PROFILES}

As was illustrated in the previous section, burnup profiles available in the CE $14 \times 14$ database span a range of burnup profile shapes for each burnup range. It is desired to obtain a burnup profile that can conservatively (in terms of its effect on the calculated $\mathrm{k}_{\mathrm{eff}}$ in a cask model) represent this burnup range. Rather than attempt to study each individual shape, it was decided to examine composite burnup profiles developed from various combinations of the upper and lower bounds of the range of shapes. Figure 29 illustrates composite shapes formed from the maximum and minimum at each axial location for the 8- to 12-GWd/MTU range of burnup profiles. These profiles were shown in Fig. 26. The upper bound curve represents the set of the twenty highest points from the 20 axial zones in this database subset; similarly, the lower bound curve represents the twenty lowest points axially from the same burnup range.

Note that all burnup profiles in the database are normalized to an average of 1.0, and therefore only represent a burnup "shape." The actual burnup profile used in a calculation will be the product of an assembly's average burnup and a burnup determined for each zone in a given model from an assumed burnup shape. Any shape derived as a set of high or low points (or any combination thereof) must be renormalized to an average value of 1.0 since combinations of arbitrary points from a set of normalized curves will not necessarily be normalized themselves.

This work assumes that for a given set of burnup profiles, a conservative profile is bounded by the upper and lower ranges of the set of profiles. Although there are an infinite number of possible shapes within these bounds, this study considers only combinations of high and low points for each axial region (i.e., combinations of the upper and lower bound curves) for each burnup range. This will not necessarily provide a definition or identification of the most limiting burnup shape within each range, but should provide an estimate of the effect of varying burnup shapes and the general characteristics of the most limiting shape. Upper and lower bounds for each axial zone and for all burnup ranges are given in Table 18 .

In order to study a range of burnup shapes, it is necessary to develop a shorthand notation to identify each shape or combination of shapes. Since for each axial zone (and for each burnup range) there are only two burnup values considered [high $(\mathrm{H})$ or low $(\mathrm{L})]$, each axial region can be described by the assumed datum for that zone. For example, the upper-bound shape of Fig. 29 (for the 8- to12-GWd/MTU burnup range), one could describe the shaping format as 


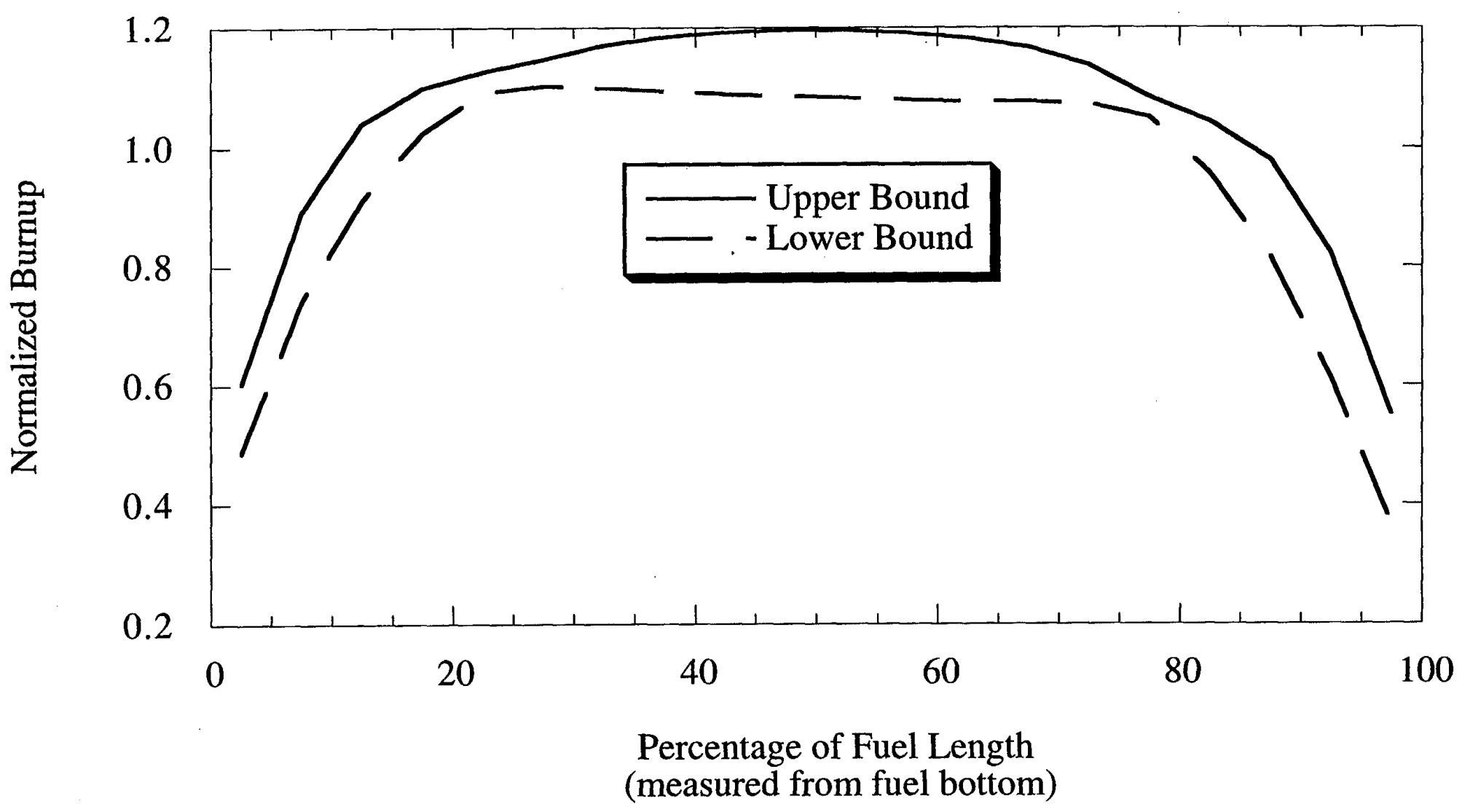

Fig. 29. Maximum and minimum bounds for 8 - to $12-\mathrm{GWd} / \mathrm{MTU}$ burnup profile range. 
Table 18. Upper and lower burnup bounds for CE $14 \times 14$ database burnup ranges

\begin{tabular}{|c|c|c|c|c|c|c|c|c|c|c|c|}
\hline \multirow{3}{*}{$\begin{array}{l}\text { Zone } \\
\text { No. }\end{array}$} & \multirow{3}{*}{$\begin{array}{l}\text { Zone center } \\
\text { (\% of fuel } \\
\text { height) }\end{array}$} & \multicolumn{10}{|c|}{ Burnup range (GWd/MTU) } \\
\hline & & \multicolumn{2}{|c|}{$8 \mathrm{~B} 12$} & \multicolumn{2}{|c|}{$16 \mathrm{~B} 24$} & \multicolumn{2}{|c|}{$24 \mathrm{~B} 36$} & \multicolumn{2}{|c|}{ 36B44 } & \multicolumn{2}{|c|}{ 44B55 } \\
\hline & & Min. & Max. & Min. & Max. & Min. & Max. & Min. & Max. & Min. & Max. \\
\hline 1 & 2.5 & 0.485 & 0.602 & 0.507 & 0.677 & 0.583 & 0.675 & 0.623 & 0.666 & 0.654 & 0.683 \\
\hline 2 & 7.5 & 0.740 & 0.891 & 0.784 & 0.916 & 0.863 & 0.920 & 0.895 & 0.916 & 0.910 & 0.921 \\
\hline 3 & 12.5 & 0.908 & 1.039 & 0.946 & 1.034 & 0.989 & 1.033 & 1.009 & 1.022 & 1.008 & 1.019 \\
\hline 4 & 17.5 & 1.023 & 1.099 & 1.039 & 1.081 & 1.041 & 1.075 & 1.042 & 1.062 & 1.040 & 1.056 \\
\hline 5 & 22.5 & 1.091 & 1.126 & 1.062 & 1.108 & 1.054 & 1.092 & 1.052 & 1.075 & 1.050 & 1.068 \\
\hline 6 & 27.5 & 1.103 & 1.147 & 1.064 & 1.128 & 1.056 & 1.100 & 1.055 & 1.078 & 1.052 & 1.071 \\
\hline 7 & 32.5 & 1.099 & 1.171 & 1.063 & 1.141 & 1.056 & 1.102 & 1.056 & 1.078 & 1.053 & 1.071 \\
\hline 8 & 37.5 & 1.094 & 1.184 & 1.063 & 1.149 & 1.056 & 1.101 & 1.057 & 1.077 & 1.054 & 1.070 \\
\hline 9 & 42.5 & 1.089 & 1.192 & 1.062 & 1.153 & 1.057 & 1.099 & 1.058 & 1.077 & 1.055 & 1.069 \\
\hline 10 & 47.5 & 1.085 & 1.196 & 1.062 & 1.155 & 1.058 & 1.098 & 1.059 & 1.076 & 1.056 & 1.068 \\
\hline 11 & 52.5 & 1.082 & 1.196 & 1.062 & 1.156 & 1.060 & 1.097 & 1.061 & 1.076 & 1.058 & 1.068 \\
\hline 12 & 57.5 & 1.079 & 1.191 & 1.063 & 1.156 & 1.061 & 1.096 & 1.062 & 1.076 & 1.059 & 1.067 \\
\hline 13 & 62.5 & 1.077 & 1.182 & 1.062 & 1.153 & 1.062 & 1.095 & 1.063 & 1.076 & 1.061 & 1.067 \\
\hline 14 & 67.5 & 1.076 & 1.167 & 1.062 & 1.145 & 1.063 & 1.095 & 1.065 & 1.075 & 1.062 & 1.068 \\
\hline 15 & 72.5 & 1.073 & 1.137 & 1.056 & 1.125 & 1.059 & 1.092 & 1.064 & 1.073 & 1.062 & 1.067 \\
\hline 16 & 77.5 & 1.050 & 1.084 & 1.041 & 1.094 & 1.050 & 1.077 & 1.057 & 1.068 & 1.056 & 1.065 \\
\hline 17 & 82.5 & 0.955 & 1.043 & 1.008 & 1.066 & 1.025 & 1.063 & 1.038 & 1.056 & 1.040 & 1.053 \\
\hline 18 & 87.5 & 0.815 & 0.978 & 0.875 & 1.022 & 0.954 & 1.023 & 0.985 & 1.017 & 0.993 & 1.016 \\
\hline 19 & 92.5 & 0.612 & 0.823 & 0.658 & 0.888 & 0.787 & 0.905 & 0.862 & 0.908 & 0.878 & 0.913 \\
\hline 20 & 97.5 & 0.365 & 0.550 & 0.399 & 0.660 & 0.542 & 0.669 & 0.612 & 0.665 & 0.638 & 0.685 \\
\hline
\end{tabular}

"НHНHНHНHНHНHНHНHНHНH," indicating that the highest value in the burnup range database was applied for each of the 20 regions. Selected burnup shapes and their shorthand shaping format identification are shown in Figs. 30 and 31. This notation is used to easily identify different combinations of the two shapes in a minimalist fashion. Shape-identifying figures such as Figs. 30 and 31 provide no additional information over the abbreviated notation.

Earlier work performed in support of an international study of burnup credit effects $\mathrm{has}^{8}$ indicated that when both actinides and fission products are present, the end effect is the greatest when the ratio of the average burnup in the end regions to the average burnup in the center region of a fuel rod is minimized. The definition of "end region" vs "center region" remains to be determined; the variation in burnup profiles shapes between low-burnup and high-burnup ranges (as illustrated in Figs. 26 and 27) indicates that perhaps these definitions change with burnup. This trend is possibly due to the importance of fission products produced at the rod ends, which in turn may be due to the lower specific power at which the fuel ends are burned relative to the fuel center. Thus important shaping formats to be studied might include "LLHHHHHHHHHHHHHHHHHHLL" or "LLLLHHHHHHHHHHHHHHLLLL." However, since the specific power effect works in the opposite direction when fission products are 


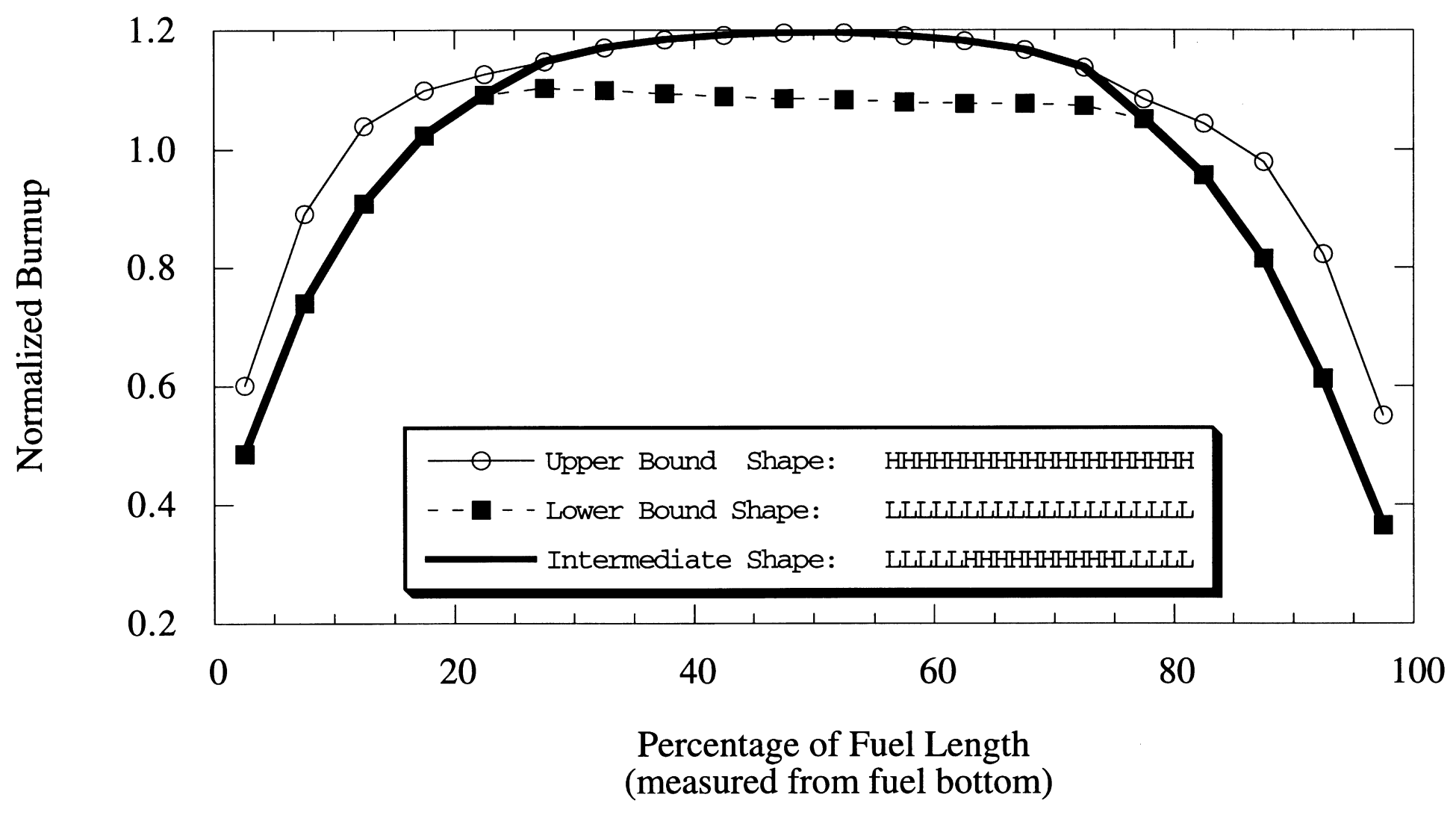

Fig. 30. Definition of burnup shape LLLLLHHHHHHHHHHLLLLL. 


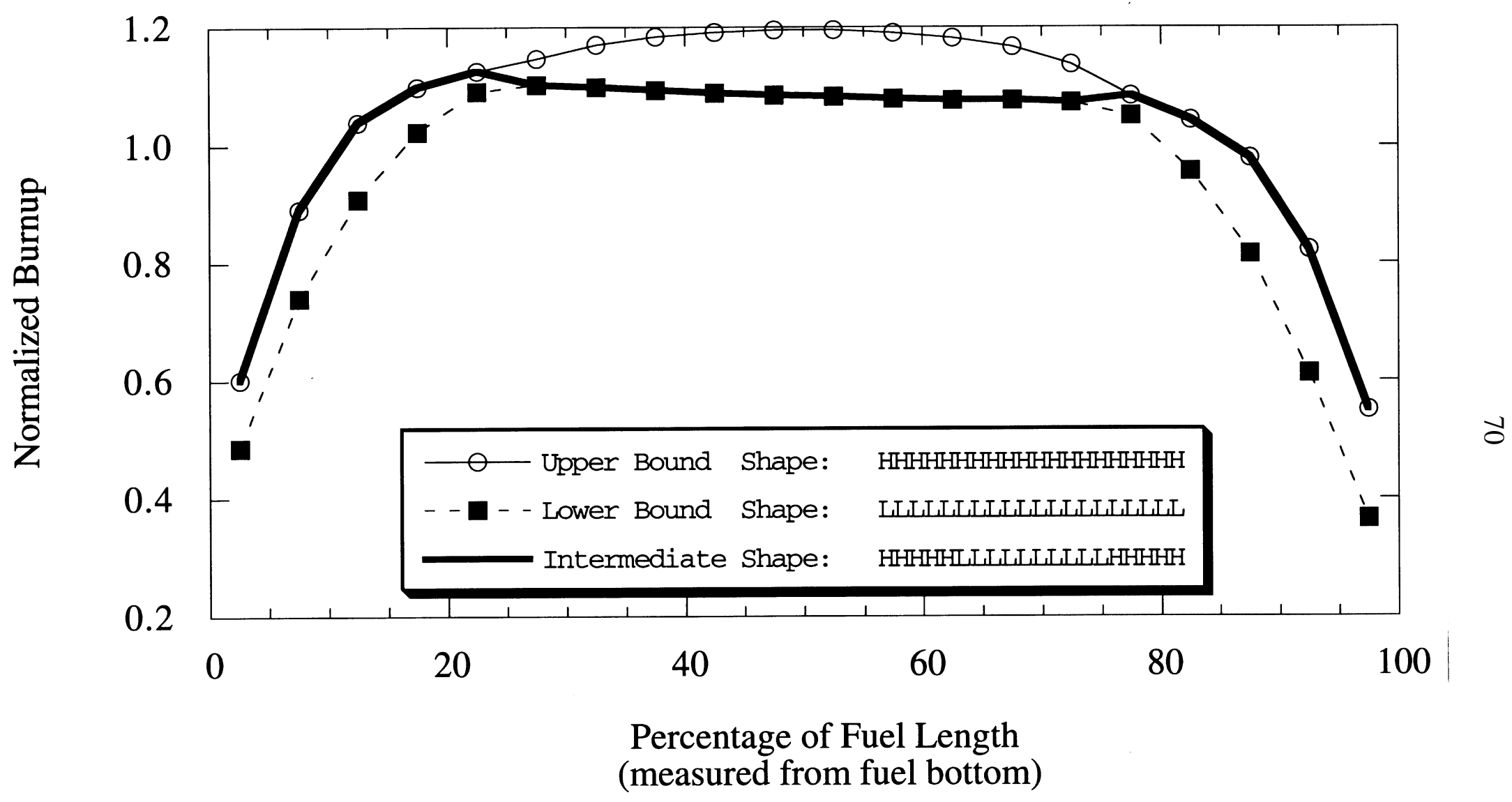

Fig. 31. Definition of burnup shape HHHHHLLLLLLLLLLHHHHH. 
removed, it is necessary to examine burnup profiles where the end/center burnup ratio is minimized. For actinides-only criticality calculations, shaping formats such as "HHLLLLLLLLLLLLLLLLLHH" or "HHHHLLLLLLLLLLLLHHHH" may be important.

To study the full range of burnup shape effects (within the extent of $\mathrm{H} / \mathrm{L}$ limits), the following 20 burnup shaping formats were considered:

$\begin{array}{ll}\text { 1. } & \text { LLLLLLLLLLLLLLLLLLLL } \\ \text { 3. } & \text { LLLLLLLLHHHHLLLLLLLL } \\ \text { 5. } & \text { LLLLLLHHHHHHHHLLLLLL } \\ \text { 7. } & \text { LLLLHHHHHHHHHHHHLLLL } \\ \text { 9. } & \text { LLHHHHHHHHHHHHHHHHLL } \\ \text { 11. } & \text { HHHHHHHHHHHHHHHHHHHH } \\ \text { 13. } & \text { HHHHHHHHLLLLHHHHHHHH } \\ \text { 15. } & \text { HHHHHHLLLLLLLLHHHHHH } \\ \text { 17. } & \text { HHHHLLLLLLLLLLLLHHHH } \\ \text { 19. } & \text { HHLLLLLLLLLLLLLLLLHH }\end{array}$

2. LLLLLLLLLHHLLLLLLLLL
4. LLLLLLLHHHHHHLLLLLLL
6. LLLLLHHHHHHHHHHLLLLL
8. LLLHHHHHHHHHHHHHHLLL
10. LHHHHHHHHHHHHHHHHHHL
12. HHHHHHHHHLLHHHHHHHHH
14. HHHHHHHLLLLLLHHHHHHH
16. HHHHHLLLLLLLLLLHHHHH
18. HHHLLLLLLLLLLLLLLHHH
20. HLLLLLLLLLLLLLLLLLLH

The above shaping formats are referenced by number (1B20) in later discussions. Note that although each of the above burnup shaping formats is symmetric, the database of burnup profiles is based on real asymmetric profiles. Thus a composite profile computed using a symmetric shaping format and a set of asymmetric profiles results in an asymmetric composite shape.

Calculations were performed for an initial enrichment of $3.6 \mathrm{wt} \%$, for assembly-averaged burnups of 10, 30, and $50 \mathrm{GWd} / \mathrm{MTU}$. For each burnup, minimum and maximum values were determined from the corresponding burnup range data. Once a shape was determined based on the above combinations, the shape was normalized to an average over all axial locations of 1.0. The KENO V.a fuel pin model was based on the same 20-zone scheme used in the burnup profile database (i.e., a 365.76-cm fuel rod comprised of twenty 18.288-cm fuel zones). Burnups were assigned to each zone by multiplying the normalized shape multiplier for each zone (from the corresponding burnup range data) by the assembly-averaged burnup. SAS2H calculations were performed for each fuel zone assuming a 1080-d continuous-operation period, such that lower burnup fuel was depleted at a correspondingly low specific power. Results of these calculations are given in Table 19 for each of the burnup shape numbers assigned above; these results are also plotted in Figs. 32 through 37 . Note that for a given burnup shaping number, although the same composite scheme (e.g., LLLHHHHHHHHHHHHHHLLL, etc.) was applied for each burnup, different axial burnup profiles will be applied for each burnup. The burnup profile is a function of the burnup, the corresponding burnupdependent range of normalized profiles, and the composite scheme.

Figures 32 through 34 illustrate the behavior of $k_{\text {eff }}$ calculated with fission products present for various burnup shapes, at assembly-averaged burnups of 10, 30, and $50 \mathrm{GWd} / \mathrm{MTU}$, respectively. These figures illustrate underburned, nominally burned, and overburned cases for the $3.6 \mathrm{wt} \%$ fuel. The underburned 10-GWd/MTU case shows no clear trend indicating sensitivity to the choice of any particular burnup shape; all calculations are statistically consistent within the $2 \sigma$ error band associated with each calculation ( $\sigma$ is the stochastic uncertainty as given in Table 19). The nominally burned 30$\mathrm{GWd} / \mathrm{MTU}$ case shows a definite trend with burnup shape, with as much as a $1.2 \%$ difference between the maximum and minimum values of $\mathrm{k}_{\mathrm{eff}}$, and about a $1 \%$ difference between the average high and average low values. Burnup shapes 5 to 9 show the highest (most conservative) prediction of $\mathrm{k}_{\mathrm{eff}}$. 
Table 19. $\mathrm{k}_{\text {eff }}$ computed for various burnup-dependent axial burnup shapes

\begin{tabular}{|c|c|c|c|c|c|c|c|c|c|c|c|c|}
\hline \multirow{2}{*}{$\begin{array}{l}\text { Composite } \\
\text { shape No. }\end{array}$} & \multicolumn{6}{|c|}{ Actinides + Fission Products } & \multicolumn{6}{|c|}{ Actinides Only } \\
\hline & \multicolumn{2}{|c|}{$10 \mathrm{GWd} / \mathrm{MTU}$} & \multicolumn{2}{|c|}{$30 \mathrm{GWd} / \mathrm{MTU}$} & \multicolumn{2}{|c|}{$50 \mathrm{GWd} / \mathrm{MTU}$} & \multicolumn{2}{|c|}{$10 \mathrm{GWd} / \mathrm{MTU}$} & \multicolumn{2}{|c|}{$30 \mathrm{GWd} / \mathrm{MTU}$} & \multicolumn{2}{|c|}{$50 \mathrm{GWd} / \mathrm{MTU}$} \\
\hline 1 & $\begin{array}{c}\mathrm{k}_{\mathrm{eff}} \\
1.0165\end{array}$ & $\begin{array}{c} \pm \sigma \\
0.0007\end{array}$ & $\begin{array}{c}k_{\text {eff }} \\
0.8998\end{array}$ & $\begin{array}{c} \pm \sigma \\
0.0007\end{array}$ & $\begin{array}{c}k_{\text {eff }} \\
0.8070\end{array}$ & $\begin{array}{c} \pm \sigma \\
0.0006\end{array}$ & $\begin{array}{c}k_{\text {eff }} \\
0.9858\end{array}$ & $\begin{array}{c} \pm \sigma \\
0.0007\end{array}$ & $\begin{array}{c}k_{\text {eff }} \\
0.8448\end{array}$ & $\begin{array}{c} \pm \sigma \\
0.0006\end{array}$ & $\begin{array}{c}k_{\text {eff }} \\
0.7252\end{array}$ & $\begin{array}{c} \pm \sigma \\
0.0006\end{array}$ \\
\hline 2 & 1.0145 & 0.0007 & 0.9010 & 0.0006 & 0.8074 & 0.0006 & 0.9866 & 0.0006 & 0.8464 & 0.0006 & 0.7279 & 0.0005 \\
\hline 3 & 1.0133 & 0.0007 & 0.9011 & 0.0007 & 0.8066 & 0.0006 & 0.9871 & 0.0007 & 0.8468 & 0.0006 & 0.7276 & 0.0005 \\
\hline 4 & 1.0155 & 0.0007 & 0.9027 & 0.0006 & 0.8072 & 0.0006 & 0.9855 & 0.0007 & 0.8470 & 0.0006 & 0.7289 & 0.0006 \\
\hline 5 & 1.0149 & 0.0007 & 0.9019 & 0.0007 & 0.8079 & 0.0006 & 0.9875 & 0.0007 & 0.8484 & 0.0006 & 0.7294 & 0.0006 \\
\hline 6 & 1.0160 & 0.0007 & 0.9019 & 0.0006 & 0.8072 & 0.0006 & 0.9864 & 0.0007 & 0.8484 & 0.0006 & 0.7290 & 0.0005 \\
\hline 7 & 1.0154 & 0.0007 & 0.9033 & 0.0006 & 0.8069 & 0.0006 & 0.9879 & 0.0006 & 0.8494 & 0.0006 & 0.7279 & 0.0005 \\
\hline 8 & 1.0136 & 0.0007 & 0.9025 & 0.0006 & 0.8075 & 0.0006 & 0.9856 & 0.0007 & 0.8486 & 0.0006 & 0.7295 & 0.0005 \\
\hline 9 & 1.0134 & 0.0007 & 0.9005 & 0.0006 & 0.8072 & 0.0006 & 0.9854 & 0.0006 & 0.8480 & 0.0006 & 0.7275 & 0.0005 \\
\hline 10 & 1.0153 & 0.0007 & 0.8976 & 0.0007 & 0.8065 & 0.0006 & 0.9846 & 0.0007 & 0.8409 & 0.0006 & 0.7245 & 0.0005 \\
\hline 11 & 1.0142 & 0.0007 & 0.8986 & 0.0006 & 0.8061 & 0.0006 & 0.9858 & 0.0007 & 0.8403 & 0.0006 & 0.7247 & 0.0005 \\
\hline 12 & 1.0162 & 0.0007 & 0.8985 & 0.0006 & 0.8055 & 0.0006 & 0.9875 & 0.0007 & 0.8387 & 0.0006 & 0.7237 & 0.0005 \\
\hline 13 & 1.0151 & 0.0007 & 0.8993 & 0.0007 & 0.8046 & 0.0006 & 0.9863 & 0.0006 & 0.8398 & 0.0006 & 0.7230 & 0.0005 \\
\hline 14 & 1.0166 & 0.0007 & 0.8999 & 0.0006 & 0.8060 & 0.0006 & 0.9872 & 0.0007 & 0.8380 & 0.0006 & 0.7240 & 0.0005 \\
\hline 15 & 1.0163 & 0.0007 & 0.8998 & 0.0006 & 0.8063 & 0.0006 & 0.9859 & 0.0007 & 0.8370 & 0.0006 & 0.7235 & 0.0005 \\
\hline 16 & 1.0165 & 0.0007 & 0.8990 & 0.0006 & 0.8063 & 0.0006 & 0.9866 & 0.0006 & 0.8380 & 0.0006 & 0.7227 & 0.0005 \\
\hline 17 & 1.0175 & 0.0007 & 0.8995 & 0.0006 & 0.8049 & 0.0006 & 0.9860 & 0.0007 & 0.8381 & 0.0006 & 0.7227 & 0.0005 \\
\hline 18 & 1.0167 & 0.0006 & 0.8995 & 0.0006 & 0.8070 & 0.0006 & 0.9861 & 0.0006 & 0.8381 & 0.0006 & 0.7222 & 0.0005 \\
\hline 19 & 1.0168 & 0.0007 & 0.8988 & 0.0006 & 0.8060 & 0.0006 & 0.9871 & 0.0006 & 0.8391 & 0.0006 & 0.7234 & 0.0005 \\
\hline 20 & 1.0160 & 0.0007 & 0.9013 & 0.0006 & 0.8070 & 0.0006 & 0.9864 & 0.0007 & 0.8450 & 0.0006 & 0.7251 & 0.0005 \\
\hline
\end{tabular}




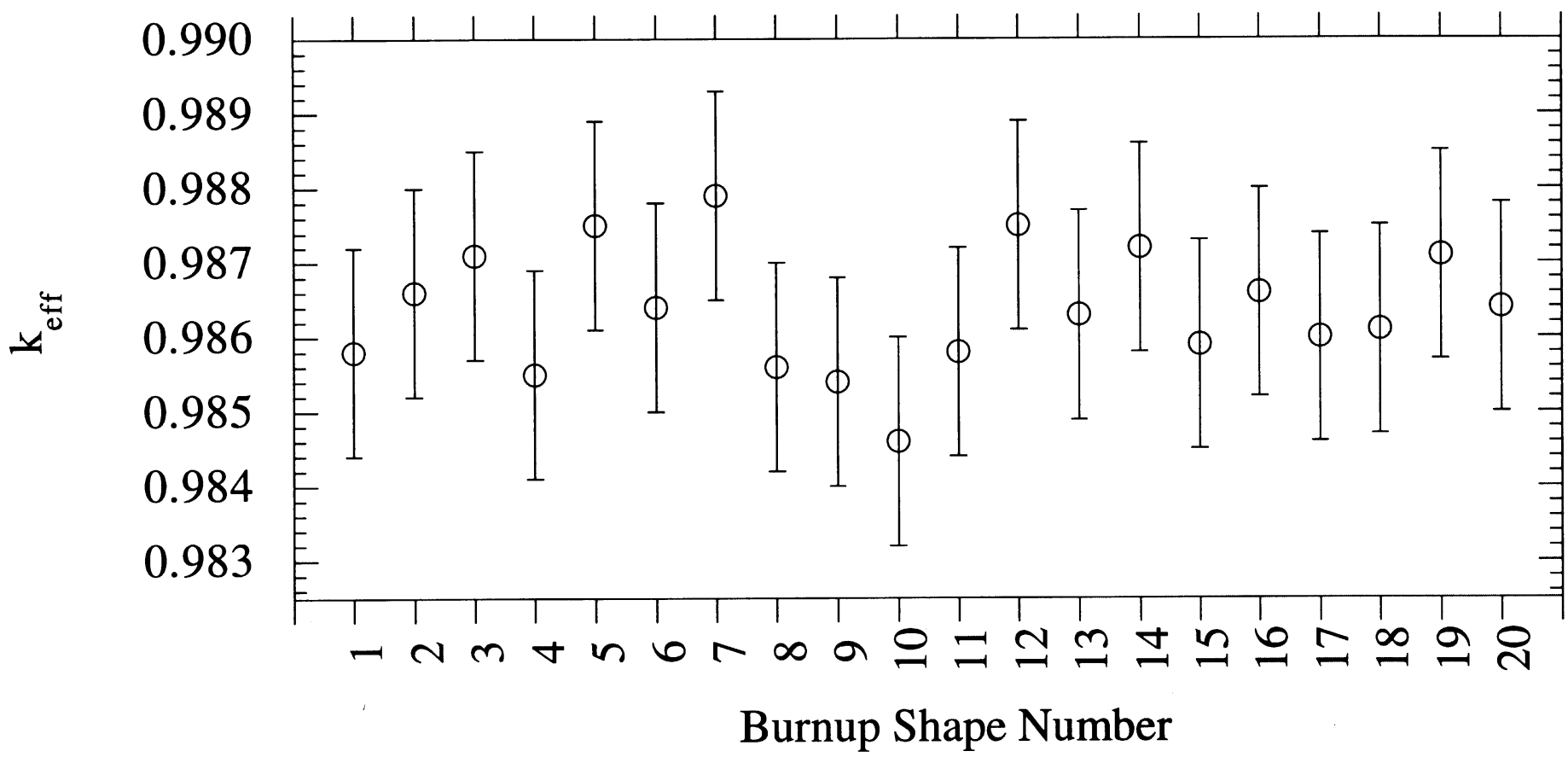

Fig. 32. $\mathrm{k}_{\mathrm{eff}}$ as a function of burnup shape, $10 \mathrm{GWd} / \mathrm{MTU}$ with actinides and fission products. 


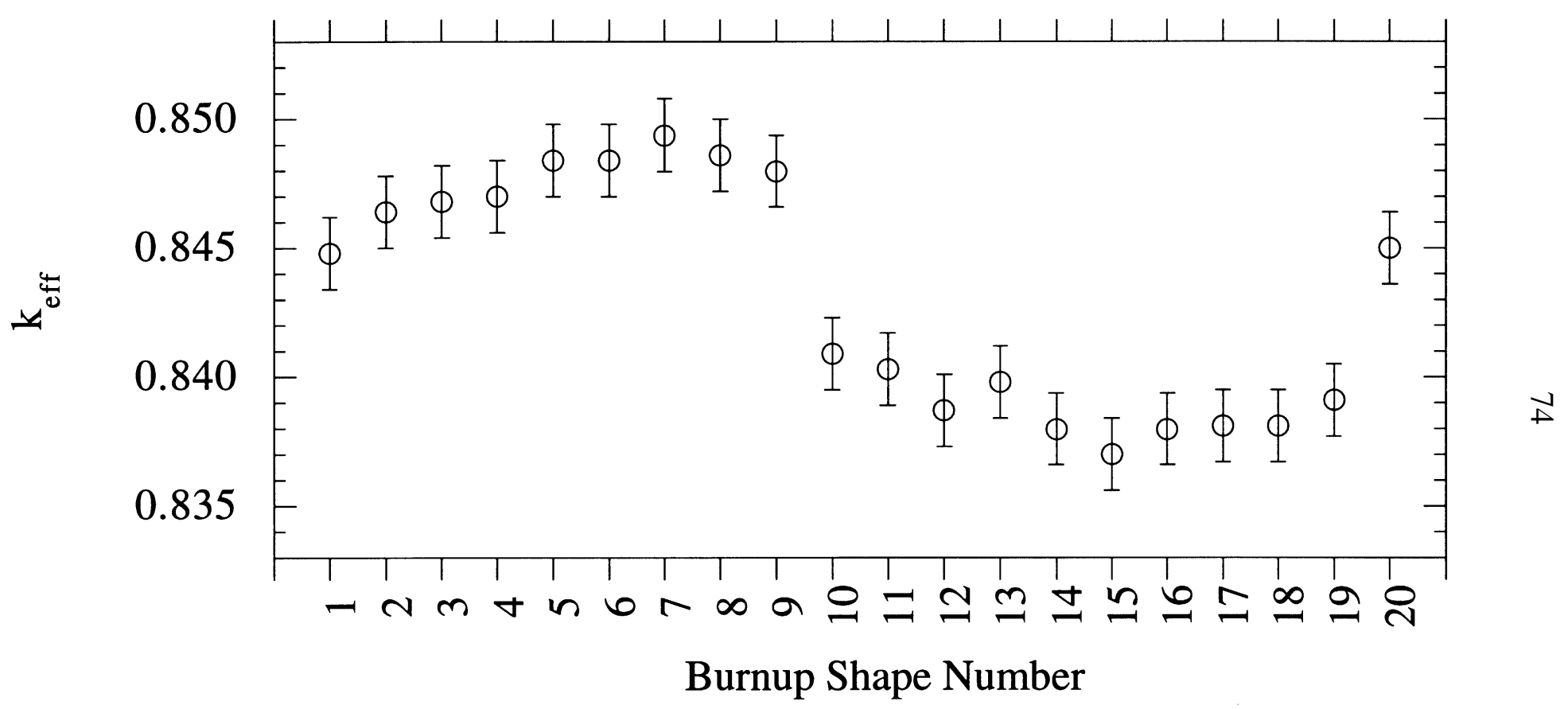

Fig. 33. $\mathrm{k}_{\mathrm{eff}}$ as a function of burnup shape, $30 \mathrm{GWd} / \mathrm{MTU}$ with actinides and fission products. 


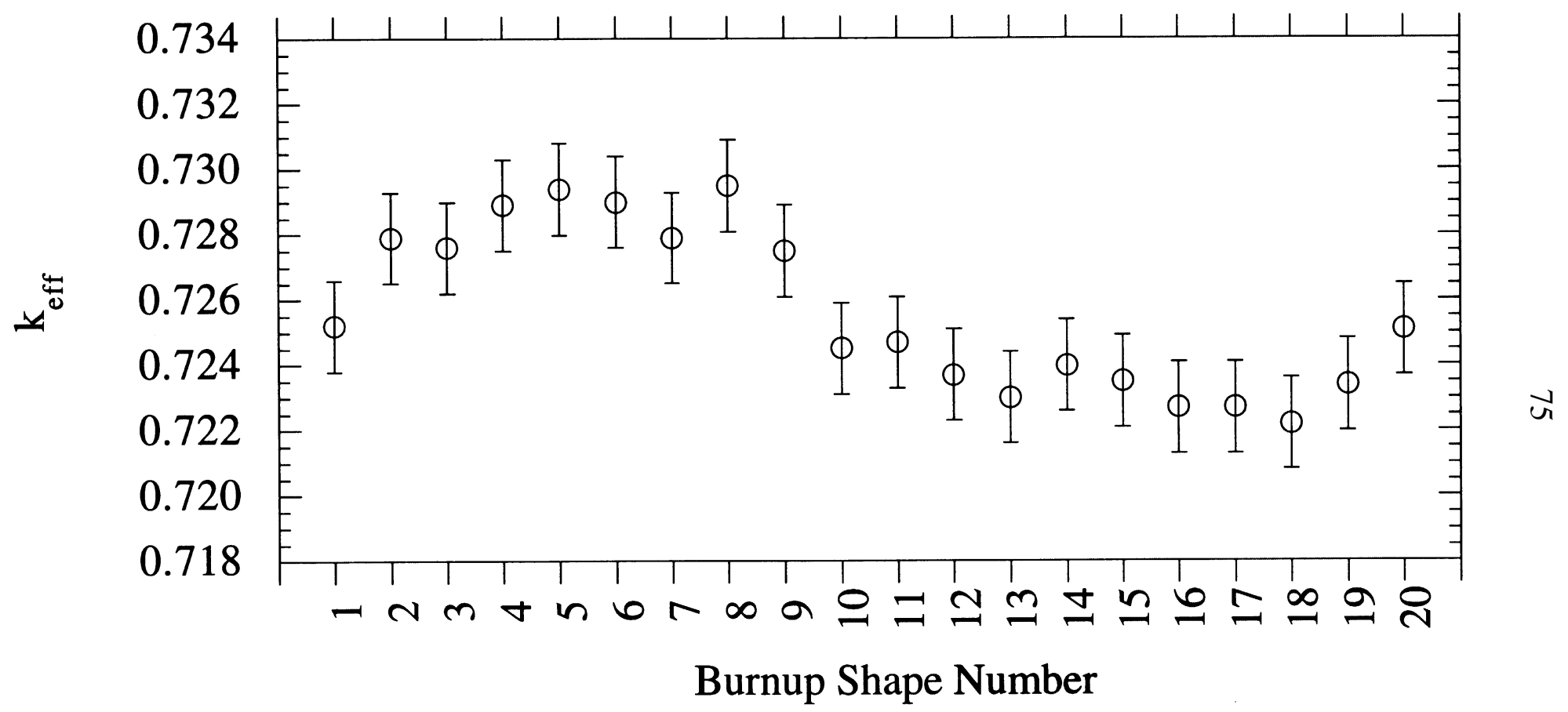

Fig. 34. $\mathrm{k}_{\mathrm{eff}}$ as a function of burnup shape, $50 \mathrm{GWd} / \mathrm{MTU}$ with actinides and fission products. 


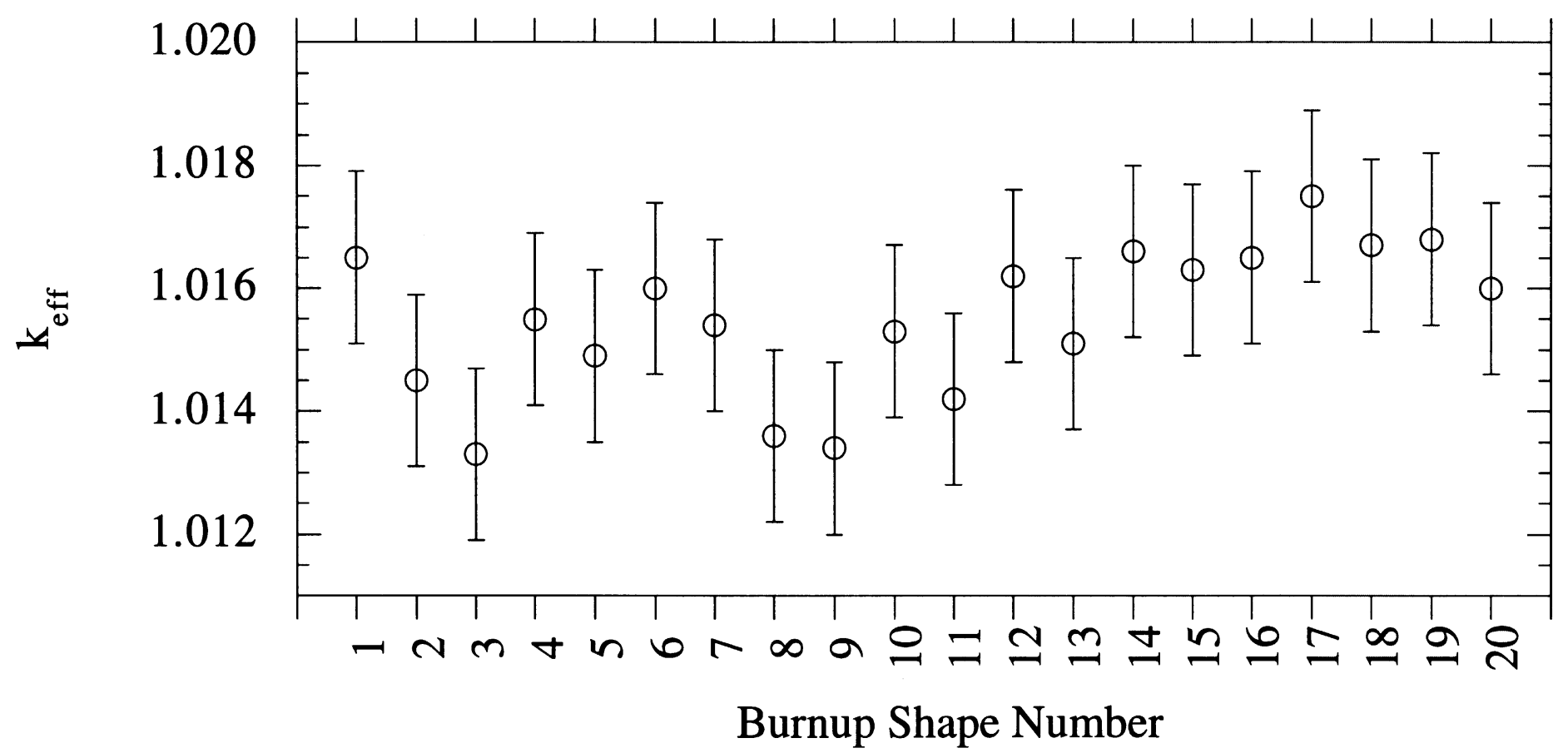

Fig. 35. $\mathrm{k}_{\text {eff }}$ as a function of burnup shape, $10 \mathrm{GWd} / \mathrm{MTU}$ with actinides only. 


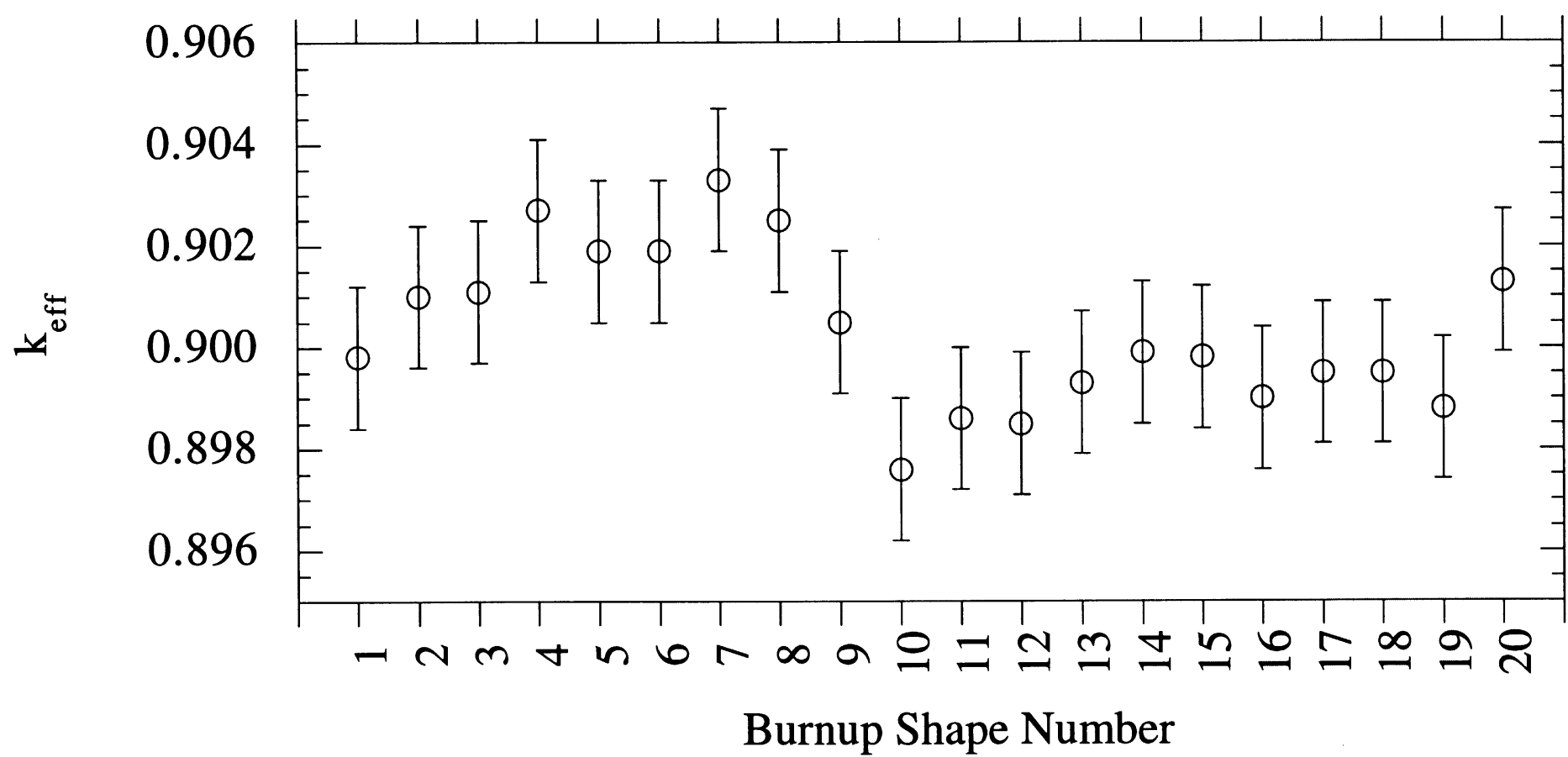

Fig. 36. $\mathrm{k}_{\mathrm{eff}}$ as a function of burnup shape, $30 \mathrm{GWd} / \mathrm{MTU}$ with actinides only. 


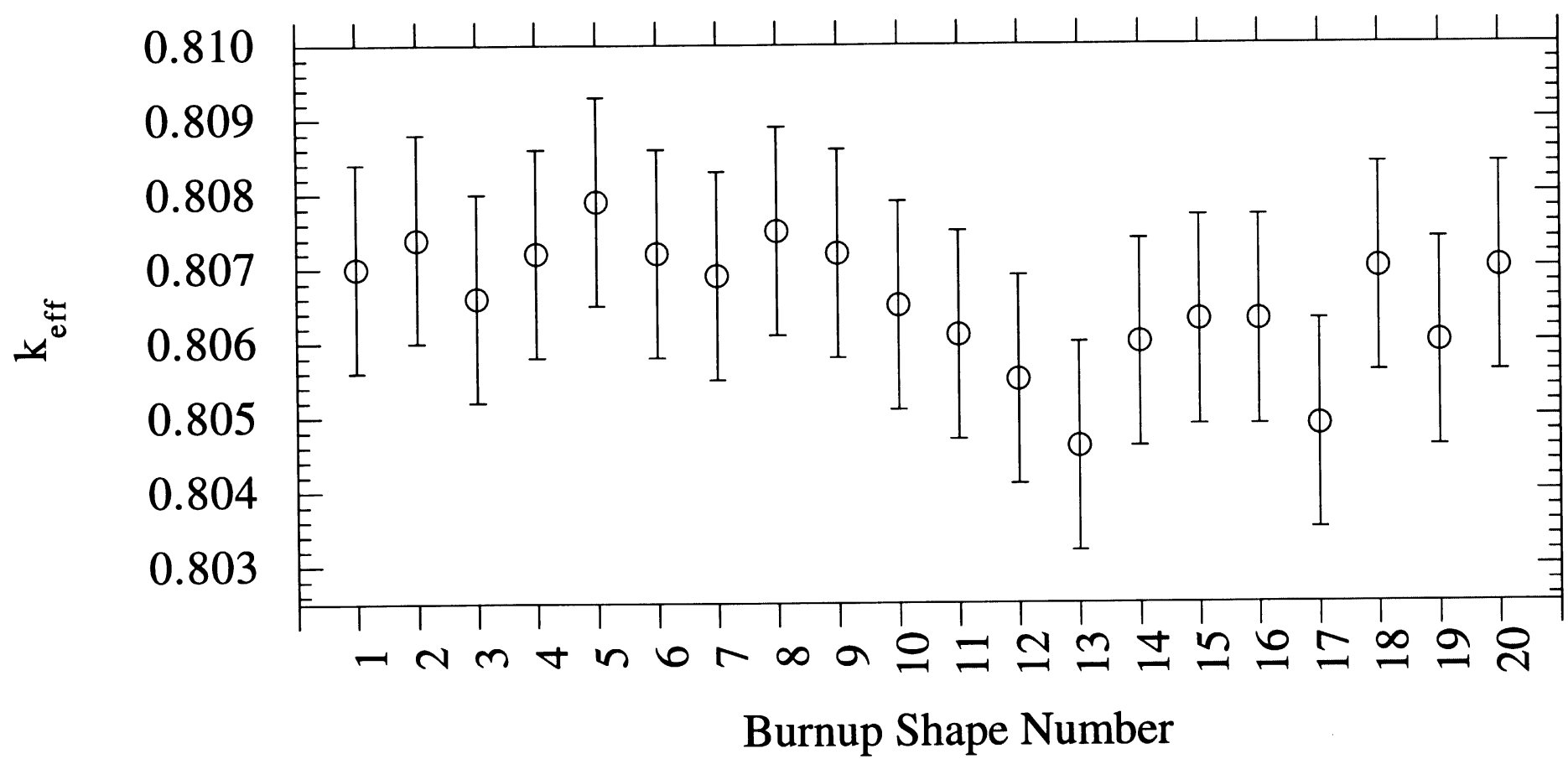

Fig. 37. $\mathrm{k}_{\text {eff }}$ as a function of burnup shape, $50 \mathrm{GWd} / \mathrm{MTU}$ with actinides only. 
These cases represent the highest central region burnup combined with the lowest end region burnup, where the end region is from 1 to 4 zones in height. The overburned 50-GWd/MTU case shows the same trend, with the highest $\mathrm{k}_{\mathrm{eff}}$ values calculated for shapes 4 to 8 . The magnitude of the difference between high and low, about $0.7 \%$, is less than that for the nominally burned cases.

Figures 35 through 37 represent the same burnup cases for criticality calculations performed with actinides only. As with the fission-product case, the low-burnup actinide-only results of Fig. 35 show no statistical difference between burnup shapes, although there appears to be a trend for a slightly higher value of $\mathrm{k}_{\text {eff }}$ for cases 14 to 20 , which represent high-end, low-center burnups. However, at a 30-GWd/MTU burnup, there is a definite trend for higher values of $k_{\text {eff }}$ for burnup shapes 4 through 8 (high center region, low end region burnups) and lower values for shapes 10 through 19 (high end region, both low and high center region burnups). The effect is very small, on the order of less than $0.5 \%$ between the average high and average low values of $\mathrm{k}_{\mathrm{eff}}$. For the high- burnup case, the same trend appears to exist, as shown in Fig. 37; however, the difference between the highs and lows is on the order of the statistical uncertainty in the calculated value of $\mathrm{k}_{\mathrm{eff}}$ and no definite conclusions can be drawn.

Based on these six sets of burnup shape studies, it appears that the shape of the assumed axial burnup profile is most significant for nominally burned fuel inside a cask configuration. Insensitivity to burnup profile for low burnup (i.e., $10 \mathrm{GWd} / \mathrm{MTU}$ ) fuel, observed both with and without fission products, is expected. Because the center region of the fuel has undergone relatively little burnup, axial fission densities during reactor operation are concentrated toward the center of the fuel, and the ends of the rods are unimportant in the calculation of $\mathrm{k}_{\mathrm{eff}}$. As burnup increases, the disparity between the total burnup in the center and that at the ends increases, and the fission density profile begins to move outward as the ends of the fuel become more important. Thus there is more sensitivity to the amount of burnup in the ends. Underprediction of end region burnup combined with overprediction of center region burnup results in an increased weighting of the lower burnup end regions, and an increase in $\mathrm{k}_{\text {eff. }}$ This situation is true whether or not fission products are present. The increasing importance of the end regions continues with burnup; however, as fuel passes nominal or design burnup, the center region of the fuel becomes so depleted that in a cask filled with identical fuel assemblies, the $\mathrm{k}_{\text {eff }}$ value is a strong function of the end regions, and the relative burnup of the center region of the fuel becomes less important. This conclusion is consistent with the behavior described earlier for the 50-GWd/MTU fuel.

The relative effect of burnup shape with increasing burnup is significantly more pronounced when fission products are present. This finding is perhaps due to the higher sensitivity of fissionproduct production to specific power during depletion relative to actinide production, as discussed in Sect. 3.3.1 and illustrated in Figs. 20 and 21. For a given level of burnup, fuel rod ends are burned at a lower specific power than the center region of the fuel. Thus fission products accumulate preferentially near the center of a fuel rod due to both specific power and burnup effects. This fissionproduct disparity increases with increasing burnup, giving an increased importance to fuel rod ends when fission products are present in the criticality calculation.

The above discussion related to fission products is speculation, and cannot be absolutely demonstrated with the available calculations. Because of the absence of well-defined trends due to the statistical variations in the KENO V.a results, additional calculations, using a multidimensional deterministic approach, will be required to completely quantify burnup shape effects. However, it appears that the use of burnup shapes 5 to 8 will yield conservative estimates of $\mathrm{k}_{\text {eff }}$ for any burnup, with 
or without fission products. The magnitude of the conservatism will be burnup- and compositiondependent, ranging from about 0.3 to $1 \% \Delta \mathrm{k}$, with fission products present to about 0.2 to $0.4 \% \Delta \mathrm{k}$ for actinides-only fuel. For purposes of this report, remaining calculations will be based on shape 7 (LLLLHHHHHHHHHHHHLLLL). The burnup profiles derived based on this composite shape and normalized to an average value of 1.0 are given in Table 20. These burnup profiles are also plotted in Fig. 38. It is worth noting that the bounding burnup shapes follow the trend mentioned earlier for burnup shapes to flatten out and broaden with increasing burnup.

\subsection{EFFECT OF AXIALLY VARYING BURNUP}

As has been discussed previously, the use of an assumed constant average burnup along the length of a modeled fuel rod can result in an erroneous estimate of $\mathrm{k}_{\mathrm{eff}}$ in a cask loaded with such fuel. This phenomena has been termed the "end effect," because it results from an inadequate representation of the low-burnup regions near the ends of spent fuel. This subsection seeks to: (1) identify a simple axial zoning scheme that results in the best calculation of $\mathrm{k}_{\mathrm{eff}}$ relative to a continuously varying axial burnup; (2) determine the magnitude of error (i.e., end effect) in the calculation of $k_{\text {eff }}$ using a uniform or average burnup approximation as a function of enrichment and burnup; and (3) provide a description of the physical phenomena that cause the end effect to vary with burnup.

\subsubsection{Determination of a Best-Estimate Axial Zoning Scheme}

Clearly, the use of a large number of very small zones, each with its own burnup-dependent isotopic composition, will provide the best approximation to the continuously varying burnup profile of a spent fuel pin. However, such detail is difficult to set up in a numerical model, and would involve a tremendous number of calculations to complete; nor is it clear that such detail is necessary. This subsection seeks to identify a simple zoning scheme that can provide the same cask $\mathrm{k}_{\text {eff }}$ value (within statistical limits) that would be obtained using a very fine zoning scheme.

Because the axial burnup database discussed in Sect. 5.1 contains burnup profiles based on 20 uniform-width regions, this zoning scheme was selected as a starting point for axial zoning analysis. The use of consistent zone sizes allows direct application of the conservative burnup shape with no interpolation. KENO V.a criticality calculations were performed assuming initial enrichments of 3.0 and $4.5 \mathrm{wt} \%$ for assembly-averaged burnups of 10, 30, and $50 \mathrm{GWd} / \mathrm{MTU}$, for isotopic compositions both with and without fission products, computed for each zone based on the zone's burnup using SAS2H and assuming a 5-year cooling period. Burnup profiles were computed based on the conservative burnup shapes given in Table 20 for each burnup range.

Earlier worl ${ }^{7,8}$ has established that the end effect is most dominant in fuel with high fissile depletion. Since burnup profiles are known to be almost flat over the central fuel region, representing 50 to $60 \%$ of the total length for high burnup, it has been assumed that central zones could be combined in the numerical model with little effect. Thus this axial zoning study attempts to define the boundary between the "center" and "ends." Axial zone models consisting of 1, 3, 5, 7, 9, 11, 13, 15, and 17 burnup zones with a variable-width central zone are shown schematically in Fig. 39, together with the 


\section{1}

Table 20. Normalized conservative burnup shapes based on CE $14 \times 14$ database

\begin{tabular}{ccccccc}
\hline & \multirow{6}{*}{$\begin{array}{c}\text { Zone } \\
\text { center }\end{array}$} & \multicolumn{5}{c}{ Burnup range (GWd/MTU) } \\
\cline { 3 - 7 } Zone & $\begin{array}{c}\text { \% of } \\
\text { ho. }\end{array}$ & & & & \\
\hline 1 & 2.5 & 0.12 & $16-24$ & $24-36$ & $36-44$ & $44-55$ \\
\hline 2 & 7.5 & 0.788 & 0.510 & 0.585 & 0.624 & 0.655 \\
3 & 12.5 & 0.914 & 0.789 & 0.866 & 0.896 & 0.911 \\
4 & 17.5 & 1.029 & 0.952 & 0.993 & 1.010 & 1.009 \\
5 & 22.5 & 1.133 & 1.045 & 1.045 & 1.044 & 1.041 \\
6 & 27.5 & 1.154 & 1.115 & 1.096 & 1.077 & 1.069 \\
7 & 32.5 & 1.178 & 1.135 & 1.104 & 1.080 & 1.072 \\
8 & 37.5 & 1.191 & 1.156 & 1.106 & 1.080 & 1.072 \\
9 & 42.5 & 1.199 & 1.160 & 1.105 & 1.079 & 1.071 \\
10 & 47.5 & 1.203 & 1.162 & 1.103 & 1.079 & 1.070 \\
11 & 52.5 & 1.203 & 1.163 & 1.102 & 1.078 & 1.069 \\
12 & 57.5 & 1.198 & 1.163 & 1.100 & 1.078 & 1.069 \\
13 & 62.5 & 1.189 & 1.160 & 1.099 & 1.078 & 1.068 \\
14 & 67.5 & 1.174 & 1.152 & 1.099 & 1.078 & 1.068 \\
15 & 72.5 & 1.144 & 1.132 & 1.096 & 1.077 & 1.069 \\
16 & 77.5 & 1.091 & 1.101 & 1.081 & 1.070 & 1.068 \\
17 & 82.5 & 0.961 & 1.014 & 1.029 & 1.040 & 1.066 \\
18 & 87.5 & 0.820 & 0.880 & 0.957 & 0.986 & 0.994 \\
19 & 92.5 & 0.616 & 0.662 & 0.790 & 0.863 & 0.879 \\
20 & 97.5 & 0.367 & 0.401 & 0.544 & 0.613 & 0.639 \\
\hline
\end{tabular}




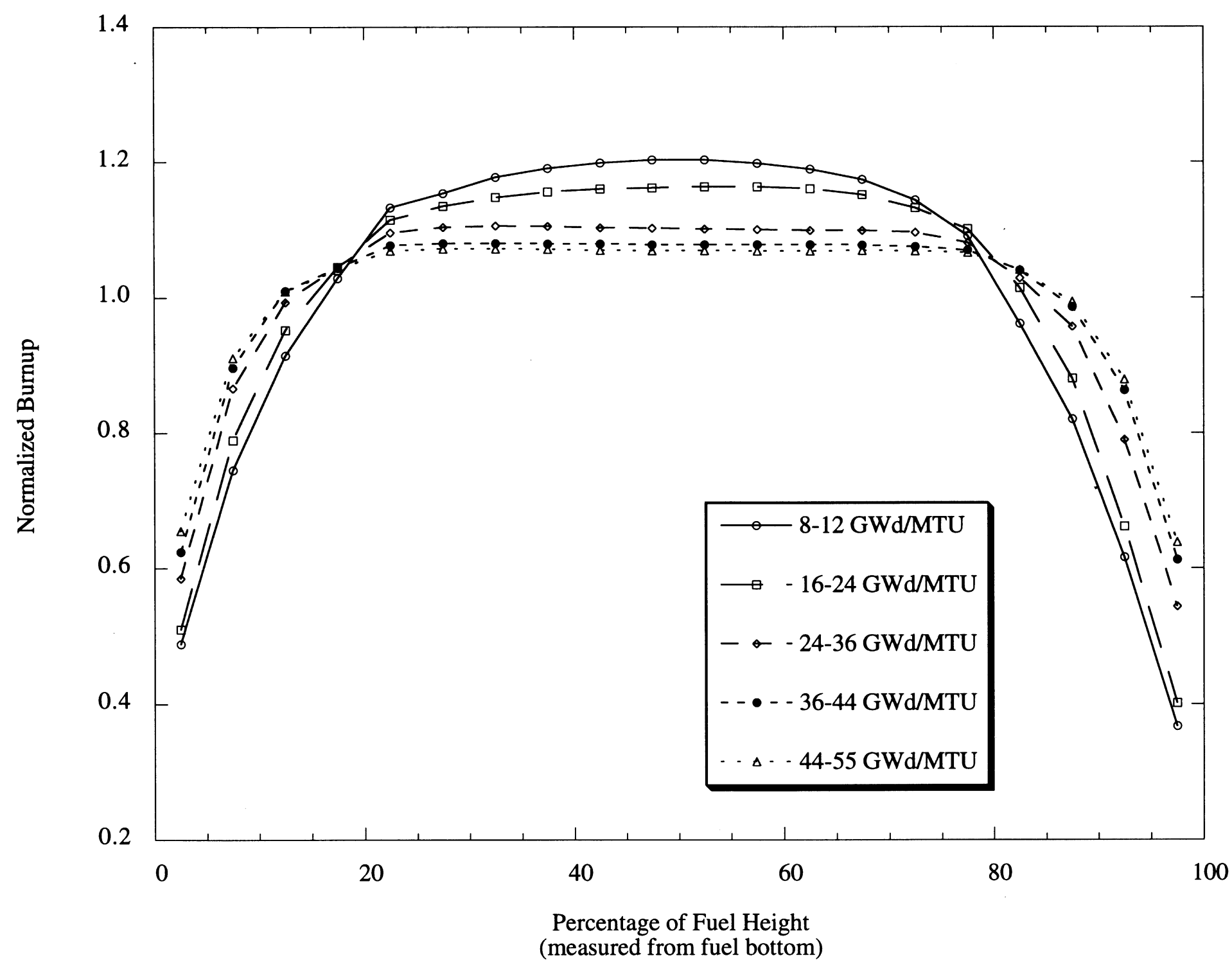

Fig. 38. Conservative burnup profiles for CE $14 \times 14$ database burnup range. 


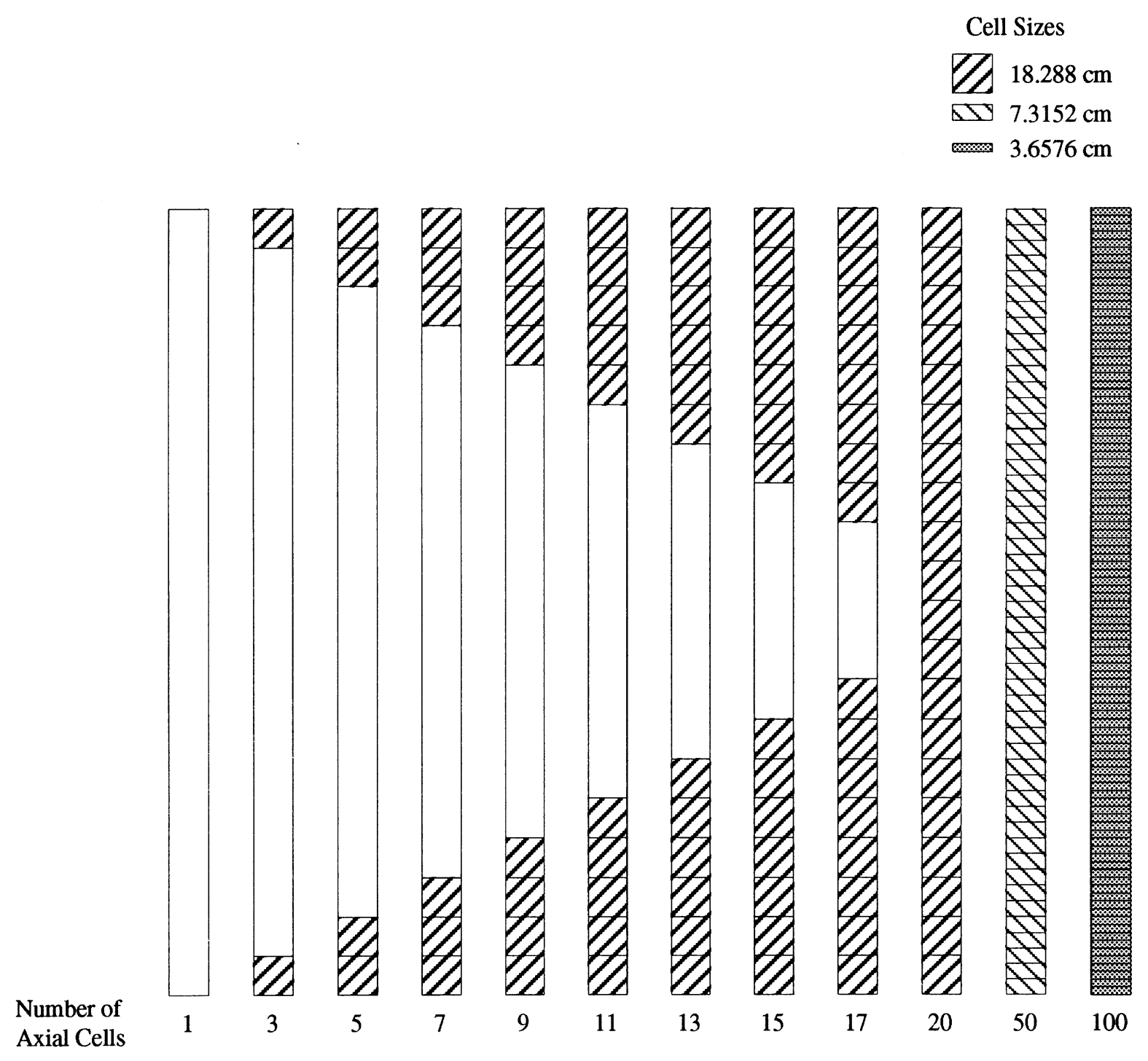

Fig. 39. Axial zoning models used in end effects zoning studies. 
baseline 20-fuel-zone model. Each of the 1 to 17 zone models was based on the 20-zone model developed for each assumed enrichment and burnup, with the central zones collapsed into a single central zone with the same burnup as the length-weighted average of the burnup in the combined zones. The single zone model represents the approximation of a uniform distribution of isotopic concentrations along the entire length of the fuel rod.

It is also necessary to generate a model based on a very fine grid of short axial zones in order to obtain the closest possible numerical approximation to continuously varying burnup. Two such finegrid models were developed: one consisting of 50 uniform zones; the second consisting of 100 uniform zones. These models are also shown schematically in Fig 39. Burnups at fuel rod positions of 0 and $100 \%$ fuel length were determined by linear extrapolation of the last two data points on either end of the database (i.e., 2.5 and $7.5 \%$, or 92.5 and $97.5 \%$ of fuel length) for each burnup range; burnups for each of the 50 and 100 zones in each model were then calculated by interpolation from database values and the extrapolated endpoint burnups. As with the 1 to 20 zone models, SAS2H calculations were performed for each axial zone, with unique isotopic concentrations and cross sections in each zone. Also, as with the other more coarse zoning models, unique cross sections were computed for only the seven burnup-sensitive actinides for all but the highest burnup zone. All remaining cross sections were computed based on the composition of the highest burnup zone. Criticality models were based on the cask configuration described earlier and detailed in Appendix E.

Results of these calculations are given in Tables 21 and 22. All $\mathrm{k}_{\text {eff }}$ values were calculated with a stochastic uncertainty $(\sigma)$ of \pm 0.0007 or less. Note that for all enrichment and burnup combinations, both with and without the inclusion of fission products in criticality calculations, results are identical (within statistical uncertainty) for 20-, 50-, and 100-zone models (as well as for models with even fewer axial cells). This behavior demonstrates that the relatively coarse representation of $1 / 20$ th-length cells at end regions of fuel is adequate for capturing axial burnup-dependent isotopic concentration variations.

As was discussed earlier, additional models with fewer axial zones in the central region were also included in the study because the nearly uniform burnup in this region would result in an essentially uniform isotopic composition. The results of the calculations for each of these models are compared with the "best-estimate" solution for each burnup/enrichment combination in Tables 21 and 22. The best-estimate solution was assumed to be the average of the 20-, 50-, and 100-zone results to reduce random variations due to the stochastic KENO V.a solution, and is given in the last row of each table [the statistical uncertainty $(\sigma)$ associated with each average is approximately 0.0004]. The results for the 1- to 20-axial-zone models are also plotted in Figs. 40 and 41 , where $\mathrm{k}_{\mathrm{eff}}$ is normalized by the bestestimate value for each set of results. The results of these calculations indicate that models based on the 7-axial-zone model of Fig. 39 are adequate for the range of enrichments and burnups analyzed both with and without fission products.

Note that end-effects calculations reported elsewhere may also be based on 3-zone, 5-zone, etc., models; however, these models are based on different zone widths (e.g., three 1/3-length zones) and therefore may support other conclusions (i.e., a specific 3-zone model tailored to a specific burnup profile may provide an adequate representation of burnup effects for that profile). In addition, many earlier calculations performed at ORNL (and elsewhere) were based on burnup profiles other than those used in this study. Scoping studies performed at ORNL indicate that the magnitude of the end effect is strongly coupled with the assumed burnup profile, especially when fission products are present. 


\section{5}

Table 21. Results of axial zoning studies (actinides + fission products)

\begin{tabular}{|c|c|c|c|c|c|c|c|c|c|c|c|c|}
\hline \multirow{4}{*}{$\begin{array}{l}\text { No. of } \\
\text { axial } \\
\text { Aeils }\end{array}$} & \multicolumn{6}{|c|}{3.0 wt $\%$} & \multicolumn{6}{|c|}{4.5 wt $\%$} \\
\hline & \multicolumn{2}{|c|}{$10 \mathrm{GWd} / \mathrm{MTU}$} & \multicolumn{2}{|c|}{$30 \mathrm{GWd} / \mathrm{MTU}$} & \multicolumn{2}{|c|}{$50 \mathrm{GWd} / \mathrm{MTU}$} & \multicolumn{2}{|c|}{$10 \mathrm{GWd} / \mathrm{MTU}$} & \multicolumn{2}{|c|}{$30 \mathrm{GWd} / \mathrm{MTU}$} & \multicolumn{2}{|c|}{$50 \mathrm{GWd} / \mathrm{MTU}$} \\
\hline & $k_{\text {eff }}$ & $\mathrm{k}-\mathrm{k}_{\text {ave }}$ & $\mathrm{k}_{\text {eff }}$ & $\mathrm{k}-\mathrm{k}_{\mathrm{ave}}$ & $\mathrm{k}_{\text {eff }}$ & $\mathrm{k}-\mathrm{k}_{\mathrm{ave}}$ & $k_{\text {eff }}$ & $\underline{\mathrm{k}-\mathrm{k}_{\mathrm{ave}}}$ & $k_{\text {eff }}$ & $\mathrm{k}-\mathrm{k}_{\mathrm{ave}}$ & $\mathrm{k}_{\text {eff }}$ & $\mathrm{k}-\mathrm{k}_{\mathrm{ave}}$ \\
\hline & & $k_{\text {ave }}$ & & $k_{\text {ave }}$ & & $k_{\text {ave }}$ & & $k_{\text {ave }}$ & & $k_{\text {ave }}$ & & $\mathrm{k}_{\text {ave }}$ \\
\hline 1 & 0.9445 & $(0.44 \%)$ & 0.7937 & $-(0.29 \%)$ & 0.6874 & $(0.12 \%)$ & 1.0467 & $(0.65 \%)$ & 0.9119 & $(0.41 \%)$ & 0.7875 & $-(0.22 \%)$ \\
\hline 3 & 0.9398 & $-(0.06 \%)$ & 0.7856 & $-(1.31 \%)$ & 0.6815 & $-(0.74 \%)$ & 1.0439 & $(0.38 \%)$ & 0.9049 & $-(0.36 \%)$ & 0.7787 & $-(1.33 \%)$ \\
\hline 5 & 0.9385 & $-(0.20 \%)$ & 0.7932 & $-(0.35 \%)$ & 0.6840 & $-(0.38 \%)$ & 1.0415 & $(0.15 \%)$ & 0.9053 & $-(0.32 \%)$ & 0.7871 & $-(0.27 \%)$ \\
\hline 7 & 0.9384 & $-(0.21 \%)$ & 0.7963 & $(0.04 \%)$ & 0.6869 & $(0.04 \%)$ & 1.0387 & $-(0.12 \%)$ & 0.9087 & $(0.06 \%)$ & 0.7885 & $-(0.09 \%)$ \\
\hline 9 & 0.9399 & $-(0.05 \%)$ & 0.7964 & $(0.05 \%)$ & 0.6862 & $-(0.06 \%)$ & 1.0391 & $-(0.08 \%)$ & 0.9089 & $(0.08 \%)$ & 0.7900 & $(0.10 \%)$ \\
\hline 11 & 0.9400 & $-(0.04 \%)$ & 0.7943 & $-(0.21 \%)$ & 0.6863 & $-(0.04 \%)$ & 1.0417 & $(0.17 \%)$ & 0.9085 & $(0.03 \%)$ & 0.7897 & $(0.06 \%)$ \\
\hline 13 & 0.9403 & $-(0.01 \%)$ & 0.7959 & $-(0.01 \%)$ & 0.6866 & $(0.00 \%)$ & 1.0417 & $(0.17 \%)$ & 0.9076 & $-(0.07 \%)$ & 0.7898 & $(0.08 \%)$ \\
\hline 15 & 0.9400 & $-(0.04 \%)$ & 0.7963 & $(0.04 \%)$ & 0.6877 & $(0.16 \%)$ & 1.0401 & $(0.02 \%)$ & 0.9092 & $(0.11 \%)$ & 0.7898 & $(0.08 \%)$ \\
\hline 17 & 0.9401 & $-(0.03 \%)$ & 0.7974 & $(0.18 \%)$ & 0.6866 & $(0.00 \%)$ & 1.0397 & $-(0.02 \%)$ & 0.9090 & $(0.09 \%)$ & 0.7897 & $(0.06 \%)$ \\
\hline 20 & 0.9393 & $-(0.12 \%)$ & 0.7963 & $(0.04 \%)$ & 0.6869 & $(0.04 \%)$ & 1.0404 & $(0.05 \%)$ & 0.9081 & $-(0.01 \%)$ & 0.7881 & $-(0.14 \%)$ \\
\hline 50 & 0.9404 & $(0.00 \%)$ & 0.7961 & $(0.01 \%)$ & 0.6868 & $(0.03 \%)$ & 1.0391 & $-(0.08 \%)$ & 0.9084 & $(0.02 \%)$ & 0.7896 & $(0.05 \%)$ \\
\hline 100 & 0.9414 & $(0.11 \%)$ & 0.7956 & $-(0.05 \%)$ & 0.6860 & $-(0.09 \%)$ & 1.0403 & $(0.04 \%)$ & 0.9080 & $-(0.02 \%)$ & 0.7899 & $(0.09 \%)$ \\
\hline $\begin{array}{c}\text { Average } \\
(20,50, \\
100)\end{array}$ & 0.9404 & - & 0.7960 & - & 0.6866 & - & 1.0399 & - & 0.9082 & - & 0.7892 & - \\
\hline
\end{tabular}

Table 22. Results of axial zoning studies (actinides only)

\begin{tabular}{|c|c|c|c|c|c|c|c|c|c|c|c|c|}
\hline \multirow{3}{*}{$\begin{array}{l}\text { No. of } \\
\text { axial } \\
\text { cells }\end{array}$} & \multicolumn{6}{|c|}{3.0 wt $\%$} & \multicolumn{6}{|c|}{4.5 wt $\%$} \\
\hline & \multicolumn{2}{|c|}{$10 \mathrm{GWd} / \mathrm{MTU}$} & \multicolumn{2}{|c|}{$30 \mathrm{GWd} / \mathrm{MTU}$} & \multicolumn{2}{|c|}{$50 \mathrm{GWd} / \mathrm{MTU}$} & \multicolumn{2}{|c|}{$10 \mathrm{GWd} / \mathrm{MTU}$} & \multicolumn{2}{|c|}{$30 \mathrm{GWd} / \mathrm{MTU}$} & \multicolumn{2}{|c|}{$50 \mathrm{GWd} / \mathrm{MTU}$} \\
\hline & $k_{\text {eff }}$ & $\frac{\mathrm{k}-\mathrm{k}_{\mathrm{ave}}}{\mathrm{k}_{\mathrm{ave}}}$ & $k_{\text {eff }}$ & $\frac{\mathrm{k}-\mathrm{k}_{\text {ave }}}{\mathrm{k}_{\mathrm{ave}}}$ & $\mathrm{k}_{\mathrm{eff}}$ & $\frac{\mathrm{k}-\mathrm{k}_{\text {ave }}}{\mathrm{k}_{\text {ave }}}$ & $k_{\text {eff }}$ & $\frac{\mathrm{k}-\mathrm{k}_{\text {ave }}}{\mathrm{k}_{\mathrm{ave}}}$ & $k_{\text {eff }}$ & $\frac{\mathrm{k}-\mathrm{k}_{\text {ave }}}{\mathrm{k}_{\mathrm{ave}}}$ & $\mathrm{k}_{\mathrm{eff}}$ & $\frac{\mathrm{k}-\mathrm{k}_{\mathrm{ave}}}{\mathrm{k}_{\mathrm{ave}}}$ \\
\hline 1 & 0.9726 & $(0.51 \%)$ & 0.8543 & $(0.61 \%)$ & 0.7731 & $(0.90 \%)$ & 1.0751 & $(0.55 \%)$ & 0.9701 & $(0.64 \%)$ & 0.8748 & $\overline{(0.83 \%)}$ \\
\hline 3 & 0.9693 & $(0.17 \%)$ & 0.8486 & $-(0.06 \%)$ & 0.7680 & $(0.23 \%)$ & 1.0717 & $(0.23 \%)$ & 0.9645 & $(0.06 \%)$ & 0.8673 & $-(0.03 \%)$ \\
\hline 5 & 0.9688 & $(0.11 \%)$ & 0.8499 & $(0.09 \%)$ & 0.7672 & $(0.13 \%)$ & 1.0702 & $(0.09 \%)$ & 0.9637 & $-(0.02 \%)$ & 0.8663 & $-(0.15 \%)$ \\
\hline 7 & 0.9674 & $-(0.03 \%)$ & 0.8504 & $(0.15 \%)$ & 0.7675 & $(0.17 \%)$ & 1.0698 & $(0.06 \%)$ & 0.9630 & $-(0.09 \%)$ & 0.8685 & $(0.10 \%)$ \\
\hline 9 & 0.9674 & $-(0.03 \%)$ & 0.8499 & $(0.09 \%)$ & 0.7665 & $(0.04 \%)$ & 1.0695 & $(0.03 \%)$ & 0.9639 & $(0.00 \%)$ & 0.8684 & $(0.09 \%)$ \\
\hline 11 & 0.9674 & $-(0.03 \%)$ & 0.8507 & $(0.19 \%)$ & 0.7670 & $(0.10 \%)$ & 1.0709 & $(0.16 \%)$ & 0.9645 & $(0.06 \%)$ & 0.8679 & $(0.03 \%)$ \\
\hline 13 & 0.9682 & $(0.05 \%)$ & 0.8493 & $(0.02 \%)$ & 0.7659 & $-(0.04 \%)$ & 1.0708 & $(0.15 \%)$ & 0.9652 & $(0.13 \%)$ & 0.8685 & $(0.10 \%)$ \\
\hline 15 & 0.9682 & $(0.05 \%)$ & 0.8484 & $-(0.08 \%)$ & 0.7671 & $(0.12 \%)$ & 1.0688 & $-(0.04 \%)$ & 0.9640 & $(0.01 \%)$ & 0.8695 & $(0.22 \%)$ \\
\hline 17 & 0.9670 & $-(0.07 \%)$ & 0.8508 & $(0.20 \%)$ & 0.7667 & $(0.07 \%)$ & 1.0699 & $(0.07 \%)$ & 0.9642 & $(0.03 \%)$ & 0.8683 & $(0.08 \%)$ \\
\hline 20 & 0.9677 & $(0.00 \%)$ & 0.8496 & $(0.06 \%)$ & 0.7676 & $(0.18 \%)$ & 1.0701 & $(0.08 \%)$ & 0.9647 & $(0.08 \%)$ & 0.8678 & $(0.02 \%)$ \\
\hline 50 & 0.9673 & $-(0.04 \%)$ & 0.8499 & $(0.09 \%)$ & 0.7658 & $-(0.05 \%)$ & 1.0687 & $-(0.05 \%)$ & 0.9646 & $(0.07 \%)$ & 0.8678 & $(0.02 \%)$ \\
\hline 100 & 0.9680 & $(0.03 \%)$ & 0.8478 & $-(0.15 \%)$ & 0.7653 & $-(0.12 \%)$ & 1.0689 & $-(0.03 \%)$ & 0.9624 & $-(0.16 \%)$ & 0.8672 & $-(0.05 \%)$ \\
\hline $\begin{array}{c}\text { Average } \\
(20,50 \\
100)\end{array}$ & 0.9677 & - & 0.8491 & - & 0.7662 & - & 1.0692 & - & 0.9639 & - & 0.8676 & - \\
\hline
\end{tabular}




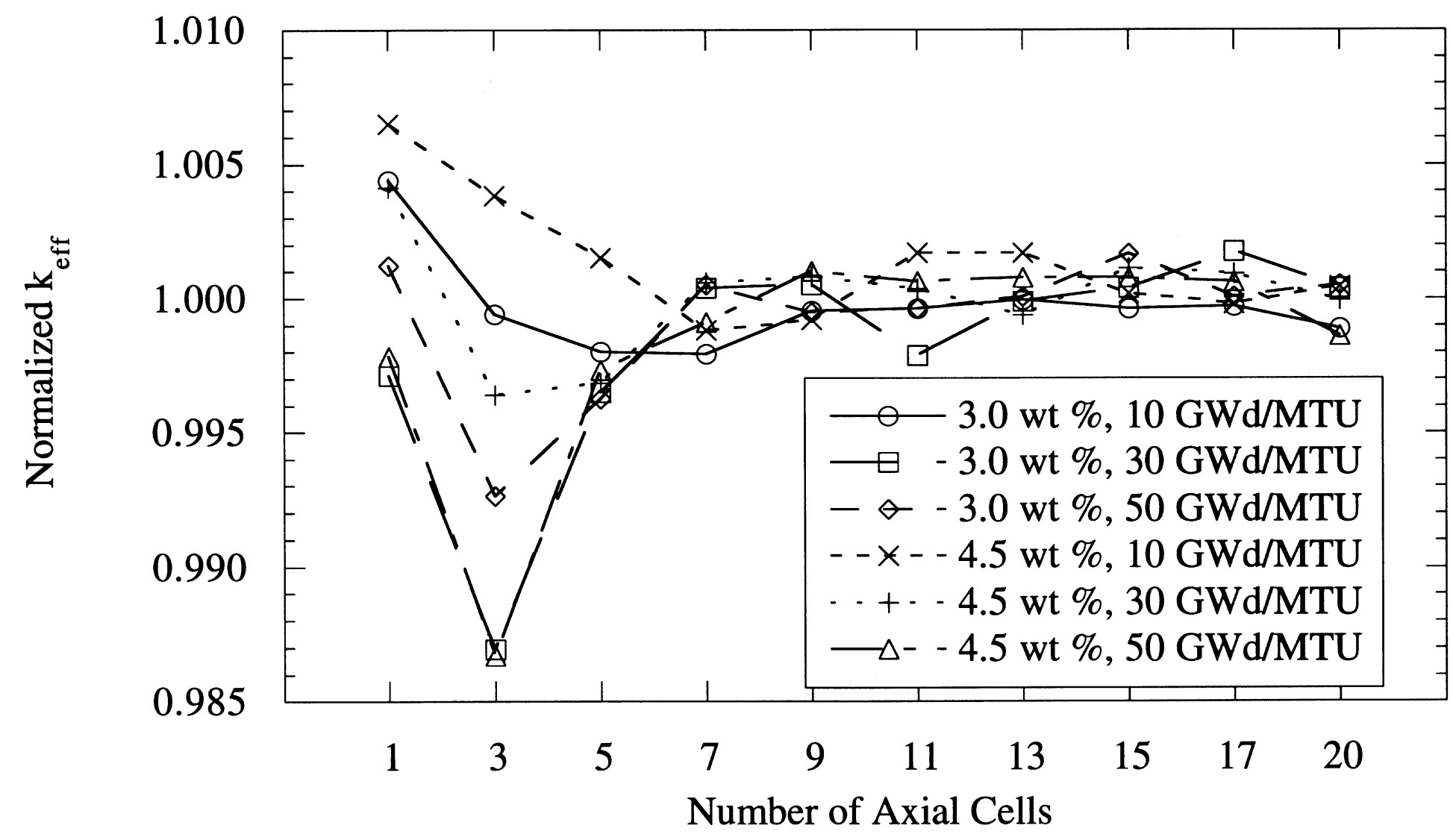




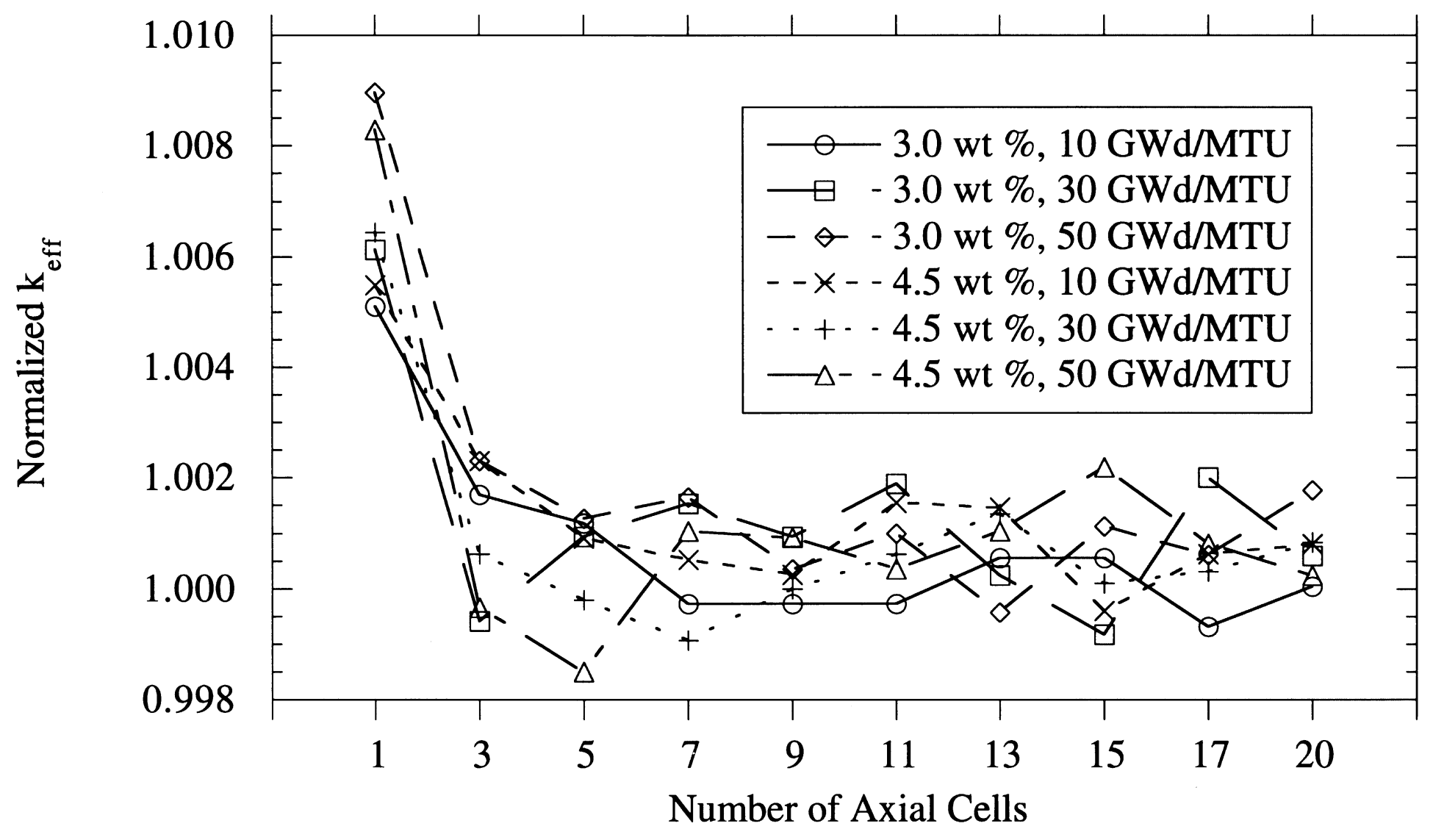

Fig. 41. $\mathrm{k}_{\mathrm{eff}}$ as a function of various axial zoning models (actinides only). 
For example, use of a burnup profile provided in an Organization for Economic Cooperation and Development (OECD)-sponsored study of burnup credit issues for a highly burned fuel results in an end effect $\left(\mathrm{k}_{\mathrm{eff}, 1-\mathrm{zone}}-\mathrm{k}_{\mathrm{eff}, 7-\mathrm{zone}}\right)$ on the order of $4 \% \Delta \mathrm{k}$ for the MPC model used here. However, the approach taken in this work to match burnup to the most number of cells added to the ends of a fuel rod is increased, one would obtain an increase in the accuracy of the $k_{\text {eff }}$ estimate. However, as is clear in Fig. 40 and perhaps indicated in Fig. 41, limiting burnup profile for an associated burnup range should result in a limiting value of $\mathrm{k}_{\mathrm{eff}}$ in a cask criticality calculation.

Figure 42 shows a hypothetical burnup profile typical of the burnup profiles seen in moderately to highly burned fuels. Also shown in the figure are 20 subdivisions of the axial profile and burnup approximations (horizontal line segments) representative of different axial zoning models (using the zoning schemes of Fig. 39. Based on this figure, it can be seen that zoning models with more than 7 axial zones provide little additional resolution to the burnup profile; hence additional axial zones are judged to be unnecessary.

\subsubsection{Effect of a Uniform Burnup Assumption}

The simplest approach in modeling burnup distribution effects is of course to assume a constantburnup profile (i.e., ignore the axial-burnup distribution). This approach facilitates the development of numerical models in several ways: (1) conservative burnup profile shapes as discussed earlier are not required, eliminating the need for the development of a burnup profile database; (2) only one set of isotopic concentrations is required and therefore only a single depletion calculation is necessary for each criticality calculation; (3) cross-section processing is only required for one set of isotopic concentrations; (4) combination of multiple cross-section libraries into a final library for use by KENO is not needed; and (5) the KENO V.a model requires only one fuel material and a simple fuel pin geometry description. However, before one can use a uniform-burnup assumption, one must be aware of the error associated with such an assumption.

Figure 41 demonstrates that for actinides-only criticality calculations the use of a single-zone (i.e., uniform-burnup) model results in the overprediction of $\mathrm{k}_{\mathrm{eff}}$ over the entire range of enrichments and burnups studied. Thus the uniform-burnup model is conservative under an actinides-only assumption and for burnups up to $50 \mathrm{GWd} / \mathrm{MTU}$. The conservatism is on the order of less than $1 \%$ $\Delta \mathrm{k} / \mathrm{k}$.

The determination of the end effect as a function of burnup is not straightforward for calculations in which both actinides and fission products are present. As shown in Fig. 40, for low burnup the use of a uniform burnup results in a conservative overprediction of $\mathrm{k}_{\mathrm{eff}}$ on the order of $0.6 \%$ $\Delta \mathrm{k} / \mathrm{k}$; however, the end effect decreases with increasing burnup, becoming negative and therefore nonconservative for high-burnup cases. For the cases studied, the maximum underprediction of $\mathrm{k}_{\mathrm{eff}}$ is roughly $0.3 \% \Delta \mathrm{k} / \mathrm{k}$ (a $2 \sigma$ uncertainty for these calculations is on the order of $0.2 \% \Delta \mathrm{k}$ ). This trend indicates that additional conservatism is required for higher burnup fuel if a uniform-burnup approximation is used.

A more simplified approach for assessing the best axial zoning scheme and the magnitude of the end effect is described in Appendix G. The results of this approach, based on an axially uniform specific power assumption, are consistent with the results presented here. 

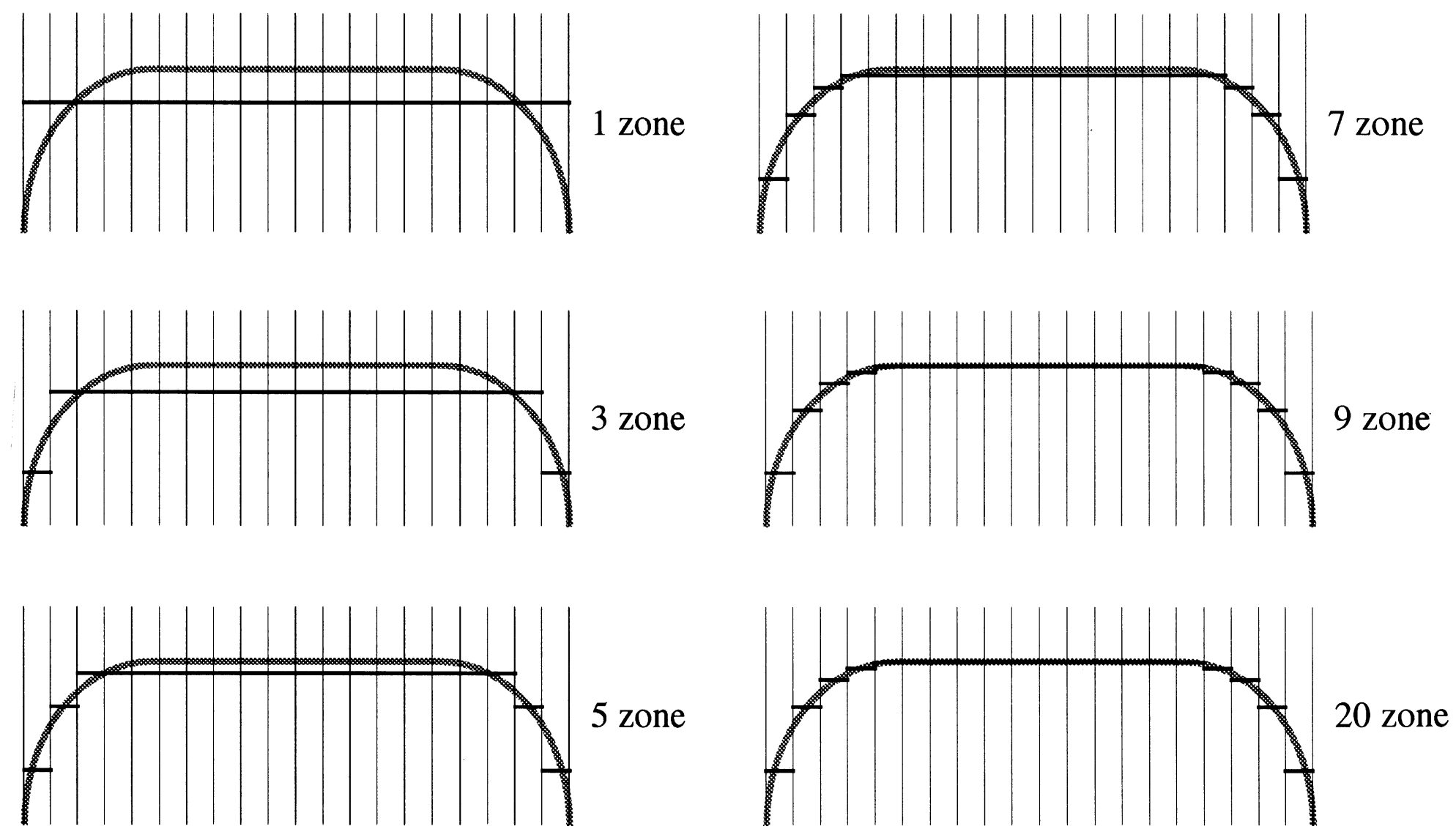

Fig. 42. Axial zoning burnup approximations to a continuous-burnup profile. 


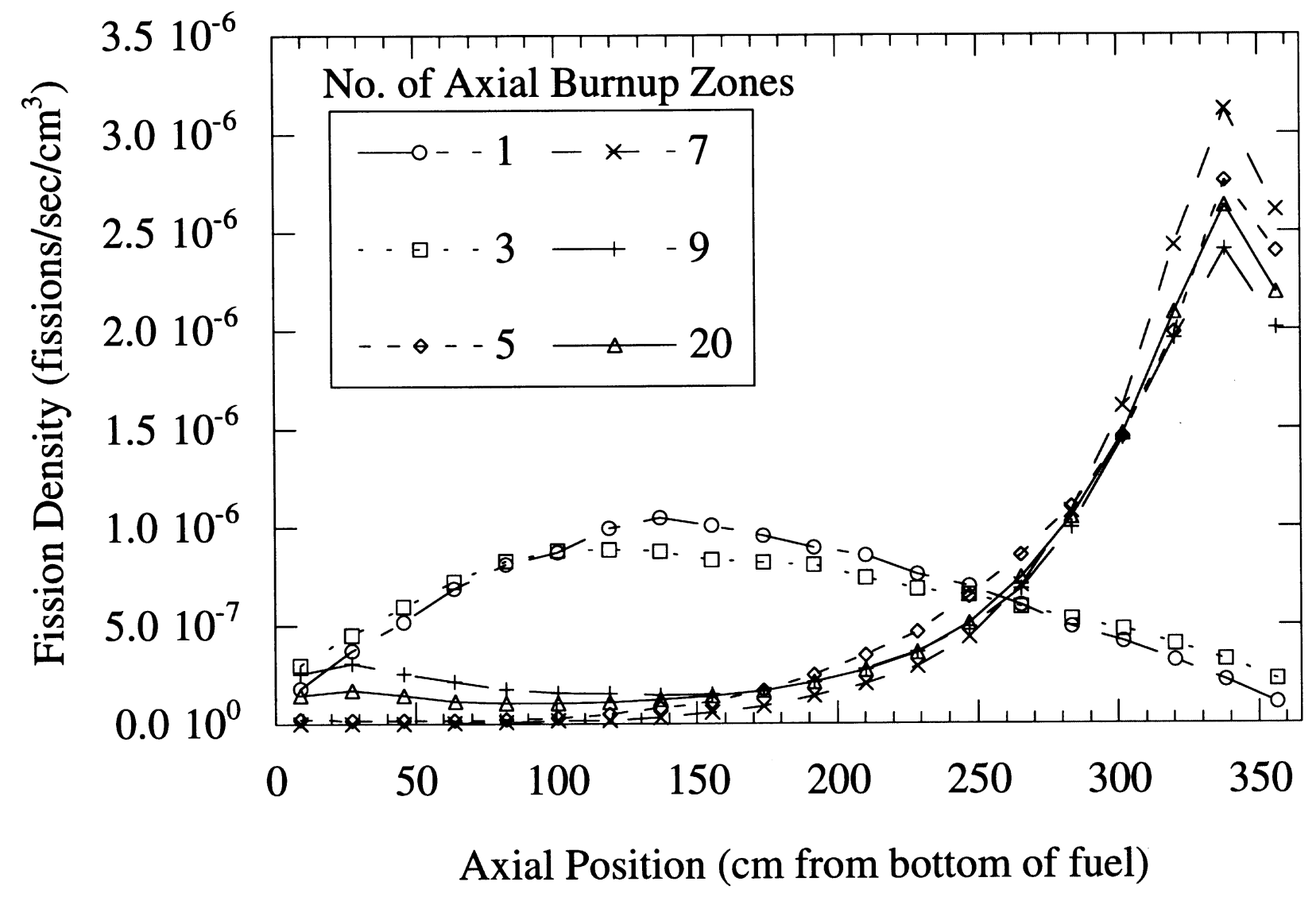

Fig. 43. Relationship between burnup and end effect (actinides + fission products). 


\subsubsection{Phenomena Related to the End Effect}

As was defined in the introduction to this section, the end effect is the erroneous prediction of the multiplication factor when assuming a uniform-burnup distribution in 1-D axial or in 3-D spent fuel models. A uniform-burnup model is always a simplifying approximation for spent fuel, and an axially varying burnup model is necessary to accurately predict $\mathrm{k}_{\mathrm{eff}}$ in spent fuel assemblies. Because burnup-generated isotopes (both actinides and fission products) are a relatively small fraction of fuel material at lower burnups but become increasingly important with higher burnups, the magnitude of the end effect would be expected to increase with increasing burnup. However, for a given burnup, the behavior of $\mathrm{k}_{\mathrm{eff}}$ as a function of the number of cells used to represent the axial burnup, as shown as Figs. 40 and 41, appears counterintuitive. One would expect that increasing the number of cells at each end from 1 to 2 would result in a shift from an overestimate of $\mathrm{k}_{\mathrm{eff}}$ to an underestimate of $\mathrm{k}_{\mathrm{eff}}$. When fission products are present, this reversal is quite large. After this point, use of additional cells does appear to improve the solution, converging on the best-estimate solution by the time as few as three zones are used to represent burnup at each end (i.e., the 7-zone model of Fig. 39.

It is believed that this behavior results from a combination of both the assumed burnup profile and the spatial neutron distribution that results from this assumption. If the isotopic distribution is incorrect, the neutron distribution simulated in a KENO V.a calculation will also be incorrect. Because $\mathrm{k}_{\mathrm{eff}}$ is driven by the combination of both isotopic distributions and the neutron distribution (i.e., reaction

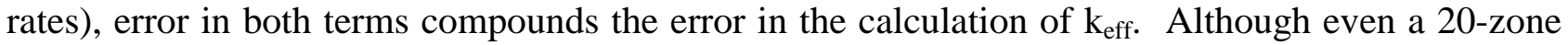
burnup distribution model does not represent the true burnup profile, results indicate that such an approximation results in a close enough approximation to the actual neutron distribution that reaction rates and therefore $\mathrm{k}_{\mathrm{eff}}$ are well estimated.

Figure 43 demonstrates the relationship between assumed burnup models and fission densities for several burnup profile models, for KENO V.a criticality calculations performed based on fuel compositions with fission products present. (In KENO V.a calculations, the fission density for an axial zone is computed as the total number of fissions in the zone divided by the volume of the zone. The total number of fissions does not include the fissions occurring in the first few generations of neutrons that are "skipped" by KENO in the calculation of $\mathrm{k}_{\mathrm{eff}}$.) These calculations were performed for highly burned (overburned) $3.0 \mathrm{wt} \%$ initial enrichment, 50-GWd/MTU burnup fuel. Fission density, the fission rate per unit volume of fuel, computed at regular intervals along the length of the rod, shows the fission reaction rate distribution along the length of a fuel rod. The figure shows the behavior of fission densities as a function of the number of axial cells in the burnup distribution model for fuel with fission products present. For a 1-zone model, the axial fission density is found to have a cosine-like shape due to the uniform burnup of the fuel. The 3-zone burnup mode1 in the figure departs from the cosine shape, but does not represent the shape expected for highly burned fuel. However, subsequent models begin to converge on a single fission density shape, indicating that the solution is approaching the correct flux profile for axial burnup profiles based on five or more axial zones. (Again, it is important to note that the axial zone numbers correspond to the zoning schemes shown in Fig. 39 and not to any general scheme.) 
The 1-zone results indicate that the central region of the fuel is overweighted and the end regions are underweighted due to the inadequacy of the uniform-burnup model. This imbalance would result in an overestimate of $\mathrm{k}_{\mathrm{eff}}$, as was observed in Fig. 40. The 3-zone results indicate that the fission density profile has been moved away from the center portions of the rod due to the presence of relatively low-burnup fuel near the rod ends. However, the peak fission density for this fuel occurs within the second axial cell from the top, as indicated by the 5-, 7-, 9-, and 20-zone results. Thus the 3-zone model, with only 1 zone at either end and a large central zone (see Fig. 39), does not adequately approximate the burnup in the region of the fuel where fission should be most important. Thus the model cannot represent the true burnup profile. Because the peak fission density occurs in the region characterized by the highly burned central zone, the reactivity of the two end regions is diluted. In fact, even though the top zone is less burned than the bottom zone in this model, the fission peak is located in the bottom of the fuel due to the asymmetry of the MPC cask model. (Scoping calculations show that this peak moves toward the more reactive top region of the fuel if symmetric boundary conditions are used.)

The shift of the fission peak toward the end of the fuel rod for the 3-zone case results in increased leakage; however, since criticality is driven by the high-burnup central zone where the fission peak is located, $k_{\text {eff }}$ drops substantially relative to the 1-zone case, as shown in Fig. 40.

For the remaining 5-, 7-, 9-, and 20-zone models, the fission density profile is found to converge on a single solution. (Differences between fission density profiles result from the fact that fission densities are estimated from essentially all neutron histories and thus include the effect of the random convergence path taken by KENO V.a early in the calculation. $\mathrm{k}_{\text {eff }}$, on the other hand, is determined from only the generations of neutrons born after convergence is achieved.) In all of these cases, the burnup in the most reactive region (i.e., the second zone from the top) is more closely approximated than in the 1- and 3-zone models. The 5-zone model may not be adequate (as indicated in Fig. 40, because of the relative importance of the region just below the fission peak; however, the 7-, 9-, and 20-zone models appear to adequately approximate the important aspects of the fuel furnup profile.

Note that the 5-, 7-, 9-, and 20-zone profiles shown in Fig. 39 indicate a strong fission density peak near the top of the fuel, but very little peak near the bottom of the fuel. In a $\mathrm{k}_{\text {eff }}$ calculation the system studied is assumed critical, and $\mathrm{k}_{\mathrm{eff}}$ is determined from a multiplier on the neutron source term which is required to maintain a critical system. Thus the problem is driven by the most reactive region of the problem which can maintain constant neutron populations. Because the top of spent fuel is typically less burned than the corresponding bottom region of the same fuel element (e.g., see Table 20, it is slightly more reactive; thus criticality is established in the more reactive upper end. The remainder of the fuel is subcritical relative to the upper end and cannot maintain an independent neutron flux; the fission density profile is therefore top-peaked. Although the less reactive lower region is subcritical, it is close enough to critical to provide significant subcritical multiplication relative to the central regions of the core. Hence there is a slight peak observed for the lower region.

Statistical uncertainty associated with each fission density value are on the order of or less than 3\% (roughly the size of the plotting symbols). Differences between the fission density profiles result from a lack of spatial convergence in the Monte Carlo solution. Once KENO V.a identifies the most reactive region of a problem, the solution is driven by the neutron multiplication properties of 


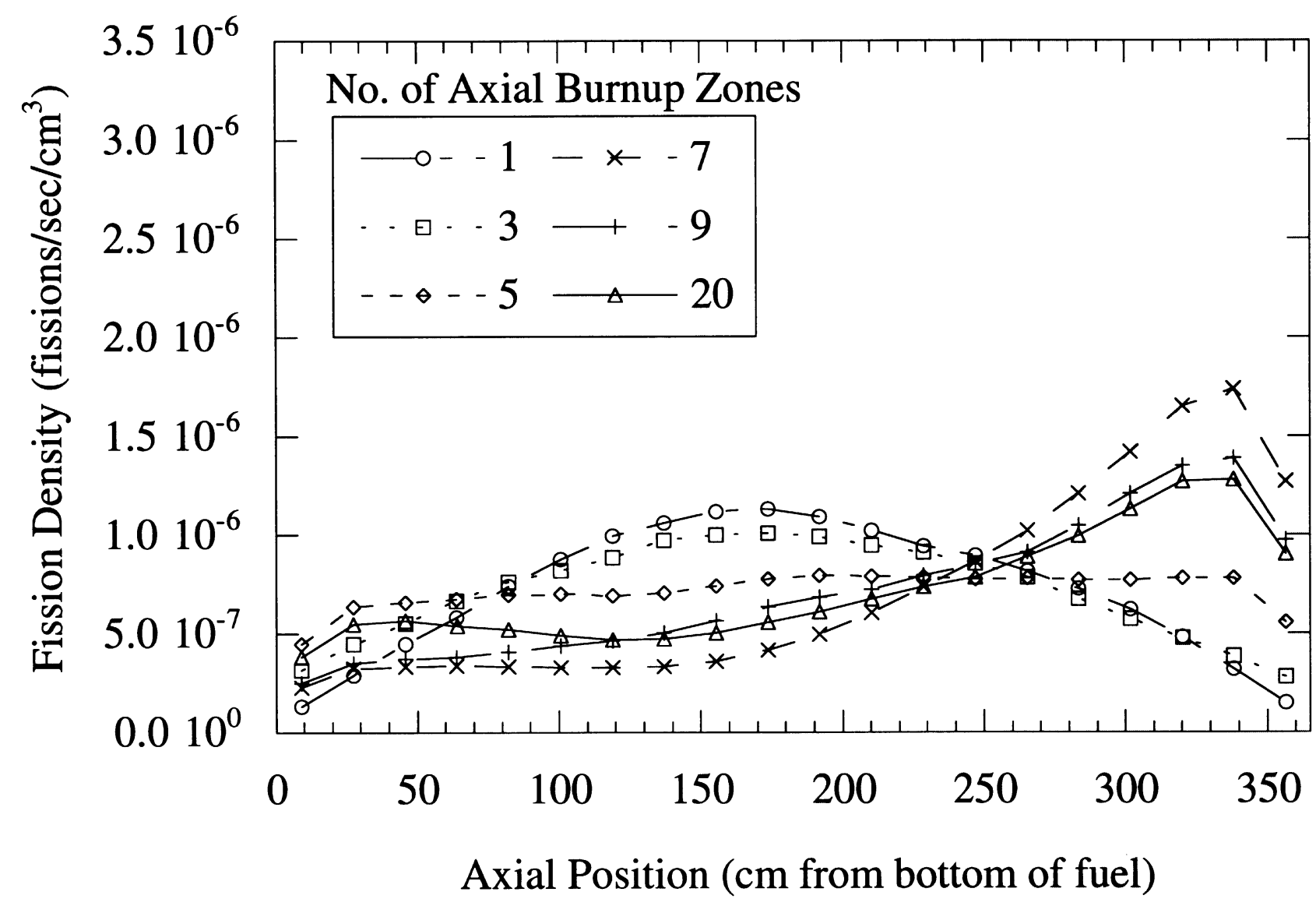

Fig. 44. Relationship between burnup and end effect (actinides only). 
that region. However, if multiple regions within a problem domain possess similar reactivities (e.g., the low-burnup ends of spent fuel assemblies in a cask), the convergence rate is reduced as the calculation tries to determine which zone is more reactive. Nevertheless, the solution is able to converge on $\mathrm{k}_{\text {eff }}$ despite the unconverged spatial solution because regions with similar reactivity are driven toward similar values of $\mathrm{k}_{\text {eff. }}$. Additional detail on such convergence issues and their relationship to Monte Carlo methods are discussed in more detail in Appendix F.

Figure 44 illustrates the fission density behavior for criticality calculations performed with actinides-only fuel models. As with its fission-product-present counterpart, the 1-zone model shows center-dominated fission, resulting in an overestimate of $\mathrm{k}_{\mathrm{eff}}$. However, for the 3-zone model, the central region fission density is not as depressed as was observed for the 3-zone model with fission products present; thus this burnup model results in a reduction in the predicted value of $\mathrm{k}_{\mathrm{eff}}$, although the reactivity change is not as large in magnitude as was observed in the fission-products-present case. For five and more axial zones in the burnup model, fission density profiles indicate that solutions are driven by end-region fissioning. In this case, however, the solution has not converged on a single solution. In the absence of fission products, the difference in the relative worth between the two ends is reduced, which, as discussed previously (and in Appendix F, slows down the convergence rate of the problem. Again, however, once a sufficient number of axial burnup zones are used (i.e., five zones), the problem begins converging on a consistent spatial solution.

Based on the above discussions, it would appear that models based on five axial burnup zones are adequate for minimizing the end effect and accurately estimating $\mathrm{k}_{\mathrm{eff}}$, both with and without fission products present in the fuel model. However, although a neutron distribution appears to be established at this point, the shape of the burnup profile is more closely approximated by the seven and more axial

zone models as suggested by Fig. 42. Based on the results plotted in Figs. 40 and 41, the 5-zone burnup model appears to result in a slight overprediction of $\mathrm{k}_{\mathrm{eff}}$ for low burnups and a small underprediction of $\mathrm{k}_{\mathrm{eff}}$ for higher burnups. The error in these 5-zone model predictions is very small but appears to be slightly greater than the uncertainty associated with the Monte Carlo calculations.

It is clear that the number of axial burnup zones required for an adequate representation of end effects is coupled to the shape of the axial burnup itself. The results described in this report were based on a set of burnup profiles obtained from a database of CE $14 \times 14$ assembly designs. Assuming this database is representative of a broader sampling of assembly designs and burnups, conclusions presented here will remain valid. Nevertheless it is recommended that studies similar to those performed in support of this section be carried out once a more complete database of axial burnup profiles becomes available.

\subsection{EFFECT OF AXIAL TEMPERATURE APPROXIMATIONS}

In 3-D modeling of spent fuel assemblies in a cask configuration, it has been demonstrated that axial-burnup distributions have a significant effect on the calculated value of $\mathrm{k}_{\mathrm{eff}}$. Because spent fuel depletion is known to be sensitive to temperature variations (due not only to Doppler broadening effects but also to water-density-driven moderation effects), it is important to assess the effect of approximations made in SAS2H depletion calculations. In the current methodology, SAS2H calculations have been performed assuming constant fuel, clad, and moderator temperatures (and 
corresponding moderator density) for all axial zone isotopic calculations. To assess the effect of axially varying temperatures, a set of calculations was performed in which 20 axial zones were used, with typical temperature variations assumed and assigned for the SAS2H calculation performed for each zone. Corresponding calculations were performed in which the assumed temperatures were held constant in each of the 20 zones, with a value derived from the length-weighted average of the variable temperature. Temperatures assumed for each axial location are listed in Table 23, based on average temperatures and typical theoretical temperature profiles.

Calculations were performed using 20-zone KENO-V.a models with isotopic concentrations generated using the axially varying and axially averaged temperatures for burnups of 10, 30, and $50 \mathrm{GWd} / \mathrm{MTU}$. Calculations were performed both with and without fission products present. All calculations were performed assuming a 5-year cooling time, and were based on $3.6 \mathrm{wt} \%$ enrichment fuel. Table 24 provides a summary of results for all cases, and shows the $\Delta \mathrm{k}$ difference between burnup-sensitive uncertainties, the effect of an assumed constant axial temperature in depletion calculations can be neglected with no significant impact.

\subsection{EFFECT OF ISOTOPIC CORRECTION FACTORS}

The effect of conservative isotopic correction factors relative to nominal isotopic concentrations was studied earlier based on deterministic 1-D infinite lattice calculations. However, because the magnitude of conservatism associated with such an approach will significantly impact its acceptability for application in burnup credit methodologies, it is felt necessary to demonstrate the conservatism of isotopic correction factors in the environment for which they are intended (i.e., within a Monte Carlo cask calculation using recommended modeling assumptions).

For this section, calculations were performed based on 3-D KENO V.a models developed from the simplest acceptable modeling assumptions; the net effect of isotopic correction factors relative to nominal isotopic predictions are then determined for such models. The "simplest acceptable assumptions" are based on the findings of the various sensitivity and parametric analyses described earlier in this report. These modeling assumptions are listed below:

\$ use of ten recommended burnup credit actinides (from Table 17) plus oxygen for criticality calculations;

\$ use of 12 recommended burnup credit fission products (from Table 17) for all criticality calculations in which fission products are included;

\$ depletion calculations based on continuous operation at a constant power level;

\$ isotopic concentrations based on a 5-year cooling time after shutdown;

\$ "nominal" or best-estimate isotopics determined from SAS2H-computed isotopics by the use of isotopic biases (from Table B-21 of Appendix B); 
Table 23. Assumed axial temperature and moderator density values

\begin{tabular}{ccccccccc}
\hline $\begin{array}{c}\text { Zone No. } \\
\text { (bottom } \\
\text { to top) }\end{array}$ & $\begin{array}{c}\text { Varying } \\
\text { fuel } \\
\text { temperature } \\
(\mathrm{K})\end{array}$ & $\begin{array}{c}\text { Uniform } \\
\text { fuel } \\
\text { temperature } \\
(\mathrm{K})\end{array}$ & $\begin{array}{c}\text { Varying } \\
\text { clad } \\
\text { temperature } \\
(\mathrm{K})\end{array}$ & $\begin{array}{c}\text { Uniform } \\
\text { clad } \\
\text { temperature } \\
(\mathrm{K})\end{array}$ & $\begin{array}{c}\text { Varying } \\
\text { moderator } \\
\text { temperature } \\
(\mathrm{K})\end{array}$ & $\begin{array}{c}\text { Uniform } \\
\text { moderator } \\
\text { temperature } \\
(\mathrm{K})\end{array}$ & $\begin{array}{c}\text { Varying } \\
\text { moderator } \\
\text { density } \\
(\mathrm{g} / \mathrm{cc})\end{array}$ & $\begin{array}{c}\text { Uniform } \\
\text { moderator } \\
\text { density } \\
(\mathrm{g} / \mathrm{cc})\end{array}$ \\
\hline 1 & 730.58 & 894.00 & 616.23 & 628.00 & 557.23 & 569.00 & 0.757 & 0.735 \\
2 & 768.47 & 894.00 & 617.77 & 628.00 & 558.77 & 569.00 & 0.754 & 0.735 \\
3 & 805.19 & 894.00 & 619.30 & 628.00 & 560.30 & 569.00 & 0.752 & 0.735 \\
4 & 839.98 & 894.00 & 620.80 & 628.00 & 561.80 & 569.00 & 0.749 & 0.735 \\
5 & 872.12 & 894.00 & 622.27 & 628.00 & 563.27 & 569.00 & 0.746 & 0.735 \\
6 & 900.95 & 894.00 & 623.70 & 628.00 & 564.70 & 569.00 & 0.743 & 0.735 \\
7 & 925.88 & 894.00 & 625.08 & 628.00 & 566.08 & 569.00 & 0.741 & 0.735 \\
8 & 946.39 & 894.00 & 626.40 & 628.00 & 567.40 & 569.00 & 0.738 & 0.735 \\
9 & 962.06 & 894.00 & 627.65 & 628.00 & 568.65 & 569.00 & 0.736 & 0.735 \\
10 & 972.57 & 894.00 & 628.83 & 628.00 & 569.83 & 569.00 & 0.734 & 0.735 \\
11 & 977.70 & 894.00 & 629.92 & 628.00 & 570.92 & 569.00 & 0.732 & 0.735 \\
12 & 977.35 & 894.00 & 630.93 & 628.00 & 571.93 & 569.00 & 0.730 & 0.735 \\
13 & 971.53 & 894.00 & 631.83 & 628.00 & 572.83 & 569.00 & 0.728 & 0.735 \\
14 & 960.34 & 894.00 & 632.64 & 628.00 & 573.64 & 569.00 & 0.726 & 0.735 \\
15 & 944.03 & 894.00 & 633.35 & 628.00 & 574.35 & 569.00 & 0.725 & 0.735 \\
16 & 922.93 & 894.00 & 633.94 & 628.00 & 574.94 & 569.00 & 0.723 & 0.735 \\
17 & 897.47 & 894.00 & 634.41 & 628.00 & 575.41 & 569.00 & 0.722 & 0.735 \\
18 & 868.19 & 894.00 & 634.78 & 628.00 & 575.78 & 569.00 & 0.722 & 0.735 \\
19 & 835.67 & 894.00 & 635.02 & 628.00 & 576.02 & 569.00 & 0.721 & 0.735 \\
20 & 800.59 & 894.00 & 635.14 & 628.00 & 576.14 & 569.00 & 0.721 & 0.735 \\
\hline
\end{tabular}

Table 24. Effect of axial temperature distributions during depletion calculations

\begin{tabular}{|c|c|c|c|c|c|c|}
\hline $\begin{array}{l}\text { Fuel } \\
\text { composition }\end{array}$ & $\begin{array}{l}\text { Fuel burnup } \\
\text { (GWd/MTU) }\end{array}$ & $\begin{array}{c}\mathrm{k}_{\text {eff }} \\
\text { (temperature } \\
\text { distribution) } \\
\end{array}$ & $\pm \sigma$ & $\begin{array}{c}\mathrm{k}_{\mathrm{eff}} \\
\text { (uniform } \\
\text { temperature ) }\end{array}$ & $\pm \sigma$ & $\Delta \mathrm{k}$ \\
\hline Actinides + & 10 & 0.9881 & 0.0007 & 0.9864 & 0.0007 & 0.0017 \\
\hline \multirow[t]{2}{*}{ fission products } & 30 & 0.8497 & 0.0006 & 0.8450 & 0.0006 & 0.0047 \\
\hline & 50 & 0.7309 & 0.0005 & 0.7251 & 0.0005 & 0.0058 \\
\hline Actinides & 10 & 1.0145 & 0.0007 & 1.0160 & 0.0007 & -0.0015 \\
\hline \multirow[t]{2}{*}{ only } & 30 & 0.9019 & 0.0006 & 0.9013 & 0.0006 & 0.0006 \\
\hline & 50 & 0.8109 & 0.0006 & 0.8070 & 0.0006 & 0.0039 \\
\hline
\end{tabular}


\$ "corrected" or conservatively bounding isotopics determined from SAS2H-computed isotopics by the use of isotopic correction factors (from Table B-21 of Appendix B);

\$ the axial burnup shape was determined from the conservative burnup profiles given in Table 20 for corresponding burnup levels. The profiles were multiplied by the assembly-averaged burnup to obtain axial-burnup profiles;

\$ axial zoning was based on the 7-zone model shown in Fig. 39. Average burnup was computed for each zone based on the above axial burnup profile. Depletion calculations were performed for each zone's burnup to obtain zone isotopics;

\$ depletion calculations for all zones in a given model were performed based on a single cycle length; specific powers were varied to obtain the required burnup for each zone.

Results for calculations based on these assumptions are given in Table 25. These results demonstrate that use of the isotopic correction factor results in a significant degree of conservatism over calculations based on best-estimate (bias-based) isotopic concentrations ranging from about 2.5\% (low burnup) to $6.5 \%$ (high burnup) for actinides-only calculations, and from roughly $4.5 \%$ to $13.0 \%$ for corresponding burnup levels based on actinides + fission product isotopics.

Table 25. Effect of isotopic correction factors on the calculation of $\mathrm{k}_{\mathrm{eff}}$ in a cask configuration

\begin{tabular}{cc|ccc|ccc}
\hline \multirow{2}{*}{$\begin{array}{c}\text { Enrichmen } \\
(\mathrm{wt} \%)\end{array}$} & Burnup & \multicolumn{3}{|c|}{ Actinides only } & \multicolumn{3}{c}{ Actinides + fission products } \\
\cline { 3 - 8 }$(\mathrm{GWd} / \mathrm{MT}$ & Nominal & Corrected & $\Delta \mathrm{k} / \mathrm{k}$ & Nominal & Corrected & $\Delta \mathrm{k} / \mathrm{k}$ \\
\hline 3.0 & 10 & 0.9661 & 1.0011 & $3.623 \%$ & 0.9381 & 0.9878 & $5.298 \%$ \\
3.0 & 30 & 0.8505 & 0.8931 & $5.009 \%$ & 0.8002 & 0.8670 & $8.348 \%$ \\
3.0 & 50 & 0.7662 & 0.8163 & $6.539 \%$ & 0.6880 & 0.7794 & $13.285 \%$ \\
3.6 & 10 & 1.0133 & 1.0443 & $3.059 \%$ & 0.9857 & 1.0337 & $4.870 \%$ \\
3.6 & 30 & 0.9007 & 0.9397 & $4.330 \%$ & 0.8480 & 0.9147 & $7.866 \%$ \\
3.6 & 50 & 0.8074 & 0.8564 & $6.069 \%$ & 0.7295 & 0.8165 & $11.926 \%$ \\
4.5 & 10 & 1.0702 & 1.0967 & $2.476 \%$ & 1.0401 & 1.0858 & $4.394 \%$ \\
4.5 & 30 & 0.9672 & 1.0013 & $3.526 \%$ & 0.9080 & 0.9767 & $7.566 \%$ \\
4.5 & 50 & 0.8674 & 0.9146 & $5.442 \%$ & 0.7908 & 0.8770 & $10.900 \%$ \\
\hline
\end{tabular}




\section{CONCLUSIONS}

Burnup credit, the allowance for the consideration of spent fuel reactivity effects in criticality analysis, raises many new issues that are not important under fresh-fuel assumptions, both in terms of the physical behavior of such systems and the modeling assumptions necessary to adequately represent spent fuel configurations. This report has sought to address many of these issues in terms of a burnup credit approach for spent fuel cask considerations. Specifically, this report has studied the sensitivity of burnup credit methods to various modeling assumptions to determine the bias, if any, in the method as a function of such assumptions and to provide, through parametric analyses, a basic understanding of spent fuel behavior as a function of initial and operating conditions.

Section 2 of this report provided a general overview of the SCALE code system and a description of the depletion and criticality computational sequences available within SCALE. All calculations performed in support of this report were accomplished through the use of Version 4.2 of the SCALE code system together with its 27BURNUPLIB cross-section library. Although many of the spent fuel trends and modeling approaches discussed in this report are independent of the analysis codes used, specific results such as biases and uncertainties are strongly tied to both the code system and the cross-section library. Thus such results should not be broadly applied or prescribed in safety analyses using other codes, other versions of SCALE, or other cross-section libraries.

Basic phenomena associated with spent fuel behavior were investigated in Sect. 2. This included a determination of a minimum set of nuclides to be used in spent fuel analysis, the importance of each nuclide relative to criticality calculations, the study of basic trends in neutron multiplication as a function of fuel enrichment, burnup, and cooling time, and the study of assumptions in depletion calculations and the sensitivity of criticality calculations to these assumptions.

Table 17 provides a summary of the minimum set of nuclides recommended for burnup credit applications. This set consists of 10 actinides, 12 fission products, and oxygen. Since oxygen is not depleted during operation it is often omitted in the discussion of burnup effects; however, it is always important to include in $\mathrm{k}_{\text {eff }}$ calculations. Partial burnup credit that neglects fission products is an option for burnup credit applications due to a sparsity of fission-product validation data; hence this report has addressed the behavior of spent fuel both with and without fission products present in criticality calculations. However, calculations indicate that the best estimate of fission-product concentrations generally represent a negative reactivity worth at least $10 \% \Delta \mathrm{k} / \mathrm{k}$ (i.e., $-10 \% \Delta \mathrm{k} / \Delta$ worth). This reactivity will generally increase with time. Using conservative estimates of fission-product concentrations reduces their worth to approximately $-4 \% \Delta \mathrm{k} / \mathrm{k}$; however, the magnitude of this worth will increase with increased availability of fission-product isotopic measurement data. Thus because of the potential worth of fission products, it is felt that efforts should be made to include fission products in burnup credit applications.

Trending analyses performed using 1-D infinite lattice calculations as a function of initial enrichment, burnup, and cooling time demonstrated several important aspects of spent fuel behavior. It was determined that reactivity worth of spent fuel after a 5-year cooling time bounds that calculated for all times out to the 200-year time frame important for transportation concerns, both with and without fission products present. Fission-product importance, in terms of reactivity worth relative to actinide worth, increases over the first 50 years of cooling, after which it remains roughly constant; furthermore, fission-product importance increases with increasing burnup. Application of conservative correction 
factors (as discussed and derived in Appendix B) based on currently available isotopic measurement data provides an additional conservatism of $5 \% \Delta \mathrm{k} / \mathrm{k}$ for actinides-only fuel and a $10 \% \Delta \mathrm{k} / \mathrm{k}$ margin when fission products are also included.

Variations in depletion parameters have different effects on different burnup credit nuclides, due to widely varying cross sections, half-life, and production mechanisms. The behavior of a specific isotope under given operating conditions is not necessarily an indicator of global fuel responses. Thus calculations that evaluate the net effect of operational assumptions on neutron multiplication are required to evaluate these assumptions, as $\mathrm{k}_{\infty}$ provides the best integral measure of such burnup effects. Values of $\mathrm{k}_{\infty}$ calculated as a function of various depletion parameters indicate that significant sensitivity exists to assume values for the parameters studied, and that a bounding approach for selection of each parameter should be taken to ensure conservatism. Reactor history should be represented as constant power operation to a given burnup level. The upper bound for specific power should be assumed for the depletion history in an actinides-only analysis; conversely, a reasonable lower bound for specific power should be assumed when fission products are included. Upper bounds for fuel and moderator temperatures and moderator soluble boron concentrations are recommended for depletion calculations whether or not fission products are included in subsequent criticality calculations. In fact, these parameters have little effect on fission-product worth.

Because of the complexity of 3-D criticality models for spent fuel cask configurations, modeling assumptions must be made to reduce the computational overhead required in a proposed spent fuel approach. Section 4 introduced the key aspects of 3-D cask configurations and presented some of the approximations and assumptions that should be considered in modeling such configurations. The database of axial-burnup profiles used to study axial effects was also introduced and discussed. The assumptions discussed in Sect. 4 were among the items studied in Sect. 5 which sought to demonstrate the validity of selected modeling assumptions and to show the amount of uncertainty or sensitivity associated with various simplifying assumptions. In particular, Sect. 5 studied the effects of variations in the shape of axial-burnup profiles, the effects of axial burnup itself and requirements for accurate modeling of axial-burnup distributions, the effect of assumed constant axial temperature profiles in depletion modeling, and finally, the effect of the use of conservative isotopics in a 3-D cask configuration. A discussion of limitations associated with Monte Carlo methods and their relationship to the current work is included in Appendix F.

Calculations demonstrated that there can be about a $1 \%$ variation in the calculated value of $\mathrm{k}_{\mathrm{eff}}$ based on different assumed burnup profiles for criticality calculations performed with fission products present in the fuel; a variation of less than $0.5 \%$ is observed when fission products are neglected. Results indicate that of the burnup profiles studied (and limited to the range of profiles in the database of CE $14 \times 14$ assemblies) one can conservatively represent a set of burnup profiles by taking the lowest sets of burnups of zones at the "ends" of the rods combined with the highest burnups for "central" zones; the "ends" are roughly represented by 1/6- to 1/4-length regions at the top and bottom of a fuel rod and thus the "central" region of the rod is the balance of the interior region of the rod. Based on these results, a set of burnup-dependent axial burnup shapes is provided in Table 20 for five sets of burnup ranges.

Studies of numerous axial zoning models showed that good agreement to a very fine grid 100zone model could be achieved with as few as seven zones both with and without fission products present, using the 7-zone model shown in Fig. 39 and the conservative burnup profiles of Table 20. Depletion calculations are required for each zone in a criticality model; therefore, it is desirable to 
minimize the number of burnup zones used in a fuel pin model. The calculations indicated that axial zoning is not necessary for the central region of spent fuel, probably due to the nearly uniform burnup profile of the central region for highly burned fuel. For low-burnup fuel, the ends of a fuel rod are not important because the inner regions of the fuel still dominate neutron production, and the number of end regions cells is unimportant.

Fuel rod models can be simplified even further by ignoring axial burnup effects and using a single zone model based on axially averaged burnup. For actinides-only fuel, such an assumption is conservative; however, the conservatism results in a nearly $1 \% \Delta \mathrm{k} / \mathrm{k}$ penalty for highly burned fuel. For criticality calculations including fission products, behavior is significantly different. At low burnups, when fission-product inventories are small, behavior is similar to that of actinides-only behavior; however, as burnup increases, the initially positive (and conservative) reactivity associated with a single-zone assumption decreases and eventually becomes negative (and therefore nonconservative). The nonconservatism increases with increasing burnup. The end effect appears to be affected by leakage; thus the effect is likely to be coupled to package design.

Because SAS2H calculations do not directly account for axial effects, there is no provision to account for axial temperature variations in the fuel, clad, and moderator during depletion calculations. In general, average temperatures are assumed for depletion calculations. If a single axial zone is assumed, an average temperature approximation is reasonable and necessary. Calculations comparing average temperature assumptions with axially varying temperatures showed that the error associated with the assumption increases with increasing burnup, but is only on the order of $-0.5 \% \Delta \mathrm{k} / \mathrm{k}$ for highly depleted fuel.

The final sensitivity analyses performed in this report revisited the effect of conservative isotopic concentrations relative to nominal concentrations. Earlier comparisons were performed using deterministic 1-D infinite lattice calculations, whereas these calculations were performed using a 3-D Monte Carlo model based on the conceptual MPC design. Results were found to be consistent with the earlier calculations, although use of conservative correction factors in the cask model calculations appears to result in additional conservatism relative to nominal isotopic concentrations. Actinides-only models with conservative isotopics are 2.5 to $6.5 \% \Delta \mathrm{k} / \mathrm{k}$ lower than nominal models for low- to highburnup ranges. Models including fission products are 4.5 to $13 \% \Delta \mathrm{k} / \mathrm{k}$ more conservative over the same burnup range.

Table 26 summarizes the results described herein by listing the recommended application of each parameter studied for burnup credit analysis. The table gives the phase of the calculation affected by the parameter (either criticality or depletion and decay calculations) and the section of the report in which the parameter was studied. The "recommended treatment" column gives recommendations for use of each parameter in calculations; the "bases" column lists the assumptions or range of independent variables applied in the study of the parameter. These recommendations are strictly valid only within the range of these bases; however, in many cases, trends can be extrapolated beyond the studied range. For example, although trends with boron concentration were evaluated only for the range of 0 to 1000 ppm boron, the trend in computed multiplication factors as a function of increasing boron concentration during depletion is clearly a smooth, increasing function, and it would be safe to extrapolate this behavior to higher boron concentrations, using engineering judgment. 
Table 26. Recommended treatment of important parameters in PWR burnup credit

\begin{tabular}{|c|c|c|c|c|}
\hline Parameter & $\begin{array}{l}\text { Calculation } \\
\text { phase }\end{array}$ & $\begin{array}{l}\text { Section } \\
\text { in text }\end{array}$ & Recommended treatment & Bases (ranges surveyed) \\
\hline $\begin{array}{l}\text { Nuclides: } \\
\text { Actinides }\end{array}$ & Criticality & 3.1 .1 & Use actinide isotopes listed in Table 17 & $\begin{array}{l}3.0-4.5 \mathrm{wt} \%{ }^{235} \mathrm{U} \\
10-50 \mathrm{GWd} / \mathrm{MTU} \\
5 \text {-year cooled }\end{array}$ \\
\hline $\begin{array}{l}\text { Fission } \\
\text { products }\end{array}$ & Criticality & 3.1 .2 & Use fission product isotopes listed in Table 17 & $\begin{array}{l}3.0-4.5 \mathrm{wt} \%{ }^{235} \mathrm{U} \\
10-50 \mathrm{GWd} / \mathrm{MTU} \\
\text { 5-year cooled }\end{array}$ \\
\hline $\begin{array}{l}\text { Cooling } \\
\text { time }\end{array}$ & $\begin{array}{l}\text { Depletion/ } \\
\text { decay }\end{array}$ & 3.3 & Isotopics should be based on a 5 -year cooling period & $\begin{array}{l}3.0-4.5 \mathrm{wt} \%{ }^{235} \mathrm{U} \\
10-50 \mathrm{GWd} / \mathrm{MTU} \\
0-200 \text { years cooled }\end{array}$ \\
\hline $\begin{array}{l}\text { Specific } \\
\text { power }\end{array}$ & $\begin{array}{l}\text { Depletion/ } \\
\text { decay }\end{array}$ & 3.4 .1 & $\begin{array}{l}\text { Actinides only: Use highest specific power expected during } \\
\text { normal operation } \\
\text { Actinides + fission products: use lowest specific power } \\
\text { expected during normal operation }\end{array}$ & $\begin{array}{l}3.0-4.5 \mathrm{wt} \%{ }^{235} \mathrm{U} \\
10-50 \mathrm{GWd} / \mathrm{MTU} \\
\text { 5-year cooled } \\
10-50 \mathrm{MW} / \mathrm{MTU}\end{array}$ \\
\hline $\begin{array}{l}\text { Operational } \\
\text { history }\end{array}$ & $\begin{array}{l}\text { Depletion/ } \\
\text { decay }\end{array}$ & 3.4 .2 & $\begin{array}{l}\text { Assume constant power operation with no downtime between } \\
\text { cycles. If fission products are present, a } 0.2 \% \Delta \mathrm{k} \text { margin } \\
\text { should be included to account for the effect of late cycle } \\
\text { variations. }\end{array}$ & $\begin{array}{l}3.0-4.5 \mathrm{wt} \%{ }^{235} \mathrm{U} \\
10-50 \mathrm{GWd} / \mathrm{MTU} \\
5 \text {-year cooled } \\
\text { power histories of Fig. } 20\end{array}$ \\
\hline $\begin{array}{l}\text { Fuel } \\
\text { temperature }\end{array}$ & $\begin{array}{l}\text { Depletion/ } \\
\text { decay }\end{array}$ & 3.5 & $\begin{array}{l}\text { Use highest expected effective fuel temperature expected } \\
\text { during normal operation }\end{array}$ & $\begin{array}{l}3.0-4.5 \mathrm{wt} \%{ }^{235} \mathrm{U}, 10-50 \mathrm{GWd} / \mathrm{MTU}, \\
10-50 \mathrm{GWd} / \mathrm{MTU} \\
5 \text {-year cooled } \\
\mathrm{T}_{\text {fuel }}=700-1100 \mathrm{~K}\end{array}$ \\
\hline $\begin{array}{l}\text { Moderator } \\
\text { temperature } \\
\text { (density) }\end{array}$ & $\begin{array}{l}\text { Depletion/ } \\
\text { decay }\end{array}$ & 3.5 & $\begin{array}{l}\text { Use lowest moderator density, corresponding to highest bulk } \\
\text { moderator temperature, expected during normal operation }\end{array}$ & $\begin{array}{l}3.0-4.5 \mathrm{wt} \%{ }^{235} \mathrm{U} \\
10-50 \mathrm{GWd} / \mathrm{MTU} \\
5 \text {-year cooled } \\
\mathrm{T}_{\text {moderator }}=500-600 \mathrm{~K}\end{array}$ \\
\hline
\end{tabular}


Table 26 (continued)

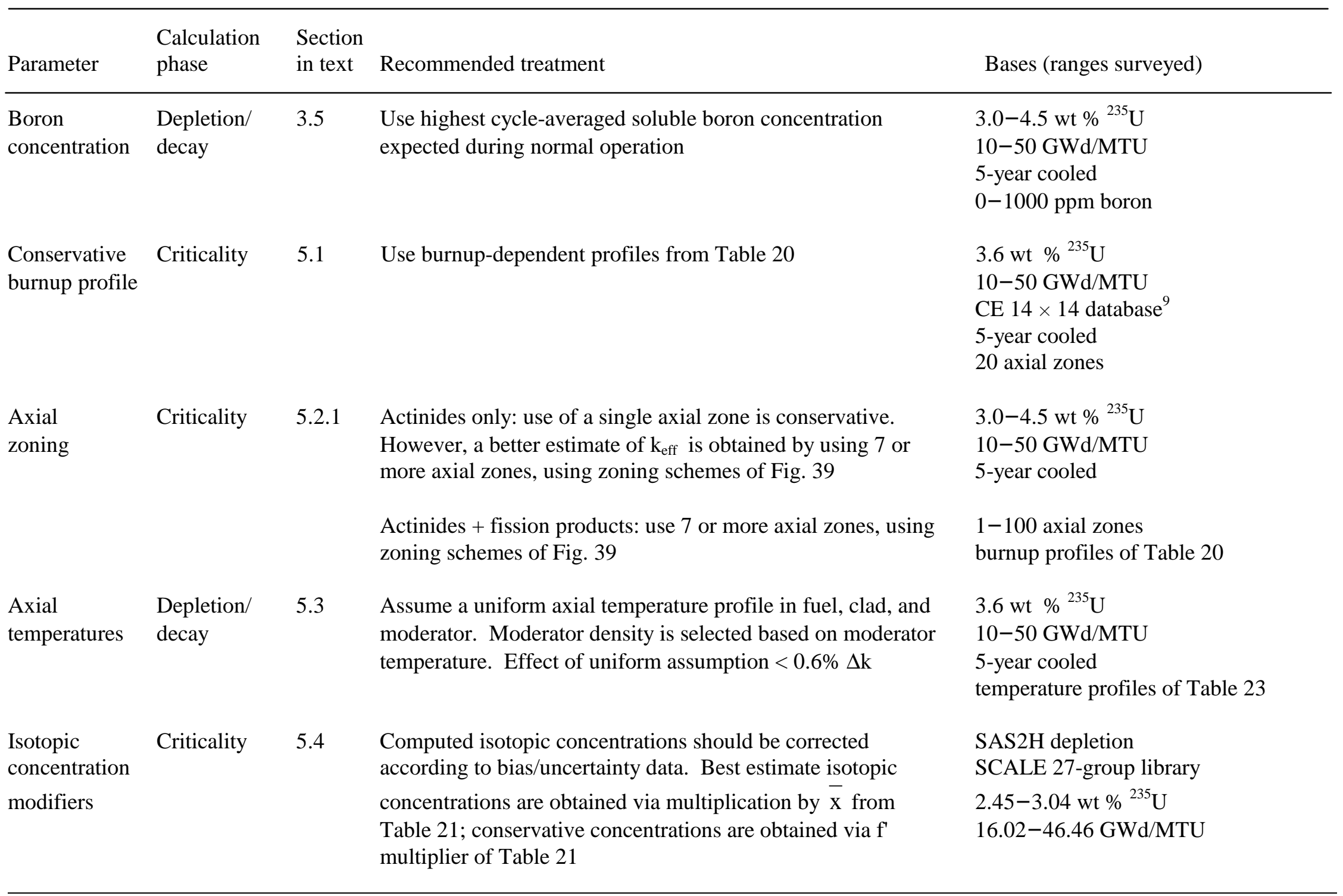


In general, sensitivity analyses indicate a strong correlation between trends studied and fissile depletion. Although not quantified in this work, fissile depletion as defined in this work is a combination of both initial enrichment and burnup (where burnup is expressed in terms of power per unit mass of uranium metal). Perhaps a study of sensitivity of $\mathrm{k}_{\infty}$ and $\mathrm{k}_{\text {eff }}$ to burnup expressed in terms of power per unit initial mass of ${ }^{235} \mathrm{U}$ would provide an improved method for classifying trends independent of enrichment. Such an approach would have reduced value at high burnup when plutonium effects are more important, but should be more instructive than trending methods used in this report. Trends measured in terms of total fissile mass may avoid such problems, but would require more bookkeeping due to the burnup dependence of fissile masses.

It should be reemphasized that the findings of this report are useful in predicting trends in spent fuel behavior based on parametric results and for determining the relative importance of different aspects of numerical models based on sensitivity analyses. However, caution should be taken in using specific numbers (e.g., margins of conservatism) in safety analyses, especially if calculations are performed using other computer codes or cross-section sets. The analyses in this report are not intended to replace safety analyses typically performed by cask designers or design reviewers. 


\section{REFERENCES}

1. T. L. Sanders et al., Feasibility and Incentives for the Consideration of Spent Fuel Operating Histories in the Criticality Analysis of Spent Fuel Shipping Casks, SAND87-0157 (TTC-0713), Sandia National Labs., 1987.

2. T. L. Sanders and R. M. Westfall, "Feasibility and Incentives for Burnup Credit in Spent Fuel Transport Casks," Nucl. Sci. Eng. 104 (1990).

3. C. V. Parks, "Parametric Neutronic Analyses Related to Burnup Credit Cask Design," SAND890018, Proc. Workshop Use of Burnup Credit in Spent Fuel Transport Casks, Washington, D.C., 1989.

4. S. P. Cerne, O. W. Hermann, and R. M. Westfall, Reactivity and Isotopic Composition of Spent PWR Fuel as a Function of Initial Enrichment, Burnup, and Cooling Time, ORNL/CSD/TM-244, Oak Ridge Nat. Lab., Martin Marietta Energy Systems, Inc., 1987.

5. M. C. Brady, "Burnup Credit Issues in Transportation and Storage," Proc. 10th International Symposium on Packaging and Transportation of Radioactive Materials, Yokohama City, Japan, 13B1 8 September 1992, Yokohama City, Japan (1992).

6. M. C. Brady and T. L. Sanders, "A Validated Methodology for Evaluating Burnup Credit in Spent Fuel Casks," Proc. International Conference on Nuclear Criticality Safety, Christ Church, Oxford, United Kingdom, September 9B13, 1991.

7. M. C. Brady, C. V. Parks, and C. R. Marotta, "End Effects in the Criticality Analysis of Burnup Credit Casks," Trans. Am. Nucl Soc. 62, 317 (November 1990).

8. M. Takano, Burnup Credit Criticality Benchmark, Phase II-A, Effect of Axial Burnup Profile (Infinite Fuel Pin Array in Water), Preliminary Results, July 11B13, 1994, Japanese Atomic Energy Research Institute, 1994.

9. R. J. Cacciapouti and S. Van Volkinburg, Axial Profile Database for the Combustion Engineering $14 \times 14$ Fuel Design, YAEC-1918, Yankee Atomic Electric Company, April 1995.

10. SCALE: A Modular Code System for Performing Standardized Computer Analyses for Licensing Evaluation, NUREG/CR-0200, Rev. 4 (ORNL/NUREG/CSD-2/R4), Vols. I, II, and III (April 1995). Available from Radiation Shielding Information Center as CCC-545.

11. O. W. Hermann and C. V. Parks, "SAS2H: A Coupled One-Dimensional Depletion and Shielding Analysis Code," Sect. S2 of SCALE: A Modular Code System for Performing Standardized Computer Analyses for Licensing Evaluation, NUREG/CR-0200, Rev. 4 
(ORNL/NUREG/CSD-2/R4), Vols. I, II, and III (April 1995). Available from Radiation Shielding Information Center as CCC-545.

12. N. F. Landers and L. M. Petrie, "CSAS: An Enhanced Criticality Safety Analysis Module with an Optimum Pitch Search Option," Sect. C4 of SCALE: A Modular Code System for Performing Standardized Computer Analyses for Licensing Evaluation, NUREG/CR-0200, Rev. 4 (ORNL/NUREG/CSD-2/R4), Vols. I, II, and III (April 1995). Available from Radiation Shielding Information Center as CCC-545.

13. O. W. Hermann and R. M. Westfall, "ORIGEN-S: A SCALE System Module to Calculate FuelDepletion, Actinide Transmutation, Fission Product Buildup and Decay, and Associated Radiation Source Terms," Sect. F7 of SCALE: A Modular Code System for Performing Standardized Computer Analyses for Licensing Evaluation, NUREG/CR-0200, Rev. 4 (ORNL/NUREG/CSD2/R4), Vols. I, II, and III (April 1995). Available from Radiation Shielding Information Center as CCC-545.

14. N. M. Greene and L. M. Petrie, "XSDRNPM: A One-Dimensional Discrete-Ordinates Code for Transport Analysis," Sect. F3 of SCALE: A Modular Code System for Performing Standardized Computer Analyses for Licensing Evaluation, NUREG/CR-0200, Rev. 4 (ORNL/NUREG/CSD2/R4), Vols. I, II, and III (April 1995). Available from Radiation Shielding Information Center as CCC-545.

15. L. M. Petrie and N. F. Landers, "KENO V.a: An Improved Monte Carlo Criticality Program with Supergrouping," Sect. F11 of SCALE: A Modular Code System for Performing Standardized Computer Analyses for Licensing Evaluation, NUREG/CR-0200, Rev. 4 (ORNL/NUREG/CSD2/R4), Vols. I, II, and III (April 1995). Available from Radiation Shielding Information Center as CCC-545.

16. N. M. Greene, "BONAMI: Resonance Self-Shielding by the Bondarenko Method," Sect. F1 of SCALE: A Modular Code System for Performing Standardized Computer Analyses for Licensing Evaluation, NUREG/CR-0200, Rev. 4 (ORNL/NUREG/CSD-2/R4), Vols. I, II, and III (April 1995). Available from Radiation Shielding Information Center as CCC-545.

17. N. M. Greene, "NITAWL-II: SCALE System Module for Performing Resonance Shielding and Working Library Production," Sect. F2 of SCALE: A Modular Code System for Performing Standardized Computer Analyses for Licensing Evaluation, NUREG/CR-0200, Rev. 4 (ORNL/NUREG/CSD-2/R4), Vols. I, II, and III (April 1995). Available from Radiation Shielding Information Center as CCC-545.

18. O. W. Hermann, "COUPLE: SCALE System Module to Process Problem-Dependent Cross Sections and Neutron Spectral Data for ORIGEN-S Analyses," Sect. F6 of SCALE: A Modular Code System for Performing Standardized Computer Analyses for Licensing Evaluation, 
NUREG/CR-0200, Rev. 4 (ORNL/NUREG/CSD-2/R4), Vols. I, II, and III (April 1995). Available from Radiation Shielding Information Center as CCC-545.

19. B. H. Wakeman and S. A. Ahmed, Evaluation of Burnup Credit for Dry Storage Casks, EPRI NP6494, Electric Power Research Institute, August 1989.

20. D. G. Napolitano and D. G. Adli, Burnup Credit Criticality Analysis Using Advanced Nodal Techniques, Yankee Atomic Electric Co., March 1992.

21. N. F. Landers et al., "The Material Information Processor for SCALE," Sect. M7 of SCALE: A Modular Code System for Performing Standardized Computer Analyses for Licensing Evaluation, NUREG/CR-0200, Rev. 4 (ORNL/NUREG/CSD-2/R4), Vols. I, II, and III (April 1995). Available from Radiation Shielding Information Center as CCC-545.

22. N. M. Greene et al., AMPX-77: A Modular Code System for Generating Coupled Multigroup Neutron-Gamma Cross-Section Libraries from ENDF/B-IV and/or ENDF/B-V, ORNL/CSD/TM283, Martin Marietta Energy Systems, Inc., Oak Ridge Natl. Lab., 1992.

23. N. M. Greene, "User's Guide for Utility Modules," Sect. M15 of SCALE: A Modular Code System for Performing Standardized Computer Analyses for Licensing Evaluation, NUREG/CR-0200, Rev. 4 (ORNL/NUREG/CSD-2/R4), Vols. I, II, and III (April 1995). Available from Radiation Shielding Information Center as CCC-545.

24. B. L. Broadhead et al., Investigation of Nuclide Importance to Functional Requirements Related to Transport and Long-Term Storage of LWR Spent Fuel, ORNL/TM-12742, Martin Marietta Energy Systems Inc., Oak Ridge Natl. Lab., 1995.

25. O. W. Hermann et al., Validation of the SCALE System for PWR Spent Fuel Isotopic Composition Analyses, ORNL/TM-12667, Martin Marietta Energy Systems, Inc., Oak Ridge Natl. Lab., 1995.

26 S. R. Bierman and R. J. Talbert, Benchmark Data for Validating Irradiated Fuel Compositions Used in Criticality Calculations, PNL-10045 (UC-722), Pacific Northwest Laboratory, 1994.

27. M. D. DeHart and S. M. Bowman, Validation of the SCALE Broad Structure 44-Group ENDF/B$V$ Cross-Section Library for Use in Criticality Safety Analyses, NUREG/CR-6102 (ORNL/TM12460), Martin Marietta Energy Systems, Inc., Oak Ridge Natl. Lab., 1994.

28. R. W. Leary and T. A. Parish, "Reactivity Effects of Nonuniform Axial Burnup Distributions on Spent Fuel," pp. 544B547 in Proc. 6th Annual International Conference on High Level Radioactive Waste Management, April 30BMay 5, 1995, Las Vegas, Nevada, (1995). 
29. S. M. Bowman et al., SCALE-4 Analysis of Pressurized Water Reactor Critical Configurations: Volume 2 - Sequoyah Unit 2 Cycle 3, ORNL/TM-12294/V2, Martin Marietta Energy Systems, Inc., Oak Ridge Natl. Lab., 1995.

30. S. M. Bowman and O. W. Hermann, SCALE-4 Analysis of Pressurized Water Reactor Critical Configurations: Volume 3 - Surry Unit 1 Cycle 2, ORNL/TM-12294/V3, Martin Marietta Energy Systems, Inc., Oak Ridge Natl. Lab., 1995.

31. Multi-Purpose Canister (MPC) Implementation Program Conceptual Design Phase Report, A20000000-00811-5705-00001 Rev 00, U.S. Department of Energy Office of Civilian Radioactive Waste Management, Washington, D.C., 1994.

32. Multi-Purpose Canister System Evaluation, DOE/RW-0445, U.S. Department of Energy Office of Civilian Radioactive Waste Management, Washington, D.C., 1994. 


\section{APPENDIX A}

ISOTOPIC RANKINGS BY ABSORPTION FRACTIONS 
3.0 wt \% U-235, 10 GWd/MTU Burnup

\begin{tabular}{lccccc} 
& \multicolumn{4}{c}{ Cooling time $(y)$} \\
& 0 & 5 & 10 & 15 & 30 \\
Productions & $7.535 \mathrm{E}+4$ & $7.527 \mathrm{E}+4$ & $7.498 \mathrm{E}+4$ & $7.476 \mathrm{E}+4$ & $7.434 \mathrm{E}+4$ \\
Absorptions & $5.869 \mathrm{E}+4$ & $5.716 \mathrm{E}+4$ & $5.714 \mathrm{E}+4$ & $5.711 \mathrm{E}+4$ & $5.704 \mathrm{E}+4$ \\
k-infinity & $1.284 \mathrm{E}+0$ & $1.317 \mathrm{E}+0$ & $1.312 \mathrm{E}+0$ & $1.309 \mathrm{E}+0$ & $1.303 \mathrm{E}+0$ \\
Act. abs & $5.332 \mathrm{E}+4$ & $5.315 \mathrm{E}+4$ & $5.310 \mathrm{E}+4$ & $5.306 \mathrm{E}+4$ & $5.298 \mathrm{E}+4$ \\
Non-actinide & & & & \\
Abs. fraction & $9.161 \mathrm{E}-2$ & $7.013 \mathrm{E}-2$ & $7.061 \mathrm{E}-2$ & $7.091 \mathrm{E}-2$ & $7.118 \mathrm{E}-2$
\end{tabular}

Fraction of total absorption rate - actinides

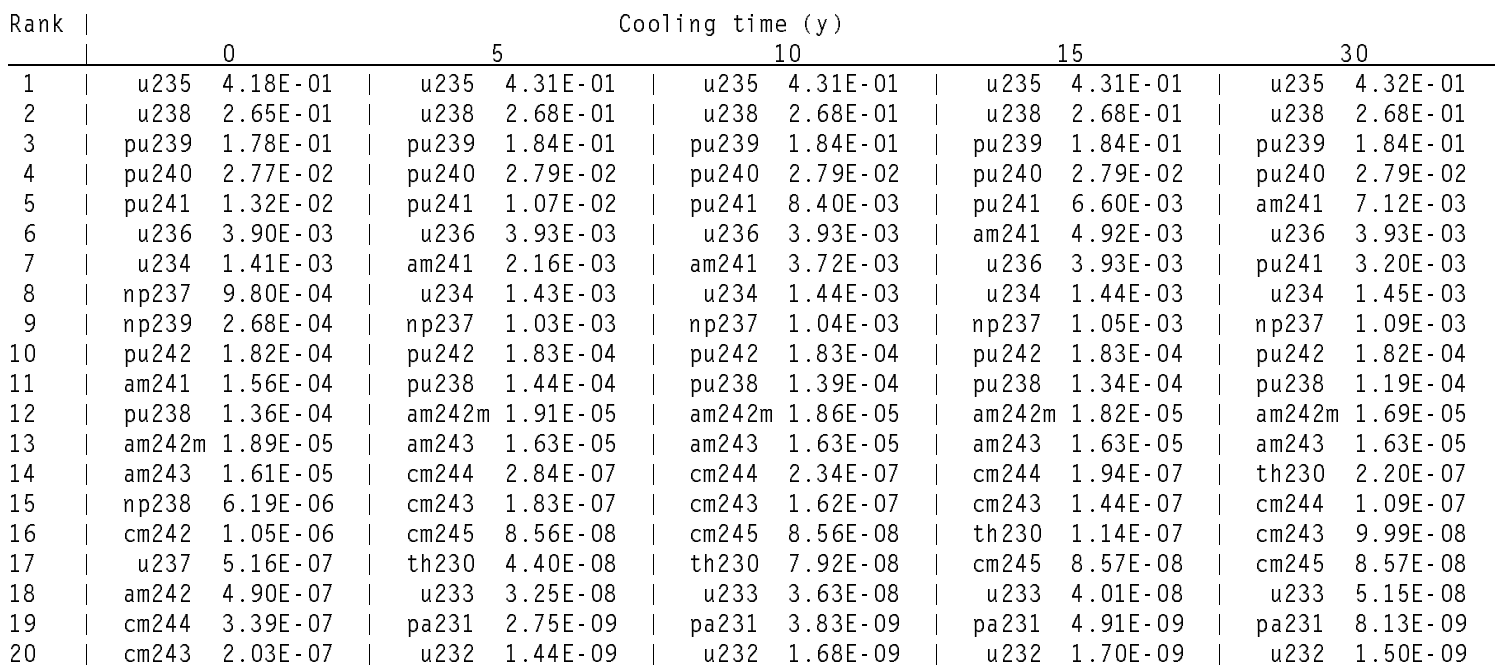

Fraction of total absorption rate - fission products

\begin{tabular}{|c|c|c|c|c|c|c|c|c|c|c|c|c|c|c|}
\hline \multicolumn{15}{|c|}{ Cooling time $(y)$} \\
\hline Rank & & 0 & & & 5 & & & 10 & & & 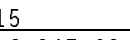 & & & 30 \\
\hline 1 & $x e 135$ & $2.47 \mathrm{E}-02$ & & sm149 & $9.33 \mathrm{E}-03$ & & sm149 & $9.33 \mathrm{E}-03$ & & sm149 & $9.34 \mathrm{E}-03$ & & sm149 & $9.35 \mathrm{E}-03$ \\
\hline 2 & sm149 & $6.92 \mathrm{E}-03$ & | & nd143 & $5.38 \mathrm{E}-03$ & & nd143 & $5.39 \mathrm{E}-03$ & & nd143 & $5.39 \mathrm{E}-03$ & & nd143 & $5.40 \mathrm{E}-03$ \\
\hline 3 & nd143 & $4.99 \mathrm{E}-03$ & | & sm151 & $4.54 \mathrm{E}-03$ & & sm151 & $4.37 \mathrm{E}-03$ & & rh103 & $4.23 \mathrm{E}-03$ & & gd 155 & $4.25 \mathrm{E}-03$ \\
\hline 4 & sm151 & $4.49 \mathrm{E}-03$ & | & rh103 & $4.24 \mathrm{E}-03$ & & rh103 & $4.23 \mathrm{E}-03$ & & sm151 & $4.21 \mathrm{E}-03$ & & h103 & $4.23 \mathrm{E}-03$ \\
\hline 5 & rh103 & $3.60 \mathrm{E}-03$ & | & xe131 & $2.40 \mathrm{E}-03$ & & gd155 & $3.32 \mathrm{E}-03$ & & $\operatorname{gd} 155$ & $3.83 \mathrm{E}-03$ & & m151 & $3.76 \mathrm{E}-03$ \\
\hline 6 & pm147 & $2.89 \mathrm{E}-03$ & | & gd155 & $2.26 \mathrm{E}-03$ & & xe131 & 2. $40 \mathrm{E}-03$ & & xe131 & 2. $40 \mathrm{E}-03$ & & xe131 & 2. $40 \mathrm{E}-03$ \\
\hline 7 & xe131 & $2.30 \mathrm{E}-03$ & | & $\operatorname{cs} 133$ & $2.21 \mathrm{E}-03$ & & $\operatorname{cs} 133$ & $2.22 \mathrm{E}-03$ & & $\operatorname{cs} 133$ & $2.22 \mathrm{E}-03$ & & $\operatorname{cs} 133$ & $2.22 \mathrm{E}-03$ \\
\hline 8 & cs133 & 2. $15 \mathrm{E}-03$ & | & tc 99 & $1.71 \mathrm{E}-03$ & & tc 99 & $1.71 \mathrm{E}-03$ & & tc 99 & $1.71 \mathrm{E}$ & & 99 & 1. $71 \mathrm{E}-03$ \\
\hline 9 & tc 99 & $1.68 \mathrm{E}-03$ & | & sm152 & $1.50 \mathrm{E}-03$ & & sm152 & $1.50 \mathrm{E}-03$ & & sm152 & $1.50 \mathrm{E}-03$ & & sm152 & $1.50 \mathrm{E}-03$ \\
\hline 10 & sm152 & $1.48 \mathrm{E}-03$ & | & sm147 & $1.06 \mathrm{E}-03$ & & sm147 & $1.29 \mathrm{E}-03$ & & sm147 & 1.35 & & sm147 & $1.37 \mathrm{E}-03$ \\
\hline 11 & pm148m & $1.16 \mathrm{E}-03$ & | & nd145 & $1.04 \mathrm{E}-03$ & & nd145 & $1.04 \mathrm{E}-03$ & & nd145 & 1.04 & & 145 & $1.04 \mathrm{E}-03$ \\
\hline 12 & nd145 & 1.02E-03 & | & pm147 & $8.39 \mathrm{E}-04$ & & mo 95 & $7.66 \mathrm{E}-04$ & & mo 95 & $7.66 \mathrm{~B}$ & & mo 95 & $7.67 \mathrm{E}-04$ \\
\hline 13 & eu153 & $7.15 \mathrm{E}-04$ & | & mo 95 & 7.6 & & eu153 & $7.37 \mathrm{E}-04$ & & eu153 & 7.3 & & $\Lambda 151$ & 7. $43 \mathrm{E}-04$ \\
\hline 14 & sm150 & $6.37 \mathrm{E}-04$ & | & eu153 & $7.37 \mathrm{E}-04$ & & sm150 & $6.50 \mathrm{E}-04$ & & sm150 & $6.50 \mathrm{~B}$ & & $\Lambda 153$ & $7.38 \mathrm{E}-04$ \\
\hline 15 & mo 95 & $5.51 \mathrm{E}-04$ & | & sm150 & $6.49 \mathrm{E}-04$ & & ru101 & $4.31 \mathrm{E}-04$ & & ru101 & 4.3 & & $\mathrm{~m} 150$ & $6.50 \mathrm{E}-04$ \\
\hline 16 & eu155 & $4.31 \mathrm{E}-04$ & | & ru101 & 4.3 & & ag109 & $4.09 \mathrm{E}$ & & 09 & & & 101 & \\
\hline 17 & ru101 & $4.29 \mathrm{E}-04$ & | & a g109 & $4.09 \mathrm{E}-04$ & & kr 83 & $3.39 \mathrm{E}-04$ & & eu151 & $3.96 \mathrm{E}-04$ & & g109 & $4.09 \mathrm{E}-04$ \\
\hline 18 & rh105 & $4.14 \mathrm{E}-04$ & | & $\mathrm{kr} 83$ & $3.39 \mathrm{E}-04$ & & pr141 & $2.81 \mathrm{E}-04$ & & $\mathrm{kr} 83$ & $3.39 \mathrm{E}-04$ & & r 83 & $3.40 \mathrm{E}-04$ \\
\hline 19 & ag109 & $4.03 \mathrm{E}-04$ & & pr141 & 2.8 & & & 2.71 & & pr141 & & & 141 & -04 \\
\hline 20 & $\mathrm{kr} 83$ & $3.29 \mathrm{E}-04$ & | & gd157 & 2.28 & & 57 & $2.28 \mathrm{E}-04$ & & $\operatorname{gd} 157$ & 2.28 & & dd 157 & $2.29 E-04$ \\
\hline 21 & pr141 & $2.49 \mathrm{E}-04$ & | & la139 & $2.21 \mathrm{E}-04$ & & pm147 & $2.26 \mathrm{E}-04$ & & la139 & $2.21 \mathrm{E}-04$ & & Ta139 & $2.21 \mathrm{E}-04$ \\
\hline 22 & eu154 & $2.45 \mathrm{E}-04$ & & eu155 & 2.1 & & 1a139 & $2.21 \mathrm{E}-04$ & & pd105 & $2.09 \mathrm{E}-04$ & & 105 & $2.09 \mathrm{E}-04$ \\
\hline 23 & la139 & $2.15 \mathrm{E}-04$ & & pd105 & 2.0 & & & $2.09 \mathrm{E}-04$ & & 13 & & & 113 & $2.03 E-04$ \\
\hline 24 & sm147 & $2.08 \mathrm{E}-04$ & | & $\operatorname{cd} 113$ & $2.02 \mathrm{E}-04$ & & $\operatorname{cd} 113$ & $2.02 \mathrm{E}-04$ & & $\operatorname{cs} 135$ & 1. $90 \mathrm{E}-04$ & & $\operatorname{cs} 135$ & $1.90 \mathrm{E}-04$ \\
\hline 25 & pd105 & $2.04 \mathrm{E}-04$ & | & $\operatorname{cs} 135$ & $1.90 \mathrm{E}-04$ & & $\operatorname{cs} 135$ & $1.90 \mathrm{E}-04$ & & zr 93 & $1.54 \mathrm{E}-04$ & & zr 93 & $1.54 \mathrm{E}-04$ \\
\hline 26 & gd157 & $1.96 \mathrm{E}-04$ & & eu154 & $1.68 \mathrm{E}-04$ & & zr 93 & $1.54 \mathrm{E}-04$ & & mo 97 & & & mo 97 & 1.11E-04 \\
\hline 27 & $\mathrm{~cd} 113$ & $1.92 \mathrm{E}-04$ & | & zr 93 & $1.54 \mathrm{E}-04$ & & eu154 & 1.12E-04 & & $i 129$ & 9.55 & & $i 129$ & $9.56 \mathrm{E}-05$ \\
\hline 28 & $\operatorname{cs} 135$ & $1.87 \mathrm{E}-04$ & $\mid$ & eu151 & $1.41 \mathrm{E}-04$ & & mo 97 & $1.11 \mathrm{E}-04$ & & pd108 & $9.51 \mathrm{E}-05$ & & pd 108 & $9.51 \mathrm{E}-05$ \\
\hline 29 & pm148 & $1.86 \mathrm{E}-04$ & & mo 97 & 1.1 & & eu155 & $1.01 \mathrm{E}-04$ & & nd144 & $8.73 \mathrm{E}-05$ & & nd 144 & $8.74 \mathrm{E}-05$ \\
\hline 30 & zr 93 & $1.53 \mathrm{E}-04$ & 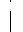 & $i 129$ & $9.54 \mathrm{E}-05$ & & $¡ 129$ & $9.54 \mathrm{E}-05$ & & eu154 & 7. $49 \mathrm{E}-05$ & & pd107 & $6.33 \mathrm{E}-05$ \\
\hline
\end{tabular}


3. wt \% U-235, 3ø GWd/MTU Burnup

\begin{tabular}{lccccc} 
& \multicolumn{5}{c}{ Cooling time $(y)$} \\
& 0 & 5 & 10 & 15 & 30 \\
Productions & $6.400 \mathrm{E}+4$ & $6.240 \mathrm{E}+4$ & $6.098 \mathrm{E}+4$ & $5.987 \mathrm{E}+4$ & $5.776 \mathrm{E}+4$ \\
Absorptions & $5.878 \mathrm{E}+4$ & $5.744 \mathrm{E}+4$ & $5.744 \mathrm{E}+4$ & $5.734 \mathrm{E}+4$ & $5.695 \mathrm{E}+4$ \\
k-infinity & $1.089 \mathrm{E}+0$ & $1.086 \mathrm{E}+0$ & $1.062 \mathrm{E}+0$ & $1.044 \mathrm{E}+0$ & $1.014 \mathrm{E}+0$ \\
Act. abs & $5.030 \mathrm{E}+4$ & $4.988 \mathrm{E}+4$ & $4.964 \mathrm{E}+4$ & $4.942 \mathrm{E}+4$ & $4.895 \mathrm{E}+4$ \\
Non-actinide & & & & & \\
Abs. fraction & $1.442 \mathrm{E}-1$ & $1.317 \mathrm{E}-1$ & $1.358 \mathrm{E}-1$ & $1.381 \mathrm{E}-1$ & $1.404 \mathrm{E}-1$
\end{tabular}

\begin{tabular}{|c|c|c|c|c|c|c|c|c|c|c|c|}
\hline \multirow[t]{2}{*}{ Rank } & \multicolumn{11}{|c|}{$\begin{array}{c}\text { Fraction of total absorption rate - actinides } \\
\text { Cooling time }(y)\end{array}$} \\
\hline & & 0 & & 5 & & & 10 & & 15 & & 30 \\
\hline 1 & 1239 & $2.66 \mathrm{E}-01$ & & 239 & $2.73 \mathrm{E}-01$ & pu239 & $2.73 \mathrm{E}-01$ & 4239 & $2.74 \mathrm{E}-01$ & 4239 & $2.75 \mathrm{E}-01$ \\
\hline 2 & 4238 & $2.62 \mathrm{E}-01$ & i & & $65 \mathrm{E}-01$ & & & u238 & $2.65 \mathrm{E}-01$ & u238 & \\
\hline 3 & 35 & $1.78 \mathrm{E}-01$ & r & 35 & $1.82 \mathrm{E}-01$ & u235 & $1.82 \mathrm{E}-01$ & u235 & $1.82 \mathrm{E}-01$ & u235 & $1.84 \mathrm{E}-01$ \\
\hline 4 & pu240 & $6.49 \mathrm{E}-02$ & i & pu240 & $6.55 \mathrm{E}-02$ & pu240 & $6.54 \mathrm{E}-02$ & pu240 & $6.54 \mathrm{E}-02$ & pu240 & $6.55 \mathrm{E}-02$ \\
\hline 5 & 41 & $6.4 \varepsilon$ & i & & -02 & 41 & 4. & 41 & 3. & 41 & 02 \\
\hline 6 & 36 & 6.71 & 1 & 41 & 02 & 41 & & 241 & 2.4 & 1241 & \\
\hline 7 & p237 & $4.33 \mathrm{E}-03$ & r & u236 & $6.77 \mathrm{E}-03$ & 1236 & 6.7 & u236 & 6.78 & u236 & -03 \\
\hline 8 & 12 & 3.0 & i & & 4. & & & 37 & & 37 & \\
\hline 9 & 38 & 2.08 & & & 03 & & & & & 42 & \\
\hline 10 & 241 & $1.89 \mathrm{E}-03$ & i & pu238 & $2.27 \mathrm{E}-03$ & 38 & 2.1 & 38 & 2. & 2438 & $1.89 \mathrm{E}-03$ \\
\hline & | & 1.0 & t & & & & & & & 34 & \\
\hline 12 & | & 1.02 & & & 1. & 3 & & 43 & 1. & 243 & 1. \\
\hline 13 & $a m 242 m$ & $3.66 \mathrm{E}-04$ & t & $a m 242 m$ & $3.66 \mathrm{E}-04$ & $\mathrm{am} 242 \mathrm{~m}$ & $3.57 \mathrm{E}-04$ & $a m 242 m$ & $3.49 \mathrm{E}-04$ & $a m 242 m$ & $3.27 \mathrm{E}-04$ \\
\hline 14 & | & 3.21 & & & & & & & & & \\
\hline 15 & | & 8.15 & & & 5.6 & & & & 05 & 44 & 2 \\
\hline 16 & $\mathrm{~cm} 245$ & $5.48 \mathrm{E}-05$ & | & $\mathrm{cm} 243$ & $1.59 \mathrm{E}-05$ & $\mathrm{~cm} 243$ & $1.41 \mathrm{E}-05$ & $\mathrm{~cm} 243$ & $1.25 \mathrm{E}-05$ & $\mathrm{~cm} 243$ & $8.71 \mathrm{E}-06$ \\
\hline 17 & | np238 & 3.3 & & $\mathrm{~cm} 246$ & $1.06 \mathrm{E}-07$ & $\mathrm{~cm} 246$ & & $\mathrm{~cm} 246$ & & $\operatorname{th} 230$ & \\
\hline 18 & & & & & 7.0 & & & & 1.0 & u233 & $156 \mathrm{~F}$ \\
\hline 19 & $\mathrm{~cm} 243$ & $1.77 \mathrm{E}-05$ & & $\operatorname{th} 230$ & $4.07 \mathrm{E}-08$ & th230 & $6.70 \mathrm{E}-08$ & th230 & $9.42 \mathrm{E}-08$ & $\mathrm{~cm} 246$ & $1.05 \mathrm{E}-07$ \\
\hline 20 & $\operatorname{am} 242$ & $6.96 \mathrm{E}-06$ & & $\mathrm{~cm} 247$ & $2.56 \mathrm{E}-08$ & $\mathrm{~cm} 247$ & $2.56 \mathrm{E}-08$ & $\mathrm{~cm} 247$ & $2.56 \mathrm{E}-08$ & $\mathrm{~cm} 247$ & $2.56 \mathrm{E}-08$ \\
\hline
\end{tabular}

Fraction of total absorption rate - fission products

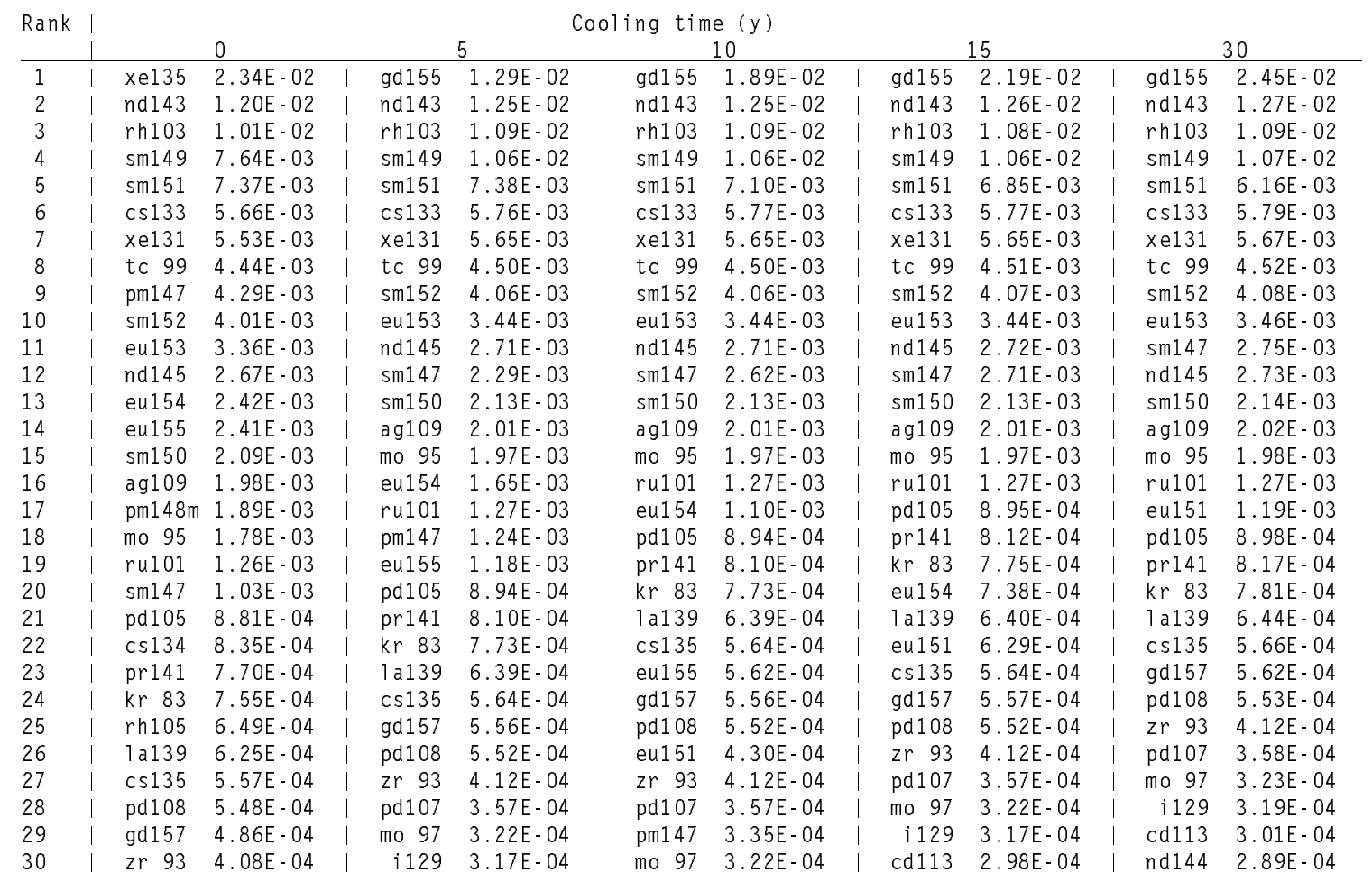




\section{2}

3. wt \% U-235, 50 GWd/MTU Burnup

\begin{tabular}{lccccc} 
& \multicolumn{4}{c}{ Cooling time $(y)$} \\
& 0 & 5 & 10 & 15 & 30 \\
Productions & $5.531 \mathrm{E}+4$ & $5.301 \mathrm{E}+4$ & $5.104 \mathrm{E}+4$ & $4.948 \mathrm{E}+4$ & $4.650 \mathrm{E}+4$ \\
Absorptions & $5.796 \mathrm{E}+4$ & $5.757 \mathrm{E}+4$ & $5.791 \mathrm{E}+4$ & $5.791 \mathrm{E}+4$ & $5.744 \mathrm{E}+4$ \\
k-infinity & $9.543 \mathrm{E}-1$ & $9.208 \mathrm{E}-1$ & $8.814 \mathrm{E}-1$ & $8.544 \mathrm{E}-1$ & $8.095 \mathrm{E}-1$ \\
Act. abs & $4.723 \mathrm{E}+4$ & $4.690 \mathrm{E}+4$ & $4.663 \mathrm{E}+4$ & $4.636 \mathrm{E}+4$ & $4.570 \mathrm{E}+4$ \\
Non-actinide & & & & & \\
Abs. fraction & $1.851 \mathrm{E}-1$ & $1.854 \mathrm{E}-1$ & $1.946 \mathrm{E}-1$ & $1.994 \mathrm{E}-1$ & $2.044 \mathrm{E}-1$
\end{tabular}

Fraction of total absorption rate - actinides

\begin{tabular}{|c|c|c|c|c|c|c|c|c|c|c|c|}
\hline \multirow[t]{2}{*}{ Rank } & \multicolumn{11}{|c|}{ Cooling time $(y)$} \\
\hline & & 0 & & 5 & 5 & & 10 & & 15 & & 30 \\
\hline 1 & pu239 & $2.79 \mathrm{E}-01$ & & pu239 & $2.83 \mathrm{E}-01$ & pu239 & $2.81 \mathrm{E}-01$ & pu239 & $2.81 \mathrm{E}-01$ & pu239 & $2.83 \mathrm{E}-01$ \\
\hline 2 & u238 & $2.59 \mathrm{E}-01$ & | & u238 & $2.60 \mathrm{E}-01$ & u238 & $2.59 \mathrm{E}-01$ & u238 & $2.59 \mathrm{E}-01$ & u238 & $2.60 \mathrm{E}-01$ \\
\hline 3 & pu241 & $9.25 \mathrm{E}-02$ & | & pu240 & $8.18 \mathrm{E}-02$ & pu240 & $8.18 \mathrm{E}-02$ & pu240 & $8.20 \mathrm{E}-02$ & pu240 & $8.27 \mathrm{E}-02$ \\
\hline 4 & pu240 & $8.11 \mathrm{E}-02$ & | & pu241 & $7.31 \mathrm{E}-02$ & u235 & $6.50 \mathrm{E}-02$ & u235 & $6.50 \mathrm{E}-02$ & u235 & $6.57 \mathrm{E}-02$ \\
\hline 5 & u235 & $6.50 \mathrm{E}-02$ & | & u235 & $6.54 \mathrm{E}-02$ & pu241 & $5.71 \mathrm{E}-02$ & pu241 & $4.48 \mathrm{E}-02$ & $\operatorname{am} 241$ & $4.79 \mathrm{E}-02$ \\
\hline 6 & np237 & $7.43 \mathrm{E}-03$ & । & $\operatorname{am} 241$ & $1.62 \mathrm{E}-02$ & $\operatorname{am} 241$ & $2.61 \mathrm{E}-02$ & $\operatorname{am} 241$ & $3.38 \mathrm{E}-02$ & pu241 & $2.19 \mathrm{E}-02$ \\
\hline 7 & u236 & $7.27 \mathrm{E}-03$ & | & np237 & $7.55 \mathrm{E}-03$ & np237 & $7.56 \mathrm{E}-03$ & np237 & $7.63 \mathrm{E}-03$ & np237 & $7.96 \mathrm{E}-03$ \\
\hline 8 & pu242 & $6.83 \mathrm{E}-03$ & 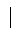 & u236 & $7.31 \mathrm{E}-03$ & u236 & $7.31 \mathrm{E}-03$ & u236 & $7.32 \mathrm{E}-03$ & u236 & 7.33E-03 \\
\hline 9 & pu238 & $6.42 \mathrm{E}-03$ & I & pu242 & $6.85 \mathrm{E}-03$ & I pu242 & $6.84 \mathrm{E}-03$ & pu242 & $6.83 \mathrm{E}-03$ & pu242 & $6.82 \mathrm{E}-03$ \\
\hline 10 & $\operatorname{am} 243$ & $4.26 \mathrm{E}-03$ & | & pu238 & $6.70 \mathrm{E}-03$ & pu238 & $6.39 \mathrm{E}-03$ & pu238 & $6.14 \mathrm{E}-03$ & pu238 & $5.52 \mathrm{E}-03$ \\
\hline 11 & $\operatorname{am} 241$ & $3.21 \mathrm{E}-03$ & 1 & am243 & $4.27 \mathrm{E}-03$ & $\operatorname{am} 243$ & $4.25 \mathrm{E}-03$ & $\operatorname{am} 243$ & $4.25 \mathrm{E}-03$ & $\operatorname{am} 243$ & $4.25 \mathrm{E}-03$ \\
\hline 12 & u234 & $7.21 \mathrm{E}-04$ & | & u234 & $8.34 \mathrm{E}-04$ & u234 & $9.36 \mathrm{E}-04$ & u234 & $1.04 \mathrm{E}-03$ & u234 & $1.32 \mathrm{E}-03$ \\
\hline 13 & am242m & $6.72 \mathrm{E}-04$ & 1 & $a m 242 m$ & $6.60 \mathrm{E}-04$ & am242m & $6.39 \mathrm{E}-04$ & $\mathrm{~cm} 245$ & $6.25 \mathrm{E}-04$ & $\mathrm{~cm} 245$ & $6.30 \mathrm{E}-04$ \\
\hline 14 & $\mathrm{~cm} 244$ & $6.49 \mathrm{E}-04$ & 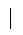 & $\mathrm{cm} 245$ & $6.30 \mathrm{E}-04$ & $\mathrm{~cm} 245$ & $6.25 \mathrm{E}-04$ & $a m 242 m$ & $6.24 \mathrm{E}-04$ & $a m 242 m$ & $5.85 \mathrm{E}-04$ \\
\hline 15 & $\mathrm{~cm} 245$ & $6.26 \mathrm{E}-04$ & 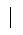 & $\mathrm{cm} 244$ & $5.43 \mathrm{E}-04$ & $\mathrm{~cm} 244$ & $4.50 \mathrm{E}-04$ & $\mathrm{~cm} 244$ & $3.73 \mathrm{E}-04$ & $\mathrm{~cm} 244$ & $2.12 \mathrm{E}-04$ \\
\hline 16 & np239 & $3.62 \mathrm{E}-04$ & | & $\mathrm{cm} 243$ & $5.29 \mathrm{E}-05$ & $\mathrm{~cm} 243$ & $4.67 \mathrm{E}-05$ & $\mathrm{~cm} 243$ & $4.13 \mathrm{E}-05$ & $\mathrm{~cm} 243$ & $2.88 \mathrm{E}-05$ \\
\hline 17 & $\mathrm{~cm} 242$ & $6.86 \mathrm{E}-05$ & | & $\mathrm{cm} 246$ & $2.53 \mathrm{E}-06$ & $\mathrm{~cm} 246$ & $2.52 \mathrm{E}-06$ & $\mathrm{~cm} 246$ & $2.52 \mathrm{E}-06$ & $\mathrm{~cm} 246$ & $2.51 \mathrm{E}-06$ \\
\hline 18 & np238 & $6.63 \mathrm{E}-05$ & | & $\mathrm{cm} 247$ & $1.06 \mathrm{E}-06$ & $\mathrm{~cm} 247$ & $1.06 \mathrm{E}-06$ & $\mathrm{~cm} 247$ & $1.06 \mathrm{E}-06$ & $\mathrm{~cm} 247$ & $1.06 \mathrm{E}-06$ \\
\hline 19 & $\mathrm{~cm} 243$ & $5.95 \mathrm{E}-05$ & | & u233 & $8.74 \mathrm{E}-08$ & u233 & $1.15 \mathrm{E}-07$ & u233 & $1.44 \mathrm{E}-07$ & u233 & $2.31 \mathrm{E}-07$ \\
\hline 20 & $\operatorname{am} 242$ & $1.36 \mathrm{E}-05$ & | & u232 & $6.86 \mathrm{E}-08$ & u232 & $7.75 \mathrm{E}-08$ & u232 & $7.74 \mathrm{E}-08$ & $\operatorname{th} 230$ & $1.63 \mathrm{E}-07$ \\
\hline
\end{tabular}

Fraction of total absorption rate - fission products

\begin{tabular}{|c|c|c|c|c|c|c|c|c|c|c|c|c|c|c|}
\hline \multirow[t]{2}{*}{ Rank } & \multicolumn{14}{|c|}{ Cooling time $(y)$} \\
\hline & & 0 & & & 5 & & & 10 & & & 15 & & & 30 \\
\hline 1 & $x e 135$ & $2.20 \mathrm{E}-02$ & | & gd155 & $2.94 \mathrm{E}-02$ & & gd155 & $4.27 \mathrm{E}-02$ & & gd155 & $4.92 \mathrm{E}-02$ & & gd155 & $5.51 \mathrm{E}-02$ \\
\hline 2 & nd143 & $1.55 \mathrm{E}-02$ & & nd143 & $1.58 \mathrm{E}-02$ & & nd143 & $1.57 \mathrm{E}-02$ & & nd143 & $1.57 \mathrm{E}-02$ & & d143 & $1.59 \mathrm{E}-02$ \\
\hline 3 & rh103 & $1.40 \mathrm{E}-02$ & | & rh103 & $1.48 \mathrm{E}-02$ & & rh103 & $1.47 \mathrm{E}-02$ & & rh103 & 1. $46 \mathrm{E}-02$ & & 103 & $1.46 \mathrm{E}-02$ \\
\hline 4 & sm151 & $9.62 \mathrm{E}-03$ & | & sm149 & $1.04 \mathrm{E}-02$ & & $\operatorname{sm} 149$ & $1.04 \mathrm{E}-02$ & & $\operatorname{sm} 149$ & $1.04 \mathrm{E}-02$ & & $\operatorname{sm} 149$ & $1.05 \mathrm{E}-02$ \\
\hline 5 & $\operatorname{cs} 133$ & $8.23 \mathrm{E}-03$ & | & sm151 & $9.38 \mathrm{E}-03$ & & sm151 & $8.94 \mathrm{E}-03$ & & sm151 & $8.60 \mathrm{E}-03$ & & $\operatorname{cs} 133$ & $8.33 \mathrm{E}-03$ \\
\hline 6 & sm149 & $7.43 \mathrm{E}-03$ & | & $\operatorname{cs} 133$ & $8.31 \mathrm{E}-03$ & & $\operatorname{cs} 133$ & $8.30 \mathrm{E}-03$ & & $\operatorname{cs133}$ & $8.30 \mathrm{E}-03$ & & m151 & $76 \mathrm{E}-03$ \\
\hline 7 & xe131 & $7.29 \mathrm{E}-03$ & i & xe131 & $7.37 \mathrm{E}-03$ & & xe131 & $7.35 \mathrm{E}-03$ & & xe131 & $7.35 \mathrm{E}-03$ & & xe131 & $7.37 \mathrm{E}-03$ \\
\hline 8 & tc 99 & $6.51 \mathrm{E}-03$ & 1 & tc 99 & $6.56 \mathrm{E}-03$ & & tc 99 & $6.55 \mathrm{E}-03$ & & tc 99 & $6.55 \mathrm{E}-03$ & & c 99 & $6.57 \mathrm{E}-03$ \\
\hline 9 & eu153 & $6.00 \mathrm{E}-03$ & | & eu153 & $6.06 \mathrm{E}-03$ & & eu153 & $6.03 \mathrm{E}-03$ & & eu153 & $6.03 \mathrm{E}-03$ & & u153 & $6.06 \mathrm{E}-03$ \\
\hline 10 & sm152 & $5.70 \mathrm{E}-03$ & 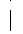 & sm152 & $5.74 \mathrm{E}-03$ & & sm152 & $5.73 \mathrm{E}-03$ & & $\operatorname{sm} 152$ & $5.73 \mathrm{E}-03$ & & sm152 & $5.75 \mathrm{E}-03$ \\
\hline 11 & eu154 & $5.60 \mathrm{E}-03$ & | & $n d 145$ & $3.95 \mathrm{E}-03$ & & nd145 & $3.93 \mathrm{E}-03$ & & nd145 & $3.93 \mathrm{E}-03$ & & nd145 & $3.95 \mathrm{E}-03$ \\
\hline 12 & eu155 & $5.54 \mathrm{E}-03$ & | & eu154 & 3.7 & & ag109 & $3.63 E-03$ & & ag109 & 3.6 & & 109 & $3.64 \mathrm{E}-03$ \\
\hline 13 & $\mathrm{pm} 147$ & $4.15 \mathrm{E}-03$ & 1 & ag109 & $3.63 \mathrm{E}-03$ & & sm150 & $3.41 \mathrm{E}-03$ & & sm150 & $3.41 \mathrm{E}-03$ & & sm150 & $3.43 \mathrm{E}-03$ \\
\hline 14 & nd145 & $3.93 \mathrm{E}-03$ & | & sm150 & $3.42 \mathrm{E}-03$ & & sm147 & $3.10 \mathrm{E}-03$ & & sm147 & 3.18 & & sm147 & $3.22 \mathrm{E}-03$ \\
\hline 15 & ag109 & $3.60 \mathrm{E}-03$ & | & mo 95 & 2.87 & & mo 95 & $2.86 \mathrm{E}-03$ & & mo 95 & $2 . \varepsilon$ & & 095 & E- 03 \\
\hline 16 & sm150 & $3.41 \mathrm{E}-03$ & i & sm147 & $2.79 \mathrm{E}-03$ & & eu154 & $2.49 \mathrm{E}-03$ & & ru101 & $2.05 \mathrm{E}-03$ & & ru101 & $2.05 \mathrm{E}-03$ \\
\hline 17 & mo 95 & $2.72 \mathrm{E}-03$ & | & eu155 & $2.66 \mathrm{E}-03$ & & ru101 & $2.05 \mathrm{E}-03$ & & pd105 & 1.7 & & d105 & $1.75 \mathrm{E}-03$ \\
\hline 18 & ru101 & $2.04 \mathrm{E}-03$ & 1 & ru101 & 2.0 & & $\mathrm{pd}$ & $1.74 \mathrm{E}-03$ & & 54 & 1. & & 151 & $1.49 \mathrm{E}-03$ \\
\hline 19 & $\mathrm{pm} 148 \mathrm{~m}$ & $1.89 \mathrm{E}-03$ & 1 & pd105 & $1.75 \mathrm{E}-03$ & & pr141 & $1.29 \mathrm{E}-03$ & & pr141 & $1.29 \mathrm{E}-03$ & & pr141 & $1.29 \mathrm{E}-03$ \\
\hline 20 & $\operatorname{cs} 134$ & $1.80 \mathrm{E}-03$ & i & pr141 & $1.29 \mathrm{E}-03$ & & eu155 & $1.26 \mathrm{E}-03$ & & pd108 & 1.17 & & pd 108 & $1.17 \mathrm{E}-03$ \\
\hline 21 & pd105 & $1.74 \mathrm{E}-03$ & | & pm147 & 1.1 & & pd108 & $1.17 \mathrm{E}-03$ & & 57 & & & 157 & $1.09 \mathrm{E}-03$ \\
\hline 22 & sm147 & $1.59 \mathrm{E}-03$ & | & pd108 & 1.17 & & $\operatorname{gd} 157$ & $1.08 \mathrm{E}-03$ & & 1a139 & $1.02 \mathrm{E}$ & & 7a139 & $1.03 \mathrm{E}-03$ \\
\hline 23 & pr141 & $1.26 \mathrm{E}-03$ & 1 & $\operatorname{gd} 157$ & $1.09 \mathrm{E}-03$ & & 1a139 & 1.02E-03 & & kr 83 & $9.58 \mathrm{E}-04$ & & $\mathrm{kr} 83$ & $9.66 \mathrm{E}-04$ \\
\hline 24 & pd108 & $1.17 \mathrm{E}-03$ & $\mid$ & la139 & 1.0 & & $\mathrm{kr} 83$ & $9.58 \mathrm{E}-04$ & & $\operatorname{cs} 135$ & & & $\operatorname{cs} 135$ & $9.15 \mathrm{E}-04$ \\
\hline 25 & la139 & $1.02 \mathrm{E}-03$ & | & kr 83 & 9.6 & & $\operatorname{cs} 135$ & $9.12 \mathrm{E}-04$ & & eu151 & 7.85 & & pd 107 & $7.73 \mathrm{E}-04$ \\
\hline 26 & gd157 & $9.95 \mathrm{E}-04$ & 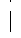 & $\operatorname{cs} 135$ & $9.15 \mathrm{E}-04$ & & pd107 & $7.70 \mathrm{E}-04$ & & pd107 & $7.70 \mathrm{E}-04$ & & zr 93 & $6.19 \mathrm{E}-04$ \\
\hline 27 & $\mathrm{kr} 83$ & $9.59 \mathrm{E}-04$ & $\mid$ & pd107 & $7.73 \mathrm{E}-04$ & & zr 93 & $6.18 \mathrm{E}-04$ & & $\operatorname{zr} 93$ & & & $i 129$ & $5.43 \mathrm{E}-04$ \\
\hline 28 & & $9.11 \mathrm{E}-04$ & & zr 93 & & & & $5.39 \mathrm{E}-04$ & & eu155 & $6.00 \mathrm{E}-04$ & & gd 154 & $5.38 \mathrm{E}-04$ \\
\hline 29 & rh105 & $7.87 \mathrm{E}-04$ & & $i 129$ & $5.42 \mathrm{E}-04$ & & eu151 & $5.37 \mathrm{E}-04$ & & $i 129$ & $5.39 \mathrm{E}-04$ & & mo 97 & $5.18 \mathrm{E}-04$ \\
\hline 30 & pd107 & $7.70 \mathrm{E}-04$ & & mo 97 & $5.18 \mathrm{E}-04$ & & mo 97 & $5.17 \mathrm{E}-04$ & & mo 97 & $5.16 \mathrm{E}-04$ & & nd144 & $5.15 \mathrm{E}-04$ \\
\hline
\end{tabular}


3.6 wt \% U-235, $10 \mathrm{GWd} / \mathrm{MTU}$ Burnup

\begin{tabular}{lccccc} 
& \multicolumn{4}{c}{ Cooling time $(y)$} \\
& 0 & 5 & 10 & 15 & 30 \\
Productions & $8.761 \mathrm{E}+4$ & $8.762 \mathrm{E}+4$ & $8.737 \mathrm{E}+4$ & $8.719 \mathrm{E}+4$ & $8.684 \mathrm{E}+4$ \\
Absorptions & $6.604 \mathrm{E}+4$ & $6.438 \mathrm{E}+4$ & $6.436 \mathrm{E}+4$ & $6.435 \mathrm{E}+4$ & $6.429 \mathrm{E}+4$ \\
k-infinity & $1.327 \mathrm{E}+0$ & $1.361 \mathrm{E}+0$ & $1.358 \mathrm{E}+0$ & $1.355 \mathrm{E}+0$ & $1.351 \mathrm{E}+0$ \\
Act. abs & $6.037 \mathrm{E}+4$ & $6.021 \mathrm{E}+4$ & $6.017 \mathrm{E}+4$ & $6.014 \mathrm{E}+4$ & $6.008 \mathrm{E}+4$ \\
Non-actinide & & & & \\
Abs. fraction & $8.582 \mathrm{E}-2$ & $6.477 \mathrm{E}-2$ & $6.510 \mathrm{E}-2$ & $6.533 \mathrm{E}-2$ & $6.552 \mathrm{E}-2$
\end{tabular}

Fraction of total absorption rate - actinides

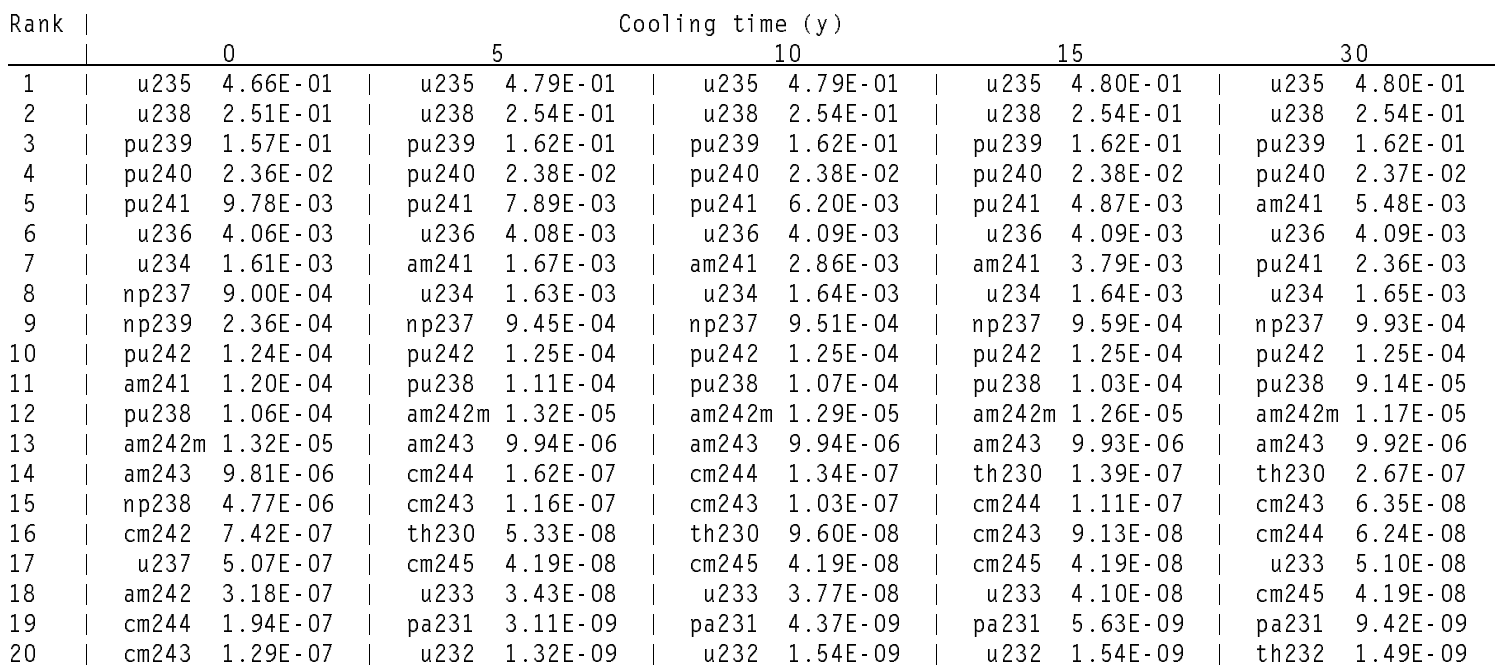

Fraction of total absorption rate - fission products

\begin{tabular}{|c|c|c|c|c|c|c|c|c|c|c|c|c|c|c|}
\hline \multirow[t]{2}{*}{ Rank } & \multicolumn{14}{|c|}{ Cooling time $(y)$} \\
\hline & & 0 & & & 5 & & & 10 & & & 15 & & & 30 \\
\hline 1 & $x e 135$ & $2.36 \mathrm{E}-02$ & | & $s m 149$ & $9.13 \mathrm{E}-03$ & & sm149 & $9.14 \mathrm{E}-03$ & & $\operatorname{sm149}$ & $9.14 \mathrm{E}-03$ & & $\operatorname{sm} 149$ & $9.15 \mathrm{E}-03$ \\
\hline 2 & $\operatorname{sm} 149$ & $7.06 \mathrm{E}-03$ & & nd143 & $4.80 \mathrm{E}-03$ & & nd143 & $4.80 \mathrm{E}-03$ & & nd143 & $4.80 \mathrm{E}-03$ & & nd 143 & $4.80 \mathrm{E}-03$ \\
\hline 3 & nd143 & $4.45 \mathrm{E}-03$ & | & sm151 & $4.32 \mathrm{E}-03$ & & sm151 & $4.16 \mathrm{E}-03$ & & sm151 & $4.00 \mathrm{E}-03$ & & 103 & $3.88 \mathrm{E}-03$ \\
\hline 4 & sm151 & $4.28 \mathrm{E}-03$ & | & rh103 & $3.88 \mathrm{E}-03$ & & rh103 & $3.88 \mathrm{E}-03$ & & rh103 & $3.88 \mathrm{E}-03$ & & sm151 & $3.57 \mathrm{E}-03$ \\
\hline 5 & rh103 & $3.32 \mathrm{E}-03$ & | & xe131 & $2.26 \mathrm{E}-03$ & & gd155 & $2.73 \mathrm{E}-03$ & & $\operatorname{gd} 155$ & $3.14 \mathrm{E}-03$ & & gd 155 & $3.48 \mathrm{E}-03$ \\
\hline 6 & pm147 & $2.79 \mathrm{E}-03$ & | & $\operatorname{cs} 133$ & $2.11 \mathrm{E}-03$ & & xe131 & $2.26 \mathrm{E}-03$ & & xe131 & $2.26 \mathrm{E}-03$ & & 131 & $2.26 \mathrm{E}-03$ \\
\hline 7 & xe131 & $2.18 \mathrm{E}-03$ & i & gd155 & $1.86 \mathrm{E}-03$ & & $\operatorname{cs} 133$ & $2.11 \mathrm{E}-03$ & & $\operatorname{cs} 133$ & $2.11 \mathrm{E}-03$ & & $\operatorname{cs} 133$ & $2.11 \mathrm{E}-03$ \\
\hline 8 & $\operatorname{cs} 133$ & $2.05 \mathrm{E}-03$ & I & tc 99 & $1.65 \mathrm{E}-03$ & & tc 99 & $1.65 \mathrm{E}-03$ & & tc 99 & $1.65 \mathrm{E}-03$ & & c 99 & $1.65 \mathrm{E}-03$ \\
\hline 9 & tc 99 & $1.62 \mathrm{E}-03$ & | & sm152 & $1.37 \mathrm{E}-03$ & & sm152 & $1.37 \mathrm{E}-03$ & & sm152 & 1.3 & & 152 & $1.37 \mathrm{E}-03$ \\
\hline 10 & sm152 & $1.35 \mathrm{E}-03$ & | & sm147 & $1.03 \mathrm{E}-03$ & & sm147 & $1.25 \mathrm{E}-03$ & & $\operatorname{sm} 147$ & $1.31 \mathrm{E}-03$ & & sm147 & $1.33 \mathrm{E}-03$ \\
\hline 11 & $\mathrm{pm} 148 \mathrm{~m}$ & $1.07 \mathrm{E}-03$ & | & nd145 & $9.80 \mathrm{E}-04$ & & nd145 & $9.81 \mathrm{E}-04$ & & nd145 & 9.81 & & nd145 & $9.81 \mathrm{E}-04$ \\
\hline 12 & nd145 & $9.65 \mathrm{E}-04$ & 1 & $\mathrm{pm} 147$ & 8.12 & & mo 95 & $7.30 \mathrm{E}-04$ & & mo 95 & 7.3 & & 151 & $7.38 \mathrm{E}-04$ \\
\hline 13 & eu153 & $6.20 \mathrm{E}-04$ & . & mo 95 & $7.30 \mathrm{E}-04$ & & eu153 & $6.37 \mathrm{E}-04$ & & eu153 & $6.38 \mathrm{E}-04$ & & mo 95 & $7.30 \mathrm{E}-04$ \\
\hline 14 & sm150 & $5.68 \mathrm{E}-04$ & | & eu153 & $6.37 \mathrm{E}-04$ & & sm150 & $5.79 \mathrm{E}-04$ & & sm150 & & & 4153 & $6.38 \mathrm{E}-04$ \\
\hline 15 & mo 95 & $5.25 \mathrm{E}-04$ & | & sm150 & -04 & & ru101 & $4.18 \mathrm{E}-04$ & & ru101 & 4. & & 150 & $5.79 \mathrm{E}-04$ \\
\hline 16 & ru101 & $4.16 \mathrm{E}-04$ & | & ru101 & $4.18 \mathrm{E}-04$ & & ag109 & $3.32 \mathrm{E}-04$ & & eu151 & 3.94 & & ru101 & $4.18 \mathrm{E}-04$ \\
\hline 17 & eu155 & $3.65 \mathrm{E}-04$ & | & ag109 & $3.32 \mathrm{E}-04$ & & $\mathrm{kr} 83$ & $3.07 \mathrm{E}-04$ & & ag109 & 3.3 & & ag109 & $3.32 \mathrm{E}-04$ \\
\hline 18 & rh105 & 3.34 & | & $\mathrm{kr} 83$ & 3.0 & & eu151 & $2.70 \mathrm{E}-04$ & & $\mathrm{kr} 83$ & 3. & & 83 & $3.07 \mathrm{E}-04$ \\
\hline 19 & ag109 & $3.27 \mathrm{E}-04$ & | & pr141 & $2.55 \mathrm{E}-04$ & & pr141 & $2.55 \mathrm{E}-04$ & & pr141 & 2.5 & & r141 & $2.55 \mathrm{E}-04$ \\
\hline 20 & $\mathrm{kr} 83$ & $2.99 \mathrm{E}-04$ & | & $\operatorname{cs} 135$ & $2.00 \mathrm{E}-04$ & & pm147 & $2.19 \mathrm{E}-04$ & & $\operatorname{cs} 135$ & 2.0 & & $\operatorname{cs} 135$ & $2.00 \mathrm{E}-04$ \\
\hline 21 & pr141 & $2.26 \mathrm{E}-04$ & $\mid$ & la139 & 1.98 & & $\operatorname{cs} 135$ & $2.00 \mathrm{E}-04$ & & 1a139 & & & 7a139 & $1.98 \mathrm{E}-04$ \\
\hline 22 & sm147 & $2.02 \mathrm{E}-04$ & | & gd157 & $1.95 \mathrm{E}-04$ & & 1a139 & $1.98 \mathrm{E}-04$ & & gd157 & 1.5 & & gd 157 & $1.96 \mathrm{E}-04$ \\
\hline 23 & $\operatorname{cs} 135$ & $1.98 \mathrm{E}-04$ & i & $\operatorname{cd} 113$ & $1.91 \mathrm{E}-04$ & & gd157 & $1.95 \mathrm{E}-04$ & & $\operatorname{cd} 113$ & $1.91 \mathrm{E}-04$ & & cd113 & $1.91 \mathrm{E}-04$ \\
\hline 24 & la139 & $1.93 \mathrm{E}-04$ & 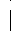 & pd105 & 1.83 & & $\operatorname{cd} 113$ & $1.91 \mathrm{E}-04$ & & pd105 & & & pd105 & $1.83 \mathrm{E}-04$ \\
\hline 25 & eu154 & $1.93 \mathrm{E}-04$ & | & eu155 & $1.79 \mathrm{E}-04$ & & pd105 & $1.83 \mathrm{E}-04$ & & zr 93 & 1.5 & & zr 93 & $1.51 \mathrm{E}-04$ \\
\hline 26 & cd113 & $1.82 \mathrm{E}-04$ & | & zr 93 & $1.51 \mathrm{E}-04$ & & zr 93 & $1.51 \mathrm{E}-04$ & & mo 97 & $1.06 \mathrm{E}-04$ & & mo 97 & $1.06 \mathrm{E}-04$ \\
\hline 27 & pd105 & $1.79 \mathrm{E}-04$ & & eu151 & 1.41 & & mo 97 & $1.06 \mathrm{E}-04$ & & $i 129$ & 8.3 & & $i 129$ & $8.36 \mathrm{E}-05$ \\
\hline 28 & & $1.71 \mathrm{E}-04$ & | & eu154 & $1.32 \mathrm{E}-04$ & & eu154 & $8.81 \mathrm{E}-05$ & & nd144 & & & nd144 & $7.87 \mathrm{E}-05$ \\
\hline 29 & $\mathrm{pm} 148$ & $1.70 \mathrm{E}-04$ & & mo 97 & $1.06 \mathrm{E}-04$ & & eu155 & $8.55 E-05$ & & pd108 & $7.86 \mathrm{E}-05$ & & pd 108 & $7.86 \mathrm{E}-05$ \\
\hline 30 & zr 93 & $1.50 \mathrm{E}-04$ & & $\lceil 129$ & $8.35 \mathrm{E}-05$ & & $i 129$ & $8.36 \mathrm{E}-05$ & & eu154 & $5.88 \mathrm{E}-05$ & & ba 137 & $5.44 \mathrm{E}-05$ \\
\hline
\end{tabular}




\section{4}

3.6 wt \% U-235, 3ø GWd/MTU Burnup

\begin{tabular}{lccccc} 
& \multicolumn{4}{c}{ Cooling time $(y)$} \\
& 0 & 5 & 10 & 15 & 30 \\
Productions & $7.409 \mathrm{E}+4$ & $7.258 \mathrm{E}+4$ & $7.123 \mathrm{E}+4$ & $7.018 \mathrm{E}+4$ & $6.819 \mathrm{E}+4$ \\
Absorptions & $6.514 \mathrm{E}+4$ & $6.359 \mathrm{E}+4$ & $6.358 \mathrm{E}+4$ & $6.348 \mathrm{E}+4$ & $6.313 \mathrm{E}+4$ \\
k-infinity & $1.138 \mathrm{E}+0$ & $1.141 \mathrm{E}+0$ & $1.120 \mathrm{E}+0$ & $1.105 \mathrm{E}+0$ & $1.080 \mathrm{E}+0$ \\
Act. abs & $5.627 \mathrm{E}+4$ & $5.583 \mathrm{E}+4$ & $5.562 \mathrm{E}+4$ & $5.543 \mathrm{E}+4$ & $5.501 \mathrm{E}+4$ \\
Non-actinide & & & & & \\
Abs. fraction & $1.362 \mathrm{E}-1$ & $1.219 \mathrm{E}-1$ & $1.252 \mathrm{E}-1$ & $1.269 \mathrm{E}-1$ & $1.286 \mathrm{E}-1$
\end{tabular}

Fraction of total absorption rate - actinides

\begin{tabular}{|c|c|c|c|c|c|c|c|c|c|c|c|}
\hline \multirow[t]{2}{*}{ Rank } & \multirow{2}{*}{\multicolumn{8}{|c|}{ Cooling time $(y)$}} & & \multirow{2}{*}{\multicolumn{2}{|c|}{30}} \\
\hline & & & & 5 & & 10 & & 15 & & & \\
\hline 1 & pu239 & $2.51 \mathrm{E}-01$ & pu239 & $2.58 \mathrm{E}-01$ & pu239 & $2.58 \mathrm{E}-01$ & pu239 & $2.58 \mathrm{E}-01$ & & pu239 & $2.59 \mathrm{E}-01$ \\
\hline 2 & u238 & $2.50 \mathrm{E}-01$ & u238 & $2.53 \mathrm{E}-01$ & u238 & $2.53 \mathrm{E}-01$ & u238 & $2.53 \mathrm{E}-01$ & & u238 & $2.54 \mathrm{E}-01$ \\
\hline 3 & u235 & 2. $28 \mathrm{E}-01$ & u235 & $2.35 \mathrm{E}-01$ & u235 & $2.35 \mathrm{E}-01$ & u235 & $2.35 \mathrm{E}-01$ & & u235 & $2.37 \mathrm{E}-01$ \\
\hline 4 & pu240 & $5.89 \mathrm{E}-02$ & pu240 & $5.94 \mathrm{E}-02$ & pu240 & $5.93 \mathrm{E}-02$ & pu240 & $5.93 \mathrm{E}-02$ & & pu240 & $5.93 \mathrm{E}-02$ \\
\hline 5 & pu241 & $5.54 \mathrm{E}-02$ & pu241 & $4.46 \mathrm{E}-02$ & pu241 & $3.51 \mathrm{E}-02$ & pu241 & $2.76 \mathrm{E}-02$ & & am241 & $3.07 \mathrm{E}-02$ \\
\hline 6 & u236 & $7.28 \mathrm{E}-03$ & am241 & $1.01 \mathrm{E}-02$ & am241 & $1.65 \mathrm{E}-02$ & am241 & $2.16 \mathrm{E}-02$ & & pu241 & $1.34 \mathrm{E}-02$ \\
\hline 7 & np237 & $4.17 \mathrm{E}-03$ & u236 & $7.34 \mathrm{E}-03$ & u236 & $7.35 \mathrm{E}-03$ & u236 & $7.36 \mathrm{E}$ & & u236 & $7.37 \mathrm{E}-03$ \\
\hline 8 & pu242 & $2.39 \mathrm{E}-03$ & $n p 237$ & $4.30 \mathrm{E}-03$ & np237 & $4.33 \mathrm{E}-03$ & np237 & $4.38 \mathrm{E}-03$ & & nр237 & $4.59 \mathrm{E}-03$ \\
\hline 9 & $\operatorname{am} 241$ & $1.73 \mathrm{E}-03$ & pu242 & $2.41 \mathrm{E}-03$ & pu242 & $2.40 \mathrm{E}-03$ & pu242 & $2.40 \mathrm{E}$ & & pu242 & $2.40 \mathrm{E}-03$ \\
\hline 10 & pu238 & 1.72E-03 & pu238 & $1.86 \mathrm{E}-03$ & pu238 & $1.79 \mathrm{E}-03$ & pu238 & $1.72 \mathrm{E}$ & & pu238 & $1.54 \mathrm{E}-03$ \\
\hline 11 & u234 & $1.21 \mathrm{E}-03$ & u234 & $1.26 \mathrm{E}-03$ & u234 & $1.30 \mathrm{E}-03$ & u234 & $1.33 \mathrm{E}-03$ & & u234 & $1.41 \mathrm{E}-03$ \\
\hline 12 & & $7.24 \mathrm{E}$ & am243 & $7.32 \mathrm{E}-04$ & am243 & 7.31E & $\operatorname{am} 243$ & 7.31 & & $\operatorname{am} 243$ & $7.30 \mathrm{E}-04$ \\
\hline 13 & am242m & $3.23 \mathrm{E}-04$ & am242m & $3.24 \mathrm{E}-04$ & $\mathrm{am} 242 \mathrm{~m}$ & $3.16 \mathrm{E}-04$ & am242m & $3.09 \mathrm{E}-04$ & & $\mathrm{am} 242 \mathrm{~m}$ & $2.89 \mathrm{E}-04$ \\
\hline 14 & np239 & $2.85 \mathrm{E}-04$ & $\mathrm{~cm} 244$ & $4.45 \mathrm{E}-05$ & $\mathrm{~cm} 244$ & $3.68 \mathrm{E}-05$ & $\mathrm{~cm} 245$ & $3.30 \mathrm{E}-05$ & & $\mathrm{~cm} 245$ & $3.32 \mathrm{E}-05$ \\
\hline 15 & $\mathrm{~cm} 244$ & $5.33 \mathrm{E}-05$ & $\mathrm{~cm} 245$ & $3.29 \mathrm{E}-05$ & $\mathrm{~cm} 245$ & $3.29 \mathrm{E}-05$ & $\mathrm{~cm} 244$ & $3.04 \mathrm{E}$ & & $\mathrm{cm} 244$ & $1.72 \mathrm{E}-05$ \\
\hline 16 & $\mathrm{~cm} 245$ & $3.21 \mathrm{E}-05$ & $\mathrm{~cm} 243$ & $1.22 \mathrm{E}-05$ & $\mathrm{~cm} 243$ & $1.08 \mathrm{E}-05$ & $\mathrm{~cm} 243$ & $9.58 \mathrm{E}$ & & $\mathrm{cm} 243$ & $6.67 \mathrm{E}-06$ \\
\hline 17 & np238 & $2.73 \mathrm{E}-05$ & u233 & $7.78 \mathrm{E}-08$ & u233 & $9.34 \mathrm{E}-08$ & th230 & $1.17 \mathrm{E}-07$ & & th230 & $2.22 \mathrm{E}-07$ \\
\hline 18 & $\mathrm{~cm} 242$ & $2.48 \mathrm{E}-05$ & $\mathrm{~cm} 246$ & $5.75 \mathrm{E}-08$ & $\operatorname{th} 230$ & $8.37 \mathrm{E}-08$ & u233 & 1.09E-07 & & u233 & $1.57 \mathrm{E}-07$ \\
\hline 19 & $\mathrm{~cm} 243$ & $1.36 \mathrm{E}-05$ & th230 & $5.11 \mathrm{E}-08$ & $\mathrm{~cm} 246$ & $5.75 \mathrm{E}-08$ & $\mathrm{~cm} 246$ & $5.74 \mathrm{E}-08$ & & $\mathrm{~cm} 246$ & $5.73 \mathrm{E}-08$ \\
\hline & $a m 242$ & $5.44 \mathrm{E}-06$ & u232 & $1.99 \mathrm{E}-08$ & u232 & $2.29 \mathrm{E}-08$ & u232 & $2.29 \mathrm{E}-08$ & & u232 & $2.03 \mathrm{E}-08$ \\
\hline
\end{tabular}

Fraction of total absorption rate - fission products

\begin{tabular}{|c|c|c|c|c|c|c|c|c|c|c|c|c|c|c|}
\hline \multirow[t]{2}{*}{ Rank } & \multicolumn{14}{|c|}{ Cooling time $(y)$} \\
\hline & & 0 & & & 5 & & & 10 & & & 15 & & & 30 \\
\hline 1 & $x e 135$ & $2.28 \mathrm{E}-02$ & | & $n d 143$ & $1.18 \mathrm{E}-02$ & & gd155 & $1.53 \mathrm{E}-02$ & & gd155 & $1.77 \mathrm{E}-02$ & & gd155 & $1.97 \mathrm{E}-02$ \\
\hline 2 & nd143 & $1.13 \mathrm{E}-02$ & & gd155 & $1.05 \mathrm{E}-02$ & & nd143 & $1.18 \mathrm{E}-02$ & & nd143 & $1.19 \mathrm{E}-02$ & & nd 143 & $1.19 \mathrm{E}-02$ \\
\hline 3 & rh103 & $9.45 \mathrm{E}-03$ & | & $s m 149$ & $1.04 \mathrm{E}-02$ & & $\operatorname{sm} 149$ & $1.04 \mathrm{E}-02$ & & $\operatorname{sm} 149$ & $1.04 \mathrm{E}-02$ & & m149 & $1.05 \mathrm{E}-02$ \\
\hline 4 & $\operatorname{sm} 149$ & $7.78 \mathrm{E}-03$ & | & rh103 & $1.02 \mathrm{E}-02$ & & rh103 & $1.01 \mathrm{E}-02$ & & rh103 & $1.01 \mathrm{E}-02$ & & rh103 & $1.01 \mathrm{E}-02$ \\
\hline 5 & sm151 & $6.99 \mathrm{E}-03$ & | & sm151 & $7.00 \mathrm{E}-03$ & & sm151 & $6.74 \mathrm{E}-03$ & & sm151 & $6.50 \mathrm{E}-03$ & & sm151 & $5.84 \mathrm{E}-03$ \\
\hline 6 & $\operatorname{cs} 133$ & $5.47 \mathrm{E}-03$ & | & $\operatorname{cs} 133$ & $5.58 \mathrm{E}-03$ & & $\operatorname{cs} 133$ & $5.58 \mathrm{E}-03$ & & $\operatorname{cs133}$ & $5.59 \mathrm{E}-03$ & & $s 133$ & $5.60 \mathrm{E}-03$ \\
\hline 7 & xe131 & $5.33 \mathrm{E}-03$ & i & xe131 & $5.44 \mathrm{E}-03$ & & xe131 & $5.44 \mathrm{E}-03$ & & xe131 & $5.45 \mathrm{E}-03$ & & xe131 & $5.46 \mathrm{E}-03$ \\
\hline 8 & tc 99 & $4.32 \mathrm{E}-03$ & 1 & tc 99 & $4.38 \mathrm{E}-03$ & & tc 99 & $4.39 \mathrm{E}-03$ & & tc 99 & $4.39 \mathrm{E}-03$ & & c 99 & $4.40 \mathrm{E}-03$ \\
\hline 9 & pm147 & $4.29 \mathrm{E}-03$ & | & sm152 & $3.80 \mathrm{E}-03$ & & sm152 & $3.81 \mathrm{E}-03$ & & sm152 & $3.81 \mathrm{E}-03$ & & 152 & $3.82 \mathrm{E}-03$ \\
\hline 10 & sm152 & $3.75 \mathrm{E}-03$ & | & eu153 & $3.04 \mathrm{E}-03$ & & eu153 & $3.04 \mathrm{E}-03$ & & eu153 & $3.04 \mathrm{E}-03$ & & eu153 & $3.06 \mathrm{E}-03$ \\
\hline 11 & eu153 & $2.97 \mathrm{E}-03$ & | & nd145 & $2.61 \mathrm{E}-03$ & & sm147 & $2.64 \mathrm{E}-03$ & & sm147 & $2.73 \mathrm{E}-03$ & & sm147 & $2.76 \mathrm{E}-03$ \\
\hline 12 & nd145 & $2.57 \mathrm{E}-03$ & 1 & sm147 & $2.31 \mathrm{E}-03$ & & nd145 & $2.61 \mathrm{E}-03$ & & nd145 & 2.6 & & d 145 & $2.62 \mathrm{E}-03$ \\
\hline 13 & eu154 & $2.00 \mathrm{E}-03$ & 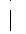 & sm150 & $1.92 \mathrm{E}-03$ & & sm150 & $1.92 \mathrm{E}-03$ & & $\operatorname{sm} 150$ & 1.93E-03 & & $\operatorname{sm} 150$ & $1.93 \mathrm{E}-03$ \\
\hline 14 & eu155 & $1.99 \mathrm{E}-03$ & | & mo 95 & $1.91 \mathrm{E}-03$ & & mo 95 & $1.91 \mathrm{E}-03$ & & mo 95 & 1.91 & & mo 95 & $1.92 \mathrm{E}-03$ \\
\hline 15 & $\operatorname{sm} 150$ & $1.89 \mathrm{E}-03$ & 1 & ag109 & 1.72 & & ag109 & $1.72 \mathrm{E}-03$ & & ag109 & 1. & & 109 & $1.72 \mathrm{E}-03$ \\
\hline 16 & $\mathrm{pm} 148 \mathrm{~m}$ & $1.82 \mathrm{E}-03$ & | & eu154 & $1.36 \mathrm{E}-03$ & & ru101 & $1.24 \mathrm{E}-03$ & & ru101 & $1.24 \mathrm{E}-03$ & & ru101 & $1.24 \mathrm{E}-03$ \\
\hline 17 & mo 95 & $1.73 \mathrm{E}-03$ & | & pm147 & $1.24 \mathrm{E}-03$ & & eu154 & $9.10 \mathrm{E}-04$ & & pd105 & 7.83 & & eu151 & $1.17 \mathrm{E}-03$ \\
\hline 18 & ag109 & $1.69 \mathrm{E}-03$ & | & ru101 & 1.2 & & $\mathrm{pd}$ & $7.82 \mathrm{E}-04$ & & pr141 & 7. & & 105 & $7.85 \mathrm{E}-04$ \\
\hline 19 & ru101 & $1.23 \mathrm{E}-03$ & | & eu155 & $9.74 \mathrm{E}-04$ & & pr141 & $7.50 \mathrm{E}-04$ & & $\mathrm{kr} 83$ & $7.44 \mathrm{E}-04$ & & pr141 & $7.54 \mathrm{E}-04$ \\
\hline 20 & sm147 & $1.04 \mathrm{E}-03$ & i & pd105 & $7.82 \mathrm{E}-04$ & & $\mathrm{kr} 83$ & $7.43 \mathrm{E}-04$ & & eu151 & $6.19 \mathrm{E}-04$ & & r 83 & 7. $49 \mathrm{E}-04$ \\
\hline 21 & pd105 & $7.71 \mathrm{E}-04$ & | & pr141 & 7.50 & & $\operatorname{cs} 135$ & $5.94 \mathrm{E}-04$ & & & & & 135 & $5.96 \mathrm{E}-04$ \\
\hline 22 & $\mathrm{kr} 83$ & $7.25 \mathrm{E}-04$ & | & $\mathrm{kr} 83$ & $7.43 \mathrm{E}-04$ & & 1a139 & $5.86 \mathrm{E}-04$ & & $\operatorname{cs} 135$ & $5.95 \mathrm{~B}$ & & 7a139 & $5.90 \mathrm{E}-04$ \\
\hline 23 & $\operatorname{cs} 134$ & 7. $12 \mathrm{E}-04$ & | & $\operatorname{cs} 135$ & $5.95 \mathrm{E}-04$ & & $\operatorname{gd} 157$ & $4.73 \mathrm{E}-04$ & & 1a139 & $5.87 \mathrm{E}-04$ & & gd 157 & $4.78 \mathrm{E}-04$ \\
\hline 24 & pr141 & 7.12E-04 & | & 1 a139 & 5.8 & & pd108 & $4.67 \mathrm{E}-04$ & & $\operatorname{gd} 157$ & & & pd 108 & $4.67 \mathrm{E}-04$ \\
\hline 25 & $\operatorname{cs} 135$ & $5.87 \mathrm{E}-04$ & | & gd157 & $4.73 \mathrm{E}-04$ & & eu155 & $4.64 \mathrm{E}-04$ & & pd108 & 4.67 & & zr 93 & $4.13 \mathrm{E}-04$ \\
\hline 26 & 1a139 & $5.73 \mathrm{E}-04$ & | & pd108 & $4.67 \mathrm{E}-04$ & & eu151 & $4.23 \mathrm{E}-04$ & & zr 93 & $4.12 \mathrm{E}-04$ & & mo 97 & $3.12 \mathrm{E}-04$ \\
\hline 27 & rh105 & $5.36 \mathrm{E}-04$ & 1 & zr 93 & $4.12 \mathrm{E}-04$ & & zr 93 & $4.12 \mathrm{E}-04$ & & mo 97 & & & pd 107 & $2.99 \mathrm{E}-04$ \\
\hline 28 & & $4.64 \mathrm{E}-04$ & & mo 97 & $3.11 \mathrm{E}-04$ & & pm147 & $3.36 \mathrm{E}-04$ & & pd107 & & & $\operatorname{cd} 113$ & $2.85 \mathrm{E}-04$ \\
\hline 29 & gd157 & $4.18 \mathrm{E}-04$ & & pd107 & $2.98 \mathrm{E}-04$ & & mo 97 & $3.11 \mathrm{E}-04$ & & $\operatorname{cd} 113$ & $2.82 \mathrm{E}-04$ & & $i 129$ & $2.83 \mathrm{E}-04$ \\
\hline 30 & zr 93 & $4.09 \mathrm{E}-04$ & & cd113 & $2.82 \mathrm{E}-04$ & & pd107 & $2.98 \mathrm{E}-04$ & & $i 129$ & $2.82 \mathrm{E}-04$ & & nd144 & $2.62 \mathrm{E}-04$ \\
\hline
\end{tabular}




\section{5}

3.6 wt \% U-235, $50 \mathrm{GWd} / \mathrm{MTU}$ Burnup

\begin{tabular}{lccccc} 
& \multicolumn{4}{c}{ Cooling time $(y)$} \\
& 0 & 5 & 10 & 15 & 30 \\
Productions & $6.172 \mathrm{E}+4$ & $5.938 \mathrm{E}+4$ & $5.739 \mathrm{E}+4$ & $5.582 \mathrm{E}+4$ & $5.283 \mathrm{E}+4$ \\
Absorptions & $6.227 \mathrm{E}+4$ & $6.164 \mathrm{E}+4$ & $6.193 \mathrm{E}+4$ & $6.192 \mathrm{E}+4$ & $6.144 \mathrm{E}+4$ \\
k-infinity & $9.911 \mathrm{E}-1$ & $9.633 \mathrm{E}-1$ & $9.267 \mathrm{E}-1$ & $9.015 \mathrm{E}-1$ & $8.599 \mathrm{E}-1$ \\
Act. abs & $5.116 \mathrm{E}+4$ & $5.077 \mathrm{E}+4$ & $5.050 \mathrm{E}+4$ & $5.023 \mathrm{E}+4$ & $4.958 \mathrm{E}+4$ \\
Non-actinide & & & & & \\
Abs. fraction & $1.785 \mathrm{E}-1$ & $1.764 \mathrm{E}-1$ & $1.846 \mathrm{E}-1$ & $1.888 \mathrm{E}-1$ & $1.931 \mathrm{E}-1$
\end{tabular}

Fraction of total absorption rate - actinides

\begin{tabular}{r|rl|} 
Rank & & \\
& & 0 \\
\hline 1 & pu239 & $2.72 \mathrm{E}-01$ \\
2 & $\mathrm{u} 238$ & $2.51 \mathrm{E}-01$ \\
3 & $\mathrm{u} 235$ & $9.81 \mathrm{E}-02$ \\
4 & pu241 & $8.63 \mathrm{E}-02$ \\
5 & pu240 & $7.69 \mathrm{E}-02$ \\
6 & $\mathrm{u} 236$ & $8.25 \mathrm{E}-03$ \\
7 & $\mathrm{np237}$ & $7.62 \mathrm{E}-03$ \\
8 & pu242 & $6.00 \mathrm{E}-03$ \\
9 & pu238 & $5.88 \mathrm{E}-03$ \\
10 & am243 & $3.40 \mathrm{E}-03$ \\
11 & am241 & $3.25 \mathrm{E}-03$ \\
12 & $\mathrm{u} 234$ & $8.96 \mathrm{E}-04$ \\
13 & am242m & $6.75 \mathrm{E}-04$ \\
14 & $\mathrm{~cm} 244$ & $4.80 \mathrm{E}-04$ \\
15 & $\mathrm{~cm} 245$ & $4.34 \mathrm{E}-04$ \\
16 & $\mathrm{np239}$ & $3.32 \mathrm{E}-04$ \\
17 & $\mathrm{~cm} 242$ & $6.47 \mathrm{E}-05$ \\
18 & $\mathrm{np238}$ & $6.06 \mathrm{E}-05$ \\
19 & $\mathrm{~cm} 243$ & $5.34 \mathrm{E}-05$ \\
20 & am242 & $1.23 \mathrm{E}-05$
\end{tabular}

\begin{tabular}{|c|c|c|c|c|c|c|c|}
\hline \multicolumn{4}{|c|}{ Cooling time $(y)$} & \multicolumn{2}{|c|}{15} & \multicolumn{2}{|c|}{30} \\
\hline pu239 & $2.77 \mathrm{E}-01$ & pu239 & $2.75 \mathrm{E}-01$ & pu239 & $2.75 \mathrm{E}-01$ & pu239 & $2.77 \mathrm{E}-01$ \\
\hline u238 & $2.52 \mathrm{E}-01$ & u238 & $2.52 \mathrm{E}-01$ & u238 & $2.52 \mathrm{E}-01$ & u238 & $2.52 \mathrm{E}-01$ \\
\hline u235 & $9.90 \mathrm{E}-02$ & u235 & $9.85 \mathrm{E}-02$ & u235 & $9.85 \mathrm{E}-02$ & u235 & $9.95 \mathrm{E}-02$ \\
\hline pu240 & $7.75 \mathrm{E}-02$ & pu240 & $7.75 \mathrm{E}-02$ & pu240 & 7. $77 \mathrm{E}-02$ & pu240 & $7.81 \mathrm{E}-02$ \\
\hline pu241 & $6.85 \mathrm{E}-02$ & pu241 & $5.35 \mathrm{E}-02$ & pu241 & $4.21 \mathrm{E}-02$ & am241 & $4.61 \mathrm{E}-02$ \\
\hline am241 & $1.57 \mathrm{E}-02$ & am241 & $2.52 \mathrm{E}-02$ & am241 & $3.26 \mathrm{E}-02$ & pu241 & $2.06 \mathrm{E}-02$ \\
\hline u236 & $8.30 \mathrm{E}-03$ & u236 & $8.31 \mathrm{E}-03$ & $u 236$ & $8.31 \mathrm{E}-03$ & u236 & $8.33 \mathrm{E}-03$ \\
\hline np237 & $7.76 \mathrm{E}-03$ & np237 & $7.78 \mathrm{E}-03$ & np237 & 7. $84 \mathrm{E}-03$ & np237 & $8.16 \mathrm{E}-03$ \\
\hline pu238 & $6.15 \mathrm{E}-03$ & pu242 & $6.00 \mathrm{E}-03$ & pu242 & $6.00 \mathrm{E}-03$ & pu242 & $5.99 \mathrm{E}-03$ \\
\hline pu242 & $6.01 \mathrm{E}-03$ & pu238 & $5.88 \mathrm{E}-03$ & pu238 & $5.65 \mathrm{E}-03$ & pu238 & $5.07 \mathrm{E}-03$ \\
\hline am243 & $3.42 \mathrm{E}-03$ & am243 & $3.40 \mathrm{E}-03$ & $a m 243$ & $3.40 \mathrm{E}-03$ & am243 & $3.40 \mathrm{E}-03$ \\
\hline u234 & $1.01 \mathrm{E}-03$ & u234 & $1.10 \mathrm{E}-03$ & u234 & $1.20 \mathrm{E}-03$ & u234 & $1.47 \mathrm{E}-03$ \\
\hline am242m & $6.65 \mathrm{E}-04$ & $a m 242 m$ & $6.45 \mathrm{E}-04$ & $\mathrm{am} 242 \mathrm{~m}$ & $6.30 \mathrm{E}-04$ & $\mathrm{am} 242 \mathrm{~m}$ & $5.91 \mathrm{E}-04$ \\
\hline $\mathrm{cm} 245$ & $4.39 \mathrm{E}-04$ & $\mathrm{~cm} 245$ & $4.36 \mathrm{E}-04$ & $\mathrm{~cm} 245$ & $4.36 \mathrm{E}-04$ & $\mathrm{~cm} 245$ & $4.39 \mathrm{E}-04$ \\
\hline $\mathrm{cm} 244$ & $4.01 \mathrm{E}-04$ & $\mathrm{~cm} 244$ & $3.32 \mathrm{E}-04$ & cm244 & $2.75 \mathrm{E}-04$ & $\mathrm{~cm} 244$ & $1.56 \mathrm{E}-04$ \\
\hline $\mathrm{cm} 243$ & $4.76 \mathrm{E}-05$ & $\mathrm{~cm} 243$ & $4.20 \mathrm{E}-05$ & $\mathrm{~cm} 243$ & $3.72 \mathrm{E}-05$ & $\mathrm{~cm} 243$ & $2.59 \mathrm{E}-05$ \\
\hline $\mathrm{cm} 246$ & $1.60 \mathrm{E}-06$ & $\mathrm{~cm} 246$ & $1.60 \mathrm{E}-06$ & $\mathrm{~cm} 246$ & $1.59 \mathrm{E}-06$ & $\mathrm{~cm} 246$ & $1.59 \mathrm{E}-06$ \\
\hline $\mathrm{cm} 247$ & $6.23 \mathrm{E}-07$ & $\mathrm{~cm} 247$ & $6.21 \mathrm{E}-07$ & $\mathrm{~cm} 247$ & $6.21 \mathrm{E}-07$ & $\mathrm{~cm} 247$ & $6.22 \mathrm{E}-07$ \\
\hline u233 & $9.96 \mathrm{E}-08$ & u233 & $1.28 \mathrm{E}-07$ & u233 & $1.57 \mathrm{E}-07$ & u233 & $2.44 \mathrm{E}-07$ \\
\hline u232 & $6.77 \mathrm{E}-08$ & u232 & 7. $63 \mathrm{E}-08$ & $\operatorname{th} 230$ & $9.68 \mathrm{E}-08$ & $\operatorname{th} 230$ & $1.97 \mathrm{E}-07$ \\
\hline
\end{tabular}

Fraction of total absorption rate - fission products

\begin{tabular}{|c|c|c|c|c|c|c|c|c|c|c|c|c|c|}
\hline \multirow[t]{2}{*}{ Rank } & \multicolumn{13}{|c|}{ Cooling time $(y)$} \\
\hline & & 0 & & & 5 & & & 10 & & & 15 & & 30 \\
\hline 1 & $x e 135$ & $2.18 \mathrm{E}-02$ & | & gd155 & $2.59 \mathrm{E}-02$ & & gd155 & $3.77 \mathrm{E}-02$ & & gd155 & $4.34 \mathrm{E}-02$ & $\operatorname{gd} 155$ & $4.87 \mathrm{E}-02$ \\
\hline 2 & nd143 & $1.56 \mathrm{E}-02$ & 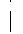 & nd143 & $1.59 \mathrm{E}-02$ & & nd143 & $1.58 \mathrm{E}-02$ & & nd143 & $1.58 \mathrm{E}-02$ & nd143 & $1.60 \mathrm{E}-02$ \\
\hline 3 & rh103 & $1.35 \mathrm{E}-02$ & | & rh103 & $1.42 \mathrm{E}-02$ & & rh103 & $1.42 \mathrm{E}-02$ & & rh103 & 1. $41 \mathrm{E}-02$ & rh103 & $1.41 \mathrm{E}-02$ \\
\hline 4 & sm151 & $9.25 \mathrm{E}-03$ & 1 & sm149 & $1.04 \mathrm{E}-02$ & & $\operatorname{sm} 149$ & $1.03 \mathrm{E}-02$ & & $\operatorname{sm} 149$ & $1.03 \mathrm{E}-02$ & $\operatorname{sm} 149$ & $1.04 \mathrm{E}-02$ \\
\hline 5 & $\operatorname{cs} 133$ & $8.11 \mathrm{E}-03$ & | & sm151 & $9.06 \mathrm{E}-03$ & & sm151 & $8.65 \mathrm{E}-03$ & & sm151 & $8.33 \mathrm{E}-03$ & $\operatorname{cs} 133$ & $8.23 \mathrm{E}-03$ \\
\hline 6 & sm149 & $7.59 \mathrm{E}-03$ & | & $\operatorname{cs} 133$ & $8.21 \mathrm{E}-03$ & & $\operatorname{cs} 133$ & $8.20 \mathrm{E}-03$ & & $\operatorname{cs} 133$ & $8.20 \mathrm{E}-03$ & sm151 & $7.51 \mathrm{E}-03$ \\
\hline 7 & xe131 & $7.21 \mathrm{E}-03$ & i & xe131 & $7.30 \mathrm{E}-03$ & & xe131 & $7.29 \mathrm{E}-03$ & & xe131 & $7.29 \mathrm{E}-03$ & xe131 & $7.31 \mathrm{E}-03$ \\
\hline 8 & tc 99 & $6.44 \mathrm{E}-03$ & i & tc 99 & $6.50 \mathrm{E}-03$ & & tc 99 & $6.50 \mathrm{E}-03$ & & tc 99 & $6.50 \mathrm{E}-03$ & c 99 & $6.52 \mathrm{E}-03$ \\
\hline 9 & eu153 & $5.57 \mathrm{E}-03$ & | & eu153 & $5.64 \mathrm{E}-03$ & & eu153 & $5.61 \mathrm{E}-03$ & & eu153 & & 153 & $5.64 \mathrm{E}-2 \mathrm{l}$ \\
\hline 10 & sm152 & $5.46 \mathrm{E}-03$ & | & sm152 & $5.51 \mathrm{E}-03$ & & sm152 & $5.50 \mathrm{E}-03$ & & sm152 & $5.51 \mathrm{E}-03$ & sm152 & $5.52 \mathrm{E}-03$ \\
\hline 11 & eu154 & $4.99 \mathrm{E}-03$ & 1 & nd145 & $3.91 \mathrm{E}-03$ & & nd145 & $3.90 \mathrm{E}-03$ & & nd145 & $3.90 \mathrm{E}-03$ & nd 145 & $3.91 \mathrm{E}-03$ \\
\hline 12 & eu155 & $4.93 \mathrm{E}-03$ & | & eu154 & $3.35 \mathrm{E}-03$ & & ag109 & $3.26 \mathrm{E}-03$ & & sm147 & 3.29 & sm147 & $3.33 \mathrm{E}-03$ \\
\hline 13 & pm147 & $4.22 \mathrm{E}-03$ & | & ag109 & $3.26 \mathrm{E}-03$ & & sm147 & $3.20 \mathrm{E}-03$ & & ag109 & $3.26 \mathrm{E}-03$ & g109 & $3.27 \mathrm{E}-03$ \\
\hline 14 & nd145 & $3.88 \mathrm{E}-03$ & | & sm150 & $3.20 \mathrm{E}-03$ & & sm150 & $3.19 \mathrm{E}-03$ & & sm150 & 3.1 & sm150 & $3.21 \mathrm{E}-03$ \\
\hline 15 & ag109 & $3.23 \mathrm{E}-03$ & | & sm147 & $2.89 \mathrm{E}-03$ & & mo 95 & $2.84 \mathrm{E}-03$ & & mo 95 & 2.84 & 95 & $2.85 \mathrm{E}-03$ \\
\hline 16 & sm150 & $3.18 \mathrm{E}-03$ & 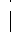 & mo 95 & $2.85 \mathrm{E}-03$ & & eu154 & $2.23 \mathrm{E}-03$ & & ru101 & 2. $01 \mathrm{E}-03$ & ru101 & $2.01 \mathrm{E}-03$ \\
\hline 17 & mo 95 & $2.70 \mathrm{E}-03$ & $\mid$ & eu155 & $2.37 \mathrm{E}-03$ & & ru101 & $2.01 \mathrm{E}-03$ & & pd105 & & d 105 & $1.57 \mathrm{E}-03$ \\
\hline 18 & ru101 & $2.01 \mathrm{E}-03$ & | & ru101 & $2.01 \mathrm{E}-03$ & & pd105 & $1.57 \mathrm{E}-03$ & & eu154 & 1.4 & eu151 & $1.47 \mathrm{E}-03$ \\
\hline 19 & $\mathrm{pm} 148 \mathrm{~m}$ & $1.88 \mathrm{E}-03$ & | & pd105 & $1.57 \mathrm{E}-03$ & & pr141 & $1.23 \mathrm{E}-03$ & & pr141 & $1.23 \mathrm{E}-03$ & pr141 & $1.24 \mathrm{E}-03$ \\
\hline 20 & sm147 & $1.66 \mathrm{E}-03$ & | & pr141 & $1.24 \mathrm{E}-03$ & & eu155 & $1.13 \mathrm{E}-03$ & & pd108 & & pd108 & $1.03 \mathrm{E}-03$ \\
\hline 21 & $\operatorname{cs} 134$ & $1.62 \mathrm{E}-03$ & & pm147 & 1.21 & & pd108 & $1.03 \mathrm{E}$ & & $\mathrm{kr} 83$ & & 83 & 9.90 \\
\hline 22 & pd105 & $1.56 \mathrm{E}-03$ & | & pd108 & $1.03 \mathrm{E}-03$ & & $\mathrm{kr} 83$ & $9.81 \mathrm{E}-04$ & & 1a139 & $9.70 \mathrm{E}-04$ & la139 & $9.77 \mathrm{E}-04$ \\
\hline 23 & pr141 & $1.20 \mathrm{E}-03$ & | & $\mathrm{kr} 83$ & $9.86 \mathrm{E}-04$ & & 1a139 & $9.70 \mathrm{E}-04$ & & $\operatorname{cs} 135$ & 9.66 & $\operatorname{cs} 135$ & $9.70 \mathrm{E}-04$ \\
\hline 24 & pd108 & 1.03 & & 7 a139 & $9.74 \mathrm{E}-04$ & & $\operatorname{cs} 135$ & $9.66 \mathrm{E}-04$ & & gd157 & & $\operatorname{gd} 157$ & $9.63 \mathrm{E}-04$ \\
\hline 25 & $\mathrm{kr} 83$ & $9.77 \mathrm{E}-04$ & | & $\operatorname{cs} 135$ & $9.69 \mathrm{E}-04$ & & gd157 & $9.52 \mathrm{E}-04$ & & eu151 & $7.78 \mathrm{E}-04$ & pd107 & $6.73 \mathrm{E}-04$ \\
\hline 26 & la139 & $9.66 \mathrm{E}-04$ & $\mid$ & gd157 & $9.58 \mathrm{E}-04$ & & pd107 & $6.71 \mathrm{E}-04$ & & pd107 & $6.71 \mathrm{E}-04$ & zr 93 & $6.31 \mathrm{E}-04$ \\
\hline 27 & $\operatorname{cs} 135$ & $9.64 \mathrm{E}-04$ & & pd107 & $6.73 \mathrm{E}-04$ & & zr 93 & $6.30 \mathrm{E}-04$ & & 93 & & mo 97 & $5.09 \mathrm{E}-04$ \\
\hline 28 & gd157 & $8.76 \mathrm{E}-04$ & & zr 93 & $6.31 \mathrm{E}-04$ & & eu151 & $5.32 \mathrm{E}-04$ & & eu155 & $5.37 \mathrm{E}-04$ & $i 129$ & $5.01 \mathrm{E}-04$ \\
\hline 29 & rh105 & $6.93 \mathrm{E}-04$ & 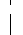 & mo 97 & $5.09 \mathrm{E}-04$ & & mo 97 & $5.08 \mathrm{E}-04$ & & mo 97 & $5.08 \mathrm{E}-04$ & gd 154 & $4.88 \mathrm{E}-04$ \\
\hline 30 & pd107 & $6.69 \mathrm{E}-04$ & & $\lceil 129$ & $4.99 \mathrm{E}-04$ & & $i 129$ & $4.97 \mathrm{E}-04$ & & $\lceil 129$ & $4.97 \mathrm{E}-04$ & nd 144 & $4.83 \mathrm{E}-04$ \\
\hline
\end{tabular}




\section{5 wt \% U-235, $10 \mathrm{GWd} / \mathrm{MTU}$ Burnup}

\begin{tabular}{lccccc} 
& \multicolumn{4}{c}{ Cooling time $(y)$} \\
& 0 & 5 & 10 & 15 & 30 \\
Productions & $1.059 \mathrm{E}+5$ & $1.060 \mathrm{E}+5$ & $1.058 \mathrm{E}+5$ & $1.057 \mathrm{E}+5$ & $1.054 \mathrm{E}+5$ \\
Absorptions & $7.695 \mathrm{E}+4$ & $7.515 \mathrm{E}+4$ & $7.514 \mathrm{E}+4$ & $7.513 \mathrm{E}+4$ & $7.510 \mathrm{E}+4$ \\
k-infinity & $1.376 \mathrm{E}+0$ & $1.410 \mathrm{E}+0$ & $1.408 \mathrm{E}+0$ & $1.406 \mathrm{E}+0$ & $1.403 \mathrm{E}+0$ \\
Act. abs & $7.088 \mathrm{E}+4$ & $7.073 \mathrm{E}+4$ & $7.071 \mathrm{E}+4$ & $7.069 \mathrm{E}+4$ & $7.064 \mathrm{E}+4$ \\
Non-actinide & \multicolumn{5}{c}{} \\
Abs. fraction & $7.887 \mathrm{E}-2$ & $5.884 \mathrm{E}-2$ & $5.902 \mathrm{E}-2$ & $5.917 \mathrm{E}-2$ & $5.931 \mathrm{E}-2$
\end{tabular}

Fraction of total absorption rate - actinides

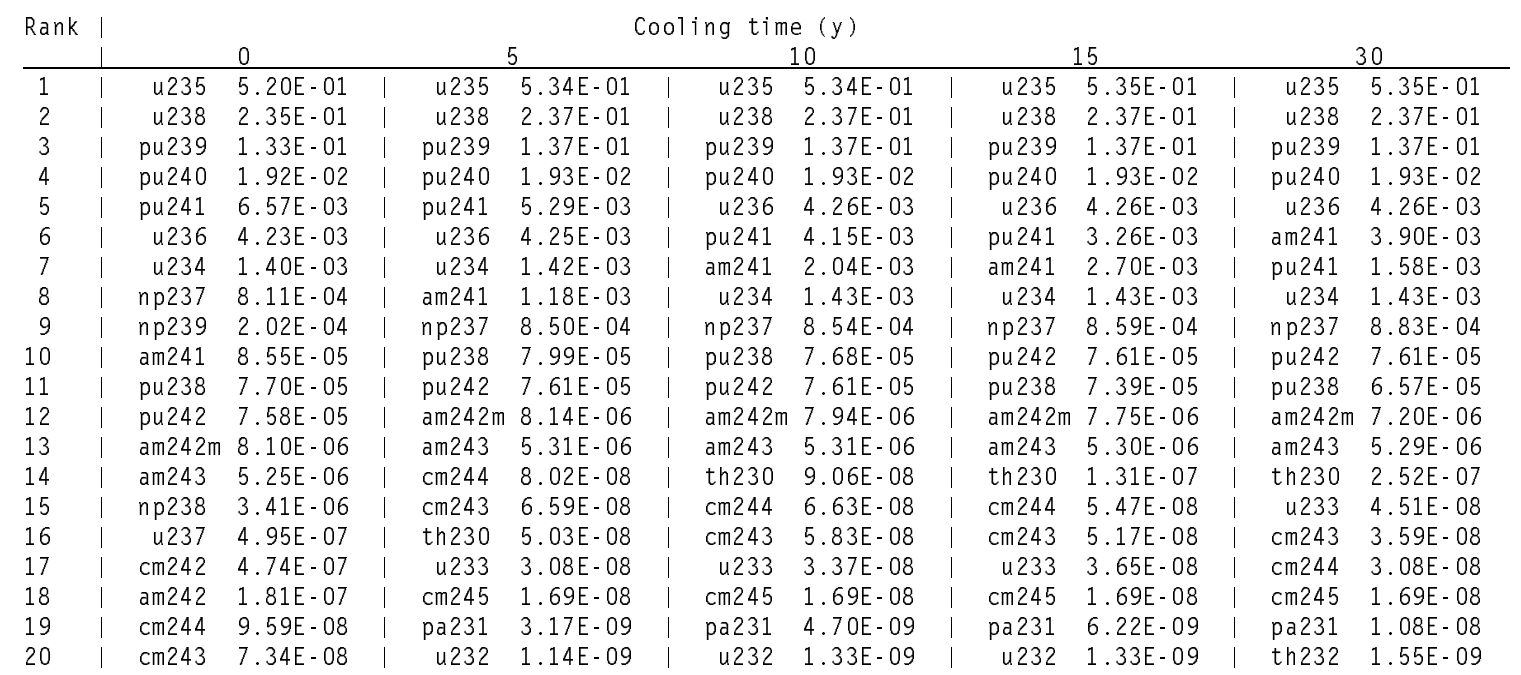

Fraction of total absorption rate - fission products

\begin{tabular}{|c|c|c|c|c|c|c|c|c|c|c|c|c|c|c|}
\hline \multirow{2}{*}{ Rank } & & \multirow{2}{*}{\multicolumn{10}{|c|}{$\underset{10}{\text { Cooling time }}(y)$}} & & \multirow{2}{*}{\multicolumn{2}{|c|}{30}} \\
\hline & & & & & & & & & 10 & & & & & \\
\hline 1 & & $x e 135$ & $2.18 \mathrm{E}-02$ & & sm149 & $8.97 \mathrm{E}-03$ & & sm149 & $8.97 \mathrm{E}-03$ & $\mathrm{sm149}$ & $8.97 \mathrm{E}-03$ & & sm149 & $8.98 \mathrm{E}-03$ \\
\hline 2 & & $\operatorname{sm} 149$ & $7.26 \mathrm{E}-03$ & & nd143 & $4.10 \mathrm{E}-03$ & & nd143 & $4.10 \mathrm{E}-03$ & nd143 & $4.10 \mathrm{E}-03$ & & 143 & $4.10 \mathrm{E}-03$ \\
\hline 3 & & sm151 & $4.01 \mathrm{E}-03$ & & sm151 & $4.03 E-03$ & & sm151 & $3.87 \mathrm{E}-03$ & $\mathrm{~m} 151$ & $3.73 \mathrm{E}-03$ & & 103 & $3.50 \mathrm{E}-03$ \\
\hline 4 & & nd143 & $3.81 \mathrm{E}-03$ & 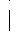 & rh103 & $3.50 \mathrm{E}-03$ & & rh103 & $3.50 \mathrm{E}-03$ & rh103 & $3.50 \mathrm{E}-03$ & & n151 & $3.32 \mathrm{E}-03$ \\
\hline 5 & & rh103 & $3.01 \mathrm{E}-03$ & । & xe131 & $2.11 \mathrm{E}-03$ & & $\operatorname{gd} 155$ & $2.13 \mathrm{E}-03$ & d155 & $2.45 \mathrm{E}-03$ & & gd 155 & $2.71 \mathrm{E}-03$ \\
\hline 6 & & pm147 & $2.68 \mathrm{E}-03$ & & cs133 & $1.99 \mathrm{E}-03$ & & xe131 & $2.11 \mathrm{E}-03$ & 131 & 2. $11 \mathrm{E}-03$ & & 131 & $2.11 \mathrm{E}-03$ \\
\hline 7 & & & $2.04 \mathrm{E}-03$ & 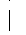 & tc 99 & 1.5 & & $\operatorname{cs} 133$ & 1.9 & 133 & $1.99 \mathrm{E}-03$ & & 133 & \\
\hline 8 & & cs133 & $1.94 \mathrm{E}-03$ & i & $\operatorname{gd} 155$ & $1.46 \mathrm{E}-03$ & & tc 99 & $1.57 \mathrm{E}-03$ & 99 & $1.57 \mathrm{E}-03$ & & 99 & $1.57 \mathrm{E}-03$ \\
\hline 9 & & & $1.54 \mathrm{E}-03$ & & & 1.2 & & sm152 & $1.22 \mathrm{E}-03$ & sm147 & 1.25 & & 147 & $1.27 \mathrm{E}-03$ \\
\hline 10 & & 152 & $1.20 \mathrm{E}-$ & & & 9.8 & & 47 & 1.2 & & 1.22 & & & 1.22 \\
\hline 11 & & pm148m & $9.65 \mathrm{E}-04$ & & 45 & $9.06 \mathrm{E}-04$ & & nd145 & $9.07 \mathrm{E}-04$ & 145 & $9.07 \mathrm{E}-04$ & & 145 & $9.07 \mathrm{E}-04$ \\
\hline 12 & & nd145 & $8.94 \mathrm{E}-04$ & & & 7.7 & & 95 & $6.87 \mathrm{E}-04$ & 95 & 6.8 & & 151 & $7.31 \mathrm{E}-04$ \\
\hline 13 & & & $5.21 \mathrm{E}-$ & & 95 & -04 & & & 5.3 & 153 & 5. & & 95 & $6.87 \mathrm{E}$ \\
\hline 14 & & mo 95 & $4.95 \mathrm{E}-04$ & & eu153 & 5.3 & & $\operatorname{sm} 150$ & $5.03 \mathrm{E}-04$ & 150 & $5.03 \mathrm{E}$ & & 153 & $5.35 \mathrm{E}-04$ \\
\hline 15 & & & $4.95 \mathrm{E}-04$ & & & 5.0 & & ru101 & $4.02 \mathrm{~F}$ & 101 & & & & $5.03 \mathrm{E}$ \\
\hline 16 & & & 4.00E- & & 01 & 4.0 & & $\mathrm{kr} 83$ & $2.69 \mathrm{E}$ & 151 & 3.9 & & 101 & $4.02 \mathrm{E}$ \\
\hline 17 & & eu155 & $2.98 \mathrm{E}-04$ & & $\mathrm{kr} 83$ & $2.69 \mathrm{E}-04$ & & eu151 & $2.68 \mathrm{E}-04$ & $r 83$ & 2.6 & & 83 & $2.69 \mathrm{E}-04$ \\
\hline 18 & & & $2.62 \mathrm{E}-04$ & & & 2.5 & & & 2.5 & 9109 & & & 109 & \\
\hline 19 & & 05 & $2.56 \mathrm{E}-$ & & & 2.2 & & 41 & 2.2 & 41 & 2.2 & & 41 & $2.25 \mathrm{E}$ \\
\hline 20 & & ag109 & $2.54 \mathrm{E}-04$ & & 35 & $2.12 \mathrm{E}-04$ & & $\operatorname{cs} 135$ & $2.12 \mathrm{E}-04$ & s135 & 2. $12 \mathrm{E}-04$ & & $\operatorname{cs} 135$ & $2.12 \mathrm{E}-04$ \\
\hline 21 & & & 2. $10 \mathrm{E}-04$ & & & 1.7 & & & 2.0 & 13 & & & & \\
\hline 22 & & & 2.00 & & & .04 & & & 1.7 & 39 & 17 & & 39 & $172 \mathrm{~F}$ \\
\hline 23 & & sm147 & $1.95 \mathrm{E}-04$ & & gd157 & $1.67 \mathrm{E}-04$ & & 1a139 & $1.72 \mathrm{E}-04$ & gd157 & $1.67 \mathrm{E}-04$ & & $\operatorname{gd} 157$ & $1.67 \mathrm{E}-04$ \\
\hline 24 & & $\operatorname{cd} 113$ & $1.72 \mathrm{E}-04$ & & pd105 & 1.5 & & $\operatorname{gd} 157$ & $1.67 \mathrm{E}-$ & pd105 & & & pd 105 & \\
\hline 25 & & & $1.68 \mathrm{E}-$ & & & & & & 1.57 & r 93 & & & 93 & 1 \\
\hline 26 & & p & $1.54 \mathrm{E}-04$ & & & 1.4 & & zr 93 & $1.47 \mathrm{E}-04$ & mo 97 & 1.00 & & mo 97 & $1.00 \mathrm{E}-04$ \\
\hline 27 & & $\mathrm{pm} 148$ & $1.51 \mathrm{E}-04$ & & eu151 & 1.4 & & mo 97 & $1.00 \mathrm{E}-04$ & $\lceil 129$ & & & $\lceil 129$ & $7.10 \mathrm{E}-05$ \\
\hline 28 & & & $1.49 \mathrm{E}-04$ & & & 1.0 & & $i 129$ & $7.10 \mathrm{E}$ & nd144 & & & nd144 & \\
\hline 29 & & & 1. $46 \mathrm{E}-04$ & & & 9.7 & & eu155 & $6.96 \mathrm{E}-1$ & pd108 & $6.24 \mathrm{E}-05$ & & pd 108 & $6.24 \mathrm{E}-05$ \\
\hline 30 & & eu154 & 1. $44 \mathrm{E}-04$ & 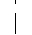 & $i 129$ & $7.10 \mathrm{E}-05$ & & nd144 & $6.90 \mathrm{E}-05$ & $\mathrm{pm} 147$ & $5.60 \mathrm{E}-05$ & & ba 137 & $4.66 \mathrm{E}-05$ \\
\hline
\end{tabular}




\section{5 wt \% U-235, 30 GWd/MTU Burnup}

$\begin{array}{lccccc} & 0 & 5 & 10 & 15 & 30 \\ \text { Productions } & 9.038 \mathrm{E}+4 & 8.901 \mathrm{E}+4 & 8.778 \mathrm{E}+4 & 8.682 \mathrm{E}+4 & 8.502 \mathrm{E}+4 \\ \text { Absorptions } & 7.535 \mathrm{E}+4 & 7.354 \mathrm{E}+4 & 7.353 \mathrm{E}+4 & 7.346 \mathrm{E}+4 & 7.317 \mathrm{E}+4 \\ \text { k-infinity } & 1.200 \mathrm{E}+0 & 1.210 \mathrm{E}+0 & 1.194 \mathrm{E}+0 & 1.182 \mathrm{E}+0 & 1.162 \mathrm{E}+0 \\ \text { Act. abs } & 6.589 \mathrm{E}+4 & 6.546 \mathrm{E}+4 & 6.528 \mathrm{E}+4 & 6.513 \mathrm{E}+4 & 6.479 \mathrm{E}+4 \\ \text { Non-actinide } & & & & & \\ \text { Abs. fraction } & 1.255 \mathrm{E}-1 & 1.099 \mathrm{E}-1 & 1.121 \mathrm{E}-1 & 1.133 \mathrm{E}-1 & 1.145 \mathrm{E}-1\end{array}$

Fraction of total absorption rate - actinides

\begin{tabular}{|c|c|c|c|c|c|c|c|c|c|c|}
\hline \multirow[t]{2}{*}{ Rank } & \multicolumn{8}{|c|}{ Cooling time $(y)$} & \multirow{2}{*}{\multicolumn{2}{|c|}{30}} \\
\hline & & 0 & & 5 & & 10 & & 15 & & \\
\hline 1 & u235 & $2.96 \mathrm{E}-01$ & u235 & $3.04 \mathrm{E}-01$ & u235 & $3.04 \mathrm{E}-01$ & u235 & $3.04 \mathrm{E}-01$ & u235 & $3.06 \mathrm{E}-01$ \\
\hline 2 & u238 & $2.35 \mathrm{E}-01$ & u238 & $2.38 \mathrm{E}-01$ & u238 & $2.38 \mathrm{E}-01$ & u238 & 2. $38 \mathrm{E}-01$ & u238 & $2.38 \mathrm{E}-01$ \\
\hline 3 & pu239 & $2.29 \mathrm{E}-01$ & pu239 & $2.36 \mathrm{E}-01$ & pu239 & $2.36 \mathrm{E}-01$ & pu239 & 2. $36 \mathrm{E}-01$ & pu239 & $2.36 \mathrm{E}-01$ \\
\hline 4 & pu240 & $5.14 \mathrm{E}-02$ & pu240 & $5.18 \mathrm{E}-02$ & pu240 & $5.17 \mathrm{E}-02$ & pu240 & $5.17 \mathrm{E}-02$ & pu240 & $5.16 \mathrm{E}-02$ \\
\hline 5 & pu241 & $4.38 \mathrm{E}-02$ & pu241 & $3.53 \mathrm{E}-02$ & pu241 & $2.77 \mathrm{E}-02$ & pu241 & $2.18 \mathrm{E}-02$ & am241 & $2.56 \mathrm{E}-02$ \\
\hline 6 & u236 & $7.89 \mathrm{E}-03$ & $\operatorname{am} 241$ & $8.47 \mathrm{E}-03$ & am241 & $1.39 \mathrm{E}-02$ & am241 & $1.80 \mathrm{E}-02$ & pu241 & 1.06E-02 \\
\hline 7 & np237 & $3.90 \mathrm{E}-03$ & u236 & $7.95 \mathrm{E}-03$ & u236 & $7.96 \mathrm{E}-03$ & u236 & 7.9 & u236 & $7.97 \mathrm{E}-03$ \\
\hline 8 & pu242 & $1.74 \mathrm{E}-03$ & np237 & $4.02 \mathrm{E}-03$ & np237 & $4.04 \mathrm{E}-03$ & np237 & $4.08 \mathrm{E}-03$ & np237 & $4.25 \mathrm{E}-03$ \\
\hline 9 & am241 & $1.49 \mathrm{E}-03$ & pu242 & $1.74 \mathrm{E}-03$ & pu242 & $1.74 \mathrm{E}-03$ & pu242 & 1.7 & pu242 & $1.74 \mathrm{E}-03$ \\
\hline 10 & pu238 & 1. $30 \mathrm{E}-03$ & pu238 & $1.39 \mathrm{E}-03$ & pu238 & $1.34 \mathrm{E}-03$ & pu238 & -03 & u234 & $1.27 \mathrm{E}-03$ \\
\hline 11 & u234 & 1. $11 \mathrm{E}-03$ & u234 & $1.15 \mathrm{E}-03$ & u234 & $1.18 \mathrm{E}-03$ & u234 & $1.20 \mathrm{E}-03$ & pu238 & $1.15 \mathrm{E}-03$ \\
\hline 12 & $\operatorname{am} 243$ & $4.52 \mathrm{E}$ & am243 & 4.56 & am243 & 4.56 & $\operatorname{am} 243$ & & am243 & $4.55 \mathrm{E}-04$ \\
\hline 13 & am242m & $2.62 \mathrm{E}-04$ & am242m & $2.63 \mathrm{E}-04$ & am242m & $2.57 \mathrm{E}-04$ & am242m & 2.51 & $a m 242 m$ & $2.35 \mathrm{E}-04$ \\
\hline 14 & np239 & 2. $43 \mathrm{E}-04$ & $\mathrm{~cm} 244$ & $2.52 \mathrm{E}-05$ & $\mathrm{~cm} 244$ & $2.08 \mathrm{E}-05$ & $\mathrm{~cm} 244$ & $1.72 \mathrm{E}-05$ & $\mathrm{~cm} 245$ & $1.60 \mathrm{E}-05$ \\
\hline 15 & $\mathrm{~cm} 244$ & $3.02 \mathrm{E}-05$ & $\mathrm{~cm} 245$ & $1.59 \mathrm{E}-05$ & cm245 & $1.59 \mathrm{E}-05$ & $\mathrm{~cm} 245$ & 1.5 & $\mathrm{~cm} 244$ & $9.70 \mathrm{E}-06$ \\
\hline 16 & np238 & $2.03 \mathrm{E}-05$ & $\mathrm{~cm} 243$ & $8.40 \mathrm{E}-06$ & $\mathrm{~cm} 243$ & 7. $44 \mathrm{E}-06$ & $\mathrm{~cm} 243$ & 6.5 & $\mathrm{~cm} 243$ & $4.58 \mathrm{E}-06$ \\
\hline 17 & $\mathrm{~cm} 242$ & $1.90 \mathrm{E}-05$ & u233 & $7.38 \mathrm{E}-08$ & u233 & $8.78 \mathrm{E}-08$ & $\operatorname{th} 230$ & 1. $15 \mathrm{E}-07$ & th230 & $2.17 \mathrm{E}-07$ \\
\hline 18 & $\mathrm{~cm} 245$ & $1.55 \mathrm{E}-05$ & $\operatorname{th} 230$ & $5.04 \mathrm{E}-08$ & $\operatorname{th} 230$ & $8.23 \mathrm{E}-08$ & u233 & $1.02 \mathrm{E}-07$ & u233 & $1.44 \mathrm{E}-07$ \\
\hline 19 & $\mathrm{~cm} 243$ & $9.35 \mathrm{E}-06$ & $\mathrm{~cm} 246$ & $2.55 \mathrm{E}-08$ & $\mathrm{~cm} 246$ & $2.55 \mathrm{E}-08$ & $\mathrm{~cm} 246$ & $2.55 \mathrm{E}-08$ & $\mathrm{~cm} 246$ & $2.54 \mathrm{E}-08$ \\
\hline & & $3.78 \mathrm{E}-06$ & u232 & $1.74 \mathrm{E}-08$ & u232 & $2.00 \mathrm{E}-08$ & u232 & $2.01 \mathrm{E}-08$ & u232 & $1.77 \mathrm{E}-08$ \\
\hline
\end{tabular}

Fraction of total absorption rate - fission products

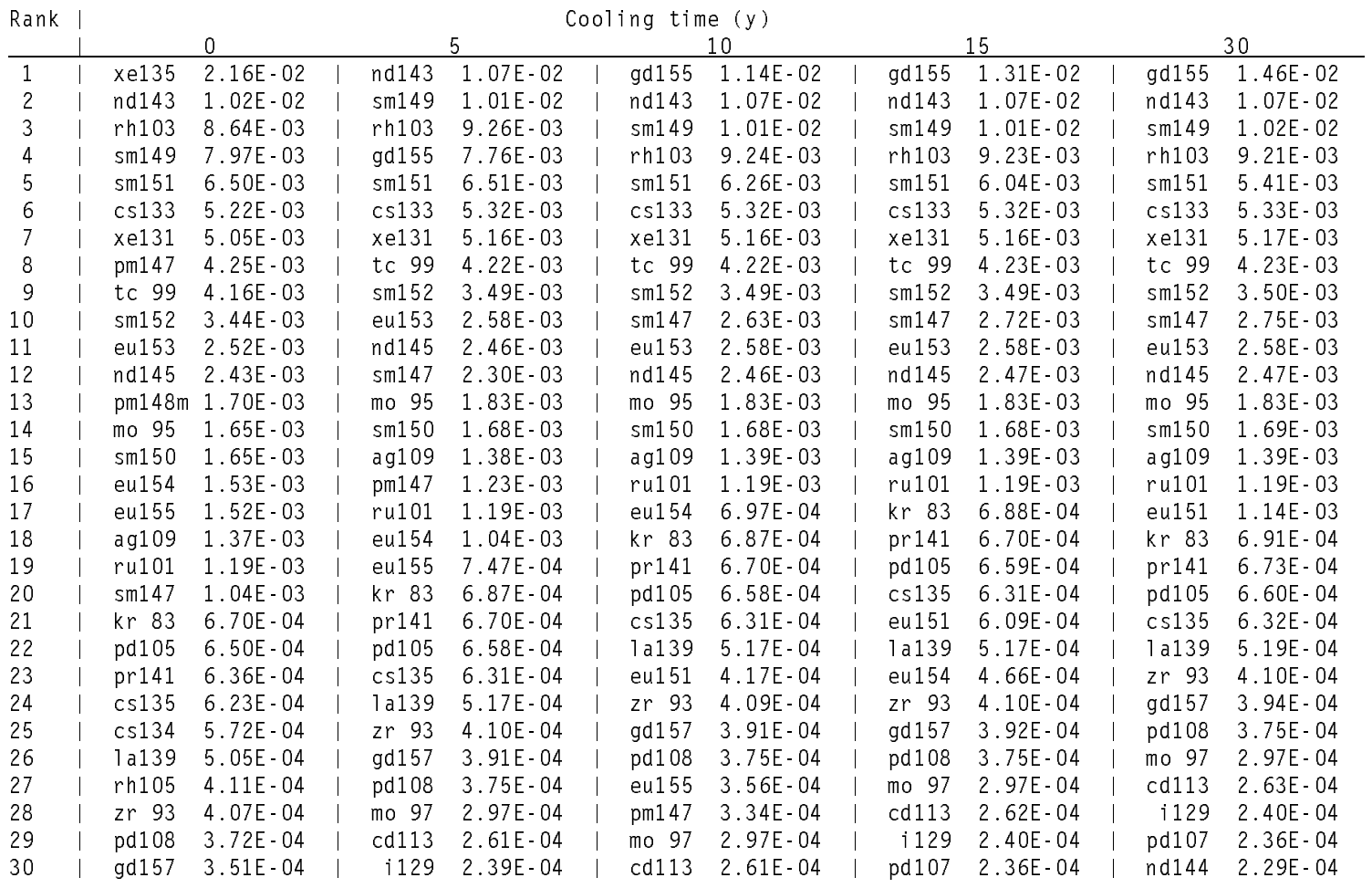


4.5 wt \% U-235, 50 GWd/MTU Burnup

\begin{tabular}{lccccc} 
& \multicolumn{4}{c}{ Cooling time $(y)$} \\
& 0 & 5 & 10 & 15 & 30 \\
Productions & $7.380 \mathrm{E}+4$ & $7.143 \mathrm{E}+4$ & $6.944 \mathrm{E}+4$ & $6.787 \mathrm{E}+4$ & $6.491 \mathrm{E}+4$ \\
Absorptions & $7.030 \mathrm{E}+4$ & $6.930 \mathrm{E}+4$ & $6.952 \mathrm{E}+4$ & $6.950 \mathrm{E}+4$ & $6.904 \mathrm{E}+4$ \\
k-infinity & $1.050 \mathrm{E}+0$ & $1.031 \mathrm{E}+0$ & $9.987 \mathrm{E}-1$ & $9.766 \mathrm{E}-1$ & $9.402 \mathrm{E}-1$ \\
Act. abs & $5.851 \mathrm{E}+4$ & $5.805 \mathrm{E}+4$ & $5.779 \mathrm{E}+4$ & $5.753 \mathrm{E}+4$ & $5.692 \mathrm{E}+4$ \\
Non-actinide & & & & & \\
Abs. fraction & $1.678 \mathrm{E}-1$ & $1.623 \mathrm{E}-1$ & $1.688 \mathrm{E}-1$ & $1.722 \mathrm{E}-1$ & $1.756 \mathrm{E}-1$
\end{tabular}

Fraction of total absorption rate - actinides

\begin{tabular}{|c|c|c|c|c|c|c|c|c|c|c|c|c|c|c|}
\hline \multirow[t]{2}{*}{ Rank } & \multicolumn{14}{|c|}{ Cooling time $(y)$} \\
\hline & & 0 & & 5 & 5 & & & 10 & & & 15 & & & 30 \\
\hline 1 & pu239 & $2.60 \mathrm{E}-01$ & & pu239 & $2.65 \mathrm{E}-01$ & & pu239 & $2.64 \mathrm{E}-01$ & & 4239 & $2.64 \mathrm{E}-01$ & & pu239 & $2.65 \mathrm{E}-01$ \\
\hline 2 & u238 & $2.38 \mathrm{E}-01$ & & u238 & $2.40 \mathrm{E}-01$ & & u238 & $2.40 \mathrm{E}-01$ & & u238 & $2.40 \mathrm{E}-01$ & & u238 & $2.40 \mathrm{E}-01$ \\
\hline 3 & u235 & $1.53 \mathrm{E}-01$ & 1 & $u 235$ & $1.55 \mathrm{E}-01$ & & $u 235$ & $1.55 \mathrm{E}-01$ & & u235 & $1.55 \mathrm{E}-01$ & & u235 & $1.56 \mathrm{E}-01$ \\
\hline 4 & pu241 & $7.60 \mathrm{E}-02$ & | & pu240 & $7.09 \mathrm{E}-02$ & & pu240 & $7.08 \mathrm{E}-02$ & & pu240 & $7.09 \mathrm{E}-02$ & & pu240 & $7.11 \mathrm{E}-02$ \\
\hline 5 & pu240 & $7.03 \mathrm{E}-02$ & I & pu241 & $6.06 \mathrm{E}-02$ & & pu241 & $4.74 \mathrm{E}-02$ & & pu241 & $3.73 \mathrm{E}-02$ & & $\mathrm{~m} 241$ & $4.27 \mathrm{E}-02$ \\
\hline 6 & u236 & $9.39 \mathrm{E}-03$ & I & $a \mathrm{~m} 241$ & $1.47 \mathrm{E}-02$ & & $\operatorname{am} 241$ & $2.34 \mathrm{E}-02$ & & $\operatorname{am} 241$ & $3.02 \mathrm{E}-02$ & | & pu241 & $1.82 \mathrm{E}-02$ \\
\hline 7 & np237 & $7.57 \mathrm{E}-03$ & | & $u 236$ & $9.46 \mathrm{E}-03$ & & $\mathrm{u} 236$ & $9.46 \mathrm{E}-03$ & & $u 236$ & $9.47 \mathrm{E}-03$ & & u236 & $9.48 \mathrm{E}-03$ \\
\hline 8 & pu238 & $4.92 \mathrm{E}-03$ & I & np237 & $7.72 \mathrm{E}-03$ & & np237 & $7.75 \mathrm{E}-03$ & & np237 & $7.81 \mathrm{E}-03$ & & np237 & $8.10 \mathrm{E}-03$ \\
\hline 9 & pu242 & $4.89 \mathrm{E}-03$ & I & pu238 & $5.16 \mathrm{E}-03$ & & pu238 & $4.94 \mathrm{E}-03$ & & pu242 & $4.89 \mathrm{E}-03$ & & pu242 & $4.88 \mathrm{E}-03$ \\
\hline 10 & am241 & $3.23 \mathrm{E}-03$ & | & pu242 & $4.90 \mathrm{E}-03$ & & pu242 & $4.89 \mathrm{E}-03$ & & pu238 & $4.75 \mathrm{E}-03$ & & pu238 & $4.26 \mathrm{E}-03$ \\
\hline 11 & am243 & $2.42 \mathrm{E}-03$ & 1 & am243 & $2.43 \mathrm{E}-03$ & & am243 & $2.43 \mathrm{E}-03$ & & $a m 243$ & $2.42 \mathrm{E}$ & & am243 & $2.42 \mathrm{E}-03$ \\
\hline 12 & u234 & $8.67 \mathrm{E}-04$ & | & u234 & $9.68 \mathrm{E}-04$ & & u234 & $1.06 \mathrm{E}-03$ & & u234 & $1.14 \mathrm{E}-03$ & & u234 & $1.38 \mathrm{E}-03$ \\
\hline 13 & $a m 242 m$ & $6.55 \mathrm{E}-04$ & | & $a m 242 m$ & $6.49 \mathrm{E}-04$ & & $a m 242 m$ & $6.31 \mathrm{E}-04$ & & $a m 242 m$ & $6.16 \mathrm{E}-04$ & & $a m 242 m$ & $5.77 \mathrm{E}-04$ \\
\hline 14 & $\mathrm{~cm} 244$ & $3.09 \mathrm{E}-04$ & $\mid$ & $\mathrm{cm} 244$ & $2.58 \mathrm{E}-04$ & & $\mathrm{~cm} 245$ & $2.53 \mathrm{E}-04$ & & $\mathrm{~cm} 245$ & 2.5 & & $\mathrm{~cm} 245$ & $2.55 \mathrm{E}-04$ \\
\hline 15 & np239 & $2.88 \mathrm{E}-04$ & | & $\mathrm{cm} 245$ & $2.54 \mathrm{E}-04$ & & $\mathrm{~cm} 244$ & $2.13 \mathrm{E}-04$ & & $\mathrm{~cm} 244$ & $1.77 \mathrm{E}-04$ & & $\mathrm{~cm} 244$ & $1.00 \mathrm{E}-04$ \\
\hline 16 & $\mathrm{~cm} 245$ & $2.51 \mathrm{E}-04$ & | & $\mathrm{cm} 243$ & $3.92 \mathrm{E}-05$ & & $\mathrm{~cm} 243$ & $3.47 \mathrm{E}-05$ & & $\mathrm{~cm} 243$ & $3.07 \mathrm{E}-05$ & & $\mathrm{~cm} 243$ & $2.14 \mathrm{E}-05$ \\
\hline 17 & $\mathrm{~cm} 242$ & $5.75 \mathrm{E}-05$ & $\mid$ & $\mathrm{cm} 246$ & $8.26 \mathrm{E}-07$ & & $\mathrm{~cm} 246$ & $8.25 \mathrm{E}-07$ & & $\mathrm{~cm} 246$ & $8.24 \mathrm{E}-07$ & & $\mathrm{~cm} 246$ & $8.22 \mathrm{E}-07$ \\
\hline 18 & np238 & $4.95 \mathrm{E}-05$ & | & $\mathrm{cm} 247$ & $2.90 \mathrm{E}-07$ & & $\mathrm{~cm} 247$ & $2.90 \mathrm{E}-07$ & & $\mathrm{~cm} 247$ & 2.90 & & $\mathrm{~cm} 247$ & $2.90 \mathrm{E}-07$ \\
\hline 19 & $\mathrm{~cm} 243$ & $4.39 \mathrm{E}-05$ & | & u233 & $1.01 \mathrm{E}-07$ & & u233 & $1.28 \mathrm{E}-07$ & & u233 & $1.56 \mathrm{E}-07$ & & u233 & $2.40 \mathrm{E}-07$ \\
\hline 20 & am242 & $1.01 \mathrm{E}-05$ & & u232 & $6.25 \mathrm{E}-08$ & & u232 & $7.06 \mathrm{E}-08$ & & $\operatorname{th} 230$ & $9.92 E-08$ & & th230 & $2.00 \mathrm{E}-07$ \\
\hline
\end{tabular}

Fraction of total absorption rate - fission products

\begin{tabular}{|c|c|c|c|c|c|c|c|c|c|c|c|c|c|c|}
\hline \multirow[t]{2}{*}{ Rank } & & \multirow{2}{*}{\multicolumn{10}{|c|}{ Cooling time $(y)$}} & \multirow{2}{*}{\multicolumn{3}{|c|}{30}} \\
\hline & & & & & & & & & & & & & & \\
\hline 1 & & $x e 135$ & $2.12 \mathrm{E}-02$ & & gd155 & $2.10 \mathrm{E}-02$ & & gd155 & $3.05 \mathrm{E}-02$ & gd155 & $3.51 \mathrm{E}-02$ & & gd155 & $3.93 \mathrm{E}-02$ \\
\hline 2 & & nd143 & $1.51 \mathrm{E}-02$ & & nd143 & $1.55 \mathrm{E}-02$ & & nd143 & $1.54 \mathrm{E}-02$ & nd143 & $1.54 \mathrm{E}-02$ & & nd 143 & $1.55 \mathrm{E}-02$ \\
\hline 3 & & rh103 & $1.27 \mathrm{E}-02$ & 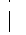 & rh103 & $1.34 \mathrm{E}-02$ & & rh103 & $1.33 \mathrm{E}-02$ & 103 & $1.33 \mathrm{E}-02$ & & 103 & $1.33 \mathrm{E}-02$ \\
\hline 4 & & sm151 & $8.69 \mathrm{E}-03$ & & sm149 & $1.02 \mathrm{E}-02$ & & sm149 & $1.02 \mathrm{E}-02$ & $\operatorname{sm} 149$ & $1.02 \mathrm{E}-02$ & | & n149 & \\
\hline 5 & & $\operatorname{cs} 133$ & $7.88 \mathrm{E}-03$ & 1 & sm151 & $8.56 \mathrm{E}-03$ & & sm151 & $8.19 \mathrm{E}-03$ & $\operatorname{cs} 133$ & $7.99 \mathrm{E}-03$ & I & s133 & $8.01 \mathrm{E}-03$ \\
\hline 6 & & $\operatorname{sm} 149$ & $7.82 \mathrm{E}-03$ & & $\operatorname{cs} 133$ & $7.98 \mathrm{E}-03$ & & $\operatorname{cs} 133$ & $7.98 \mathrm{E}-03$ & $\mathrm{~m} 151$ & $7.89 \mathrm{E}-03$ & & 131 & \\
\hline 7 & & 131 & 7. $04 \mathrm{E}-03$ & 1 & xe131 & -03 & & xe131 & $7.12 \mathrm{E}-03$ & 131 & 7.1 & & 151 & \\
\hline 8 & & tc 99 & $6.30 \mathrm{E}-03$ & 1 & tc 99 & 6.3 & & tc 99 & $6.37 \mathrm{E}-03$ & 99 & 6.37 & | & 99 & \\
\hline 9 & & sm152 & $5.11 \mathrm{E}-03$ & & sm152 & 5 & & sm152 & $5.16 \mathrm{E}-03$ & 152 & 5 & & 152 & \\
\hline 10 & & & $4.94 \mathrm{E}$ & & & & & & $5.00 \mathrm{E}$ & 53 & & & & \\
\hline 11 & & pm147 & $4.29 \mathrm{E}-03$ & & 45 & 3.7 & & nd145 & $3.78 \mathrm{E}-03$ & 145 & 3. & | & 145 & \\
\hline 12 & & eu154 & $4.13 \mathrm{E}-03$ & & & & & sm147 & $3.32 \mathrm{E}-03$ & 147 & & & 147 & \\
\hline 13 & & & $4.06 \mathrm{E}$ & & 50 & 2.8 & & sm150 & $2.87 \mathrm{E}$ & 150 & & & 150 & \\
\hline 14 & & nd 145 & $3.75 \mathrm{E}-03$ & & eu154 & 2.7 & & mo 95 & $2.78 \mathrm{E}-03$ & ag109 & $2.7 \varepsilon$ & ( & 95 & 2. \\
\hline 15 & & & $2.85 \mathrm{E}-03$ & & & & & & $2.77 \mathrm{E}$ & & & & 109 & \\
\hline 16 & & 09 & $2.75 \mathrm{E}$ & & & 2.7 & & 01 & 1.96 & 101 & 1. & & 01 & \\
\hline 17 & & mo 95 & $2.63 \mathrm{E}-03$ & & eu155 & 1.9 & & eu154 & $1.85 \mathrm{E}-03$ & d105 & 1.3 & 1 & eu151 & 1. \\
\hline 18 & & ru101 & 1.95 & & & & & & 1.35 & 154 & & & 105 & \\
\hline 19 & & & 1.83 & & & 1. & & 41 & 1.13 & 41 & 1 & & 41 & \\
\hline 20 & & sm147 & 1.74E- 03 & & 47 & 1.2 & & $\operatorname{cs} 135$ & $1.03 \mathrm{E}-03$ & s135 & 1. & & $\operatorname{cs} 135$ & \\
\hline 21 & & $\operatorname{cs} 134$ & $1.35 \mathrm{E}-03$ & & pr141 & 1.1 & & $\mathrm{kr} 83$ & $9.75 \mathrm{E}-04$ & $r 83$ & 9. & & $\mathrm{kr} 83$ & 9. \\
\hline 22 & & & 1.34 & & & & & & 9.33 & 139 & & & la139 & \\
\hline 23 & & 41 & 1.10 & & $\mathrm{kr} 83$ & 9.7 & & 39 & $8.83 \mathrm{E}$ & d108 & 8. & & 08 & \\
\hline 24 & & $\operatorname{cs} 135$ & $1.03 \mathrm{E}-03$ & & la139 & 8.8 & & $\mathrm{pd} 108$ & $8.59 \mathrm{E}-04$ & gd157 & 7.75 & & gd 157 & -04 \\
\hline 25 & & $\mathrm{kr} 83$ & $9.65 \mathrm{E}-04$ & & & & & & $7.78 \mathrm{E}-04$ & eu151 & & & 93 & \\
\hline 26 & & la139 & $8.75 \mathrm{E}-\mathrm{C}$ & & gd157 & 7.8 & & zr 93 & $6.39 \mathrm{E}-04$ & 93 & & & 107 & \\
\hline 27 & & pd108 & $8.56 \mathrm{E}-04$ & & zr 93 & $6.40 \mathrm{E}-04$ & & pd107 & $5.49 \mathrm{E}-04$ & pd107 & $5.49 \mathrm{E}-04$ & & mo 97 & $4.93 E-04$ \\
\hline 28 & & gd157 & $7.17 \mathrm{E}-04$ & & pd107 & -04 & & eu151 & $5.26 \mathrm{E}-04$ & mo 97 & & & $i 129$ & \\
\hline 29 & & $\operatorname{zr} 93$ & $6.37 \mathrm{E}-04$ & & mo 97 & 4. & & mo 97 & $4.92 \mathrm{E}-04$ & eu155 & & & nd 144 & \\
\hline 30 & & $\operatorname{gd} 155$ & $5.83 \mathrm{E}-04$ & & $i 129$ & $4.38 \mathrm{E}-04$ & & $i 129$ & $4.36 \mathrm{E}-04$ & $i 129$ & $4.36 \mathrm{E}-04$ & & $\operatorname{gd} 154$ & $4.16 \mathrm{E}-\mathrm{C}$ \\
\hline
\end{tabular}




\section{APPENDIX B}

\section{STATISTICAL METHODS FOR TREATING ISOTOPIC CALCULATIONAL BIAS}

Because it is not feasible to determine experimentally the multiplication factor of an array of fuel assemblies during the loading of spent fuel casks, it is necessary to derive loading limits for casks using computational methods. The American National Standard for Nuclear Criticality Safety in Operations with Fissionable Material Outside Reactors (ANSI/ANS-8.1 1 .1.1 states the following: "Bias shall be established by correlating the results of criticality experiments with results obtained for these same systems by the method being validated." Specific guidance for use of calculational methods in the analysis of LWR fuel is provided in the American National Standard for Criticality Safety Criteria for the Handling, Storage, and Transportation of LWR Fuel Outside Reactors (ANSI/ANS-8.17) B.2 In anticipated spent fuel applications, the isotopic composition of a spent fuel unit will not be measured directly and must be computed from initial conditions and exposure history, and therefore has potential to introduce calculational uncertainty. Until sufficient data are available for spent fuel criticals, any bias and uncertainty determined based on calculations of critical configurations cannot be assumed to account for uncertainty in spent fuel isotopics. Thus it is necessary to determine an independent approach that can be used to make a conservative account for the uncertainties and biases associated with the calculation of isotopic composition.

In order to determine bias and uncertainty terms, both measured data and computed isotopic data based on the experimental measurements are required for each individual isotope. This section provides (1) the background, source, and results of experimental measurements of selection isotopic concentrations in spent fuel; and (2) a statistical technique for the determination of an isotopic correction factor to account for biases and uncertainties in both computed and measured isotopic concentrations, together with isotopic correction factors computed using this approach, the results of the experimental measurements, and the corresponding calculated concentrations.

\section{B.1 CHEMICAL ASSAY MEASUREMENTS}

Two well-documented sources of experimental measurements have been identified with respect to the actinides and fission products selected for burnup credit: (1) data from the Materials Characterization Center (MCC) at the Pacific Northwest Laboratorie 3.3 .3 (PNL) and (2) data from a consortium of European laboratories based on fuel taken from the German Obrigheim reactor B.4. The fuel assemblies analyzed at the MCC consisted of three $14 \times 14$ Combustion Engineering $(\mathrm{CE})$ assemblies from the Calvert Cliffs Unit 1 reactor and one $15 \times 15$ Westinghouse assembly from the H. B. Robinson Unit 2. From each assembly, a specific fuel pin was selected for study. The MCC data were selected as a basis for validation because of detailed fuel information collected before assemblies were destructively assayed. These data included reactor, assembly, and fuel pin specifications, irradiation histories, a description of unusual events that occurred during each assembly's lifetime, burnup measurements, and detailed axial scans using gamma spectroscopy. In addition, radiochemical assays were performed on individual fuel pellets taken from three (Calvert Cliffs) or four (H. B. Robinson) axial positions in each fuel rod studied in order to provide a 
distribution of burnups. For each pellet, measurements were performed for the major actinides, cesium isotopes, and ${ }^{99} \mathrm{Tc}$. Other fission products of importance to burnup credit activities were subsequently measured for one of the Calvert Cliffs assemblies. Fission product assays for this single sample were performed by independent organizations at PNL, Los Alamos National Laboratory (LANL), and the Khlopin Radium Institute (KRI) in St. Petersburg, Russia.

The Obrigheim data were chosen because they represented assembly-averaged data. The Obrigheim fuel was assayed by two methods: In the first approach a fuel assembly was physically divided into full-length halves. One 12-ft half from each assembly was then dissolved and assayed. In the second method, individual fuel pellets were removed from a specific pin in the remaining halfassembly and assayed in a manner similar to the MCC data; however, individual pellet data have not been included in current validation work. (The results from the dissolved assembly analyses provide "assembly-averaged" isotopic values that, in comparison with individual pellet measurements, are more consistent with the spatially independent point-depletion techniques typically used to characterize fuel for away-from-reactor applications.) Obrigheim data are based on samples that were independently evaluated at four different European laboratories.

Between the MCC and Obrigheim measurements, assays were performed on a total of 19 different samples. Because selected fission products were measured based only on three locations in a single Calvert Cliffs, only three data points exist for these nuclides. On the other hand, primary actinides such as ${ }^{235} \mathrm{U}$ were measured in all assays at all facilities. In some cases, specific isotopic measurements were not performed or were not reported by various facilities. Thus the measured data range from 3 to 19 samples per isotope.

The radiochemical analyses of spent fuel isotopic compositions were performed at several different laboratories. The fuel samples from the Calvert Cliffs and H. B. Robinson reactors (or 68\% of the cases) were analyzed by the MCC at PNL. The MCC is responsible for providing spent fuel Approved Testing Materials (ATMs) for radiochemical measurements conducted by PNL for the Department of Energy (DOE) Office of Civilian Radioactive Waste Management (OCRWM). Approved QA procedures were applied in these analyses. An estimate of the standard deviation uncertainty of each type of analytical measurement was included in the data documentation. Although a minor part of the isotopic measurement uncertainty was at a somewhat high level, there was a more significant part of the analysis uncertainty in the range of 1.6 to 5\%. Thus with regard to both the QA procedures and the effective experimental precision, the radiochemical analyses conducted by the MCC for the OCRWM project reported here are qualified for application in a validation approach.

Fuel samples from the Obrigheim PWR in Germany were analyzed independently by four European laboratories: European Institute for Transuranic Elements (TUI), Institute for Radiochemistry (IRCH), Karlsruhe Reprocessing Plant (WAK), and the International Atomic Energy Agency (IAEA). Analytical methods ensuring accuracy, such as the domestic QA procedures, are not referenced in the available documentation of the measured data. Also, explicit uncertainties of the measurements for isotopes significant to burnup credit were not completely presented with the data. However, the scatter in the data of significant isotopes from independent measurements of four laboratories was appropriately small, thus the analyses are similarly qualified for application in a validation approach. 
For each of the 19 experimentally measured samples, SAS2H calculations were performed based on the initial composition and the unique operating history of each sample. These calculations and their results are described in detail in ref. B.5. Isotopic concentration results for each of these calculations are given in Tables B-1 through B-19 for the 19 different samples, along with the results of the one to four measurements performed on each nuclide for each sample. Blank entries in the table represent isotopic measurements that were not performed or not reported. These tables include only burnup credit nuclides, although in many cases other nuclides were assayed (see ref. B.5).

For mass numbers 147,151 , and 155 , assay measurements were unable to distinguish between the multiple isotopes present. Thus measured values are reported for the combined concentrations of isotopes of each mass. Since SAS2H calculations are not affected by the limitations of mass spectroscopy, calculations yielded concentrations for each unique nuclide. Thus in Tables B-1 through B-3, representing samples for which measurements were made for each of these mass numbers, the calculated value is given for each isotope in the measurement, together with the sum of all calculations for the given mass number. This sum is compared with the combined measured concentration to obtain the relative error. It is assumed that this error applies to each isotope individually. 
122

Table B-1. ATM-104, fuel assembly D047, rod MKP109 at $13.20 \mathrm{~cm}, 27.35 \mathrm{GWd} / \mathrm{MTU}$

\begin{tabular}{|c|c|c|c|c|c|c|c|}
\hline $\begin{array}{c}\text { Nuclide } \\
\text { (Z and name) }\end{array}$ & $\begin{array}{l}\text { Calculated } \\
\text { concentration } \\
\left(\mathrm{mg} / \mathrm{g} \mathrm{UO}_{2}\right)\end{array}$ & $\begin{array}{l}\text { Measurement } 1 \\
\text { MCC at PNL }^{a} \\
\left(\mathrm{mg} / \mathrm{g} \mathrm{UO}_{2}\right)\end{array}$ & $\frac{\left(\mathrm{C}-\mathrm{M}_{1}\right)}{\mathrm{M}_{1}}$ & $\begin{array}{c}\text { Measurement } \\
2 \\
\text { KRI, Russia }^{b} \\
\left(\mathrm{mg} / \mathrm{g} \mathrm{UO}_{2}\right) \\
\end{array}$ & $\frac{\left(\mathrm{C}-\mathrm{M}_{2}\right)}{\mathrm{M}_{2}}$ & $\begin{array}{c}\text { Measurement } \\
3 \\
\mathrm{LANL}^{b} \\
\left(\mathrm{mg} / \mathrm{g} \mathrm{UO}_{2}\right) \\
\end{array}$ & $\frac{\left(\mathrm{C}-\mathrm{M}_{3}\right)}{\mathrm{M}_{3}}$ \\
\hline 43 tc 99 & $1.005 \mathrm{E}-5^{\mathrm{c}}$ & $9.590 \mathrm{E}-6^{c}$ & $4.80 \%$ & & & & \\
\hline $55 \operatorname{cs} 133$ & 8.601E-1 & $8.500 \mathrm{E}-1$ & $1.19 \%$ & & & & \\
\hline $55 \operatorname{cs} 135$ & $3.935 \mathrm{E}-1$ & $3.600 \mathrm{E}-1$ & $9.31 \%$ & & & & \\
\hline 60 nd143 & $6.206 \mathrm{E}-1$ & $6.171 \mathrm{E}-1$ & $0.57 \%$ & $6.212 \mathrm{E}-1$ & $-0.10 \%$ & $6.222 \mathrm{E}-1$ & $-0.26 \%$ \\
\hline 60 nd145 & $5.131 \mathrm{E}-1$ & $5.100 \mathrm{E}-1$ & $0.61 \%$ & $5.100 \mathrm{E}-1$ & $0.61 \%$ & $5.100 \mathrm{E}-1$ & $0.61 \%$ \\
\hline $61 \mathrm{pm} 147$ & $3.085 \mathrm{E}-2$ & & & & & & \\
\hline $62 \operatorname{sm} 147$ & $1.859 \mathrm{E}-1$ & & & & & & \\
\hline $\begin{array}{r}62 \mathrm{pm} 147 \\
+\mathrm{sm} 147\end{array}$ & $2.167 \mathrm{E}-1$ & $2.173 \mathrm{E}-1$ & $-0.28 \%$ & $2.030 \mathrm{E}-1$ & $6.75 \%$ & $2.188 \mathrm{E}-1$ & $-0.96 \%$ \\
\hline $62 \operatorname{sm} 149$ & $2.169 \mathrm{E}-3$ & $2.856 \mathrm{E}-3$ & $-24.05 \%$ & $2.397 \mathrm{E}-3$ & $-9.51 \%$ & $1.989 \mathrm{E}-3$ & $9.05 \%$ \\
\hline $62 \operatorname{sm} 150$ & $2.030 \mathrm{E}-1$ & $1.993 \mathrm{E}-1$ & $1.86 \%$ & $1.942 \mathrm{E}-1$ & $4.53 \%$ & $2.009 \mathrm{E}-1$ & $1.05 \%$ \\
\hline $62 \operatorname{sm} 151$ & $1.012 \mathrm{E}-2$ & & & & & & \\
\hline 63 eu151 & $4.320 \mathrm{E}-4$ & & & & & & \\
\hline $\begin{array}{ll}63 & \operatorname{sm} 151 \\
& +\mathrm{eu} 151\end{array}$ & $1.055 \mathrm{E}-2$ & $8.925 \mathrm{E}-3$ & $18.21 \%$ & $8.109 \mathrm{E}-3$ & $30.10 \%$ & $8.415 \mathrm{E}-3$ & $25.37 \%$ \\
\hline $62 \operatorname{sm} 152$ & $9.721 \mathrm{E}-2$ & $8.262 \mathrm{E}-2$ & $17.66 \%$ & $8.007 \mathrm{E}-2$ & $21.41 \%$ & $8.313 \mathrm{E}-2$ & $16.94 \%$ \\
\hline 63 eu153 & $7.443 \mathrm{E}-2$ & $7.446 \mathrm{E}-2$ & $-0.04 \%$ & 7.497E-2 & $-0.72 \%$ & $7.701 \mathrm{E}-2$ & $-3.35 \%$ \\
\hline 63 eu155 & $3.885 \mathrm{E}-3$ & & & & & & \\
\hline $64 \operatorname{gd} 155$ & $4.524 \mathrm{E}-3$ & & & & & & \\
\hline $\begin{array}{r}64 \text { eu155 } \\
+\operatorname{gd} 155\end{array}$ & $8.410 \mathrm{E}-3$ & $4.233 \mathrm{E}-3$ & $98.68 \%$ & $6.426 \mathrm{E}-3$ & $30.87 \%$ & & \\
\hline $92 \mathrm{u} 234$ & $1.612 \mathrm{E}-1$ & $1.600 \mathrm{E}-1$ & $0.75 \%$ & & & & \\
\hline 92 u235 & $8.002 \mathrm{E}+0$ & $8.470 \mathrm{E}+0$ & $-5.53 \%$ & & & & \\
\hline 92 u236 & $3.237 \mathrm{E}+0$ & $3.140 \mathrm{E}+0$ & $3.09 \%$ & & & & \\
\hline 92 u238 & $8.372 \mathrm{E}+2$ & $8.425 \mathrm{E}+2$ & $-0.63 \%$ & & & & \\
\hline 94 pu238 & $9.789 \mathrm{E}-2$ & $1.010 \mathrm{E}-1$ & $-3.08 \%$ & & & & \\
\hline 94 pu239 & $4.280 \mathrm{E}+0$ & $4.264 \mathrm{E}+0$ & $0.38 \%$ & & & & \\
\hline 94 pu240 & $1.614 \mathrm{E}+0$ & $1.719 \mathrm{E}+0$ & $-6.11 \%$ & & & & \\
\hline 94 pu241 & $7.087 \mathrm{E}-1$ & $6.810 \mathrm{E}-1$ & $4.07 \%$ & & & & \\
\hline 94 pu242 & $2.769 \mathrm{E}-1$ & $2.890 \mathrm{E}-1$ & $-4.19 \%$ & & & & \\
\hline 95 am241 & $8.572 \mathrm{E}-4^{c}$ & $8.560 \mathrm{E}-4^{c}$ & $0.14 \%$ & & & & \\
\hline
\end{tabular}

${ }^{a}$ See ref. B.5.

${ }^{b}$ See ref. B.3.

${ }^{c}$ Curies/g-UO ${ }_{2}$. 
Table B-2. ATM-104, fuel assembly D047, rod MKP109 at $27.70 \mathrm{~cm}, 37.12 \mathrm{GWd} / \mathrm{MTU}$

\begin{tabular}{|c|c|c|c|}
\hline $\begin{array}{c}\text { Nuclide } \\
\text { (Z and name) }\end{array}$ & $\begin{array}{l}\text { Calculated } \\
\text { concentration } \\
\left(\mathrm{mg} / \mathrm{g} \mathrm{UO}_{2}\right)\end{array}$ & 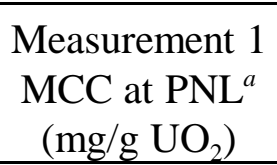 & $\frac{\left(C-M_{1}\right)}{M_{1}}$ \\
\hline 43 tc 99 & $1.303 \mathrm{E}-5^{b}$ & $1.230 \mathrm{E}-5^{b}$ & $5.93 \%$ \\
\hline $55 \mathrm{cs} 133$ & $1.110 \mathrm{E}+0$ & $1.090 \mathrm{E}+0$ & $1.83 \%$ \\
\hline $55 \operatorname{cs} 135$ & 4.317E-1 & $4.000 \mathrm{E}-1$ & $7.92 \%$ \\
\hline $60 \mathrm{nd} 143$ & 7.234E-1 & $7.160 \mathrm{E}-1$ & $1.03 \%$ \\
\hline 60 nd145 & $6.547 \mathrm{E}-1$ & $6.530 \mathrm{E}-1$ & $0.26 \%$ \\
\hline $61 \mathrm{pm} 147$ & $3.455 \mathrm{E}-2$ & & \\
\hline $62 \operatorname{sm} 147$ & $2.078 \mathrm{E}-1$ & & \\
\hline $\begin{array}{r}62 \mathrm{pm} 147 \\
+\mathrm{sm} 147\end{array}$ & $2.423 \mathrm{E}-1$ & $2.540 \mathrm{E}-1$ & $-4.61 \%$ \\
\hline $62 \mathrm{sm} 149$ & $2.371 \mathrm{E}-3$ & $3.000 \mathrm{E}-3$ & $-20.97 \%$ \\
\hline $62 \operatorname{sm} 150$ & $2.840 \mathrm{E}-1$ & $2.710 \mathrm{E}-1$ & $4.80 \%$ \\
\hline $62 \operatorname{sm} 151$ & $1.148 \mathrm{E}-2$ & & \\
\hline 63 eu151 & $4.811 \mathrm{E}-4$ & & \\
\hline $\begin{array}{ll}63 & \text { sm151 } \\
& + \text { eu151 }\end{array}$ & $1.196 \mathrm{E}-2$ & $9.300 \mathrm{E}-3$ & $28.60 \%$ \\
\hline $62 \operatorname{sm} 152$ & $1.258 \mathrm{E}-1$ & $1.040 \mathrm{E}-1$ & $20.96 \%$ \\
\hline 63 eu153 & $1.095 \mathrm{E}-1$ & $1.090 \mathrm{E}-1$ & $0.46 \%$ \\
\hline 63 eu155 & $6.790 \mathrm{E}-3$ & & \\
\hline $64 \operatorname{gd} 155$ & $7.854 \mathrm{E}-3$ & & \\
\hline $\begin{array}{r}64 \text { eu155 } \\
+ \text { gd } 155\end{array}$ & $1.464 \mathrm{E}-2$ & $7.100 \mathrm{E}-3$ & $106.20 \%$ \\
\hline 92 u234 & $1.395 \mathrm{E}-1$ & $1.400 \mathrm{E}-1$ & $-0.36 \%$ \\
\hline $92 \mathrm{u} 235$ & $4.723 \mathrm{E}+0$ & $5.170 \mathrm{E}+0$ & $-8.65 \%$ \\
\hline 92 u236 & $3.631 \mathrm{E}+0$ & $3.530 \mathrm{E}+0$ & $2.86 \%$ \\
\hline $92 \mathrm{u} 238$ & $8.298 \mathrm{E}+2$ & $8.327 \mathrm{E}+2$ & $-0.35 \%$ \\
\hline 94 pu238 & $1.881 \mathrm{E}-1$ & $1.890 \mathrm{E}-1$ & $-0.48 \%$ \\
\hline 94 pu239 & $4.415 \mathrm{E}+0$ & $4.357 \mathrm{E}+0$ & $1.33 \%$ \\
\hline 94 pu240 & $2.066 \mathrm{E}+0$ & $2.239 \mathrm{E}+0$ & $-7.73 \%$ \\
\hline 94 pu241 & $9.332 \mathrm{E}-1$ & $9.030 \mathrm{E}-1$ & $3.34 \%$ \\
\hline 94 pu242 & $5.551 \mathrm{E}-1$ & $5.760 \mathrm{E}-1$ & $-3.63 \%$ \\
\hline 95 am241 & $1.103 \mathrm{E}-3^{b}$ & $1.180 \mathrm{E}-3^{b}$ & $-6.53 \%$ \\
\hline
\end{tabular}

${ }^{a}$ See ref. B.5

${ }^{b} \mathrm{Curies} / \mathrm{g}-\mathrm{UO}_{2}$. 
Table B-3. ATM-104, fuel assembly D047, rod MKP109 at $165.22 \mathrm{~cm}, 44.34 \mathrm{GWd} / \mathrm{MTU}$

\begin{tabular}{|c|c|c|c|}
\hline $\begin{array}{c}\text { Nuclide } \\
\text { (Z and name) }\end{array}$ & $\begin{array}{c}\text { Calculated } \\
\text { concentration } \\
\left(\mathrm{mg} / \mathrm{g} \mathrm{UO}_{2}\right) \\
\end{array}$ & $\begin{array}{c}\text { Measurement } 1 \\
\mathrm{MCC} \text { at PNL }^{a} \\
\left(\mathrm{mg} / \mathrm{g} \mathrm{UO}_{2}\right)\end{array}$ & $\frac{\left(\mathrm{C}-\mathrm{M}_{1}\right)}{\mathrm{M}_{1}}$ \\
\hline 43 tc 99 & $1.500 \mathrm{E}-5^{b}$ & $1.350 \mathrm{E}-5^{b}$ & $11.11 \%$ \\
\hline $55 \operatorname{cs} 133$ & $1.273 \mathrm{E}+0$ & $1.240 \mathrm{E}+0$ & $2.66 \%$ \\
\hline $55 \operatorname{cs} 135$ & $4.605 \mathrm{E}-1$ & 4.300E-1 & $7.09 \%$ \\
\hline 60 nd143 & 7.757E-1 & $7.630 \mathrm{E}-1$ & $1.66 \%$ \\
\hline 60 nd145 & $7.463 \mathrm{E}-1$ & $7.440 \mathrm{E}-1$ & $0.31 \%$ \\
\hline $61 \mathrm{pm} 147$ & $3.586 \mathrm{E}-2$ & & \\
\hline $62 \operatorname{sm} 147$ & $2.137 \mathrm{E}-1$ & & \\
\hline $62 \mathrm{pm} 147$ & $2.496 \mathrm{E}-1$ & $2.680 \mathrm{E}-1$ & $-6.87 \%$ g 135 \\
\hline$+\operatorname{sm} 147$ & & & \\
\hline $62 \operatorname{sm} 149$ & $2.592 \mathrm{E}-3$ & 4.700E-3 & $-44.85 \%$ \\
\hline $62 \operatorname{sm} 150$ & $3.449 \mathrm{E}-1$ & $3.610 \mathrm{E}-1$ & $-4.46 \%$ \\
\hline $62 \operatorname{sm} 151$ & $1.285 \mathrm{E}-2$ & & \\
\hline 63 eu151 & $5.345 \mathrm{E}-4$ & & \\
\hline $\begin{aligned} 63 & \text { sm151 } \\
& + \text { eu } 151\end{aligned}$ & $1.338 \mathrm{E}-2$ & $9.780 \mathrm{E}-3$ & $36.81 \%$ \\
\hline $62 \operatorname{sm} 152$ & $1.443 \mathrm{E}-1$ & $1.210 \mathrm{E}-1$ & $19.26 \%$ \\
\hline 63 eu153 & $1.344 \mathrm{E}-1$ & $1.480 \mathrm{E}-1$ & $-9.19 \%$ \\
\hline 63 eu155 & $9.311 \mathrm{E}-3$ & & \\
\hline $64 \operatorname{gd} 155$ & $1.074 \mathrm{E}-2$ & & \\
\hline $\begin{array}{r}64 \text { eu155 } \\
+ \text { gd } 155\end{array}$ & $2.005 \mathrm{E}-2$ & $9.820 \mathrm{E}-3$ & $104.18 \%$ \\
\hline $92 \mathrm{u} 234$ & $1.255 \mathrm{E}-1$ & $1.200 \mathrm{E}-1$ & $4.58 \%$ \\
\hline $92 \mathrm{u} 235$ & $3.199 \mathrm{E}+0$ & $3.540 \mathrm{E}+0$ & $-9.63 \%$ \\
\hline 92 u236 & $3.753 \mathrm{E}+0$ & $3.690 \mathrm{E}+0$ & $1.71 \%$ \\
\hline $92 \mathrm{u} 238$ & $8.236 \mathrm{E}+2$ & $8.249 \mathrm{E}+2$ & $-0.16 \%$ \\
\hline 94 pu238 & $2.693 \mathrm{E}-1$ & $2.690 \mathrm{E}-1$ & $0.11 \%$ \\
\hline 94 pu239 & $4.559 \mathrm{E}+0$ & $4.357 \mathrm{E}+0$ & $4.64 \%$ \\
\hline 94 pu240 & $2.324 \mathrm{E}+0$ & $2.543 \mathrm{E}+0$ & $-8.61 \%$ \\
\hline 94 pu241 & $1.065 \mathrm{E}+0$ & $1.020 \mathrm{E}+0$ & $4.41 \%$ \\
\hline 94 pu242 & $7.858 \mathrm{E}-1$ & $8.400 \mathrm{E}-1$ & $-6.45 \%$ \\
\hline 95 am241 & $1.236 \mathrm{E}-3^{b}$ & $1.310 \mathrm{E}-3^{b}$ & $-5.65 \%$ \\
\hline
\end{tabular}

${ }^{a}$ See ref. B.5.

${ }^{b}$ Curies $/ \mathrm{g}-\mathrm{UO}_{2}$. 
Table B-4. ATM-103, fuel assembly D101, rod MLA098 at $8.9 \mathrm{~cm}, 18.68 \mathrm{GWd} / \mathrm{MTU}$

\begin{tabular}{|c|c|c|c|}
\hline $\begin{array}{c}\text { Nuclide } \\
\text { (Z and name) }\end{array}$ & $\begin{array}{c}\text { Calculated } \\
\text { concentration } \\
\left(\mathrm{mg} / \mathrm{g} \mathrm{UO}_{2}\right)\end{array}$ & $\begin{array}{l}\text { Measurement } 1 \\
\mathrm{MCC} \text { at PNL } \\
\left(\mathrm{mg} / \mathrm{g} \mathrm{UO}_{2}\right)\end{array}$ & $\frac{\left(\mathrm{C}-\mathrm{M}_{1}\right)}{\mathrm{M}_{1}}$ \\
\hline 43 tc 99 & $7.095 \mathrm{E}-6^{b}$ & $7.070 \mathrm{E}-6^{b}$ & $0.35 \%$ \\
\hline $55 \operatorname{cs} 135$ & $3.053 \mathrm{E}-7^{b}$ & $2.790 \mathrm{E}-7^{b}$ & $9.43 \%$ \\
\hline $92 \mathrm{u} 234$ & $1.604 \mathrm{E}-1$ & $1.400 \mathrm{E}-1$ & $14.57 \%$ \\
\hline $92 \mathrm{u} 235$ & $1.008 \mathrm{E}+1$ & $1.025 \mathrm{E}+1$ & $-1.66 \%$ \\
\hline $92 \mathrm{u} 236$ & $2.482 \mathrm{E}+0$ & $2.500 \mathrm{E}+0$ & $-0.72 \%$ \\
\hline $92 \mathrm{u} 238$ & $8.453 \mathrm{E}+2$ & $8.551 \mathrm{E}+2$ & $-1.15 \%$ \\
\hline 94 pu238 & $3.990 \mathrm{E}-2$ & $4.850 \mathrm{E}-2$ & $-17.73 \%$ \\
\hline 94 pu239 & $3.885 \mathrm{E}+0$ & $3.945 \mathrm{E}+0$ & $-1.52 \%$ \\
\hline 94 pu240 & $1.159 \mathrm{E}+0$ & $1.243 \mathrm{E}+0$ & $-6.76 \%$ \\
\hline 94 pu241 & $4.503 \mathrm{E}-1$ & $4.542 \mathrm{E}-1$ & $-0.86 \%$ \\
\hline 94 pu242 & $1.241 \mathrm{E}-1$ & $1.394 \mathrm{E}-1$ & $-10.98 \%$ \\
\hline 95 am241 & $6.511 \mathrm{E}-4^{b}$ & $6.670 \mathrm{E}-4^{b}$ & $-2.38 \%$ \\
\hline
\end{tabular}

${ }^{a}$ See ref. B.5.

${ }^{b}$ Curies/g- $\mathrm{UO}_{2}$.

Table B-5. ATM-103, fuel assembly D101, rod MLA098 at $24.3 \mathrm{~cm}, 26.62 \mathrm{GWd} / \mathrm{MTU}$

\begin{tabular}{|c|c|c|c|c|}
\hline & $\begin{array}{c}\text { Nuclide } \\
\text { (Z and name) }\end{array}$ & $\begin{array}{l}\text { Calculated } \\
\text { concentration } \\
\left(\mathrm{mg} / \mathrm{g} \mathrm{UO}_{2}\right)\end{array}$ & $\begin{array}{l}\text { Measurement } 1 \\
\mathrm{MCC} \text { at PNL }^{a} \\
\left(\mathrm{mg} / \mathrm{g} \mathrm{UO}_{2}\right)\end{array}$ & $\frac{\left(\mathrm{C}-\mathrm{M}_{1}\right)}{\mathrm{M}_{1}}$ \\
\hline 43 & tc 99 & $9.758 \mathrm{E}-6^{b}$ & $9.370 \mathrm{E}-6^{b}$ & $4.14 \%$ \\
\hline 55 & $\operatorname{cs} 135$ & $3.424 \mathrm{E}-7^{b}$ & $3.120 \mathrm{E}-7^{b}$ & $9.74 \%$ \\
\hline 92 & $\mathrm{u} 234$ & $1.422 \mathrm{E}-1$ & $1.210 \mathrm{E}-1$ & $17.52 \%$ \\
\hline 92 & $\mathrm{u} 235$ & $6.638 \mathrm{E}+0$ & $6.940 \mathrm{E}+0$ & $-4.35 \%$ \\
\hline 92 & $\mathrm{u} 236$ & $2.977 \mathrm{E}+0$ & $2.990 \mathrm{E}+0$ & $-0.43 \%$ \\
\hline 92 & $\mathrm{u} 238$ & $8.395 \mathrm{E}+2$ & $8.538 \mathrm{E}+2$ & $-1.67 \%$ \\
\hline 94 & pu238 & $9.006 \mathrm{E}-2$ & $9.690 \mathrm{E}-2$ & $-7.06 \%$ \\
\hline 94 & pu239 & $4.218 \mathrm{E}+0$ & $4.252 \mathrm{E}+0$ & $-0.80 \%$ \\
\hline 94 & pu240 & $1.634 \mathrm{E}+0$ & $1.766 \mathrm{E}+0$ & $-7.47 \%$ \\
\hline 94 & pu241 & $6.972 \mathrm{E}-1$ & $6.822 \mathrm{E}-1$ & $2.20 \%$ \\
\hline 94 & pu242 & $3.042 \mathrm{E}-1$ & $3.301 \mathrm{E}-1$ & $-7.85 \%$ \\
\hline 95 & $\operatorname{am} 241$ & $9.981 \mathrm{E}-4^{b}$ & $9.910 \mathrm{E}-4^{b}$ & $0.72 \%$ \\
\hline
\end{tabular}


Table B-6. ATM-103, fuel assembly D101, rod MLA098 at $161.7 \mathrm{~cm}, 33.17 \mathrm{GWd} / \mathrm{MTU}$

\begin{tabular}{lccc}
\hline $\begin{array}{c}\text { Nuclide } \\
\text { (Z and name) }\end{array}$ & $\begin{array}{c}\text { Calculated } \\
\text { concentration } \\
\left(\mathrm{mg} / \mathrm{g} \mathrm{UO}_{2}\right)\end{array}$ & $\begin{array}{c}\text { Measurement } 1 \\
\mathrm{MCC} \text { at PNL } \\
\left(\mathrm{mg} / \mathrm{g} \mathrm{UO}_{2}\right)\end{array}$ & \begin{tabular}{c}
$\left(\mathrm{C}-\mathrm{M}_{1}\right)$ \\
\hline 43 tc 99
\end{tabular} $\mathrm{M}_{1}$ \\
$55 \mathrm{cs} 135$ & $3.177 \mathrm{E}-5^{b}$ & $1.130 \mathrm{E}-5^{b}$ & $4.16 \%$ \\
$92 \mathrm{u} 234$ & $1.680 \mathrm{E}-7^{b}$ & $3.320 \mathrm{E}-7^{b}$ & $10.84 \%$ \\
$92 \mathrm{u} 235$ & $4.663 \mathrm{E}+0$ & $1.200 \mathrm{E}-1$ & $7.33 \%$ \\
$92 \mathrm{u} 236$ & $3.219 \mathrm{E}+0$ & $4.780 \mathrm{E}+0$ & $-2.45 \%$ \\
$92 \mathrm{u} 238$ & $8.342 \mathrm{E}+2$ & $3.260 \mathrm{E}+0$ & $-1.26 \%$ \\
$94 \mathrm{pu} 238$ & $1.468 \mathrm{E}-1$ & $8.422 \mathrm{E}+2$ & $-0.95 \%$ \\
$94 \mathrm{pu} 239$ & $4.423 \mathrm{E}+0$ & $1.483 \mathrm{E}-1$ & $-1.01 \%$ \\
$94 \mathrm{pu} 240$ & $1.946 \mathrm{E}+0$ & $4.187 \mathrm{E}+0$ & $5.64 \%$ \\
$94 \mathrm{pu} 241$ & $8.647 \mathrm{E}-1$ & $2.111 \mathrm{E}+0$ & $-7.82 \%$ \\
$94 \mathrm{pu} 242$ & $4.976 \mathrm{E}-1$ & $8.125 \mathrm{E}-1$ & $6.42 \%$ \\
$95 \mathrm{am} 241$ & $1.229 \mathrm{E}-3^{b}$ & $5.474 \mathrm{E}-1$ & $-9.10 \%$ \\
\hline
\end{tabular}

${ }^{a}$ See ref. B.5.

${ }^{b}$ Curies/g-UO ${ }_{2}$.

Table B-7. ATM-106, fuel assembly BT03, rod NBD107 at $11.28 \mathrm{~cm}, 31.40 \mathrm{GWd} / \mathrm{MTU}$

\begin{tabular}{|c|c|c|c|c|}
\hline & $\begin{array}{c}\text { Nuclide } \\
\text { (Z and name) }\end{array}$ & $\begin{array}{c}\text { Calculated } \\
\text { concentration } \\
\left(\mathrm{mg} / \mathrm{g} \mathrm{UO}_{2}\right)\end{array}$ & 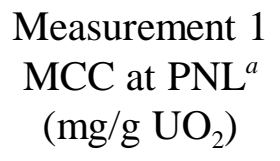 & $\frac{\left(\mathrm{C}-\mathrm{M}_{1}\right)}{\mathrm{M}_{1}}$ \\
\hline 43 & tc 99 & $1.116 \mathrm{E}-5^{b}$ & $7.700 \mathrm{E}-6^{b}$ & $44.94 \%$ \\
\hline 55 & $\operatorname{cs} 135$ & $4.637 \mathrm{E}-7$ & $4.040 \mathrm{E}-7$ & $14.78 \%$ \\
\hline 92 & $\mathrm{u} 234$ & $1.206 \mathrm{E}-1$ & $1.530 \mathrm{E}-1$ & $-21.18 \%$ \\
\hline 92 & $\mathrm{u} 235$ & $3.823 \mathrm{E}+0$ & $3.860 \mathrm{E}+0$ & $-0.96 \%$ \\
\hline 92 & $\mathrm{u} 236$ & $2.899 \mathrm{E}+0$ & $2.860 \mathrm{E}+0$ & $1.36 \%$ \\
\hline 92 & u238 & $8.376 \mathrm{E}+2$ & $8.446 \mathrm{E}+2$ & $-0.83 \%$ \\
\hline 94 & pu238 & $1.471 \mathrm{E}-1$ & $1.426 \mathrm{E}-1$ & $3.16 \%$ \\
\hline 94 & pu239 & $4.037 \mathrm{E}+0$ & $3.814 \mathrm{E}+0$ & $5.85 \%$ \\
\hline 94 & pu240 & $1.951 \mathrm{E}+0$ & $2.067 \mathrm{E}+0$ & $-5.61 \%$ \\
\hline 94 & pu241 & 7.393E-1 & $7.260 \mathrm{E}-1$ & $1.83 \%$ \\
\hline 94 & pu242 & $4.890 \mathrm{E}-1$ & $5.463 \mathrm{E}-1$ & $-10.49 \%$ \\
\hline 95 & am241 & $1.196 \mathrm{E}-3^{b}$ & $1.180 \mathrm{E}-3^{b}$ & $1.36 \%$ \\
\hline
\end{tabular}

${ }^{a}$ See ref. B.5.

${ }^{b} \mathrm{Curies} / \mathrm{g}-\mathrm{UO}_{2}$. 
Table B-8. ATM-106, fuel assembly BT03, rod NBD107 at $19.92 \mathrm{~cm}, 37.27 \mathrm{GWd} / \mathrm{MTU}$

\begin{tabular}{lccc}
\hline $\begin{array}{l}\text { Nuclide } \\
(\mathrm{Z} \text { and name })\end{array}$ & $\begin{array}{c}\text { Calculated } \\
\text { concentration } \\
\left(\mathrm{mg} / \mathrm{g} \mathrm{UO}_{2}\right)\end{array}$ & $\begin{array}{c}\text { Measurement } 1 \\
\mathrm{MCC}^{2} \mathrm{PNL} \\
\left(\mathrm{mg} / \mathrm{g} \mathrm{UO}_{2}\right)\end{array}$ & \begin{tabular}{c}
$\left(\mathrm{C}-\mathrm{M}_{1}\right)$ \\
\hline 43 tc 99
\end{tabular} $\mathbf{M}_{1}$ \\
$55 \mathrm{cs} 135$ & $4.286 \mathrm{E}-5^{b}$ & $8.960 \mathrm{E}-6^{b}$ & $43.53 \%$ \\
$92 \mathrm{u} 234$ & $1.110 \mathrm{E}-1$ & $4.150 \mathrm{E}-7^{b}$ & $17.88 \%$ \\
$92 \mathrm{u} 235$ & $2.593 \mathrm{E}+0$ & $1.270 \mathrm{E}-1$ & $-12.60 \%$ \\
$92 \mathrm{u} 236$ & $3.002 \mathrm{E}+0$ & $2.710 \mathrm{E}+0$ & $-4.32 \%$ \\
$92 \mathrm{u} 238$ & $8.327 \mathrm{E}+2$ & $3.030 \mathrm{E}+0$ & $-0.92 \%$ \\
$94 \mathrm{pu} 238$ & $2.013 \mathrm{E}-1$ & $8.438 \mathrm{E}+2$ & $-1.32 \%$ \\
$94 \mathrm{pu} 239$ & $4.083 \mathrm{E}+0$ & $1.947 \mathrm{E}-1$ & $3.39 \%$ \\
$94 \mathrm{pu} 240$ & $2.181 \mathrm{E}+0$ & $3.835 \mathrm{E}+0$ & $6.47 \%$ \\
$94 \mathrm{pu} 241$ & $8.313 \mathrm{E}-1$ & $2.321 \mathrm{E}+0$ & $-6.03 \%$ \\
$94 \mathrm{pu} 242$ & $6.891 \mathrm{E}-1$ & $8.130 \mathrm{E}-1$ & $2.25 \%$ \\
95 am241 & $1.316 \mathrm{E}-3^{b}$ & $7.753 \mathrm{E}-1$ & $-11.12 \%$ \\
\hline
\end{tabular}

${ }^{a}$ See ref. B.5.

${ }^{b}$ Curies/g-UO ${ }_{2}$.

Table B-9. ATM-106, fuel assembly BT03, rod NBD107 at $161.21 \mathrm{~cm}, 46.46 \mathrm{GWd} / \mathrm{MTU}$

\begin{tabular}{lccc}
\hline $\begin{array}{l}\text { Nuclide } \\
(\mathrm{Z} \text { and name })\end{array}$ & $\begin{array}{c}\text { Calculated } \\
\text { concentration } \\
\left(\mathrm{mg} / \mathrm{g} \mathrm{UO}_{2}\right)\end{array}$ & $\begin{array}{c}\text { Measurement } 1 \\
\mathrm{MCC}^{2} \mathrm{PNL}^{a} \\
\left(\mathrm{mg} / \mathrm{g} \mathrm{UO}_{2}\right)\end{array}$ & \begin{tabular}{c}
$\left(\mathrm{C}-\mathrm{M}_{1}\right)$ \\
\hline 43 tc 99
\end{tabular} $\mathrm{M}_{1}$ \\
55 cs135 & $1.527 \mathrm{E}-5^{b}$ & $1.090 \mathrm{E}-5^{b}$ & $40.09 \%$ \\
$92 \mathrm{u} 234$ & $5.334 \mathrm{E}-7^{b}$ & $4.790 \mathrm{E}-7^{b}$ & $11.36 \%$ \\
$92 \mathrm{u} 235$ & $9.845 \mathrm{E}-2$ & $7.490 \mathrm{E}-2$ & $31.44 \%$ \\
$92 \mathrm{u} 236$ & $1.426 \mathrm{E}+0$ & $1.406 \mathrm{E}+0$ & $1.42 \%$ \\
$92 \mathrm{u} 238$ & $3.024 \mathrm{E}+0$ & $3.040 \mathrm{E}+0$ & $-0.53 \%$ \\
94 pu238 & $8.244 \mathrm{E}+2$ & $8.272 \mathrm{E}+2$ & $-0.34 \%$ \\
94 pu239 & $2.903 \mathrm{E}-1$ & $2.842 \mathrm{E}-1$ & $2.15 \%$ \\
94 pu240 & $4.210 \mathrm{E}+0$ & $3.766 \mathrm{E}+0$ & $11.79 \%$ \\
94 pu241 & $2.453 \mathrm{E}+0$ & $2.599 \mathrm{E}+0$ & $-5.62 \%$ \\
94 pu242 & $9.443 \mathrm{E}-1$ & $8.862 \mathrm{E}-1$ & $6.56 \%$ \\
95 am241 & $1.005 \mathrm{E}+0$ & $1.169 \mathrm{E}+0$ & $-14.03 \%$ \\
\hline${ }^{a}$ See ref. B.5. & $1.452 \mathrm{E}-3^{b}$ & $2.180 \mathrm{E}-3^{b}$ & $-33.39 \%$ \\
${ }^{b} \mathrm{Curies} / \mathrm{g}-\mathrm{UO}_{2}$. & & &
\end{tabular}


Table B-10. ATM-101, fuel assembly B0-5, rod N-9 at $11.00 \mathrm{~cm}, 16.02 \mathrm{GWd} / \mathrm{MTU}$

\begin{tabular}{|c|c|c|c|}
\hline $\begin{array}{c}\text { Nuclide } \\
\text { (Z and name) } \\
\end{array}$ & $\begin{array}{c}\text { Calculated } \\
\text { concentration } \\
\left(\mathrm{mg} / \mathrm{g} \mathrm{UO}_{2}\right) \\
\end{array}$ & $\begin{array}{c}\text { Measurement } 1 \\
\mathrm{MCC} \text { at } \mathrm{PNL}^{a} \\
\left(\mathrm{mg} / \mathrm{g} \mathrm{UO}_{2}\right)\end{array}$ & $\frac{\left(\mathrm{C}-\mathrm{M}_{1}\right)}{\mathrm{M}_{1}}$ \\
\hline 43 tc 99 & $6.114 \mathrm{E}-6^{b}$ & $5.440 \mathrm{E}-6^{b}$ & $12.39 \%$ \\
\hline $92 \mathrm{u} 235$ & $1.076 \mathrm{E}+1$ & $1.070 \mathrm{E}+1$ & $0.56 \%$ \\
\hline $92 \mathrm{u} 236$ & $2.156 \mathrm{E}+0$ & $2.190 \mathrm{E}+0$ & $-1.55 \%$ \\
\hline $92 \mathrm{u} 238$ & $8.477 \mathrm{E}+2$ & $8.470 \mathrm{E}+2$ & $0.08 \%$ \\
\hline 94 pu238 & $2.871 \mathrm{E}-2$ & $2.830 \mathrm{E}-2$ & $1.45 \%$ \\
\hline 94 pu239 & $3.894 \mathrm{E}+0$ & $3.640 \mathrm{E}+0$ & $6.98 \%$ \\
\hline $94 \mathrm{pu} 240$ & $1.073 \mathrm{E}+0$ & $1.090 \mathrm{E}+0$ & $-1.56 \%$ \\
\hline $94 \mathrm{pu} 241$ & $3.219 \mathrm{E}-1$ & $3.040 \mathrm{E}-1$ & $5.89 \%$ \\
\hline
\end{tabular}

${ }^{a}$ See ref. B.5.

${ }^{b}$ Curies/g-UO ${ }_{2}$.

Table B-11. ATM-101, fuel assembly B0-5, rod N-9 at $26.00 \mathrm{~cm}, 23.81 \mathrm{GWd} / \mathrm{MTU}$

\begin{tabular}{lccc}
\hline $\begin{array}{l}\text { Nuclide } \\
(\mathrm{Z} \text { and name })\end{array}$ & $\begin{array}{c}\text { Calculated } \\
\text { concentration } \\
\left(\mathrm{mg} / \mathrm{g} \mathrm{UO}_{2}\right)\end{array}$ & $\begin{array}{c}\text { Measurement } 1 \\
\mathrm{MCC}^{2} \mathrm{PNL}^{a} \\
\left(\mathrm{mg} / \mathrm{g} \mathrm{UO}_{2}\right)\end{array}$ & $\frac{\left(\mathrm{C}-\mathrm{M}_{1}\right)}{\mathrm{M}_{1}}$ \\
\hline 43 tc 99 & $8.782 \mathrm{E}-6^{b}$ & $8.090 \mathrm{E}-6^{b}$ & $8.55 \%$ \\
$92 \mathrm{u} 235$ & $7.312 \mathrm{E}+0$ & $7.210 \mathrm{E}+0$ & $1.41 \%$ \\
$92 \mathrm{u} 236$ & $2.680 \mathrm{E}+0$ & $2.740 \mathrm{E}+0$ & $-2.19 \%$ \\
$92 \mathrm{u} 238$ & $8.419 \mathrm{E}+2$ & $8.470 \mathrm{E}+2$ & $-0.60 \%$ \\
$94 \mathrm{pu} 238$ & $7.012 \mathrm{E}-2$ & $6.950 \mathrm{E}-2$ & $0.89 \%$ \\
$94 \mathrm{pu} 239$ & $4.331 \mathrm{E}+0$ & $4.020 \mathrm{E}+0$ & $7.74 \%$ \\
$94 \mathrm{pu} 240$ & $1.601 \mathrm{E}+0$ & $1.670 \mathrm{E}+0$ & $-4.13 \%$ \\
$94 \mathrm{pu} 241$ & $5.340 \mathrm{E}-1$ & $5.040 \mathrm{E}-1$ & $5.95 \%$ \\
\hline${ }^{a} \mathrm{See}$ ref. B.5. & & & \\
${ }^{b} \mathrm{Curies} / \mathrm{g}-\mathrm{UO}_{2}$. & & &
\end{tabular}


Table B-12. ATM-101, fuel assembly B0-5, rod N-9 at $199.0 \mathrm{~cm}, 28.47 \mathrm{GWd} / \mathrm{MTU}$

\begin{tabular}{lccc}
\hline $\begin{array}{c}\text { Nuclide } \\
(\mathrm{Z} \text { and name })\end{array}$ & $\begin{array}{c}\text { Calculated } \\
\text { concentration } \\
\left(\mathrm{mg} / \mathrm{g} \mathrm{UO}_{2}\right)\end{array}$ & $\begin{array}{c}\text { Measurement } 1 \\
\mathrm{MCC}^{2} \mathrm{PNL} \\
\left(\mathrm{mg} / \mathrm{g} \mathrm{UO}_{2}\right)\end{array}$ & \begin{tabular}{c}
$\left(\mathrm{C}-\mathrm{M}_{1}\right)$ \\
\hline 43 tc 99
\end{tabular} $\mathrm{M}_{1}$ \\
$92 \mathrm{u} 235$ & $1.026 \mathrm{E}-5^{b}$ & $8.950 \mathrm{E}-6^{b}$ & $14.64 \%$ \\
$92 \mathrm{u} 236$ & $5.880 \mathrm{E}+0$ & $6.180 \mathrm{E}+0$ & $-4.85 \%$ \\
$92 \mathrm{u} 238$ & $2.883 \mathrm{E}+0$ & $2.820 \mathrm{E}+0$ & $2.23 \%$ \\
$94 \mathrm{pu} 238$ & $8.379 \mathrm{E}+2$ & $8.340 \mathrm{E}+2$ & $0.47 \%$ \\
$94 \mathrm{pu} 239$ & $1.066 \mathrm{E}-1$ & $1.140 \mathrm{E}-1$ & $-6.49 \%$ \\
$94 \mathrm{pu} 240$ & $4.625 \mathrm{E}+0$ & $4.390 \mathrm{E}+0$ & $5.35 \%$ \\
94 pu241 & $1.873 \mathrm{E}+0$ & $1.970 \mathrm{E}+0$ & $-4.92 \%$ \\
\hline${ }^{a}$ See ref. B.5. & $6.844 \mathrm{E}-1$ & $6.810 \mathrm{E}-1$ & $0.50 \%$ \\
${ }^{b} \mathrm{Curies} / \mathrm{g}-\mathrm{UO}_{2}$. & & &
\end{tabular}

Table B-13. ATM-101, fuel assembly B0-5, rod N-9 at $226.0 \mathrm{~cm}, 31.66 \mathrm{GWd} / \mathrm{MTU}$

\begin{tabular}{|c|c|c|c|}
\hline $\begin{array}{l}\text { Nuclide } \\
\text { (Z and name) }\end{array}$ & $\begin{array}{c}\text { Calculated } \\
\text { concentration } \\
\left(\mathrm{mg} / \mathrm{g} \mathrm{UO}_{2}\right)\end{array}$ & 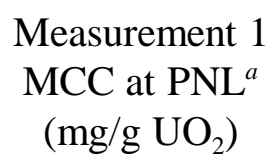 & $\frac{\left(\mathrm{C}-\mathrm{M}_{1}\right)}{\mathrm{M}_{1}}$ \\
\hline 43 tc 99 & $1.124 \mathrm{E}-5^{b}$ & $1.010 \mathrm{E}-5^{b}$ & $11.29 \%$ \\
\hline $92 \mathrm{u} 235$ & $5.022 \mathrm{E}+0$ & $4.860 \mathrm{E}+0$ & $3.33 \%$ \\
\hline $92 \mathrm{u} 236$ & $2.988 \mathrm{E}+0$ & $3.000 \mathrm{E}+0$ & $-0.40 \%$ \\
\hline $92 \mathrm{u} 238$ & $8.352 \mathrm{E}+2$ & $8.420 \mathrm{E}+2$ & $-0.81 \%$ \\
\hline 94 pu238 & $1.333 \mathrm{E}-1$ & $1.300 \mathrm{E}-1$ & $2.54 \%$ \\
\hline 94 pu239 & $4.739 \mathrm{E}+0$ & $4.200 \mathrm{E}+0$ & $12.83 \%$ \\
\hline $94 \mathrm{pu} 240$ & $2.032 \mathrm{E}+0$ & $2.120 \mathrm{E}+0$ & $-4.15 \%$ \\
\hline $94 \mathrm{pu} 241$ & $7.551 \mathrm{E}-1$ & $6.920 \mathrm{E}-1$ & $9.12 \%$ \\
\hline
\end{tabular}


Table B-14. Fuel assembly 170, batch 94, 25.93 GWd/MTU

\begin{tabular}{|c|c|c|c|c|c|c|c|c|c|}
\hline $\begin{array}{c}\text { Nuclide } \\
\text { (Z and name) }\end{array}$ & $\begin{array}{c}\text { Calculated } \\
\text { conc. } \\
\left(\mathrm{mg} / \mathrm{g} \mathrm{UO}_{2}\right) \\
\end{array}$ & $\begin{array}{c}\text { Meas. } 1 \\
\text { TUI }^{a} \\
\left(\mathrm{mg} / \mathrm{g} \mathrm{UO}_{2}\right) \\
\end{array}$ & $\frac{\left(\mathrm{C}-\mathrm{M}_{1}\right)}{\mathrm{M}_{1}}$ & $\begin{array}{c}\text { Meas. } 2 \\
\text { IAEA }^{a} \\
\left(\mathrm{mg}^{2} / \mathrm{g} \mathrm{UO}_{2}\right) \\
\end{array}$ & $\frac{\left(\mathrm{C}-\mathrm{M}_{2}\right)}{\mathrm{M}_{2}}$ & $\begin{array}{c}\text { Meas. } 3 \\
\mathrm{WAK}^{a} \\
\left(\mathrm{mg} / \mathrm{g} \mathrm{UO}_{2}\right) \\
\end{array}$ & $\frac{\left(\mathrm{C}-\mathrm{M}_{3}\right)}{\mathrm{M}_{3}}$ & $\begin{array}{c}\text { Meas. } 4 \\
\text { IRCH }^{a} \\
\left(\mathrm{mg}^{\prime} / \mathrm{g} \mathrm{UO}_{2}\right) \\
\end{array}$ & $\frac{\left(\mathrm{C}-\mathrm{M}_{4}\right)}{\mathrm{M}_{4}}$ \\
\hline 92 u235 & $1.059 \mathrm{E}+1$ & $1.130 \mathrm{E}+1$ & $-6.28 \%$ & $1.080 \mathrm{E}+1$ & $-1.94 \%$ & $1.090 \mathrm{E}+1$ & $-2.84 \%$ & $1.080 \mathrm{E}+1$ & $-1.94 \%$ \\
\hline 92 u236 & $3.628 \mathrm{E}+0$ & $3.610 \mathrm{E}+0$ & $0.50 \%$ & $3.570 \mathrm{E}+0$ & $1.62 \%$ & $3.570 \mathrm{E}+0$ & $1.62 \%$ & $3.620 \mathrm{E}+0$ & $0.22 \%$ \\
\hline 94 pu238 & $8.518 \mathrm{E}-2$ & $8.200 \mathrm{E}-2$ & $3.88 \%$ & $8.610 \mathrm{E}-2$ & $-1.07 \%$ & $7.210 \mathrm{E}-2$ & $18.14 \%$ & & \\
\hline 94 рu239 & $5.098 \mathrm{E}+0$ & $4.910 \mathrm{E}+0$ & $3.83 \%$ & $4.830 \mathrm{E}+0$ & $5.55 \%$ & $4.580 \mathrm{E}+0$ & $11.31 \%$ & $4.900 \mathrm{E}+0$ & $4.04 \%$ \\
\hline 94 рu240 & $1.705 \mathrm{E}+0$ & $1.830 \mathrm{E}+0$ & $-6.83 \%$ & $1.800 \mathrm{E}+0$ & $-5.28 \%$ & $1.720 \mathrm{E}+0$ & $-0.87 \%$ & $1.840 \mathrm{E}+0$ & $-7.34 \%$ \\
\hline 94 pu241 & $1.051 \mathrm{E}+0$ & $1.000 \mathrm{E}+0$ & $5.10 \%$ & $9.700 \mathrm{E}-1$ & $8.35 \%$ & $9.500 \mathrm{E}-1$ & $10.63 \%$ & $9.900 \mathrm{E}-1$ & $6.16 \%$ \\
\hline 94 рu242 & $2.749 \mathrm{E}-1$ & $3.200 \mathrm{E}-1$ & $-14.09 \%$ & $3.100 \mathrm{E}-1$ & $-11.32 \%$ & 3.030E-1 & $-9.27 \%$ & $3.150 \mathrm{E}-1$ & $-12.73 \%$ \\
\hline
\end{tabular}

Table B-15. Fuel assembly 172, batch $92,26.54 \mathrm{GWd} / \mathrm{MTU}$

\begin{tabular}{|c|c|c|c|c|c|c|c|c|c|}
\hline $\begin{array}{c}\text { Nuclide } \\
\text { (Z and name) } \\
\end{array}$ & $\begin{array}{c}\text { Calculated } \\
\text { conc. } \\
\left(\mathrm{mg} / \mathrm{g} \mathrm{UO}_{2}\right) \\
\end{array}$ & $\begin{array}{c}\text { Meas. } 1 \\
\text { TUI }^{a} \\
\left(\mathrm{mg} / \mathrm{g} \mathrm{UO}_{2}\right) \\
\end{array}$ & $\frac{\left(\mathrm{C}-\mathrm{M}_{1}\right)}{\mathrm{M}_{1}}$ & $\begin{array}{c}\text { Meas. } 2 \\
\text { IAEA }^{a} \\
\left(\mathrm{mg} / \mathrm{g} \mathrm{UO}_{2}\right) \\
\end{array}$ & $\frac{\left(\mathrm{C}-\mathrm{M}_{2}\right)}{\mathrm{M}_{2}}$ & $\begin{array}{c}\text { Meas. } 3 \\
\text { WAK }^{a} \\
\left(\mathrm{mg} / \mathrm{g} \mathrm{UO}_{2}\right) \\
\end{array}$ & $\frac{\left(\mathrm{C}-\mathrm{M}_{3}\right)}{\mathrm{M}_{3}}$ & $\begin{array}{c}\text { Meas. } 4 \\
\mathrm{IRCH}^{a} \\
\left(\mathrm{mg} / \mathrm{g} \mathrm{UO}_{2}\right) \\
\end{array}$ & $\frac{\left(\mathrm{C}-\mathrm{M}_{4}\right)}{\mathrm{M}_{4}}$ \\
\hline 92 u235 & $1.029 \mathrm{E}+1$ & $1.070 \mathrm{E}+1$ & $-3.83 \%$ & $1.060 \mathrm{E}+1$ & $-2.92 \%$ & $1.040 \mathrm{E}+1$ & $-1.06 \%$ & $1.060 \mathrm{E}+1$ & $-2.92 \%$ \\
\hline $92 \mathrm{u} 236$ & $3.672 \mathrm{E}+0$ & $3.690 \mathrm{E}+0$ & $-0.49 \%$ & $3.600 \mathrm{E}+0$ & $2.00 \%$ & $3.560 \mathrm{E}+0$ & $3.15 \%$ & $3.640 \mathrm{E}+0$ & $0.88 \%$ \\
\hline $94 \mathrm{pu} 238$ & $9.142 \mathrm{E}-2$ & $8.400 \mathrm{E}-2$ & $8.83 \%$ & $9.380 \mathrm{E}-2$ & $-2.54 \%$ & & & & \\
\hline 94 pu239 & $5.122 \mathrm{E}+0$ & $4.760 \mathrm{E}+0$ & $7.61 \%$ & $4.780 \mathrm{E}+0$ & $7.15 \%$ & $4.490 \mathrm{E}+0$ & $14.08 \%$ & $4.820 \mathrm{E}+0$ & $6.27 \%$ \\
\hline $94 \mathrm{pu} 240$ & $1.755 \mathrm{E}+0$ & $1.910 \mathrm{E}+0$ & $-8.12 \%$ & $1.840 \mathrm{E}+0$ & $-4.62 \%$ & $1.730 \mathrm{E}+0$ & $1.45 \%$ & $1.850 \mathrm{E}+0$ & $-5.14 \%$ \\
\hline 94 pu241 & $1.073 \mathrm{E}+0$ & $9.700 \mathrm{E}-1$ & $10.62 \%$ & $9.900 \mathrm{E}-1$ & $8.38 \%$ & $9.400 \mathrm{E}-1$ & $14.15 \%$ & $1.010 \mathrm{E}+0$ & $6.24 \%$ \\
\hline $94 \mathrm{pu} 242$ & $2.886 \mathrm{E}-1$ & $3.250 \mathrm{E}-1$ & $-11.20 \%$ & 3.300E-1 & $-12.55 \%$ & 3.200E-1 & $-9.81 \%$ & $3.350 \mathrm{E}-1$ & $-13.85 \%$ \\
\hline
\end{tabular}

Table B-16. Fuel assembly 176, batch 91, 27.99 GWd/MTU

\begin{tabular}{|c|c|c|c|c|c|c|c|c|c|}
\hline $\begin{array}{c}\begin{array}{c}\text { Nuclide } \\
\text { (Z and name) }\end{array} \\
\end{array}$ & $\begin{array}{c}\text { Calculated } \\
\text { conc. } \\
\left(\mathrm{mg} / \mathrm{g} \mathrm{UO}_{2}\right) \\
\end{array}$ & $\begin{array}{c}\text { Meas. } 1 \\
\text { TUI }^{a} \\
\left(\mathrm{mg} / \mathrm{g} \mathrm{UO}_{2}\right) \\
\end{array}$ & $\frac{\left(\mathrm{C}-\mathrm{M}_{1}\right)}{\mathrm{M}_{1}}$ & $\begin{array}{c}\text { Meas. } 2 \\
\text { IAEA }^{a} \\
\left(\mathrm{mg}^{2} \mathrm{~g} \mathrm{UO}_{2}\right) \\
\end{array}$ & $\frac{\left(\mathrm{C}-\mathrm{M}_{2}\right)}{\mathrm{M}_{2}}$ & $\begin{array}{c}\text { Meas. } 3 \\
\text { WAK }^{a} \\
\left(\mathrm{mg} / \mathrm{g} \mathrm{UO}_{2}\right) \\
\end{array}$ & $\frac{\left(\mathrm{C}-\mathrm{M}_{3}\right)}{\mathrm{M}_{3}}$ & $\begin{array}{c}\text { Meas. } 4 \\
\mathrm{IRCH}^{a} \\
\left(\mathrm{mg} / \mathrm{g} \mathrm{UO}_{2}\right) \\
\end{array}$ & $\frac{\left(\mathrm{C}-\mathrm{M}_{4}\right)}{\mathrm{M}_{4}}$ \\
\hline 92 u235 & $9.598 \mathrm{E}+0$ & $9.800 \mathrm{E}+0$ & $-2.06 \%$ & $9.800 \mathrm{E}+0$ & $-2.06 \%$ & $9.900 \mathrm{E}+0$ & $-3.05 \%$ & $9.900 \mathrm{E}+0$ & $-3.05 \%$ \\
\hline 92 u236 & $3.767 \mathrm{E}+0$ & $3.700 \mathrm{E}+0$ & $1.81 \%$ & $3.680 \mathrm{E}+0$ & $2.36 \%$ & $3.660 \mathrm{E}+0$ & $2.92 \%$ & $3.740 \mathrm{E}+0$ & $0.72 \%$ \\
\hline 94 pu238 & $1.028 \mathrm{E}-1$ & $9.700 \mathrm{E}-2$ & $5.98 \%$ & 1.067E-1 & $-3.66 \%$ & $8.070 \mathrm{E}-2$ & $27.39 \%$ & & \\
\hline 94 pu239 & $5.171 \mathrm{E}+0$ & $4.960 \mathrm{E}+0$ & $4.25 \%$ & $4.870 \mathrm{E}+0$ & $6.18 \%$ & $4.830 \mathrm{E}+0$ & $7.06 \%$ & $5.040 \mathrm{E}+0$ & $2.60 \%$ \\
\hline 94 pu240 & $1.835 \mathrm{E}+0$ & $1.930 \mathrm{E}+0$ & $-4.92 \%$ & $1.900 \mathrm{E}+0$ & $-3.42 \%$ & $1.880 \mathrm{E}+0$ & $-2.39 \%$ & $1.970 \mathrm{E}+0$ & $-6.85 \%$ \\
\hline 94 pu241 & $1.136 \mathrm{E}+0$ & $1.060 \mathrm{E}+0$ & $7.17 \%$ & $1.050 \mathrm{E}+0$ & $8.19 \%$ & $1.040 \mathrm{E}+0$ & $9.23 \%$ & $1.080 \mathrm{E}+0$ & $5.19 \%$ \\
\hline 94 pu242 & $3.298 \mathrm{E}-1$ & $3.760 \mathrm{E}-1$ & $-12.29 \%$ & 3.620E-1 & $-8.90 \%$ & $3.700 \mathrm{E}-1$ & $-10.86 \%$ & $3.780 \mathrm{E}-1$ & $-12.75 \%$ \\
\hline
\end{tabular}

${ }^{a}$ See ref. B.5. 
Table B-17. Fuel assembly 168 , batch $86,28.40$ GWd/MTU

\begin{tabular}{|c|c|c|c|c|c|c|c|c|c|}
\hline $\begin{array}{c}\text { Nuclide } \\
(\mathrm{Z} \text { and name })\end{array}$ & $\begin{array}{c}\text { Calculated } \\
\text { conc. } \\
\left(\mathrm{mg} / \mathrm{g} \mathrm{UO}_{2}\right)\end{array}$ & $\begin{array}{c}\text { Meas. } 1 \\
\text { TUI }^{a} \\
\left(\mathrm{mg} / \mathrm{g} \mathrm{UO}_{2}\right) \\
\end{array}$ & $\frac{\left(\mathrm{C}-\mathrm{M}_{1}\right)}{\mathrm{M}_{1}}$ & $\begin{array}{c}\text { Meas. } 2 \\
\text { IAEA }^{a} \\
\left(\mathrm{mg}^{2} / \mathrm{g} \mathrm{UO}_{2}\right) \\
\end{array}$ & $\frac{\left(\mathrm{C}-\mathrm{M}_{2}\right)}{\mathrm{M}_{2}}$ & $\begin{array}{c}\text { Meas. } 3 \\
\mathrm{WAK}^{a} \\
\left(\mathrm{mg} / \mathrm{g} \mathrm{UO}_{2}\right) \\
\end{array}$ & $\frac{\left(\mathrm{C}-\mathrm{M}_{3}\right)}{\mathrm{M}_{3}}$ & $\begin{array}{c}\text { Meas. } 4 \\
\text { IRCH }^{a} \\
\left(\mathrm{mg}^{\prime} / \mathrm{g} \mathrm{UO}_{2}\right) \\
\end{array}$ & $\frac{\left(\mathrm{C}-\mathrm{M}_{4}\right)}{\mathrm{M}_{4}}$ \\
\hline 92 u235 & $9.415 \mathrm{E}+0$ & $9.600 \mathrm{E}+0$ & $-1.93 \%$ & $9.700 \mathrm{E}+0$ & $-2.94 \%$ & $9.700 \mathrm{E}+0$ & $-2.94 \%$ & $9.700 \mathrm{E}+0$ & $-2.94 \%$ \\
\hline 92 u236 & $3.792 \mathrm{E}+0$ & $3.720 \mathrm{E}+0$ & $1.94 \%$ & $3.730 \mathrm{E}+0$ & $1.66 \%$ & $3.750 \mathrm{E}+0$ & $1.12 \%$ & & \\
\hline 94 pu238 & 1.059E-1 & $1.190 \mathrm{E}-1$ & $-11.01 \%$ & $1.111 \mathrm{E}-1$ & $-4.68 \%$ & $8.610 \mathrm{E}-2$ & $23.00 \%$ & & \\
\hline 94 pu239 & $5.188 \mathrm{E}+0$ & $5.060 \mathrm{E}+0$ & $2.53 \%$ & $5.080 \mathrm{E}+0$ & $2.13 \%$ & $4.900 \mathrm{E}+0$ & $5.88 \%$ & & \\
\hline 94 pu240 & $1.856 \mathrm{E}+0$ & $2.080 \mathrm{E}+0$ & $-10.77 \%$ & $2.030 \mathrm{E}+0$ & $-8.57 \%$ & $1.960 \mathrm{E}+0$ & $-5.31 \%$ & & \\
\hline 94 рu241 & $1.156 \mathrm{E}+0$ & $1.130 \mathrm{E}+0$ & $2.30 \%$ & $1.110 \mathrm{E}+0$ & $4.14 \%$ & $1.070 \mathrm{E}+0$ & $8.04 \%$ & & \\
\hline 94 pu242 & $3.422 \mathrm{E}-1$ & 3.970E-1 & $-13.80 \%$ & $3.900 \mathrm{E}-1$ & $-12.26 \%$ & $4.350 \mathrm{E}-1$ & $-21.33 \%$ & & \\
\hline
\end{tabular}

Table B-18. Fuel assembly 171, batch 89, 29.04 GWd/MTU

\begin{tabular}{|c|c|c|c|c|c|c|c|c|c|}
\hline $\begin{array}{c}\text { Nuclide } \\
\text { ( } \mathrm{Z} \text { and name) } \\
\end{array}$ & $\begin{array}{c}\text { Calculated } \\
\text { conc. } \\
\left(\mathrm{mg} / \mathrm{g} \mathrm{UO}_{2}\right) \\
\end{array}$ & $\begin{array}{c}\text { Meas. } 1 \\
\text { TUI }^{a} \\
\left(\mathrm{mg} / \mathrm{g} \mathrm{UO}_{2}\right) \\
\end{array}$ & $\frac{\left(\mathrm{C}-\mathrm{M}_{1}\right)}{\mathrm{M}_{1}}$ & $\begin{array}{c}\text { Meas. } 2 \\
\text { IAEA }^{a} \\
\left(\mathrm{mg} / \mathrm{g} \mathrm{UO}_{2}\right) \\
\end{array}$ & $\frac{\left(\mathrm{C}-\mathrm{M}_{2}\right)}{\mathrm{M}_{2}}$ & $\begin{array}{c}\text { Meas. } 3 \\
\mathrm{WAK}^{a} \\
\left(\mathrm{mg} / \mathrm{g} \mathrm{UO}_{2}\right) \\
\end{array}$ & $\frac{\left(\mathrm{C}-\mathrm{M}_{3}\right)}{\mathrm{M}_{3}}$ & $\begin{array}{c}\text { Meas. } 4 \\
\mathrm{IRCH}^{a} \\
\left(\mathrm{mg} / \mathrm{g} \mathrm{UO}_{2}\right) \\
\end{array}$ & $\frac{\left(\mathrm{C}-\mathrm{M}_{4}\right)}{\mathrm{M}_{4}}$ \\
\hline 92 u235 & $9.129 \mathrm{E}+0$ & $9.600 \mathrm{E}+0$ & $-4.91 \%$ & $9.500 \mathrm{E}+0$ & $-3.91 \%$ & $9.600 \mathrm{E}+0$ & $-4.91 \%$ & $9.600 \mathrm{E}+0$ & $-4.91 \%$ \\
\hline $92 \mathrm{u} 236$ & $3.830 \mathrm{E}+0$ & $3.740 \mathrm{E}+0$ & $2.41 \%$ & $3.760 \mathrm{E}+0$ & $1.86 \%$ & $3.750 \mathrm{E}+0$ & $2.13 \%$ & $3.760 \mathrm{E}+0$ & $1.86 \%$ \\
\hline 94 pu238 & $1.114 \mathrm{E}-1$ & $1.060 \mathrm{E}-1$ & $5.09 \%$ & $1.144 \mathrm{E}-1$ & $-2.62 \%$ & $8.340 \mathrm{E}-2$ & $33.57 \%$ & & \\
\hline 94 pu239 & $5.210 \mathrm{E}+0$ & $5.000 \mathrm{E}+0$ & $4.20 \%$ & $5.040 \mathrm{E}+0$ & $3.37 \%$ & $4.830 \mathrm{E}+0$ & $7.87 \%$ & & \\
\hline 94 pu240 & $1.892 \mathrm{E}+0$ & $2.010 \mathrm{E}+0$ & $-5.87 \%$ & $2.030 \mathrm{E}+0$ & $-6.80 \%$ & $1.950 \mathrm{E}+0$ & $-2.97 \%$ & & \\
\hline 94 pu241 & $1.184 \mathrm{E}+0$ & $1.120 \mathrm{E}+0$ & $5.71 \%$ & $1.130 \mathrm{E}+0$ & $4.78 \%$ & $1.070 \mathrm{E}+0$ & $10.65 \%$ & & \\
\hline 94 pu 242 & $3.611 \mathrm{E}-1$ & $4.120 \mathrm{E}-1$ & $-12.35 \%$ & $4.080 \mathrm{E}-1$ & $-11.50 \%$ & $3.900 \mathrm{E}-1$ & $-7.41 \%$ & 4.100E-1 & $-11.93 \%$ \\
\hline
\end{tabular}

${ }^{a}$ See ref. B.5.

Table B-19. Fuel assembly 176, batch 90, 29.52 GWd/MTU

\begin{tabular}{|c|c|c|c|c|c|c|c|c|c|}
\hline $\begin{array}{c}\text { Nuclide } \\
\text { (Z and name) }\end{array}$ & $\begin{array}{c}\text { Calculated } \\
\text { conc. } \\
\left(\mathrm{mg} / \mathrm{g} \mathrm{UO}_{2}\right)\end{array}$ & $\begin{array}{c}\text { Meas. } 1 \\
\text { TUI }^{a} \\
\left(\mathrm{mg}^{\prime} \mathrm{g} \mathrm{UO}_{2}\right) \\
\end{array}$ & $\frac{\left(\mathrm{C}-\mathrm{M}_{1}\right)}{\mathrm{M}_{1}}$ & $\begin{array}{c}\text { Meas. } 2 \\
\text { IAEA }^{a} \\
\left(\mathrm{mg}^{\prime} / \mathrm{g} \mathrm{UO}_{2}\right)\end{array}$ & $\frac{\left(\mathrm{C}-\mathrm{M}_{2}\right)}{\mathrm{M}_{2}}$ & $\begin{array}{c}\text { Meas. } 3 \\
\text { WAK }^{a} \\
\left(\mathrm{mg} / \mathrm{g} \mathrm{UO}_{2}\right)\end{array}$ & $\frac{\left(\mathrm{C}-\mathrm{M}_{3}\right)}{\mathrm{M}_{3}}$ & $\begin{array}{c}\text { Meas. } 4 \\
\text { IRCH }^{a} \\
\left(\mathrm{mg} / \mathrm{g} \mathrm{UO}_{2}\right)\end{array}$ & $\frac{\left(\mathrm{C}-\mathrm{M}_{4}\right)}{\mathrm{M}_{4}}$ \\
\hline $92 \quad$ u235 & $8.917 \mathrm{E}+0$ & $9.100 \mathrm{E}+0$ & $-2.01 \%$ & $9.200 \mathrm{E}+0$ & $-3.08 \%$ & $9.20 \mathrm{E}+00$ & $-3.08 \%$ & $9.20 \mathrm{E}+00$ & $-3.08 \%$ \\
\hline 92 u236 & $3.859 \mathrm{E}+0$ & $3.830 \mathrm{E}+0$ & $0.76 \%$ & $3.780 \mathrm{E}+0$ & $2.09 \%$ & $3.75 \mathrm{E}+00$ & $2.91 \%$ & $3.86 \mathrm{E}+00$ & $-0.03 \%$ \\
\hline 94 pu238 & $1.159 \mathrm{E}-1$ & $1.150 \mathrm{E}-1$ & $0.78 \%$ & $1.187 \mathrm{E}-1$ & $-2.36 \%$ & 8.77E-02 & $32.16 \%$ & & \\
\hline 94 pu239 & $5.224 \mathrm{E}+0$ & $5.000 \mathrm{E}+0$ & $4.48 \%$ & $4.910 \mathrm{E}+0$ & $6.40 \%$ & $4.80 \mathrm{E}+00$ & $8.83 \%$ & $5.06 \mathrm{E}+00$ & $3.24 \%$ \\
\hline 94 pu240 & $1.921 \mathrm{E}+0$ & $2.050 \mathrm{E}+0$ & $-6.29 \%$ & $2.030 \mathrm{E}+0$ & $-5.37 \%$ & $1.99 \mathrm{E}+00$ & $-3.47 \%$ & $2.07 \mathrm{E}+00$ & $-7.20 \%$ \\
\hline 94 pu241 & $1.204 \mathrm{E}+0$ & $1.140 \mathrm{E}+0$ & $5.61 \%$ & $1.120 \mathrm{E}+0$ & $7.50 \%$ & $1.10 \mathrm{E}+00$ & $9.45 \%$ & $1.15 \mathrm{E}+00$ & $4.70 \%$ \\
\hline 94 pu242 & $3.745 \mathrm{E}-1$ & 4.350E-1 & $-13.91 \%$ & $4.200 \mathrm{E}-1$ & $-10.83 \%$ & 4.65E-01 & $-19.46 \%$ & 4.30E-01 & $-12.91 \%$ \\
\hline
\end{tabular}




\section{B.2 ISOTOPIC CORRECTION FACTORS}

Differences between calculated and measured isotopic concentrations for any given fuel sample result from biases and uncertainties. Isotopic uncertainty is a consequence of the variation of physical parameters in a random fashion relative to modeled parameters, combined with the random error associated with experimental measurements. Isotopic bias, on the other hand, is the offset between the measured nuclide concentration for a given nuclide and the corresponding calculational prediction of the concentration of that nuclide after uncertainties have been accounted for. Isotopic bias can result from both the method used in experimental measurements and from the assumptions, data, and method used in computational prediction of nuclide densities.

In theory, because uncertainty is a random error, it becomes very small with a large sample population. True bias, on the other hand, cannot be reduced by increasing the sample size. However, the estimated isotopic bias (referred to hereafter simply as "bias") does vary with sample size, as it is not separable from its uncertainty components. For multiple samples, the bias is estimated by the average difference between the computed and measured isotopic concentrations for each isotope of interest, normalized by the average experimental value. Thus based on a set of $n$ independent measurements, the bias $\beta$ is given by

$$
\beta=\frac{1}{n} \sum_{\mathrm{i}=1}^{n} \frac{\left(\mathrm{C}_{\mathrm{i}}-\mathrm{E}_{\mathrm{i}}\right)}{\mathrm{E}_{\mathrm{i}}}=\frac{1}{n} \sum_{\mathrm{i}=1}^{n} \frac{\mathrm{C}_{\mathrm{i}}}{\mathrm{E}_{\mathrm{i}}}-1,
$$

where $\mathrm{C}_{\mathrm{i}}$ is the calculated isotopic concentration corresponding to a specific measured concentration $\mathrm{E}_{\mathrm{i}}$ of a given isotope. Given another isotopic concentration calculated using the same procedure, the bias can be used to determine a best estimate of the isotopic concentration that would be experimentally measured:

$$
E=\frac{C}{\beta+1}
$$

Unfortunately, this approach has limited application because it does not account for uncertainty in the bias. Thus for conservatism, a more rigorous approach is required to obtain a bounding estimate of isotopic concentrations which includes uncertainty contributions. Using statistical methods, it is possible to conservatively estimate, at a given level of confidence, upper and lower bounds for isotopic concentrations in a spent fuel material. The following subsection describes such an approach. This description is followed by a demonstration of the approach using the isotopic measurements and calculations presented in the previous section to determine conservative correction factors. 


\section{B.2.1 Statistical Method for Determination of Isotopic Correction Factors}

In the approach described here, an isotopic correction factor is derived based on the statistical variations in the measured isotopic concentration relative to calculated concentrations for the same isotope over the range of all experimental measurements for the selected isotope. For any given isotope, a ratio between experimentally measured and the corresponding calculated isotopic concentration may be defined as

$$
x_{i}=\frac{E_{i}}{C_{i}},
$$

where $\mathrm{C}$ and $\mathrm{E}$ are as defined earlier for the ith sample of a set of samples. Given a population of ratios for all fuel samples for which spent fuel analysis is considered, the population mean and variance are defined as $\mu$ and $\sigma^{2}$. For a given level of confidence, any member of the population will be found within the range $\mu \pm \mathrm{N}_{c} \sigma$, where $\mathrm{N}_{c}$ is determined based on an $\alpha$ confidence level (generally $\alpha$ is selected as 95 or $99 \%$ ). However, population mean and variance cannot be directly ascertained without the destructive assay of every available fuel sample. Thus it is necessary to estimate the mean and variance in terms of the mean and variance of a subset of samples selected to represent the entire population. The mean of the sample set (and the estimate for $\mu$ ) is given as $\overline{\mathrm{x}}$, where for a sample set comprised of $n$ samples,

$$
\overline{\mathrm{x}}=\frac{1}{\mathrm{n}} \sum_{\mathrm{i}=1}^{\mathrm{n}} \mathrm{x}_{\mathrm{i}} \approx \mu .
$$

It is possible that multiple measurements may be performed on a single sample. For simplicity, it is assumed that if $\mathrm{m}_{\mathrm{i}}$ measurements are performed on the ith sample, then

$$
\mathrm{x}_{\mathrm{i}}=\overline{\mathrm{x}}_{\mathrm{i}}=\frac{1}{\mathrm{~m}_{\mathrm{i}}} \sum_{\mathrm{j}=1}^{\mathrm{m}_{\mathrm{i}}} \mathrm{x}_{\mathrm{i}, \mathrm{j}} .
$$

Assuming the set of $\mathrm{x}_{\mathrm{i}}$ 's for a given isotope have a normal distribution about the mean of the sample set, the sample variance is given as

$$
\mathrm{s}^{2}=\frac{1}{(\mathrm{n}-1)} \sum_{\mathrm{i}=1}^{\mathrm{n}}\left(\mathrm{x}_{\mathrm{i}}-\overline{\mathrm{x}}\right)^{2} .
$$

This formulation does not take credit for the reduced variance associated with multiple measurements, if any. Reduced variance could be explicitly included in a modified form of Eq. (B.5) 
by weighting $x_{i}$ based on the number of independent measurements taken on sample $i$; however, the approach described here is conservative in neglecting the reduced variance, and is simpler to implement.

Using Eqs. (B.3) through (B.6), one can obtain $\overline{\mathrm{x}}$ and $\mathrm{s}^{2}$ as estimates of the population's mean and variance. If $\overline{\mathrm{x}}$ and $\mathrm{s}^{2}$ are reasonable estimates of $\mu$ and $\sigma^{2}$, then bounding limits of $\overline{\mathrm{x}}$ are given by $\overline{\mathrm{x}} \pm \mathrm{N}_{\alpha} \mathrm{s}$. Again, the value of $\mathrm{N}$ depends on the statistical confidence desired for a bounding limit. Clearly, as $n$ (the number of samples in the population subset used to establish the estimated parameters) becomes large, one has a reasonable confidence that the sample parameters are good estimates of the population parameters. However, when the sample population is small, there is limited confidence that the sample parameters represent the population parameters. Thus a second statistical parameter is required to relate a second level of confidence, $\rho$, to the estimate of the population mean and variance. For a set of normally distributed data points, one may use a tolerance interval approach 1.6 to assign a "tolerance factor" $\mathrm{T}_{\alpha / \mathrm{\rho}}$ value for N. Under this approach, for a given $\alpha$ and $\rho$, there is a $\rho$ probability that a future value of $x_{i}$ will lie within the range $\overline{\mathrm{x}} \pm \mathrm{T}_{\alpha / \rho} \cdot \mathrm{s}$, with an $\alpha$ confidence. Reference B.6 provides tabulated values of $\mathrm{T}_{\alpha / \rho}$ for common values of $\alpha$ and $\rho$ and for a range of values of $n$. In such tables, it is observed that $T_{\alpha / \rho}$ is large relative to $\mathrm{N}_{\alpha}$ for small values of $\mathrm{n}$, but approached $\mathrm{N}_{\alpha}$ as $\mathrm{n}$ gets large.

Recall that $\mathrm{x}$ represents the ratio of measured to calculated isotopic concentrations for a given isotope. Thus the limits of $\overline{\mathrm{X}} \pm \mathrm{T}_{\alpha / \rho} \cdot \mathrm{s}$ represent the expected upper and lower bounds for measured to calculated ratios with a confidence of $\alpha$ with a probability $\rho$. Given a calculated isotopic concentration $\mathrm{C}$, the minimum and maximum expected measured (actual) composition are given by

$$
\mathrm{E}_{\max }=\mathrm{f}_{\max } \cdot \mathrm{C}=\left(\overline{\mathrm{x}}+\mathrm{T}_{\alpha / \rho} \cdot \mathrm{s}\right) \cdot \mathrm{C}
$$

and

$$
\mathrm{E}_{\min }=\mathrm{f}_{\min } \cdot \mathrm{C}=\left(\overline{\mathrm{x}}-\mathrm{T}_{\alpha / \rho} \cdot \mathrm{s}\right) \cdot \mathrm{C}
$$

where $\mathrm{f}_{\min }$ and $\mathrm{f}_{\max }$ are minimum and maximum isotopic correction factors respectively. In other words, if a subsequent experimental measurement were performed for a selected isotope in a given sample, Eqs. (B.7a) and (B.7b) predict the upper and lower bounds, with an $\alpha / \rho$ confidence, for the measured concentration based on a calculated concentration for the same sample. Thus in any sample it is possible to predict the maximum and minimum concentrations that might be expected (again, with an $\alpha / \rho$ confidence level) in a given fuel sample based on a calculated concentration.

In a spent fuel criticality calculation, a conservative approach in the prediction of a neutron multiplication factor, $\mathrm{k}$, is to assume the maximum concentration of fissile (neutron-producing) isotopes combined with the minimum concentration of nonfissile (neutron-absorbing) isotopes, to set an uppermost expected limit on $\mathrm{k}$. Thus for a set of isotopes present in a criticality calculation, one must determine the limiting isotopic concentration for each isotope by using a correction factor appropriate for the isotope. Based on Eqs. (B.7a) and (B.7b) and the above discussion, these correction factors may be written for each isotope I as 


$$
\mathrm{f}_{\mathrm{I}, \mathrm{fissile}}=\mathrm{f}_{\mathrm{I}, \max }=\overline{\mathrm{x}}_{\mathrm{I}}+\mathrm{T}_{\mathrm{I}, \alpha / \rho} \cdot \mathrm{s}_{\mathrm{I}} \text {, }
$$

and

$$
\mathrm{f}_{\mathrm{I}, \text { nonfissile }}=\mathrm{f}_{\mathrm{I}, \min }=\overline{\mathrm{x}}_{\mathrm{I}}-\mathrm{T}_{\mathrm{I}, \alpha / \mathrm{p}} \cdot \mathrm{S}_{\mathrm{I}} \cdot
$$

The estimated bounding concentration of isotope $\mathrm{I}, \epsilon_{\mathrm{I}}$, is then simply given as

$$
\epsilon_{\mathrm{I}}=\mathrm{f}_{\mathrm{I}} \cdot \mathrm{C}_{\mathrm{I}} \cdot
$$

Clearly, to be included in a criticality calculation, isotopic measurements must be available for each isotope I such that $\mathrm{f}_{\mathrm{I}}$ can be computed for the isotope. As the number of experimental measurements is increased, the term $\mathrm{s}_{\mathrm{I}}$ will generally decrease or remain constant, and $\mathrm{T}_{\alpha / \mathrm{p}}$ will decrease; hence the margin between the average ratio and the bounding limit will decrease with an increased number of experimental measurements. Isotopic correction factors based on a limited number of experimental measurements are therefore generally overly conservative, although the conservatism is statistically justified.

Additional conservatism can be included in this approach by disallowing compensating effects. Although unlikely, it is possible that the most conservative correction factor for an isotope will result in a value for $\varepsilon_{\mathrm{I}}$ that is less conservative (in a relative sense) than the calculated concentration. In other words, for a fissile material, if $\mathrm{f}_{\mathrm{I} \text {,fissile }}$ is less than 1.0 , then $\varepsilon_{\mathrm{I}}$ will be less than $\mathrm{C}$, and $\mathrm{C}$ represents the more conservative value (since $\mathrm{C}$ would result in increased neutron production). Conversely, for nonfissile isotopes, $\mathrm{f}_{\mathrm{I} \text {,nonfissile }}>1.0$ means that $\boldsymbol{\varepsilon}_{\mathrm{I}}$ will be greater than $\mathrm{C}$, and again $\mathrm{C}$ represents the more conservative value (since $\mathrm{C}$ would result in less neutron absorption). Thus to disallow such behavior, modified correction factor $\left(f^{\prime}\right)$ formulations can be written based on Eqs. (B.8a) and (B.8b) as

$$
\mathrm{f}_{\text {I,fissile }}^{\prime}=\max \left[\left(\overline{\mathrm{x}}_{\mathrm{I}}+\mathrm{T}_{\mathrm{I}, \alpha / \rho} \cdot \mathrm{s}_{\mathrm{I}}\right), 1.0\right] \text {, }
$$

and

$$
\mathrm{f}_{\mathrm{I}, \text { nonfissile }}^{\prime}=\min \left[\left(\overline{\mathrm{x}}_{\mathrm{I}}-\mathrm{T}_{\mathrm{I}, \alpha / \mathrm{p}} \cdot \mathrm{s}_{\mathrm{I}}\right), 1.0\right]
$$

\section{B.2.2 Calculation of Isotopic Correction Factors}

Tables B-1 through B-19 of this Appendix provide all information required to calculate isotopic correction factors for each of the burnup credit actinides and fission products. However, the preceding derivation was based on the assumption that the distribution of $\mathrm{x}_{\mathrm{i}}$ 's for each isotope represents a normal distribution. Thus before applying this approach, it is necessary to test the data available for each isotope to verify that it does represent a normal distribution. A commonly accepted approach to test a set of data for normality is the W-test of Shapiro and Wilk B.7 The implementation of this approach is beyond the scope of this report, but it is described in detail in 
ref. B.8. Using this approach, a parameter $\mathrm{W}$ is calculated for a set of data for a given confidence level. If the calculated value of $\mathrm{W}$ is greater than the tabulated minimum acceptable value of $\mathrm{W}$, referred to as the critical value or $\mathrm{W}^{*}$, the set of data is considered normally distributed.

For each burnup credit isotope, the set of $\mathrm{x}_{\mathrm{i}}$ 's available for the isotope was compiled and used to compute $\mathrm{W}$ for the distribution of data. Results of these calculations and the corresponding value of $\mathrm{W}^{*}$ for the number of data points are provided in Table B-20, based on an assumed $95 \%$ confidence level. With the exception of ${ }^{99} \mathrm{Tc},{ }^{238} \mathrm{Pu}$, and ${ }^{241} \mathrm{Am}$, all isotopes are found to be normally distributed (i.e., $\mathrm{W}>\mathrm{W}^{*}$ ). These results suggest that the ratios of experimentally measured to computed concentrations are generally normally distributed. With the exception of ${ }^{241} \mathrm{Am}$, the remaining isotopes are close to normal distributions $\left(\mathrm{W} \sim \mathrm{W}^{*}\right)$.

Table B-20. Normality tests for measured/calculated isotopic concentration data

\begin{tabular}{lccc}
\hline Isotope & $\begin{array}{c}\text { Number of } \\
\text { measurements }\end{array}$ & $\begin{array}{c}\text { W } \\
\text { (95\% confidence) }\end{array}$ & $\begin{array}{c}\mathrm{W}^{*} \\
\text { (95\% confidence) }\end{array}$ \\
\hline${ }^{99} \mathrm{Tc}$ & 13 & 0.814 & 0.869 \\
${ }^{133} \mathrm{Cs}$ & 3 & 0.996 & 0.772 \\
${ }^{135} \mathrm{Cs}$ & 9 & 0.904 & 0.835 \\
${ }^{143} \mathrm{Nd}$ & 3 & 0.985 & 0.772 \\
${ }^{145} \mathrm{Nd}$ & 3 & 0.853 & 0.772 \\
${ }^{147} \mathrm{Sm}$ & 3 & 0.940 & 0.772 \\
${ }^{149} \mathrm{Sm}$ & 3 & 0.904 & 0.772 \\
${ }^{150} \mathrm{Sm}$ & 3 & 0.915 & 0.772 \\
${ }^{151} \mathrm{Sm}$ & 3 & 0.975 & 0.772 \\
${ }^{152} \mathrm{Sm}$ & 3 & 0.934 & 0.772 \\
${ }^{153} \mathrm{Eu}$ & 3 & 0.878 & 0.772 \\
${ }^{155} \mathrm{Gd}$ & 3 & 0.774 & 0.772 \\
${ }^{234} \mathrm{U}$ & 9 & 0.954 & 0.835 \\
${ }^{235} \mathrm{U}$ & 19 & 0.959 & 0.901 \\
${ }^{236} \mathrm{U}$ & 19 & 0.933 & 0.901 \\
${ }^{238} \mathrm{U}$ & 13 & 0.995 & 0.869 \\
${ }^{238} \mathrm{Pu}$ & 19 & 0.842 & 0.901 \\
${ }^{239} \mathrm{Pu}$ & 19 & 0.948 & 0.901 \\
${ }^{240} \mathrm{Pu}$ & 19 & 0.959 & 0.901 \\
${ }^{241} \mathrm{Pu}$ & 19 & 0.965 & 0.901 \\
${ }^{242} \mathrm{Pu}$ & 9 & 0.955 & 0.882 \\
${ }^{241} \mathrm{Am}$ & & 0.635 & \\
& 3 & & 0.835 \\
\hline
\end{tabular}


Additional measurements are expected to result in sets of $\mathrm{x}_{\mathrm{i}}$ that are normally distributed, since most isotopes already meet or are close to the $\mathrm{W}^{*}$ criteria. It is possible that for the limited number of data points available, biases in measurement techniques between various facilities would result in data that are normally distributed within each laboratory's measurements. Because of the bias, however, they have different normal distributions that become non-normal when combined. Unfortunately, insufficient data exist to test this hypothesis.

For purposes of this report, biases computed for each isotope will be considered to be valid, despite the fact that some data appear non-normal and therefore violate the assumptions made in the derivation of the bias method. However, subsequent safety-related calculations should carefully consider the use of such biases and should include additional isotopic-specific margins (e.g., a larger multiplier on $\sigma$ ) to account for uncertainty in the validity of such bias and uncertainty terms.

Table B-21 lists the results of isotopic bias and correction factor calculations for each of the burnup credit nuclides (with the exception of oxygen, which is not significantly depleted in spent fuel). The number of samples, $n$, is the number of unique experimental samples used in the chemical assay analysis of each nuclide. The bias, $\beta$, given in column 3, was calculated using Eq. (B.1), and was used with Eq. (B.2) to provide an estimate of the actual (expected) contents of spent fuel in parametric analyses. $\overline{\mathrm{x}}$ was calculated for each isotope using Eq. (B.4) [and (B.5) when multiple measurements were performed on a single sample]; s was computed based on Eq. (B.6) $\left(\mathrm{s}=\sqrt{\mathrm{s}^{2}}\right)$. Finally, $\mathrm{f}$ and $\mathrm{f}^{\prime}$ are the nominal and modified isotopic correction factors calculated from Eqs. (B.8) and (B.10), respectively, using a tolerance factor T obtained assuming a 95\% confidence level with a $95 \%$ probability. Note that $\mathrm{f} \neq \mathrm{f}^{\prime}$ for ${ }^{240} \mathrm{Pu}$ and ${ }^{242} \mathrm{Pu}$.

The bias $\beta$ (based on the ratio of $\mathrm{C} / \mathrm{E}$ for a number of experiments) given in Table $\mathrm{B}-21$ is not the same as a bias that could be derived from $\overline{\mathrm{x}}$ (computed from the ratio $\mathrm{E} / \mathrm{C}$ for the same experiments), since $\mathrm{E}=\mathrm{C} /(1+\beta)\{$ Eq. (B.2) $\}$ and $\mathrm{E}=\mathrm{C} \cdot \overline{\mathrm{x}}$ [which can be deduced from Eq. (B.3)], but $1 /(1+\beta) \neq \overline{\mathrm{x}}$. The earlier definition of bias was derived and applied in sensitivity calculations prior to the development of the isotopic correction factor approach, hence the inconsistency. The difference between $1 /(1+\beta)$ and $\bar{x}$ is small; therefore, this difference is not significant in terms of its effect on parametric evaluations of sensitivities. 
Table B-21. Bias, uncertainty, and isotopic correction factors for burnup credit nuclides

\begin{tabular}{|c|c|c|c|c|c|c|c|}
\hline Isotope & $\begin{array}{l}\text { No. of } \\
\text { samples } \\
\text { (n) }\end{array}$ & $\operatorname{Bias}(\beta)$ & $\overline{\mathrm{x}}$ & $\mathrm{S}$ & $\mathrm{T}_{95 / 95, \mathrm{n}}{ }^{a}$ & f & $\mathrm{f}^{\prime}$ \\
\hline${ }^{99} \mathrm{Tc}$ & 13 & 0.1585 & 0.8767 & 0.106 & 2.671 & 0.594 & 0.594 \\
\hline${ }^{133} \mathrm{Cs}$ & 3 & 0.0150 & 0.9814 & 0.007 & 7.656 & 0.928 & 0.928 \\
\hline${ }_{135} \mathrm{Cs}$ & 9 & 0.1133 & 0.9022 & 0.027 & 3.031 & 0.820 & 0.820 \\
\hline${ }^{143} \mathrm{Nd}$ & 3 & 0.0114 & 0.9909 & 0.008 & 7.656 & 0.930 & 0.930 \\
\hline${ }^{145} \mathrm{Nd}$ & 3 & 0.0050 & 0.9961 & 0.002 & 7.656 & 0.981 & 0.981 \\
\hline${ }^{147} \mathrm{Sm}$ & 3 & -0.0339 & 1.0349 & 0.047 & 7.656 & 0.675 & 0.675 \\
\hline${ }^{149} \mathrm{Sm}$ & 3 & -0.2528 & 1.3972 & 0.368 & 7.656 & $0.000^{b}$ & $0.000^{b}$ \\
\hline${ }^{150} \mathrm{Sm}$ & 3 & -0.0808 & 0.9924 & 0.048 & 7.656 & 0.625 & 0.625 \\
\hline${ }^{151} \mathrm{Sm}$ & 3 & 0.2993 & 0.7707 & 0.037 & 7.656 & 0.487 & 0.487 \\
\hline${ }^{152} \mathrm{Sm}$ & 3 & 0.1925 & 0.8362 & 0.008 & 7.656 & 0.775 & 0.775 \\
\hline${ }^{153} \mathrm{Eu}$ & 3 & -0.0393 & 1.0370 & 0.057 & 7.656 & 0.601 & 0.601 \\
\hline${ }^{155} \mathrm{Gd}$ & 3 & 0.8924 & 0.5361 & 0.085 & 7.656 & $0.000^{b}$ & $0.000^{c}$ \\
\hline${ }^{234} \mathrm{U}$ & 9 & 0.0472 & 0.9757 & 0.154 & 3.031 & 0.509 & 0.509 \\
\hline${ }^{235} \mathrm{U}^{c}$ & 19 & -0.0265 & 1.0305 & 0.035 & 2.423 & 1.115 & 1.115 \\
\hline${ }^{236} \mathrm{U}$ & 19 & 0.0063 & 0.9936 & 0.016 & 2.423 & 0.955 & 0.955 \\
\hline${ }^{238} \mathrm{U}$ & 13 & -0.0064 & 1.0064 & 0.006 & 2.671 & 0.990 & 0.990 \\
\hline${ }^{238} \mathrm{Pu}$ & 19 & 0.0092 & 0.9967 & 0.069 & 2.423 & 0.830 & 0.830 \\
\hline${ }^{239} \mathrm{Pu}{ }^{c}$ & 19 & 0.0507 & 0.9508 & 0.034 & 2.423 & 1.033 & 1.033 \\
\hline${ }^{240} \mathrm{Pu}$ & 19 & -0.0558 & 1.0615 & 0.020 & 2.423 & 1.013 & 1.000 \\
\hline${ }^{241} \mathrm{Pu}^{c}$ & 19 & 0.052 & 0.9531 & 0.026 & 2.423 & 1.016 & 1.016 \\
\hline${ }^{242} \mathrm{Pu}$ & 15 & -0.1097 & 1.1160 & 0.043 & 2.566 & 1.006 & 1.000 \\
\hline${ }^{241} \mathrm{Am}$ & 9 & -0.0574 & 1.0800 & 0.164 & 3.031 & 0.583 & 0.583 \\
\hline
\end{tabular}

${ }^{\text {aSee ref. B-6. }}$

${ }^{b}$ Factors less than zero are set to zero, since negative concentrations are meaningless.

${ }^{c}$ Fissile isotope.

\section{B.3 REFERENCES}

B.1 American National Standard for Nuclear Criticality Safety in Operations with Fissionable Materials Outside Reactors, ANSI/ANS-8.1-1983 (Reaffirmed November 1988).

B.2 American National Standard for Criticality Safety Criteria for the Handling, Storage, and Transportation of LWR Fuel Outside Reactors, ANSI/ANS-8.17-1984 (Reaffirmed August 1989). 
B.3 S. R. Bierman and R. J. Talbert, Benchmark Data for Validating Irradiated Fuel Compositions Used in Criticality Calculations, PNL-10045 (UC-722), Pacific Northwest Laboratory, 1994.

B.4 U. Hesse, Verification of the OREST (HAMMER-ORIGEN) Depletion Program System Using Post-Irradiation Analyses of Fuel Assemblies 168, 170, 171, and 176 from Obrigheim Reactor, (ORNL-TR-88/20), GRS-A-962, Gesellschaft für Reaktorsicherheit (GRS) $\mathrm{mbH}(1984)$.

B.5 O. W. Hermann et al., Validation of the SCALE System for PWR Spent Fuel Isotopic Composition Analyses, ORNL/TM-12667, Martin Marietta Energy Systems, Inc., Oak Ridge Natl. Lab., 1995.

B.6 R. E. Odeh and D. B. Owen, Tables for Normal Tolerance Limits, Sampling Plans, and Screening, Marcel Dekker Inc., New York, 1980.

B.7 S. S. Shapiro and M. B. Wilk, "An Analysis of Variance Test for Normality (Complete Samples)," Biometrika 52, 591- 611 (1965).

B.8 T. J. Lorenzen and V. L. Anderson, Design of Experiments: A No-Name Approach, Marcel Dekker Inc., New York, 1993. 
APPENDIX C

SENSITIVITY COEFFICIENTS FOR BURNUP CREDIT NUCLIDES 
3.0 wt \% Initial Enrichment, $10 \mathrm{GWd} / \mathrm{MTU}$ Burnup, 5 y Cooled, Actinides + Fission Products

\begin{tabular}{|c|c|c|c|c|c|}
\hline I sotope & $\begin{array}{c}\text { Perturbation } \\
(\%)\end{array}$ & $\begin{array}{l}\text { Sensitivity } \\
\text { With Bias }\end{array}$ & $\begin{array}{l}\text { Coefficient } \\
\text { Rank }\end{array}$ & $\begin{array}{r}{[\{(\text { delta } k) /} \\
\text { without Bias }\end{array}$ & $\begin{array}{l}/\{\text { (de } 1 \\
\text { Rank }\end{array}$ \\
\hline$u-234$ & 100.0 & $-1.479 E-03$ & (14) & $-1.556 \mathrm{E}-03$ & $(16)$ \\
\hline$u-235$ & 1.0 & $1.568 \mathrm{E}-01$ & $(2)$ & $1.499 E-01$ & $(2)$ \\
\hline$u-236$ & 25.0 & $-3.602 E-03$ & $(10)$ & $-3.656 E-03$ & $(10)$ \\
\hline$u-238$ & 1.0 & $-1.761 \mathrm{E}-01$ & ( 1 ) & $-1.780 \mathrm{E}-01$ & $(1)$ \\
\hline$p u-238$ & 100.0 & $-1.287 \mathrm{E}-04$ & $(22)$ & $-1.363 E-04$ & $(23)$ \\
\hline pu- 239 & 1.0 & $4.743 E-02$ & $(3)$ & $5.052 \mathrm{E}-02$ & $(3)$ \\
\hline$p u-240$ & 2.0 & $-2.613 E-02$ & $(4)$ & $-2.526 \mathrm{E}-02$ & $(4)$ \\
\hline pu- 241 & 2.0 & $4.821 \mathrm{E}-03$ & $(8)$ & $4.813 \mathrm{E}-03$ & $(9)$ \\
\hline$p u-242$ & 25.0 & $-2.254 \mathrm{E}-04$ & $(21)$ & $-2.244 E-04$ & (21) \\
\hline$a m-241$ & 10.0 & $-2.493 E-03$ & (11) & $-2.406 \mathrm{E}-03$ & $(12)$ \\
\hline 0 & 25.0 & $-1.000 E-02$ & $(6)$ & $-1.001 E-02$ & $(6)$ \\
\hline tc -99 & 25.0 & $-1.769 E-03$ & (13) & $-2.085 E-03$ & (14) \\
\hline cs -133 & 25.0 & $-2.348 E-03$ & $(12)$ & $-2.405 E-03$ & (13) \\
\hline CS -135 & 100.0 & $-1.207 E-04$ & (23) & $-1.443 E-04$ & $(22)$ \\
\hline nd -143 & 10.0 & $-6.111 E-03$ & $(7)$ & $-6.254 \mathrm{E}-03$ & $(7)$ \\
\hline nd -145 & 25.0 & $-1.126 \mathrm{E}-03$ & (18) & $-1.155 E-03$ & (17) \\
\hline sm- 147 & 25.0 & $-1.158 E-03$ & (17) & $-1.123 E-03$ & ( 18$)$ \\
\hline sm- 149 & 10.0 & $-1.849 \mathrm{E}-02$ & $(5)$ & $-1.411 \mathrm{E}-02$ & $(5)$ \\
\hline sm- 150 & 25.0 & $-7.077 \mathrm{E}-04$ & $(20)$ & $-7.054 \mathrm{E}-04$ & $(20)$ \\
\hline sm- 151 & 10.0 & $-3.940 E-03$ & $(9)$ & $-5.212 \mathrm{E}-03$ & $(8)$ \\
\hline sm- 152 & 25.0 & $-1.319 E-03$ & (15) & $-1.604 \mathrm{E}-03$ & (15) \\
\hline eu- 153 & 25.0 & $-8.361 E-04$ & (19) & $-8.339 E-04$ & (19) \\
\hline $\mathrm{gd}-155$ & 25.0 & $-1.319 E-03$ & (16) & $-2.598 E-03$ & (11) \\
\hline
\end{tabular}

3.0 wt \% Initial Enrichment, 30 GWd/MTU Burnup, $5 y$ Cooled, Actinides + Fission Products Isotope Perturbation Sensitivity Coefficient $[\{($ delta $k) / k\} /\{($ delta $N) / N\}]$ (\%) With Bias Rank Without Bias Rank

\begin{tabular}{|c|c|c|c|c|c|}
\hline$u-234$ & 100.0 & $-1.122 \mathrm{E}-03$ & (22) & $-1.163 E-03$ & (22) \\
\hline$u-235$ & 1.0 & $1.189 \mathrm{E}-01$ & ( 3$)$ & $1.153 \mathrm{E}-01$ & ( 3 ) \\
\hline$u-236$ & 25.0 & $-5.783 E-03$ & (13) & $-5.786 E-03$ & ( 13$)$ \\
\hline$u-238$ & 1.0 & $-1.741 \mathrm{E}-01$ & $(1)$ & $-1.730 E-01$ & $(1)$ \\
\hline pu- 238 & 100.0 & $-2.169 E-03$ & $(21)$ & $-2.108 E-03$ & (21) \\
\hline pu- 239 & 1.0 & $1.455 \mathrm{E}-01$ & $(2)$ & $1.409 \mathrm{E}-01$ & $(2)$ \\
\hline pu- 240 & 2.0 & $-5.659 E-02$ & $(4)$ & $-5.436 E-02$ & $(4)$ \\
\hline pu- 241 & 2.0 & $3.995 E-02$ & $(5)$ & $4.065 E-02$ & $(5)$ \\
\hline pu- 242 & 25.0 & $-3.538 E-03$ & (17) & $-3.252 E-03$ & (17) \\
\hline$a m-241$ & 10.0 & $-1.360 E-02$ & $(8)$ & $-1.267 E-02$ & $(9)$ \\
\hline 0 & 25.0 & $-1.168 \mathrm{E}-02$ & $(9)$ & $-1.168 E-02$ & $(10)$ \\
\hline tc -99 & 25.0 & $-4.756 E-03$ & (14) & $-5.445 E-03$ & $(14)$ \\
\hline cs -133 & 25.0 & $-6.125 E-03$ & $(12)$ & $-6.201 \mathrm{E}-03$ & (12) \\
\hline CS -135 & 100.0 & $-3.900 E-04$ & $(23)$ & $-4.349 E-04$ & $(23)$ \\
\hline nd -143 & 10.0 & $-1.531 \mathrm{E}-02$ & $(7)$ & $-1.522 \mathrm{E}-02$ & $(8)$ \\
\hline nd -145 & 25.0 & $-3.043 E-03$ & (18) & $-3.025 E-03$ & (18) \\
\hline sm- 147 & 25.0 & $-2.397 E-03$ & $(20)$ & $-2.344 E-03$ & $(20)$ \\
\hline sm- 149 & 10.0 & $-2.416 \mathrm{E}-02$ & $(6)$ & $-1.787 \mathrm{E}-02$ & $(6)$ \\
\hline sm- 150 & 25.0 & $-2.473 E-03$ & $(19)$ & $-2.495 E-03$ & (19) \\
\hline $\mathrm{sm}-151$ & 10.0 & $-6.943 E-03$ & (11) & $-8.886 E-03$ & $(11)$ \\
\hline sm- 152 & 25.0 & $-3.691 E-03$ & $(16)$ & $-4.311 E-03$ & (15) \\
\hline eu- 153 & 25.0 & $-4.185 E-03$ & $(15)$ & $-4.008 E-03$ & $(16)$ \\
\hline $\mathrm{gd}-155$ & 25.0 & $-8.371 E-03$ & $(10)$ & $-1.577 \mathrm{E}-02$ & $(7)$ \\
\hline
\end{tabular}




\section{3}

3.0 wt \% Initial Enrichment, 50 GWd/MTU Burnup, 5y Cooled, Actinides + Fission Products

\begin{tabular}{|c|c|c|c|c|c|}
\hline Isotope & $\begin{array}{c}\text { Perturbation } \\
(\%)\end{array}$ & $\begin{array}{l}\text { Sensitivity } \\
\text { With Bias }\end{array}$ & $\begin{array}{l}\text { Coefficient } \\
\text { Rank }\end{array}$ & $\begin{array}{c}{[\{(\text { delta } k) / k} \\
\text { without Bias }\end{array}$ & $\begin{array}{l}/\{\text { (de } 1 \\
\text { Rank }\end{array}$ \\
\hline$u-234$ & 100.0 & $-8.610 E-04$ & $(22)$ & $-8.778 E-04$ & $(22)$ \\
\hline$u-235$ & 1.0 & $6.683 E-02$ & $(5)$ & $6.274 E-02$ & $(5)$ \\
\hline$u-236$ & 25.0 & $-6.135 E-03$ & (17) & $-6.107 \mathrm{E}-03$ & ( 17$)$ \\
\hline$u-238$ & 1.0 & $-1.701 \mathrm{E}-01$ & $(2)$ & $-1.657 \mathrm{E}-01$ & $(2)$ \\
\hline$p u-238$ & 100.0 & $-6.654 E-03$ & $(16)$ & $-6.233 E-03$ & $(16)$ \\
\hline$p u-239$ & 1.0 & $2.243 \mathrm{E}-01$ & $(1)$ & $2.329 E-01$ & $(1)$ \\
\hline$p u-240$ & 2.0 & $-7.358 \mathrm{E}-02$ & $(4)$ & $-6.919 E-02$ & ( 4) \\
\hline pu- 241 & 2.0 & $8.180 E-02$ & $(3)$ & $8.273 E-02$ & $(3)$ \\
\hline$p u-242$ & 25.0 & $-7.275 E-03$ & (14) & $-6.731 E-03$ & (15) \\
\hline am- 241 & 10.0 & $-2.019 E-02$ & $(9)$ & $-1.848 E-02$ & $(9)$ \\
\hline 0 & 25.0 & $-1.277 \mathrm{E}-02$ & (10) & $-1.274 \mathrm{E}-02$ & (10) \\
\hline tc -99 & 25.0 & $-7.032 E-03$ & (15) & $-7.910 E-03$ & (13) \\
\hline CS -133 & 25.0 & $-8.947 E-03$ & (12) & $-8.920 E-03$ & (12) \\
\hline CS -135 & 100.0 & $-6.629 \mathrm{E}-04$ & (23) & $-7.217 \mathrm{E}-04$ & (23) \\
\hline nd -143 & 10.0 & $-2.026 \mathrm{E}-02$ & $(8)$ & $-1.955 E-02$ & $(7)$ \\
\hline nd -145 & 25.0 & $-4.519 E-03$ & (19) & $-4.417 \mathrm{E}-03$ & (19) \\
\hline sm- 147 & 25.0 & $-2.882 E-03$ & $(21)$ & $-2.748 E-03$ & (21) \\
\hline sm- 149 & 10.0 & $-2.574 E-02$ & $(6)$ & $-1.850 E-02$ & $(8)$ \\
\hline sm- 150 & 25.0 & $-4.167 \mathrm{E}-03$ & $(20)$ & $-4.061 \mathrm{E}-03$ & $(20)$ \\
\hline sm- 151 & 10.0 & $-9.437 E-03$ & (11) & $-1.159 \mathrm{E}-02$ & (11) \\
\hline sm- 152 & 25.0 & $-5.312 \mathrm{E}-03$ & (18) & $-6.081 E-03$ & (18) \\
\hline eu- 153 & 25.0 & $-7.628 \mathrm{E}-03$ & (13) & $-7.156 \mathrm{E}-03$ & (14) \\
\hline $\mathrm{gd}-155$ & 25.0 & $-2.043 E-02$ & $(7)$ & $-3.725 E-02$ & $(6)$ \\
\hline
\end{tabular}

3.6 wt \% Initial Enrichment, $10 \mathrm{GWd} / \mathrm{MTU}$ Burnup, $5 y$ Cooled, Actinides + Fission Products

Isotope Perturbation Sensitivity Coefficient $[\{($ delta $k) / k\} /\{($ de 1 ta $N) / N\}]$

(\%) With Bias Rank Without Bias Rank

\begin{tabular}{|c|c|c|c|c|c|}
\hline$u-234$ & 100.0 & $-1.689 \mathrm{E}-03$ & (14) & $-1.778 \mathrm{E}-03$ & (15) \\
\hline$u-235$ & 1.0 & $1.456 \mathrm{E}-01$ & $(2)$ & $1.415 \mathrm{E}-01$ & $(2)$ \\
\hline$u-236$ & 25.0 & $-3.718 E-03$ & (9) & $-3.774 E-03$ & $(9)$ \\
\hline$u-238$ & 1.0 & $-1.650 E-01$ & $(1)$ & $-1.670 \mathrm{E}-01$ & ( 1$)$ \\
\hline pu- 238 & 100.0 & $-1.007 E-04$ & (23) & $-1.006 E-04$ & (23) \\
\hline pu- 239 & 1.0 & $3.331 \mathrm{E}-02$ & $(3)$ & $3.556 \mathrm{E}-02$ & ( 3$)$ \\
\hline$p u-240$ & 2.0 & $-2.285 E-02$ & (4) & $-2.165 E-02$ & ( 4$)$ \\
\hline pu- 241 & 2.0 & $3.486 E-03$ & $(10)$ & $3.480 E-03$ & (10) \\
\hline pu- 242 & 25.0 & $-1.548 E-04$ & $(21)$ & $-1.239 E-04$ & $(22)$ \\
\hline am- 241 & 10.0 & $-1.859 E-03$ & $(12)$ & $-1.779 E-03$ & (14) \\
\hline & 25.0 & $-9.730 E-03$ & $(6)$ & $-9.712 E-03$ & $(6)$ \\
\hline tc -99 & 25.0 & $-1.704 \mathrm{E}-03$ & (13) & $-1.980 \mathrm{E}-03$ & (13) \\
\hline CS -133 & 25.0 & $-2.231 E-03$ & $(11)$ & $-2.289 E-03$ & (11) \\
\hline CS -135 & 100.0 & $-1.317 E-04$ & $(22)$ & $-1.469 E-04$ & (21) \\
\hline nd -143 & 10.0 & $-5.423 E-03$ & $(7)$ & $-5.568 E-03$ & $(7)$ \\
\hline nd -145 & 25.0 & $-1.054 E-03$ & (18) & $-1.083 E-03$ & (17) \\
\hline sm- 147 & 25.0 & $-1.116 \mathrm{E}-03$ & $(16)$ & $-1.083 E-03$ & (18) \\
\hline sm- 149 & 10.0 & $-1.766 \mathrm{E}-02$ & $(5)$ & $-1.346 \mathrm{E}-02$ & $(5)$ \\
\hline sm- 150 & 25.0 & $-6.199 E-04$ & $(20)$ & $-6.497 E-04$ & $(20)$ \\
\hline $\mathrm{sm}-151$ & 10.0 & $-3.719 E-03$ & $(8)$ & $-4.949 E-03$ & $(8)$ \\
\hline sm- 152 & 25.0 & $-1.209 E-03$ & (15) & $-1.454 E-03$ & (16) \\
\hline eu- 153 & 25.0 & $-7.436 \mathrm{E}-04$ & (19) & $-7.116 \mathrm{E}-04$ & (19) \\
\hline $\mathrm{gd}-155$ & 25.0 & $-1.085 E-03$ & $(17)$ & $-2.134 E-03$ & $(12)$ \\
\hline
\end{tabular}


3.6 wt \% Initial Enrichment, 30 GWd/MTU Burnup, $5 y$ Cooled, Actinides + Fission Products

\begin{tabular}{|c|c|c|c|c|c|}
\hline Isotope & $\begin{array}{c}\text { Perturbation } \\
(\%)\end{array}$ & $\begin{array}{l}\text { Sensitivity } \\
\text { With Bias }\end{array}$ & $\begin{array}{l}\text { Coefficient } \\
\text { Rank }\end{array}$ & $\begin{array}{c}{[\{(\text { delta } k) / k} \\
\text { without Bias }\end{array}$ & $\begin{array}{l}/\{\text { (de } 1 \\
\text { Rank }\end{array}$ \\
\hline$u-234$ & 100.0 & $-1.328 E-03$ & $(22)$ & $-1.385 E-03$ & $(22)$ \\
\hline$u-235$ & 1.0 & $1.283 E-01$ & $(2)$ & $1.260 \mathrm{E}-01$ & $(2)$ \\
\hline$u-236$ & 25.0 & $-6.181 \mathrm{E}-03$ & $(12)$ & $-6.226 \mathrm{E}-03$ & $(12)$ \\
\hline$u-238$ & 1.0 & $-1.663 E-01$ & $(1)$ & $-1.655 E-01$ & $(1)$ \\
\hline pu- 238 & 100.0 & $-1.798 \mathrm{E}-03$ & $(21)$ & $-1.745 E-03$ & (21) \\
\hline pu- 239 & 1.0 & $1.076 \mathrm{E}-01$ & $(3)$ & $1.134 \mathrm{E}-01$ & $(3)$ \\
\hline pu- 240 & 2.0 & $-5.106 \mathrm{E}-02$ & $(4)$ & $-4.948 E-02$ & ( 4) \\
\hline pu- 241 & 2.0 & $2.983 E-02$ & $(5)$ & $3.059 E-02$ & $(5)$ \\
\hline$p u-242$ & 25.0 & $-2.892 E-03$ & (18) & $-2.663 E-03$ & ( 18) \\
\hline am- 241 & 10.0 & $-1.211 \mathrm{E}-02$ & $(8)$ & $-1.134 \mathrm{E}-02$ & $(10)$ \\
\hline 0 & 25.0 & $-1.135 \mathrm{E}-02$ & $(9)$ & $-1.134 \mathrm{E}-02$ & $(9)$ \\
\hline tc -99 & 25.0 & $-4.627 E-03$ & (14) & $-5.290 \mathrm{E}-03$ & (14) \\
\hline CS -133 & 25.0 & $-5.928 E-03$ & (13) & $-6.010 E-03$ & (13) \\
\hline cs -135 & 100.0 & $-4.156 \mathrm{E}-04$ & (23) & $-4.678 \mathrm{E}-04$ & (23) \\
\hline nd -143 & 10.0 & $-1.446 \mathrm{E}-02$ & $(7)$ & $-1.439 \mathrm{E}-02$ & $(7)$ \\
\hline nd -145 & 25.0 & $-2.928 \mathrm{E}-03$ & (17) & $-2.915 E-03$ & (17) \\
\hline sm- 147 & 25.0 & $-2.458 \mathrm{E}-03$ & (19) & $-2.375 E-03$ & (19) \\
\hline sm- 149 & 10.0 & $-2.332 E-02$ & $(6)$ & $-1.727 \mathrm{E}-02$ & $(6)$ \\
\hline sm- 150 & 25.0 & $-2.277 \mathrm{E}-03$ & $(20)$ & $-2.267 E-03$ & $(20)$ \\
\hline sm- 151 & 10.0 & $-6.687 E-03$ & (11) & $-8.547 E-03$ & (11) \\
\hline sm- 152 & 25.0 & $-3.434 \mathrm{E}-03$ & $(16)$ & $-4.066 \mathrm{E}-03$ & (15) \\
\hline eu- 153 & 25.0 & $-3.687 E-03$ & (15) & $-3.562 E-03$ & (16) \\
\hline $\mathrm{gd}-155$ & 25.0 & $-6.796 \mathrm{E}-03$ & (10) & $-1.285 E-02$ & $(8)$ \\
\hline
\end{tabular}

3.6 wt \% Initial Enrichment, 50 GWd/MTU Burnup, $5 y$ Cooled, Actinides + Fission Products Isotope Perturbation Sensitivity Coefficient $[\{($ delta $k) / k\} /\{($ delta $N) / N\}]$ (\%) With Bias Rank Without Bias Rank

\begin{tabular}{|c|c|c|c|c|c|}
\hline$u-234$ & 100.0 & $-1.052 E-03$ & (22) & $-1.075 E-03$ & $(22)$ \\
\hline$u-235$ & 1.0 & $8.815 E-02$ & $(3)$ & $8.581 E-02$ & ( 3 ) \\
\hline$u-236$ & 25.0 & $-6.826 E-03$ & $(15)$ & $-6.794 E-03$ & ( 14$)$ \\
\hline$u-238$ & 1.0 & $-1.653 E-01$ & $(2)$ & $-1.542 \mathrm{E}-01$ & $(2)$ \\
\hline pu- 238 & 100.0 & $-6.133 E-03$ & (17) & $-5.778 E-03$ & (18) \\
\hline pu- 239 & 1.0 & $1.963 \mathrm{E}-01$ & $(1)$ & $1.907 \mathrm{E}-01$ & $(1)$ \\
\hline pu- 240 & 2.0 & $-6.941 E-02$ & (4) & $-6.542 E-02$ & $(5)$ \\
\hline pu- 241 & 2.0 & $6.811 E-02$ & $(5)$ & $6.947 E-02$ & $(4)$ \\
\hline pu- 242 & 25.0 & $-6.564 E-03$ & $(16)$ & $-6.064 E-03$ & (16) \\
\hline$a m-241$ & 10.0 & $-1.947 E-02$ & $(8)$ & $-1.789 E-02$ & $(9)$ \\
\hline 0 & 25.0 & $-1.250 \mathrm{E}-02$ & $(10)$ & $-1.247 E-02$ & $(10)$ \\
\hline tc -99 & 25.0 & $-6.952 E-03$ & (14) & $-7.828 E-03$ & (13) \\
\hline CS -133 & 25.0 & $-8.812 E-03$ & $(12)$ & $-8.811 E-03$ & (12) \\
\hline CS -135 & 100.0 & $-7.097 E-04$ & $(23)$ & $-7.740 E-04$ & $(23)$ \\
\hline nd -143 & 10.0 & $-2.043 E-02$ & $(7)$ & $-1.975 E-02$ & $(7)$ \\
\hline nd -145 & 25.0 & $-4.466 E-03$ & $(19)$ & $-4.379 E-03$ & (19) \\
\hline sm- 147 & 25.0 & $-2.993 E-03$ & $(21)$ & $-2.859 E-03$ & $(21)$ \\
\hline sm- 149 & 10.0 & $-2.526 \mathrm{E}-02$ & $(6)$ & $-1.826 \mathrm{E}-02$ & $(8)$ \\
\hline sm- 150 & 25.0 & $-3.938 E-03$ & $(20)$ & $-3.864 E-03$ & $(20)$ \\
\hline $\mathrm{sm}-151$ & 10.0 & $-9.178 E-03$ & (11) & $-1.134 E-02$ & (11) \\
\hline sm- 152 & 25.0 & $-5.116 E-03$ & $(18)$ & $-5.860 E-03$ & $(17)$ \\
\hline eu- 153 & 25.0 & $-7.101 \mathrm{E}-03$ & (13) & $-6.690 \mathrm{E}-03$ & $(15)$ \\
\hline $\mathrm{gd}-155$ & 25.0 & $-1.808 \mathrm{E}-02$ & $(9)$ & $-3.312 \mathrm{E}-02$ & $(6)$ \\
\hline
\end{tabular}




\section{5}

4.5 wt \% Initial Enrichment, 10 GWd/MTU Burnup, 5 y Cooled, Actinides + Fission Products

\begin{tabular}{|c|c|c|c|c|c|}
\hline Isotope & $\begin{array}{c}\text { Perturbation } \\
(\%)\end{array}$ & $\begin{array}{l}\text { Sensitivity } \\
\text { With Bias }\end{array}$ & $\begin{array}{l}\text { Coefficient } \\
\text { Rank }\end{array}$ & $\begin{array}{c}{[\{(\text { delta } k) / k} \\
\text { without Bias }\end{array}$ & $\begin{array}{l}\text { \{ } \text { (de } 1 \\
\text { Rank }\end{array}$ \\
\hline$u-234$ & 100.0 & $-1.980 E-03$ & (11) & $-2.081 E-03$ & (11) \\
\hline$u-235$ & 1.0 & $1.310 E-01$ & $(2)$ & $1.279 \mathrm{E}-01$ & $(2)$ \\
\hline$u-236$ & 25.0 & $-3.870 E-03$ & $(8)$ & $-3.895 E-03$ & $(9)$ \\
\hline$u-238$ & 1.0 & $-1.526 E-01$ & $(1)$ & $-1.546 \mathrm{E}-01$ & $(1)$ \\
\hline pu- 238 & 100.0 & $-7.445 E-05$ & (23) & $-7.435 E-05$ & $(23)$ \\
\hline pu- 239 & 1.0 & $2.010 \mathrm{E}-02$ & ( 3$)$ & $2.156 \mathrm{E}-02$ & $(3)$ \\
\hline pu- 240 & 2.0 & $-1.935 E-02$ & $(4)$ & $-1.858 E-02$ & $(4)$ \\
\hline pu- 241 & 2.0 & $1.859 E-03$ & $(12)$ & $1.861 E-03$ & (13) \\
\hline$p u-242$ & 25.0 & $-8.944 E-05$ & $(22)$ & $-8.932 E-05$ & $(22)$ \\
\hline$a m-241$ & 10.0 & $-1.340 E-03$ & (14) & $-1.338 E-03$ & (15) \\
\hline 0 & 25.0 & $-9.438 E-03$ & $(6)$ & $-9.426 \mathrm{E}-03$ & $(6)$ \\
\hline tc -99 & 25.0 & $-1.608 E-03$ & (13) & $-1.873 E-03$ & (12) \\
\hline CS -133 & 25.0 & $-2.114 E-03$ & $(10)$ & $-2.171 E-03$ & $(10)$ \\
\hline cs -135 & 100.0 & $-1.489 \mathrm{E}-04$ & (21) & $-1.709 \mathrm{E}-04$ & $(21)$ \\
\hline nd -143 & 10.0 & $-4.615 E-03$ & $(7)$ & $-4.832 E-03$ & $(7)$ \\
\hline nd -145 & 25.0 & $-9.824 E-04$ & (17) & $-1.011 \mathrm{E}-03$ & (18) \\
\hline sm- 147 & 25.0 & $-1.072 E-03$ & (15) & $-1.070 \mathrm{E}-03$ & (17) \\
\hline sm- 149 & 10.0 & $-1.675 E-02$ & $(5)$ & $-1.293 E-02$ & $(5)$ \\
\hline sm- 150 & 25.0 & $-5.359 \mathrm{E}-04$ & $(20)$ & $-5.650 E-04$ & $(20)$ \\
\hline sm- 151 & 10.0 & $-3.499 E-03$ & $(9)$ & $-4.683 E-03$ & $(8)$ \\
\hline sm- 152 & 25.0 & $-1.072 \mathrm{E}-03$ & (16) & $-1.308 E-03$ & (16) \\
\hline eu- 153 & 25.0 & $-6.254 E-04$ & (19) & $-6.246 E-04$ & $(19)$ \\
\hline $\mathrm{gd}-155$ & 25.0 & $-8.635 E-04$ & (18) & $-1.665 E-03$ & (14) \\
\hline
\end{tabular}

4.5 wt \% Initial Enrichment, 30 GWd/MTU Burnup, $5 y$ Cooled, Actinides + Fission Products

Isotope Perturbation Sensitivity Coefficient $[\{($ delta $k) / k\} /\{($ de 1 ta $N) / N\}]$

(\%) With Bias Rank Without Bias Rank

$\begin{array}{rrrrrr}\text { u-234 } & 100.0 & -1.607 \mathrm{E}-03 & (21) & -1.679 \mathrm{E}-03 & (21) \\ \mathrm{u}-235 & 1.0 & 1.327 \mathrm{E}-01 & (2) & 1.297 \mathrm{E}-01 & (2) \\ \mathrm{u}-236 & 25.0 & -6.600 \mathrm{E}-03 & (10) & -6.615 \mathrm{E}-03 & (12) \\ \mathrm{u}-238 & 1.0 & -1.539 \mathrm{E}-01 & (1) & -1.543 \mathrm{E}-01 & (1) \\ \mathrm{pu}-238 & 100.0 & -1.344 \mathrm{E}-03 & (22) & -1.314 \mathrm{E}-03 & (22) \\ \mathrm{pu}-239 & 1.0 & 7.570 \mathrm{E}-02 & (3) & 7.547 \mathrm{E}-02 & (3) \\ \mathrm{pu}-240 & 2.0 & -4.423 \mathrm{E}-02 & (4) & -4.283 \mathrm{E}-02 & (4) \\ \mathrm{pu}-241 & 2.0 & 1.956 \mathrm{E}-02 & (6) & 2.035 \mathrm{E}-02 & (5) \\ \mathrm{pu}-242 & 25.0 & -2.143 \mathrm{E}-03 & (19) & -1.934 \mathrm{E}-03 & (20) \\ \mathrm{am}-241 & 10.0 & -1.012 \mathrm{E}-02 & (9) & -9.412 \mathrm{E}-03 & (10) \\ \mathrm{o} & 25.0 & -1.092 \mathrm{E}-02 & (8) & -1.089 \mathrm{E}-02 & (8) \\ \mathrm{tc}-99 & 25.0 & -4.389 \mathrm{E}-03 & (14) & -5.020 \mathrm{E}-03 & (14) \\ \mathrm{cs}-133 & 25.0 & -5.613 \mathrm{E}-03 & (12) & -5.699 \mathrm{E}-03 & (13) \\ \mathrm{cs}-135 & 100.0 & -4.593 \mathrm{E}-04 & (23) & -5.088 \mathrm{E}-04 & (23) \\ \mathrm{nd}-143 & 10.0 & -1.293 \mathrm{E}-02 & (7) & -1.297 \mathrm{E}-02 & (7) \\ \mathrm{nd}-145 & 25.0 & -2.722 \mathrm{E}-03 & (17) & -2.748 \mathrm{E}-03 & (17) \\ \mathrm{sm}-147 & 25.0 & -2.450 \mathrm{E}-03 & (18) & -2.340 \mathrm{E}-03 & (18) \\ \mathrm{sm}-149 & 10.0 & -2.194 \mathrm{E}-02 & (5) & -1.645 \mathrm{E}-02 & (6) \\ \mathrm{sm}-150 & 25.0 & -1.973 \mathrm{E}-03 & (20) & -2.001 \mathrm{E}-03 & (19) \\ \mathrm{sm}-151 & 10.0 & -6.124 \mathrm{E}-03 & (11) & -7.887 \mathrm{E}-03 & (11) \\ \mathrm{sm}-152 & 25.0 & -3.164 \mathrm{E}-03 & (15) & -3.697 \mathrm{E}-03 & (15) \\ \mathrm{eu}-153 & 25.0 & -3.130 \mathrm{E}-03 & (16) & -3.019 \mathrm{E}-03 & (16) \\ \mathrm{gd}-155 & 25.0 & -5.035 \mathrm{E}-03 & (13) & -9.566 \mathrm{E}-03 & (9) \\ & & & & & \end{array}$




\section{6}

4.5 wt \% Initial Enrichment, 50 GWd/MTU Burnup, 5 y Cooled, Actinides + Fission Products

\begin{tabular}{|c|c|c|c|c|c|}
\hline Isotope & $\begin{array}{c}\text { Perturbation } \\
(\%)\end{array}$ & $\begin{array}{l}\text { Sensitivity } \\
\text { With Bias }\end{array}$ & $\begin{array}{l}\text { Coefficient } \\
\text { Rank }\end{array}$ & $\begin{array}{c}{[\{(\text { delta } k) / k} \\
\text { without Bias }\end{array}$ & $\begin{array}{l}/\{\text { (de } 1 \\
\text { Rank }\end{array}$ \\
\hline$u-234$ & 100.0 & $-1.323 E-03$ & $(22)$ & $-1.350 E-03$ & $(22)$ \\
\hline$u-235$ & 1.0 & $1.099 E-01$ & $(3)$ & $1.078 E-01$ & $(3)$ \\
\hline$u-236$ & 25.0 & $-7.586 \mathrm{E}-03$ & (13) & $-7.537 \mathrm{E}-03$ & (14) \\
\hline$u-238$ & 1.0 & $-1.498 E-01$ & $(1)$ & $-1.467 \mathrm{E}-01$ & $(1)$ \\
\hline pu- 238 & 100.0 & $-5.135 E-03$ & (17) & $-4.886 E-03$ & (18) \\
\hline pu- 239 & 1.0 & $1.478 \mathrm{E}-01$ & $(2)$ & $1.457 \mathrm{E}-01$ & $(2)$ \\
\hline pu- 240 & 2.0 & $-6.224 E-02$ & $(4)$ & $-5.877 \mathrm{E}-02$ & ( 4$)$ \\
\hline pu- 241 & 2.0 & $5.058 E-02$ & $(5)$ & $5.293 E-02$ & $(5)$ \\
\hline$p u-242$ & 25.0 & $-5.524 E-03$ & (16) & $-5.090 E-03$ & (17) \\
\hline am- 241 & 10.0 & $-1.799 E-02$ & $(8)$ & $-1.671 \mathrm{E}-02$ & $(9)$ \\
\hline 0 & 25.0 & $-1.206 \mathrm{E}-02$ & (10) & $-1.204 \mathrm{E}-02$ & (10) \\
\hline tc -99 & 25.0 & $-6.730 E-03$ & (14) & $-7.615 \mathrm{E}-03$ & (13) \\
\hline CS -133 & 25.0 & $-8.520 E-03$ & (12) & $-8.547 E-03$ & (12) \\
\hline cs -135 & 100.0 & $-7.683 \mathrm{E}-04$ & (23) & $-8.450 E-04$ & (23) \\
\hline nd -143 & 10.0 & $-1.974 \mathrm{E}-02$ & $(7)$ & $-1.933 \mathrm{E}-02$ & $(7)$ \\
\hline nd -145 & 25.0 & $-4.279 E-03$ & (19) & $-4.235 E-03$ & (19) \\
\hline sm- 147 & 25.0 & $-3.112 E-03$ & $(21)$ & $-2.992 \mathrm{E}-03$ & (21) \\
\hline sm- 149 & 10.0 & $-2.441 E-02$ & $(6)$ & $-1.778 \mathrm{E}-02$ & $(8)$ \\
\hline sm- 150 & 25.0 & $-3.540 E-03$ & $(20)$ & $-3.497 \mathrm{E}-03$ & $(20)$ \\
\hline sm- 151 & 10.0 & $-8.655 E-03$ & (11) & $-1.078 E-02$ & (11) \\
\hline sm- 152 & 25.0 & $-4.785 E-03$ & (18) & $-5.478 \mathrm{E}-03$ & $(16)$ \\
\hline eu- 153 & 25.0 & $-6.302 E-03$ & (15) & $-5.983 E-03$ & (15) \\
\hline $\mathrm{gd}-155$ & 25.0 & $-1.459 E-02$ & $(9)$ & $-2.700 E-02$ & $(6)$ \\
\hline
\end{tabular}

3.0 wt \% Initial Enrichment, 10 GWd/MTU Burnup, 5y Cooled, Actinides On $1 y$

Isotope Perturbation Sensitivity Coefficient $[\{($ delta $k) / k\} /\{($ de 1 ta $N) / N\}]$

(\%) With Bias Rank Without Bias Rank

$\begin{array}{rrrrrr}\text { u-234 } & 100.0 & -1.529 \mathrm{E}-03 & (9) & -1.604 \mathrm{E}-03 & (9) \\ \mathrm{u}-235 & 1.0 & 1.351 \mathrm{E}-01 & (2) & 1.311 \mathrm{E}-01 & (2) \\ \mathrm{u}-236 & 25.0 & -3.675 \mathrm{E}-03 & (7) & -3.702 \mathrm{E}-03 & (7) \\ \mathrm{u}-238 & 1.0 & -1.838 \mathrm{E}-01 & (1) & -1.843 \mathrm{E}-01 & (1) \\ \text { pu-238 } & 100.0 & -1.390 \mathrm{E}-04 & (11) & -1.388 \mathrm{E}-04 & (11) \\ \text { pu-239 } & 1.0 & 3.938 \mathrm{E}-02 & (3) & 4.240 \mathrm{E}-02 & (3) \\ \text { pu-240 } & 2.0 & -2.664 \mathrm{E}-02 & (4) & -2.545 \mathrm{E}-02 & (4) \\ \text { pu-241 } & 2.0 & 4.634 \mathrm{E}-03 & (6) & 4.624 \mathrm{E}-03 & (6) \\ \text { pu-242 } & 25.0 & -2.161 \mathrm{E}-04 & (10) & -1.853 \mathrm{E}-04 & (10) \\ \text { am-241 } & 10.0 & -2.548 \mathrm{E}-03 & (8) & -2.391 \mathrm{E}-03 & (8) \\ 0 & 25.0 & -1.001 \mathrm{E}-02 & (5) & -9.963 \mathrm{E}-03 & (5)\end{array}$


3.0 wt \% Initial Enrichment, 30 GWd/MTU Burnup, $5 y$ Cooled, Actinides On 1y

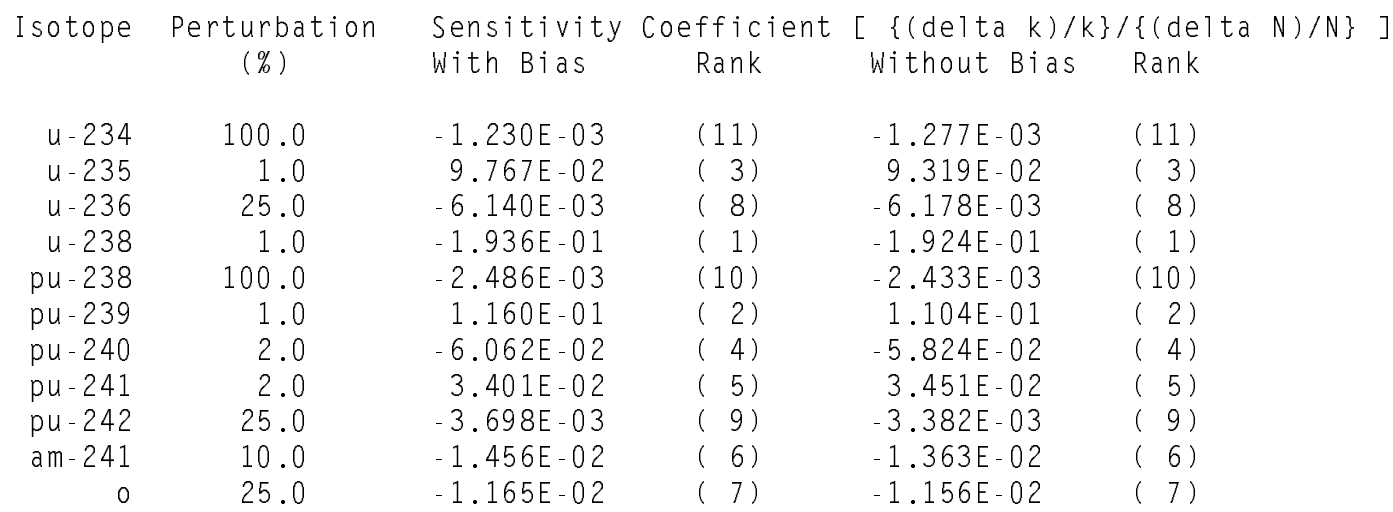

3.0 wt \% Initial Enrichment, 50 GWd/MTU Burnup, $5 y$ Cooled, Actinides On1y

Isotope Perturbation Sensitivity Coefficient $[\{($ delta $k) / k\} /\{($ de 1 ta $N) / N\}]$

(\%) With Bias Rank Without Bias Rank

$\begin{array}{rrrrrr}\text { U-234 } & 100.0 & -9.772 \mathrm{E}-04 & (11) & -1.015 \mathrm{E}-03 & (11) \\ \mathrm{u}-235 & 1.0 & 5.558 \mathrm{E}-02 & (5) & 4.981 \mathrm{E}-02 & (5) \\ \mathrm{u}-236 & 25.0 & -6.707 \mathrm{E}-03 & (10) & -6.729 \mathrm{E}-03 & (10) \\ \mathrm{u}-238 & 1.0 & -2.002 \mathrm{E}-01 & (1) & -1.992 \mathrm{E}-01 & (1) \\ \text { pu-238 } & 100.0 & -8.211 \mathrm{E}-03 & (8) & -7.969 \mathrm{E}-03 & (8) \\ \text { pu-239 } & 1.0 & 1.792 \mathrm{E}-01 & (2) & 1.786 \mathrm{E}-01 & (2) \\ \text { pu-240 } & 2.0 & -8.143 \mathrm{E}-02 & (3) & -7.753 \mathrm{E}-02 & (3) \\ \text { pu-241 } & 2.0 & 6.946 \mathrm{E}-02 & (4) & 6.813 \mathrm{E}-02 & (4) \\ \text { pu-242 } & 25.0 & -7.703 \mathrm{E}-03 & (9) & -7.180 \mathrm{E}-03 & (9) \\ \text { am-241 } & 10.0 & -2.242 \mathrm{E}-02 & (6) & -2.086 \mathrm{E}-02 & (6) \\ 0 & 25.0 & -1.246 \mathrm{E}-02 & (7) & -1.233 \mathrm{E}-02 & (7)\end{array}$

3.6 wt \% Initial Enrichment, 10 GWd/MTU Burnup, 5y Cooled, Actinides On $1 y$

Isotope Perturbation Sensitivity Coefficient $[\{($ delta $k) / k\} /\{($ de 1 ta $N) / N\}]$

(\%) With Bias Rank Without Bias Rank

$\begin{array}{rrrrrr}\text { u-234 } & 100.0 & -1.746 \mathrm{E}-03 & (9) & -1.834 \mathrm{E}-03 & (9) \\ \mathrm{u}-235 & 1.0 & 1.231 \mathrm{E}-01 & (2) & 1.208 \mathrm{E}-01 & (2) \\ \mathrm{u}-236 & 25.0 & -3.820 \mathrm{E}-03 & (6) & -3.847 \mathrm{E}-03 & (6) \\ \mathrm{u}-238 & 1.0 & -1.716 \mathrm{E}-01 & (1) & -1.730 \mathrm{E}-01 & (1) \\ \text { pu-238 } & 100.0 & -1.120 \mathrm{E}-04 & (11) & -1.119 \mathrm{E}-04 & (11) \\ \text { pu-239 } & 1.0 & 2.686 \mathrm{E}-02 & (3) & 2.833 \mathrm{E}-02 & (3) \\ \text { pu-240 } & 2.0 & -2.350 \mathrm{E}-02 & (4) & -2.237 \mathrm{E}-02 & (4) \\ \text { pu-241 } & 2.0 & 2.983 \mathrm{E}-03 & (7) & 2.982 \mathrm{E}-03 & (7) \\ \text { pu-242 } & 25.0 & -1.494 \mathrm{E}-04 & (10) & -1.493 \mathrm{E}-04 & (10) \\ \text { am-241 } & 10.0 & -1.939 \mathrm{E}-03 & (8) & -1.865 \mathrm{E}-03 & (8) \\ 0 & 25.0 & -9.727 \mathrm{E}-03 & (5) & -9.722 \mathrm{E}-03 & (5)\end{array}$




\section{8}

3.6 wt \% Initial Enrichment, 30 GWd/MTU Burnup, 5y Cooled, Actinides On 1y

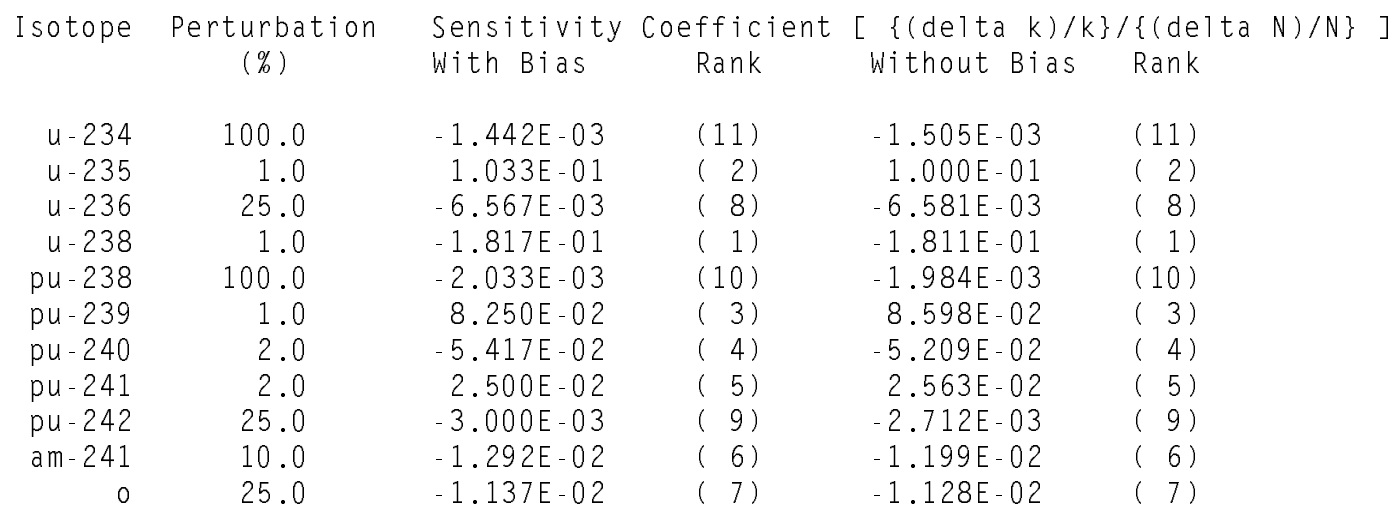

3.6 wt \% Initial Enrichment, 50 GWd/MTU Burnup, 5y Cooled, Actinides On1y

Isotope Perturbation Sensitivity Coefficient $[\{($ delta $k) / k\} /\{($ delta $N) / N\}]$

(\%) With Bias Rank Without Bias Rank

$\begin{array}{rrrrrr}\text { U-234 } & 100.0 & -1.197 \mathrm{E}-03 & (11) & -1.241 \mathrm{E}-03 & (11) \\ \mathrm{u}-235 & 1.0 & 7.088 \mathrm{E}-02 & (4) & 6.702 \mathrm{E}-02 & (4) \\ \mathrm{u}-236 & 25.0 & -7.437 \mathrm{E}-03 & (9) & -7.464 \mathrm{E}-03 & (8) \\ \mathrm{u}-238 & 1.0 & -1.924 \mathrm{E}-01 & (1) & -1.830 \mathrm{E}-01 & (1) \\ \text { pu-238 } & 100.0 & -7.483 \mathrm{E}-03 & (8) & -7.274 \mathrm{E}-03 & (9) \\ \text { pu-239 } & 1.0 & 1.528 \mathrm{E}-01 & (2) & 1.422 \mathrm{E}-01 & (2) \\ \text { pu-240 } & 2.0 & -7.640 \mathrm{E}-02 & (3) & -7.292 \mathrm{E}-02 & (3) \\ \text { pu-241 } & 2.0 & 5.707 \mathrm{E}-02 & (5) & 5.661 \mathrm{E}-02 & (5) \\ \text { pu-242 } & 25.0 & -6.958 \mathrm{E}-03 & (10) & -6.449 \mathrm{E}-03 & (10) \\ \text { am-241 } & 10.0 & -2.154 \mathrm{E}-02 & (6) & -2.002 \mathrm{E}-02 & (6) \\ 0 & 25.0 & -1.226 \mathrm{E}-02 & (7) & -1.214 \mathrm{E}-02 & (7)\end{array}$

4.5 wt \% Initial Enrichment, 10 GWd/MTU Burnup, 5y Cooled, Actinides On $1 y$

Isotope Perturbation Sensitivity Coefficient $[\{($ delta $k) / k\} /\{($ de 1 ta $N) / N\}]$

(\%) With Bias Rank Without Bias Rank

$\begin{array}{rrrrrr}\text { U-234 } & 100.0 & -2.034 \mathrm{E}-03 & (7) & -2.142 \mathrm{E}-03 & (7) \\ \mathrm{u}-235 & 1.0 & 1.086 \mathrm{E}-01 & (2) & 1.064 \mathrm{E}-01 & (2) \\ \mathrm{u}-236 & 25.0 & -3.939 \mathrm{E}-03 & (6) & -3.968 \mathrm{E}-03 & (6) \\ \mathrm{u}-238 & 1.0 & -1.574 \mathrm{E}-01 & (1) & -1.589 \mathrm{E}-01 & (1) \\ \mathrm{pu}-238 & 100.0 & -7.910 \mathrm{E}-05 & (11) & -7.910 \mathrm{E}-05 & (11) \\ \mathrm{pu}-239 & 1.0 & 1.510 \mathrm{E}-02 & (4) & 1.581 \mathrm{E}-02 & (4) \\ \text { pu-240 } & 2.0 & -1.941 \mathrm{E}-02 & (3) & -1.905 \mathrm{E}-02 & (3) \\ \text { pu-241 } & 2.0 & 1.800 \mathrm{E}-03 & (8) & 1.795 \mathrm{E}-03 & (8) \\ \text { pu-242 } & 25.0 & -8.604 \mathrm{E}-05 & (10) & -8.639 \mathrm{E}-05 & (10) \\ \text { am-241 } & 10.0 & -1.366 \mathrm{E}-03 & (9) & -1.294 \mathrm{E}-03 & (9) \\ 0 & 25.0 & -9.431 \mathrm{E}-03 & (5) & -9.432 \mathrm{E}-03 & (5)\end{array}$




\section{9}

4.5 wt \% Initial Enrichment, 30 GWd/MTU Burnup, $5 y$ Cooled, Actinides On 1y

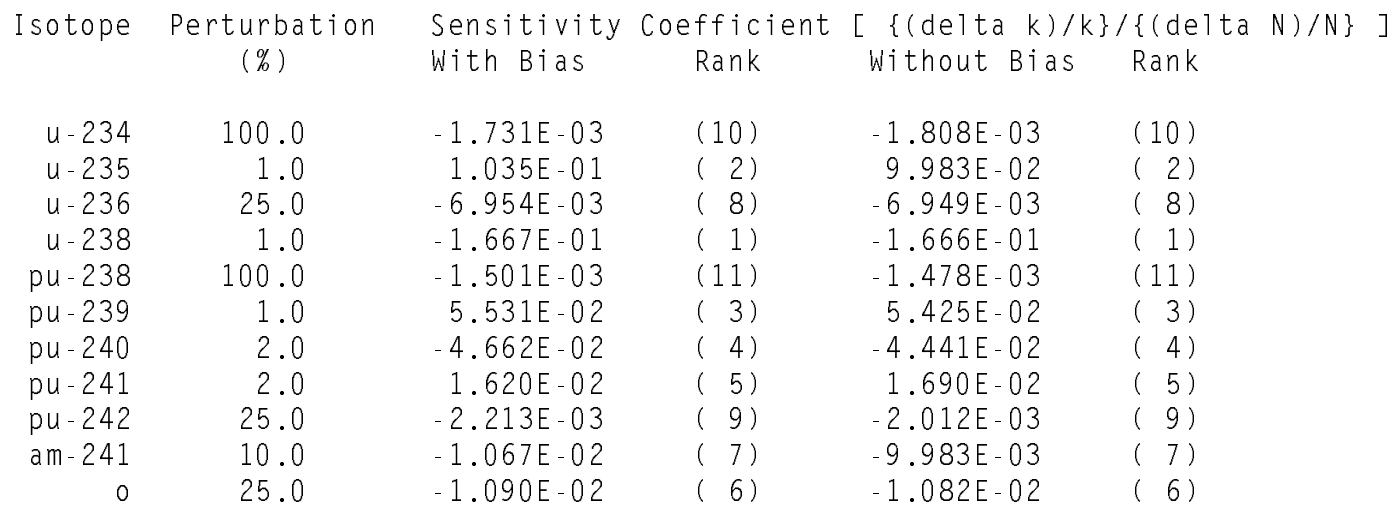

4.5 wt \% Initial Enrichment, 50 GWd/MTU Burnup, $5 y$ Cooled, Actinides On $1 y$

Isotope Perturbation Sensitivity Coefficient $[\{($ delta $k) / k\} /\{($ delta $N) / N\}]$

(\%) With Bias Rank Without Bias Rank

$\begin{array}{rrrrrr}\text { u-234 } & 100.0 & -1.484 \mathrm{E}-03 & (11) & -1.544 \mathrm{E}-03 & (11) \\ \mathrm{u}-235 & 1.0 & 8.505 \mathrm{E}-02 & (3) & 8.061 \mathrm{E}-02 & (3) \\ \mathrm{u}-236 & 25.0 & -8.227 \mathrm{E}-03 & (8) & -8.267 \mathrm{E}-03 & (8) \\ \mathrm{u}-238 & 1.0 & -1.710 \mathrm{E}-01 & (1) & -1.707 \mathrm{E}-01 & (1) \\ \text { pu-238 } & 100.0 & -6.153 \mathrm{E}-03 & (9) & -6.003 \mathrm{E}-03 & (9) \\ \text { pu-239 } & 1.0 & 1.102 \mathrm{E}-01 & (2) & 1.038 \mathrm{E}-01 & (2) \\ \text { pu-240 } & 2.0 & -6.769 \mathrm{E}-02 & (4) & -6.475 \mathrm{E}-02 & (4) \\ \text { pu-241 } & 2.0 & 4.122 \mathrm{E}-02 & (5) & 4.202 \mathrm{E}-02 & (5) \\ \text { pu-242 } & 25.0 & -5.832 \mathrm{E}-03 & (10) & -5.386 \mathrm{E}-03 & (10) \\ \text { am-241 } & 10.0 & -1.961 \mathrm{E}-02 & (6) & -1.844 \mathrm{E}-02 & (6) \\ 0 & 25.0 & -1.194 \mathrm{E}-02 & (7) & -1.183 \mathrm{E}-02 & (7)\end{array}$




\section{APPENDIX D \\ RESULTS OF 1-D PARAMETRIC STUDY OF $\mathbf{k}_{\infty}$ WITH ENRICHMENT, BURNUP, AND COOLING TIME}

The following tables provide $\mathrm{k}_{\infty}$ values calculated for fuel enrichments of 3.0, 3.6, and 4.5 wt $\%{ }^{235} \mathrm{U}$, for burnups of 10,30 , and $50 \mathrm{GWd} / \mathrm{MTU}$, for various cooling times ranging from 0 to 200 years. General trends observed in these results are discussed and illustrated in Sect. 3.3 of this report.

For comparison with the results that would be obtained under a fresh fuel assumption, values of $\mathrm{k}_{\infty}$ have also been calculated for each fuel enrichment for zero burnup. These values are 1.3721, 1.4113, and 1.4529 for fresh fuel enrichments of 3.0, 3.6, and $4.5 \mathrm{wt} \%{ }^{235} \mathrm{U}$ respectively. The values are applicable for comparison with both actinides-only and actinides + fission products analyses, since the same fresh fuel loading is assumed in both types of analysis. These values do not change measurably over a 200-year decay time. Isotopic concentrations assumed for fresh fuel do not require depletion calculations; hence no isotopic correction factor or bias correction was applied in the fresh fuel calculations. 
Table D-1. Best estimate $\mathrm{k}_{\infty}$ as a function of enrichment, burnup, and cooling time (actinides only)

\begin{tabular}{|c|c|c|c|c|c|c|c|c|c|}
\hline \multirow{2}{*}{$\begin{array}{l}\text { Initial } \\
\text { enrichment } \\
\text { burnup } \\
\text { (GWd/MTU) }\end{array}$} & \multicolumn{3}{|c|}{$3.0 \mathrm{wt} \%$} & \multicolumn{3}{|c|}{$3.6 \mathrm{wt} \%$} & \multicolumn{3}{|c|}{$4.5 \mathrm{wt} \%$} \\
\hline & 10 & 30 & 50 & 10 & 30 & 50 & 10 & 30 & 50 \\
\hline $\begin{array}{l}\text { Cooling time } \\
\text { (y) }\end{array}$ & & & & & & & & & \\
\hline 0 & 1.2977 & 1.1684 & 1.0814 & 1.3426 & 1.2191 & 1.1243 & 1.3926 & 1.2814 & 1.1860 \\
\hline 0.25 & 1.2977 & 1.1684 & 1.0828 & 1.3425 & 1.2189 & 1.1251 & 1.3926 & 1.2810 & 1.1859 \\
\hline 0.5 & 1.2975 & 1.1669 & 1.0804 & 1.3424 & 1.2176 & 1.1230 & 1.3925 & 1.2799 & 1.1840 \\
\hline 0.75 & 1.2972 & 1.1654 & 1.0781 & 1.3422 & 1.2164 & 1.1209 & 1.3923 & 1.2790 & 1.1821 \\
\hline 1 & 1.2970 & 1.1640 & 1.0758 & 1.3420 & 1.2152 & 1.1188 & 1.3922 & 1.2780 & 1.1802 \\
\hline 2.5 & 1.2956 & 1.1560 & 1.0629 & 1.3409 & 1.2083 & 1.1071 & 1.3915 & 1.2725 & 1.1697 \\
\hline 5 & 1.2935 & 1.1439 & 1.0435 & 1.3393 & 1.1979 & 1.0896 & 1.3904 & 1.2642 & 1.1540 \\
\hline 10 & 1.2900 & 1.1238 & 1.0110 & 1.3367 & 1.1806 & 1.0604 & 1.3885 & 1.2504 & 1.1278 \\
\hline 25 & 1.2835 & 1.0861 & 0.9495 & 1.3318 & 1.1486 & 1.0053 & 1.3851 & 1.2249 & 1.0788 \\
\hline 50 & 1.2796 & 1.0627 & 0.9105 & 1.3289 & 1.1290 & 0.9707 & 1.3831 & 1.2095 & 1.0486 \\
\hline 100 & 1.2791 & 1.0581 & 0.9010 & 1.3286 & 1.1255 & 0.9631 & 1.3830 & 1.2071 & 1.0427 \\
\hline 150 & 1.2801 & 1.0623 & 0.9067 & 1.3294 & 1.1294 & 0.9689 & 1.3836 & 1.2107 & 1.0484 \\
\hline 200 & 1.2811 & 1.0670 & 0.9132 & 1.3303 & 1.1339 & 0.9751 & 1.3843 & 1.2145 & 1.0546 \\
\hline
\end{tabular}


Table D-2. Best estimate $\mathrm{k}_{\infty}$ as a function of enrichment, burnup, and cooling time (actinides + fission products)

\begin{tabular}{|c|c|c|c|c|c|c|c|c|c|}
\hline \multirow{2}{*}{$\begin{array}{l}\text { Initial } \\
\text { enrichment } \\
\text { burnup } \\
\text { (GWd/MTU) }\end{array}$} & \multicolumn{3}{|c|}{$3.0 \mathrm{wt} \%$} & \multicolumn{3}{|c|}{$3.6 \mathrm{wt} \%$} & \multicolumn{3}{|c|}{$4.5 \mathrm{wt} \%$} \\
\hline & 10 & 30 & 50 & 10 & 30 & 50 & 10 & 30 & 50 \\
\hline $\begin{array}{l}\text { Cooling time } \\
\text { (y) }\end{array}$ & & & & & & & & & \\
\hline 0 & 1.2591 & 1.0935 & 0.9831 & 1.3042 & 1.1445 & 1.0226 & 1.3549 & 1.2079 & 1.0833 \\
\hline 0.25 & 1.2569 & 1.0852 & 0.9688 & 1.3023 & 1.1368 & 1.0084 & 1.3533 & 1.2011 & 1.0702 \\
\hline 0.5 & 1.2565 & 1.0830 & 0.9651 & 1.3019 & 1.1349 & 1.0050 & 1.3530 & 1.1995 & 1.0672 \\
\hline 0.75 & 1.2561 & 1.0809 & 0.9615 & 1.3016 & 1.1331 & 1.0017 & 1.3527 & 1.1981 & 1.0642 \\
\hline 1 & 1.2557 & 1.0790 & 0.9581 & 1.3012 & 1.1314 & 0.9986 & 1.3525 & 1.9666 & 1.0614 \\
\hline 2.5 & 1.2535 & 1.0679 & 0.9393 & 1.2995 & 1.1218 & 0.9812 & 1.3511 & 1.1889 & 1.0459 \\
\hline 5 & 1.2505 & 1.0525 & 0.9135 & 1.2971 & 1.1085 & 0.9574 & 1.3494 & 1.1781 & 1.0247 \\
\hline 10 & 1.2463 & 1.0292 & 0.8753 & 1.2939 & 1.0883 & 0.9224 & 1.3470 & 1.1620 & 0.9933 \\
\hline 25 & 1.2397 & 0.9909 & 0.8143 & 1.2890 & 1.0558 & 0.8670 & 1.3436 & 1.1360 & 0.9436 \\
\hline 50 & 1.2366 & 0.9694 & 0.7796 & 1.2868 & 1.0377 & 0.8360 & 1.3423 & 1.1219 & 0.9162 \\
\hline 100 & 1.2371 & 0.9662 & 0.7717 & 1.2875 & 1.0355 & 0.8299 & 1.3432 & 1.1209 & 0.9118 \\
\hline 150 & 1.2388 & 0.9708 & 0.7768 & 1.2890 & 1.0400 & 0.8352 & 1.3445 & 1.1251 & 0.9173 \\
\hline 200 & 1.2404 & 0.9754 & 0.7824 & 1.2904 & 1.0446 & 0.8407 & 1.3456 & 1.1292 & 0.9231 \\
\hline
\end{tabular}


Table D-3. Conservative estimate $\mathrm{k}_{\infty}$ as a function of enrichment, burnup, and cooling time (actinides only)

\begin{tabular}{|c|c|c|c|c|c|c|c|c|c|}
\hline \multirow{2}{*}{$\begin{array}{l}\text { Initial } \\
\text { enrichment } \\
\text { burnup } \\
\text { (GWd/MTU) }\end{array}$} & \multicolumn{3}{|c|}{3.0 wt $\%$} & \multicolumn{3}{|c|}{$3.6 \mathrm{wt} \%$} & \multicolumn{3}{|c|}{$4.5 \mathrm{wt} \%$} \\
\hline & 10 & 30 & 50 & 10 & 30 & 50 & 10 & 30 & 50 \\
\hline $\begin{array}{l}\text { Cooling time } \\
\text { (y) }\end{array}$ & & & & & & & & & \\
\hline 0 & 1.3229 & 1.2005 & 1.1180 & 1.3655 & 1.2487 & 1.1583 & 1.4128 & 1.3075 & 1.2183 \\
\hline 0.25 & 1.3230 & 1.2008 & 1.1199 & 1.3655 & 1.2488 & 1.1595 & 1.4128 & 1.3074 & 1.2186 \\
\hline 0.5 & 1.3228 & 1.1998 & 1.1181 & 1.3654 & 1.2480 & 1.1578 & 1.4127 & 1.3067 & 1.2172 \\
\hline 0.75 & 1.3226 & 1.1988 & 1.1163 & 1.3653 & 1.2471 & 1.1562 & 1.4127 & 1.3060 & 1.2159 \\
\hline 1 & 1.3225 & 1.1978 & 1.1146 & 1.3652 & 1.2463 & 1.1547 & 1.4126 & 1.3054 & 1.2146 \\
\hline 2.5 & 1.3215 & 1.1920 & 1.1049 & 1.3645 & 1.2414 & 1.1459 & 1.4121 & 1.3017 & 1.2072 \\
\hline 5 & 1.3201 & 1.1833 & 1.0903 & 1.3634 & 1.2342 & 1.1327 & 1.4114 & 1.2961 & 1.1960 \\
\hline 10 & 1.3177 & 1.1686 & 1.0652 & 1.3617 & 1.2220 & 1.1102 & 1.4102 & 1.2868 & 1.1771 \\
\hline 25 & 1.3133 & 1.1408 & 1.0165 & 1.3584 & 1.1991 & 1.0665 & 1.4080 & 1.2692 & 1.1409 \\
\hline 50 & 1.3106 & 1.1230 & 0.9844 & 1.3565 & 1.1847 & 1.0382 & 1.4067 & 1.2583 & 1.1178 \\
\hline 100 & 1.3102 & 1.1187 & 0.9756 & 1.3562 & 1.1816 & 1.0309 & 1.4066 & 1.2563 & 1.1125 \\
\hline 150 & 1.3108 & 1.1212 & 0.9792 & 1.3567 & 1.1839 & 1.0346 & 1.4070 & 1.2584 & 1.1161 \\
\hline 200 & 1.3114 & 1.1240 & 0.9833 & 1.3572 & 1.1865 & 1.0387 & 1.4074 & 1.2606 & 1.1200 \\
\hline
\end{tabular}


Table D-4. Conservative estimate $\mathrm{k}_{\infty}$ as a function of enrichment, burnup, and cooling time (actinides + fission products)

\begin{tabular}{|c|c|c|c|c|c|c|c|c|c|}
\hline \multirow{2}{*}{$\begin{array}{l}\text { Initial } \\
\text { enrichment } \\
\text { burnup } \\
\text { (GWd/MTU) }\end{array}$} & \multicolumn{3}{|c|}{$3.0 \mathrm{wt} \%$} & \multicolumn{3}{|c|}{$3.6 \mathrm{wt} \%$} & \multicolumn{3}{|c|}{$4.5 \mathrm{wt} \%$} \\
\hline & 10 & 30 & 50 & 10 & 30 & 50 & 10 & 30 & 50 \\
\hline $\begin{array}{l}\text { Cooling time } \\
\text { (y) }\end{array}$ & & & & & & & & & \\
\hline 0 & 1.3028 & 1.1521 & 1.0509 & 1.3464 & 1.2015 & 1.0905 & 1.3951 & 1.2626 & 1.1505 \\
\hline 0.25 & 1.3026 & 1.1520 & 1.0521 & 1.3462 & 1.2012 & 1.0910 & 1.3949 & 1.2619 & 1.1502 \\
\hline 0.5 & 1.3024 & 1.1508 & 1.0503 & 1.3460 & 1.2002 & 1.0893 & 1.3947 & 1.2612 & 1.1488 \\
\hline 0.75 & 1.3022 & 1.1497 & 1.0485 & 1.3458 & 1.1993 & 1.0876 & 1.3946 & 1.2604 & 1.1474 \\
\hline 1 & 1.3020 & 1.1487 & 1.0468 & 1.3457 & 1.1983 & 1.0861 & 1.3945 & 1.2597 & 1.1460 \\
\hline 2.5 & 1.3009 & 1.1426 & 1.0370 & 1.3448 & 1.1932 & 1.0771 & 1.3938 & 1.2556 & 1.1383 \\
\hline 5 & 1.2993 & 1.1338 & 1.0224 & 1.3436 & 1.1857 & 1.0638 & 1.3929 & 1.2497 & 1.1269 \\
\hline 10 & 1.2968 & 1.1191 & 0.9980 & 1.3417 & 1.1735 & 1.0418 & 1.3917 & 1.2403 & 1.1083 \\
\hline 25 & 1.2927 & 1.0921 & 0.9513 & 1.3388 & 1.1513 & 0.9998 & 1.3898 & 1.2233 & 1.0734 \\
\hline 50 & 1.2905 & 1.0753 & 0.9212 & 1.3373 & 1.1378 & 0.9732 & 1.3889 & 1.2132 & 1.0517 \\
\hline 100 & 1.2907 & 1.0721 & 0.9138 & 1.3377 & 1.1357 & 0.9673 & 1.3894 & 1.2122 & 1.0478 \\
\hline 150 & 1.2918 & 1.0752 & 0.9179 & 1.3387 & 1.1386 & 0.9716 & 1.3903 & 1.2149 & 1.0520 \\
\hline 200 & 1.2927 & 1.0784 & 0.9223 & 1.3395 & 1.1416 & 0.9759 & 1.3910 & 1.2176 & 1.0563 \\
\hline
\end{tabular}




\section{APPENDIX E \\ PHYSICAL AND NUMERICAL DESCRIPTIONS OF NOMINAL CONDITIONS FOR DEPLETION AND CRITICALITY MODELS}

All calculations performed in support of this report were based on a standard Westinghouse $17 \times 17$ assembly design. One-dimensional pin-cell calculations were performed using a single-pin model in an infinite lattice with pin and lattice pitch specifications based on those of the Westinghouse design. Three-dimensional cask calculations were based on nominal assembly design specifications. Table E-1 provides a summary of the key aspects of the assembly design. The assembly configuration is illustrated in Fig. E-1, showing the location of control rod and instrumentation guide tubes. The figure also shows the assembly located within an MPC basket position, and supplies principal component dimensions.

Depletion calculations for 1-D and 3-D criticality calculations were performed using SAS2H. Table E-2 lists the modeling assumptions used for baseline depletion calculations. Note that some of these values were changed in selected sensitivity calculations. A sample SAS2H depletion listing is provided in Table E-3. Note that the operating history shown in this example was varied significantly for various sensitivity calculations.

In the 3-D KENO V.a models, a rough approximation was made to represent upper and lower hardware regions of each assembly. Lower hardware was assumed to extend $10 \mathrm{~cm}$ below the active fuel length, and upper hardware length was assumed to be $30 \mathrm{~cm}$. Rather than trying to model the details of the hardware design, the hardware regions were assumed to be a homogenous mixture of $50 \%$ water and 50\% SS-304. In addition, grid spacers located with the active length of the fuel rod were neglected. 
Table E-1. Westinghouse $17 \times 17$ fuel assembly design specifications

\begin{tabular}{ll}
\hline \multicolumn{1}{c}{ Parameter } & \multicolumn{1}{c}{ Data } \\
\hline Fuel rod data: & $0.819 \mathrm{~cm}$ \\
Fuel diameter & $0.836 \mathrm{~cm}$ \\
Clad inner diameter & $0.950 \mathrm{~cm}$ \\
Rod outer diameter & $365.76 \mathrm{~cm}$ \\
Fuel length & $\mathrm{UO}_{2}(95 \%$ theoretical density) \\
Fuel material & Zircaloy \\
Clad material & Void \\
Gas gap material & \\
& \\
Control rod guide tube data & $1.123 \mathrm{~cm}$ \\
Inner diameter & $1.204 \mathrm{~cm}$ \\
Outer diameter & Zircaloy \\
Tube material & \\
& \\
Instrumentation guide tube data & \\
Inner diameter & $1.128 \mathrm{~cm}$ \\
Outer diameter & $1.209 \mathrm{~cm}$ \\
Tube material & Zircaloy \\
& \\
Assembly data: & \\
Lattice & Westinghouse $17 \times 17$ standard \\
No. of fuel rods & 264 \\
No. of C/R guide tubes & 24 \\
No. of instrumentation tubes & 1 \\
Lattice pitch & $1.260 \mathrm{~cm}$ \\
Moderator & Water \\
\hline &
\end{tabular}




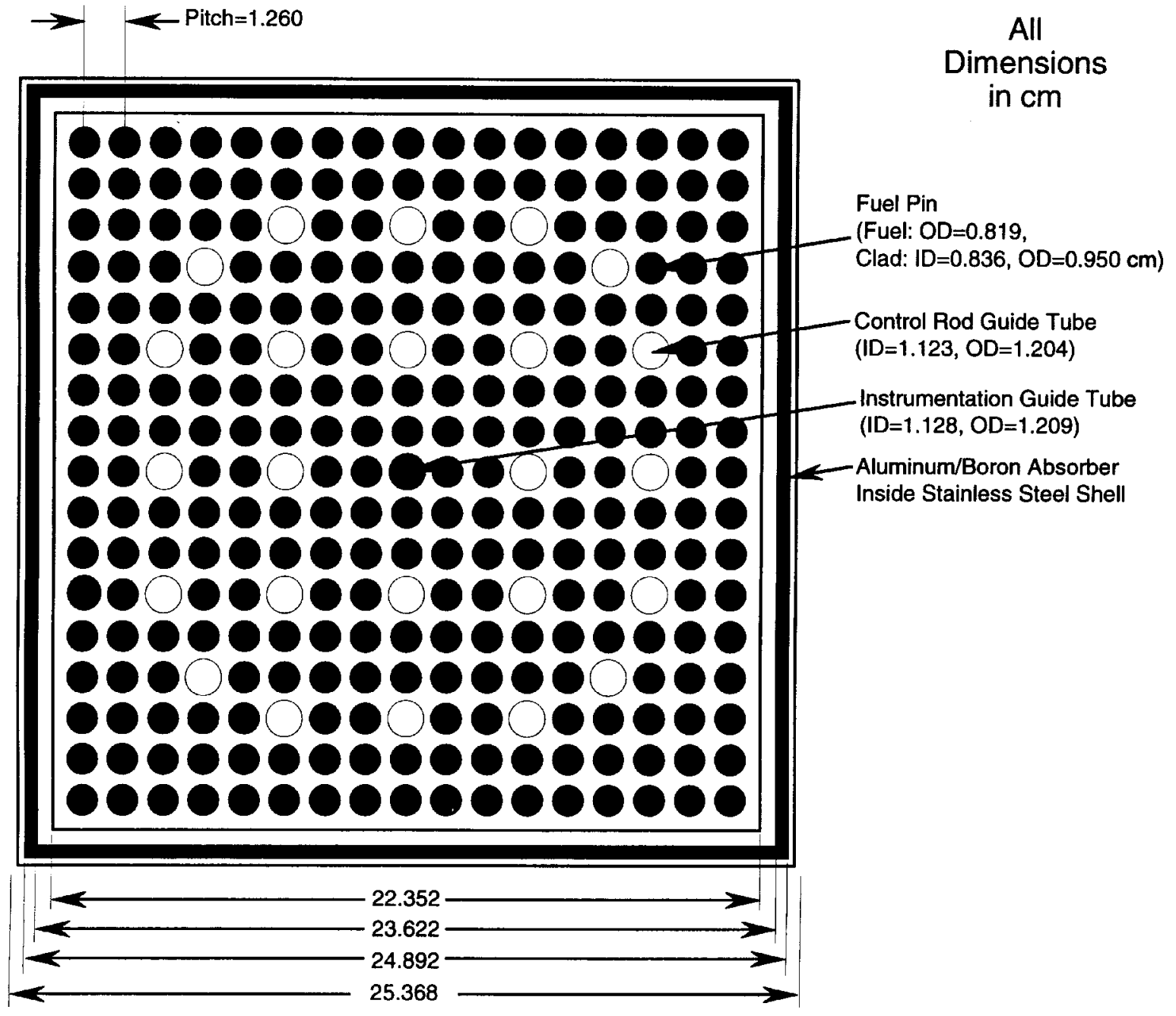

Fig. E-1. Westinghouse $17 \times 17$ assembly configuration within MPC basket design. 
Table E-2. Assumed reactor conditions for nominal depletion calculations

\begin{tabular}{ll}
\hline \multicolumn{1}{c}{ Parameter } & \multicolumn{1}{c}{ Data } \\
\hline Fuel temperature & $894 \mathrm{~K}$ \\
Clad temperature & $628 \mathrm{~K}$ \\
Moderator temperature & $569 \mathrm{~K}$ \\
Moderator density & $0.735 \mathrm{~g} / \mathrm{cm}^{3}$ \\
Boron concentration & $450 \mathrm{ppm}$ \\
\hline
\end{tabular}


Table E-3. SCALE input listing for a typical depletion calculation

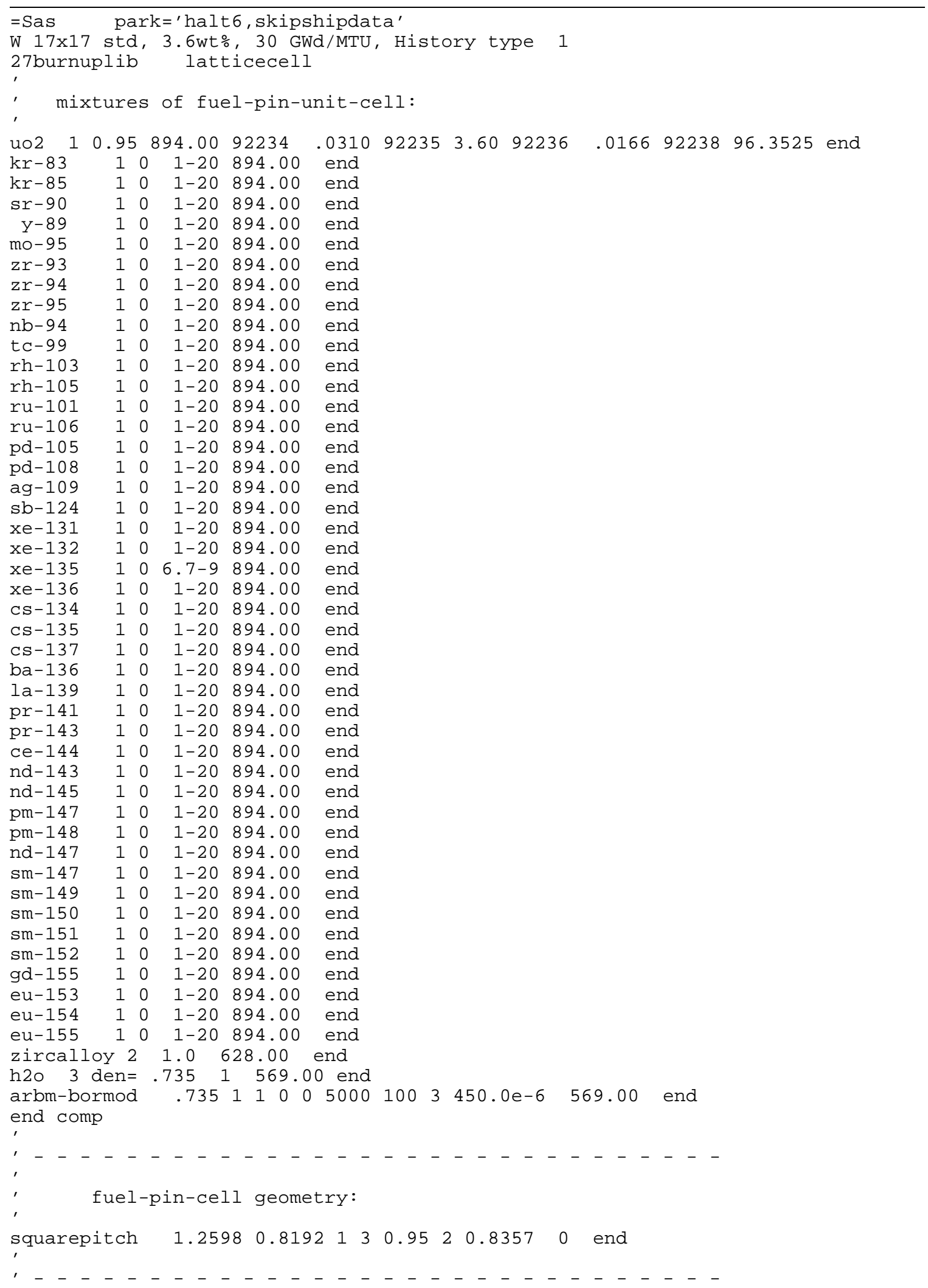


Table E-3 (continued)

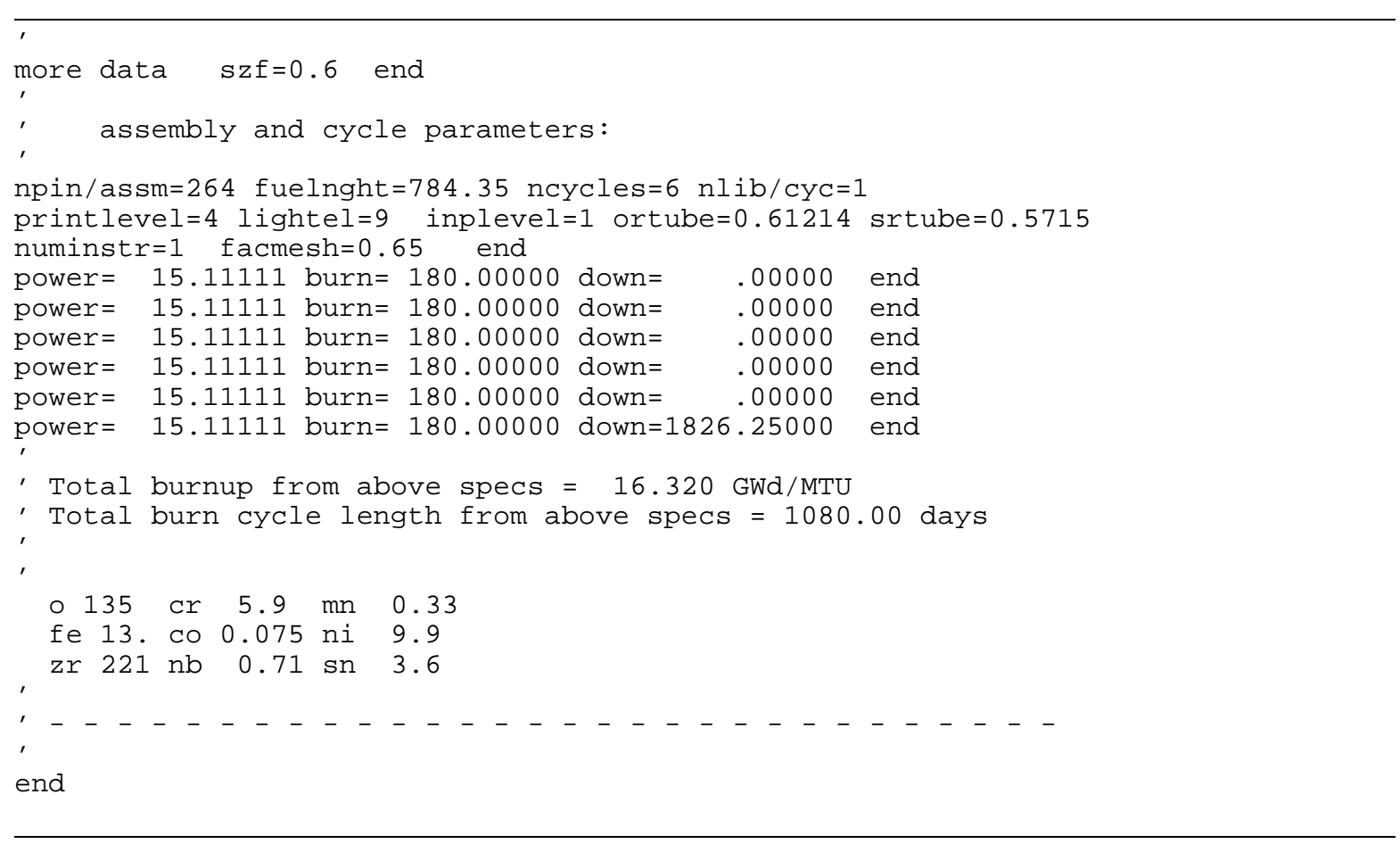


163

Table E-4. SCALE input listing for a 7-zone MPC criticality calculation

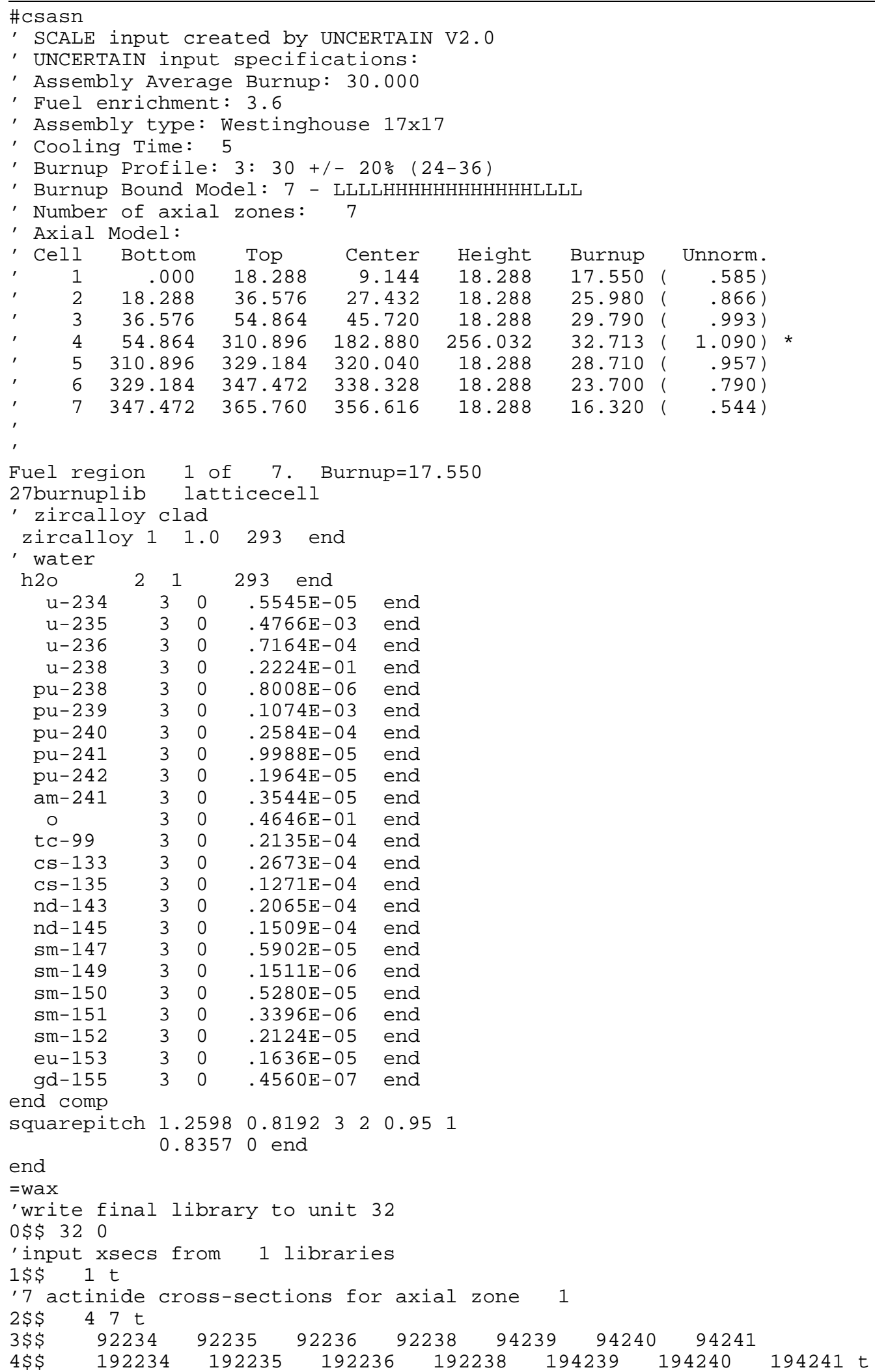


Table E-4 (continued)

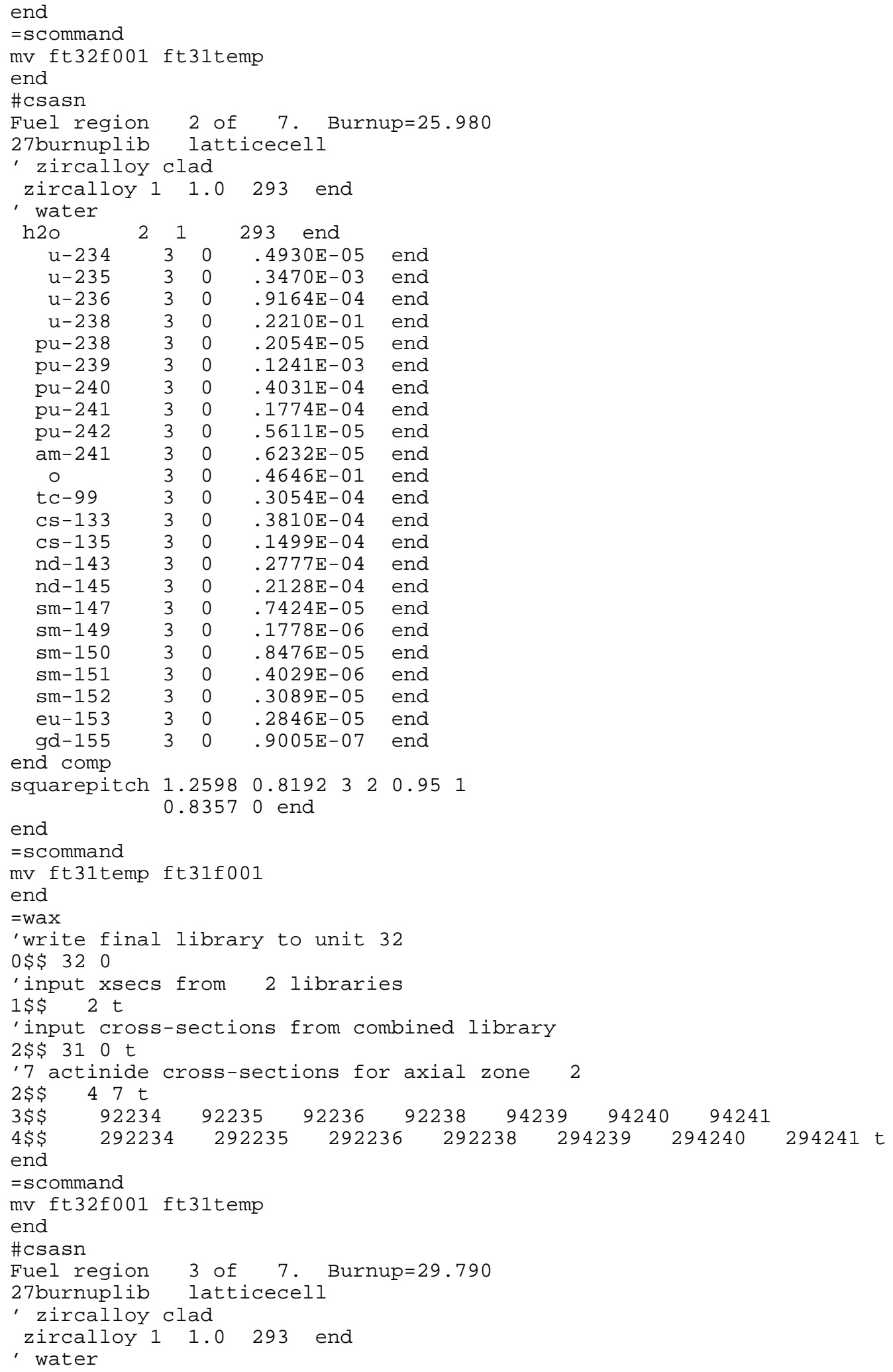


165

Table E-4 (continued)

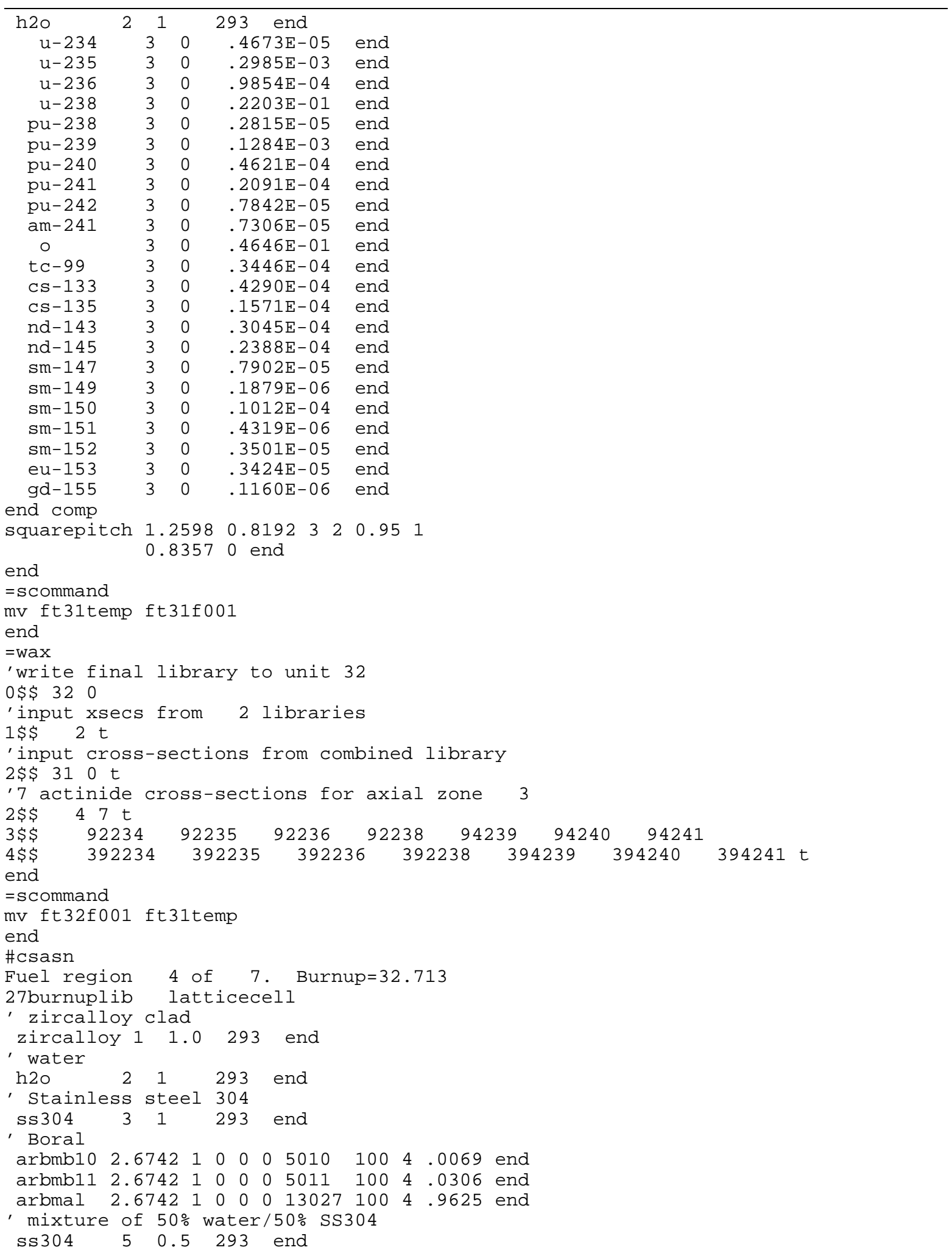


Table E-4 (continued)

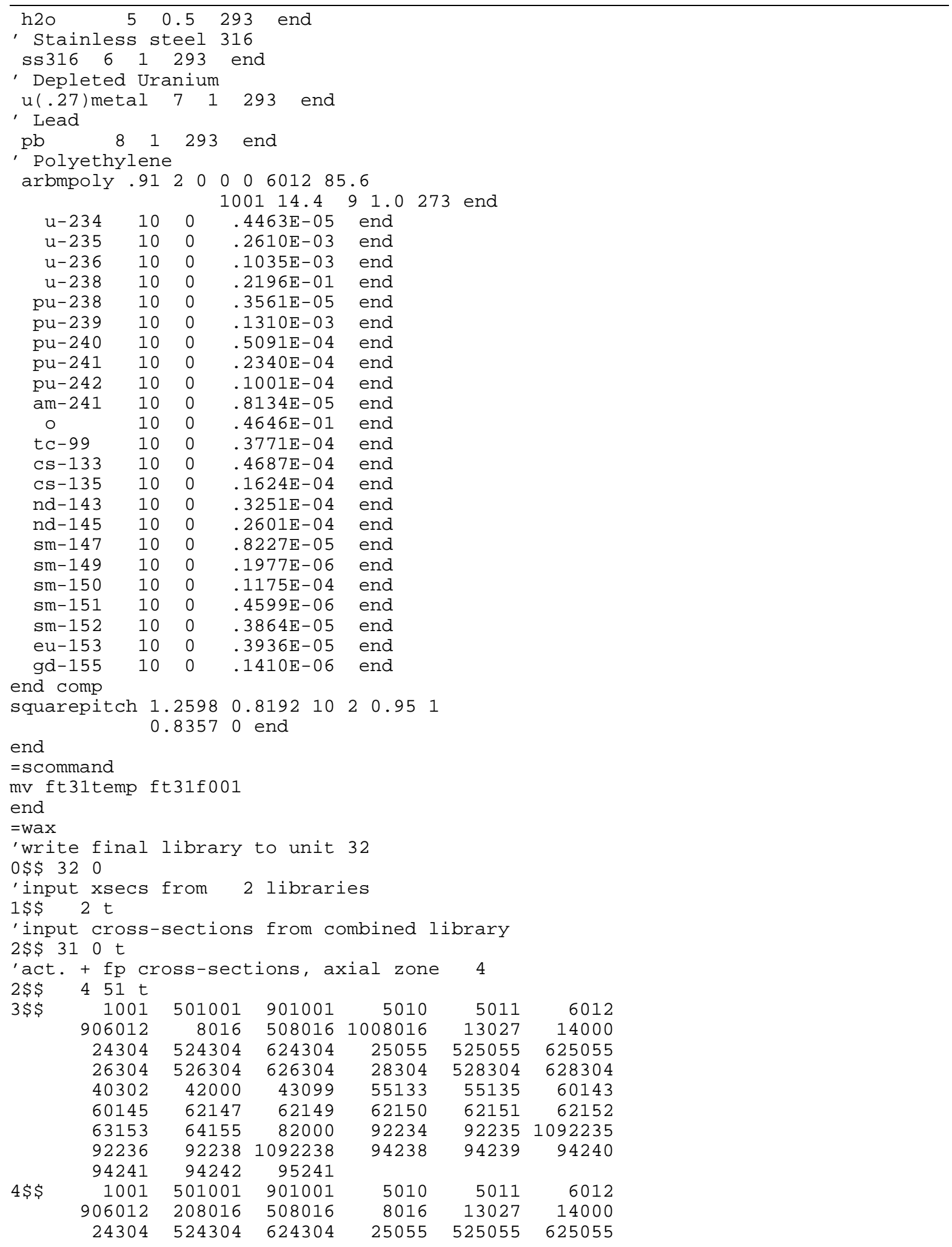


Table E-4 (continued)

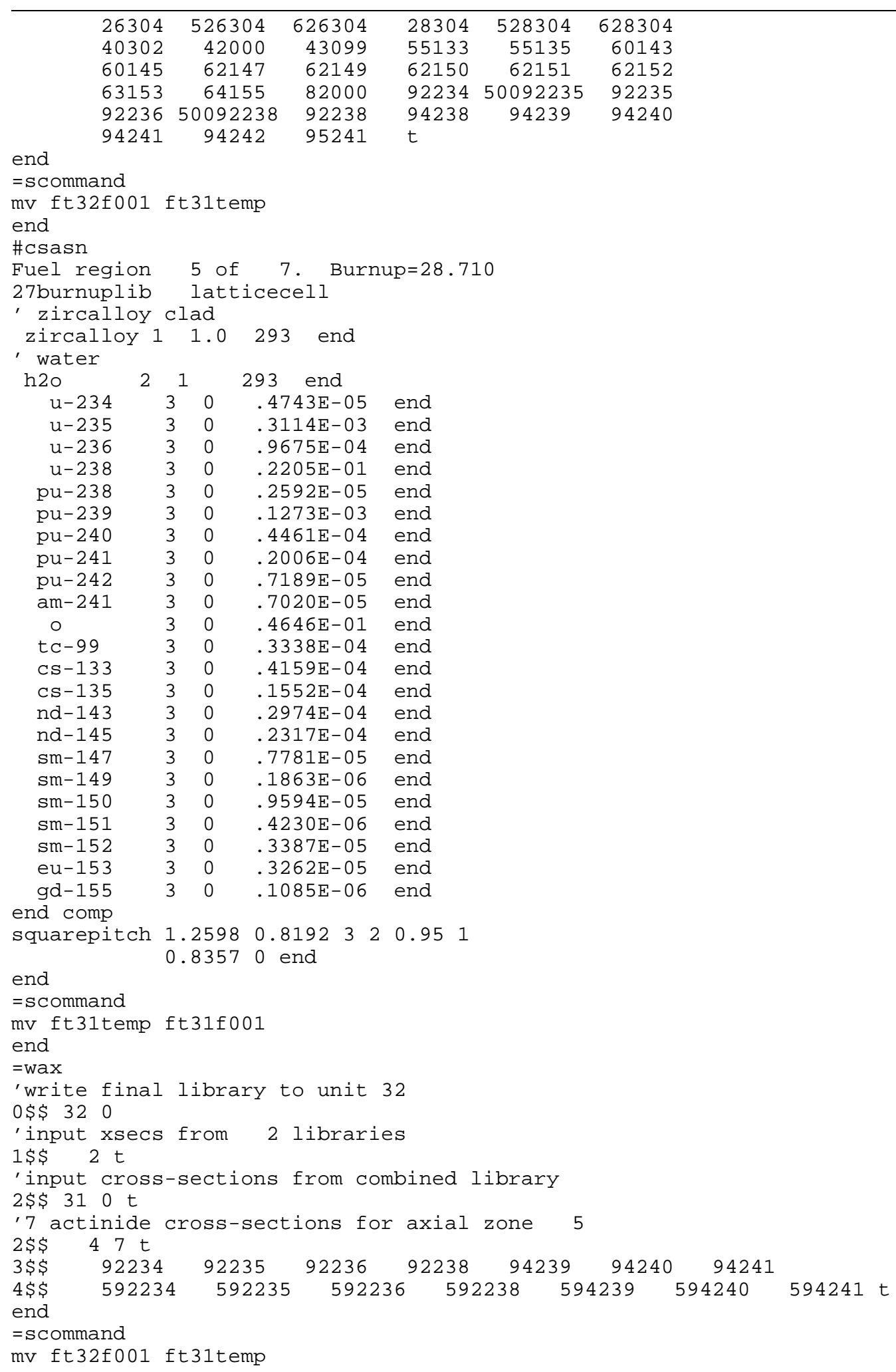


Table E-4 (continued)

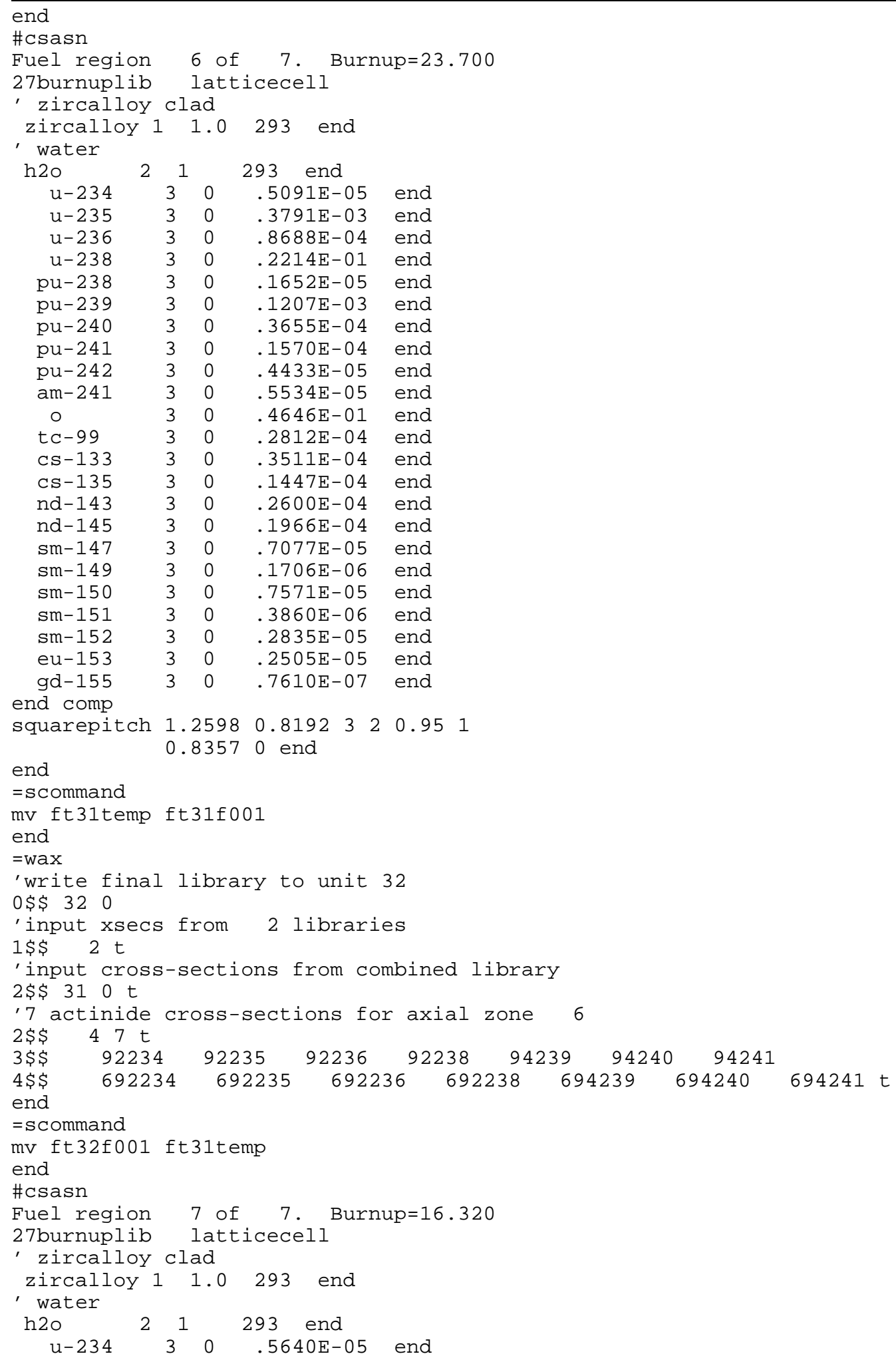


169

Table E-4 (continued)

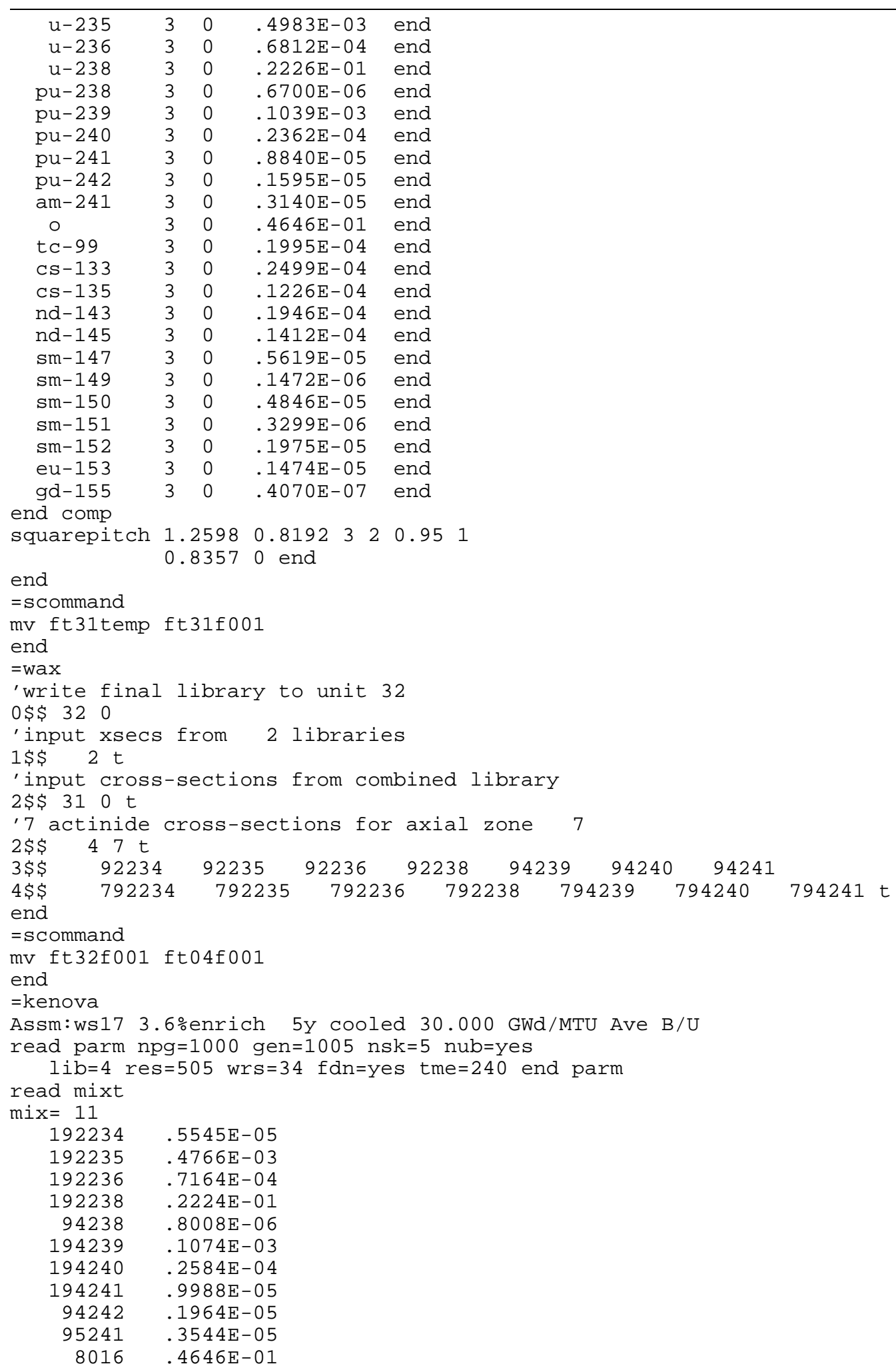


170

Table E-4 (continued)

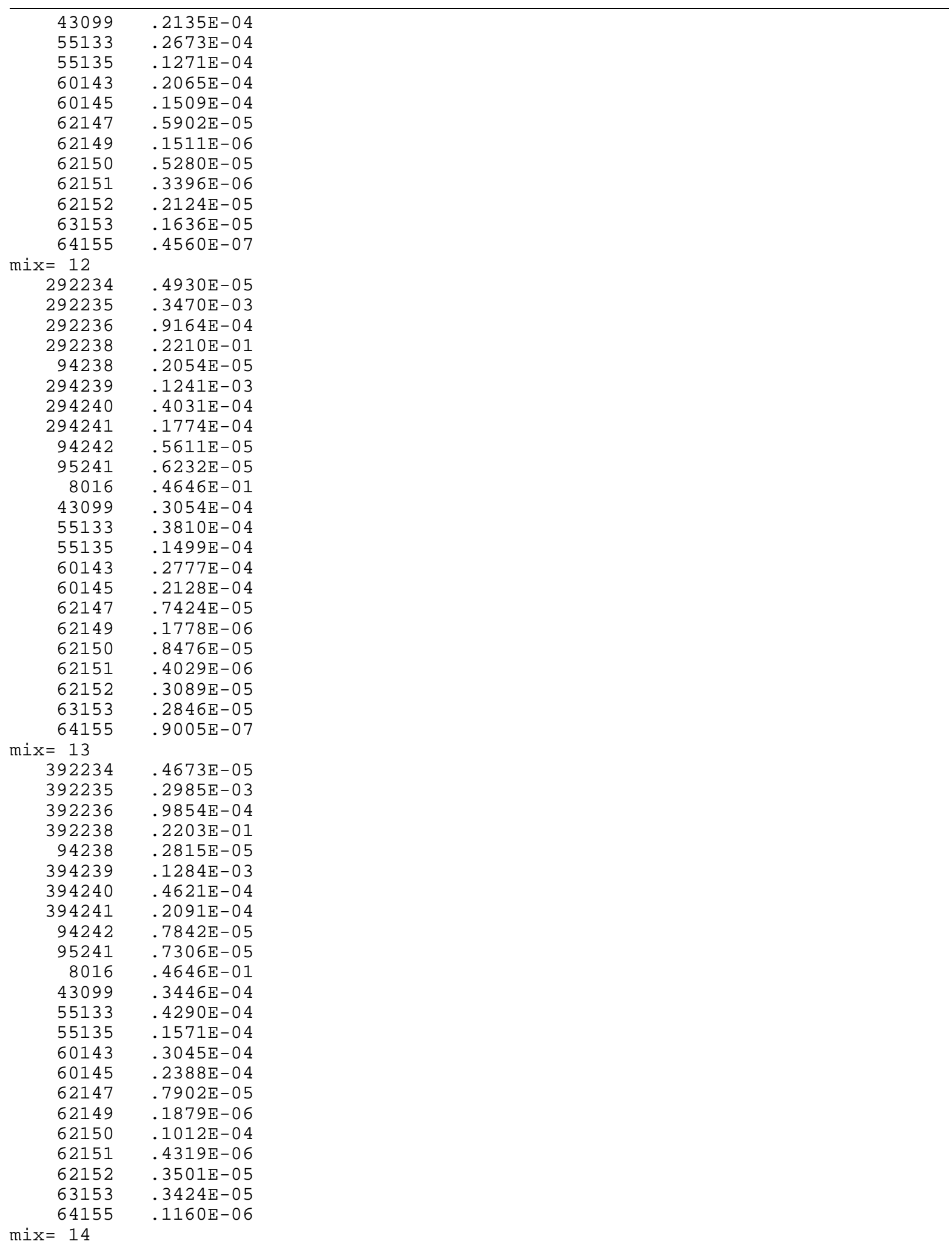


Table E-4 (continued)

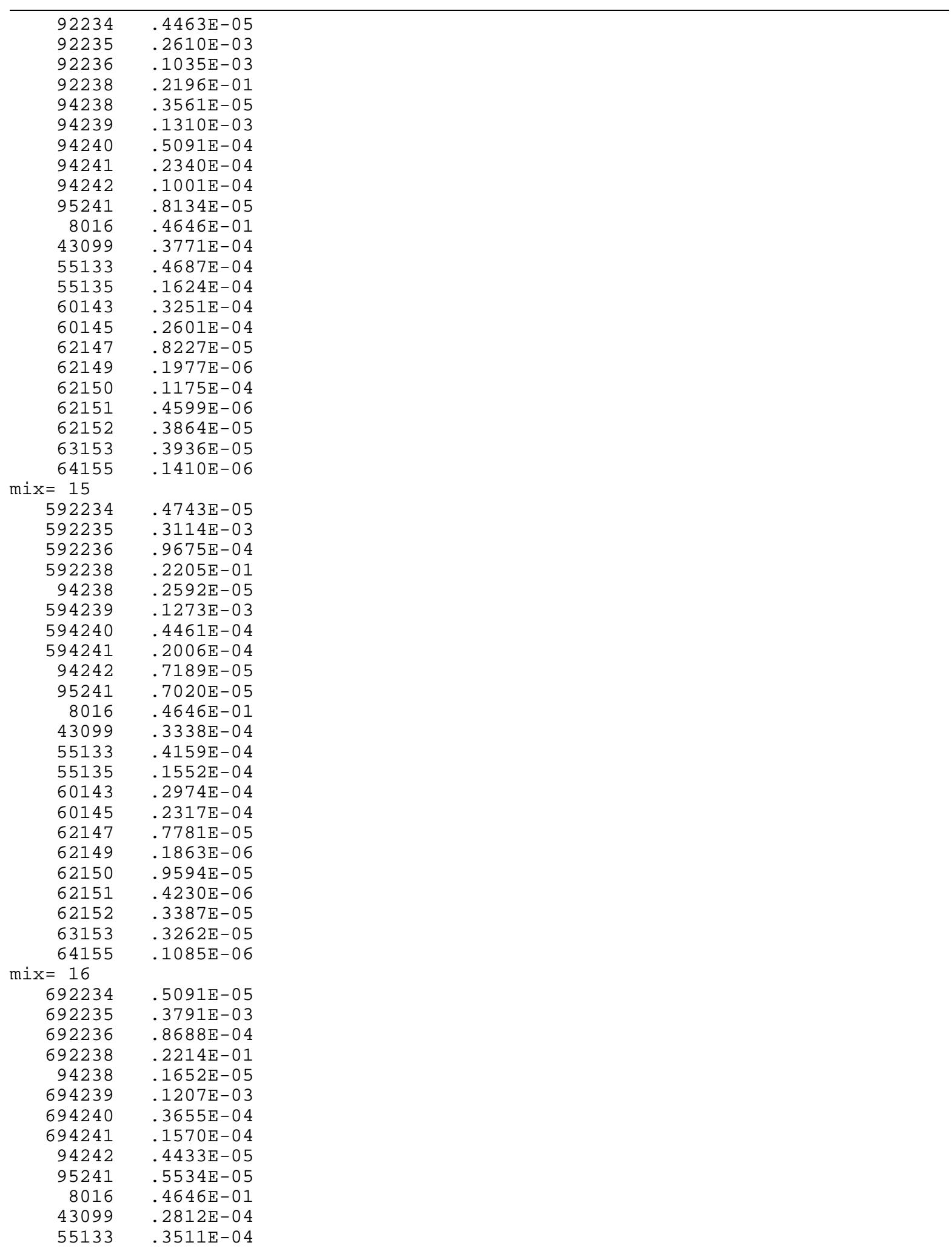


Table E-4 (continued)

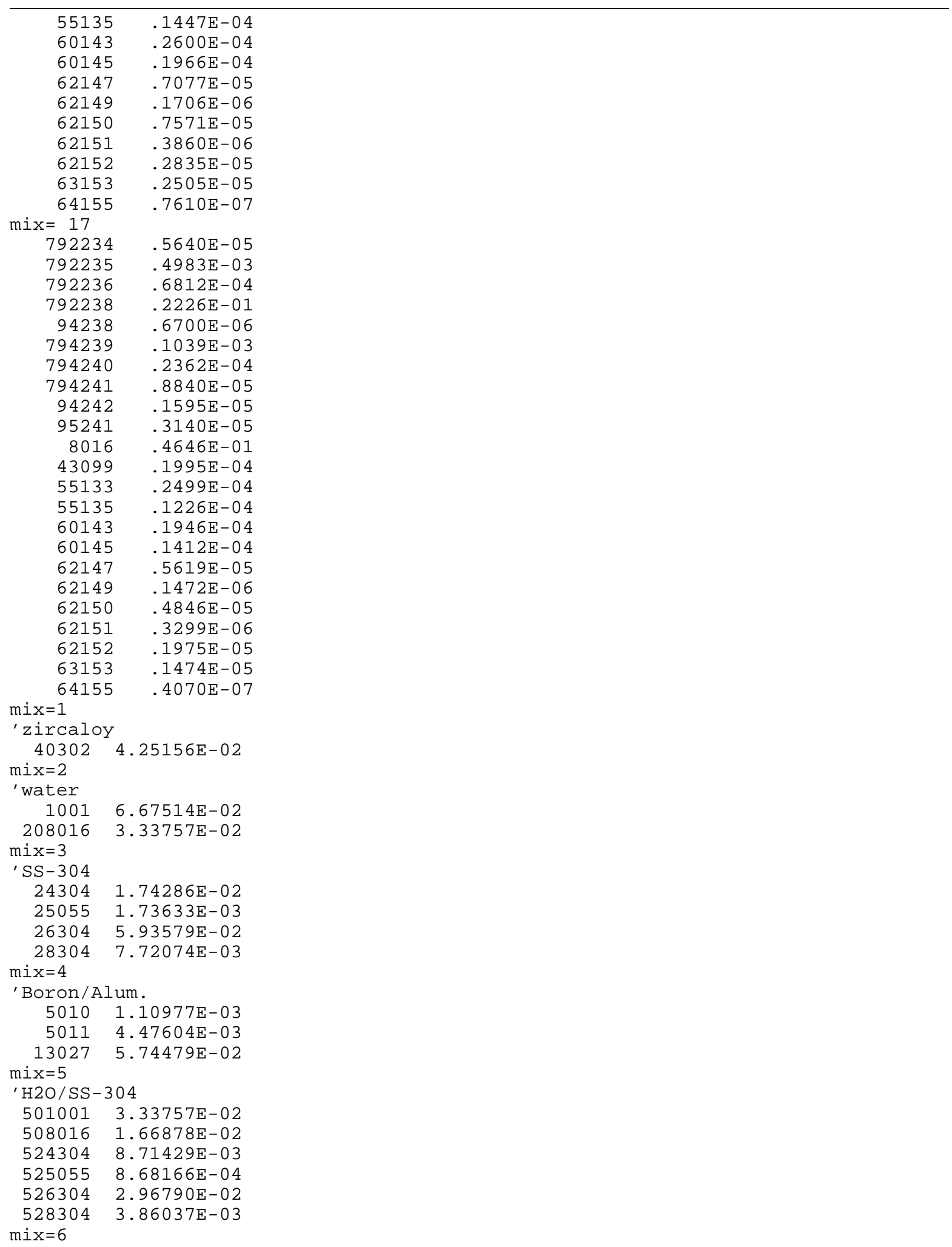


Table E-4 (continued)

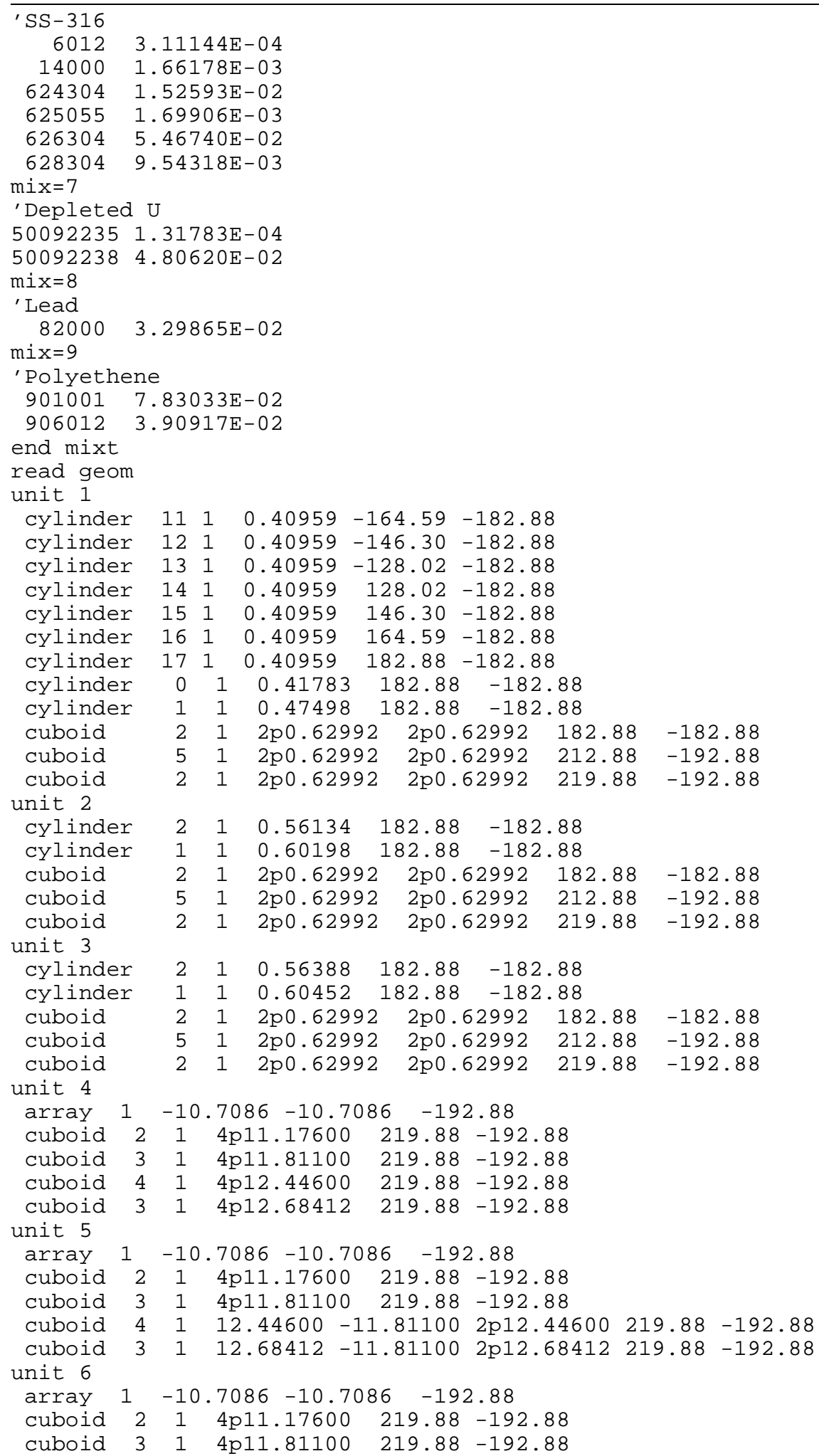


Table E-4 (continued)

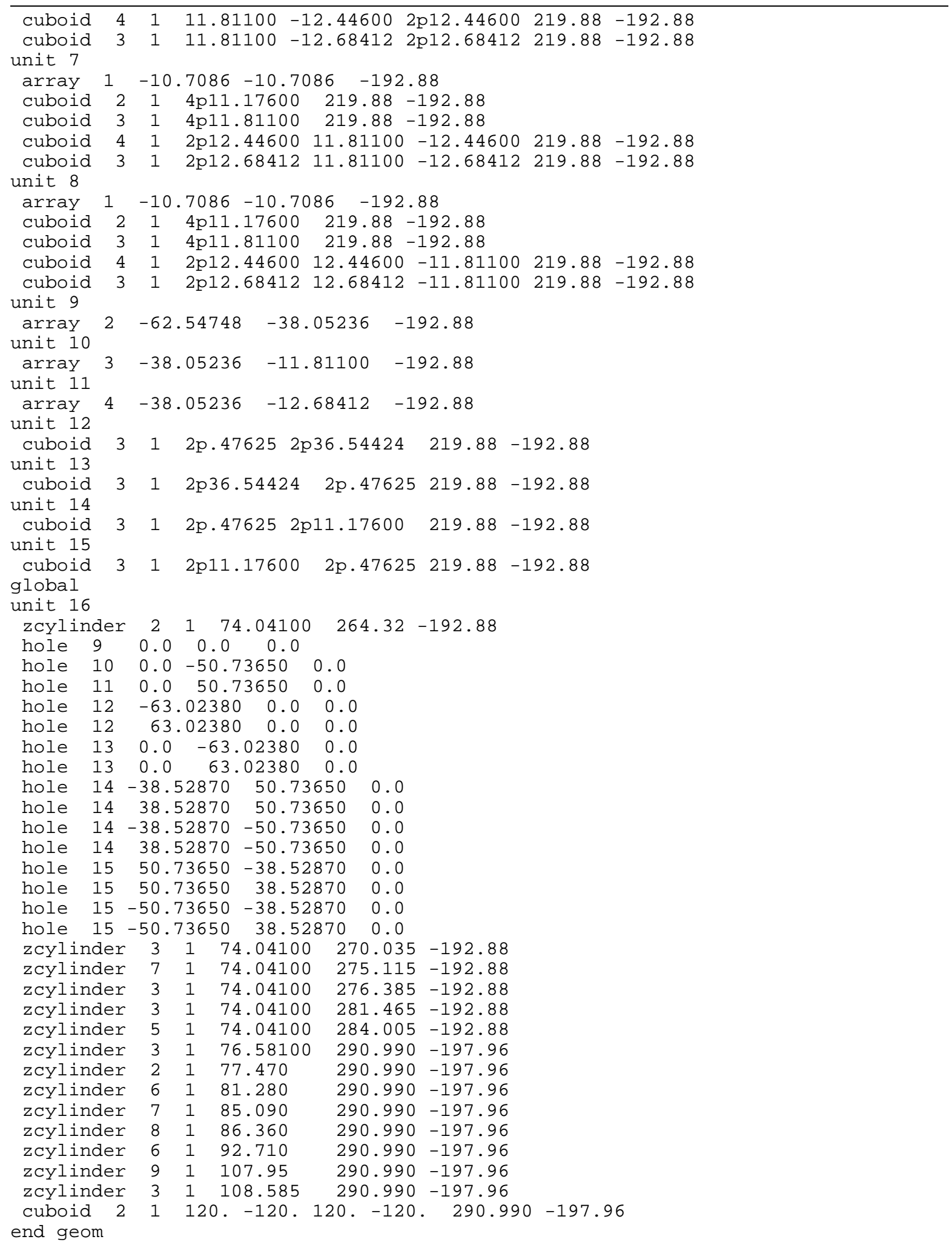


Table E-4 (continued)

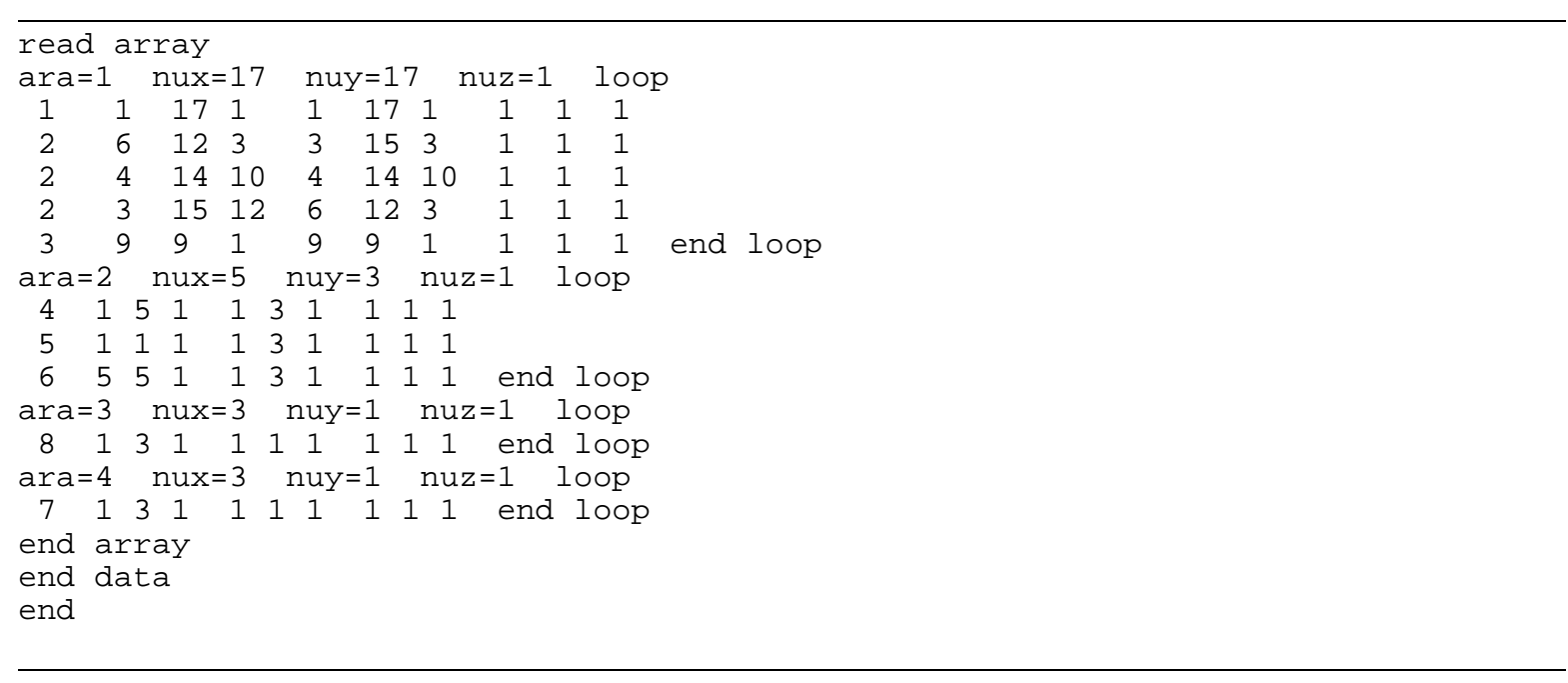


Three-dimensional KENO Va. calculations performed in this report were based on an MPC conceptual design for a 125-ton, 21-assembly large cask. This cask consists of two components: the MPC itself is a 153-cm-OD cylinder containing 21 assembly storage positions. The MPC is loaded inside a 217-cm-OD cylindrical transportation cask. KENO Va. models of the full-cask configuration are based on the MPC loaded within the transportation cask. Because analyses are based on accident conditions (i.e., a flooded cask), all void space between fuel and cask components are assumed to be filled with water. Figures E-2 through E-5 provide the specifications for both the MPC and the transportation cask. For the purposes of the KENO Va. model, irregular features (e.g., lift trunnions) were ignored. Also, the radial material configurations shown in Fig. E-4 were assumed to extend the full length of the cask, rather than the partial axial lengths shown in Fig. E-5.

Table E-4 provides a SCALE input listing for a MPC-based criticality calculation, assuming a seven-zone axial burnup distribution. The calculation begins with seven sets of CSASN calculations, based on isotopics for each of the seven burnup zones (each set of isotopics was obtained from an earlier SAS2H calculation). Each CSASN calculation is followed by a WAX calculation to extract required nuclides from the resultant cross-section library and to store them in a temporary library. Note that cross sections for only the seven burnup sensitive actinides are copied from six of the seven burnup zones; cross sections for the remaining nuclides are copied only from the highest burnup zone. Once all CSASN/WAX operations are completed, a final WAX calculation is performed to combine the seven temporary cross-section libraries into a single, final cross-section library. This library is then used by the subsequent KENO Va. criticality calculation. The KENO Va. model used in all calculations is similar to that given in the input listing; only the isotopic concentrations and the number of axial zones changed between models. 


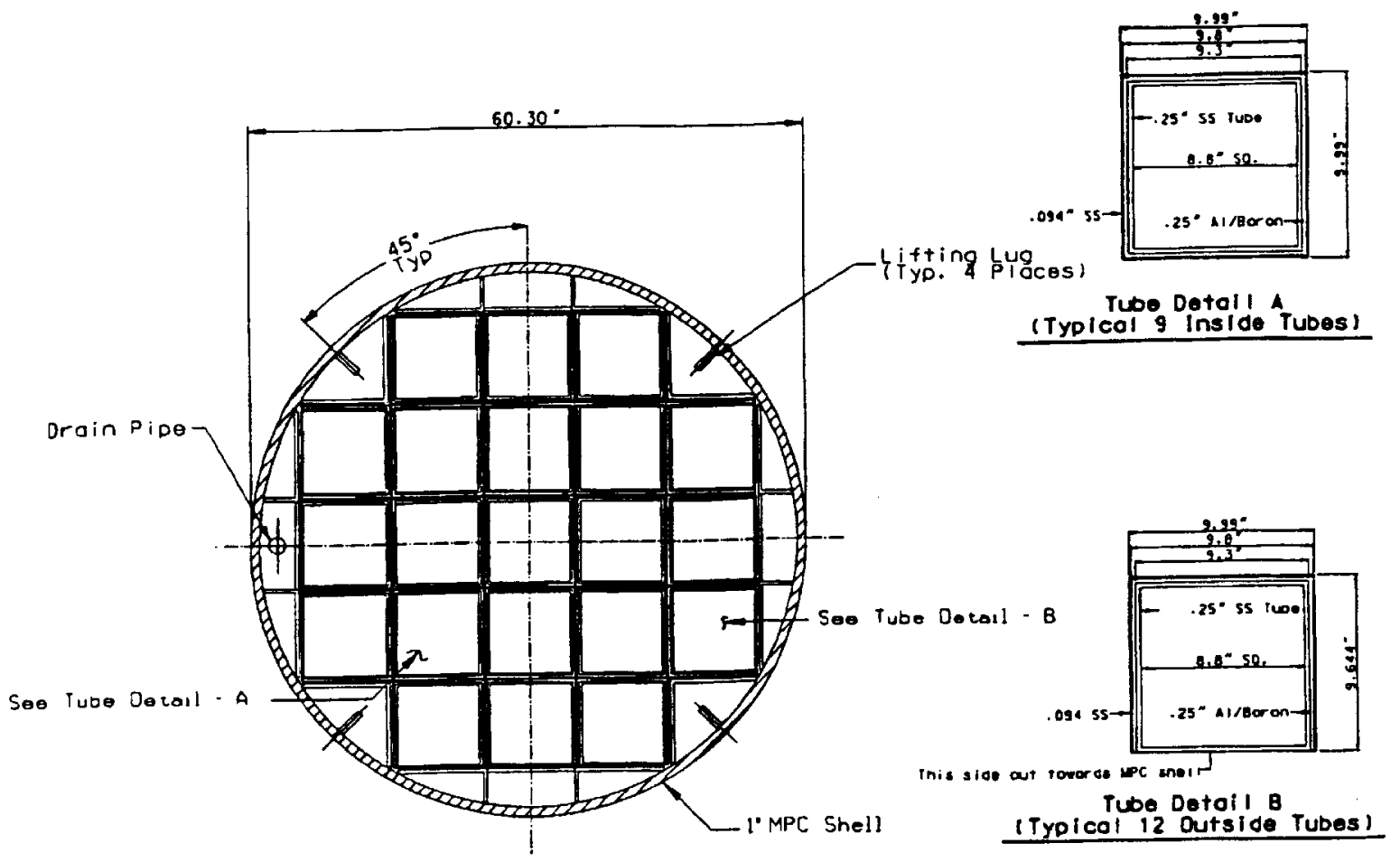

Fig. E-2. MPC 21-position large cask design (end section view). 

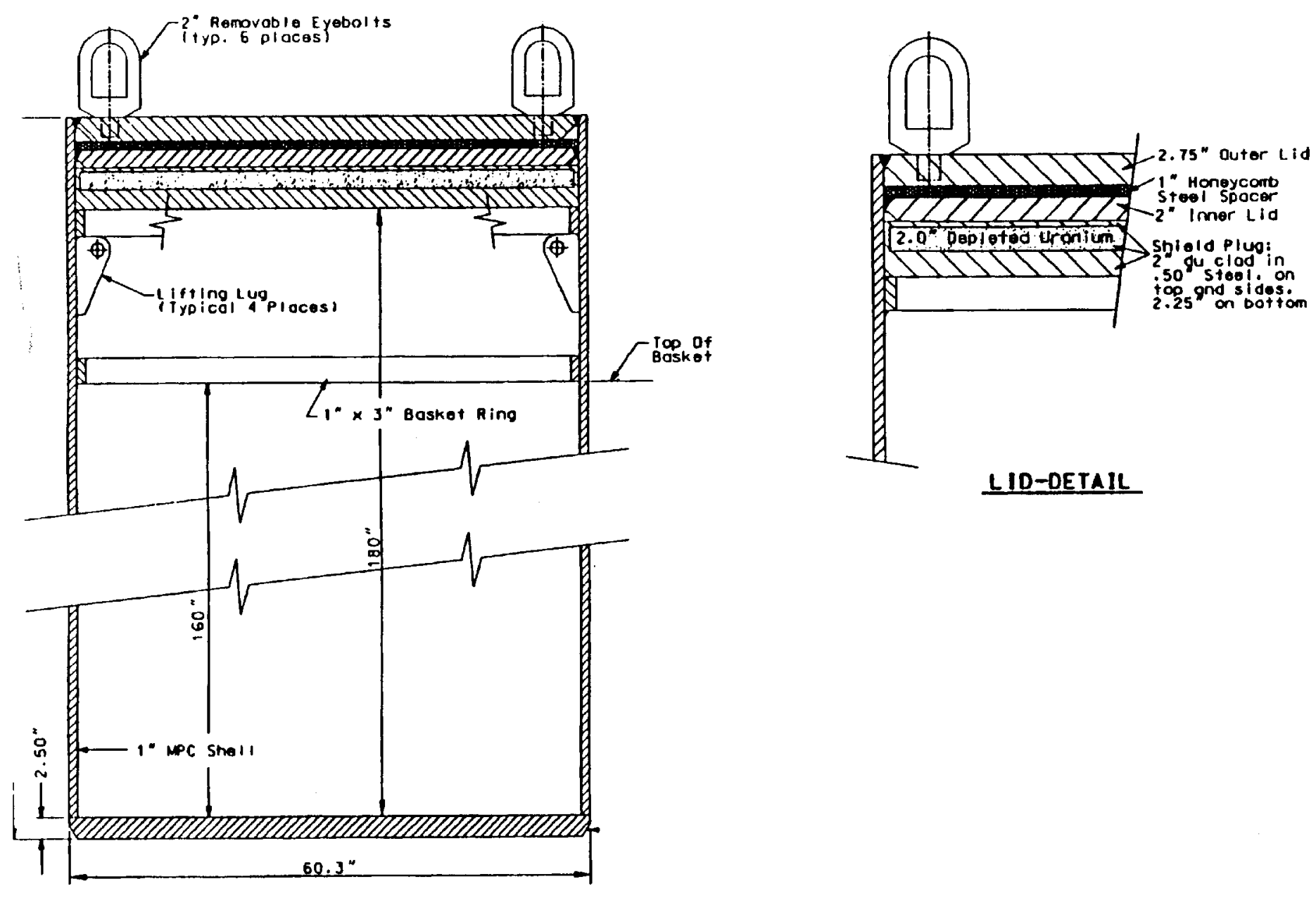

Fig. E-3. MPC 21-position large cask design (side section view). 


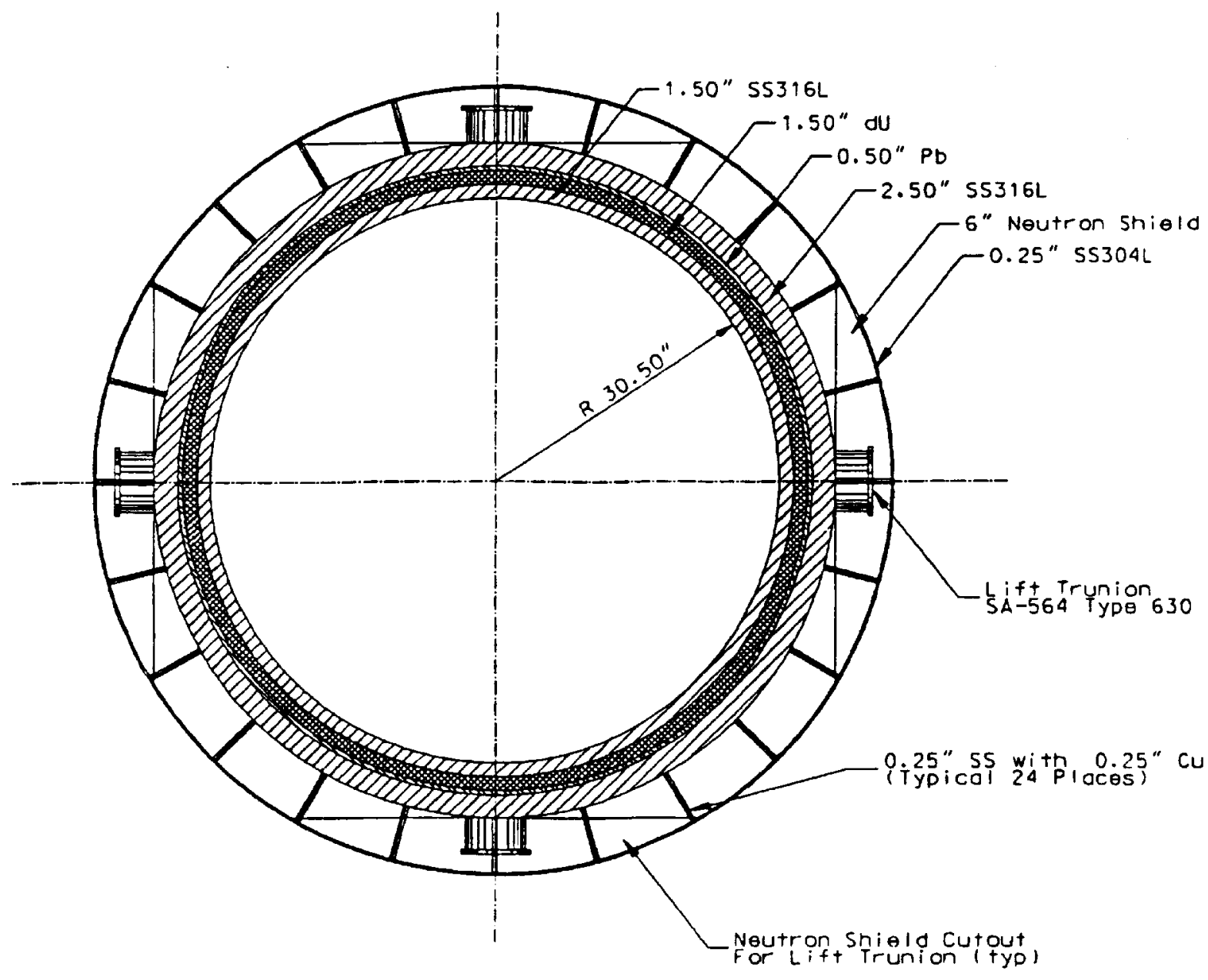

Fig. E-4. Large transportation cask design (end-section view). 


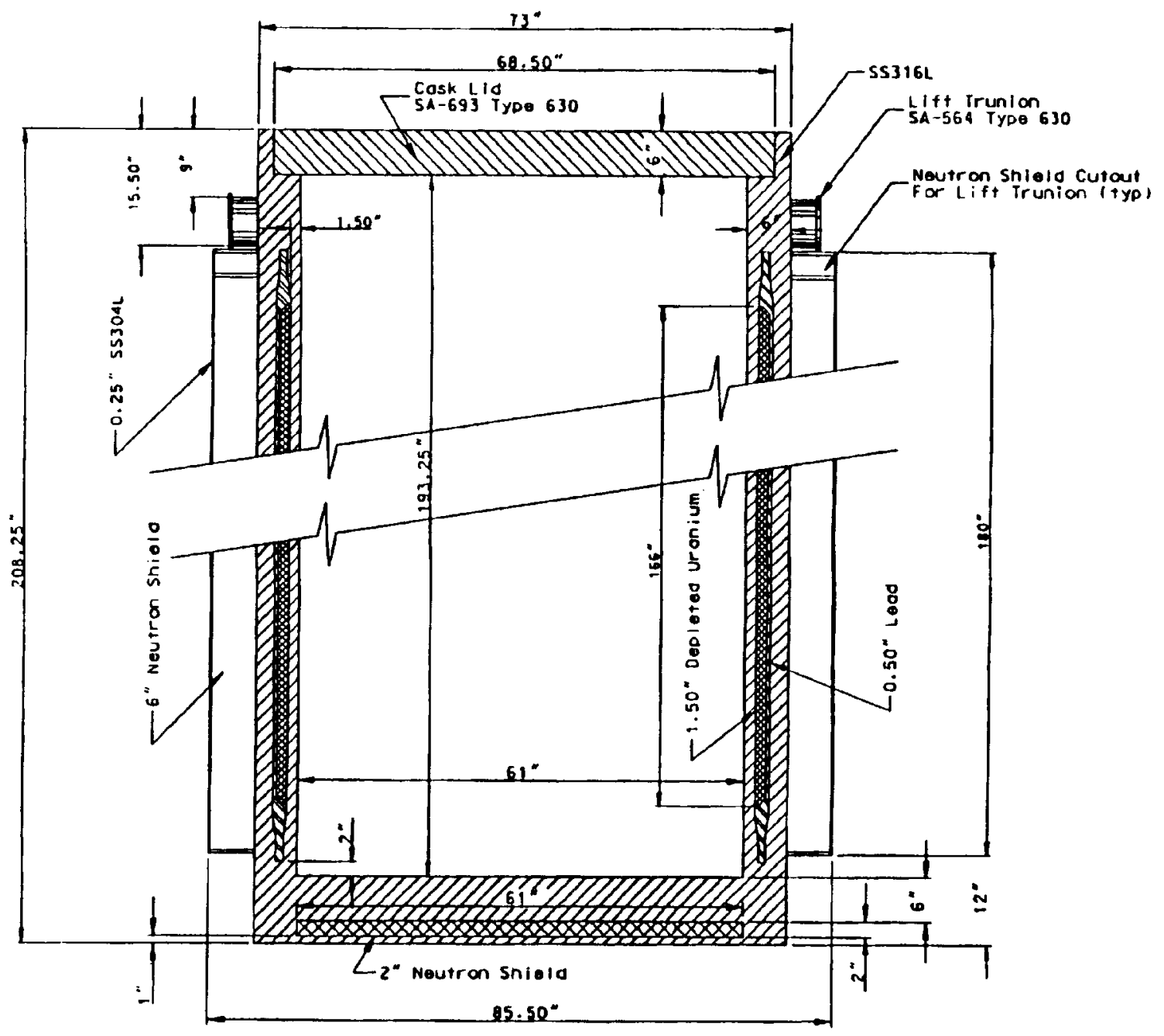

Fig. E-5. Large transportation cask design (side-section view). 


\section{APPENDIX F}

\section{CONSIDERATIONS IN THE USE OF MONTE CARLO CALCULATIONS IN 3-D CASK CONFIGURATIONS}

Although Monte Carlo methods provide extremely powerful tools for analysis of complex 3-D configurations, there are associated limits for such methods. This Appendix is intended to provide a brief discussion of some of the limitations known to exist in KENO Va. cask models resulting from its stochastic nature, to demonstrate that such limitations have been recognized and considered in the interpretation of results from the numerical simulation of multidimensional cask effects. Limitations discussed here are (1) the interpretation of $\Delta \mathrm{k}$ sensitivity results including stochastic uncertainty; (2) convergence of solution on $\mathrm{k}_{\mathrm{eff}}$; and (3) convergence of solution on proper regions of fuel rod for highly burned fuel.

Because of its stochastic nature, the value of $\mathrm{k}_{\text {eff }}$ computed in a KENO Va. calculation is reported as $\mathrm{k}_{\text {eff }} \pm \sigma$, where $\sigma$ represents a band about $\mathrm{k}_{\text {eff }}$ in which the actual value of $\mathrm{k}_{\text {eff }}$ is predicted to lie, with a $68 \%$ confidence level. All KENO Va. calculations described in this report were performed with $10^{6}$ histories, and a resulting value of $\sigma$ of 0.0007 or less. However, when determining a value of $\Delta \mathrm{k}$, the uncertainty associated with this difference (e.g., $\mathrm{k}_{1}-\mathrm{k}_{2}$ ) must be determined based on the individual uncertainties. Statistically, for two uncertainties $\sigma_{1}$ and $\sigma_{2}$, the combined uncertainty is given by

$$
\sigma_{1-2}=\sqrt{\sigma_{1}^{2}+\sigma_{2}^{2}}
$$

Thus the maximum uncertainty for $\Delta \mathrm{k}$ values reported in this work is obtained by assuming $\sigma_{1}=$ $\sigma_{2}=0.0007$, and therefore $\sigma_{1-2}=0.0010$. Therefore, $\Delta \mathrm{k}$ values given in this report are estimated to within $0.001(0.1 \%)$ with a $68 \%$ confidence. Note that although additional uncertainty is added when $\Delta \mathrm{k}$ changes are reported in terms of reactivity $(\Delta \mathrm{k} / \mathrm{k})$, the added uncertainty is very small because sigma is small relative to $\mathrm{k}$ and has little effect on a division operation. Thus this additional uncertainty is neglected.

Because of the size of the cask configuration studied in this report, it is necessary to run a large number of neutron histories in order to guarantee that the problem domain has been adequately sampled and the solution for $\mathrm{k}_{\text {eff }}$ has converged. As was mentioned earlier, all KENO Va. calculations were run with $10^{6}$ histories, using 1005 generations of 1000 neutrons each, and throwing out the first five generations. (The first few generations are used to determine the source distribution of the geometry, and therefore contain the effect of the initially assumed uniform source distribution. Thus they are omitted to eliminate the effect of the initial assumption.) Examination of KENO Va. output for a broad sampling of burnups, enrichments, number of axial zones, and for calculations with and without fission products indicate rather quick convergence, usually within the first 200 to 500 generations. This rapid convergence is probably due to the fact that all fuel elements within each model are identical; therefore, the KENO Va. calculation is able to move quickly to the most reactive axial region of the fuel, which drives the $\mathrm{k}_{\text {eff }}$ calculation. Additionally, because of the 
uniformity in the fuel and in the basket materials, there are no small pockets of important material which might be missed with insufficient sampling. Note that most fuel models allowed axial variations in fuel content, although there were no "small" regions with significant changes in content resulting in an isolated high-reactivity region.

Numerical determination of the most reactive portion of the fueled region of a cask is necessary in order to obtain a representative value of $k_{\text {eff }}$ for the cask. KENO Va. has been adequately benchmarked against numerous fresh fuel critical experiments and has been shown to be quite capable of determining an extremely good estimate of $\mathrm{k}_{\text {eff }}$ for such problems. In fresh fuel experiments, the central region of the fuel lattice is most reactive due to leakage at all outer boundaries. However, in highly depleted fuels such as those present in the high-burnup cases studied in this report, it is known that the two relatively low-burnup end regions of all fuel located in the cask are both highly reactive relative to the axial center region of the fuel. It is possible that either end of the fuel could become critical independent of the opposite end. KENO Va. has not been benchmarked against such fuel configurations due to the lack of experimental data. Hence it is desirable to have some assurance that KENO Va. is able to obtain convergence on the correct value of $\mathrm{k}_{\text {eff }}$ under such conditions.

As was discussed in the body of this report, criticality calculations are driven by the highest reactivity region of the problem domain. This situation is true not only for KENO Va. calculations, but for any solution to the transport equation (e.g., discrete-ordinates methods). This behavior is due to the fact that a given system is considered critical when any subregion of the system can maintain a constant neutron population with time. The value of $\mathrm{k}_{\text {eff }}$ computed for the system is driven by the critical subregion, although $\mathrm{k}_{\text {eff }}$ represents the net neutron multiplication for the entire system. When several regions of a problem domain have reactivities approaching that of the maximum reactivity region, the convergence rate of the problem is reduced. Mathematically, this behavior is due to the higher order spatial modes of the flux solution; for problems with multiple driving regions, the magnitude of the eigenvalues for the higher order spatial modes are large, approaching that of the primary eigenvalue $\left(\mathrm{k}_{1}=\mathrm{k}_{\text {eff }}=1.0\right.$ for a critical system). Hence the time required for the higher order spatial modes to decay away is increased, requiring additional time (iterations) to converge to a steady- state solution. However, because regions with similar reactivity would result in a similar value of $\mathrm{k}_{\text {eff }}$, convergence on $\mathrm{k}_{\text {eff }}$ is much more rapid than spatial convergence. Again, it is important to note that such behavior is not specific to Monte Carlo methods; spatial convergence will lag behind the convergence of $\mathrm{k}_{\mathrm{eff}} / \mathrm{k}_{\Delta}$ for deterministic discreteordinates calculations given a similar problem domain.

High-order spatial flux modes and the necessity of iterations to obtain spatial convergence result from an incorrect guess at the initial flux (i.e., neutron source) distribution as an initial condition. If the flux profile is known a priori, convergence iteration would not be required. Clearly, however, if the true flux profile is known, the transport calculation would not be necessary. In any transport calculation, convergence can be accelerated by providing a close estimate of the flux or neutron source as an initial condition. Often one may know the approximate neutron distribution from the solution of similar problems. In estimating initial conditions, it is essential that any initial condition specification provide source neutrons in the high-reactivity regions of the problem in order to ensure that neutron multiplication for that region is calculated. This approach is usually not a serious problem for deterministic methods, as numerical diffusion will act as a source term. 
However, in Monte Carlo calculations where spatial regions are randomly sampled and highimportance regions might be missed, poor specification of a starting source can result in an incorrect solution.

To demonstrate the effect of a poor starting source estimate, KENO Va. $\mathrm{k}_{\text {eff }}$ calculations were performed to demonstrate the effect of various starting distributions for initial conditions for a fuel burnup which results in two highly reactive end regions. Assuming a highly burned fuel (3.0 wt \% initial enrichment burned to $50 \mathrm{GWd} / \mathrm{MTU}$ ), which was shown in Sect. 5.2.3 of this report, to result in dominant end regions in the determination of $\mathrm{k}_{\text {eff }}$, calculations were performed with a variety of starting sources. For simplicity, the calculations were based on a single Westinghouse $17 \times 17$ fuel pin with reflective boundary conditions applied at the radial pin-cell boundaries, but with axial boundary conditions identical to those of the cask models used in the body of this report. Four different starting sources were assumed: (1) all neutrons starting in the radial center of the fuel at a point located $50 \mathrm{~cm}$ above the bottom of the fuel, (2) all neutrons starting in the radial center of the fuel at a point located $50 \mathrm{~cm}$ below the top of the fuel $(315.76 \mathrm{~cm}$ above the bottom of the fuel), (3) neutrons starting at both the locations described in 1 and 2, and (4) neutrons started uniformly along the length of the fuel pin. Items 1 through 3 approximate the source expected for (a) a highly reactive bottom region, (b) a highly reactive top region, and (c) simultaneous highly reactive top and bottom regions, respectively. Based on the earlier calculations it is suspected that (c) is true but that the upper regions of the rod are more reactive, and therefore item (b) is also appropriate (see Fig. 43 of the body of this report). Values of $\mathrm{k}_{\text {eff }}$ determined based on these four starting neutron sources are given in Table F-1. Axial fission density distributions are plotted in Fig. F-1.

It can be seen that of the four cases, only the "bottom-start" results are inconsistent with the other results. The value of $\mathrm{k}_{\text {eff }}$ for the bottom-start case is about $0.5 \%$ lower than the other three values, which are all in close agreement. Additionally, the fission density profile for the bottom-start case indicates that the system is being driven by the bottom fuel region, rather than by the more highly reactive top region. Clearly, failure to represent the more important region located near the top of the fuel in the starting source estimate results in an erroneous estimate of the actual fuel behavior. Since the most highly reactive region generates the highest estimate of $\mathrm{k}_{\text {eff }}$, use of any starting distribution which fails to identify the most highly reactive region will result in the nonconservative underprediction of $\mathrm{k}_{\mathrm{eff}}$.

Table F-1. Values of $\mathrm{k}_{\mathrm{eff}}$ computed for various neutron starting guesses

\begin{tabular}{lc}
\hline Neutron starting location in fuel & $\mathrm{k}_{\text {eff }} \pm \sigma$ \\
$50 \mathrm{~cm}$ above bottom & $0.9094 \pm 0.0005$ \\
$315.76 \mathrm{~cm}$ above bottom & $0.9146 \pm 0.0005$ \\
Both 50 and $315.76 \mathrm{~cm}$ above bottom & $0.9148 \pm 0.0005$ \\
Uniform along length & $0.9147 \pm 0.0004$ \\
\hline
\end{tabular}




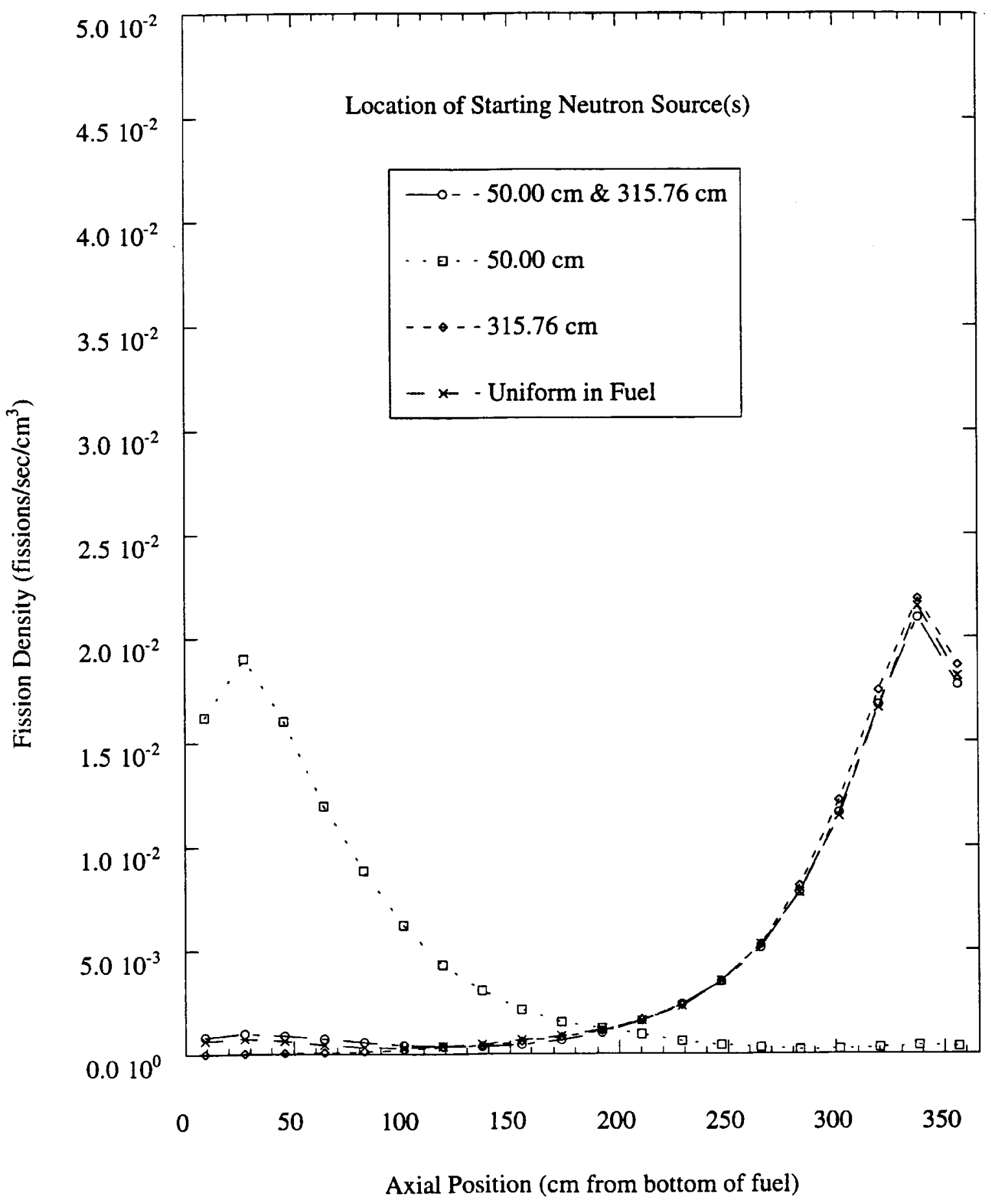

Fig. F-1. Fission densities computed for various neutron source guesses. 
Note that the use of a uniform starting distribution was able to identify the most highly reactive region of the fuel, and can be used without any specific knowledge of the "best" starting source. It is for this reason that a uniform starting distribution (the default in KENO Va.) is recommended for burnup credit cask calculations. Additionally, to ensure a broad spatial sampling of fuel regions, it is recommended that a large number of neutrons/generation be specified for such calculations. The KENO Va. default is 300; however, this may be inadequate. Calculations described in this report were based on 1000 neutrons/generation. 


\section{APPENDIX G SIMPLIFIED AXIAL MODELING}

The methodology described in Sect. 4 and illustrated in Fig. 28 of the body of this report provided a rigorous aproach for the modeling of axial burnup profiles in a multizone burnup approximation. The time required to complete a KENO V.a calculation is relatively insensitive to the number of axial zones applied in a model, and multiple CSASN calculations can be completed in a reasonable time period. However, SAS2H depletion calculations can be quite time consuming; for the typical depletion calculation performed in this study, a single depletion calculation would require roughly a half-hour on an IBM RS/6000-580 class workstation. For a single, detailed 100zone model, approximately 50 hours of CPU time would be required just to prepare the burnupdependent isotopics. Even for a 7-zone model, 3.5 hours would be required. Independent depletion calculations were performed for each axial region in the axial zoning studies described in Sect. 5.2 and shown in Figs. 40 and 41 in order to explicitly represent the axially varying specific power in the fuel as would be experienced in an operating power reactor. However, as was shown in Sect. 3.4.1, the sensitivity of neutron multiplication to specific power is fairly small over a broad range of specific powers. Thus one may reasonably approximate the axial burnup profile in a spent fuel model by assuming a single specific power during the depletion cycle. One may then estimate the isotopic composition in a multizone model from a single depletion calculation. By selecting sufficiently small calculational timesteps in the depletion calculation, it is possible to obtain a set of burnup-dependent isotopic concentration libraries from which the isotopics for any desired burnup can be determined by interpolation.

A code sequence known as SNIKR has been developed and used at ORNL to automate the process of interpolating isotopics for user-specified burnups, performing a final decay calculation to account for postirradiation cooling time, and formatting the final nuclide densities into the form required by CSASN and KENO V.a input. Although SNIKR is not a part of the SCALE package, it is used together with SCALE modules to prepare data for subsequent SCALE calculations. The SNIKR package is described in detail in ref. G.1.

Using the axial zone models described in the body of this report (see Fig. 39), and performing a single SAS2H calculation for each fuel enrichment with an assumed specific power of 37.5 MW/MTU, KENO V.a axial burnup models were developed and used to assess trends in $k_{\text {eff }}$ as a function of the various axial burnup approximations. Calculations were performed for fuel enrichments of 3.6 and $4.5 \mathrm{wt} \%$ (note that results given in the body of the report were for enrichments of 3.0 and $4.5 \mathrm{wt} \%$ ). Results are given in Tables G-1 and G-2 and are plotted in Figs. G-1 and G-2. The $\mathrm{k}_{\mathrm{eff}}$ values in the figure were normalized in the same manner as was described for Figs. 40 and 41.

Note that the trends shown in these figures are consistent with those observed in Figs. 40 and 41. Furthermore, comparison of average $k_{\text {eff }}$ values (average $k_{\text {eff }}$ is calculated as the average of the 20-, 50-, and 100-zone models) shows very close agreement between the more rigorous approach described earlier and the simplified approach described here. In general, the agreement is close to the stochastic uncertainty of the calculation. Thus this simplified approach should be considered in future analyses. 
Table G-1. Results of axial zoning studies using simplified approach (actinides + fission products)

\begin{tabular}{|c|c|c|c|c|c|c|c|c|c|c|c|c|}
\hline \multirow{3}{*}{$\begin{array}{l}\text { No.of } \\
\text { axial } \\
\text { cells }\end{array}$} & \multicolumn{6}{|c|}{$3.6 \mathrm{wt} \%$} & \multicolumn{6}{|c|}{$4.5 \mathrm{wt} \%$} \\
\hline & \multicolumn{2}{|c|}{$10 \mathrm{GWd} / \mathrm{MTU}$} & \multicolumn{2}{|c|}{$30 \mathrm{GWd} / \mathrm{MTU}$} & \multicolumn{2}{|c|}{$50 \mathrm{GWd} / \mathrm{MTU}$} & \multicolumn{2}{|c|}{$10 \mathrm{GWd} / \mathrm{MTU}$} & \multicolumn{2}{|c|}{$30 \mathrm{GWd} / \mathrm{MTU}$} & \multicolumn{2}{|c|}{$50 \mathrm{GWd} / \mathrm{MTU}$} \\
\hline & $\mathrm{k}_{\mathrm{eff}}$ & $\frac{\mathrm{k}-\mathrm{k}_{\mathrm{ave}}}{\mathrm{k}_{\mathrm{ave}}}$ & $\mathrm{k}_{\text {eff }}$ & $\frac{\mathrm{k}-\mathrm{k}_{\mathrm{ave}}}{\mathrm{k}_{\mathrm{ave}}}$ & $\mathrm{k}_{\mathrm{eff}}$ & $\frac{\mathrm{k}-\mathrm{k}_{\mathrm{ave}}}{\mathrm{k}_{\mathrm{ave}}}$ & $k_{\text {eff }}$ & $\frac{\mathrm{k}-\mathrm{k}_{\mathrm{ave}}}{\mathrm{k}_{\mathrm{ave}}}$ & $\mathrm{k}_{\text {eff }}$ & $\frac{\mathrm{k}-\mathrm{k}_{\mathrm{ave}}}{\mathrm{k}_{\mathrm{ave}}}$ & $\mathrm{k}_{\text {eff }}$ & $\frac{\mathrm{k}-\mathrm{k}_{\text {ave }}}{\mathrm{k}_{\text {ave }}}$ \\
\hline 1 & 0.9873 & $(0.58 \%)$ & 0.8461 & $(0.22 \%)$ & 0.7272 & $(-0.27 \%)$ & 1.0411 & $(0.58 \%)$ & 0.9115 & $(0.31 \%)$ & 0.7910 & $(-0.06 \%)$ \\
\hline 3 & 0.9814 & $(-0.02 \%)$ & 0.8376 & $(-0.79 \%)$ & 0.7213 & $(-1.07 \%)$ & 1.0355 & $(0.04 \%)$ & 0.9008 & $(-0.87 \%)$ & 0.7817 & $(-1.23 \%)$ \\
\hline 5 & 0.9817 & $(0.01 \%)$ & 0.8378 & $(-0.77 \%)$ & 0.7283 & $(-0.11 \%)$ & 1.0358 & $(0.07 \%)$ & 0.9047 & $(-0.44 \%)$ & 0.7877 & $(-0.48 \%)$ \\
\hline 7 & 0.9793 & $(-0.24 \%)$ & 0.8423 & $(-0.23 \%)$ & 0.7307 & $(0.21 \%)$ & 1.0353 & $(0.02 \%)$ & 0.9066 & $(-0.23 \%)$ & 0.7910 & $(-0.06 \%)$ \\
\hline 9 & 0.9810 & $(-0.06 \%)$ & 0.8429 & $(-0.16 \%)$ & 0.7282 & $(-0.13 \%)$ & 1.0357 & $(0.06 \%)$ & 0.9057 & $(-0.33 \%)$ & 0.7923 & $(0.11 \%)$ \\
\hline 11 & 0.9838 & $(0.22 \%)$ & 0.8440 & $(-0.03 \%)$ & 0.7291 & $(-0.00 \%)$ & 1.0354 & $(0.03 \%)$ & 0.9063 & $(-0.26 \%)$ & 0.7910 & $(-0.06 \%)$ \\
\hline 13 & 0.9822 & $(0.06 \%)$ & 0.8443 & $(0.00 \%)$ & 0.7299 & $(0.11 \%)$ & 1.0370 & $(0.18 \%)$ & 0.9080 & $(-0.08 \%)$ & 0.7894 & $(-0.26 \%)$ \\
\hline 15 & 0.9822 & $(0.06 \%)$ & 0.8464 & $(0.25 \%)$ & 0.7300 & $(0.12 \%)$ & 1.0341 & $(-0.10 \%)$ & 0.9066 & $(-0.23 \%)$ & 0.7901 & $(-0.17 \%)$ \\
\hline 17 & 0.9807 & $(-0.10 \%)$ & 0.8469 & $(0.31 \%)$ & 0.7298 & $(0.09 \%)$ & 1.0346 & $(-0.05 \%)$ & 0.9067 & $(-0.22 \%)$ & 0.7917 & $(0.03 \%)$ \\
\hline 20 & 0.9813 & $(-0.03 \%)$ & 0.8459 & $(0.19 \%)$ & 0.7282 & $(-0.13 \%)$ & 1.0360 & $(0.09 \%)$ & 0.9083 & $(-0.04 \%)$ & 0.7923 & $(0.11 \%)$ \\
\hline 50 & 0.9845 & $(0.29 \%)$ & 0.8422 & $(-0.24 \%)$ & 0.7288 & $(-0.05 \%)$ & 1.0341 & $(-0.10 \%)$ & 0.9094 & $(0.08 \%)$ & 0.7913 & $(-0.02 \%)$ \\
\hline 100 & 0.9791 & $(-0.26 \%)$ & 0.8447 & $(0.05 \%)$ & 0.7304 & $(0.17 \%)$ & 1.0352 & $(0.01 \%)$ & 0.9084 & $(-0.03 \%)$ & 0.7908 & $(-0.08 \%)$ \\
\hline Ave. & 0.9816 & - & 0.8443 & - & 0.7291 & - & 1.0351 & - & 0.9087 & - & 0.7915 & - \\
\hline
\end{tabular}

Table G-2. Results of axial zoning studies using simplified approach (actinides only)

\begin{tabular}{|c|c|c|c|c|c|c|c|c|c|c|c|c|}
\hline \multirow{3}{*}{$\begin{array}{r}\text { No. of } \\
\text { axial } \\
\text { cells }\end{array}$} & \multicolumn{6}{|c|}{$3.6 \mathrm{wt} \%$} & \multicolumn{6}{|c|}{$4.5 \mathrm{wt} \%$} \\
\hline & \multicolumn{2}{|c|}{$10 \mathrm{GWd} / \mathrm{MTU}$} & \multicolumn{2}{|c|}{$30 \mathrm{GWd} / \mathrm{MTU}$} & \multicolumn{2}{|c|}{$50 \mathrm{GWd} / \mathrm{MTU}$} & \multicolumn{2}{|c|}{$10 \mathrm{GWd} / \mathrm{MTU}$} & \multicolumn{2}{|c|}{$30 \mathrm{GWd} / \mathrm{MTU}$} & \multicolumn{2}{|c|}{$50 \mathrm{GWd} / \mathrm{MTU}$} \\
\hline & $\mathrm{k}_{\mathrm{eff}}$ & $\frac{\mathrm{k}-\mathrm{k}_{\text {ave }}}{\mathrm{k}_{\text {ave }}}$ & $\mathrm{k}_{\mathrm{eff}}$ & $\frac{\mathrm{k}-\mathrm{k}_{\text {ave }}}{\mathrm{k}_{\mathrm{ave}}}$ & $\mathrm{k}_{\text {eff }}$ & $\frac{\mathrm{k}-\mathrm{k}_{\text {ave }}}{\mathrm{k}_{\text {ave }}}$ & $\mathrm{k}_{\text {eff }}$ & $\frac{\mathrm{k}-\mathrm{k}_{\text {ave }}}{\mathrm{k}_{\text {ave }}}$ & $\mathrm{k}_{\mathrm{eff}}$ & $\frac{\mathrm{k}-\mathrm{k}_{\text {ave }}}{\mathrm{k}_{\text {ave }}}$ & $\mathrm{k}_{\text {eff }}$ & $\frac{\mathrm{k}-\mathrm{k}_{\mathrm{ave}}}{\mathrm{k}_{\mathrm{ave}}}$ \\
\hline 1 & 1.0215 & $(0.49 \%)$ & 0.9069 & $(0.49 \%)$ & 0.8111 & $(0.52 \%)$ & 1.0769 & $(0.61 \%)$ & 0.9731 & $(0.67 \%)$ & 0.8738 & $(0.70 \%)$ \\
\hline 3 & 1.0169 & $(0.03 \%)$ & 0.8989 & $(-0.40 \%)$ & 0.8037 & $(-0.39 \%)$ & 1.0703 & $(-0.00 \%)$ & 0.9674 & $(0.08 \%)$ & 0.8657 & $(-0.23 \%)$ \\
\hline 5 & 1.0147 & $(-0.18 \%)$ & 0.9004 & $(-0.23 \%)$ & 0.8035 & $(-0.42 \%)$ & 1.0721 & $(0.17 \%)$ & 0.9627 & $(-0.41 \%)$ & 0.8675 & $(-0.02 \%)$ \\
\hline 7 & 1.0149 & $(-0.16 \%)$ & 0.9015 & $(-0.11 \%)$ & 0.8068 & $(-0.01 \%)$ & 1.0689 & $(-0.13 \%)$ & 0.9641 & $(-0.26 \%)$ & 0.8699 & $(0.25 \%)$ \\
\hline 9 & 1.0150 & $(-0.15 \%)$ & 0.9003 & $(-0.24 \%)$ & 0.8060 & $(-0.11 \%)$ & 1.0692 & $(-0.11 \%)$ & 0.9620 & $(-0.48 \%)$ & 0.8681 & $(0.05 \%)$ \\
\hline 11 & 1.0153 & $(-0.12 \%)$ & 0.9025 & $(0.00 \%)$ & 0.8081 & $(0.15 \%)$ & 1.0689 & $(-0.13 \%)$ & 0.9663 & $(-0.03 \%)$ & 0.8674 & $(-0.03 \%)$ \\
\hline 13 & 1.0165 & $(-0.01 \%)$ & 0.9030 & $(0.06 \%)$ & 0.8074 & $(0.07 \%)$ & 1.0701 & $(-0.02 \%)$ & 0.9647 & $(-0.20 \%)$ & 0.8686 & $(0.10 \%)$ \\
\hline 15 & 1.0140 & $(-0.25 \%)$ & 0.9013 & $(-0.13 \%)$ & 0.8084 & $(0.19 \%)$ & 1.0686 & $(-0.16 \%)$ & 0.9634 & $(-0.33 \%)$ & 0.8685 & $(0.09 \%)$ \\
\hline 17 & 1.0158 & $(-0.08 \%)$ & 0.9021 & $(-0.04 \%)$ & 0.8062 & $(-0.08 \%)$ & 1.0707 & $(0.03 \%)$ & 0.9628 & $(-0.40 \%)$ & 0.8666 & $(-0.13 \%)$ \\
\hline 20 & 1.0165 & $(-0.01 \%)$ & 0.9033 & $(0.09 \%)$ & 0.8072 & $(0.04 \%)$ & 1.0696 & $(-0.07 \%)$ & 0.9673 & $(0.07 \%)$ & 0.8696 & $(0.22 \%)$ \\
\hline 50 & 1.0179 & $(0.13 \%)$ & 0.9016 & $(-0.10 \%)$ & 0.8065 & $(-0.05 \%)$ & 1.0696 & $(-0.07 \%)$ & 0.9662 & $(-0.04 \%)$ & 0.8657 & $(-0.23 \%)$ \\
\hline 100 & 1.0153 & $(-0.12 \%)$ & 0.9025 & $(0.00 \%)$ & 0.8069 & $(0.00 \%)$ & 1.0718 & $(0.14 \%)$ & 0.9664 & $(-0.02 \%)$ & 0.8678 & $(0.01 \%)$ \\
\hline Ave. & 1.0166 & - & 0.9025 & - & 0.8069 & - & 1.0703 & - & 0.9666 & - & 0.8677 & - \\
\hline
\end{tabular}




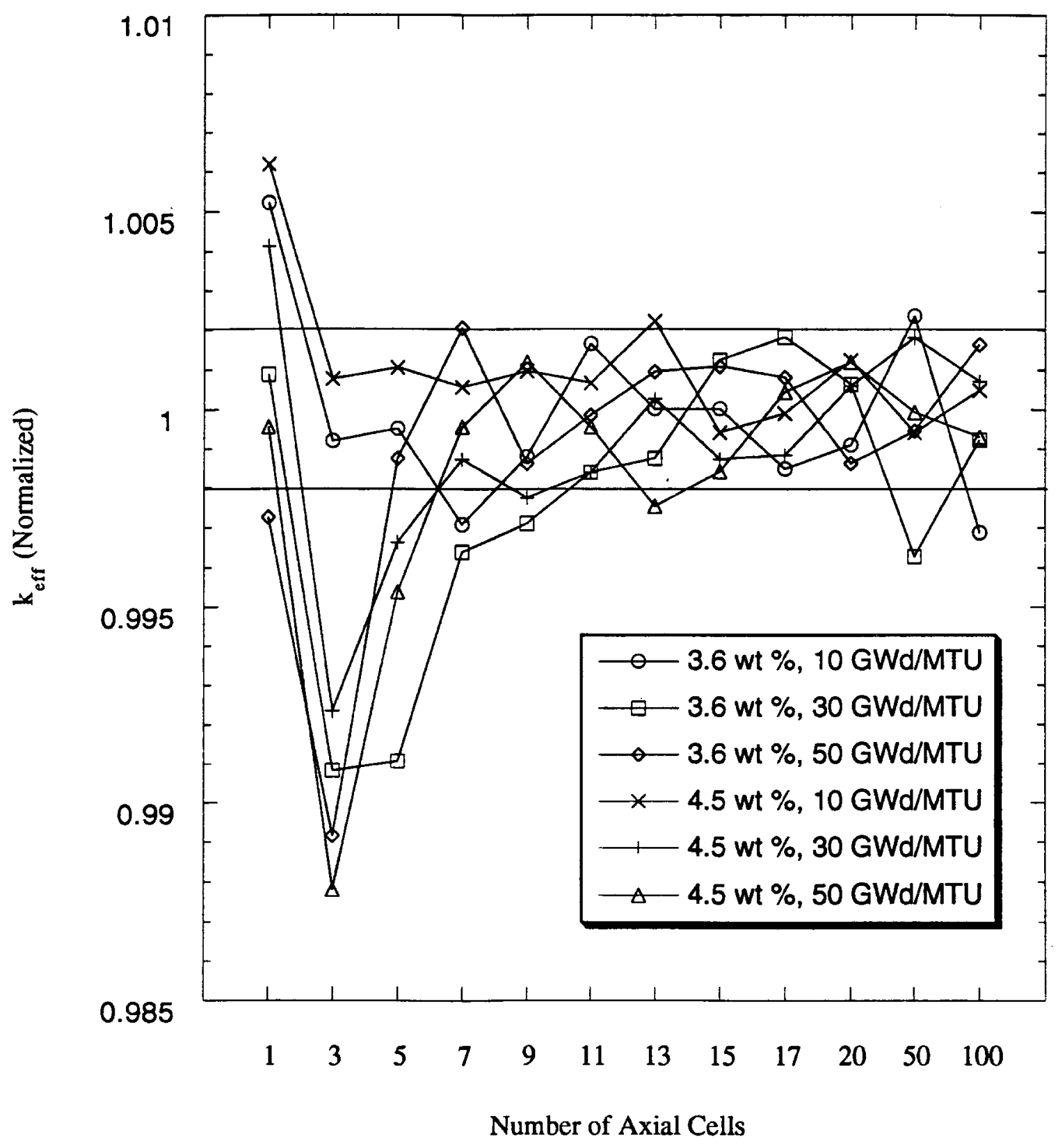

Fig. G-1. $k_{\text {eff }}$ as a function of axial burnup nodalization (actinides + fission products). 


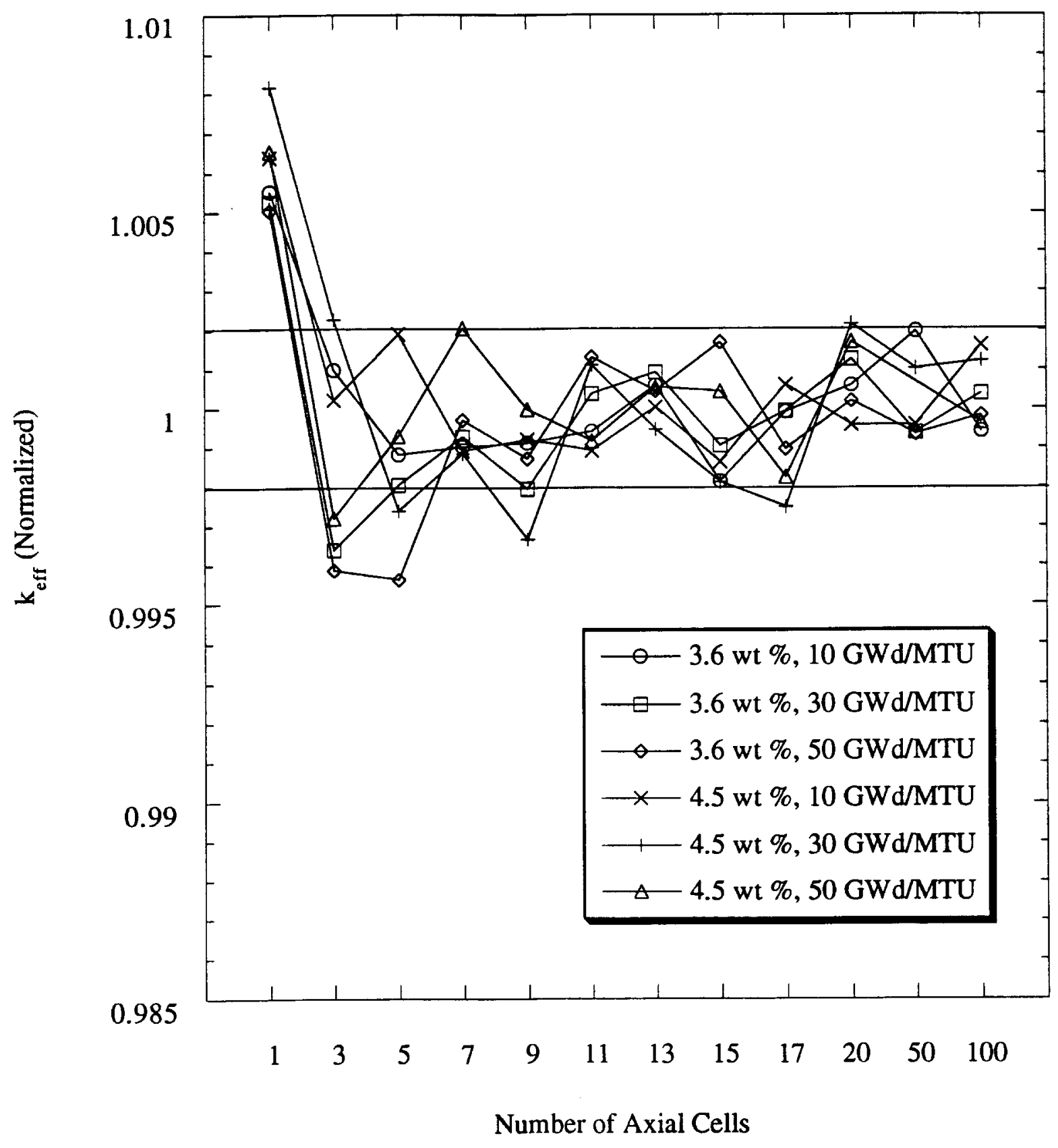

Fig. G-2. $k_{\text {eff }}$ as a function of axial burnup nodalization (actinides only). 


\section{Reference}

G.1 M. D. DeHart, SCALE-4 Analysis of Pressurized Water Reactor Critical Configurations: Volume 4-Three Mile Island Unit 1 Cycle 5, ORNL/TM-12294/V4, Martin Marietta Energy Systems, Inc., Oak Ridge Natl. Lab., 1995. 
ORNL/TM-12973

\section{INTERNAL DISTRIBUTION}

1-5. S. M. Bowman

6. B. L. Broadhead

7. J. A. Bucholz

8. R. L. Childs

9. R. D. Dabbs

10-14. M. D. DeHart

15. H. L. Dodds

16. M. B. Emmett

17. O. W. Hermann

18. D. F. Hollenbach

19. C. M. Hopper

20. D. T. Ingersoll

21. W. C. Jordan

22. M. A. Kuliasha

23. L. C. Leal

24. J. J. Lichtenwalter
25. L. F. Norris

26. C. V. Parks

27. L. M. Petrie

28. R. T. Primm

29. R. W. Roussin

30. J. C. Ryman

31. C. H. Shappert

32. R. M. Westfall

33. B. A. Worley

34. R. Q. Wright

35. Central Research Library

36-37. ORNL Y-12 Research Library Document Reference Section

38. Laboratory Records Department

39. Laboratory Records, ORNL (RC)

40. ORNL Patent Office

\section{EXTERNAL DISTRIBUTION}

41. R. Anderson, General Nuclear Systems, Inc., 220 Stoneridge Dr., Columbia, SC 29210

J. Anno, CEA/IPSN/DRS/SEc, CEN Fontenay-aux-Roses, B.P. No. 6, F-92265 Fontenay-aux-Roses, France

42. M. G. Bailey, Office of Nuclear Material Safety \& Safeguards, U.S. Nuclear Regulatory Commission, MS O6G22, Washington, DC 20555

43. L. Barrett, Office of Civilian Radioactive Waste Management, RW-232 20545, U.S. Department of Energy, Washington, DC 20545

44. P. Baylor, Office of Civilian Radioactive Waste Management, RW-36, U.S. Department of Energy, Washington, DC 20545

45. C. J. Benson, Bettis Atomic Power Laboratory, P.O. Box 79, West Mifflin, PA 15122

46. J. Bickel, U.S. Department of Energy, Albuquerque Operations Office, P.O. Box 5400, Albuquerque, NM 87115

47. R. Bowden, British Nuclear Fuels Ltd., R101, Rutherford House, Risley Warrington WA3 6AS, United Kingdom

48. M. C. Brady, Sandia National Laboratories, 1261 Town Center Drive, Room 421A, Las Vegas, NV 89109

49. J. B. Briggs, Idaho National Engineering Laboratory, 765 Lindsey Boulevard, E.R.O.B. E-3 I-7, Idaho Falls, ID 83415-3890

50. P. Bunton, U.S. Department of Energy, RW-1, Washington, DC 20545

51. R. J. Cacciapouti, Yankee Atomic Electric Co., 580 MainSt., Bolton, MA 01740

52. D. Carlson, Office of Nuclear Material Safety \& Safeguards, U.S. Nuclear Regulatory Commission, MS O6G22, Washington, DC 20555

53. R. Carlson, Lawrence Livermore National Laboratory, P.O. Box 808, Livermore, CA 94550 
54. C. R. Chappell, U.S. Nuclear Regulatory Commission, Office of Nuclear Materials Safety and Safeguards, MS O6E6, Washington, DC 20555

55. R. Chickering, Illinois Power Company, Clinton Power Station M/C V928, Box 678, Clinton, IL 61727

56. J. S. Choi, Lawrence Livermore National Laboratory, P.O. Box 808, Livermore, CA 94550

57. J. Clark, 2650 Park Tower Drive, Suite 800, Vienna, VA 22180

58. J. Conde, Consejo de Seguridad Nuclear, Justo Dorado, 11, 28040 Madrid, Spain

59. M. Conroy, U.S. Department of Energy, M-261 Quince Orchard, Washington, DC 20585-0002

60. P. J. Cooper, Sandia National Laboratories, P.O. Box 5800, Albuquerque, NM 87185-0716

61. W. Davidson, Los Alamos National Laboratory, Group A4, MSF-611, Los Alamos, NM 87845

62. F. J. Davis, Sandia National Laboratories, P.O. Box 5800, Div. 6302, MS 1333, Albuquerque, NM 87185-0716

63. D. Dawson, Transnuclear, Inc., 2 Skyline Dr., Hawthorne, NY 10532-2120

64. T. W. Doering, TESS, B\&W Fuel Co., MS 423, Suite 527, P.O. Box 98608, 101 Convention Center Drive, Las Vegas, NV 89109

65. R. Doman, Nuclear Packaging, Inc., 1010 S. 336th St., Suite 220, Federal Way, WA 98003

66. E. Easton, U.S. Nuclear Regulatory Commission, Office of Nuclear Materials Safety and Safeguards, MS O6G22, Washington, DC 20555

67. R. C. Ewing, Sandia National Laboratories, P.O. Box 5800, Div. 6643, MS 0716, Albuquerque, NM 87185-0716

68. C. Garcia, U.S. Department of Energy, Albuquerque Operations Office, P.O. Box 5400, Albuquerque, NM 87115

69. B. Gmal, Gesellschaft fuer Anlagen-und Reaktorsicherheit, Forschungsgelaende, D-85748 Garching, Germany

70. N. T. Gulliford, AEA Technology, Winfrith Technology Centre, Dorchester, Dorset DT2 8DH, United Kingdom

71-75. D. E. Hampton, Sandia National Laboratories, P.O. Box 5800, Div. 6302, MS 1333, Albuquerque, NM 87185-0716

76. S. Hanauer, U.S. Department of Energy, RW-22, Washington, DC 20545

77. C. Haughney, U.S. Nuclear Regulatory Commission, Office of Nuclear Materials Safety and Safeguards, MS O6G22, Washington, DC 20555

78. L. Hassler, Babcock \& Wilcox, P.O. Box 10935, Lynchburg, VA 24506-0935

79. R. Hueggenberg, GNB, Gesellschaft fur Nuklear, Behaelter MBH, Z.HD. Herrn Gripe, Hollestr. 7A, D 45127 Essen, Germany

80. E. Johnson, E. R. Johnson Associates, Inc., 9302 Lee Hwy, Suite 200, Fairfax, VA 22031

81. R. Kelleher, International Atomic Energy Agency, Division of Publications, Wagramerstrasse 5, P.O. Box 100, Vienna, Austria A-1400

82. C. Kouts, Office of Civilian Radioactive Waste Management, RW-36, U.S. Department of Energy, Washington, DC 20545

83. S. Kraft, Nuclear Energy Institute, 1776 I Street, Suite 400, Washington, DC 20086

84. P. Krishna, TRW Environmental Safety Systems, 600 Maryland Ave. S.W., Suite 695, Washington, DC 20024

85. W. H. Lake, Office of Civilian Radioactive Waste Management, U.S. Department of Energy, RW-46, Washington, DC 20585

86. D. Lancaster, 2650 Park Tower Drive, Suite 800, Vienna, VA 22180

87. H. Manaktala, Manager, Engineered Barrier System, Center for Nuclear Waste Regulatory Analyses, Southwest Research Institute, 6220 Culebra Road, San Antonio, TX 78238-5166

88. C. Marotta, 1504 Columbia Ave., Rockville, MD 20850 
89. M. Mason, Transnuclear, Two Skyline Drive, Hawthorne, NY 10532-2120

90. J. Massey, Sierra Nuclear Corporation, 5619 Scotts Valley Drive, Number 240, Scotts Valley, CA 95066

91. D. Mennerdahl, E. Mennerdahl Systems, Starvägen 12, S-183 51 TÄBY, Sweden

92. W. Mings, U.S. Department of Energy, Idaho Operations Office, 550 2nd St., Idaho Falls, ID 83401

93. S. Mitake, Japan Institute of Nuclear Safety, Fujita Kankou Toranomon B.7F, 3-17-1 Toranomon, Minato-ku, Tokyo 105, Japan

94. A. Mobashevan, Roy F. Weston, Inc., 955 L'Enfant Plaza, SW, 8th Floor, Washington, DC 20024

95. R. Morgan, 2650 Park Tower Drive, Suite 800, Vienna, VA 22180

96. Y. Naito, Director, Department of Fuel Cycle, Safety Research, JAERI, 319-11 Tokai-mura, NakaGun, Ibaraki-ken, Japan

97. D. Napolitano, NAC International, 655 Engineering Drive, Suite 200, Norcross, GA 30092

98. C. W. Nilsen, Office of Nuclear Material Safety and Safeguards, U.S. Nuclear Regulatory Commission, MS TWFN-9F29, Washington, DC 20555

99. I. Nojiri, PNC, Tokai Works, Muramatsu Tokai-mura, Naka-gun Ibaraki-Ken 319-11, Japan

100. A. Nouri, CEA/IPSN/DRS/SEC, CEN Fontenay-aux-Roses, B.P. No. 6, F-92265 Fontenay-auxRoses, France

101. Office of Scientific and Technical Information, U.S. Department of Energy, P.O. Box 62, Oak Ridge, TN 37831

102. Office of the Deputy Assistant Manager for Energy Research and Development, Department of Energy Oak Ridge Operations (DOE-ORO), P.O. Box 2008, Oak Ridge, TN 37831

103. H. Okuno, Department of Fuel Cycle Safety Research, JAERI, 319-11 Tokai-mura, Naka-Gun, Ibaraki-ken, Japan

104. N. Osgood, U.S. Nuclear Regulatory Commission, Office of Nuclear Materials Safety and Safeguards, MS O6E6, Washington, DC 20555

105-107. O. Ozer, Electric Power Research Institute, 3412 Hillview Ave., Palo Alto, CA 94304

108. P. Pacquin, General Nuclear Systems, Inc., 220 Stoneridge Dr., Columbia, SC 29210

109. T. Parish, Department of Nuclear Engineering, Texas A \& M University, College Station, TX 778433313

110. G. Poullot, CEA/IPSN/DRS/SEC, CEN Fontenay-aux-Roses, B.P. No. 6, F-92265 Fontenay-auxRoses, France

111. M. Rahimi, 2650 Park Tower Drive, Suite 800, Vienna, VA 22180

112. B. Rasmussen, Duke Power Co., P.O. Box 33189, Charlotte, NC 28242

113. T. L. Sanders, Sandia National Laboratories, P.O. Box 5800, Div. 6609, MS 0720, Albuquerque, NM 87185-0716

114. A. Santamarina, C.E. - Cadarache, Bat. 230, CEA/DRN/DER, F-13108 St. Paul lez Durance, Cedex, France

115. E. Sartori, OECD/NEA, Data Bank, Le Seine-Saint Germain 12 boulevard des Iles, F-92130 ISSYLes-Moulineaux, France

116. B. Schnitzler, Idaho National Engineering Laboratory, 765 Lindsey Blvd., E.R.O.B. E-3 I-7, Idaho Falls, ID 83415-3885

117. H. H. Schweer, Bundesamt fuer Strahlenschutz, Albert Schweitzerst. 18, Postfach 100149, D-38226 Salzgitter, Germany

118. K. D. Seager, Sandia National Laboratories, P.O. Box 5800, Div. 6643, MS 0716, Albuquerque, NM 87185-0716

119. M. Smith, U.S. Department of Energy, Yucca Mountain Project Office, 101 Convention Center Dr., Las Vegas, NV 89190

120. M. Smith, Virginia Power Co., P.O. Box 2666, Richmond, VA 23261 
121. N. R. Smith, AEA Technology, B21 Winfrith, Dorchester, Dorset DT2 8DH, United Kingdom

122. K. B. Sorenson, Sandia National Laboratories, P.O. Box 5800, Div. 6643, MS 0716, Albuquerque, NM 87185-0716

123. J. Stewart, Department of Transport, Radioactive Materials, Transport Division, P2/23C, 2 Marsham Street, London SW1P 3EB, United Kingdom

124. F. C. Sturz, Office of Nuclear Material Safety \& Safeguards, U.S. Nuclear Regulatory Commission, MS O6G22, Washington, DC 20555

125. T. Suto, Power Reactor and Nuclear Fuel Development Corp., 1-9-13, Akasaka, Minato-Ku,, Tokyo, Japan

126. R. J. Talbert, Battelle Pacific Northwest Laboratory, P.O. Box 999, Richland, WA 99352

127. T. Taylor, INEL, P.O. Box 4000, MS 3428, Idaho Falls, ID 83403

128. B. Thomas, VECTRA Technologies, Inc., 6203 San Ignacio Ave., Suite 100, San Jose, CA 95119

129. D. A. Thomas, B\&W Fuel Co., 101 Convention Center Drive, Suite 527, MS 423, Las Vegas, NV 89109

130. P. Thorne, British Nuclear Fuels Ltd., R101, Rutherford House, Risley Warrington WA3 6AS, United Kingdom

131. J. R. Thornton, TRW Enviornmental Safety Systems, 2650 Park Tower Dr., Suite 800, Vienna, VA 22180

132. S. Turner, NUS, 230 Normandy Circle East, Palm Harbor, FL 34683

133. G. Walden, Duke Power Co., P.O. Box 33189, Charlotte, NC 28242

134. M. E. Wangler, U.S. Department of Energy, EH-33.2, Washington, DC 20585-0002

135. R. Weller, U.S. Nuclear Regulatory Commission, TWFN 7J9, Washington, DC 20555

136. A. Wells, 2846 Peachtree Walk, Duluth, GA 30136

137. W. Weyer, Wissenschaftlich-Technische Ingenieurberatung GMBH, Mozartstrasse 13, 5177 TitzRodingen, Federal Republic of Germany

138. B. H. White, Office of Nuclear Material Safety \& Safeguards, U.S. Nuclear Regulatory Commission, MS O6E6, Washington, DC 20555

139. J. Williams, Office of Civilian Radioactive Waste Management, U.S. Department of Energy, RW-46, Washington, DC 20545

140. M. L. Williams, LSU Nuclear Science Center, Baton Rouge, LA 70803

141. R. E. Wilson, EG\&G Rocky Flats, Inc., P.O. Box 464, Bldg. 886, Golden, CO 80402-0464

142-146. C. J. Withee, Office of Nuclear Material Safety \& Safeguards, U.S. Nuclear Regulatory Commission, MS O6G22, Washington, DC 20555

147. R. Yang, Electric Power Research Institute, 3412 Hillview Ave., Palo Alto, CA 94304 